
UNIVERSITY OF BRISTOL.

\section{Sidedical Tibrate.}

PRESENTED BY

THE HLISTOD

MlEI(O-HIRURCICAL SOCIETY. 

. 


\section{TEXT-BOOKS OF SCIENCE,}

MECHANICAL AND PHYSICAL,

\section{ADAPTED FOR THE USE OF STUDENTS IN PUBLIC AND SCIENCE SCHOOLS.}

PHOTOGRAPHY. By Captain W. De Wiveleslie Aeney, F.R.S. late Instructor in Chemistry and Photography at the School of Military Engineering, Chatham. With I05 Woodcuts. Price $3 s .6 d$.

On the STRENGTH of. MATERIALS and STRUCTURES : the Strength of Materials as depending on their quality and as ascertained by Testing Apparatus ; the Strength of Structures, as depending on their form and arrangement, and on the materials of which they are courposed. By Sir J. ANDERSON, C.E. Ec. Price $3 s .6 d$.

INTRODUCTION to the STUDY of ORGANIC CHEMISTRY; the CHEMISTRY of CARBON and its COMPOUNDS. By Henry E. Armstrong, Ph.D. F.C.S. With 8 Woodcuts. Price 3 s. $6 d$.

ELEMENTS of ASTRONOMY. By R. S. BALL, LL.D. F.R.S. Andrews Professor of Astronomy in the Univ. of Dublin, Royal Astronomer of Ireland. With 136 Figures and Diagranıs. Price $6 s$.

RAILWAY APPLIANCES. A Description of Details of Railway Construction subsequent to the completion of Earthworks and Masonry, including a short Notice of Railway Rolling Stock. By J. W. BARry. With 207 Woodcuts. Price $3 s .6 d$.

SYSTEMATIC MINERALOG By HILARY BAUERMIAN, F.G.S. Associate of the Royal School of Mines. With 373 Diagrams. Price 6s.

DESCRIPTIVE MINERALOGY. By Hilary BaUerMAN, F.G.S. \&z. With 236 Woodcuts and Diagrams. Price $6 s$.

METALS, their PROPERTIES and TREATMENT. By C. L. Bloxam and A. K. Huntington, Professors in King's College, London. With I 30 Wood Engravings. Price $5 s$.

PRACTICAL PHYSICS. By R. T. GlazeBrooK, M.A. F.R.S. and W. N. Shaw, M.A. With 62 Woodcuts. Price $6 s$.

PHYSICAL OPTICS. By R. T. GLAZEBrook, M.A. F.R.S. Fellow and Lecturer of Trin. Coll. Denıonstrator of Physics at the Cavendish Laboratory, Cambridge. With 183 Woodcuts of Apparatus, \&c. Price 6:.

The ART of ELECTRO-METALLURGY, including all known Processes of Electro-Deposition. By G. Gore, LL.D. F.R.S. With 56 Woodcuts. Price $6 s$.

ALGEBRA and TRIGONOMETRY. By the Rev. IVilliam Nathaniel Griffin, B.D. Price 3 s. $6 d$.

NOTES on the ELEMENTS of ALGEBRA and TRIGONOMETRY. With SOLUTIONS of the more difficult QUES. TIONS. By the Rev. W. N. GrifFin, B.D. Price $3 s .6 d$.

London : LONGMANS, GREEN, \& CO. 
ELECTRICTTY and MAGNETISM. By FLEEMING JENKIN, F.R.SS. L. \& E. Professor of Engineering in the University of Edinburgh. Price ${ }_{3} s .6 d$.

THEORY OF HEAT. By J. Clerk MAXwell, M. A. LL.D. Edin. F.R.SS. L. \& E. With $4 \pi$ Woodcuts. Price $3 s .6 d$.

\section{TECHNICAC ARITHMETIC and MENSURA-} TiON. By Charles W. Merrtfield, F.R.S. Price $3 s .6 d$.

\section{KEY to MERRIFIELD'S TEXT-BOOK of TECH-} NICAL ARITHMETIC and MENSURATION. By the Rev. JOHN HUNTER, M.A. formerly Vice-Principal of the National Suciety's Training College, Battersea. Price $3 s .6 d$.

\section{INTRODUCTION to the STUDY of INORGANIC} CHEMISTRY. By IVILltam ALLEN Miller, M.D.LL.D. F.R.S. With 7 I Woodcuts. Price $3 s .62$.

TEL FGRAPHY. By W. H. PREECE, C. E. and J.SIVEwright, M.A. With 160 Woodcuts. Price 5 s.

THE STUDY OF ROCKS, an ELEMENTARY TextBook of PETROLOGY. By Frank RUTLey, F.G.S. of Her Majesty's Geological Survey. With 6 Plates and 88 iVoodcuts. Price 4s. 6 .

WORKSHOP APPLIANCES, including Descriptions of some of the Gauging and Measuring Instruments-Hand Cutting Tools, Lathes, Drilling, Planing, and other Machine Tools used by Engineers. By C. P. B. Shelley, M.I.C.E. With 292 Wondcuts. Price $4 s .6 d$.

STRUCTURAL and PHYSIOLOGICAL BOTANY. By Dr. Oтto IVIthelm Thome, Professor of Botány, School of Science and Art, Cologne. Translated by A. W. Benwett, M.A. B.Sc. F.L.S. With 600 Woodcuts. Price $6 s$.

QUANTITATIVE CHEMICAL ANALYSIS. By T. E. Thorpe, F.R.S.E. Ph.D. Professor of Chemistry in the Andersonian University, Glasgow. With 88 Woodcuts. Price $45.6 d$.

MANUAL of QUATITATIVE ANALYSIS and LABORATORY PRACTICE. By T. E. ThORPE, Ph.D. F.R.S.E. Professor of Chemistry in the Andersonian University, Glasgow ; and M. M. Pattison Mutr. Price $3 s .6 d$.

INTRODUCTION to the STUDY of CHEMICAL PHILOSOPHY ; the PRINCIPLES Of THEORETICAL and SYSTEMATICAL CHEMISTRY. By William A. Tilden, B.Sc. London, F.C.S. With 5 Woodcuts. Price $3 s .6 d$. With Answers to Problems, $4 s .6$

ELEMENTS of MACHINE DESIGN ; an Introduction to the Principles which determine the Arrangement and Proportion of the Parts of Machines, and a Collection of Rules for Machine Design. By WV. Cawthorne Univin, B.Sc. Assoc. Inst. C.E. With 325 Woodcuts. Price 6s.

PLANE and SOLID GEOMETRY. By the Rev. I. W. WATSON, formerly Eellow of Trinity College, Cambridge. Price ${ }_{3} s .62$.

London: LONGMANS, GREEN, \& CO. 


\title{
TEXT-BOOKS OF SCIENCE
}

\author{
ADAPTED FOR THE USE OF
}

ARTISANS AND STUDENTS IN PUBLIC AND SCIENCE SCHOOLS

$B O T A N Y$ 




LONDON : I'RINTED BY SPOTTISWOODE AND CO., NEIV-STREET SQUARE AND PARLIANENT STREET 







$$
\text { TEXT-BOOK }
$$

OF

\section{STRUCTURAL AND PHYSIOLOGICAL}



OTTO W. THOMÉ

RECTOR OF THE HIGH SCHOOL, COLOLNE

ANI

ALFRED W. BENNETT, M.A., B.Sc., F.L.S.

LECTURER ON BOTANY AT ST 'THOMAS'S HOSPITAL

ILLUSTRATED WITH ABOUT 600 WOODCUTS AND A COLOURED MAP

FIFTII EDITION

REVISED AND CORRECTED THROUGHOUT

WITIL SEVERAL NEIV IVOODCUTS

\section{LONDON}

L O N G A N S, GRE EN, A N D C O. 1885 







\section{PREFACE}

TO

\section{THE FIFTH EDITION.}

Since the first introduction of 'Thomé's 'Text-book of Botany' to the English reader, eight years ago, material alterations have been made in the examinations conducted by the University of London. Women being now admitted to all the examinations of the University, the special examination for women has been discontinued. The only lower examinations at which a knowledge of Vegetable Morphology and Physiology is compulsory are now the Preliminary Scientific (M.B.) and the Intermediate Examination for B.Sc. At the full B.Sc. Pass Examination, Botany is an optional subject. For these three examinations, and for that in Honours in Botany at the Preliminary Scientific Examination, it is believed that the present work contains all the information which it is necessary for candiclates to acquire. A sufficiently full account is given of the types, both of Flowering and Flowerless Plants, a special knowledge of which is required by the examiners. But it cannot be too strongly impressed on the student that a 
mere book-knowledge of this, as of any other science, is absolutely valueless. He must make himself practically acquainted, with the aid of the microscope, and, if possible, under the guidance of a competent teacher, with the minute structure of plants, and with the life-history of the various forms. For the higher examinations, those for Honours in Botany at the Intermediate and Full B.Sc. examinations, and for the Degree of D.Sc., the candidate is recommended to consult the more advanced text-books named in the preface to the first edition. The new regulations for the examinations referred to above come into use for the first time in July next.

During these eight years very great advance has been made in various branches of botanical science. The lifehistory of many of the lower forms has been for the first time followed out, and great light thrown on their genetic relationships. The present editor has in consequence found it necessary to replace Thomés system of classification of the lower Cryptogams by one more in accordance with the views of the best authorities founded on these recent observations.

In addition to this, he would call attention to the following points in which recent histological research has added greatly to our knowledge, or has caused the modification of views previously held. The paragraphs (pp. IS6-192) relating to the structure of the pollen-grain in $A$ ngiosperms, the mode of fertilisation in Angiosperms and Gymnosperms, and the formation of the embryo and endosperm, have been entirely rewritten. The same is the case with regard to the account of the phenomena of Cell-division and the 1)ivision of the Nucleus (pp. 32-35). The discovery of the Continuity of Protoplasm (p. 3I) has thrown an entirely new 
light on many of the phenomena of Vegetable I'hysiology; while that of Apogamy and Apospory in Ferns (p. $3^{1} \mathrm{G}$ ) supplies the last links in the chain which connects together the various modes of sexual and non-sexual reproduction. On all other points of importance it has been the aim of the editor to bring the present edition fully abreast of the most recent discoveries and observations.

A. IV. B. .

6 Park Village kas', Regent's Pakk:

April ISS5. 



\section{EDITOR'S PREFACE.}

THE original of the present work is the recognised Textbook of Botany in use in the technical schools of Germany; and its success in fulfilling the object for which it was written may be inferred from the fact that, published for the first time in I869, it is now in a fourth edition. An English translation and edition has been undertaken-primarily at the suggestion of the Rev. Alexander Irving of Wellington College-from the belief that no work of the same scope is yet to be found in the English language, embracing the whole range of Elementary Botany, and yet of a size and price to bring it within the reach of nearly all students of Natural Science.

One of the great objects of a study of Natural Science being the cultivation of the observant faculties in relation to the phenomena of nature, the greater part-and that the most useful-of the student's knowledge must always be gained in the field, or with the dissecting-knife in hand. Still he will need to be guided by the experience of previous observers, and to be acquainted with the recognised descriptive terms used in his science. It is for these purposes, and not to replace the necessity for observations of his own, 
that he should use a Text-book. Examiners in Natural Science now almost universally attach great importance to dissecting and microscopical work, as the best indication of practical acquaintance with the subject, without, however, abandoning the additional test of requiring clear and correct answers to written questions.

In editing the present work, the object especially kept in view has been to make it useful to candidates preparing for the Science examinations conducted by the Educational Department at South Kensington, or for those at the University of London. Botany now forms a portion of nine different examinations at the London University :--the Preliminary Scientific Examination required from all medical students (both the Pass examination and that for Honours); the First Bachelor of Science (Pass and Honours); the Second Bachelor of Science (Pass and Honours); the General Examination for Women (Honours); the Doctor of Scrence in Vegetable Physiology ; and the Doctor of Science in Systematic Botany. In the first five of these (the Preliminary Scientific Pass and Honours; the First Bachelor of Science Pass and Honours; and the Second Bachelor of Science Pass) it is believed the present work will be found a sufficient Text-book; for the Second Bachelor of Science Honours, the Examination for Women in Honours, and the Doctor of Science in either branch, the student should consult some more advanced treatise, as the English edition of Sachs's Text-book (Clarendon Press) for Anatomy and Physiology, and Dr. Hooker's edition of Le Maout and Decaisne's 'Traité Général' (Longmans) for Classification. The examinations for the First and Second Bachelor of Science have recently undergone complete revision, the revised regulations coming into force for the first time during 


\section{Preface.}

the present year. At the First Bachelor of Science Pass, special attention is directed to certain types of vegetable life named in the syllabus. The sum of our present knowledge respecting these types will be found stated in the following pages, either in the text or in editorial notes ; but the editor desires to impress upon his readers the necessity of their making themselves practically acquainted with these forms of life, and comparing their observations with the description, before presenting themselves for examination. At the Second Bachelor of Science Pass, the examination in Botany, which is optional, requires, in addition to a general acquaintance with the principles of Morphology and Physiology, a knowledge of the structure and development of certain groups of Phanerogams and Cryptogams, an account of which will also be found here.

In the chapters on Anatomy and Physiology, the original work has been very closely followed; only a few alterations being made, to render it in harmony with the recognised use of terms in this country. Any additions to our knowledge acquired since the publication of the German work are referred to in foot-notes. The same remark applies to the chapter on Special Morphology and Classification, as far as Cryptogams are concerned. But the section on the Classification of Phanerogams has been entirely rewritten. The system of classification adhered to in the original work differs in so many points from that in use in this country, that it would bealmost useless to the English student. The natural orders have therefore been entirely rearranged, in accordance with Bentham and Hooker's system, and a detailed description is given only of the more important ones. The minutiæ of Classification were considered out of place in an elementary Text-book, and would moreover swell it to an unwieldy size. 
The seventh and eighth chapters have been considerably compressed, and some portions have been altered. In editing them pains have been taken to avoid, as far as possible, the putting forward of geological or geographical theories as demonstrated truths. The young student cannot be too cautious about forming or adopting theories, except as mere modes of classifying facts, which must be morlified as our knowledge of facts increases. Some general notion of the distribution of plants in space and time is essential to him; but he should, as far as possible, check and correct his theories by getting together and collating a large fund of observation. The chapter on the Geographical Distribution of Plants is a brief epitome of Grisebach's conclusions, as stated in his 'Vegetation der Erde,' of which there is as yet no English translation. All editorial additions throughout the work are distinguished by being placed between square brackets.

It would be impossible, even were it desirable, to define, in an elementary work of this kind, every scientific term in use by every writer; many of those not mentioned in these pages carry their own explanation with them. Some additions have been made by the editor to those included in the original work; and it is believed that every term necessary to the young student will be found defined either in the text or in the glossarial index at the end. Reference is made, in this index, not only to the pages where an explanation of each term will be met with, but also to every figure in which it is illustrated. In the Latin names of British plants, the one adopted in Hooker's 'Student's Flora' is in all cases used.

A. W. B.

“6 Park Village east, Regent's Paris:

Fanuary 1877 . 


\section{CONTENTS.}



CHAPTER

I. Tile Cell as AN INdividual . . . . . 7

II. The Clill as a Member of a Group of similali

CELls . . . . . . . . 35

III. The Construction of the Plant out of Cells 55

IV. Tile External Form of Plants . • . . 69

V. THE LIFE OF THE PLANT . . . . . . I5S

VI. Speciat Morphology and Classification • • 237

VII. The Changes Whicit Have TAKEN Place IN THE VEGETATION OF THE GLOBE IN THE COURSE OF Geological. Periods . . . . . 417

Viti. Botanical Geograpiy . . . . 432

Glossartal INDEX . . . . . . , . 463 



\section{STRUCTURAL AND PHYSIOLOGICAL}

\section{B O T A N Y.}



\section{INTRODUCTION.}

THE province of Botany, or the Natural History of the Vegetable Kingdom, is to depict the plant from as many different points of view as possible.

It is impossible to give a brief and exact definition of a plant, if such a definition is intended to include all plants. It is true that from the earliest times the numberless substances that are found on the earth have been distinguished into living or organic and lifeless or inorganic,--animals and plants being included in the former, minerals in the latter class; but it is impossible to define accurately the bounds of these three kingdoms. Whether a body has life or not is a point easily determined, since the presence of life is manifested by various capabilitics, the most universally distributed of which are those for absorbing and assimilating a variety of food materials. We know also from experience that the higher and more perfectly organised animals differ from the higher plants in possessing sensibility and a power of voluntary motion. But when we descend from the higher 
animals and plants to the less perfect organisms belonging to these two kingdoms of nature, we come eventually, on the boundaries of each, to organisms so small and so imperfectly developed that it is scarcely possible to pronounce an opinion whether they are of animal or vegetable nature. The most superficial glance over the vegetable world shows us that in both the external form and internal structure of plants - the number of which has been estimated to amount to 300,000 -there exists such an endless diversity that we must content ourselves with describing the forms of most common occurrence, the most important laws of their internal structure, life, and distribution, and the classification of the best known and most important plants.

Morphology, or the Comparative Anatomy of plants, embraces an acquaintance with their most important organs, and hence with their external form. By combining with this the history of development of the separate organs, i.e. the mode in which they are produced, we are enabled to obtain a correct comprehension of, and to describe, the different parts of a plant. By the Anatomy of plants we understand a knowledge of their intemal structure. The Physiology of plants is concerned with their vital phenomena [and the different functions of the various organs]. Botanical Geography treats of the distribution of plants over the surface of the globe. Palaophytology, or Vegetable Palæontology, makes us acquainted with the remains that still exist of the vegetation of earlier geological epochs. Classification has to do with the distribution of plants according to their characters [or relationship to one another]. Practical, or Applied Botany, finally, explains the useful or injurious properties of plants.

In the earliest times the knowledge of plants was limited to those from which food was obtained, and to a few which afforded poisonous or curative substances, the properties of which had been ascertained by a happy or unfortunate accident, or by the observation of an animal impelled by instinct to their use. The knowledge thus laboriously gained must 
often have been again lost, until at length an acquaintance with medicinal plants became a speciality of the priests, and the healing art founded upon it a part of religion.

The father of medicine, as he has been termed, Hippocrates, who lived in the fifth century before Christ, extended the observations that had hitherto been made; and we know that he enumerated upwards of 200 species which were at that time used in medicine. But it was not till the following century that a really scientific work on botany appeared, written by the celebrated tutor of Alexander the Great, Aristotle. His work is unfortunately lost ; but his ideas have come to us in the writings of his pupil Theophrastus, who described 400 or 500 different plants in their relation to agriculture, domestic economy, and medicine. At his death the new structure fell to pieces, or at all events we do not find that any further progress was made with it. This was the state of things until, in the first century after Christ, Dioscorides wrote a treatise on medicine, in which over 600 medicinal plants were described, though often briefly and in. sufficiently, and the elder Pliny collected what was most noteworthy from the writings of his predecessors. The position in which botany stood at that time may be understood from the naive statement of Pliny that there were, it is true, more plants in the hedges, fields, and roadsides than those he had described, but they had no names, and were of no use. The works of Pliny and Dioscorides remained the best on the stibject till the sixteenth century, and enjoyed the highest reputation. At that time German investigators arose who aroused the study of plants from its long rest, and earned therefrom the honourable title of the fathers of botany. The first of these was Otto Brunfels of Mayence (ob. I 534); other German scholars followed closely upon him, Bock (ob. 1554), Fuchs (ob. 1566), and Gessner (ob. 1565); as well as some belonging to other countries, Ma-


and Clusius (ob. r609). But no one of these made any 
great advance; for none of them went beyond a more or less careful description of different plants.

Cæsalpinius (ob. 1603$)$ was the first to devote himself to a systematic classification of plants. He derived his principles mainly from the characters of the fruit and from the position of the perianth in reference to the pistil; but his primary division of the vegetable kingdom was into woody and herbaceous plants. His example was followed by others, and the science received an ever-increasing impetus, directed by such men as Tabernæmontanus (ob. 1590), Alpinus (ob. r6r6), and Camerarius (ob. I72r), an impetus which was greatly assisted by the great store of botanical material derived from travels in the East and in America. But there were no means of comparing these fresh discoveries with one another, in consequence of a want of correspondence in the names given to the same plant by different investigators. The brothers John and Caspar Bauhin (ob. 16 13 and 1624 ) were the first to endeavour to overcome this difficulty. From this time the number of botanists increased so greatly that we can mention only those who introduced new and influential ideas.

The originator of the Latin botanical nomenclature was Jung (ob. $6_{577}$, rector of the gymnasium at Hamburgh. Soon afterwards, in 1700 , Tournefort (06. 1 708) propounded a new system, and was the first to classify plants into strictly defined genera. A year before his death, the great reformer of botany, the Swede Carl von Linné (Linnæus, ob. 1778), was born. It was he who first raised botany to the rank which it should have attained long before, of an edifice resting on a firm foundation; for to him we owe the first system of nomenclature and description of a truly scientific character. But this was not all ; for Linneus propounded the celebrated system that bears his name, which has indeed since been replaced by others of a much more natural character, but which is unequalled in practical value if the purpose is simply to name any given plant, or to assign its 
position in the system to any newly-discovered species. The Linnean system is an artificial one, since it is not founded on a combination of all, nor even of several, characters of a plant, but takes into account only single characters as the primary principle of classification. There were therefore necessarily opponents of the system. The first to propose in its place a natural system was the French botanist A. L. de Jussieu $\left(o b . \mathrm{I}_{3} 6\right.$ ), who took as his starting-point the presence and the structure of the embryo. $\mathrm{He}$ was shortly followed by A. P. De Candolle (06. I84I) and Endlicher (ob. I 849); the foundation of the primary classification being with the former anatomical structure, with the latter the mode of growth. The efforts to construct better systems are not yet brought to a conclusion; and we cannot yet see their end. In the meantime botanists are vigorously at work in completing the botanical material, whether by the compilation of 'Floras' which treat of the plants of particular districts, or by travels through districts hitherto unknown or not yet sufficiently explored.

If we now attempt to sketch in a few lines the history of the development of the remaining departments of botanical science; -it appears, as might be expected, that the study of the anatomy of plants came into existence shortly after the discovery of the art of manufacturing magnifying lenses. The English botanist Grew (ob. I 7 I I) and Malpighi of Bologna (ob. I694) must be considered as the true founders of this study. After the ground had been successfully broken by their researches, it was almost entirely neglected rluring the eighteenth century, and the investigation has only recently been again resumed, and this branch of botany carried to a truly remarkable perfection by our contemporaries A. Braun (ob. 1877), Göppert (ob. 1884), Von Mohl (ob. I872), Schacht (ob. I864), Schleiden (ob. 1882), Unger (ob. 1870), and many others.

While during the eighteenth century the study of anatomy lay dormant, especial interest was excited by problems 
of physiology, and a great many pioneers of science occupied themselves with their solution; among whom may be especially mentioned Hales (ob. I76I), Bonnet (ob. 1793), Duhamel (ob. I 781 ), Priestley (ob. I804), and Ingenhousz (ob. I 799).

Reference must not be omitted to the fact that the poet Goethe established the science of morphology on a firmer basis by his writings ; and that it was reserved for Alexander von Humboldt (ob. I859), at the commencement of this. century, to put the study of Botanical Geography into a scientific shape. Palæophytology was advanced especially by Brongniart (ob. 1876), Unger, Göppert, \&c. We must, however, refrain from entering into detail with regard to the labours of our own contemporaries; and will only name the most eminent recent German botanists who have not hitherto: been mentioned, viz., among others, De Bary, Caspary, Dippel, Hanstein (ob. I 880), Hartig, Hildebrand, Hoffmann, Hofmeister (ob. I877), Karsten, Von Martius (ob. 1868), Milde (ob. I87 I), Nägeli, Pringsheim, Rabenhorst, Sachs, [Strasburger], and Schwendener. ${ }^{1}$

${ }^{3}$ [The dates, which do not in all cases agree exactly with those stated by the author, are given on the authority of Sachs, in his 'Geschichte der Botanik.' As the author has given most prominence to German botanists, it may be allowed to name the following in addition, as worthy of mention. Among systematists Ray (ob. 1705) holds an important place ; and the present comparative perfection of our system of classification is due largely to Lindley (ob. I 865) and Bentham (ob. I884). Vegetable anatomy owes much to the observations and publications of A. St. Hilaire (ob. 1853), Robert Brown (ob. 1858), Sir. W. Hooker (ol. 1865), Payer, Cohn, Sir J. D. Hooker, Asa Gray, and Berkeley; physiology to C. C. Sprengel (ol. I 8 I6), Boussingault, and Darwin (ob. I882).--ED.] 


\section{CHAPTER I.}

THE CELL AS AN INDIVIDUAL.

IF a small quantity of the green mould (Penicillium gtaucum) which commonly appears on articles of food that have been kept for a few days, is examined under the microscope, it is found to present somewhat the appearance of a minute tree (Fig. I). The stem is simple, but bears at its summit a number of branches resembling strings of beads. Each of these strings easily breaks up into its separate members; and each of these members has the form of a tiny spherical bladder with a delicate coat, enclosing contents of a peculiar composition. All the branches and the main stem consist of similar bodies, differing only in their greater length ; and these bodies



FIg. I.-Green mould, Penicilliam glaucum. ( $x$ about 80 diam.)

are termed cells. In the example which we have chosen the individual cells are connected with one another only like beads on a necklace; but a close examination shows us that all parts of all plants are formed of cells, or are composed of structures which have themselves been formed out of cells. Examples of this are furnished by the ripe but not too succulent. flesh of fruits such as the 
apple, slices of leaves which are not too delicate, such as the cabbage, etc. Since therefore, at least at a certain period of their existence, all plants consist of one or more cells, these are termed the elementary organs of plants. There is only this one kind of elementary organ, which may vary greatly in its form and behaviour, but is always the same in its essentinl nature.

Until recently the essential constituents of the cell were considered to be a more or less firm cell-zcall (Fig. 2 a),



f. 2. - A cell from the root of the lizard-orchis, Orchis hircina: at the cell-wall, consisting of cellulose $: b$ the protoplasm contracted by alcohol; $c$ the nucleus with a nucleolus. ( $x$ 200.) differing in its chemical composition from the contents of the cell, a cell-fluid enclosed by it, and the mucleus, c, occurring in the latter. The cell-fluid was again divided into two principal elements, the watery cell-sap, and the mucilaginous semi-fluid protoplasm, $b$, in the clear transparent hyaline substance of which are imbedded a larger or smaller number of granules, generally of very small size. Some even went so far as to consider the cell-wall the most important element, and the term cell was applied even to the walls of perfectly dead cells which had lost the whole of their contents. But since cells were subsequently observed in which, at least for a certain period of their existence, such a firm wall, differing chemically from their contents, was wanting, and since also there are cells in which a nucleus is never found, it became necessary to modify the idea of a cell, and the only essential constituent is now held to be the protoplasm. In the vegetable kingdom this protoplasm rarely remains permanently uninvested by a firm envelope, but is usually sooner or later enclosed in an elastic more or less solid membrane, the substance of which 
it secretes out of itself. Only those cells are in a living state which still contain protoplasm; such alone can grow, produce new chemical combinations, and, under favourable circumstances, give rise to new cells. Cells destitute of protoplasm are of service to the plant only by their hardness, their power of attracting water, and their form, or as protecting envelopes.

Every mass of protoplasm, whether free or enclosed in a cell-wall, has a definite external boundary, where a layer of it is distinguished from the internal portion by the absence of the imbedded granules, and by its greater transparency. This layer, called the parietal or primordial utricle, is not sharply defined on its inside, but passes gradually into the granular and less dense internal mass; it is thin, being only very rarely of a measurable thickness. The protoplasm which is contained within a cell-wall does not generally entirely fill up the cavity, but more often occurs as a delicate parietal layer lining the cell-wall on the inside, and surrounding the hollow cavity filled with watery cell-sap.

The protoplasm is a compound of different organic substances, among which albuminous (nitrogenous) are never absent, and usually constitute the bulk of it. It therefore easily coagulates, often merely by the addition of water ; and this is especially the case in the cells of those plants which do not live in water. It revertheless contains abundance of water, and is usually very turgescent; i.e. it possesses in a high degree the power of absorbing water between its most minute particles, and swelling up in consequence somewhat in the manner of a gum. This power of absorbing water is, however, limited; as soon as it exceeds a certain amount, a watery fluid is exudcd in drops in the interior of the mass of protoplasm, forming cavities or vacnoles within it. The protoplasm can combine with water only slowly and not in any desired proportion; and, evcn when most strongly magnificd, presents the appearance of being separated by sharp outlines from the watery fluid which surrounds it, or which fills up the cavities in its interior. Watcr passes easily through a layer of protoplasm; but the lattcr offers, in the living state, a strong resistance to substances, such as colouring matters or salts, dissolved in watcr, which is generally overcome only by such injuries as destroy the life of the cell.

Every formation of new cells which can bc submittcd to observation begins with a change in the protoplasm, the truc body of the cell ; and this substance is conscclucntly the origin of all new devclopmcnt. It cannot therefore be destitutc of structure, but must be alrcady organiscd; 
and it must be simply the imperfection of our microscopes which prevents us from recognizing that organisation which is a necessary accompaniment of all vital phenomena. One of the most important of these phe-



F1G. 3.-Circulation of proto. plasm in an elongated cell of the celandine; $k$ the nucleus with a nucleolus. The arrows indicate the direction of the currents. $\left(x_{460 .}\right)$ nomena is its motility or power of movement. A continuous, even though generally extremely slow and imperceptible, movement of the minute particles is inseparable from the idea of life; and that movements of this kind must be especially energetic in the case of protoplasm may be inferred from its extreme importance to the life of the plant; although they are usually not visible. Pcrceptiblc movements are espccially clcarly scen in some of those cells -tcrmed primordial cells-which are not enclosed in a firm cell-wall; the movements of the protoplasm being often so vignrous in them that the cells are propelled to a considerable distance from their original position, and present to the beginncr the appearance of animal organisms enclowed with voluntary power of motion. Instances of this are furnished by the 'swarming' motion of swarmspores and antherozoids, the amœba-like movements of the Myxomycetes, \&c. Protoplasm which is enclosed in a ccll-wall has ordinarily no power of escaping from its envelope; but even when so enclosed the microscope shows a 'streaming' of the protoplasm in all young living eells. The course of the current is usually only along the wall, and in simple spiral or reticulate lines, and is then termed rotation, as in Chara and Vallisneria (Fig. 40, p. 25); when, as in the filaments of Tradescantia, it passes in thrcads and bands transverscly through the cell-sap, it is called circulation (Fig. 3). The currents are apparently irregular, now advancing, now retreating, sometimes suddenly arrested and commencing again with increascd rapidity, and again forning for themselves acw paths through the cell-sap. 
Possibly in all, at all events in the immense majority of cells, is a mucleus or cytoblast. In the dead state the nucleus is a spherical or flattened lenticular body of from 0.004 to $0.04 \mathrm{~mm}$. diameter; they often possess a pellicle, and contain one or more mucleoli (see Figs. 2 and 3). In the living condition they are often very difficult to recognise, but appear to be larger than when dead, and of variable irregularly



FIG. 4. - Spherical cell from the flesh of the peach. ( $x$ 370.)



FiG. 5. - Ellipsoidal cell from the flesh of the peach. $(x$ 370.)



Fig. 6. - Hour-glass shaped cell from the flesh of the peach. $(\times 370$.

jagged form. [Although, as a rule, each perfect cell contains only a single nucleus, examples of multinucleated cells are not uncommon, as



Fig. 7.- Stellate cell from the horizontal septum of the air passages of the flowering rush, Butomus umn. bellatus. $\left(x x_{730 .}\right)$



Frg. 8.-Disc-shaped cell : a unicellular Alga, Cos. cinodiscus. $(x$ 39o.)



FIG. 9.- Crescent-shaped cel! of a stoma (guard. cell).

in the cmbryo-sac and suspensor of I.eguminosx, and in the Siphonocladacex, a group of Alga with remarliably large branched cells.] 
The form and size of the naked cell (without cell-wall) are very various, in consequence of the constantly changing motion of the protoplasm. In those which are enclosed in a firm wall or membrane of cellulose, the cell-wall determines the size and form of the cell. Although cells vary relatively so greatly in size, they are generally very minute even in their mature state, being scarcely visible to the naked eye, or usually altogether invisible. The unicellular Micrococcus



Fig. 10. - Tabular cell from the epidermis of Callitrichic.



FIG. 1I.-Irregularly stellate cell : a desmid, Euastrum cru $x \cdot n c l i t c u s i s .\left(x 4_{400}\right)$

(Fig. 380, p. 245), for example, is from $0.00 \mathrm{I}$ to $0.002 \mathrm{~mm}$. broad and long; the diameter of pollen-grains varies between $0 . \mathrm{I}$ and $0.0075 \mathrm{~mm}$., [while the pollen-tubes may attain a length of I or 2 inches]. There are, however, cells of a larger size in the Characer ; thus Nitella has cylindrical cells more than $50 \mathrm{~mm}$. long, and I $\mathrm{mm}$. in diameter; [and in some groups of Algæ, as the Vaucheriacer and Siphonocladaceæ, the individual consists of a single much-branched cell many centimetres in length]. The walls which bound the cells are seldom flat, but usually curved, of perfectly spherical, cylindrical, or even branched and arborescent form. The most common forms of cells are-spherical (Fig. 4); 




FIG. 12. - Tetrahedral cells : spore of a fern in various positions (greatly magnified).




Fig. 16.-Polyhedral cell from the pith of Acacia lopianutha; $a$ seen in transverse, $b$ in longitudinal section. ( $x$ 370.)



Fic. 17.-Branched bast-cell of the larch. ( $x$ 200.)



Fig. I 8.-Part of a bast-cell of the oleander, trented with ammoniacal cupric oxide : $s^{\prime} s^{\prime}$ spiral bands of the outer shell ; $s^{\prime \prime}$ spiral bands of the inner shell; the former nearly dissolved, the latter partially; $t$ third innermost mass of layers. ( $x$ 800 .) 
ellipsoidal (Fig. 5); hour-glass-shaped (Fig. 6); stellate (Figs. 7 and II); disc-shaped (Fig. 8); crescent-shaped (Fig. 9); tabular (Fig. ro); tetrahedral (Fig. I2); prismatic (Fig. I3); fusiform (Figs. I4, I5); polyhedral (Fig. I6); irregularly branched (Fig. I7).

All these forms, to which many others might be added, are produced from cells which are originally more or less spherical, according as the pressure to which they are subject from the adjacent cells is greater or less, and according as the vigour of their growth on all sides is more or less uniform. It is by far most probable that the growth of the cellwall, when once formed, takes place solely by intussusception, that is, by the intercalation of fresh particles of cellulose among those already in existence. This process is the essential element of those long-enduring changes of a physical and chemical character to which the cell-wall is subject during its growth, causing it to be of essentially different nature from the shell of a mussel, on the inner side of which new layers are being constantly deposited. The wall serves not only for the external protection of the cell, but is most intinately connected with its life; so that even when the cell has long ceased to exercise an active influence on the life of the plant by the formation of new cells or by the secretion of special substances within it, other changes are still proceeding in the cell-wall, which may often be perceived even by the naked eye ; as in ebony-wood, the innermost layers or 'duramen' of which become of a darker colour than the 'alburnum' or layers of wood which lie nearest to the bark.

The cell-wall appears at first as a thin, apparently structureless membrane (the primary cell-wall); in the course of its growth, however, several layers, thickeninglayers, are apparently deposited at an early period on the inside. Although under the microscope these layers seem very clearly defined from one another and from the primary cell-wall, such a definition does not actually always exist (see Figs. 19-2I). The fact that the cell-wall appears to consist of several layers depends on the unequal density of the separate lamellæ; and this can be cxplained by an unequal absorption of water, the layers appearing as if quite unstratified when dry. Always less evident than the thickening-layers, there can be perceived on the cell-wall 
delicate spiral, longitudinal, and transverse striations (Fig. 26, p. I 8); and this striation is also, as a rule, only the result



FIG. 19.-Transverse section of a cell of the pith of Clematis vitalba: $p$ primary cell-wall; $t$ innermost thickening-layer: P pore-canal : $i$ intercellular space. $(x ; 80$.

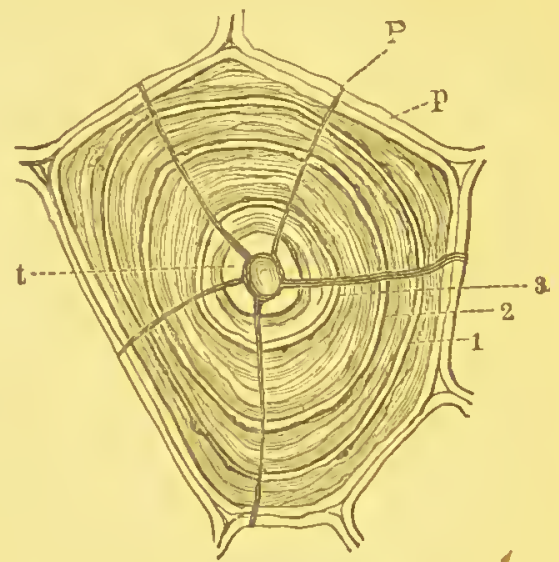

FiG. 20.-Dast-cell from the stem of Uranic gnyanensis, with several shells $(\mathrm{r}, 2,3, t)$ and simple pore-canals $\mathbf{P} ; \not p$ primary cellwall of an adjacent cell. $\left(x 7^{80}\right.$.)

of an unequal absorption of water. The formation of shells, in which the cell-wall is split up into two or more strata of

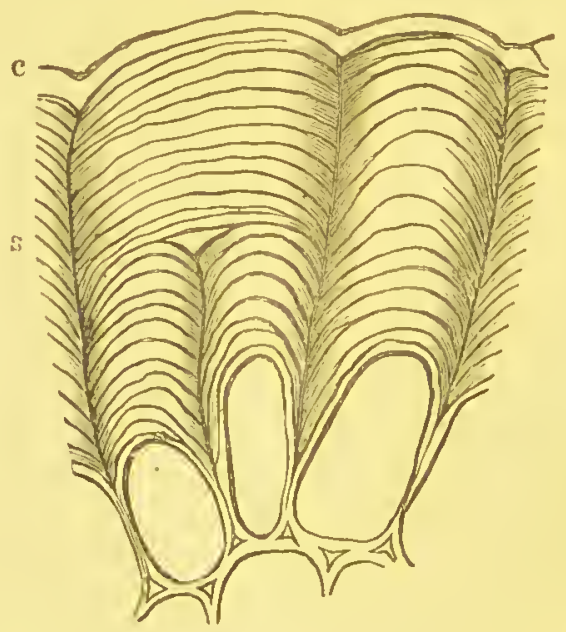

FiG. 21.-Longitudinal section through several cells of the epidermis of the mistletoe thickened on one side only; s thickening-laycrs; $c$ cuticle. $(x 660$.)

different chemical and physical properties, must be clearly distinguished from the thickening-layers. Each of these 


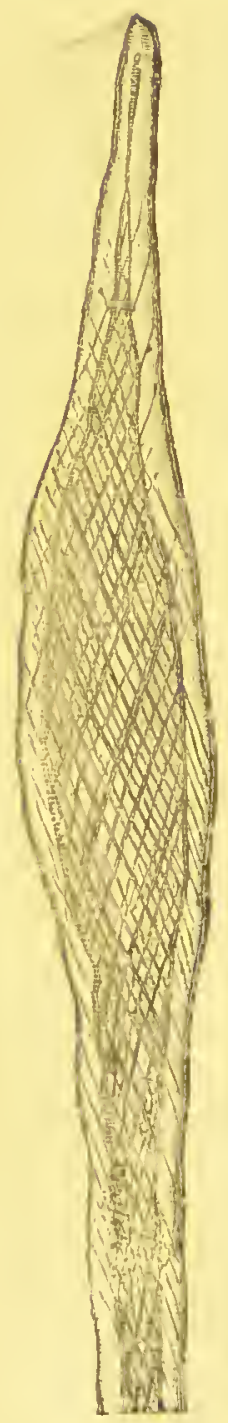

FIG. 26, - Bast-cell of Cynnuchum vincetoxicum, with iniercrossing spiral striations. $(x 370$.

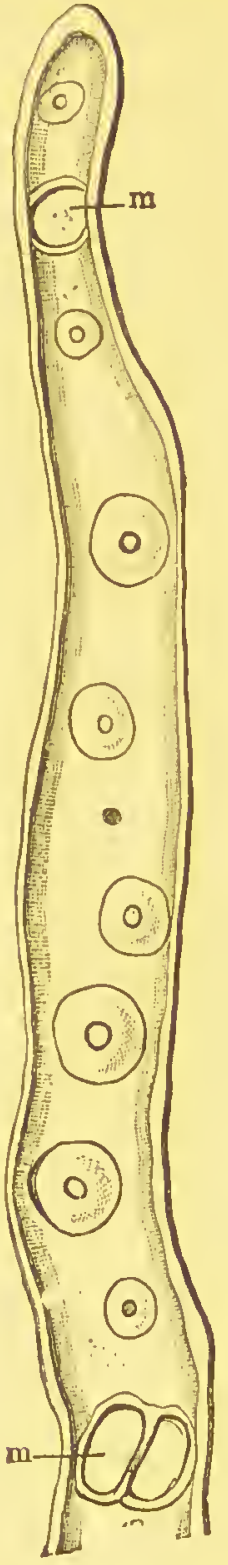

FIG. 27.-Wood-cell (tracheid) of the Scotcly fir, witls "bordered pits ; $m m$ pores connecting the cells of the wood with those of the me. dullary rajs. $(x+00$.

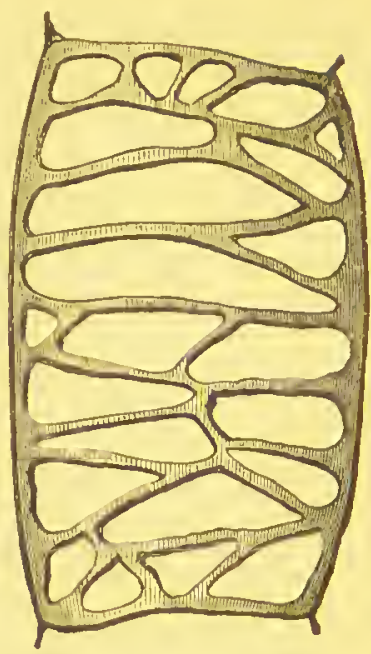

FIG. 28.-Reticulately thickened cell of the touch-me-not, Impratiens noli-me-tangere. (x 370.)

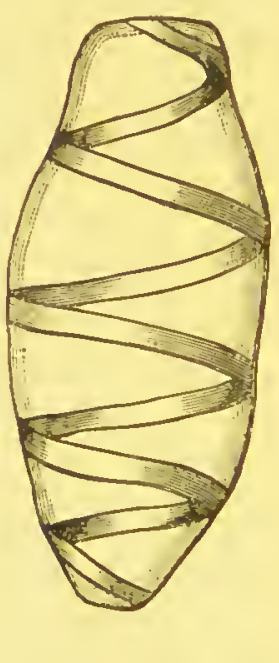

FIG. 29.-A spiral cell from a cactus, Opuntin Tuna, with strongly thickened spiral band. $(x$ 400.) 
several spiral bands (Fig. I 8, p. I4). The thickening-layers often increase so considerably that the space enclosed by the cell-wall, the ccll-cavity, almost entirely disappears (Fig. 20).

The increase of the cell-wall in thickness is almost invariably uniform only in its earliest stage; a want of uniformity very soon sets in at various spots. This is especially manifested at the corners and edges, the cellcavity being always more or less rounded off; but it sub-

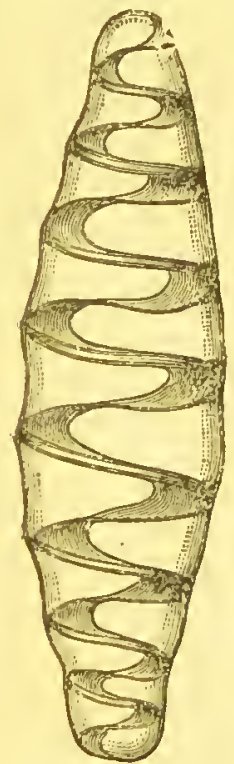

Fig. 30.-A spiral cell from a cactus, Mamillaria, with flattened spiral band. $(x 400$.

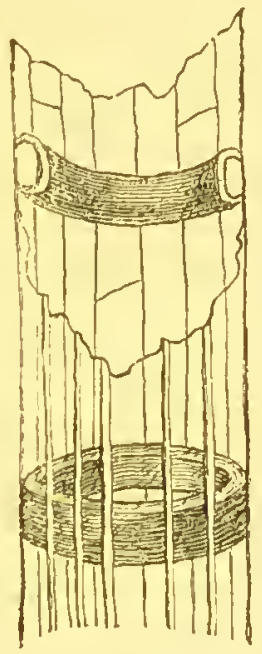

Fig. 3I. - Piece of an annular cell from the stem of the Turkish wheat: the edges of contiguous cells are visible on the cell-wall. $\left(x_{500}\right)$

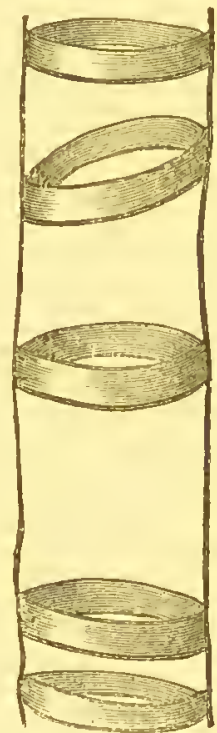

FIG. 32. - Annular cell from Arundo donax, with strongly thickened rings placed at different distances and different angles. $(x$ 400.)

sequently often takes place only on one side (Fig. 2 I), or so slightly at particular sipots that pitted or pore-canals are formed at those spots. These are sometimes simple (Figs. 19, 20), sometimes branched (Fig. 25). The canals from adjoining cells constantly meet; sometimes they are widened at their base into bordered pits (Fig. 22); and the membrane between these frequently disappears, so that cells become thus actually perforated (Figs. 23, 24). According to the development of 
the pits or of the thickening-layers we distinguish between pitted cells (Fig. 27), reticulated cells (Fig. 28), spiral cells (Figs. 29, 30), annular cells (Figs. 31-34), and scalariform (ladder-like) cells (Fig. 36). A slevenchymatous cell (Fig. 25)

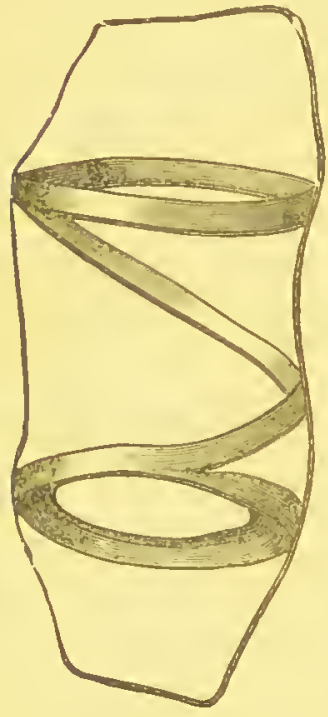

F1G. 33. - Annular cell from an Opuntia with rings passing over into a spiral band. $(x$ 400.)

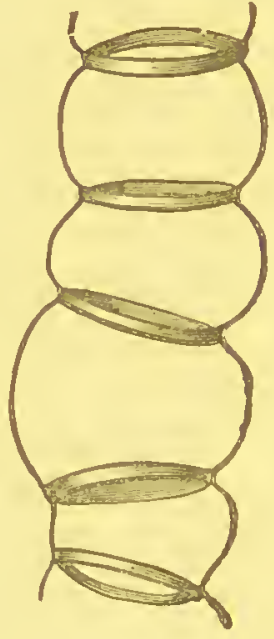

FIG. 34. - Annular cell from the balsam, $\mathrm{Bal}$. samina hortensis, with the primary cell-wall bulging into a barrelshape between the rings. ( $x$ 400.)

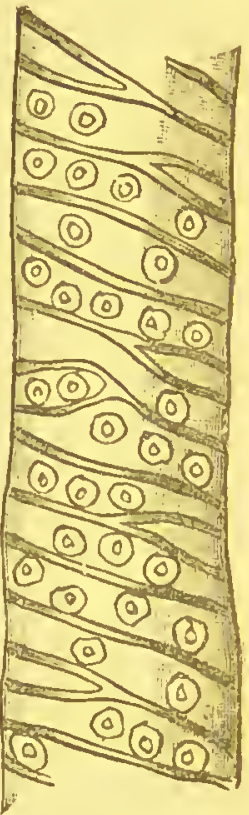

F1G. 35.-Piece of a reticulate and pitted vessel (tracheid) from the lime, Tilia grandi. folia. $(x+400$.

is one in which the cell-wall has become uniformly very greatly thickened and hardened.

The increase in thickness of the cell-wall takes a very peculiar form in the epidermal cells of many Urticacex and of some other plants. In the interior of specially enlarged cells, stratified and finally clubshaped outgrowths of the wall are formed, in which are deposited small crystals, scarcely or not at all distinguishable as such, of calcium carbonate (Fig. 37). These clustered structures are known as cystoliths. 
The cell-wall consists of a peculiar substance called cellulose, having the chemical composition $\mathrm{C}_{6} \mathrm{H}_{10} \mathrm{O}_{5}$. It is found in the pure state only. in young cells; in older cells it is often concealed by other bodies which are said to incrust it, or becomes altogether transformed into other substances. Cell-walls are intimately permented, by means of incrustation or infiltration, by other substances which are deposited among the particles of cellulose. The cell-walls of many
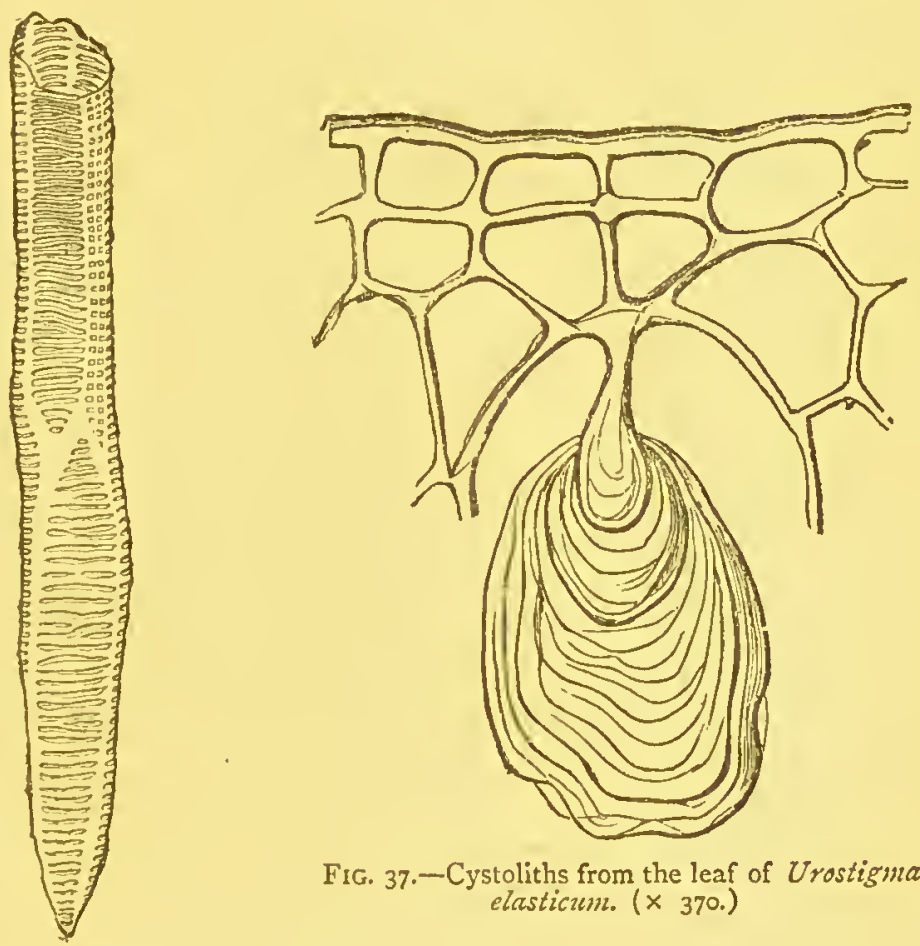

FIG. 37.-Cystoliths from the leaf of Urostigma elasticum. ( $\times 370$.

FIG. 36. - Scalariform cell from the underground stem of the brake, Pteris aquilina. $(\times 500$.

Algæ are converted by incrustation into actual coats of silica, which are often marked with very beautiful tracings, so fine that they are uscd as test-objects under the microscope; and this is especially the case in the diatoms (Fig. 38). Coats of silica and other inorganic incrusting masses often remain as skeletons after combustion of the cells. 
The direct transformation of cellulose into other substances is also a very common phenomenon. The products of tranformation thus formed either impart special properties to the cell-wall, or they are
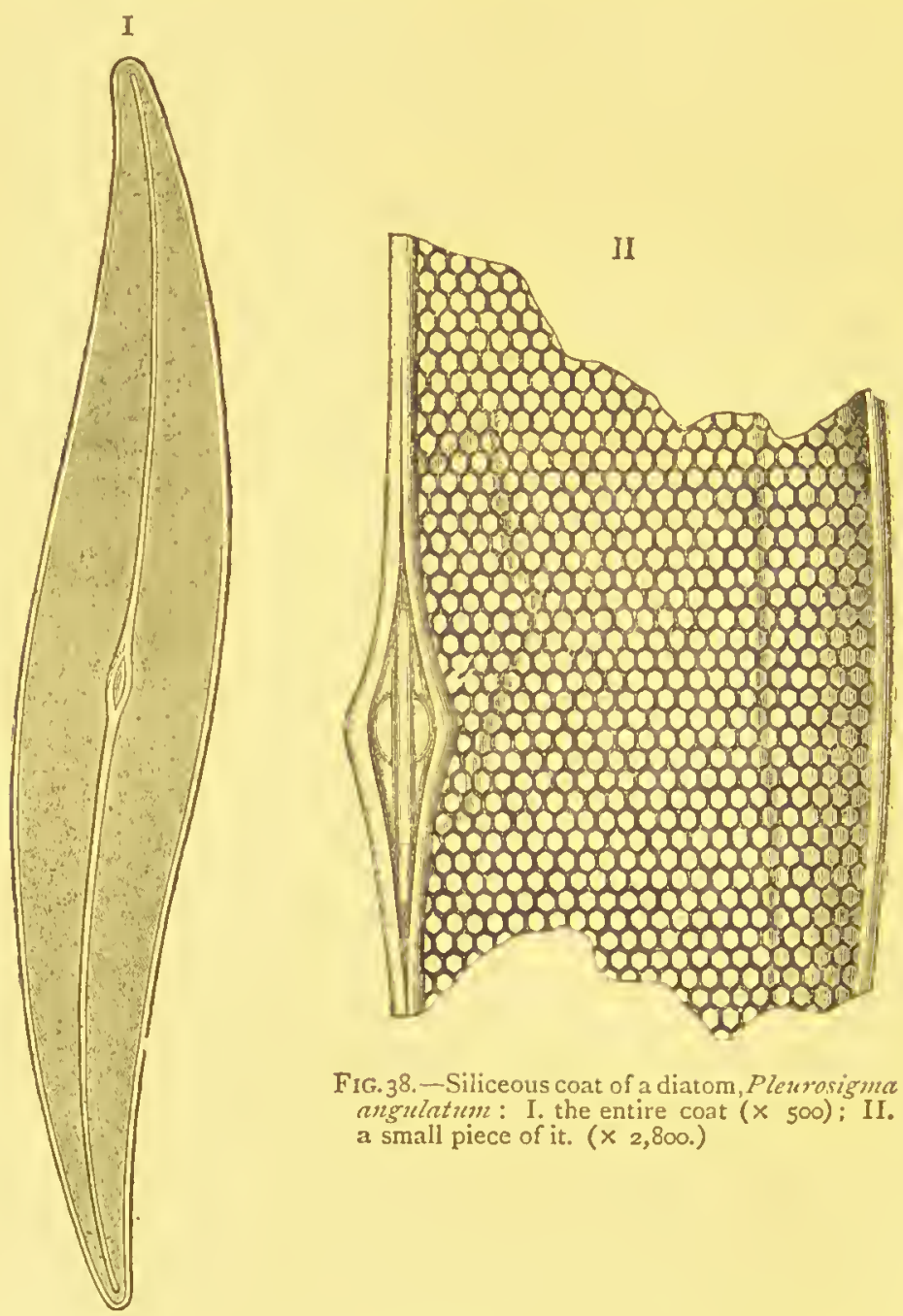

FIG.38.-Siliceous coat of a diatom, Plewrosigne angulatum: I. the entire coat $(x 500) ;$ II. a small piece of it. $\left(x_{2,800}\right)$

used for the future economy of the plant, or must be looked on as excreta. The most common examples of the first kind are afforded by the lignifaction and suberisation of cell-walls; i.e. the processes by which cellulose is converted into lignin or cork. The various cases of 
the second kind, in which the transformed and absorbed portions of the cell-wall are retained to support the life of the plant, havc been comprised under the term resorption. To this class belong the disappcarance of particular portions of the cell-wall in the coalescence of cells to be hereafter described, as well as the resorption in the formation of bordercd pits, in which the cell-walls between the canals have become absorbed. As examples of excreta produced from cellulose by transformation, and no longer of scrvice for the life of the plant, at least in the formation and nourishment of cells, we may regard gum-arabic, cherry-gum, gumtragacanth, and other similar substances. In some cases only particular

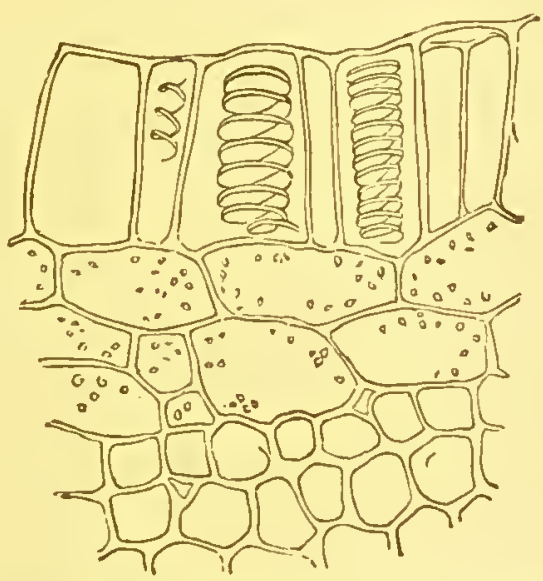

FIG. 39.-Transverse section of a piece of the testa of the seed of Polemonium caruleum. After moistening with water the layers of swollen cells emerge above the outermost cells in the form of a jelly (after Unger).

cells are subject to these transformations; in others all without distinction. Thus, for example, in the stem of the cherry or plum-tree, gum may be produced from any kind of cell. Of a somewhat similar nature to this formation of gum is the conversion into mucilage of the epidermal cclls of many seeds, as in linseed and quince seeds. In these cases the cellwall is excessively thickened; but, wliile othcrwise retaining all its special characteristics, the innermost layers swell up to an extraordinary cxtent in water, so that they burst the outer layers which have not the same property, and emcrge as a transparcnt mucilage (Fig. 39). The secrctions of cells, which will be referred to hercafter, must not be confounded with thesc products of transformation of the cell-wall.

Besides protoplasm, the nucleus, the watery cell-sap, 
and the solid substances and gases contained in it in a state of solution, there occur also in the cell various special cell-contents. Among the more important substances of this nature are albuminous or proteinaceous substances, chlorophyll, other pigments, starch crystalline formations, aleurone, resin, oils, caoutchouc, sugar, tannic acid, and inulin.

Chlorophyll, the source of the green colour of plants, is always combined with particles of protoplasm of definite form, which in consequence appcar of a green colour, and are called chlorophiyll-bodies. These occur only in those cells which possess a cell-wall, never in naked primordial cclls. They are usually lenticular, rarely in the form of bands (as in the Conjugata, Fig. 4I), stellate figures, or in undefined flakes. Chemists are not yet agreed as to the chemical composition of chlorophyll ; but it is probably composed of two independent colouring substances, a golden yellow and a blue-grcen; it is possible also that iron is an essential constituent of it. The access of light is also an indispensable condition for its formation. Plants usually green become bleached or etiolated when grown in the dark; a very small quantity of light is, however, sufficient to produce chlorophyll in many plants that grow in the shade. The germinating seeds of many Coniferæ and the fronds of ferns afford a striking exception, becoming green even in absolute darkness when the temperature is sufficiently high. The chlorophyll-bodies, which arise from and in the protoplasm, remain subsequently imbedded in it, and are especially found in a motionless layer of the parietal coating; rarely, as in Vallisueria spiralis (Fig. 40), in the currents themselves of the protoplasm. They consist of a colourless protoplasmic funda. mental substance, in which the green colouring matter is imbedded. They possess no proper membrane, although the outermost layer is denser, the density decreasing gradually towards the fluid interior. In their interior are often found granules of starch, which have been formed there under the influence of light. The chlorophyll-bodies do not usually increase greatly in size; when fully formed they multiply by division, each splitting up into two ncw bodies. [Chlorophyll is readily soluble in alcohol, and possesses a distinct and characteristic spectrum. Much attention has recently been paid to its constitution. Pringsheim regards as its most important ingredient a substance whicht he calls hypochlorin, which can be scparated in the form of brown glutinous drops, in which the green colouring matter is dissolved. When 
Sirst formed, the chlorophyll-bodies are almost destitute of colour. When kept in the dark, the green parts of a plant become gradually bleached or etiolated, from the disappearance of the chlorophyll-grains. The variegated colour of leaves in autumn is due to a transformation of the cllorophyll into other analogous substances.]

The parts of plants which are not green, as the petals, have peculiar tigments in their cells, sometimes dissolved, sometimes as solid particles. Particles of a red pigment are found, for example, in Adonis autumnalis, $0.004 \mathrm{~mm}$. in diameter, of an orange colour in Zinnia elegans, yellow in
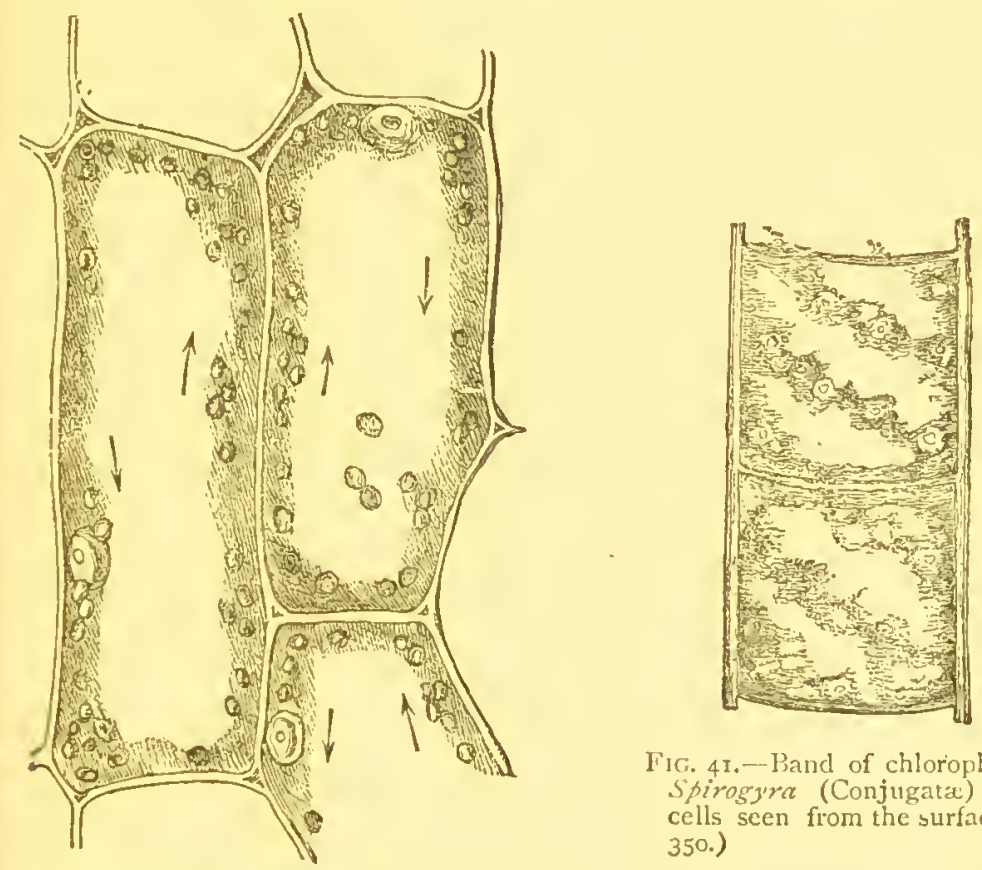

Fic. 41.- Band of chlorophyll in Spirogyra (Conjugata): two cells seen fiom the surface. ( $x$

FIG. 40.-Cells from the leaf of Vallis. 350.) ucria spiralis. The round bodies are grains of chlorophyll; the arrows denote the direction of the currents of protoplasm. ( $\times 800$.)

Kerria japonica. A violet colnur is always, a blue colour usually, due to clissolved pigments. As an example how peculiarly the separate pigments may be distributed in different superimposed layers of cells, the marginal flowers in the capitulum of Zimnia elegans are scarlet on the upper, light yellow on the underside, the uppermost layers of cells contain a purple sap with orange granules, all the rest a rolourless sap with a smaller number of light yellow granules. Only those cells which 
are filled with air appear white; a black appearance depends on a dark shade of a violet or brown colour. The conditions which favour the formation of the bright pigments are not yet known; the agency of
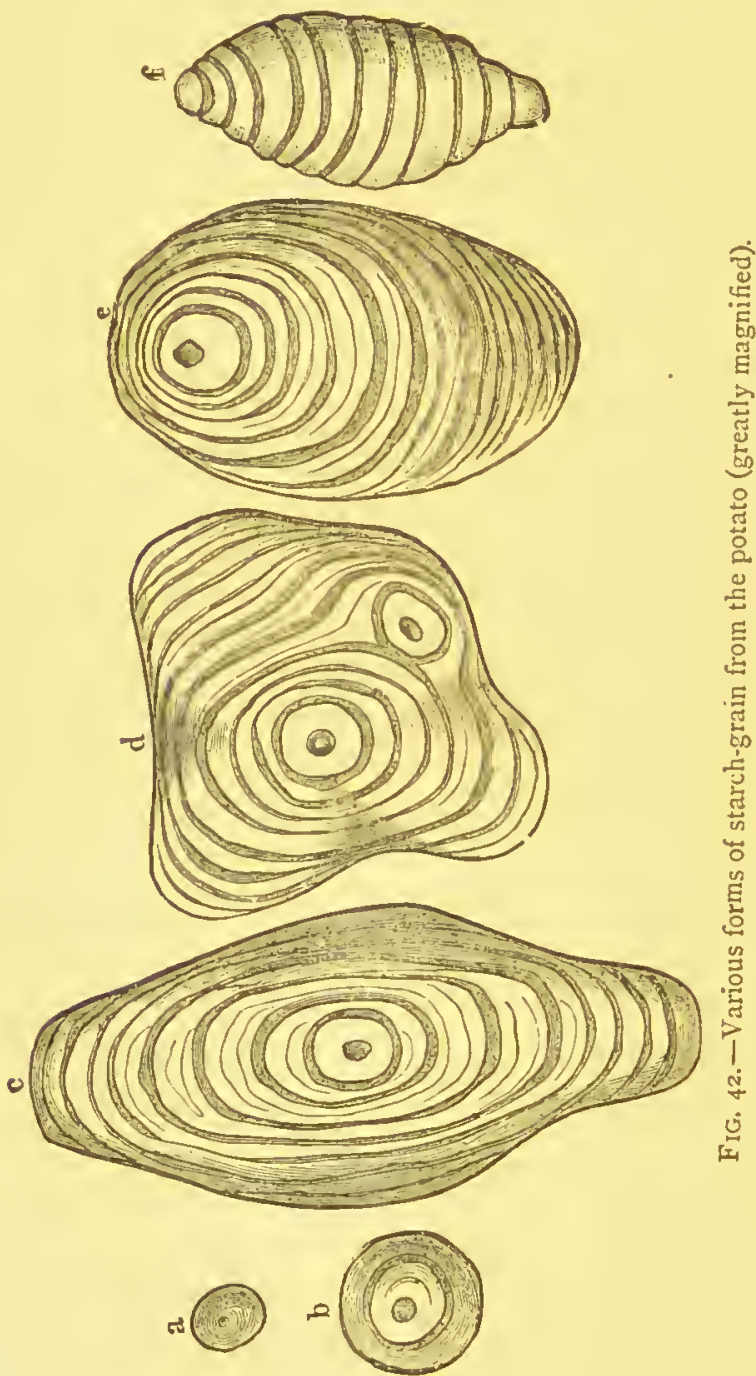

light is not probable, since the bright colouring of flowers appenrs as. soon as the form of the parts of the flower is determined, cren though in the dark. 
Still more widely distributed in the vegetable kingdom than chlorophyll is slarch. With a great external variability in form, grains of starch possess the common characteristic of turning an indigo-blue colour on treating with an aqueous solution of iodine. They have the same chemical composition as cellulose, $\mathrm{C}_{6} \mathrm{H}_{10} \mathrm{O}_{5}$; they are insoluble in cold water, but swell up very strongly in boiling water, forming a naste. If starch mixed with snliva is heated for some time to $45^{\circ}$ or $55^{\circ} \mathrm{C}$. , the substance which is coloured blue by iodine is removed. The conclusion which aaturally follows, that starch consists of the substance that is coloured blue by iodine, granulose, together with a cellulose substance that is not so coloured, called farinose, must not, however, be considered as finally determined. The grains of starch are formed originally within the chlorophyll (Fig. 47). On their first origin they appear



FIG. 43. - Starch. grain from the scarlet-runner. $(x 660$.

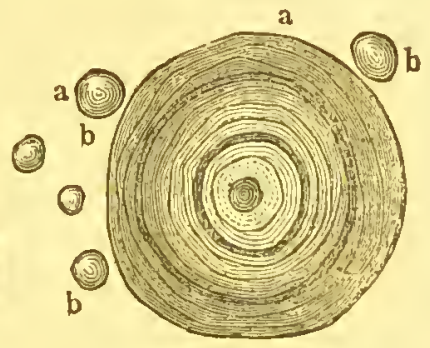

Fig. 44. - $a, b$, starch. grains from rye. $(x$ 660.)

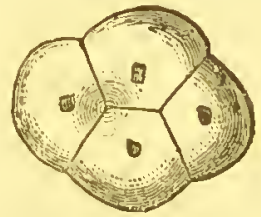

FIG. 45.- Starch-grain from the stem of the sarsaparilla, Sinilax Sarsaparilla. (x 66o.)

as infinitesimally small bodies, which are invariably of a spherical form until they have attained a certain size. In the course of their further growth they deviate in a variety of ways from this form (Figs. 42-46). The fully-developed starch-grains of the sorrel and of the tuberous roots of the orchis are spherical ; those of the grains of cereals lenticular ; of the potato ovoid; grains of the shape of a rod or bone are found in the latex of tropical Euphorbias, \&c. (Fig. 46.)

Mature starch-grains consist, as a rulc, of a number of layers which appear to have been deposited around a central or eccentric nucleus; but it is impossible to believe that separate layers have been actually so formed in the course of growth; it is much more probable that they grow by intussusccption (sce p. 15), and that the stratification is only the conscquence of the layers or shells containing a larger or smaller quantity of water, as is shown by perfectly dry grains of starch being unstratificrl throughout. Those grains which contain two or more 
nuclei, surrounded by a common system of peripheral layers, are termed semi-compound (Fig. 42 d); compound when the divisions which
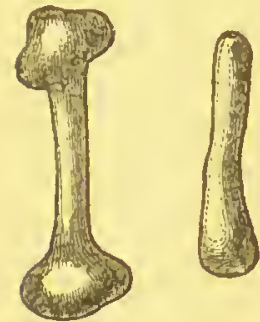

Fig. 46. - Starch-
grains from the lagrains from the lasplendens. $(\times 660$.

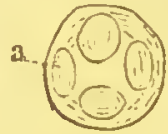

FIG. 47. - Chlorophyll-grain of $P_{i-}$ lea muscosa, enclosing four starchgrains, a (greatly magnified).
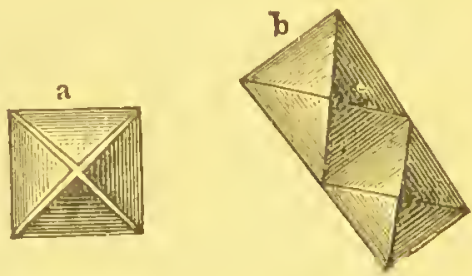

Fig. 48.-Crystals from the leaf of Begonia heraclcifolia; $a$, a single quadrate octohedron : $b$, twin-crystals of the same form. $(x 660$.

separate the grains have advanced as far as the outer circumference (Fig. 45). In opposition to these truly compound grains those are
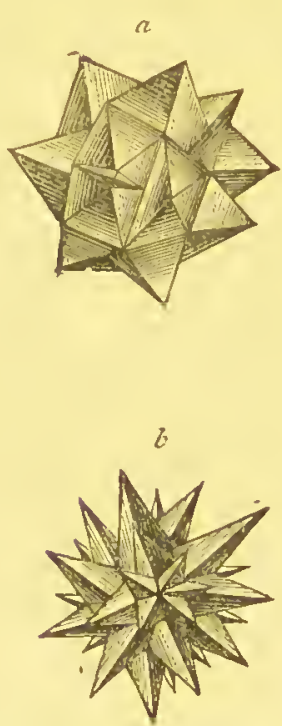

Fig.49.-Groups of crystals; $\alpha$ from the leaf of Begonia heracleifolin (quad. rate octohedra) $; \quad b$ from the stem of Urostigma clasticum. ( $x$ 660.)



FIG. 50.-Cell from the stem of Aloë retrese, with raphides. $(\times 320$.

called pseudn-compound whore several are enclosed togrether in one vesicle, as in a grain of chlorophyll (Fig. 47). Only in a comparatively 
small number of groups of plants has no stareh been found; but this oecurs throughout the elass of Fungi. The purpose of the formation of stareh is that it may be stored up in the eells as a reserve footmaterial, which beeomes clissolved in the subsequent formation of new

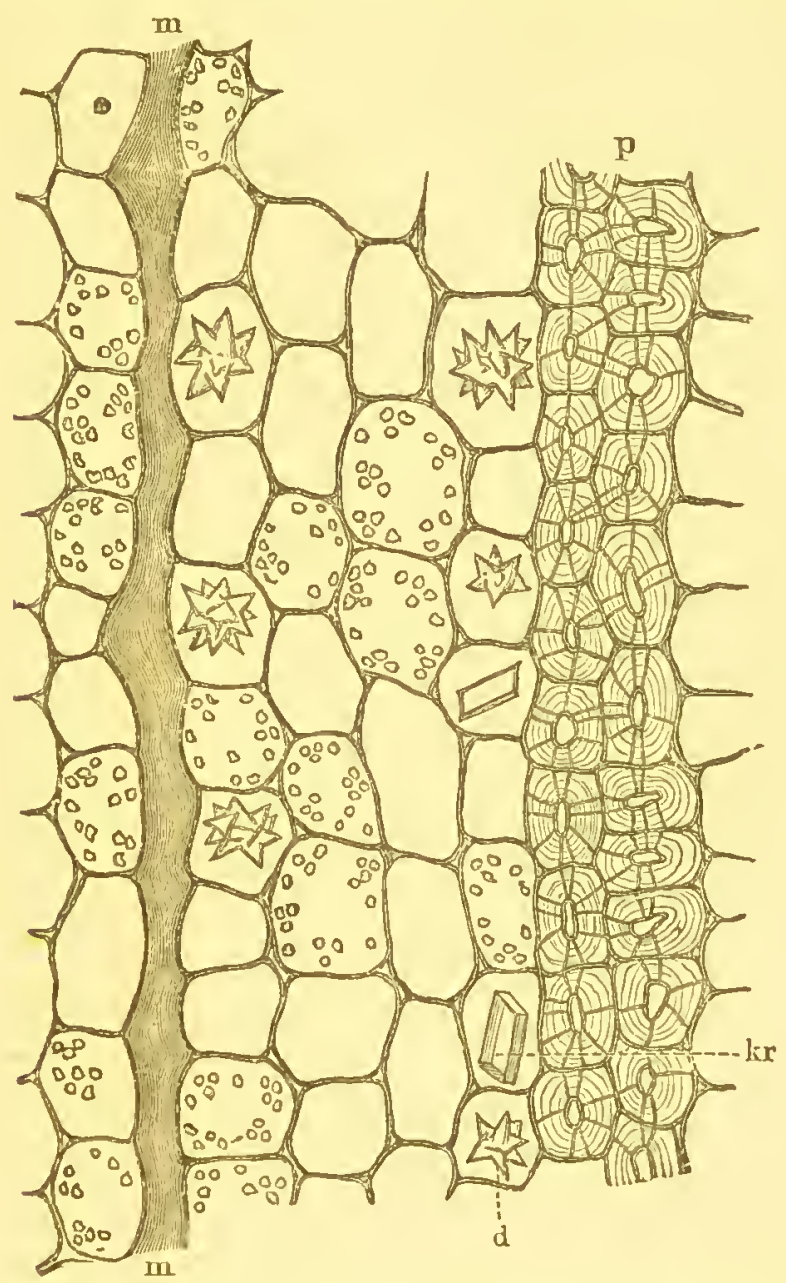

FIG. 5x.-Longitudinal section through the inncr bark of the stem of Hoyre carnosa. Together with the thin-walled parenchyma, partly containing chlorophyll with starch-grains, partly crystals $d$ and $i r$, are bands of very strongly thickened pitted parenchymatous cells $p$, and laticifcrous vesscls $m m .(\times 250$.

eells, and ean then be used as a formative material. It is, therefore, deposited in especially large quantities in bulbs, tubers, seeds, pollengrains, and generally in those organs which, when vegetation awalies, 
form the starting-points of the new formation of large numbers of cells. (See also Chap. V.)

Crystals occur in particular cells in almost all the higher vascular plants, less often also in the less highly organised Cryptogams; and in Conifers are also frequently found imbedded in the cell-wall. They usually consist of calcium oxalate. The crystals, when separate, contain six equivalents of water of crystallisation; their stem-form is a blunt quadrate octahedron (Figs. 48, 49, 5I ). The bundles of acicular crystals or raphides (Fig. 50) have, on the other hand, only two equivalents of water of crystallisation.

The allumimous or proteinaceous substances contained in the ccll are of special importance, since theystand in the closest relationship to

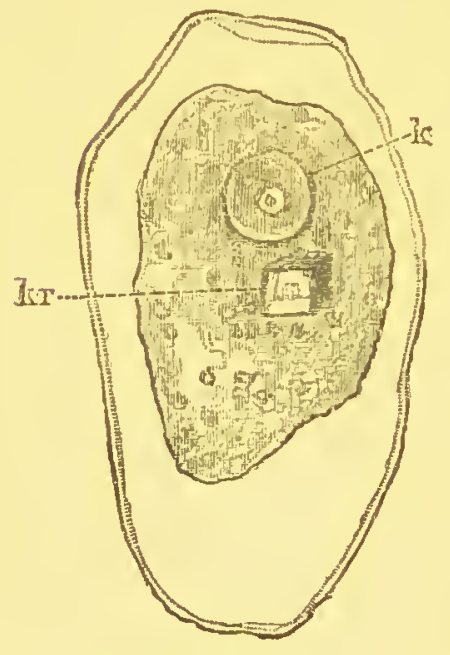

FiG. 52.-Crystalloid $k r$, in a parenchymatous cell of the potato-tuber; $k$ nucleus. $(\times 420$.



FIG.53.- Sphere-crystals of inulin in a parenchymatous cell from a tuber of the dahlia preserved in alcohol, after addition of nitric acid. $(x 420$.

protoplasm. Their presence is generally detected with tolerable ease under the microscope, being coloured red by the addition of water and sulphuric acid or mercury subnitrate. They usually appear to be perfectly dissolved in the cell-sap, often as granular masscs, more rarely in a crystalline form, as protcin-crystals or crystalloids. They exhibit all the esscntial properties of protoplasm, and are not true 
crystals, differing from these essentially in many respects. The cubic crystalloids of the potato, for example (Fig. 52), are not dissolved by water, but break up in a peculiar manner, so as to appear as if composed of several layers. Crystalloids generally occur in the cells in which reserve food-materials are stored up for future use, especially in oily seeds.

Grains of aleurone occur frequently in the endosperm and the cotyledons. In seeds which contain starch this alluminous substance includes only a little oil, and does not form grantles, as in the grasses, bean, vetch, sweet chestnut, \&c. In oily seeds, on the contrary, such as the Brazil nut, nutmeg, Umbelliferæ, \&c., it replaces the starch-grains. Crystals of calcium oxalate, or roundish or clustered granules (globoids), a double calcium and magnesium phosphate in which the latter is greatly in excess, are frequently found in the grains of aleurone, imbedded in albuminous substance.

The roots of Compositæ [and of some other plants], and less often the stems, contain a peculiar substance called imulin. In the living cell it occurs only in solution, and is only precipitated on evaporation or on the addition of alcohol or of some other substance that has a strong attraction for water. If the process is successfully and rapidly performed, the inulin has the form of fine granules which have often a frothy appearance ; but if the process goes on for a consiclerable time, it forms beautiful spherical bodies, called sphere-crystals (Fig. 53). In its composition inulin is analogous to starch.

Besides these substances and those already mentioned, others often occur dissolved in the cell-sap, the presence of which is proved by chemical tests, but which cannot be detected in the cell itself even by the microscope. To this class belong especially the alkaioids, strychnine, brucine, chinine, cinchonine, \&c.

[Continuity of Protoplasm. The cell, while in a living condition, has till lately been regarded as being always a perfectly closed vesicle with unperforated cell-walls. Recent researches have, however, shown that in some cases, especially in endosperm-cells, in the motile organs of such leaves as those of Mimosa, and in the fronds of many Floridex, very delicate threads of protoplasm pass through the cell-wall, and maintain a connection between the protoplasmic contents of adjoining cells. The sieve-pores 
of sieve-tubes are also penetrated by similar threads of protoplasm.]

By the term Cell-formation is understood the mode of origin and multiplication of cells. Four main types of cellformation may be distinguished :-

I. The Renerval or Rejuvenescence of a cell, i.e. the formation of a single new cell from the entire protoplasm of a cell already in existence. This occurs in the formation of

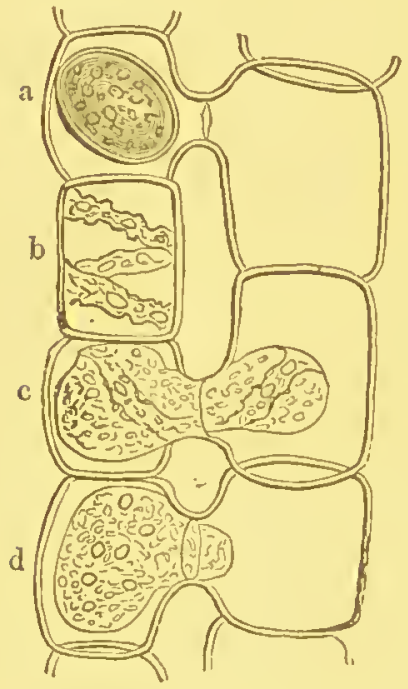

FIG. 54.-Conjugation and formation of zygosperm in Spirogyra guinina: $a$ a mature zygo. sperm; $b$ a cell not yet conjugated: $c, d$ successive stages of conjugation. ( $x 320$.)

a zoospore out of the entire contents of a vegetative cell, especially among the Algæe (see Classification of Algæ, Chap. VI.)

2. Conjugation, or the coalescence of two or more protoplasmic bodies in the formation of a cell. This begins with the lateral approach of two neighbouring cells, and the appearance of an opening at the point of contact, concluding with the complete union of the contents of the two cells for the purpose of reproduction. In its typical form it is limited to a few Alga and Fungi. (Fig. 54.)

3. Cell-dicision, or the division of the protoplasmic contents of the original mother-cell into portions from which are formed the new daughter-cells. When the original cell possesses a nucleus, this process is preceded by the division of the nucleus. This is by far the most common form of the multiplication of cells, since upon it depends all normal vegetable growth.

In the course of the division of the cell, the nucleus undergoes great changes. It becomes coarsely granular, and appears striated longitudinally in a direction at right 
angles to that in which the cell is dividing; the separate threads become thicker in the middle, and form the nuclear
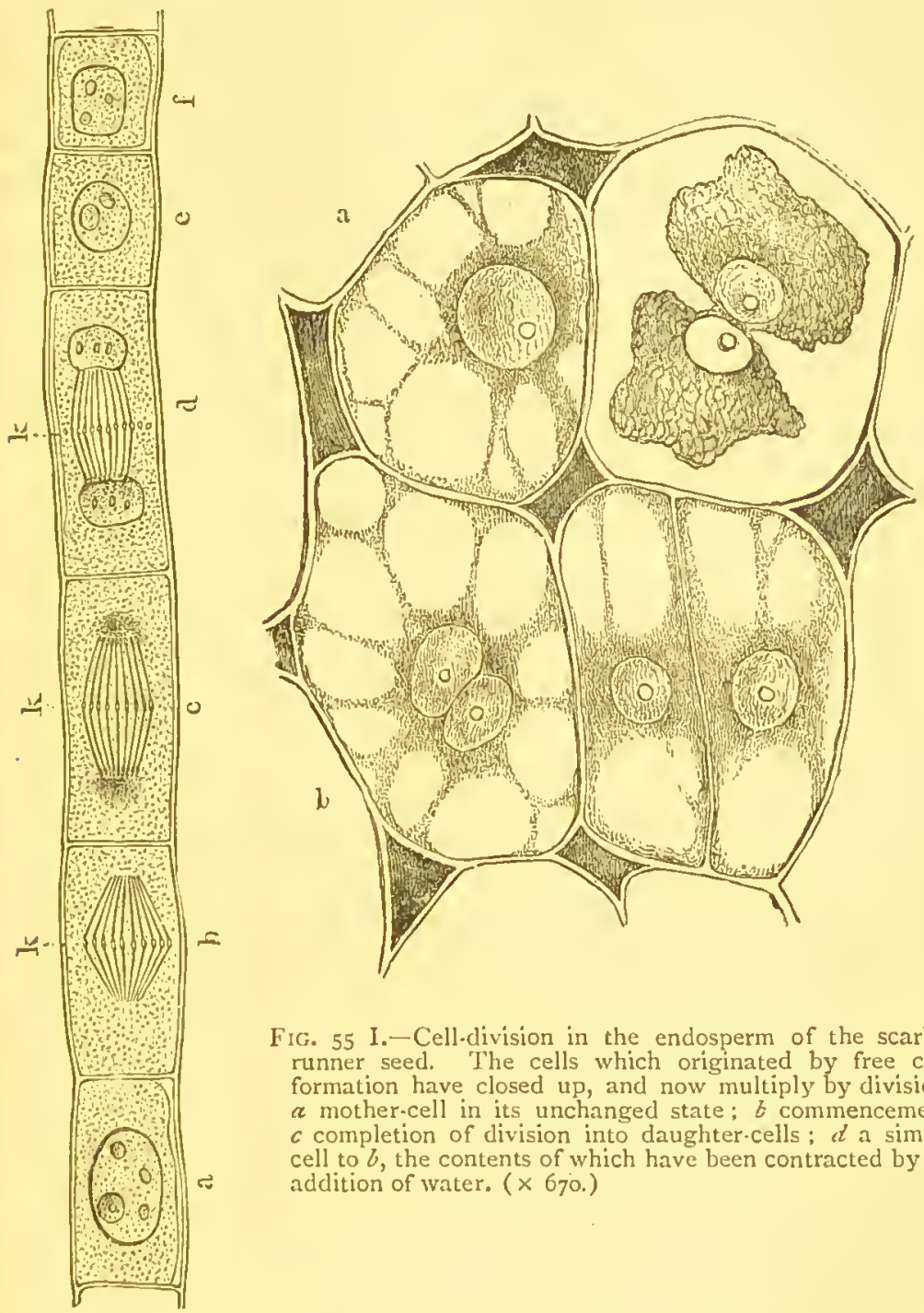

Fig. 55 I.-Cell-division in the endosperm of the scarletrunner seed. The cells which originated by free cellformation have closed up, and now multiply by division; $a$ mother-cell in its unchanged state; $b$ commencement, $c$ completion of division into daughter-cells; $d$ a similar cell to $b$, the contents of which have been contracted by the addition of vater. $(\times 670$.)

FIG. 54 A.-Cell-division in the hair of a filament of Tradescantia (after Stras. burger). In $b$ the nucleus has already assumed the striated condition; in $c$ the division of the nucleus is completed; in $d$ the nuclear plate $k$ is already formed, and the young nuclei further developed; $c, f$ young cells in which division has just taken place; $a$ mature cell. 
plate (see Fig. $54 \mathrm{~A}$ ), the two new nuclei being formed at its ends. After the division of the nucleus, the first stage of cell-division, the formation of the new cell-wall takes place, which may be either gradual or simultaneous. In the latter case (Fig. 55 I) the formation of the nuclear plate is followed by that of a plate of cellulose, the first rudiment of the new cell-wall. The threads of the original nucleus which still remain then disappear, and the daughter-cells are now fully formed. When the cell-wall is formed gradually, it first makes its appearance as a narrow ring on the inner surface of the wall of the mother-cell, this ring gradually increasing in breadth until it becomes a plate which divides the entire cavity of the mother-cell into two chambers. This mode occurs in the formation of the cellwall of many filamentous Algæ (Fig. 56); the simultaneous formation is the ordinary mode of increase of vegetative organs.

A special form of cell-division is that known as Gemma. tion, which occurs especially in Saccharomyces (see Fig. $38 \mathrm{r}$, p. 249). A vesicular protuberance here makes its appearance on the mother-cell, into which a portion of the proto plasm enters; this protuberance is ultimately cut off by a wall of cellulose, and the two cells then separate from one another. The daughter-cell may put out similar buds before its separation from the mother-cell ; and in this way colonies of buds are formed.

4. In Free Cell-formation the masses of protoplasm of the mother-cell collect around the nuclei previously produced, and thus form themselves into new cells which remain enclosed within the mother-cell, the life of which still continues for a time. In most cases they have already formed a cell-wall of cellulose while still enclosed within the mother-cell, as in the case of pollen-grains and the embryosac of Phanerogams (Fig. 55 II.) ; less often not till after their escape, as occurs in zoospores. [Free cell-formation 
occurs only in the formation of organs connected directly
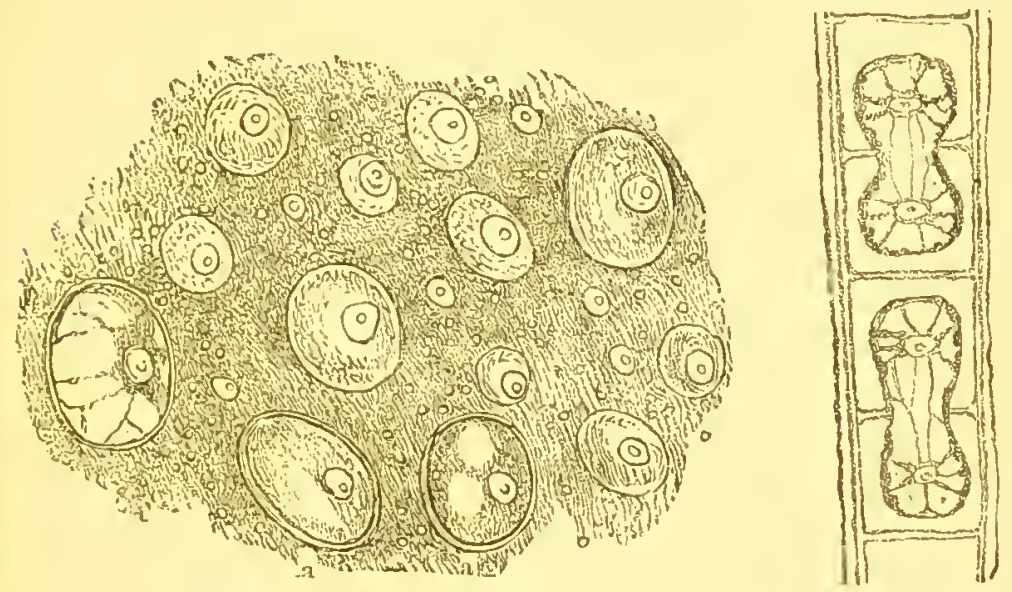

F1G. 55 II.-Free cell-formation in the embryo-sac of the scarlet-runner: $a$ a cells already perfect. $(\times 670)$

Fig. 56.--Two cells of Spirogyra in the act of division, after contraction of the cell-contents by the addition of a solution of sugar, the portions of the cell-wall already formed being thus made visible. In each half of the cell is a secondary nucleus, from which bands of protoplasm proceed to the margin. (Strongly magnified.)

or indirectly with reproduction, not with ordinary vegetative growth.]

\section{CHAPTER II.}

THE CELL AS A MEMBER OF A GROUP OF SIMILAR CELLS.

ONLY a comparatively small number of plants consist, during the whole period of their existence, of a single cell; in the greater number the cells are united into groups. The production of these groups of cells is caused by two circumstances:- In the first place, the cell-walls of young contiguous cells, where they are in contact with one another, amalgamate into a homogeneous mass; and secondly, cells originally distinct coalesce with one another when the portions of the walls that are in contact are of nearly the same naturc. This union of adjacent cells is so intimate 
that it can be artificially destroyed only by chemical reagents which dissolve the outermost layers of the cell-walls themselves. It nevertheless happens very frequently that, in consequence of the unequal growth of adjacent cells, the cell-walls which have already coalesced again partially or entirely separate from one another, so that a cavity or intercellular space is formed between these cells (Figs. 60, 63) The form and arrangement of these small intercellular spaces differ greatly in different plants, and in different parts of the same plant. They occur, for example, between the spherical cells of certain groups, where they form together a system of intercellular passages, which often increase into capacious air-cavities, air-canals, or large open spaces. The causes which co-operate in the formation of these intercellular spaces may be very various; in addition to the separation of cells previously united, a dismemberment and subsequent drying up of dead cells may be especially mentioned.

There is no spccial substance uniting and uniformly cementing together the individual cells; but if groups of thick-walled cells are

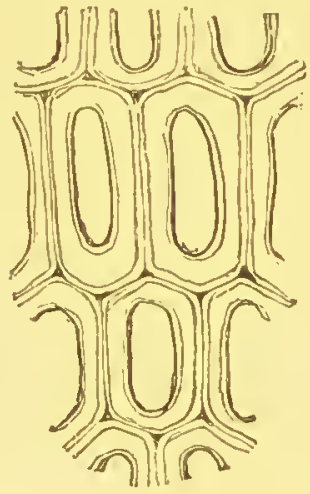

FlG. 57. -The so-called ' intercellular substance," as delicate lines which unite in the angles between the cells of the wood of a Conifer. ( $x$ 400.)

course of their growth some important change in their chcmical nature. the contiguous cells are connected together by a uniform meciian layer apparently common to the two cells. It was the figuring of this structure (Fig. 57) which originated the idea of a peculiar 'intercellular substance' not belonging to the cells; but a more exact investigation. especially of the development of the groups of cells, shows that even in these cases there is no independent median lnyer, but ratlicr a region whcre a coalescencc has taken place of contiguous ccll-walls which may have undergone in the

examincd, it is generally found that 
Certain differences exist in the groups of similar cells, according to which they are distinguished as families of colonies, tissues; and fusions of cells.

A cell-family originates from a single mother-cell; and each of the daughter-cells preserves its own individuality,

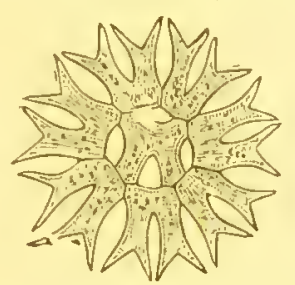

Fıg. 58.-A family of Pediastrum rotula (an Alga) consisting of eight cells. ( $x$ 250.) which can even proceed as far as separation from the family. In Pediastrum rotula, for example (Fig. 58), the green contents of each mother-cell break up into several spherical daughter-cells; the innermosi membrane of each separate mother-cell then protrudes through a fissure and rapidly enlarges, in order to make room, in the cells formed in it, for a cresping motion which lasts for some time. As soon as
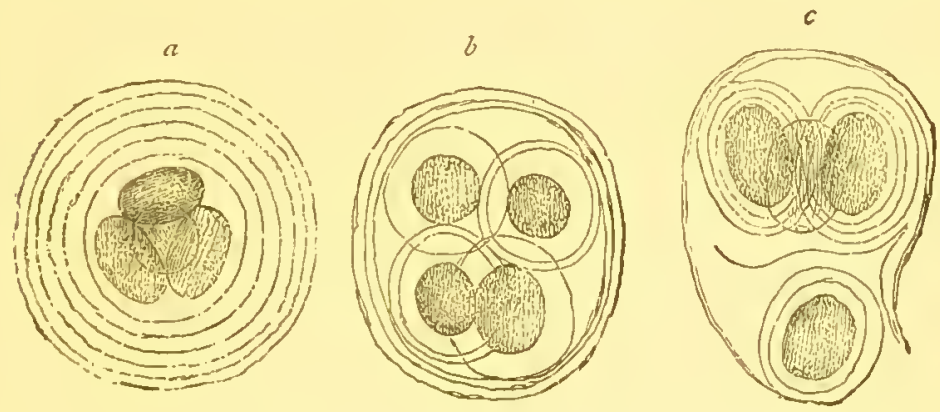

FIG. 59.-Pleurococcus superbus: $a$ a family of four cells; the cells themselves are naked, but the whole family is enclosed in a common cell-wall consisting of six layers; $b$ each cell has developed a separate cell-wall ; $c$ the original cell-walls have burst, and the separate cells have become free ; they continute for some time in motion, then come to rest, and develope new families. (After Cienkowski, $\times$ 320.)

this motion ceases, the sister-cells place themselves together so as to form a plate, and produce in their development a. new colony. Cell-families occur only in the lowest classes of plants, the Algæ and Fungi (Fig. 59).

The union of cells into tissues and cell-fusions is permanent, and is combined with a limitation in various ways of the 
functions of the separate cells. In the former the cells unite only into a group, the elements (separate cells) of which can still be easily recognised, and still possess a certain individu-

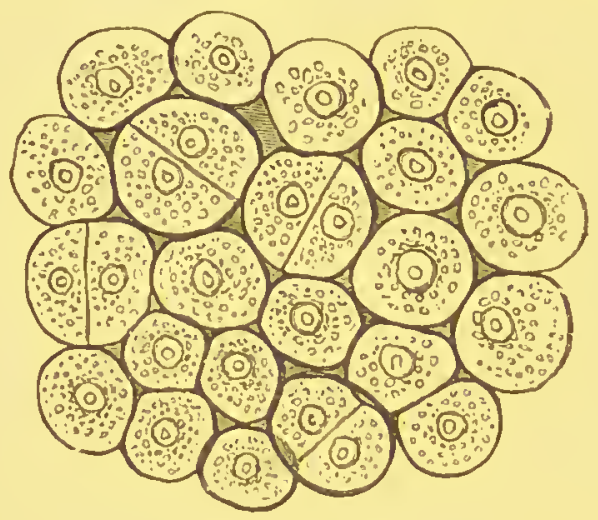

FIG. 60. - Transverse section through the growing point or primary parenchyma of the fig, Ficus carica; the cells are still roundish and in the act of dividing. $(x+200$.

ality ; in the latter, on the contrary, the separate cells coalesce into a single individual, the elements of which are often com-

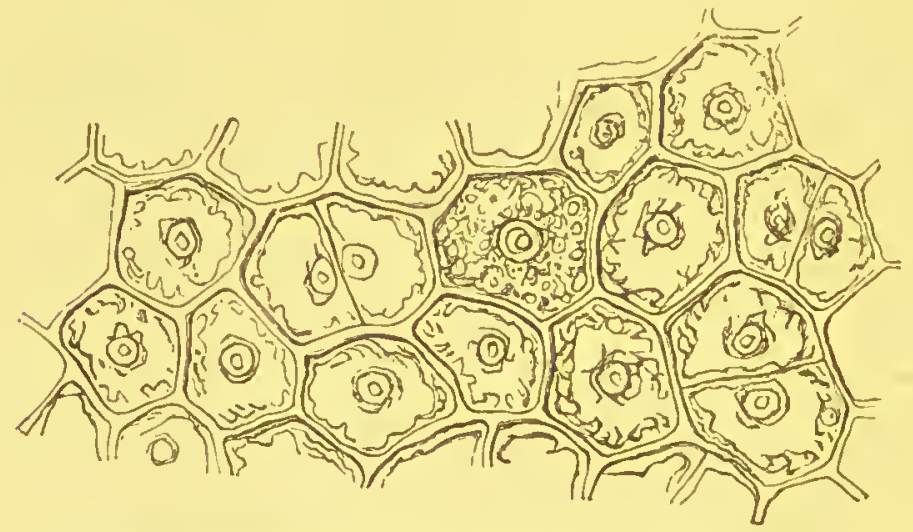

FIG. 6r.-Parenchymatous tissue : transverse section through a deeply buried part of the pith of the apex of the plumule of the horse-chestnut : the cells have become crowded and hence polygonal; only a few have as yet divided. $(x 800$.)

pletely indistinguishable as such. Both are of much greater importance in the vegetable world than cell-families, since their occurrence is incomparably more frequent. 
If the cells which constitute a tissue are pointed at their ends, much longer than broad, and dovetailing into one another, the tissue is called prosenchyma. If the cells, on the other hand, are arranged in rows, are bounded by flat or curved walls, and not much longer than broad, it is called parenchyma. The two kinds of tissue frequently pass over into one another, and may be more or less regular according to the mode in which the cells have been developed (Figs. 6o--63). To special forms the terms collenchyma and 'tela contextor' have been applied. The former usually consists of cells which have become more strongly thickened at the corners than at the sides; the thickening-masses are also capable of swelling, so that when they lie in water they appear glossy and swollen, and assume a gelatinous or mucilaginous character (Fig. 64). 'Tela

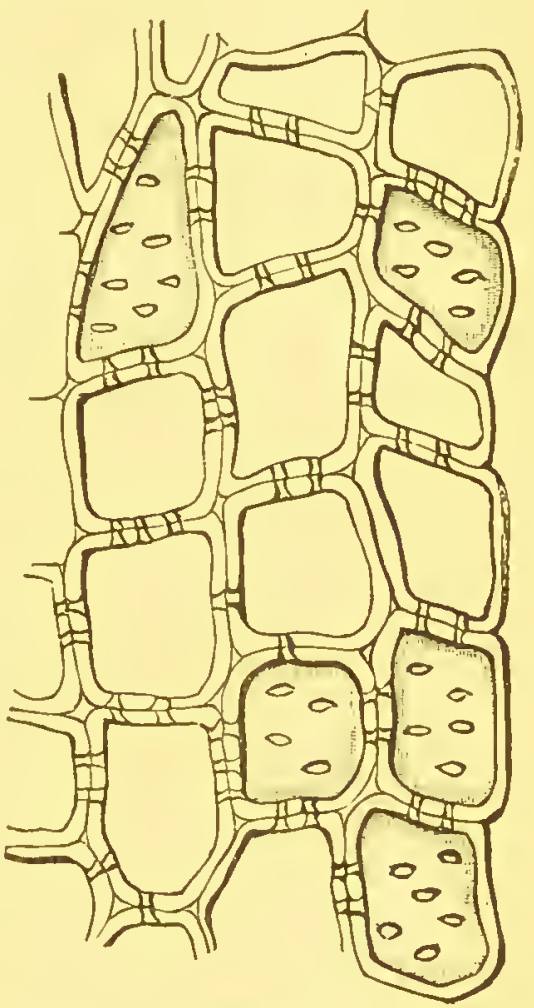

FIG. 62,-Moderately thickened pitted parenchyma from the pith of the beech. $(x 320$. contexta' is a tissue in which the simple or branched elongated thread-like cells are not regularly united to one another, as is the case in the kinds of tissues previously described. The separate cells are in this case arranged in threads which do not run parallel to one another, but cross irregularly, forming a tissue the separate cells of which are not unfrequently grown or cemented together in an intimate manner and in a variety of ways. This occurs in Fungi, Lichens, and some Algæ (Fig. 65, p. 42). Some- 
times, especially in the pileus of certain Fungi, particular cell-layers of a 'tela contexta' form an apparently regular parenchyma, in which however the whole course of development shows that we have here distinct but contiguous filaments of cells (i.e. filaments of distinct cells arranged in

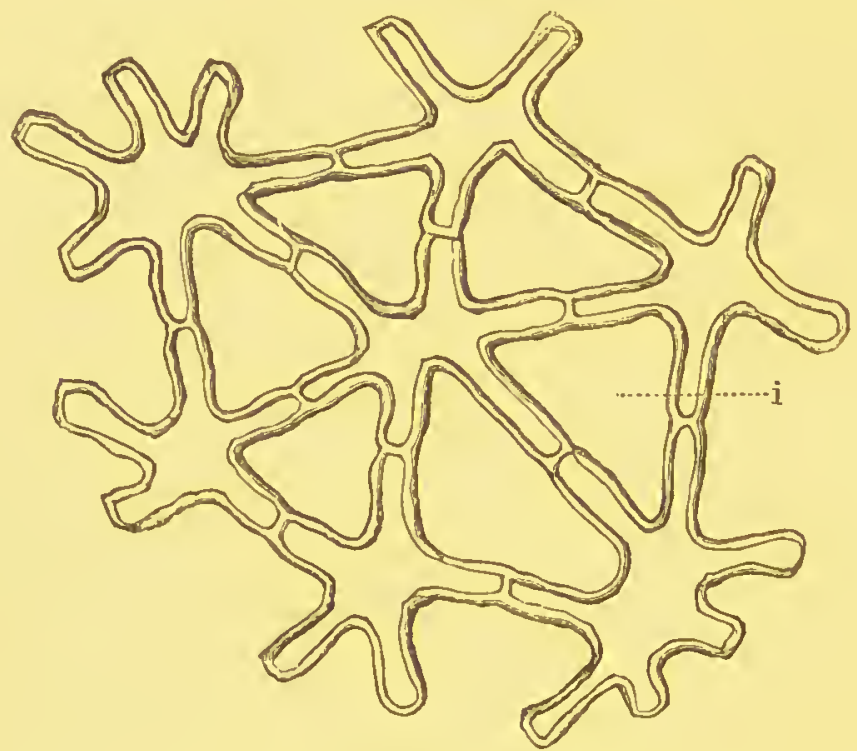

FIG. 63. - Stellate parenchyma from the pith of the rush, Funcus conglomerntus ; $i$ intercellular space. $(x 250$.

rows) ; and a tissue of this kind has therefore been called a pseudo-parenchyma. [A tissue composed entirely of sclerenchymatous cells (Fig. 25, p. 17) is known as sclerenchyma, and is one of the hardest tissues known in the vegetable kingdom. Good examples occur in the 'stone' of stonefruit, the shell of nuts, \&c.]

With respect to the production of new cells, even superficial observation shows that, at least in the higher plants, as for example in trees, it does not proceed everywhere uniformly, but is confined to particular spots. To spots of this nature the terms growing point, cone of growth, and growing or formative layer, have been applied, according to their degree of development. Instances of growing points 
occur in the apices of buds; of formative layers between the wood and the bark of [exogenous] trees. Both owe their special character to the formation of new cells or organs by means of a special tissue to which the names

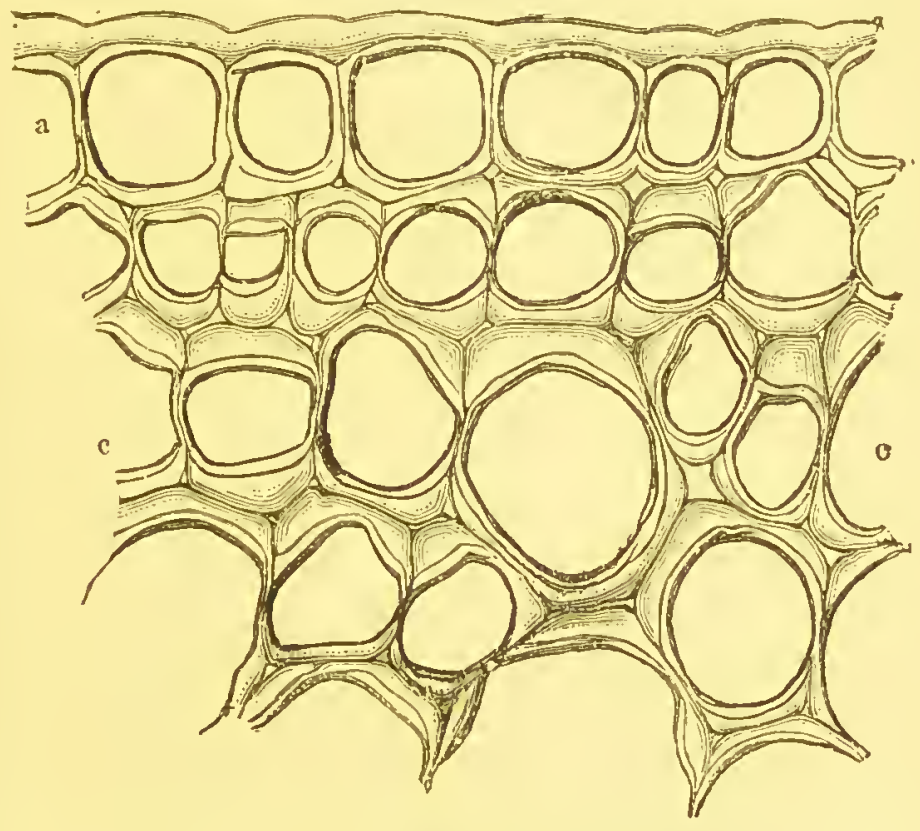

Fig. 64.-Transverse section through the collenchyma of the sowthistle, Sonchus asper: $a$ epidermis : $c$ collenchymatous cells. $(\times 670$.

formative or generating tissue and meristem have been given. In contrast to this, a tissue in which the cells are not as a rule capable of dividing, is called a permanent tissue, and the separate cells which no longer serve for the formation of new cells, permanent cells.

The generating tissue of the growing point of flowering plants is parenchymatous, and is called primary parenchyma or primary meristem, because every kind of cell and every part of the plant may or actually does develope, directly or indirectly, from it. Independently of growth by the actual increase in size of the individual cells, the apical 
growth of plants depends mainly on the constant fresh formation of this tissue.

The increase of thickness in plants, on the contrary,

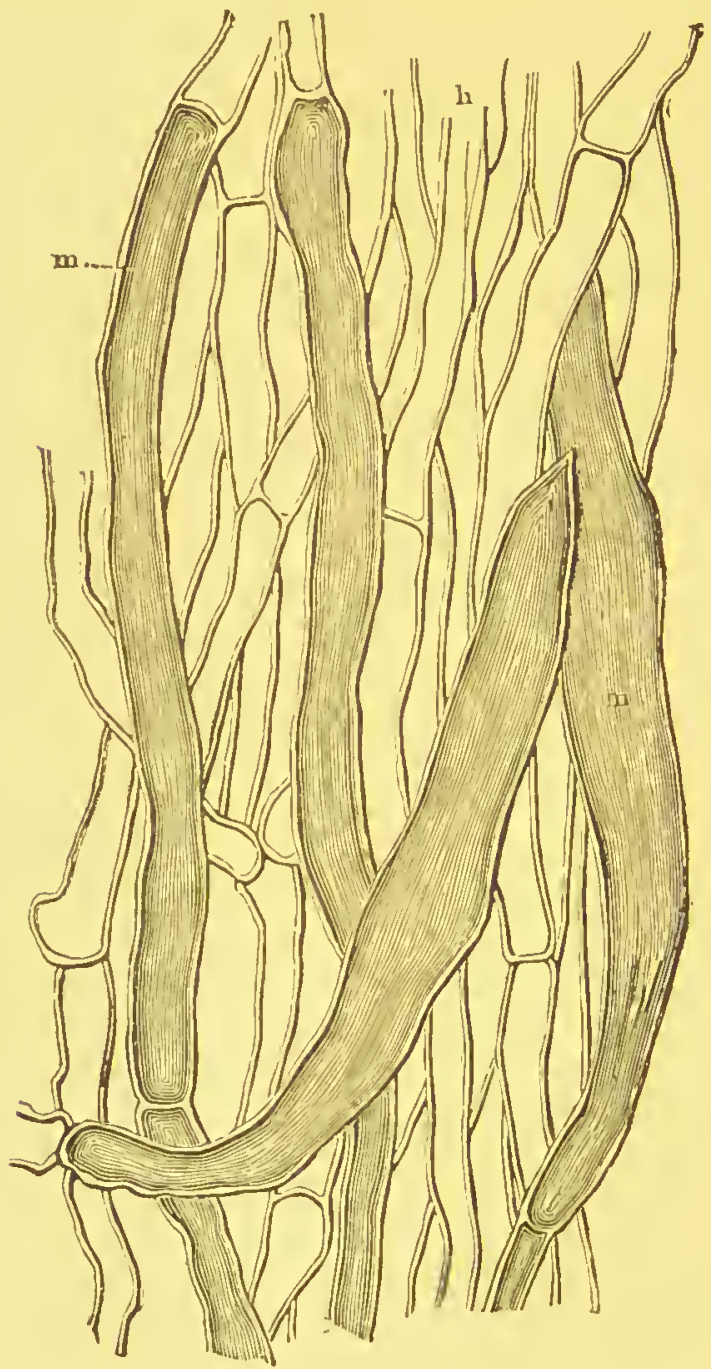

FIG. 65 - 'Tela contexta' from the medullary layer of the pileus of a Fungus, Amanita muscaria; $h$ ordinary cells; $m$ laticiferous cells. ( $\times$ 360.)

occurs especially in those parts where there are permanent structures which increase in diameter during the whole 
period of their existence, chiefly or even exclusively from the formation of a special generating tissue, the cambium. The cambium is usually a prosenchymatous tissue, not found in the growing point, but distributed elsewhere in very various parts of the plant. To it is due the final development of the fibrovascular bundles, which however originate in its forerunner, the procambium. The cambium forms, according to circumstances, a central cambium-cylinder, or isolated dispersed cambium-bundles, or a cambiumring. A thickening-ring of this character occurs, for example, in the layer formed between the wood and the bark of those trees which are characterised by the formation of annual rings. In the most lowly organised plants, the Fungi, Lichens, and Algæ, both kinds of generating tissue are wanting, and every one of the cells has an equal capacity for originating new vegetative cells, i.e. such as serve only for growth and not for reproduction. Although the production of new cells is the special province of the specific generating tissues now described, this does not imply that the elements of other tissues are entirely destitute of this power; on the contrary, it is strikingly manifested in the annual and especially in succulent parts of plants.

In direct contrast to the generating tissues are the healing-tissues, suberous tissues, or cork-tissues. The former are of service to the plant by their long-continued and vigorous growth and the formation of new cells; while the latter, dying quickly, lose their cell-sap ; their cell-walls become converted into cork, and thus form a mantle or envelope which protects the subjacent cells from injurious influences of all kinds. Two kinds of this tissue are distinguished-true cork or suber, and periderm; the two are not, however, sharply separated, but pass into one another in a variety of ways.

True cork is a very elastic tissue consisting of thin-walled, usually nearly cubical, cells (Fig. 66). It does not peel off, but often contains long clefts, as is commonly seen in the bark of the maple. 
Periderm consists of tabular cells with thicker walls, which, when looked at vertically, have a regular polygonal or stellate appearance. It has in general more vital power, and

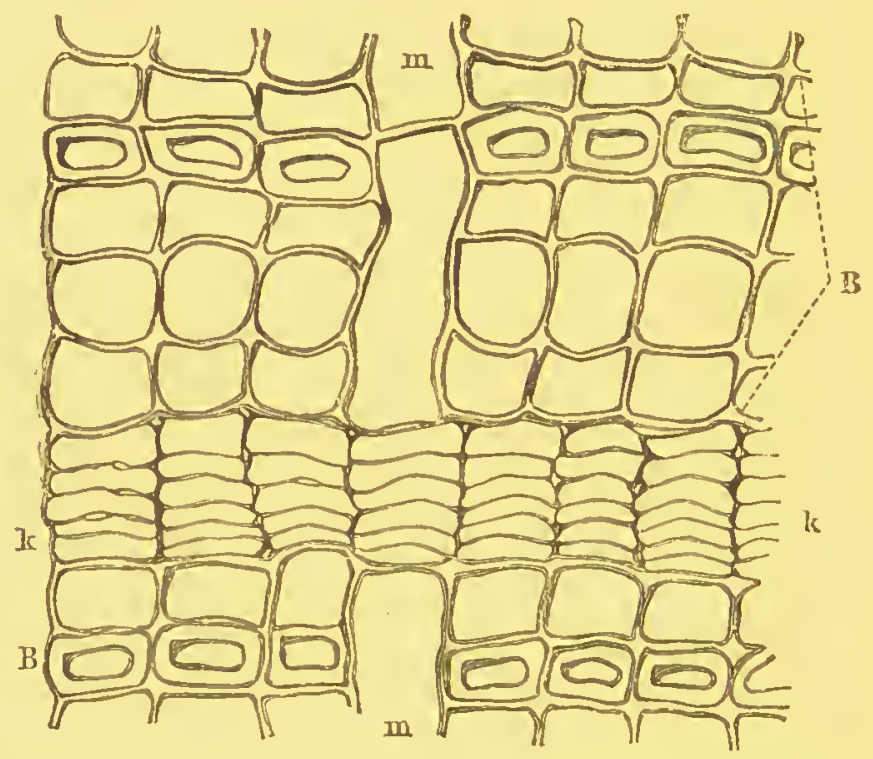

F1G. 66. - Transverse section through the bark of the juniper ; $\mathrm{B} \|$ bast-cells ; $m z$ medullary rays; $k$ layer of cork formed of thin-walled cells parallel to the circumference of the stem. ( $x 370$.

is firmer, less elastic, and more leathery than true cork. When it is several layers in thickness, thick and thinwalled layers often alternate (Fig. 67), causing frequently a peeling off, as in the birch and cherry; in the beech and silver fir, on the contrary, the periderm does not peel off.

Cork is the true healing-tissue of plants, and as such is of grent importance. In the fiesh surfaces of wounds, the uppermost layers of cells as a rule diy up, while in the tissue beneath them, still full of sap, new cells are formed which are the origin of the cork. A vcry good example of the importance of this production of cork is afforded by the cochineal-cactus. This plant is multiplied by cuttings, which would dccay at once if they were set in the ground with the surfaces of the wound fresh. The shoots which are intended as cuttings are therefore first laid for about four weeks in a dry place exposed to the sun, in 
order that a cork-tissue may be formed, which closes the wound and prevents the decay of the cutting.

Larger wounds, as, for instance, when branches are cut off, are often closed by the formation of elevated cushion-shaped masses of cells, not consisting entirely of cork-lissue, which are fresh formed over the whole surface of the wound. Such a tissue is called an overgrowth, and is seen especially in the beech, silver fir, and lime (Fig. 68). Of a similar

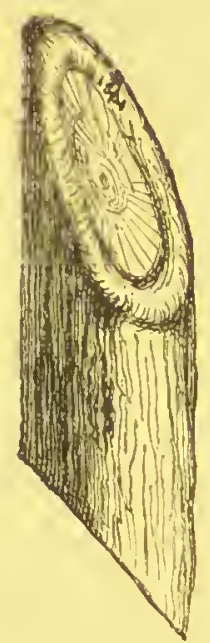

Fig. 68.-Overgrowth on a branch cut through obliquely. (natural size.)

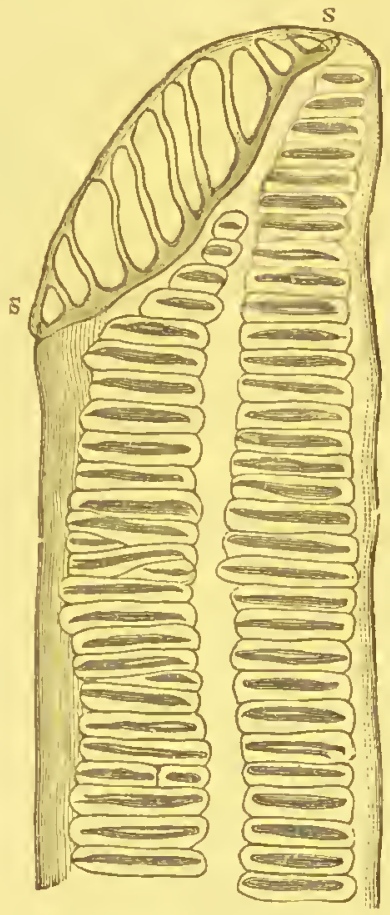

Fig. 69.-Portion of a scalariform vessel from the brake, Pteris aquiliua; $s s$ the transverse division-wall broken through in a reticulate manner. ( $x$ 370.)



Fig. 70.-Pitted vascu. lar cell from the stem of a grass, pleragmites commutuis, with numerous 'mall bordered pits. $(x+400$.

nature is the callus, to which we shall recur when speaking of reproduction by means of cuttings.

Smaller developments of cork at particular points of the surface, which assume characteristic forms according to the species, are termed lenticels. They appear in young branches before the formation of periderm, and occur in the birch, beech, elder, \&c. 


\section{The Cell as a Member of a Group.}

The special characteristic of cell-fusions consists in the cells of which they are composed uniting completely by coalescence into a uniform whole of a higher type. Unions of this kind are usually accompanied by the transformation and absorption of at least a portion of the surfaces of contact. Fusions of a less complete kind have already been described in the coalescence of the contiguous cells of 'tela contexta ;' unions of a more perfect description occur in conjugation and the formation of vessels.

The process of conjugation, to which reference has already been nuade, begins with the lateral coalescence of two contiguous cells, and the formation of an opening at the point of contact; finally the contents of the two cells coalesce in the production of a zygosperm (Fig. 54, p. 32). This process has hitherto been observed only among Fungi and Algæ, and especially in the family of Conjugatæ belonging to the latter.

Vessels arise from the coalescence of several cells, which are then termed vascular cells; the division-walls partially disappearing while the union continues at the margin. Vessels are divided, according to their form and contents, into vessels in the true sense of the word, bast-tubes or bast-fibres, sieve-tubes or bast-vessels, utricular vessels, and laticiferous vessels.

If a number of spiral cells are imagined placed one over another and coalescing from the more or less complete absorption of the partition-walls, a spiral vessel is produced. Vessels are formed in a precisely similar manner, from several of the kinds of cells previously described; and we thus get annular vessels, reticulate vessels (Fig. 35, p. 20), scalariform ressels (Fig. 69), and pitted or dotted vessels (Fig. 70). [An elongated dotted or pitted vessel is known as a duct (Fig. 35).]

The individual vaseular eells sometimes stand vertically one over another, and coalesce by their horizontal faees; sometimes they are in con. tact laterally, and with faces that stand obliquely. The partition-walls do not always entirely disappear ; but often, especially when they stand obliquely, portions remain which are more strongly thickened and of a 
reticulate or scalariform character (Fig. $69, s s$ ). True vessels usually becomc lignified, but are never branched, or at all events extremely rarely. In the mature state they contain nothing but air; but occasionally in the spring a portion of the sap sucked up by the roots is pressed into these air-containing vessels, a process on which depends, for example, the 'weeping' of wounded grape-vines. In many Vascular Clyptogams, Gymnosperms, and Monocotyledons, as well as in a few Dicotyledons, rows of vascular cells are found in places where, from the analogy of other plants, one would expect to find vessels, the partition-walls not having become absorbed. Such structures compose what is called a conducting tissue; and the separate cells are not called vascular but conducting cells.

Bast-tubes or bast-fibres are long pointed vessels-not cells, because their elements have completely coalescedusually thick-walled, rarely branched. They are not often in direct communication with one another, and then always only by lateral branches. They are commonly united into bundles, and as such form an essential part of many fibrovascular bundles (see Chap. VI.).

While in vessels the separate vascular cells of which they are composed can still be made out with tolerable ease, this is by no means the case in bast-tubcs; on which account opinion was long divided among botanists, whether bast-tubes-the development of which is generally extremely difficult to observe-are formed by the coalescence of cells, or by a single cell incrcasing from 20 to 50 times its original length. The simple consideration, however, that if the growth of bast-tubes were of the latter nature, it must be accompanied by an increase in thicliness of the entire bundle of which it formed a part, which is not actually the case, shows that they can arise only by the coalescence of celis.

A close relationship subsists between sieve-tubes, utricular vessels, and laticiferous vessels, partly on account of their form, partly of their contents; all appearing to have for their function the storing up of nutrient fluids, and the conducting of them to the parts of the plant where they are required.

Sieve-tubes or bast-vessels result from the coalescence of cells standing one over another, the partition-walls of which, or sicze-discs, have become perforated in the manner of a sieve; 
and some have also sieve-like perforations through their side-walls (Figs. $7 \mathrm{I}-74$ ). Of similar construction are lat-



Fig. 72.-Longitudinal s ct o i through the transverse particion-walls in the sieve-tubes of the gourd; $Z$ the primary cellulose-wall; $h$ the secondary cell-wall ; $v v$ the peculiar thickening which is always found in young cells; $i$ the contents contracted and passing through the perforations in the transverse partition-wall or sieve-disc.



FiG. 73. - Transverse section of a sievedisc, the upper part represented with the thickening-substance which takes the form of wart-like elevations; the lower part without it. (Stronģly magnified.)

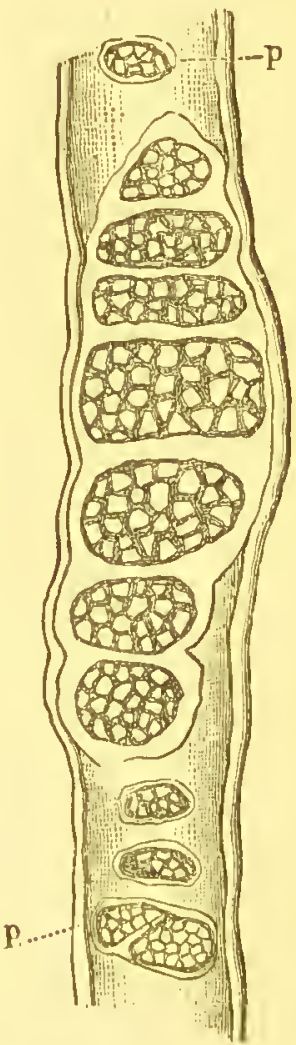

Fig. 24. - Part of a sieve-tube from the lime, Tilia grandifolia: to the sievediscs of the radial sidewall. ( $x$ about 800. ) 
ticed cells, the partition-walls of which are not actually perforated, but only thickened in a sieve-like manner. Both. contain as a rule a turbid granular sap, are mostly associated

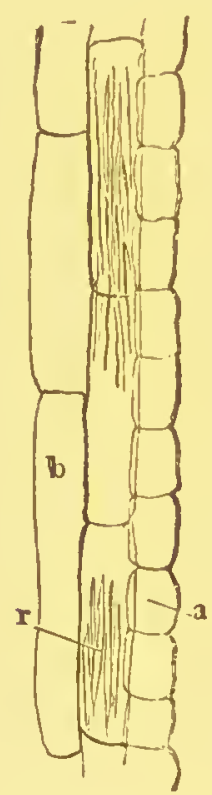

Fic. 75. - Utricular vessel with raphides $(r)$, and contiguous cells $a$ and b. from the stem of a Tradescantia. $(x$ 300.)

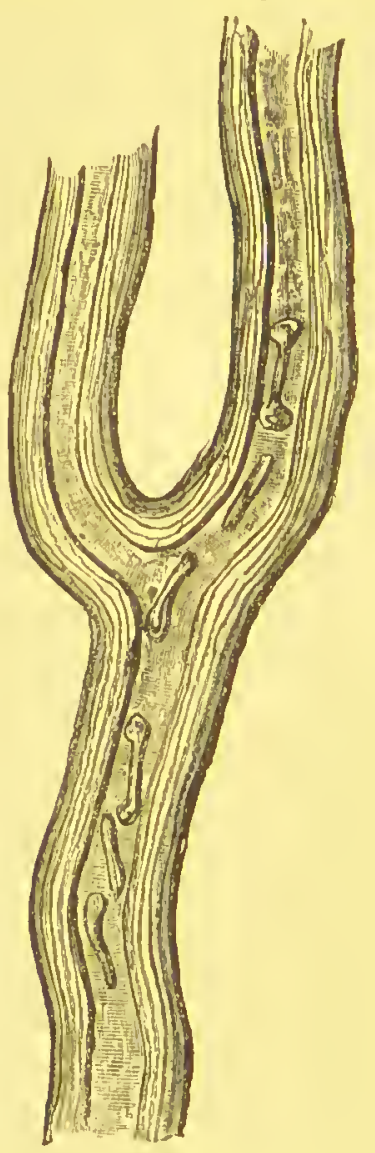

Fig. 76. - Laticiferous vessel from Enophorbia splendens, with rod-and bone-shaped granules of starch floating in the latex. $(x 250$.

in bundles, and take part in the formation of the fibrovascular bundle as soft bast.

Utricular vessels (Fig. 75) are distinguished from sievetubes by their contents and situation. The contents are clear or milky, but always include bundles of acicular crystals (raphides). Their cells, which are moderately thin-walled, 
(Fig. 75), but otherwise of very various structure, are in contact by their ends, which are either broad or narrow, and often form great systems of tubes, which are never associated into bundles, but run separately and usually in a parallel direction. They occur only in the outer cortex and in the feliar organs in most Monocotyledons and in some Dicotyledons.

Laticiferons vessels are simple or branched tubes, fiequently anastomosing, or united into a more or less close network (Figs. 76, 77). They always contain a fluid

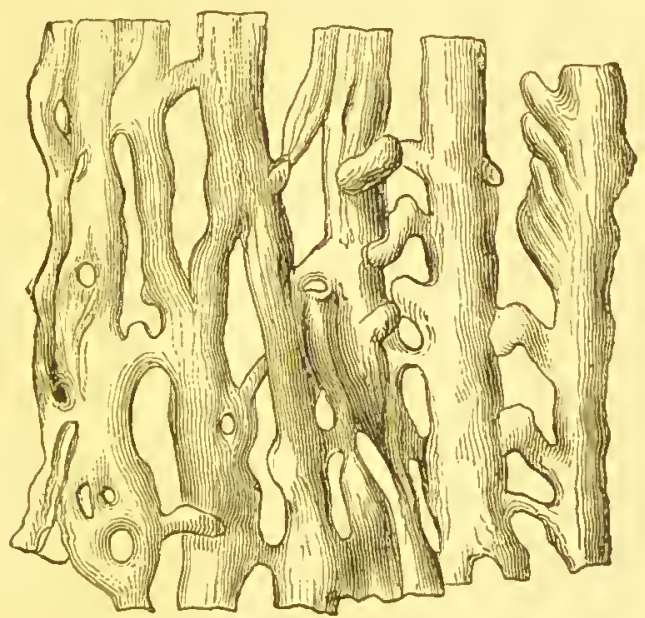

FIG. 77.-Anastomosing laticiferous vessels from a vein of a leaf of the lettuce. (After Hanstein, $x$ I6o.)

peculiar to the plant, which is often coloured and frequently of a milky appearance, and is called latex. They occur in only a comparatively small number of plants, usually in the cortex between the bast-bundles and the wood, but sometimes also in the outer cortex, the pith, and the wood. They accompany the fibrovascular bundles into the leaves. Nearly related to them are the laticiferous cells, long branched simple cells, such as occur in the Euphorbiaceæ, Moraceæ, Asclepiader, Aconitum, \&c. The latex of different plants contains a great variety of substances: gum, resin, 
albumen, opium (in Papazer somniferum), caoutchouc (in Siphonia elastica, Isonandra gutta, and species of Ficus), boneshaped grains of starch (in tropical species of Euphorbia), \&c. The laticiferous are often distinguished from the utricular vessels only by the absence of raphides. Transitional forms between sieve tubes and laticiferous vessels occur apparently in the elder and in Aceraceæ. It has not yet been certainly determined whether the latex is a product of excretion or a reserve material.

Closely connected with the laticiferous vessels are certain groups of cells, to which belong the formation and secretion of particular substances, and which have been included under the term the Secretory System. In examining them, the chief point to notice is whether the cells themselves contain the secretion formed in them, or whether it has been transferred into the nearest intercellular spaces. It is not always possible, however, to draw a sharp line of demarcation between these two conditions, which may both occur together.

Single cells of this nature, or smaller groups of cells, are called glands, while the larger sap-receptacles which extend to a greater length through the parenchyma are termed passages. These latter do not always possess a true cell-wall, not being produced by a deliquescence of cell-walls, but by masses of tissue becoming separated from one another, and thus forming a cavity between their cells; and are therefore true intercellular spaces. [They are then termed schizogenous (Figs. 78, 79). Glands are lysigenous when resulting from the absorption of a mass of tissue. Glands are also sometimes external organs, when they usually assume the form of glandular hairs containing often a fragrant essential oil, as in many Labiatæ. They may then be either simple or compound (see Fig. 92, p. 63).

According to the nature of the substance secreted, these spaces are distinguished into oil-passages, as in Umbellifera and Compositæ ; resin-passages, as in Coniferæ (Figs. 78, 79); 
gum-passages, as in Cactaceæ, Cycadeæ, Amygdaleæ, \&c.; oilglands, in the leaves of Hypericum perforatum, species of Citrus,

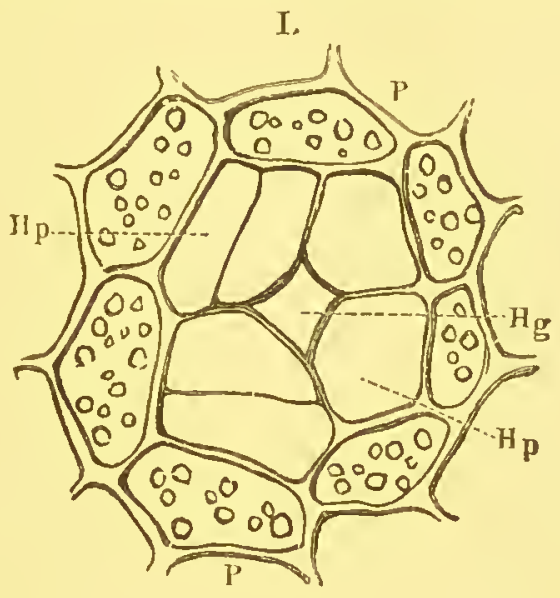

II.

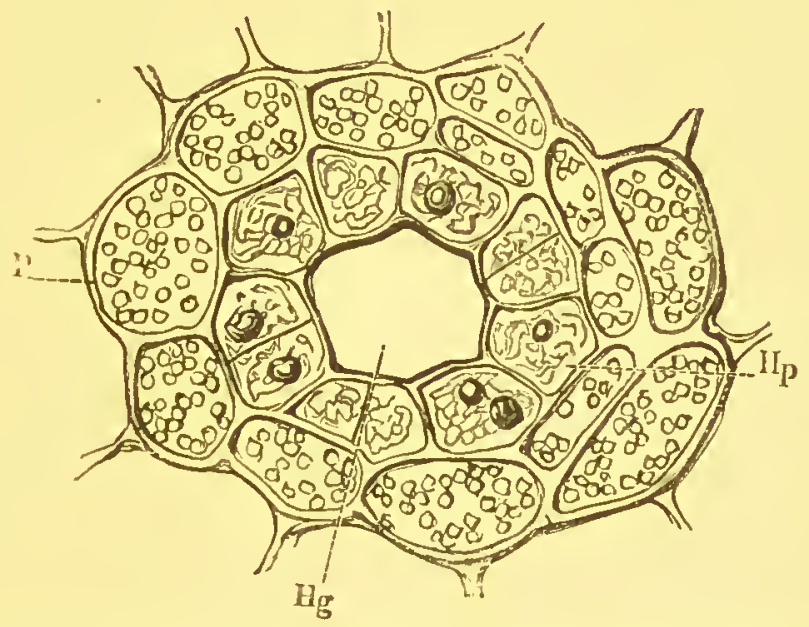

FIG. 78.-Mode of formation of resin-passages ; 1 . transverse section through a terminal shoot of Abiesexcelsa in process of development; in the cortex the small group of cells us containing starch-grains and in the act of division has separated from the rest of the cortical cells $\mathrm{P}$ which contain chlorophyll; $13 \mathrm{~g}$ the first origin of the resin-passage ( $x$ rooo). II. The same from a part more deeply imbedded; in the young wide resin-passage $\mathrm{Hg}$ the cells which contain resin form only a single layer, and contain, in addition to fine-grained starch, small drops of a volatile oil. $(x 800$.

\&c. ; camphor-glands; and resin-glands (Fig. 8o). The term honey-glands or nectaries, finally, is given to any part of a 
flower or other organ, whatever its structure, which is formed for the secretion of honey or a saccharine fluid (Figs. 265 , р. т $36 ; 266$, p. I 37 ).

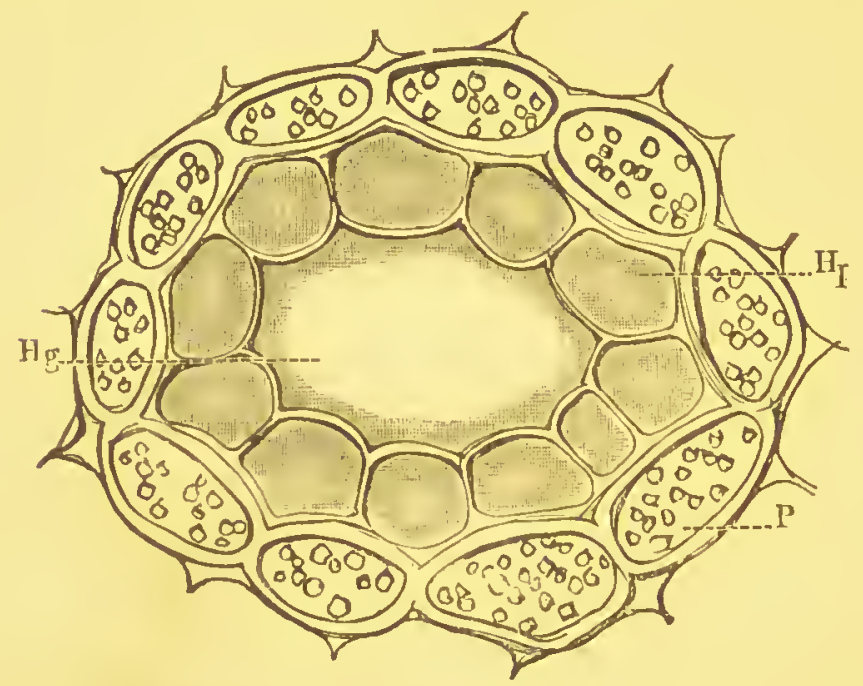

Fig. 70 -Transverse section through a mature resin-passage of Abies e-rcels: ; the cavity $\mathrm{H} g$ as well as the thin-walled cells II $\not$ are filled with a semi-fluid resin. while the thick-walled compressed cortical cells $p$ still contain small quantities of starch. $(\times 800$.

All these separations of masses of tissue are essentially different from the transformations of the cell-wall previously described; although

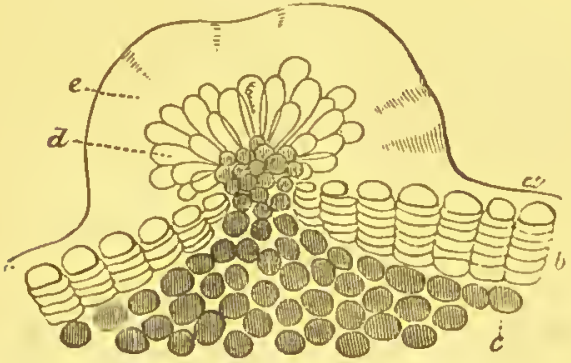

FIG. 80.-Transverse section of a resin-gland from a young birch-twig; a epidermal cells ; i a subjacent layer of cork ; $c$ collenchymatous cortical tissue; $d$ the papillz of the gland which have secreted the solid resin $\ell$. (x I00.) it happens often enough with processes of secretion that cellwalls are ruptured by the pressure of the substances stored up in them, and are carried away along with the waste products (see p. 23).

In this commection should be mentioned also certain structures which are possibly of considerable importance for the life of the plant, but which have as yet been but little studied, the overgrowths of wax: on the surface. These occur especially as a delicate bloom, 


\section{The Cell as a Menbor of a Group.}

as for example on the plum, and are sometimes dense agglomerations of rods or needles, as on the leaf of the rye, sometimes simple coatings of granules, as on the 'frosted ' leaves of many lilies; sometimes as coatings of rods which stand vertically on the surface of the cuticle, as on the leaves of the banana; or finally as incrustations, as in Opuntia.

\section{CHAPTER III.}

THE CONSTRUCtion of the PLANT OUT OF CELLS.

ALL plants consist entirely of cells and of the products of the formation and transformation of cells, which are hence called the elementary organs of the plant. Only a few plants, belonging to the class of Algæ (Fig. 8I, and Fungi, are unicellular; by far the larger number consist of many, and most of an innumerable number of cells, which take part in the construction of the plant. In the simplest multicellular plants the cells are arranged in filaments, i.e., in simple rows one above another, as in the filamentous Algæ and many Fungi (see Fig. I, p. 7). Those are more highly organised which consist of plates of cells arranged in a single layer, as

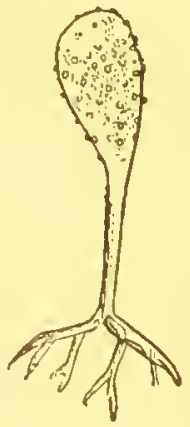

Fic. 8r.-A unicellular Alga, Botrydium: Wallrothii. (See also Fig. 383, p. 252.) occurs also in certain Algæ, e.g. the Ulvaceæ (Fig. 82). But by far the most common structure is for the plant to be composed of masses of cells radiating from one another in all directions. The course of development of this mass of cells exhibits the following variations in the different sections of the vegetable kingdom.

In the higher flowerless plants the mother-celi of an embryo or shoot breaks up into several cells of unequal value. The cell which remains at the apex, or apical cell, 
grows to be like its parent in every respect; and the same process of division is then repeated in it. The building up of the mass of cells of which the plant consists results from the division in all directions of the remaining daughter-cells (Fig. 83 1.).

In flowering plants (Fig. 83 II.) the mode of development is different. The growing end or apex of an organ, such as a root or stem, is here composed of a mass of

1.

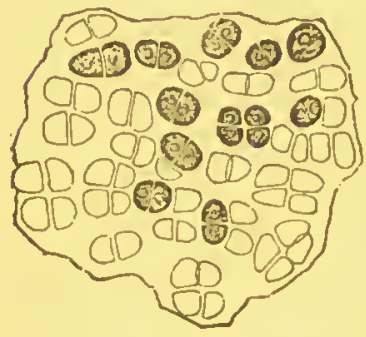

Fig. 82.-1. An Alga, Ulva brilbosa, consisting of a single plate of cells; II. Zoospores which have escaped from the empty cells. ( $x$ about 300. )

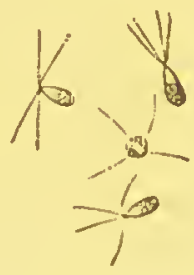

II.

the boundaries of the daughter-cells derived from the apical cell, for example $t^{3} t^{2}$, the latter being again the mother-cell of those marked $x, 2,3,4 \cdot(\times 350$.

equivalent cells-known as the punctum regetationis or grorving point-all capable of division, rich in protoplasm, thin-walled, and without intercellular spaces. From this primary meristem are developed the various kinds of tissue, which may be classed under three heads, the Fundamental. Tissue or ground-tissue, the Fibrovascular System, and the Epidermal Tissue.

The order of succession in the formation of the various groups of cells is as follows :- The first independent tissue formed is the primary epidermal tissue or dermatogen. The layers of cells lying immediately beneath then begin to develope in a peculiar manner as cortical tissue or periblem, the parenchymatous or primary cortex being formed from them. 

The Construction of the Plant out of Cells.
This tissue finally encloses the plerome or intermediate tissue,
situated not very deep down and laterally from the apex, which breaks up into the procambium and the fundamental tissue. The procambium is formed in many plants from the entire outer zone of the plerome, while in others it consists

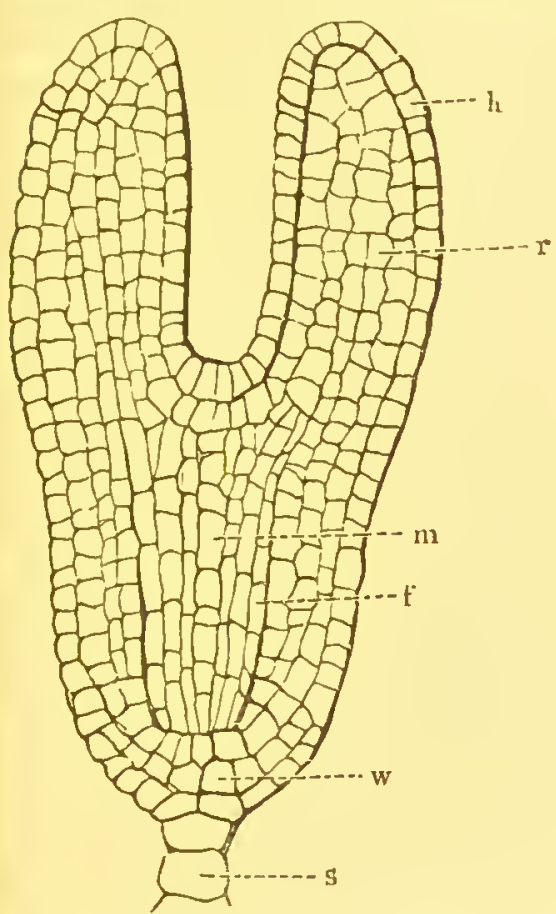

Fı. 83 1I.-Longitudinal section (partly diagrammatic) through the young embryo of the shepherd's purse; $h$ epidermal tissue (dermatogen); $r$ cortical tissue ; $\|$ fundamental tissue ; $f$ procambium; $a$ root-cap ; $s$ suspensor. (After Hanstein, magnified: see fig. $36_{3}$, p. 189 .) of only a few groups of its cells : from the fundamental tissue it is further distinguished by the arrangement and the form of its cells, which are prosenchymatous, while those of the fundamental tissue remain parenchymatous.

The contrast between the epidermal tissue and

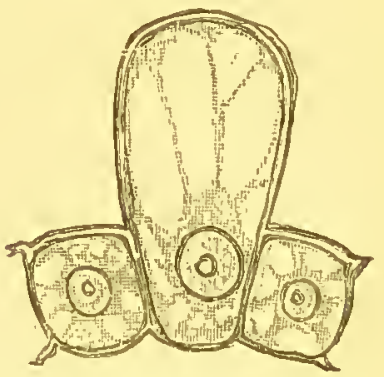

Fig. 84.-Papilla from the young stigma of Lilium bulliferme. $(x 660$.

the subjacent masses of tissue is the more evident the greater the exposure of the part of the plant to air and light, and is also usually more conspicuous in the permanent parts than in those which are more fugitive. In the lowest plants, Algæ, Fungi, and Lichens, and even in the stem of Hepaticx, the epidermal structure consists only in the outer layers of cells having thicker and firmer cell-walls and smaller cavities than the 
rest. In some Mosses and in all the more highly organised plants at least one layer of cells specially defined and developed, the epidermis, exercises special functions. In true roots, and in many root-like underground stems, as well as in many plants which grow submerged in water, it is less differentiated from the subjacent tissue than is the case in most stems and in leaves.

The outer side of the outermost layer of epidernal cells is gradually transformed into the so-called cuticle (see Fig. 21 , p. 16), a thin structureless membrane, but little sensitive to external and even to chemical agencies, insoluble, for example, in concentrated sulphuric acid or in potash. The cells of the epidermis usually contain clear or coloured fluids, occasionally crystals, rarely chlorophyll. Their form is very various, but usually tabular or conical, or sometimes even papillæform, i.e. projecting on the outside in the form of knobs or hladrlers. The peculiar appearance of many structures, such as the velvety gloss of petals, is due to papillæe of this nature (Fig. 84). In many cases there lie beneath the epiclermis peculiar layers or strings of cells (the hypodorma), which are perhaps best included in the epidermal tissue. They consist either of thick-walled prosenchymatous bundles which contribute to the greater firmness and elasticity of the epidermis, as in the aerial portion of the stem of Equiseta, and the acicular leaves of Pintus pinaster, or of collenchymatous tissue which tends to increase the difference of tension between the epidermal and the subjacent tissues (see Chap. V.). In plants with a long term of life, and which increase greatly in girth, cork is subsequently formed in the epidermal cells themselves or the subjacent layers of tissue, replacing the true epidermis, which has generally in the meantime perished.

The true epidermis consists, when young, of similar cells which are everywhere closely contiguous. In the course of growth some of these separate from one another, the derivative cells that result from one or more divisions leaving a crevice or pore between them which is called a stoma (Fig. 85 ). These are always ${ }^{1}$ enclosed by two or four cells, the guard-cells, which are crescent-shaped, and also smaller and with thinner walls than the rest of the cells of the epi-

1 Exceptions, however, occur in the case of the Marchantiex and Rhizocarper. 

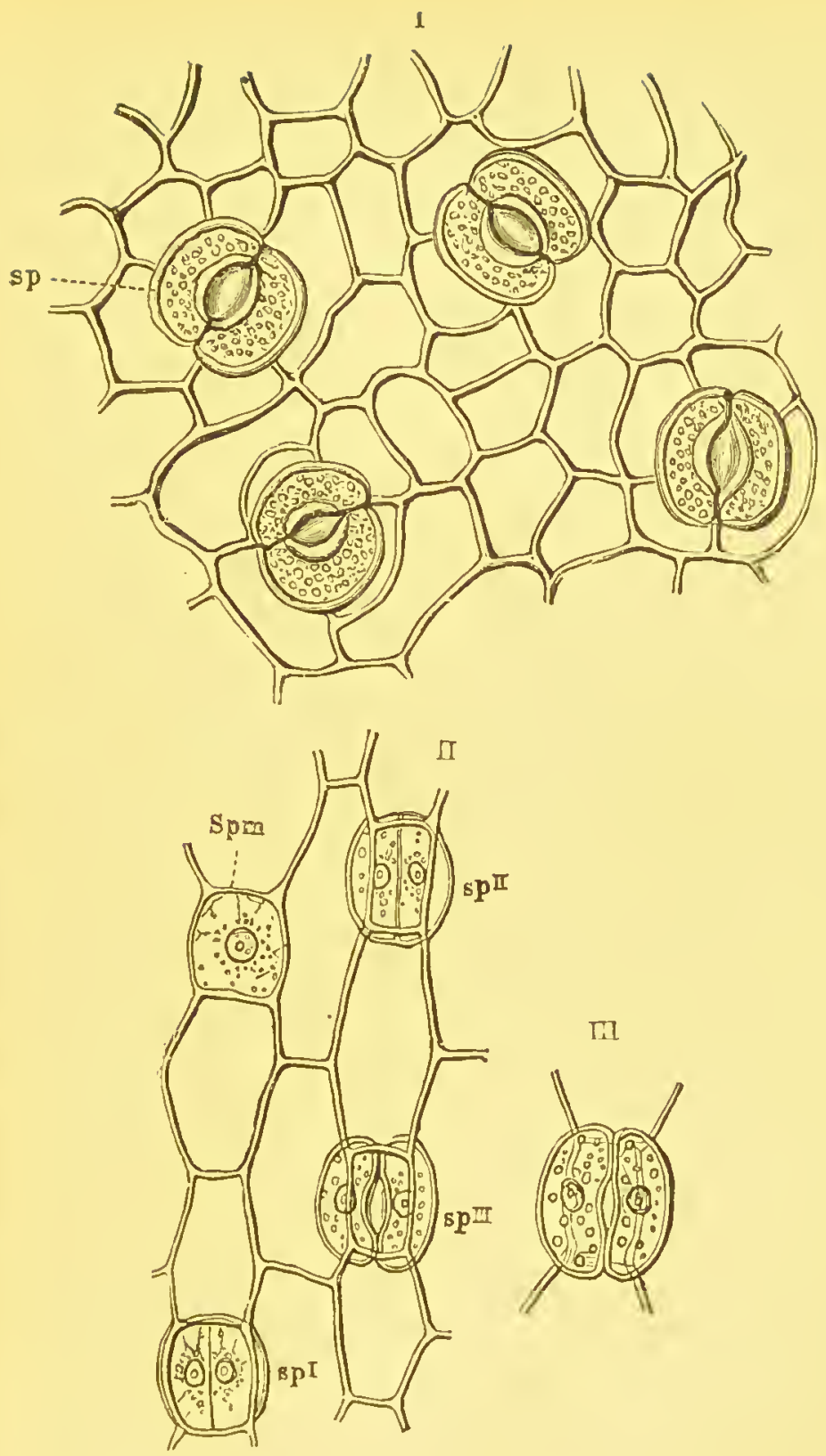

TI

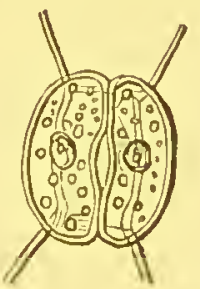

Fig. 85.-I. Horizontal section through the epidermis of the under-side of the leaf of Finonymus japoricus, looked at from below ; spstomata ( $x 370)$; II. Cotirse of development of the stoma of Arthropodium cirrhatum: $s p m$ mother.cell ready for division; $s p^{1}, s p^{11}, s p^{11}$ successive stages of division; III. Mature stoma. $(x 370$. 
clermis, and are in addition distinguished from them by containing chlorophyll. This last circumstance gave rise to. the earlier view that these cells belong to the subjacent parenchyma of the leaf rather than to the epidermis

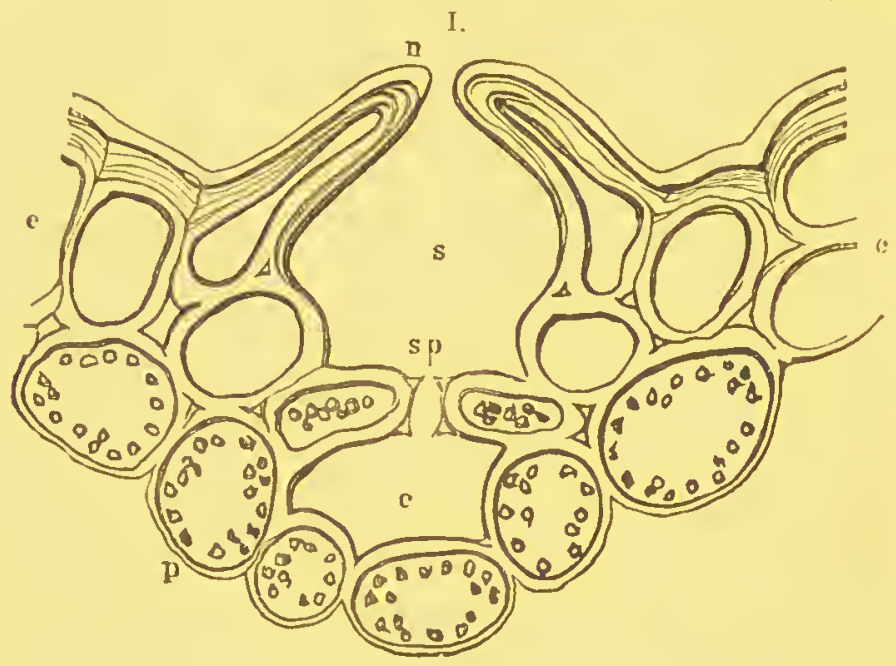

II.

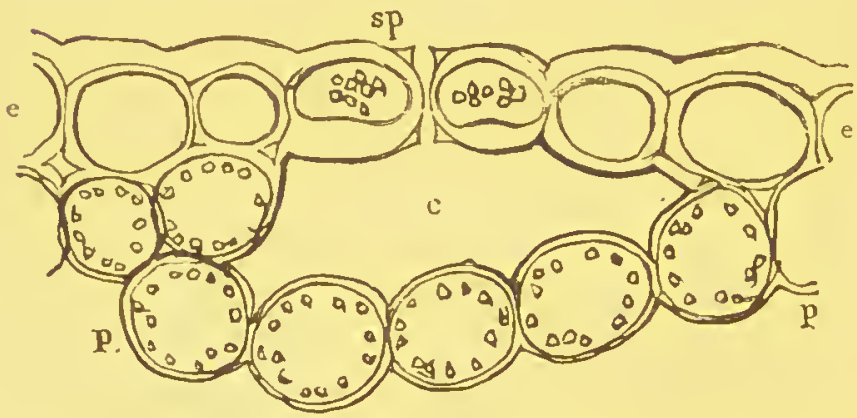

Fig. 86.-I. Transverse section through the epidermis of the leaf of Cycas revoluta: $n$ elevation of the epidermis: II. Transverse section through the epidermis of the under-side of the leaf of Polypodizm zuclgare; $e \epsilon$ epidermal cells; sp stoma; $p$ parenchyma of the leaf; $c$ air-cavity. $(\times 400$.

itself. The stomata are sometimes found at the bottom of a funnel-shaped depression, sometimes on a level with the epidermal cells; while sometimes (Fig. 86) they are even elevated to a higher level. They establish a con- 
nection between the atmosphere and the intercellular spaces in the interior filled with air. The interchange of gases which is thus brought about is regulated by the guard-cells being sometimes more and sometimes less close together, so that the pore may be occasionally closed. The perfect stoma may be regarded as consisting of three parts-the anterior or eisodial, the posterior or opisthodial opening, and the actual fissure which connects these two.

Stomata are found in all the higher plants, from the Hepaticæ upwards. 'They usually occur in the green parts, more rarely in the coloured petals (as in the hyacinth, crown imperial, \&c.), [in the coloured bract or spathe of Richardia], and in fruits and seeds (as the tulip). They are wanting in those leaves which grow submerged in water; and in floating leaves occur only on the upper surface. In most Monocotyledons both surfaces of the leaf are provided with stomata, while in Dicotyledons they are generally almost or altogether absent from the upper surface. No general rule can be given for their number nor for their arrangement, which possesses a definite character only in a few groups of plants, as e.g. the Equisetaceæ ; in Coniferæ and Grasses the arrangement is invariably linear; in the Begonias they are arranged in groups, \&c. By far the most common size of the stomata ranges-between 0.0002 and $0.0008 \mathrm{~mm}$.; but it may vary, as far as observations have yet been made, between 0.00459 (in Amaryllis formosissima), and $0.000 \mathrm{II}$ (in Amaranthus caudatus). Stomata are entirely absent from all true roots.

Hair-like bodies or trichomes are unquestionably epidermal structures, and niay be found even on the youngest parts of the stem, leaves, and roots. Under this category are included hairs, bristles, stinging hairs, prickles, scales, glands, glandular hairs, and the 'palex' of Ferns. Hairs arise by an elongation of particular epidermal cells (Figs. 87, 89); and if attached to a root are called root-hairs. They are either simple or branched, and consist of one or several cells. Bristles 

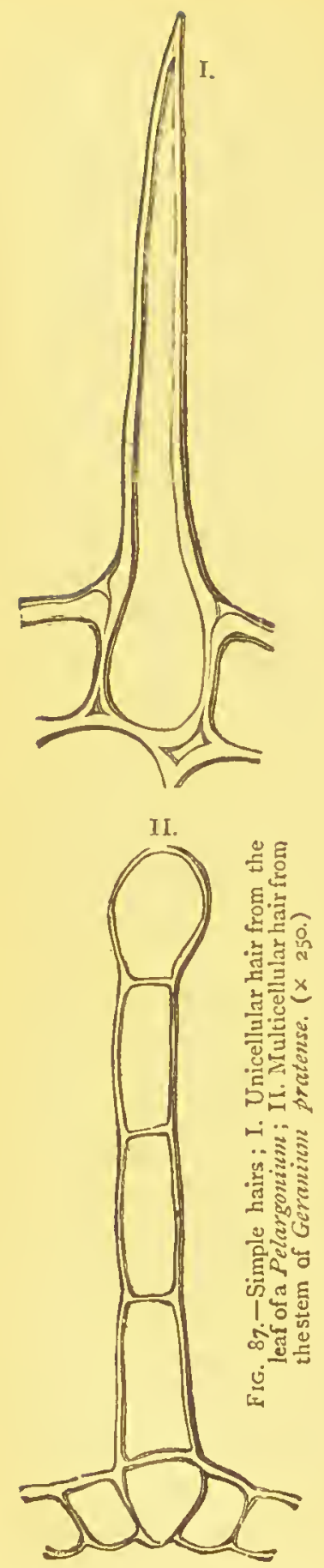

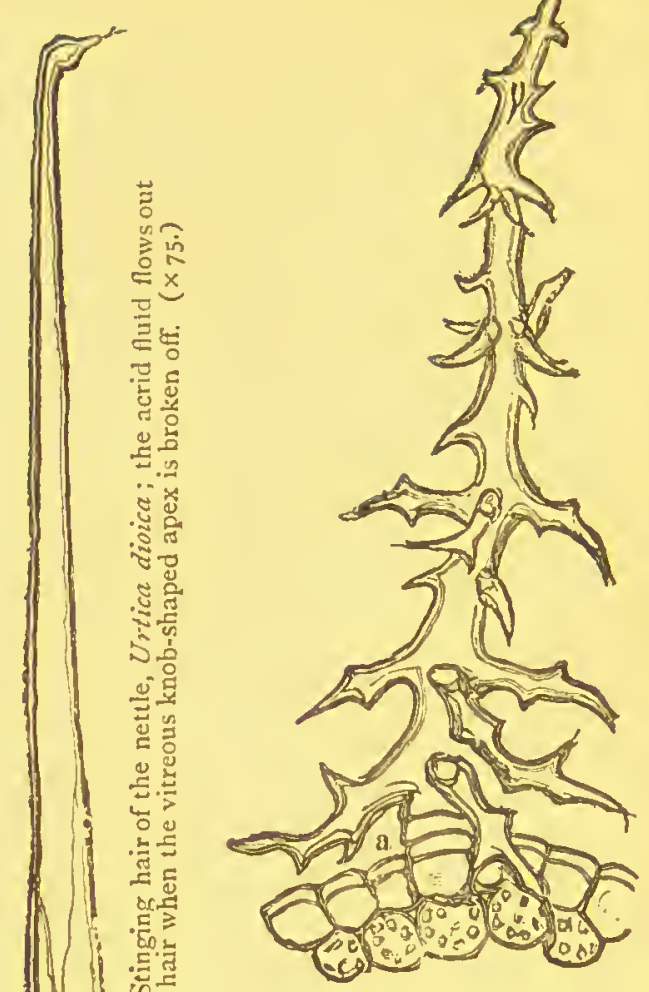

FIG. 80.-Greatly branched unicel. lular hair of Alternanthera brasilicusis, borne on thin-walled pedicel-oells. ( $x$ 250.)

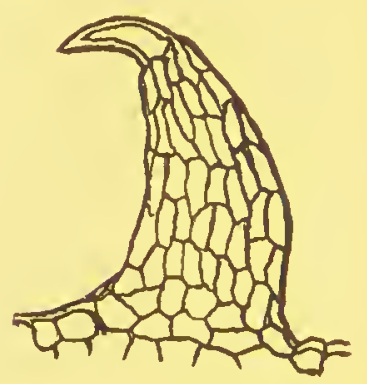

Fig. 90.-Prickle from the stem of the hop. $(\times 75$. 
result from the walls of hairs becoming thicker and woody, i.c. by the deposition of lignin. Hairs are not often found in the interior of plants, but occur in the air-passages of Nymphracex. Stinging-hairs are such as secrete an acrid irritating fluid which escapes when they are injured; they often stand, as in the stinging-nettle, on a cushion-like base (Fig. 88). Prickles (Fig. 90) consist of a great number of thick-walled woody cells. Scales [or peltate hairs] exhibit

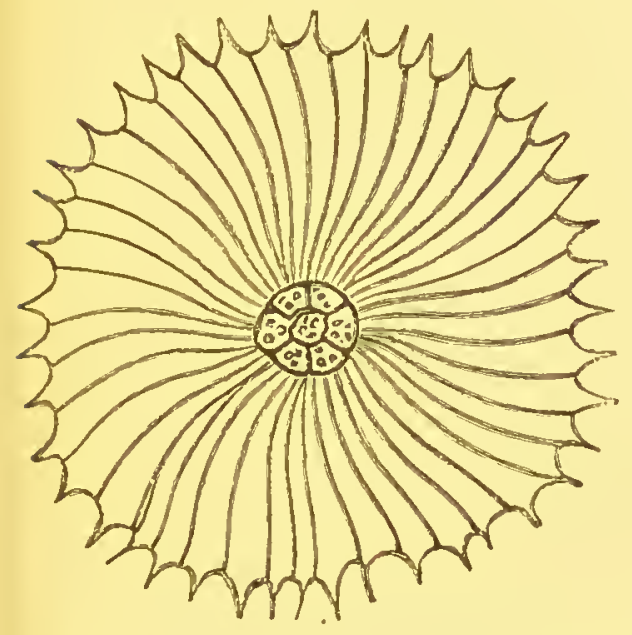

FiG. 9r.-Peltate hair from the leaf of Elceagnus, seen from above. ( $x$ 125.)

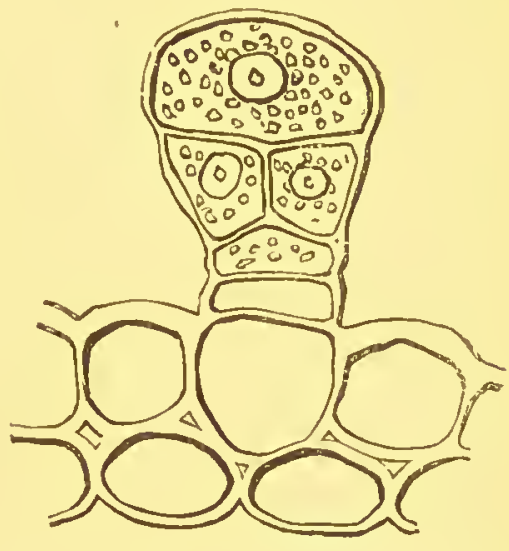

FIG. 92.-Glandular hair from the leaf-stal!: of Lamizun purpureum. ( $\times 370$.

a great coniplication of structure, consisting of an elongated epidermal cell, the pedicel-cell, which bears at its apex a number of cells expanded into the form of a shield (Fig. 9I). Glands consist of a number of cells puffed out like bladders, in which special fluids of various kinds are secreted. Thus, for example, the leaf-buds are often rendered viscid by a gummy substance, or one composed of a mixture of mucilage and drops of balsam, the first resulting generally from the conversion into mucilage of an epidermal layer lying beneath the cuticle, as in the violet, horse-chestnut, and plum. (See Fig. 80, p. 54.) If glands are elongated into 
the form of a hair, or borne on the apex of pedicel-cells, they are called glandular hairs (Fig. 92).

The primary cortex which developes out of the periblem consists commonly of thin-walled succulent parenchyma containing starch or chlorophyll ; other forms of cells, however, as laticiferous and utricular vessels and glands, as well as intercellular passages containing sap, may also occur in it. In some plants masses of cork are found deeply buried in the cortical tissue, or even beneath it, the outer parts then dying, and falling off in the form of bark, as occurs in the grapevine and plane (see Figs. 66, 67, pl. 44, 45).

Every mass of procambium consists, in its earliest stage, of similar thin-walled usually prosenchymatous cells, united together without any intercellular spaces. As the mass increases in age, some of the rows of cells become transformed into vascular or bast-cells, and from these as centres the transformation advances of the procambium-cells into permanent cells. Groups are thus formed of particular kinds of cells which, united into strings or bundles, penetrate the rest of the tissue, and as a rule constitute a firm framework, and form the fibrovascular bundles, or conducting bundles. These bundles often lie isolated in the fundamental tissue of the plant, as for instance in the veins of the leaves; but they are generally so crowded and so strongly developed by the continual formation of the tissue of which they are composed, that they finally almost entirely replace the intermediate fundamental tissue, and form almost the whole of the substance of the plant, as is the case in the wood of Dicotyledons and Conifers. The transformation of the procambial cells into permanent cells either continues until they are all so changed, or an inner layer of the procambium remains as the formative cambium. As they become older, therefore, the fibrovascular bundles either contain cambium or are destitute of it; the former being called open, the latter slosed bundles. In the open bundles the cambium is continually forming new layers of permanent cells, and the part 
of the stem or root is thus constantly increasing in thickness, as is the case in most woody Dicotyledons and Conifers. Closed bundles, on the contrary, such as are found in Cryp-

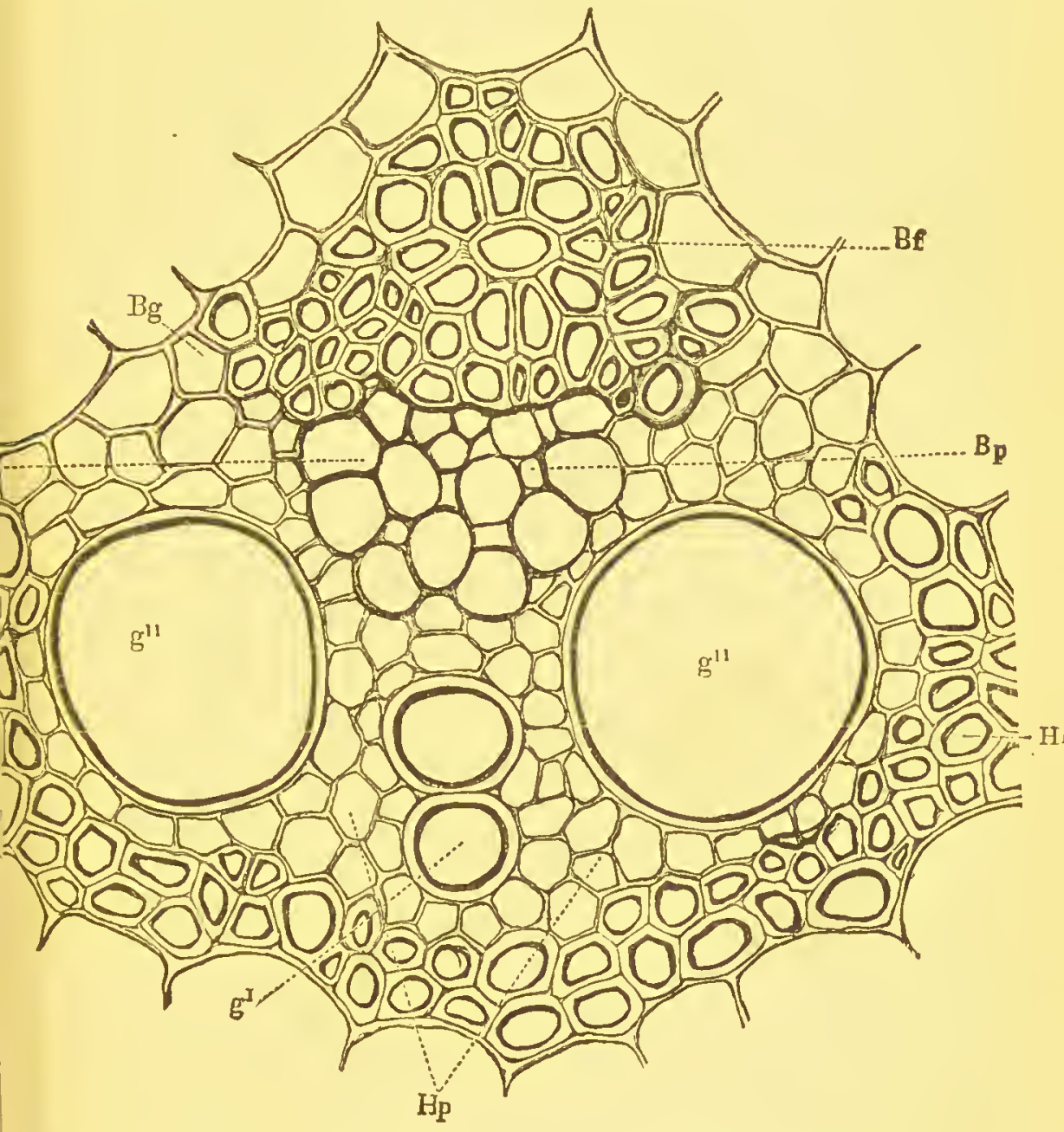

Fig. 93.-Transverse section through a fibrovascular bundle of the sugar-cane: $\mathrm{H} p$ parenchymatous cells of the xylem; $\mathrm{H} f$ wood-fibres; $g^{1}$ spiral vessels; $g^{1 \mathrm{i}}$ pitted vessels ; $\mathrm{B} \not$ bast-parenchyma; $\mathrm{B} g$ bast-vessels or sieve-tubes; $\mathrm{B} f$ bastfibres. $(x$ 360.)

togams, Monocotyledons, and a few Dicotyledons, can no longer increase in thickness. The various forms of tissue in a mature fibrovascular bundle may be divided into two 
groups, a woody portion or $x y l e m$, and a less solid portion, the bast or phloëm (Fig. 93). The xylem is composed of parenchymatous cells, wood-fibres, vascular cells, and true vessels, the walls of these various elements being generally thickened and lignified. The phloëm, on the other hand, consists of succulent and mostly thin-walled masses of parenchyma and sieve-tubes, in addition to which are - usually bast-fibres massively developed and strongly thickened. Any of these elements of the xylem and phloëm may, however, be wanting. The most common arrangement is for the xylem and phloëm in each bundle to lie side by side, the former lying towards the centre, the latter towards the cir-

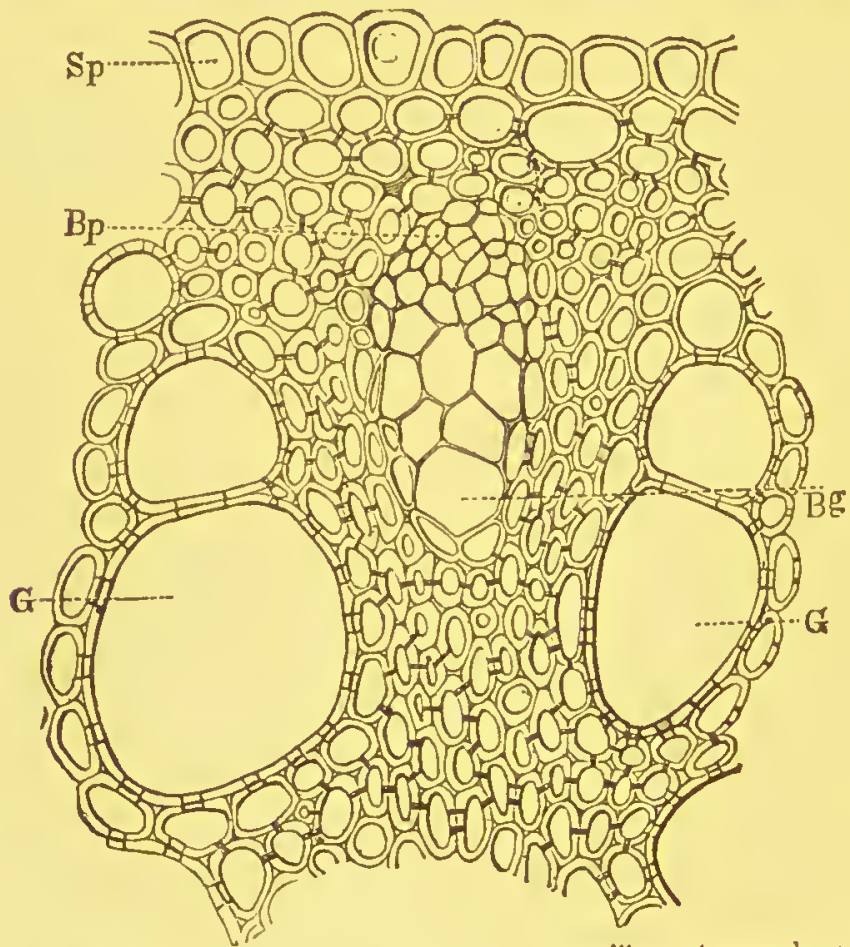

FiG. 94. - Transverse section through the root of sarsaparilla; $s \beta$ parenchyma of the root-sheath ; B $p$ bast-parenchyma; $\mathrm{B} g$ bast-vessels; $G$ vessels. ( $x$ 200.)

cumference of the stem; such bundles are termed collateral. But in Ferns and some other cases the phloëm completely encloses the xylem, and the bundles are called concentric. 
Narrow thin-walled elongated succulent cells, often found in connection with the sieve-tubes, but whose nature is not yet fully understood, have been termed cambiform tissue or permanent cambium. Cambiform tissue, latticed cells, and sieve-tubes form, together with thin-walled parenchyma, the soft bast, in contrast to the true bast, which is prosenchymatous. In many plants a ring of cells, often with strongly-thickened and lignified walls, the vascular bundle-sheath, is developed either only on the outside of the bast, or round the entire bundle, or very commonly round the whole mass of fibrovascular bundles. This is especially the case in roots, this layer of cells being there called the root-sheath or coleorhiza (Fig. 94). The separate cells of this organ are as a rule developed in a very characteristic manner.

The further development of the fibrovascular bundles is very characteristic of the different classes of plants, as is also the arrangement of the various elements in a transverse section of a bundle. Thallophytes and Characea have no fibrovascular bundles; and in Muscineæ they are either not developed at all or only in a rudimentary manner. These plants are therefore comprised under the designation Cellular Plants; the whole of the remainder, Vascular Cryptogams and Phanerogams, being termed Vascular Plants.

The fundamental tissue very commonly consists of thinwalled succulent parenchyma containing starch; but other forms of cells may also enter into its composition. In those plants which have no fibrovascular bundles the whole of the interior of the plant may be regarded as fundamental tissue. In other plants it fills up the spaces between the fibrovascular bundles and within the epidermis. Where the fibrovascular bundles are closed, Vascular Cryptogams and Endogens, and cannot therefore increase in thickness, this tissue is generally developed to the greatest extent (Fig. 95, I). In the woody portions, i.e. the stem and root, of Conifers and Dicotyledons, the fibrovascular bundles of which are open, it occupies a less considerable portion of the entire structure. In the greater number of such stems it forms a central pith, which is connected with the bark by more or less largely developed portions of cellular tissue, the medullary rays, 
(Fig. 95, II., S ${ }^{1}$ ). In by far the greater number of roots the fibrovascular bundles, on the contrary, form a cylinder destitute of pith and reaching the centre, so that the fundaI.

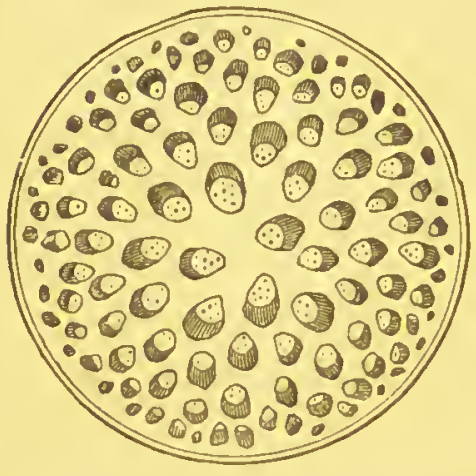

mental tissue is developed only as primary cortex.

[The fundamental tissue of the leaf, consisting of cells containing chlorophyll, and penetrated by the fibrovascular bundles, is known as the mesophiyll. The outermost of these cells, nearest to the epidermis, are often greatly elongated in a direction at right-angles to the surface, and are called palisade cells.] II.

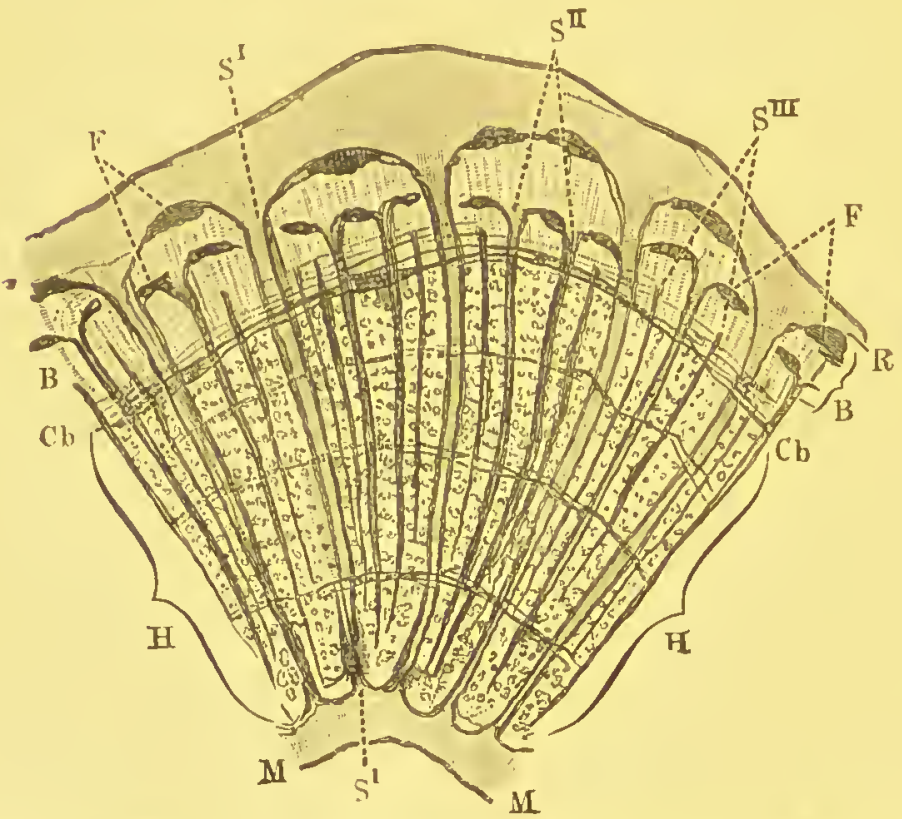

FIG. 95, - I. Diagtammatic representation of the distribution of the fibrovascular bundles in the transverse section of a palm-stem. II. Portion of the transverse section through a shoot of ivy four years old; $\mathrm{R}$ cortex; B bast-bundles: $\mathrm{H}$ wood, in which the four annual rings are distinctly visible: $\mathrm{M}$ pith; $\mathrm{s}^{2}$ medullary rays; $F$ bast-fibres: $\mathrm{c} b$ cambium; $\mathrm{s}^{11}$ primary ; $\mathrm{s}^{311}$ secondary bundles.

The various clements, the different forms of cells, tissucs, and fibrovascular bundles, are always arranged in ench species in a thoroughly characteristic manner; and from this, as wcll as from the naturc of the 
elements themselves that are present, it is very often possible to recognise the species from a small fragment of the plant. Only in comparatively few cases are the plants adapted at once for microscopical examination. When they are not so adapted, they must be dissected into small transparent pieces; and the direction in which the section has been made must also be noted. In order to examine, for example, the structure of a branch, preparations must be made, taken from it principally in the following three ways (Fig. 96) : in the transverse section $a \dot{v}$ at right angles to the axis of growth $m n$, the longitudinal section $\mathrm{cd}$ through the axis, and the tangential section of parallel to it. Sections in other directions, as the oblique $g h$, are only occasionally needed. In certain cases it is also requisite, in order to make the preparation transparent or decompose it into its separate elements, to macerate it, espccially when it is desired to determine the form and connection of the individual cells. We have here no space to enter into a detailed account of the application of the microscope to botanical investigation, and can only refer to the works of Dippel, Harting, Nägeli and Schwendener, and Schacht.

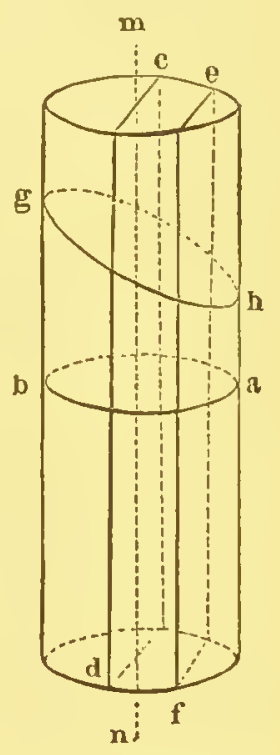

FIG. 96:-Diagram representing the various sections of a stem.

\section{CHAPTER IV.}

THE EXTERNAL FORM OF PLANTS.

IN the plants of lowest organisation, Algæ, Fungi, and Lichens, the contrast which is so manifest in those more highly developed between an axis (stem and root) and the lateral organs (leaves), is altogether vanting. With reference to this point, the vegetable kingdom is therefore divided primarily into plants without an axis or Thallophytes, and plants with an axis or Cormophytes, the term thallus being applied to an undifferentiated foliar structure.

The external differentiation of the parts in cormophytes can be very well seen in a germinating pea. If the 
leathery skin [or testa] is stripped from a pea which has been soaked in water, two large fleshy masses are seen, the cotyledons, enclosing a small cylindrical body, the axis (Figs. 97, 98), which bears two minute leaves at its extremity; the cotyledons and axis together constituting the embryo. If this pea had been planted in the ground, there would have been formed under favourable circumstances, from the growth of the axis of the embryo, the stem directed upwards and the root directed downwards. When the seed germinates (Fig. 99), a smaller or larger number of lateral organs, the leaves $(c d)$, develope, but only on the ascending pcrtion of

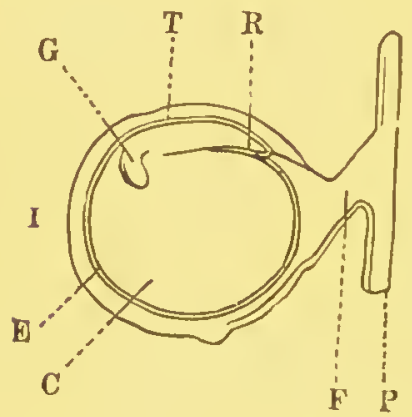

Frg. 97.-Pea, with its testa cut through: $c$ cotyledons; $G$ the plumule enveloped in minute leaves $; \mathrm{R}$ radicle: $\mathrm{T}$ axis of the embryo : 1 outcr, $\mathrm{E}$ inner integument ; F funiculus : $P$ part of the pericarp (diagrammatic).

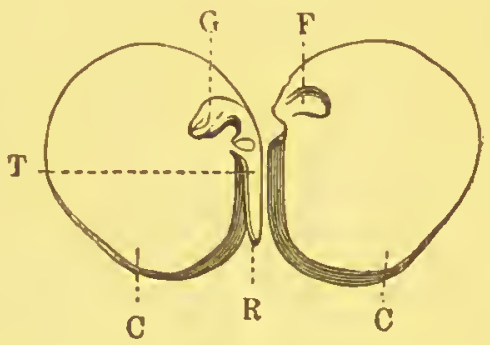

FIG. 98.-Pea split open and with the testa removed; $F$ small cavity in which the plumule or apex of the stem lay ; the other letters as in Fig. 97 (somewhat magnified).

the axis, not on the root. The form of the leaves is very variotis according to their function in the life of the plant; certain of them unite, in the form of floral leaves, together with the stem, to produce the flower. From a particular part of the flower is developed the fruit, within which are produced the secds destined for the reproduction of the species. Epidermal structures (trichomes), finally, clothe the surface at different parts.

If the history of development of an embryo, as that of the pea, is examined more closely, it is found that from a uniformly plastic mass of similar cells the root is developed 
downwards, and the stem-bud upwards. The stem-bud, or plumule, is divided from the outset into stem and leaves. The leaves therefore do not grow on a stem already formed; on the contrary, they constitute from the first, together with the stem, a hemispherical body consisting of

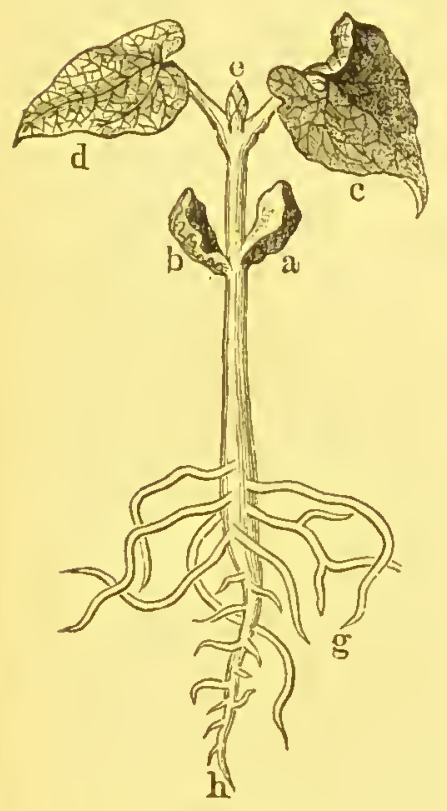

Fig. 99.-Germinating bean; $a b$ cotyledons ; $c d$ leaves ; $e$ terminal bud: $h$ primary root: $g$ lateral roots.

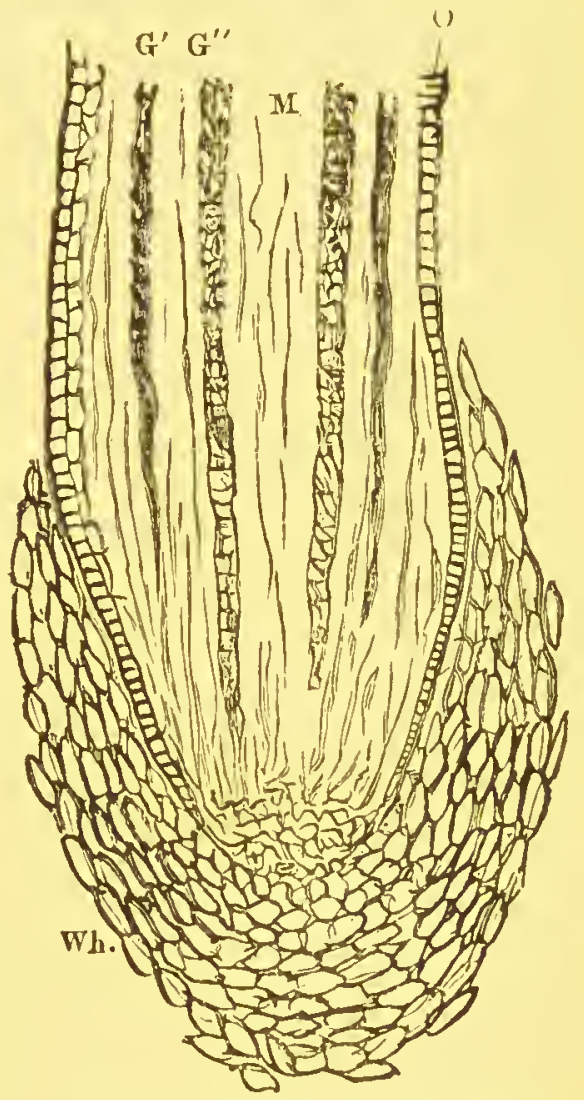

FIG. 100.-Longitudinal section through the apex of a root of Aspidistra elatior: wh root-cap; $M$ pith; o epidermis: $G^{1}$ narrow spiral vessels; $G^{11}$ broal reticulate vessels. $(\times 75)$.

primary parenchyma, which then becomes lobed. It is therefore impossible to draw accurate lines of demarcation between the three main organs of the plant, the root, stcm, and leaf. The stem is distinguished from the root only by 
bearing leaves, while the latter does not. Leaves are lateral [or appendicular] organs which do not possess any capacity of development of their own, and which may therefore be regarded in many respects as appendages attached to the entire organism, not possessing an independent life. It follows therefore naturally that the leaves and axis are subject to different laws of growth:- the axis grows at its apex, and the leaves at their base where they are attached to the axis. New leaves are developed only at the extreme end of the branch. The roots, on the other hand, have no power of forming leaves, because the outermost cells of their growing points die very early, and then cover it in the form of a cap (Fig. Ioo, wh). Beneath this root-cap, as it is termed, the production of new cells continues; while the cap itself acts as a protecting shield to the root when it penetrates into the hard soil. The growth in length of roots ceases therefore so near their apex that the portion which is at any time actually increasing in length is usually only a few millimetres long.

In the remainder of this chapter no reference will be made to flowerlcss plants, but only to flowering plants or Phanerogams, since the morphology of the former is so closely connected with their classification that it will be better spoken of under that head. Much, however, that is now described applies equally to both classes [at least to those Cryptogams which are also cormophytes], especially all that relates to the branching of the axis, the buds, phyllotaxis, the forms of leaves, secondary organs, \&c.

\section{THE ROOT.}

The Root is that part of the plant which, usually growing downwards, fixes it into the ground, and absorbs nutriment out of the soil. It bears at its apex a root-cap, and never developes leaves.

Some plants have certain characteristic kinds of roots which do not in all respects answer the description given above. Thus clasping rools, as those of the ivy, often penetrate laterally into trees, rocks, or walls. 
The aerrial roots of tropical Orchids, Pandani [and Aroids] depend from the stem and branches, and in many cases never reach the ground. The floating primary root of Trapa, which germinates while lying on the ground, at first ascends, and remains in that direction. The aquatic roots of floating plants like Lemma never attempt to become fixed in the ground; or, as in the case of Cicuta, assume a totally different appearance. The 'haustoria' of parasitic plants, finally, penetrate into the stem of their hosts, and feed on their sap. The charactcrs which include all roots, and distinguish them from stems, are the absence of leaves, and the presence of a root-cap at their extremity.

By the primary root is meant that which is formed by the downward elongation of the axis of the embryo, and which

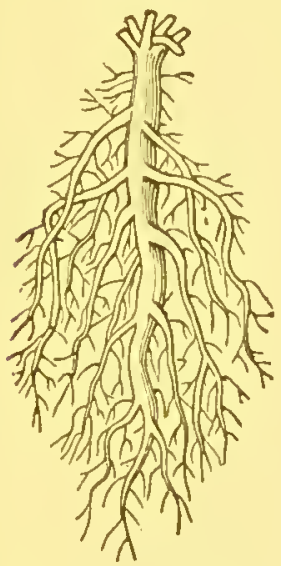

FIG. ror.-Diagram of a tap-root.

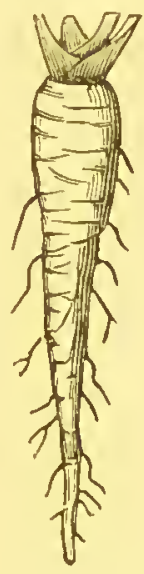

F1G. 102.-Fusiform root of the carrot.

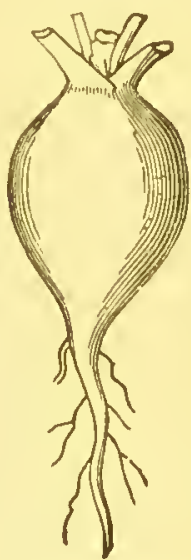

Fig. ro3.-Napiform root of the radish.

is therefore in a line with the stem. It is called a tap-root (Fig. ror) when it is thicker than the branches which proceed from it; and may then be fusiform or spindle-shaped (Fig. I02), napiform or turnip-shaped (Fig. ro.3), premorse, i.e. suddenly ending with a blunt point, as if bitten off, as in Plantago major [this is, however, strictly a rhizome], filiform (Fig. 104), or cylindrical.

Secondary or lateral roots are those which spring laterally from the stem [or from the primary root], as the clasping roots of ivy. In many plants in which the primary root remains 
undeveloped, and dies off shortly after germination, it is replaced by a number of secondary roots developed from the

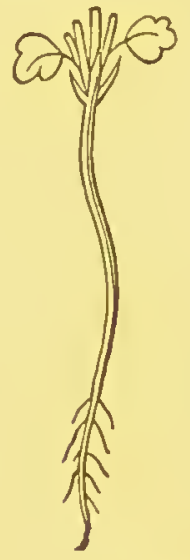

FIG. 104.-Diagram of fili-
form root.

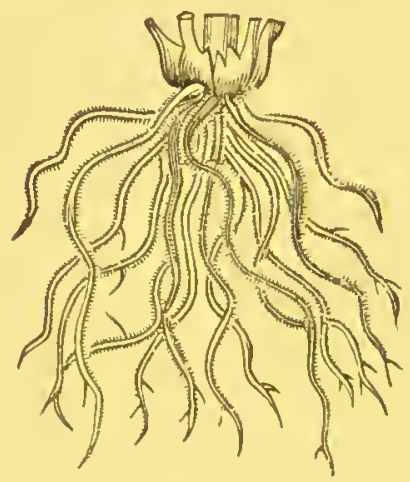

Fic. 105.--Fibrous root of a grass.

lower extremity of the stem. In Grasses, for example, these roots are filiform, and are then called fibrous roots (Fig.

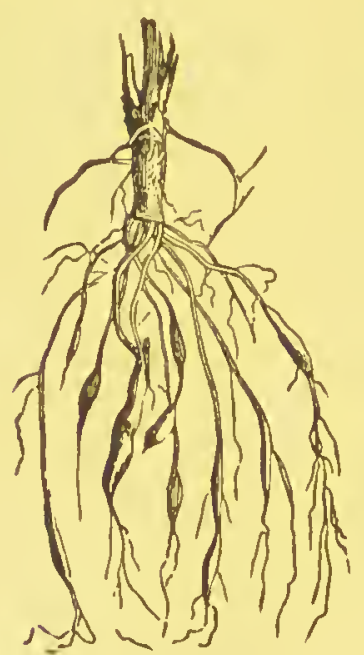

Fig. ro6.-Tuberous fasciculated root of Spiran filipendula.

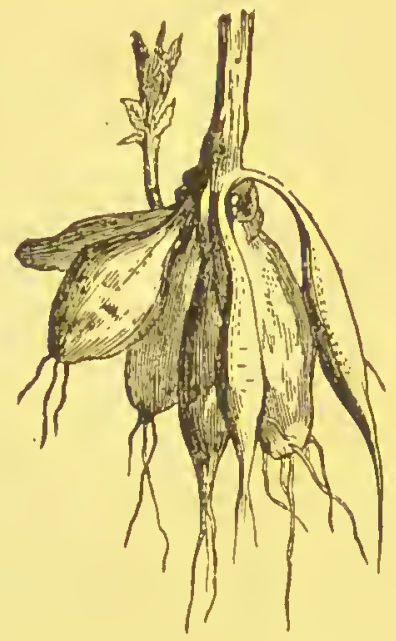

Fig. 107.-Tuberous fasciculated root of the dahlia.

I05); but not unfrequently some of them become tubcrous [i.c. much swollen at intervals, or in the middle]; and 
they are then called fasciculated (Figs. 106, 107). All roots are more or less branched, and are often clothed with extremely delicate root-hairs. If the branches of the root run principally near the surface of the ground, they are called crecping roots. With reference to their texture, they may be divided into woody and fleshy. ${ }^{1}$

\section{THE STEM.}

The Stem, in its various forms-to which a great variety of names are given from its diverse appearance, though in essential points always the same organ -is that part of the plant which is constructed for the purpose of bearing the leaves, flowers, and fruits.

In ordinary language the term is applied to those parts. of the plant only which are above ground. But a closer examination shows that many plants possess organs which must, in accordance with their function, be considered stems, but which nevertheless remain, during the whole of their existence, below the surface of the ground; and these are called underground stems. There are some plants which

1 [Any root which results from the development of the radicle or lower extremity of the axis of the embryo is a normal root; the term adventitious root being applied to those of any other origin, i.e. from the stem, either below or above ground. Aërial roots are usially adventitious, and their purpose is gencrally to absorb moisture from the atmosphere. The aërial ronts, however, of the banyan, Ficus indica, at length reach the ground, assume the character of trunks, and give to a single tree the aspect of a grove ; while those of the mangrove, Rhizophora, which also reach the ground, are true normal roots, resulting from the germination of the seed while the fruit is still attached to the tree. The roots of Monocotyledons arc nsually adventitions, the radicle rarely bcing developed, as are also tinose of Cryptogams. The roots of parasitcs, which derive thcir nourishment from the living tissue of their hosts, may be normal as in the mistletoe, Viscum album, or adventitious" as in the dodder, Cuscuta, where the original normal root which strikcs into the soil dies away, and the plant subscquently attaches itself ta its host by 'hanstoria.' 'True roots do occasionally, but very rarely, produce leaf-buds (see p. 82). The function of the root-hairs is the absorption of liquid nutriment from the soil. - ED.] 
are apparently stemless or acaulescent, with radical leaves only; but this results from the stem remaining very short and undeveloped in proportion to the root and leaves, and being therefore overlooked. Examples occur in Plantago, the turnip, [primrose], \&c. There is often a portion of the stem below the first pair of leaves, or cotyledonary leaves, intermediate between them and the root; this is then known as the tigellum or caulicle.

Those stems which spring, on germination, directly from the axis of the embryo [i.e. from its upper extremity or plummle] are called primary stems, and their ramifications secondary or lateral stems, or branches. The position of the branches on the primary axis determines what is called the habit of the plant. They are said to be verticillate or whorled when several spring from the primary stem at the same height, as in Equisetum; opposite [as in the elder] when two opposite branches are always found at the same height; decussate when each opposite pair is at right angles to those immediately above and below it, as in the lavender; dichotomous when the stem repeatedly divides into two branches of equal thickness, as in the mistletoe ; scattcred when the arrangement of the branches is apparently irregular. It sometimes happens, especially in the inflorescence of rushes, that a lateral branch completely takes the place of a primary axis the development of which has been suppressed, and continues its growth in nearly the same direction; and such a branch, which therefore consists of several successive secondary axes, is a sympodimm. The part of a stem which intervenes between two leaves is an intermode, [and the part from which a leaf springs is a node]. The length of life of the stem and roots may be only a single year, ammal; two years, biennial; or a number of years, peremial.

The most completely developed form of the aërial (above-ground) stem, the woody stem or trmk, is the characteristic of trees and smmbs. If the lower and smaller part of the stem is woody, while the upper and larger part 
dies off every year, as in Salvia officinalis, the stem is suffr 1 . ticose. In palms and some other trees the trunk is simple and unbranched, and is then a caudex; when the stem remains weak and does not become woody, it is herbaceous, and then but rarely, as in many succulent cacti, is perennial. The scape is a leafless stem bearing only flowers, springing from a flat base, or belonging to a so-called stemless plant; it may bear only a single flower as in the tulip, or several as in the lily-of-the-valley (Fig. I08), hyacinth, and Plantago. The culm is a stem the internodes of which Fig. ro8. - Rhizome and scape of the are separated by thickened lily-of-the.valley, Convallaria manodes, as in grasses, and is

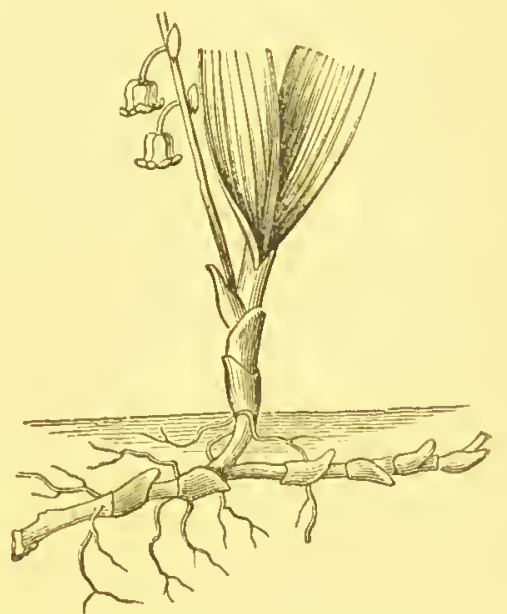
usually hollow and unbranched; the calamus on the contrary, as in rushes, is pithy and without thickened nodes. Sometimes, as in the strawberry, the stem sends out runners, i.e. branches which run along the ground, put out adventitious roots from their nodés or at their extremity, and develope there a perfect plant.

If a stem is cut through
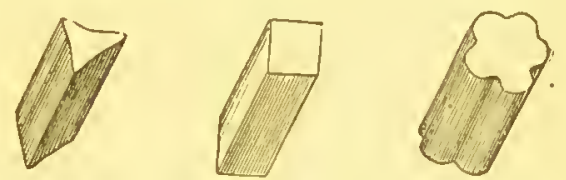

Fic.rog.-Sec- Fig.rio.-Sec- Ficriri.-Sectransversely, the figure of tion of trian- tion of square tion of 5-rib-
gular stem. stem. the section is usually more

or less round or cylindrical, or is compressed into an elliptical form; but it is often angular, for instance triangular in Carex (Fig. Io9), square in Labiatæ (Fig. I 10), five-ribbed (Fig. I I I ), \&c.

The form of the stem is usually more or less cylindrical, but often globose, two-edged, as in several species of Cactus, 
filiform as in flax, or leaf-like as in some species of Cactus and Ruscus (Fig. I I 2 ). ${ }^{1}$

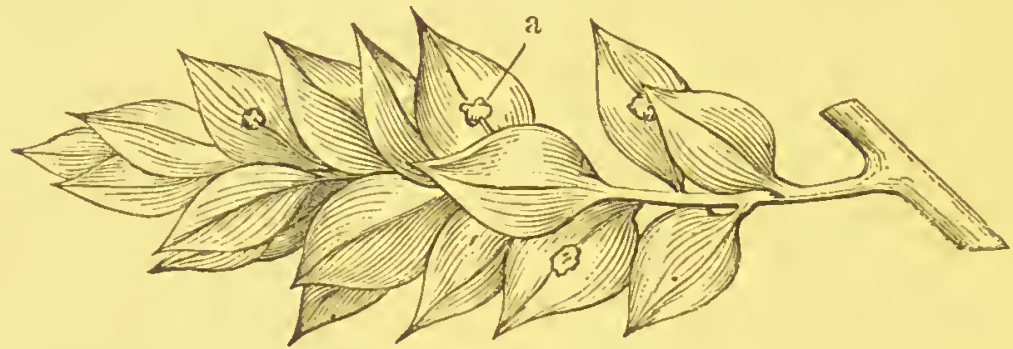

Fig. xi2.-Leaf-like branch or phylloclade of $R$ uscus aculeatus; $a$, flower.

In reference to its position, the stem may be erect, pendulous as in the sunfower, nodding as in Carduns mutans, decumbent, flexuose, creeping, where it puts out adventitious

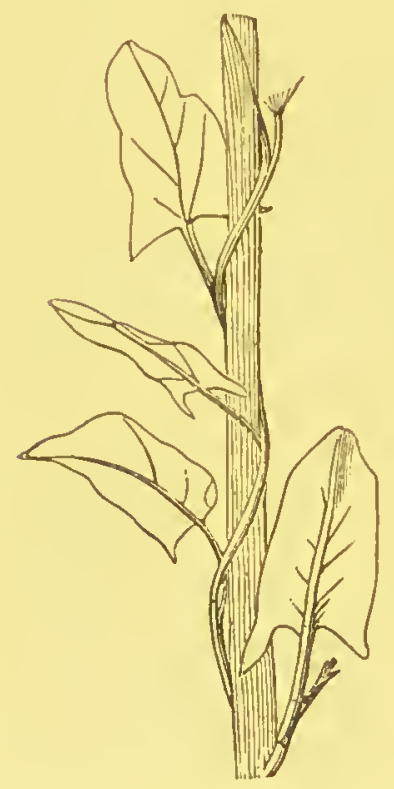

F1G. 113.-Stem of Convolvulus arvensis twining to the left.

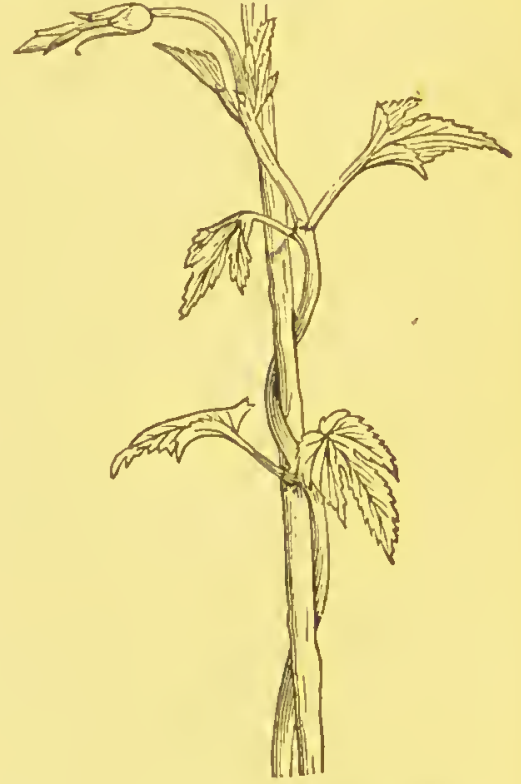

FIG. xx4.-Stem of hop twining to the right.

[The flat expanded sharp-pointed leaf-like branch of the butcher's broom, Ruscus aculeatus (Fig. II2), produced in the axil of the true scale-like leaf, and bearing the flower on its upper surface, is termed a phylloclade. - ED.] 
roots from its under-side, as in the money-wort, Lysimachia Nummularia, and periwinkle, Vinca minor, floating as in many water-plants, climbing (scandent), as in the ivy, or twoining, when it may twine either to the right, ${ }^{1}$ as in the hop or honeysuckle, or more often to the left, as in the bindweed (Figs. I 13 , I I4).

The base of the stem or underground stem is distinguished from the true root by its power of producing leaves. These are, however, often dry or deciduous, and their presence can then only be recognised by the scars they leave behind; and sometimes they disappear so early that even the scars can scarcely be made out. In such cases the earliest stages of development must be examined in order to come to a determination. The underground stem assumes peculiar forms in the rhizome, tuber, and bulb.

The rhizome (Fig. ro8, p. 77) is found in many perennial plants. It may be recognised by the leaf-scars, as also by its putting out a number of adventitious roots from its under side, and ascending annual branches (shoots) into the air from its extremity or from the neighbourhood of the leafscars. The buds of these shoots libernate beneath the ground (Fig. II5). Rhizomes are commonly branched, and not unfrequently elongated, and creep for a distance beneath the surface, as for example in couch-grass, Triti-

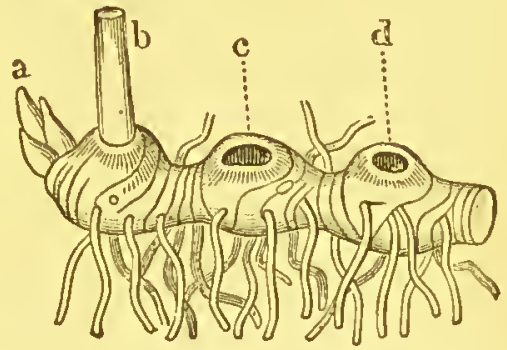

Fig. I 15.-Rhizome of Solomon's seal, Couvallaria Polygonatum. a terminal bud from which is developed the next year's stem; $b$ this year's stem; $c, d$, scars of the stems of previous years.

cum repens; but are sometimes short and compressed, as in the Iris, solid, or sometimes hollow and divided into chambers, as in the water-hemlock, Cicuta virosa.

The tuber is a thickened fleshy underground stem, with

1 [In applying the terms twining 'to the right' and 'to the left,' the reader must imagine himself in the position of the stem round which the climbing plant twines. - ED.] 
usually very small leaves which can be made out only in the young state; but in some cases, as the potato, there are a number of buds concealed in depressions, which are called eyes (Figs. I 6 , I I 7). Many plants form only one tuber, as the pig-nut, Carum bulbocastanum (Fig. II 8), others several, as the potato. The spherical or palmate

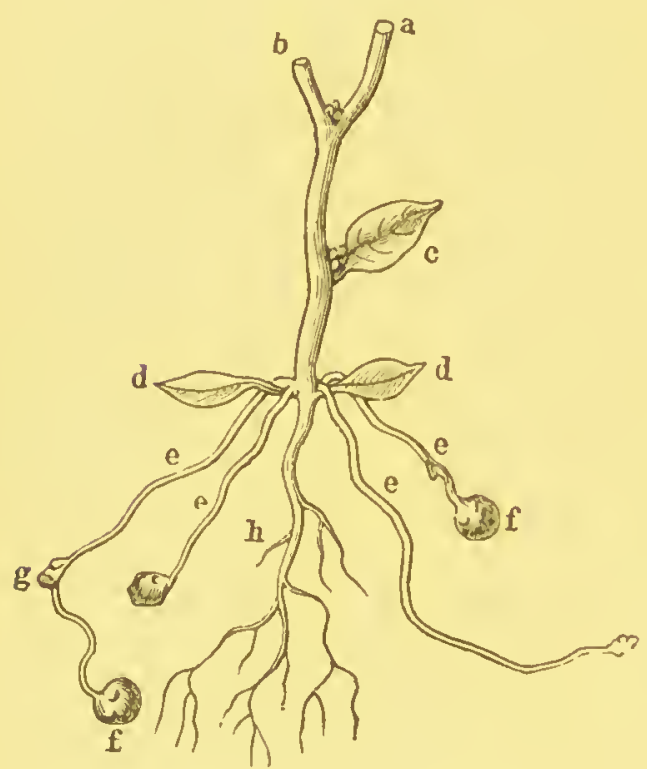

FIG. II6.-A six-weeks' old potato-plant developed from the seed, the upper branches $a b$ being cut off; $d$ cotyledons; in the axils of the cotyledons are developed the underground branches $e e$, which penetrate into the ground and form tubers $f g$ at their apex or in the axils of small leaves. The tubers are formed only on the branches which are produced in the axils of the cotyledons, never on the true roots $h$.

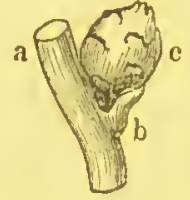

FIG. II7.-A tuber $c$ formed in the axil between a small leaf $b$ and the stem $a .\left(x_{2}.\right)$

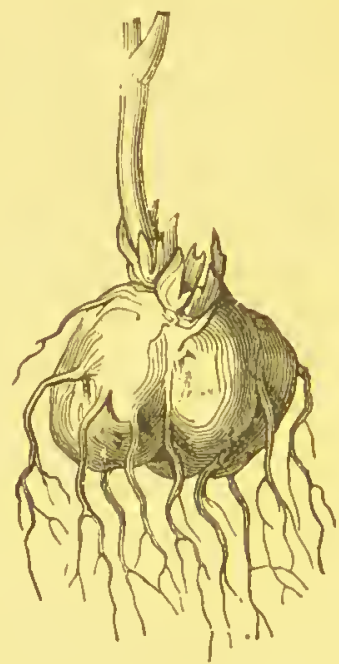

FIG. II8.-Single tuber of the pig-nut, Carum bulbocastanum (natural size).

tubers of some orchids (Figs. II I, I20) are considered by some to be tuberous roots, by others true tubers.

The bulb is also fleshy, but is distinguished by its leaves, which [in the form of scales] surround the solid base of the stem which is called the disc, or are attached to its apex. This plate or disc is either comparatively large, and when surrounded by only a few leaves, as in the crocus, is 
called a corm (Fig. I 2 I); or it may be comparatively small in proportion to the mass of the leaves, as in the onion [or

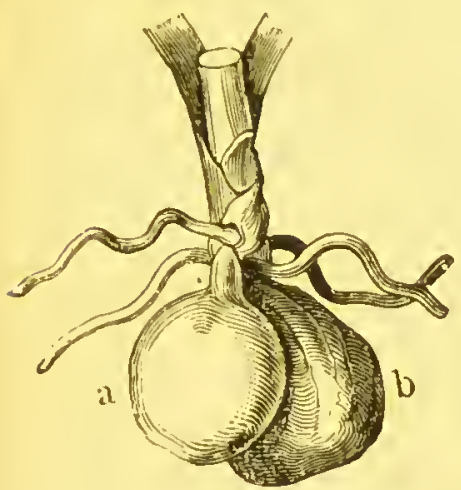

FIG. II9.-Double tuber, $a, b$, of Orchis Morio.

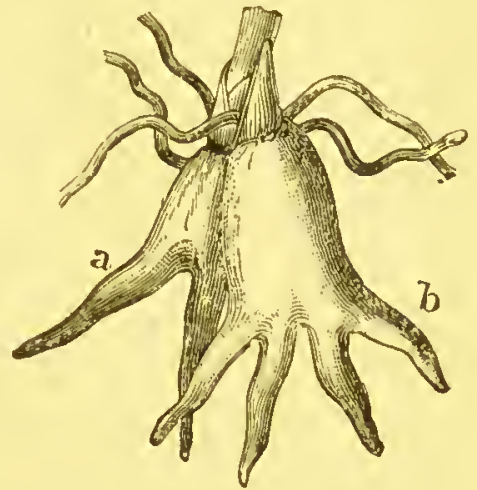

FIG. I20.-Double palmate tuber, $a$, b, of Orchis ocloratissime.

hyacinth] (Fig. I22). Further characters are derived from the character of the scales; and bulbs are hence termed scaly

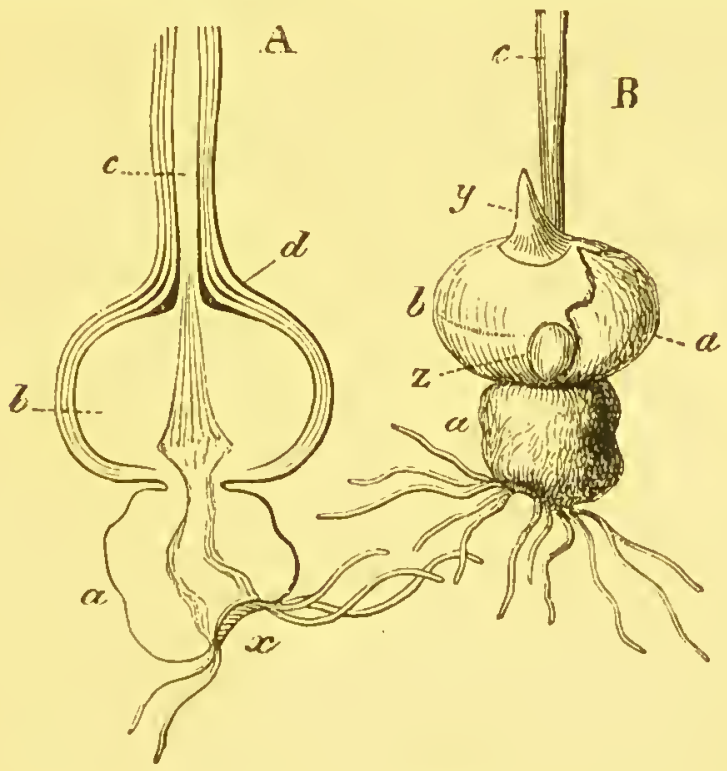

FiG. 121.-Corm of Gladiolus sigetum; A longitudinal section : a last year's, ¿ this $y$ 'er's bulb : $c$ scape a scales: $x$ roots; 13 after removal of the enveloping scales:
$y$ bud which will develop into next year's bud $z$ bulbil. 
or squamose, tumicated [in the hyacinth or onion], fibrous, \&c.

\section{THE BUD.}

Branches of the stem spring, like leaves and flowers, from buds. According to the organs which result from their development, they are distinguished into stem-buds (plumules), leaf-bud's, and flower-buds.

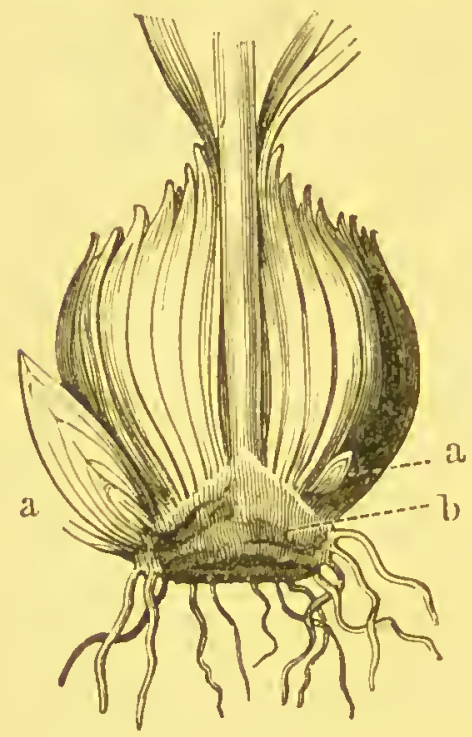

Fic. I22, - Scaly (squamose) bulb of the onion; $b$ plate or disc ; $a$ bulbils.

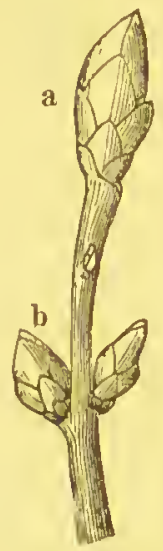

FIG. 123.- $a$ Terminal bud ; $b$ axillary bud, the lenf in the axil of which it was produced having been removed.

As respects the position of the bud, it is terminal (Fig. I 23 a) when it is situated at the end of a branch, axillary (Fig. 123 b) when it grows in the axil of a leaf, i.e. in the angle which its upper surface makes with the stem, or adzentitious when it springs from any other part of a stem except these two. The latter kind occur but rarely; the tendrils of the grape-vine (Fig. Ig6, p. roS) proceed from buds of this description. In the same manner the shoots which spring from the creeping roots. of certain plants, the plum, wild cherry, \&c., originate 
from adventitious buds. There are sometimes a few buds which do not break through the bark, but remain dormant beneath it, until the other buds on the plant have been destroyed by unfavourable circumstances such as late frosts, when these dormant buds are excited into activity, and often preserve the life of the plant. But even while in the dormant state they always increase in size, and form, for example, the balls which are found beneath the bark of the beech, chestnut, lime, \&c. Creeping stems are also sometimes developed from these, but more usually from adventitious buds. It is this production of branches on the stumps of felled trees, as on oaks and birches, which especially adapts them for growth as underwood. The bodies termed bulbils or gemma should also be mentioned here. They are stem-buds which detach themselves from the plant, and can themselves give rise to new individuals exactly like the parent. They are formed, for instance, in abundance on certain species of Allium, on the leaves of Cardamine pratensis, in the axils of the leaves of Lilium bulbiforum, between the scales of bulbs (Figs. I21, I22), [and more frequently with Cryptogams, on the fronds of 'viviparous' ferns, as Asplenium bulbiferum, normally on the thallus of Hepaticx, \&r.]

The mode of clevelopment of the buds has a great influence on the habit of the plant. If, for example, the terminal bud of the primary stem persists as such, the stem will continue to grow for a long time at its apex, as may be seen in the silver fir. Pollarded willows, on the contrary, which have lost their terminal buds, usually form at their summit a dense crown of small branches. The dichotomous branching of the mistletoe depends on the terminal bud always developing into a flower, and the lateral buds into branches.

Buds which persist through the winter are usually protected by special organs, the bud-scales, which are either of a membranous or scaly texture. They are either dry as in the oak, viscid like those of the horse-chestnut, covered with hairs, or smooth. In many cases in which they are not specially developed, as in the lilac, they are replaced by 
ordinary leaves, or by some of special form which are considered as stipules, as in the alder. 'The bud-scales usually fall off when the bud begins to swell in the spring and the enclosed parts to grow : but in some cases, as the oak and beech, they continue to grow for some time at the base.

The stem-bud is a compressed rudiment of the stem, on which account the peculiar position of the organs which are attached to it can be especially well studied in the bud by making a transverse section through it.

The relative position of the bud-scales, foliage-leaves, sepals, and petals, in the bud, or, as it is termed, their astivation, is usually imbricate, where the margins of contiguous leaves overlap one another, less often valiate, as in the calyx of the mallow (Fig. I24), where they merely touch one

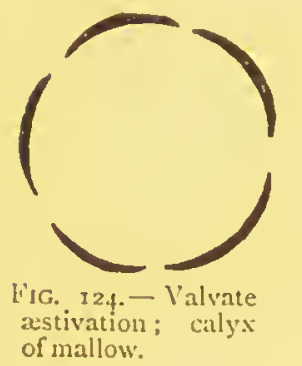

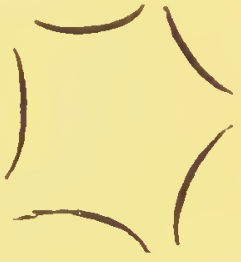

Fig. 125.-Reduplicate valvate estivation.

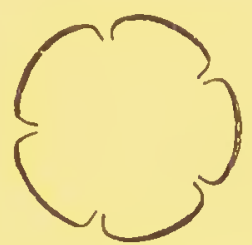

FiG. 126.-Induplicate valvate xstivation.

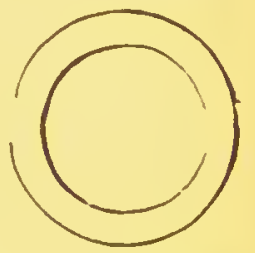

FIG. 127.-Enfolding astivation.

another by their edges. The most important modifications of the imbricate rstivation are the enfolding (Fig. 127) in which one leaf entirely encloses another, the vaxillary (Fig. I2S), peculiar to the Papilionacex, where one leaf much larger than the rest encloses the others; alternatc, as in the tulip (Fig. I 29), where two rows of floral leaves alternate regularly with one another, and quincuncial, as in the woodsorrel, the calyx of the rose, the calyx and corolla of the buttercup, \&c. (Fig. I 30), where the five leaves are so placed that between two outer ones which are entirely uncovered and two inner ones which are entirely covered, there lies a fifth (leaf 3 ), so inserted that with one of its margins it overlaps one of the two inner leaves, while the other margin is 
covered by one of the outer leaves. If the whole bud appears as if twisted spirally, the æestivation is said to be contorted; if, as in the poppy, the leaves lie in the bud irregularly crumpled up, it is crampled.

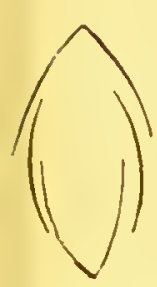

ii. I28.-Vexill.ury zestivation (if Papiliona-

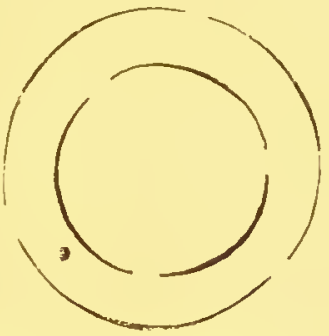

F1G. x29.-Alternate astivation of tulip.

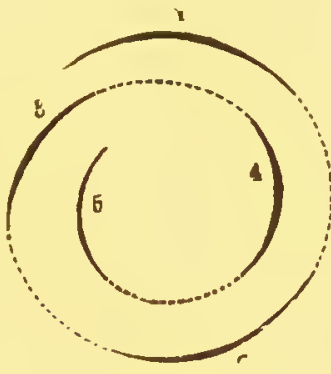

F1G. 130.-Quincuncial astivation.

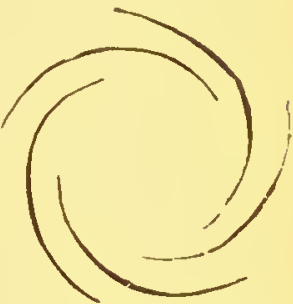

FiG. 131:-Contorted astivation.

By vernation is meant the position occupled by the separate leaves in the bud. This is flat in the leaves of Coniferæ ; simply folded (Fig. I 32 ) in those of the cherry and lime ; plicate or with many folds in those of the beech and birch Fig. I33). In their length from the apex to the base leaves
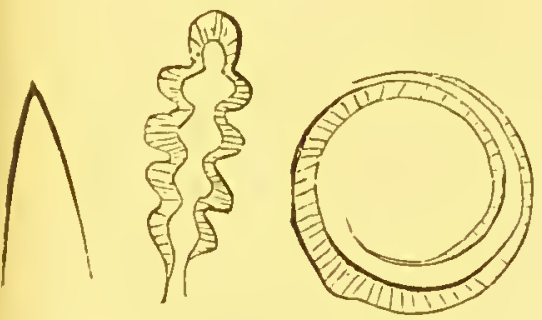

16. I32. - Fifr. I33. - Ftg. 134.-ConSimply fold- Plicate ver- volute vernaed verna- nation. tion.

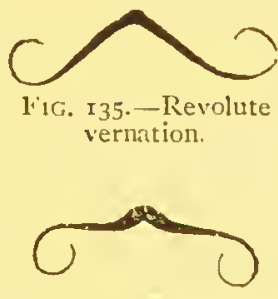

Fic. 136.-Involute vernation.

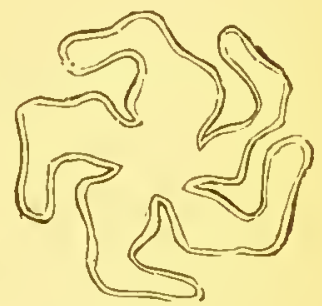

FiG. T37--Contorted vernation.

are circinate, like the fronds of ferns, where the apex is rolled up towards the base ; convolute (Fig. I34), where one margin is rolled up towards the mid-rib, as in Grasses and bananas. The sepals of Fumaria are revolute, the margins being rolled outwards (Fig. I 35 ) ; those of the sweet violet 
on the contrary are involute (Fig. I36), or rolled inwards towarcis the mid-rib. The petals of Convolnulus (Fig. I37) are contorted spirally; those of the poppy irregularly crumpled.

With respect to their anatomical structure, it may be remarked that buds are especially distinguished by the presence of formative tissues.

\section{THE LEAVES.}

It will be seen from what has now been said that the Leaves are appendicular organs of the stem. The apex is always formed first, and is therefore the oldest part of the leaf; the remaining parts being gradually interposed between it and the stem. The order of development is therefore the reverse in the leaf to what it is in the stem, where the apices are the youngest parts.

The various positions and functions of leaves necessitate their classification into four kinds:-seed-leaves or cotyledons, covering-leaves, foliage-leaves, and floral leaves. The first of these kinds will be more fully described when speaking of the seed ; the last when speaking of the flower.

Covering-leares are so called because they cover or protect other parts of the plant. In this class are included the bud-scales already described (p. 83), and the bracts or hypsophyllary leaves, i.e. those leaves in the axils of which the flowers are placed. The bud-scales are mostly brown bodies but little developed, which fall off as the development of the bud progresses, when they have fulfilled their purpose. The bracts are, on the contrary, as a rule more perfectly formed and green, or of some other colour as in the spathe of Calla [or Richardia, or the brilliant red bracts of Poinsettia, Bongainvillea, Sc.] Their presence or absence, and their more or less complete development, are important in determining the nature of the inflorescence, and in defining the characters of certain families of plants. The slumes of Grasses, the spathe of Aroidere, the palece of Composite, and 
the involucre of Umbelliferæ [and Compositæ], are different forms of bracts.

To this class belong also the scalc- or cataphyllary leaves, which are either colourless, yellowish, reddish, brown, or rarely green; often fleshy, leathery, or membranous, and which for the most part remain buried in the ground. When the true foliage-leaves are strongly developed, the scaleleaves are generally inconspicuous; while in other plants they are conspicuous, as in saprophytes which are destitute of chlorophyll and have no true leaves (Fig. 346, p. r66).

The foliage-leaves-often called simply leaves-are distributed over the stem in a great variety of ways. When there is more than one on the same level they are opposite, slccussate (Fig. 138), or verticillate (Fig. 139); when there is only one on the same level, alternate or scattered (see p. 76). Irregular as the arrangement appears in the last case, a close investigation nevertheless shows that these also are distributed on the stem in accordance with definite laws. If a spiral is drawn round the stem connecting the points of attachment of the leaves, and these are then marked on the spiral, it is found that in any particular species there is always a certain definite number of leaves on any given number of circuits made by the spiral round the stem. The course of the spiral from any one leaf to the next leaf which stands exactly vertically above or beneath it is therefore termed the leaf-cycle. In order to determine the law of phyllotaxis or leaf-arrangement in any particular species, the number of leaves in a cycle is placed as the denominator of a fraction, and the number of circuits round the stem included in the cycle as the numerator. Thus, for example, the leaves of the pear, oak (Fig. 140), poplar, and walnut, have a $\frac{2}{5}$ arrangement; i.e. five leaves are found on every two circuits which make up the cycle. In Plantago (Fig. I 4 ) the phyllotaxis is $\frac{3}{8}$. 'That the law of phyllotaxis, to which the floral leaves are also subject, must have a great influence on the restivation is self-evident: thus the quin- 
cuncial æstivation corresponds to the $\frac{2}{3}$ phyllotaxis. The spiral itself may either be a right-handed one, i.c. running from the left below to the right above, or conversely a lefthanded one. The law thus indicated is not, however,

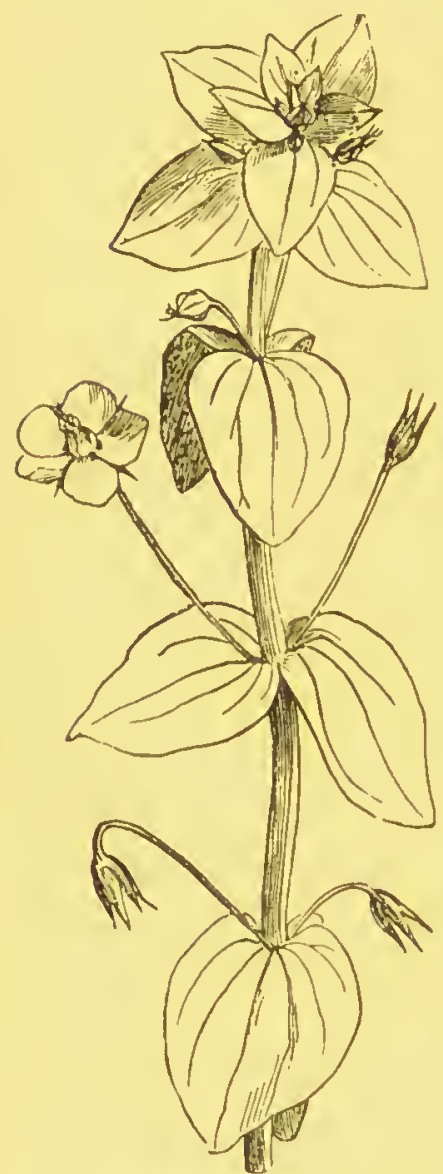

Fig. I38.-Decussate leaves of the scarlet pimpernel, Auagallis ariensis, with axillary flowers.

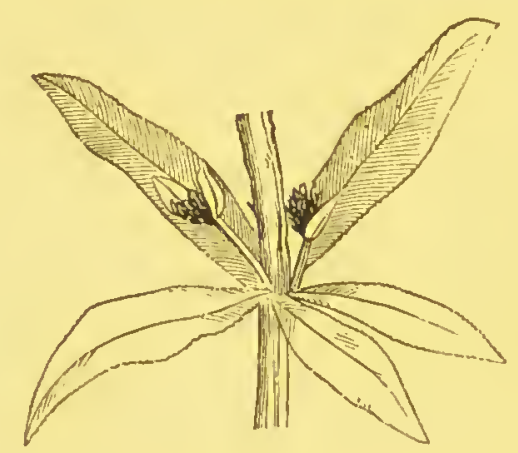

FIG. 139. - Verticillate leaves of the madder, liubia tinctormm.

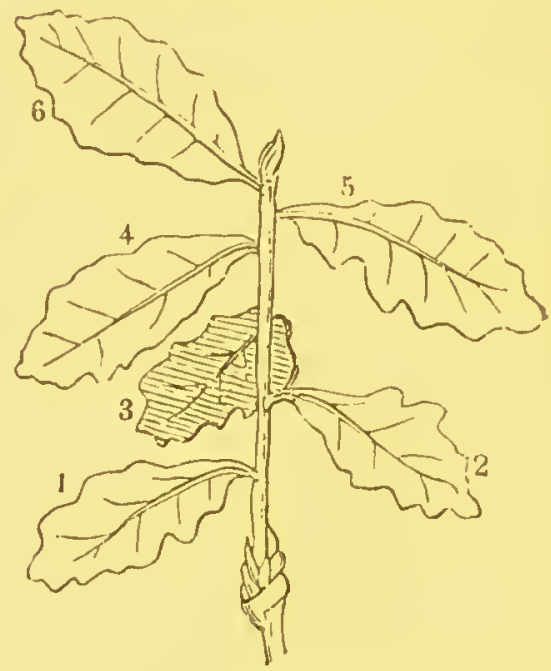

FiG. 140.-2/5 phyllotaxis of the oak.

always easy to recognize in practice. Of the leaves of Grasses, for example, one half follow a right-handed, the other half a left-handed spiral. The spiral arrangement is often obscured by the leaves standing in a fasciculate 
manner on a branch which has remained undeveloped, as in the larch.

Since the secondary axes (branches) gererally spring from axillary buds, it follows that their arrangement on the stem is dependent on the phyllotaxis of those leaves in the axils of which they arise, as is seen at once in any labiate plant. It is also easily understood that an apparently altogether irregular arrangement of the branches on the stem may be the result of the abortion of a number of buds.

A leaf of the most perfect development may be divided into its sheath, its petiole or leaf-stalk, and its lamina or flatly expanded blade, although one or other of these parts

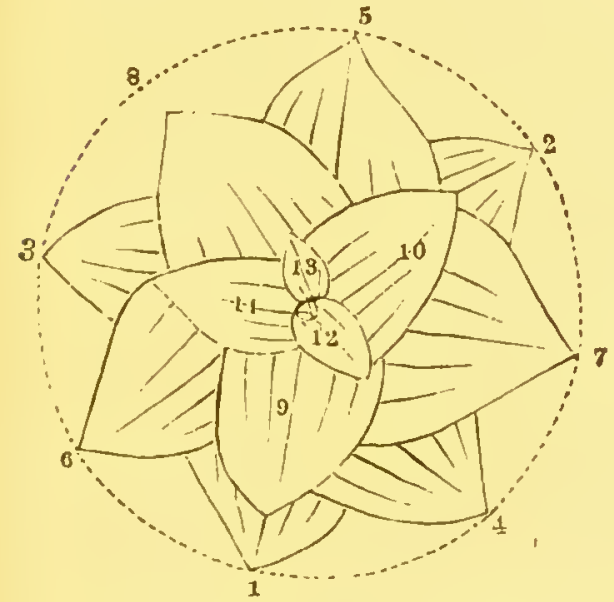

FIG. 141.-Dingram of the $3 / 8$ phyllotaxis of Plintigo.

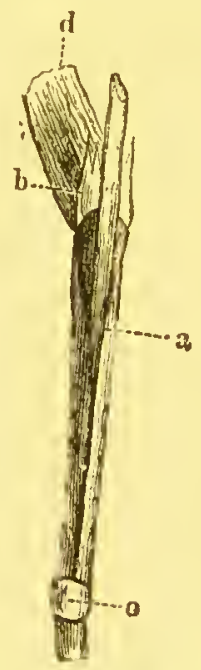

FIG. I42.- $a$ Split leaf-sheath of a grass: $b$ ligule; $d$ pat of the lamina of the leaf : $c$ node of the culm.

is most often wanting. Thus the leaves of Grasses have a sheath, but no petiole ; those of the apple and pear a petiole, but no sheath; in those of many Umbelliferæ, such as Angelica, all three parts occur.

The lcaf-shcath embraces the stem in the form of a hollow tube. In Grasses it is always split in front (Fig. 142); 
in rushes and sedges, on the contrary, closed or entire. The split sheath of many Umbelliferæ is inflated; while the closed sheath of the knot-grass, Polysomm, does not bear the leaf at its upper end, but on its back, and is in this case called an ochrea.

The petiole is not always present; and leaves are hence distinguished into petiolate or stalked, and sessile. It is often

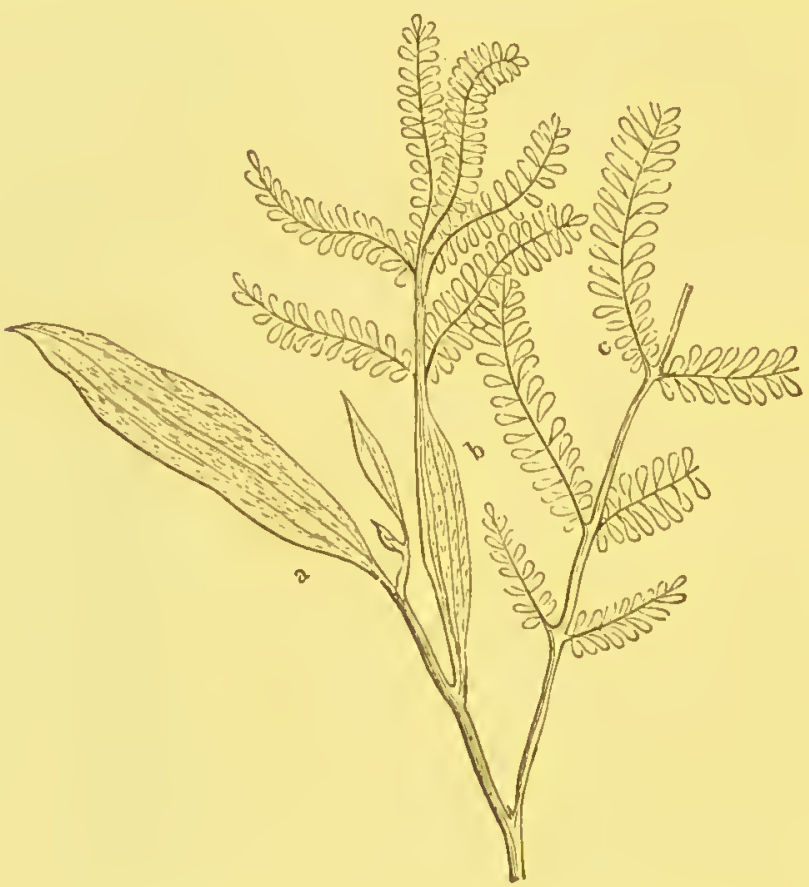

Fig. 143.--Branch of Acacia melaro $x$ ylon, showing phyllodes, $a b$.

comnected with the stem, rarely with the sheath, by a peculiar more or less swollen articulation. If this articulation is large, and a portion of it remains attached to the stem after the fall of the leaf, as in the spruce-fir, the portion that thus remains is called a pulvinus. After the fall of the leaf, the spot to which it was attached is indicated by a scar or cicatrix. The petiole may be cylindrical, semicylindrical, channeled, or flat, and is sometimes winged, or provided 
with leaf-like expansions at the side. Some Australian species of Acacia possess in the early years of their life bipinnate leaves with a more or less flatly expanded petiole (Fig. I $43, b$ ); but subsequently the pinnæe are no longer developed, the branching is also suppressed, and the simple petiole, now strongly developed into a flat plate (Fig. I43, a), performs all the functions of the leaf. Such a petiole is termed a phyllode, and is distinguished from leaves of normal structure by its mode of development, as well as by its vertical position. ${ }^{1}$

At the base of the petiole on both sides are frequently found flat leaf-like appendages, the stipules (Figs. I44, I45).

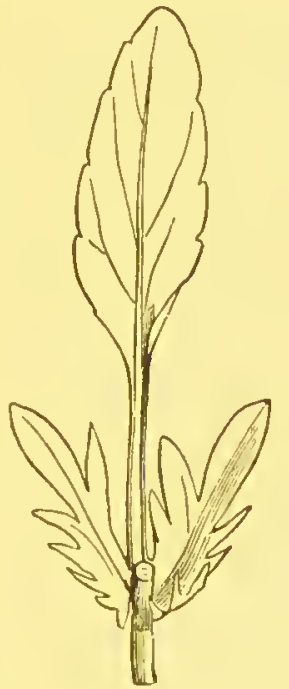

Fig. I44-Leaf of the pansy, with two large stipules.

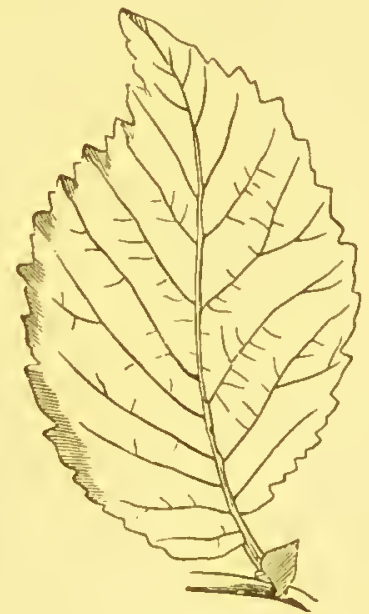

Fic. 145.-Leaf of the elm, with small stipules.

These are sometimes adherent to the petiole, or adnate, as in the rose, and occasionaliy even rum down a portion of the

' [The petiole of Sarracenia and Darlingtonia is expanded into a remarkable pitcher-likc organ capable of holding a considerable amount of fluid. The somcwhat similar pitchers of the 'pitcher-plant' or Nepenthes (Fig. 193, p. 106) are considered on the other hand to be expansions of the lamina. - ED.] 
stem itself as in the wood-vetch, Vicia sepium, when they are decurrent, and give a winged appearance, either to the petiole or to the stem. [When not adherent to the petiole they are said to be free (Fig I54, p. 95).] The stipules are mostly smaller than the true leaves, seldom larger, as in the pansy (Fig. 144). In Lathyrus Aphaca (Fig. I46), the stipules of

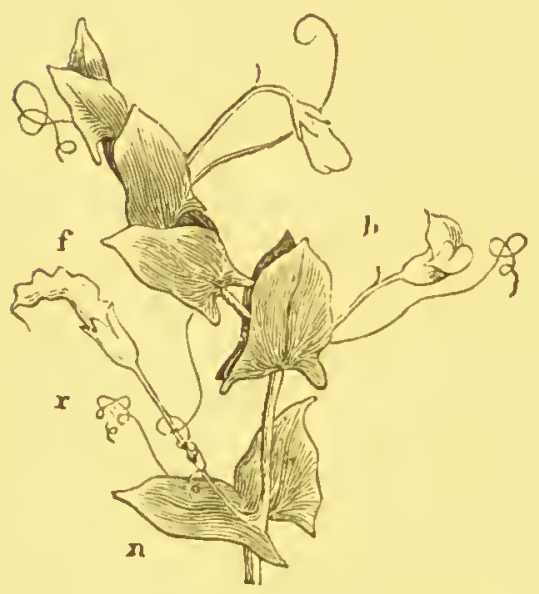

FIG. 146.-Lathyrus Afhaca: r tendril ; $b$ fower ; $f$ fruit ; $"$ stipule.



FIG. I47.-Leaf of grass: Lig. ligule; L lamina; G leaf-sheath.

the upper leaves are the only part to expand, the leaf itself degenerating into a tendril. The stipules of Gleditsclia and the common 'acacia,' Robinia psendacacia (Fig. I 84, p. I03), are spinous; they are leaf-like and persistent in the pea, membranous and deciduous in the oak and beech. ${ }^{1}$ Under the head of stipules come the ligules (Figs. I42, I47), or delicate appendages which grow at the point of union of lamina and sheath in the leaves of Grasses.

Sessile leaves sometimes partly or entirely embrace the stem, and are then amplexicaul, or semi-amplexicaul. In the former case the base is occasionally developed in a sheath-like

${ }^{1}$ [In pinnate leaves, each of the petiolules or separate petioles of the leaflets is sometimes furnished at its base with a secondary stivule or stifellar.-En. 7 
form, sometimes not, as in the common buttercup (Fig. 148). So-called perfoliatc leaves, as in Bupleurnm rotundifolium (Fig.

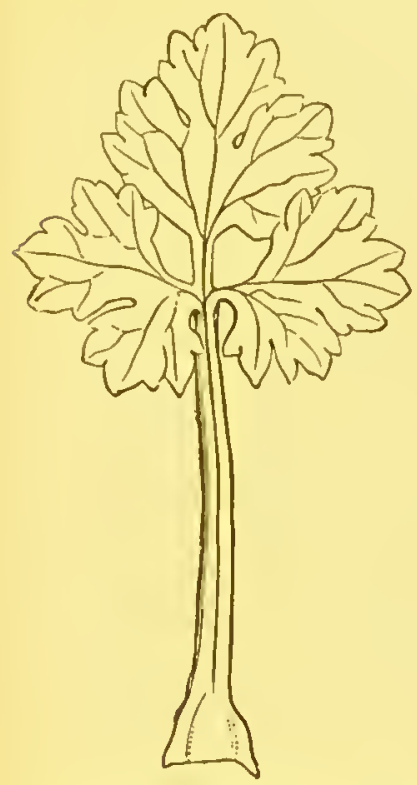

FIg. 148.-Amplexicaul leaf of the buttercup, with petiole expanded at the base.

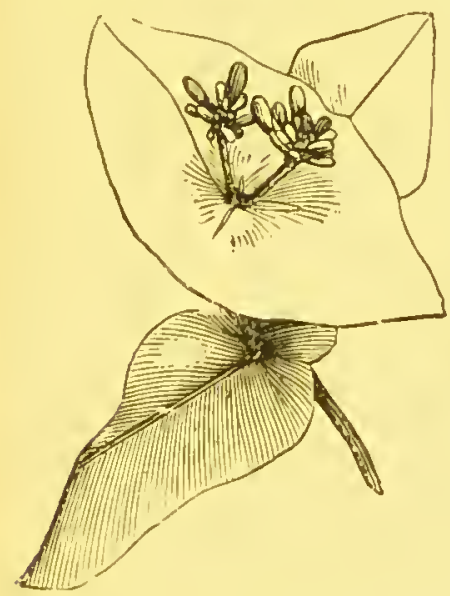

Fic. 150.-Connate leaves of the honeysuckle.

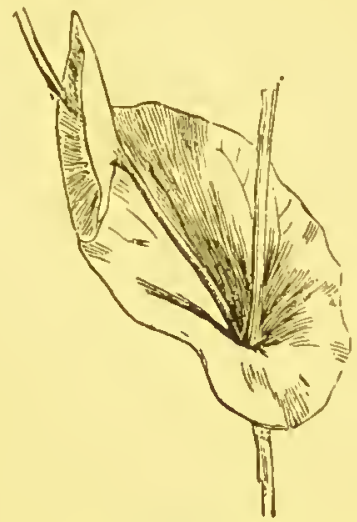

FIG. I49. - Perfoliate leat of Bupleurum rotundifolium.

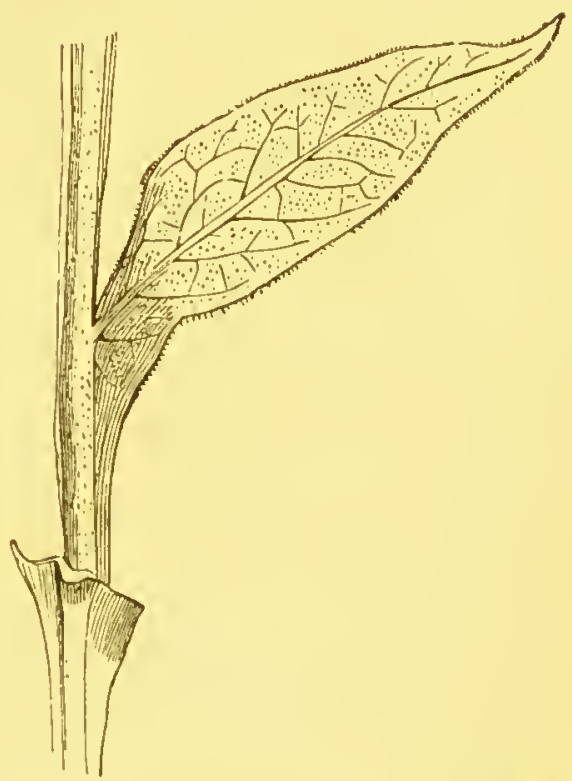

FiG. 15I.-Decurrent leaf of Sympliytum offcinale, the stem hence becoming winged on one side.

I49), or connate leaves, as in the common honeysuckle (Fir I50) [or Chlora perfoliata], are varieties of the amplexicaul 
form. In the former case the two margins of the base of the leaf have united; while the latter variety consists of two leaves which have become completely united at the base in their growth. Not unfrequently the leaf is united for a certain length with the stem, when it is said to be deenrrent [and the stem to be winged], (Figs. I5 I, 152).

The lamina or blade, the most essential part of the leaf, may assume almost any conceivable form. The first thing to observe is whether the petiole bears only a single lamina, or several, connected with it by secondary petioles or petio-

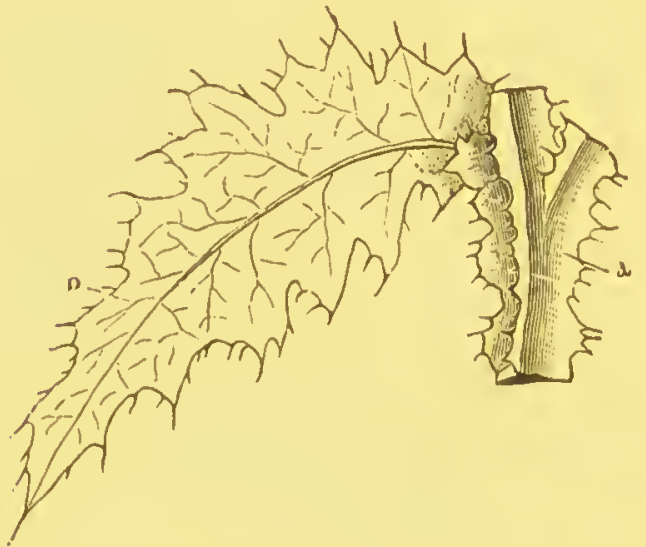

l'IG. I52.-Decurrent spiny leaves of thistle, the stem $a$ hence becoming winged.

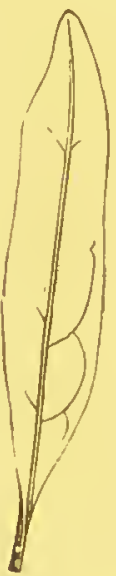

Fig. I53.-Lanceolate leaf of the privet.

lules, or by articulations. In the first case the leaf is said to be simple, in the latter cases compound.

The separate leaflets of a compound leaf, as well as the single lamina of a simple one, may have the greatest variety of external form. Lincar leaves are such as are not only many times longer than broad, but are of nearly the same width from the base to near the apex, as in nearly all Grasses. If the leaves are at the same time somewhat rigid, as in Iris, they are ensiform; and if they are also sharp-pointed like those of most Conifere, they are acieular or acerose. A lanico late leaf (Fig. I 53) is three or four times as long as broad, ancl, 
is narrowed to a point both at the base and the apex. In the elliptical or oval (Fig. I 54), and the oblong leaf, the ends

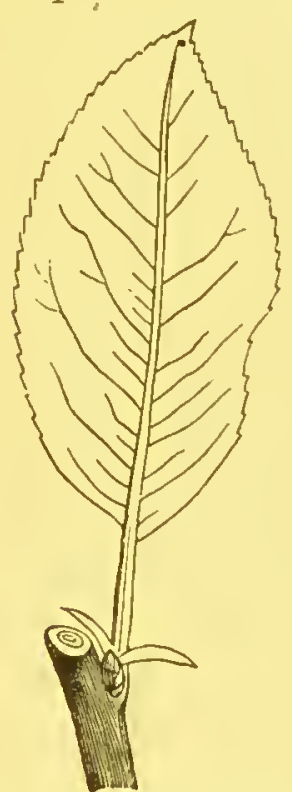

Fig. 154--Oval leaf of the apple [with two free stipules]. are equally rounded off; the former is two to three, the latter three to four times as long as broad. The terms ovate (Fig. I68, p. 98) [where the broadest part is nearer the base

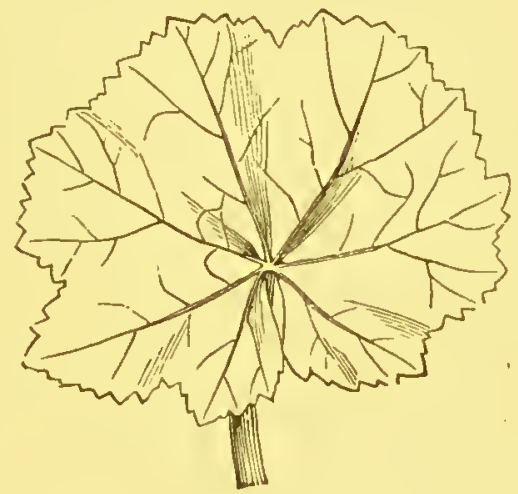

F1G. 155.-Orbicular leaf of Malar rotundifolia.

than the apex], obovatc, [where the broadest part is nearer the apex than the base], sub-rotund, orbicular (Fig. I55),

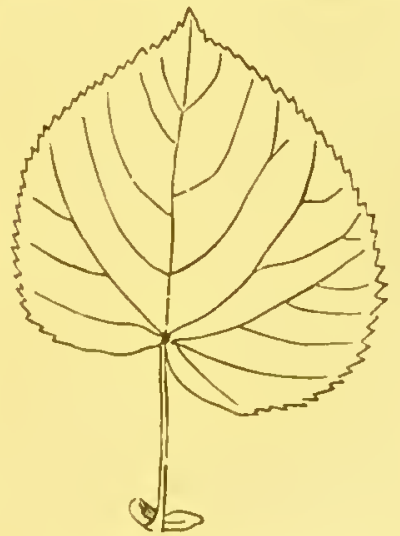

Fic. 156.-Cordate [unsymmetrical] leaf of the lime.

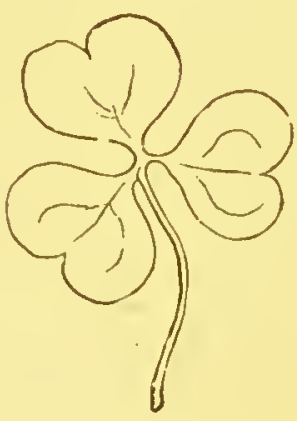

FIG. 157.-Leaf of Oxalis micrantha, with three obcordate leaflets.

cordate (Fig. 156), obcordate (Fig. I57), triangular, as in 
Atriplex patula (Fig. 158), and rhomboidal, are used in their obvious signification. A reniform leaf (Fig. 159) is one. that is broader than long, and has the apex rounded off,
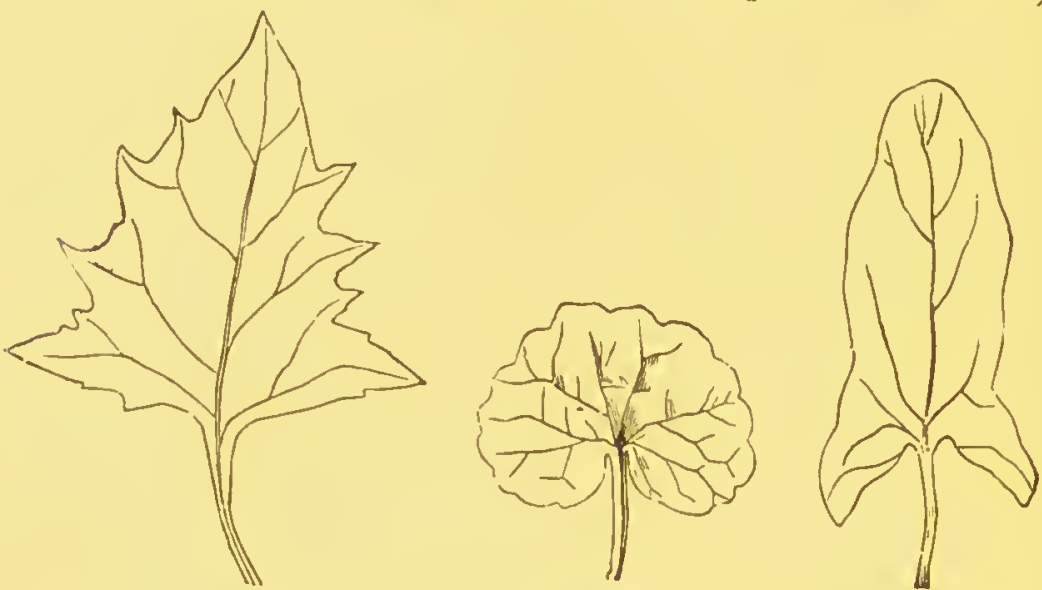

FIG. 158.-Triangular leaf of Fig. 159--Reniform leaf of Fig. I60.- SagitAtriplex patula. the ground-ivy, Nepcta Glechoma. tate leafor Convol. vulus arvensis.

with two projecting lobes at the base also rounded off. Sagittate (Fig. I60) and hastate (Fig. I6I) leaves are

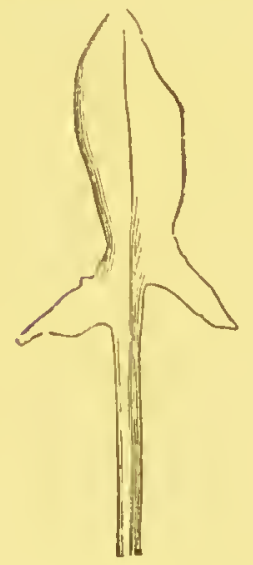

Fig. 16r.-Hastate leaf of Rumex acetosa.

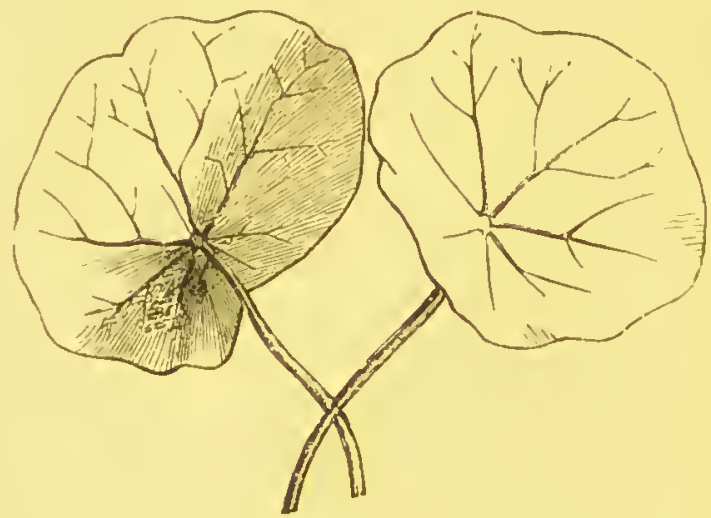

Fig. I6́2.-Peltate leaf of Troprcolus.

pointed at the apex, and have also two pointed lobes at the base; the incision bounded by these latter is acute-angled 
in the former, very obtuse-angled in the latter case. In the peltate leaf (Fig. 162), the petiole springs from the middle of the lamina [as in Hydrocotyle or Tropaolum].

In describing the form of the base of the leaf, i.e. of the part of it which is attached to the stem or petiole, some of the same terms are applicable as those already defined; as, for example, cordate, reniform, hastate, \&c. There are some others also in use. Thus the base may be cuncate or wedge-shaped (Fig. 163), when it passes gradually into the

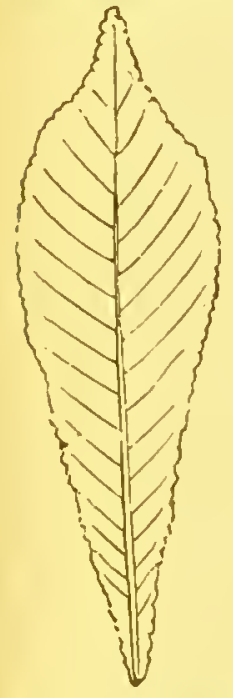

Fig. I6.3. - Cuneate leaflet from the leaf of the horse-chestnut.

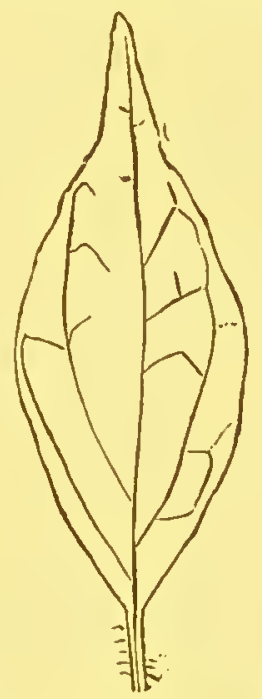

FIG. 164.-Acuminate leaf of the pellitory, Parietaria.
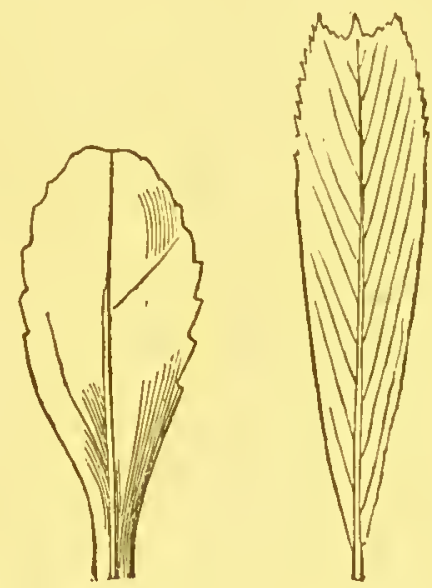

FIG. 16. - Spathu- FIG. I66-Mu. late leaf of the ox- cronate leaflet eye daisy, Chrys- of the lucerne anthemanz leucan- (magnified).

petiole; and the spathulate leaf (Fig. I65) is somewhat similar [as in the London pride, Saxifraga umbrosa]. The apex of the leaf also often requires special description. It is obtuse, acute, acuminate [when the apex narrows rapidly and lengthens into a point] (Fig. I64), mucronate (Fig. I66) [when ending abruptly in a short sharp point,] truncate [as in the tulip-tree, Liriodendron], emarginate (Fig. 167) [when indented at the apex], or obcordate (Fig. I $57, \mathrm{P} .95$ ).

In but comparatively few cases is the lamina entirely 
without incisions of any kind. In the great majority there are either smaller notches which affect only the margin, or

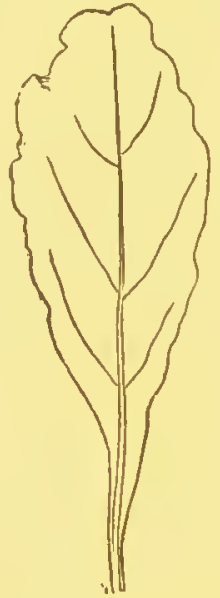

FIG. I67. - Emarginate Fig. I68,-Dentate ovate leaf of Amaranthus. leaf of the guelder-rose, Viburnum Opulus.

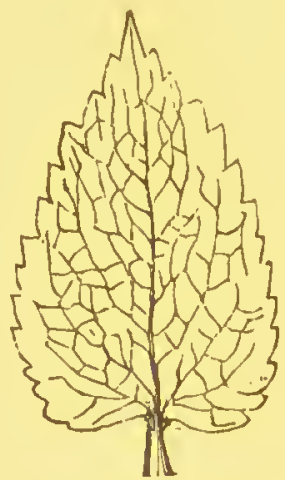

FIG. 169.-Serrate leaf of Laminm.

deeper incisions which cause the leaf to assume a different form, or both may occur on the same leaf. In reference to the margin, the leaf may be cntire [without notches of any

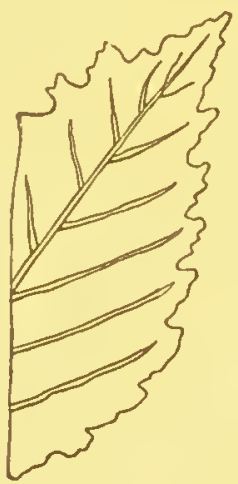

Fig. 170.-Part of the bi- Fig. I7I.-Ciliate leaf of serrate leaf of the elm.

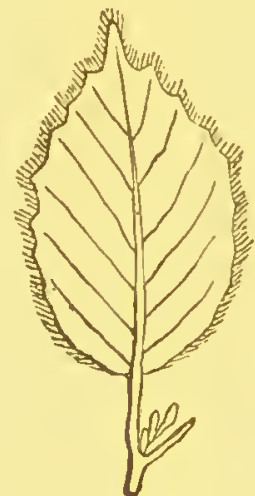

the beech.

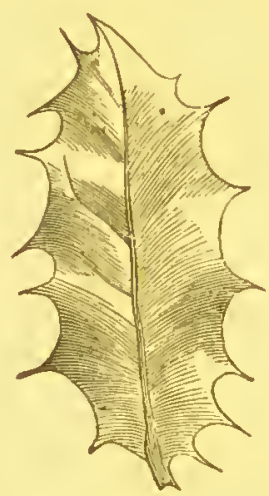

FIG. 172.- Spiny leaf of the holly.

kind, as in all Grasses, Caryophyllaceæ, Vincu, \&c.]; dcntate (Fig. r68) [when the teeth are sharp and point outwards with concave edges], serrate (Fig. I69) [when the teeth are 
sharp and point forwards towards the apex like the teeth of a saw]; biserrate (Fig. I 70); crenate (Fig. 159 ) [when the teeth are rounded off with convex edges]; or repand [when the margin is wavy]. A leaf is ciliate (Fig. I $7 \mathrm{I}$ ) [when fringed with hairs on the margin], spiny (Fig. I 72) [when the teeth are long and very sharp], rough or scabrous when provided with small scarcely visible roughnesses.

If the margin of a leaf or leaflet is more deeply cut than is indicated by the terms just mentioned, it is incised, and pinnatisect if the divisions extend [very nearly] to the mid-rib (Fig. r74); palmatisect if they extend [very nearly] to the base of the leaf (Fig. r73); pimatipartite and palmatipartite (Fig. 183, p. 102) respectively if the incisions do not extend quite

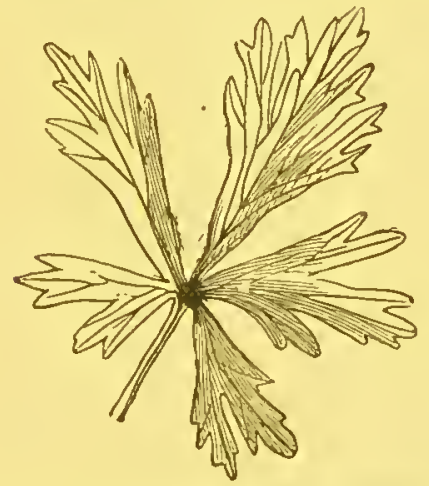

FIG. I73.-Palmatisect leaf of the monks. hood, Aconitum.

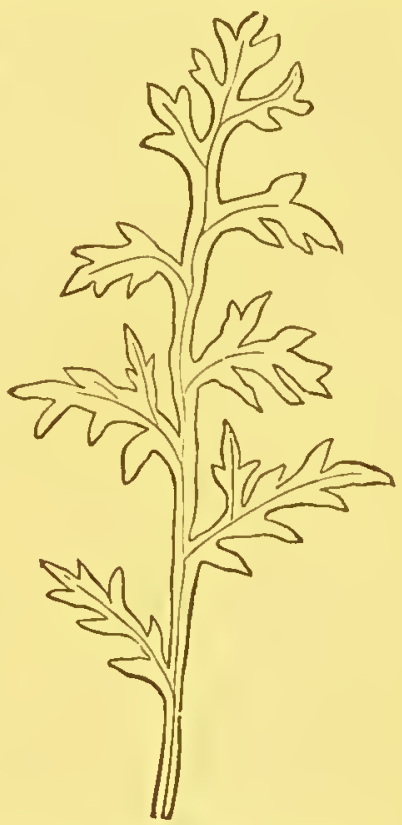

FIG. 174-Pinnatisect leaf of the common poppy, Papaver Rhars.

so far; and pinnatifid and palmatifid when they extend about half-way from the margin to the mid-rib or base of the leaf. If the divisions of a palmatifid leaf are five in number, it is called palmate (Fig. r 8r, p. ro2). Special modifications of the pinnatifid leaf are the runcinate (Fig. I 75), where the points of the large central lobes are reflexed; lyrate (Fig. I 76), where the terminal lobe is much the largest, and the others decrease 
gradually towards the base; laciniate (Fig. I77), where the leaf is irregularly cut into very narrow segments. In a slit leaf the lobes into which the margin is divided are narrow

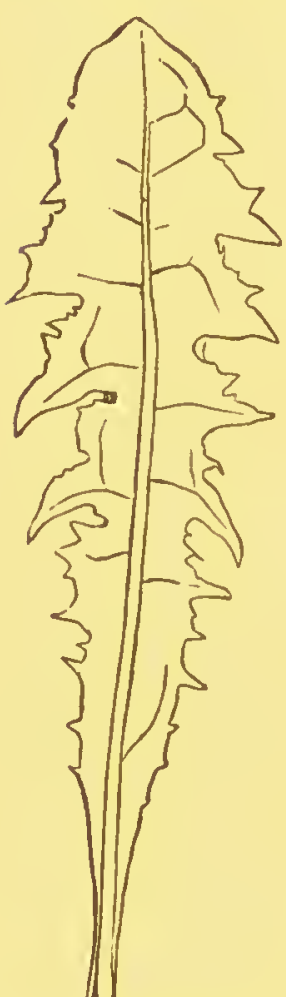

Fig 17.5.-Runcinate leaf of the dandelion. and pointed; in a lobed leaf (Fig. 179) they are broader and rounder (with the excep-

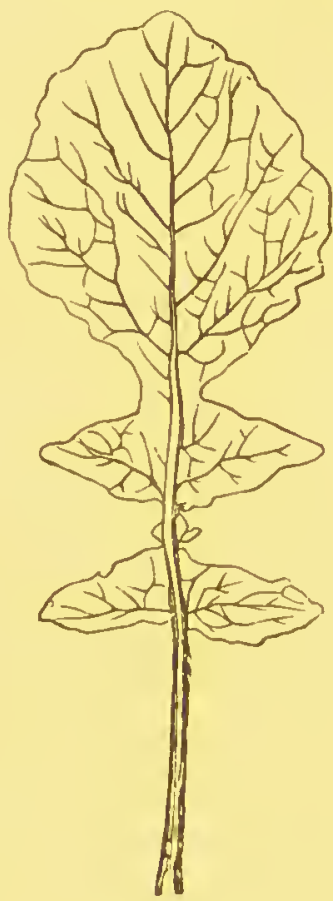

Fig. I76.-Lyrate leaf of the white mustard, Brassica alba. tion often of the terminal lobe), the incisions themselves having an acute angle; in a simuate leaf (Fig. 180)

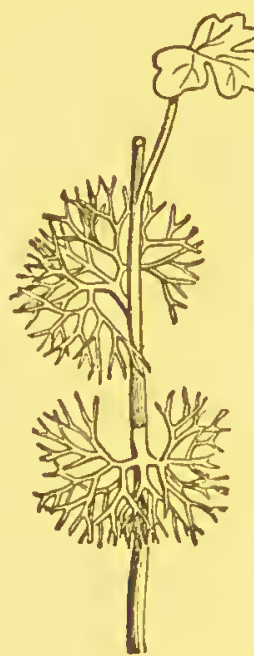

FIG. 177. - Heteromorphic leaves of the water crowfoot, Ran:uncuhs nutertilis: the floating leaves trilobed, the submerged leaves laciniate.

still broader and shallower, the incisions themselves being also rounded off. According to the number of the divisions, the leaf is trifid, trilobed (Fig. I79), fiz'-lobed, \&c., or the latter is usually called palmatilobed.

Compound leaves are classed under two principal heads, the digitate and the pinnatc. In the former, several leaflets $-3,5,7$, or less often 4 -spring from the apex of the common petiole. The most common number is 3 , as in the clover (Fig. I82, p. 102), when the leaf is said to be ternate or 
Irifoliolate. When the petiole divides at its apex into two main divisions, each of which bears several leaflets, it is pedate (Fig. I83). The pinnate leaf has its leaflets arranged on each side of a common elongated petiole, which is then called the rachis. If the rachis ends in a terminal leaflet [so that the number of the pinnæ is uneven] the leaf is unequally pinnate or $i m$ paripinnate (Fig. I84); if the number of leaflets is an even number it is paripimate or equally pinnate (Fig. I 85); and

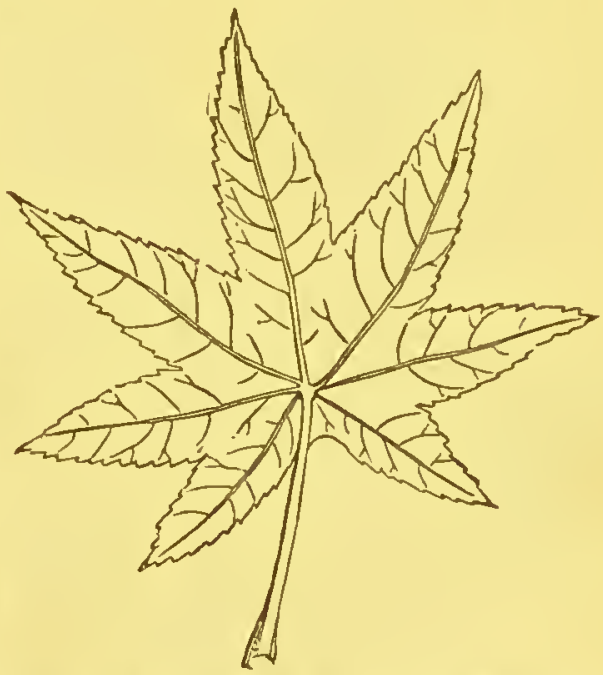

FiG. I78.-Palmatifid leaf of the castor-oil plant, Ricinus commutuis.

in this case the rachis may run into a tendril or a point (Fig. I85), or may end abruptly. The leaflets may be

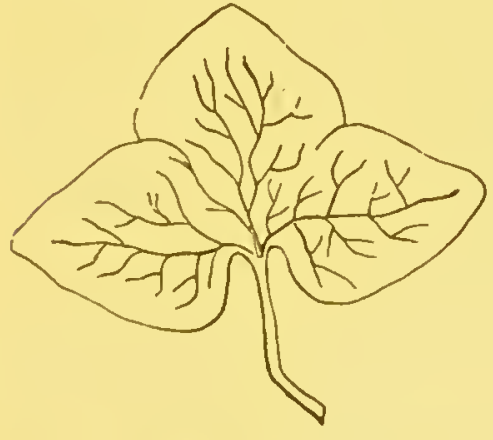

FIG. 179.-Trilobed leaf of the liepatica.

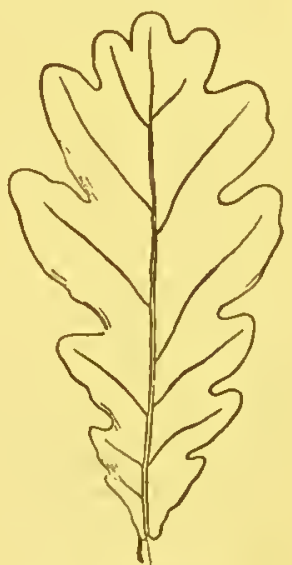

Fig. I8o.-Sinuate leaf of the oak.

opposite to one another on the rachis (Fig. I84), when cach pair forms a ' jugum,' or they may be alternate (Fig. 


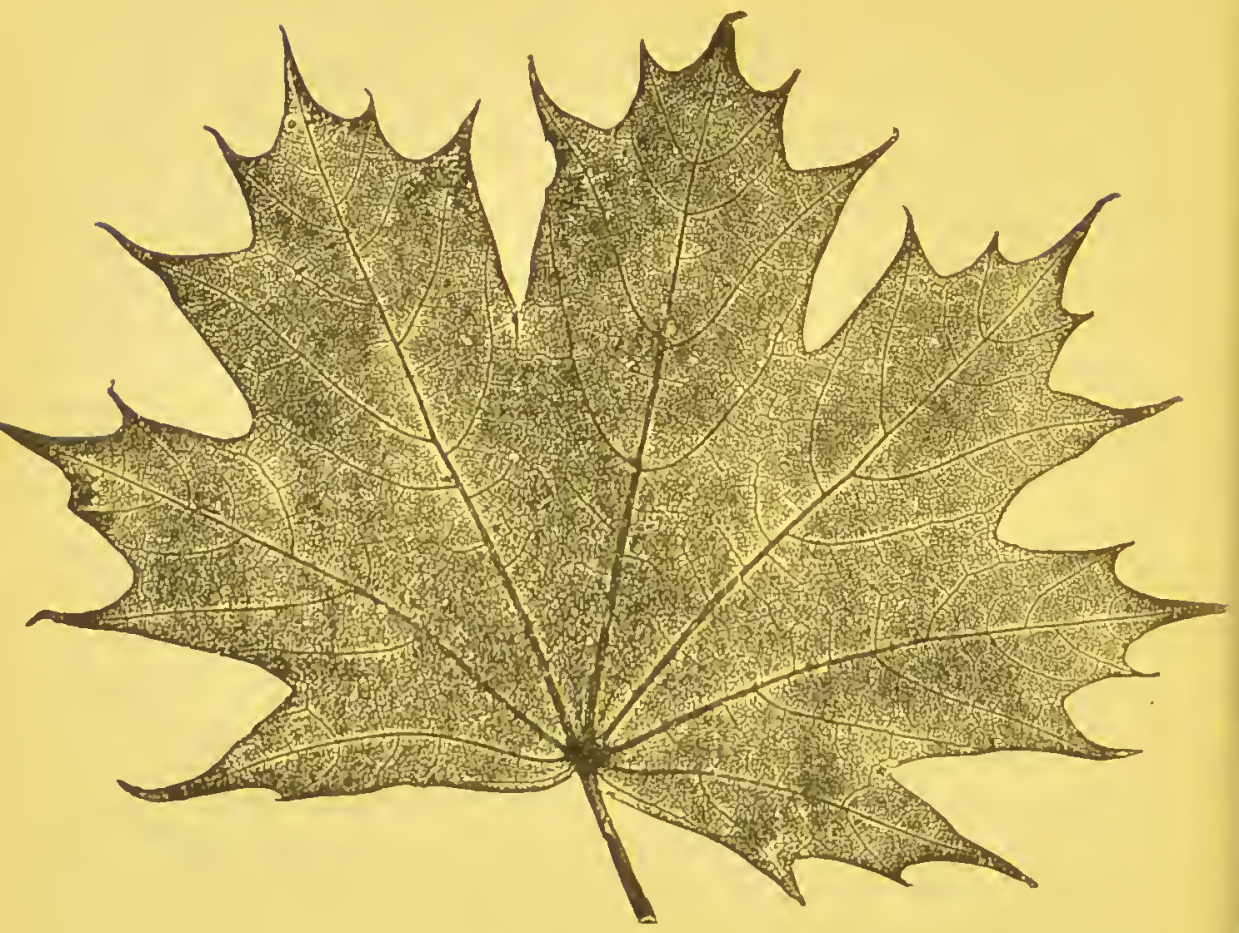

Fic, I8r.-Palmate leaf of Accracutifolium (nature-printed).

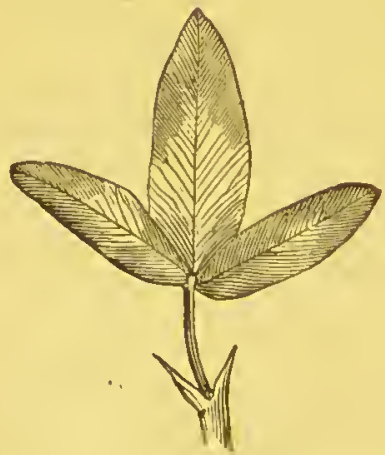

FIG. 182,-Trifoliolate leaf of the clover [with adnate stipules].

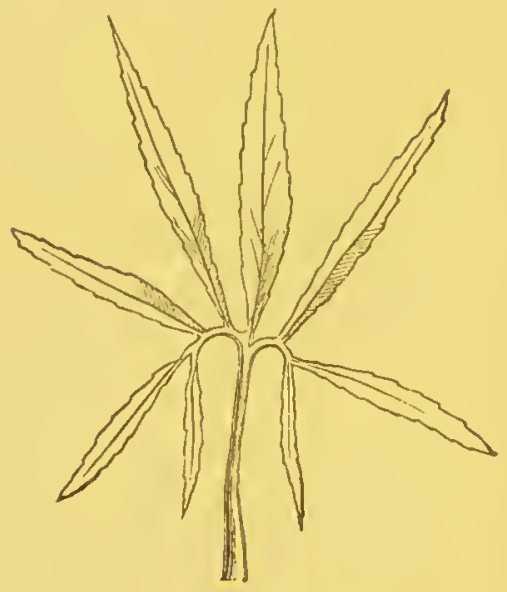

Fig. 183.-Pedate leaf of Helletiorus. 
I S5). If large and small leaflets alternate with one another, the leaf is interruptedly pinnate (Figs. I86, I87).

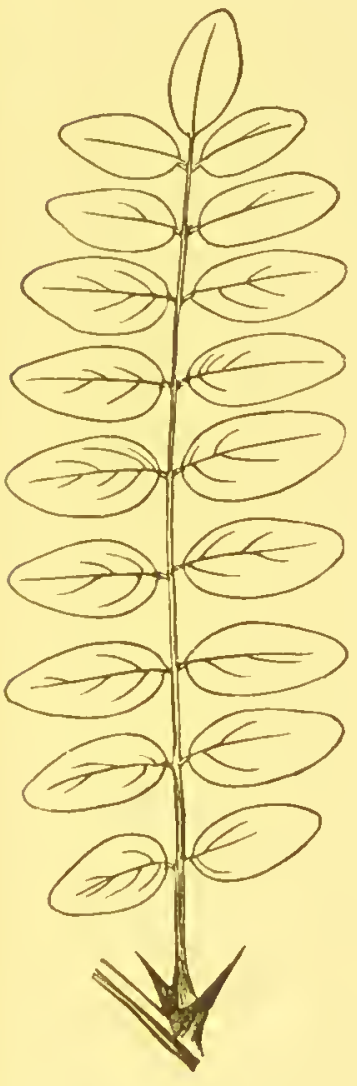

Fig. $184 .-$ Imparipiunate leaf of the 'acacia' Fobinin Pseridacacin. with opposite leaflet. [and spinous stipules].

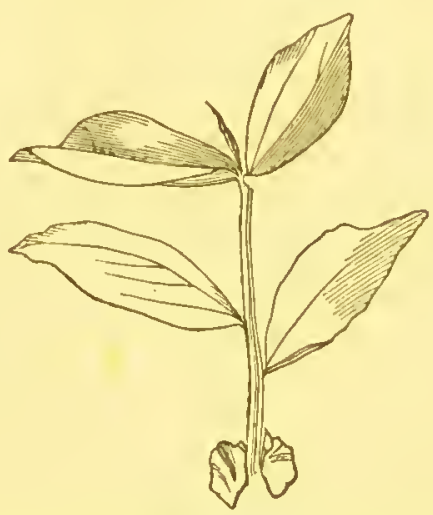

FIG. 185.-Paripinnate leaf of Lathyrus mincrorlizizs [with auriculate or car-shaped stipules] the rachis ending ir: a point.
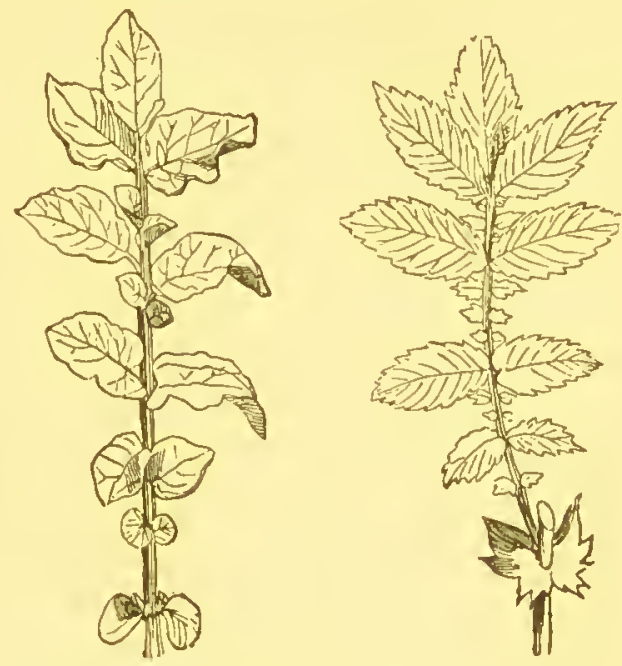

Ii 1G. 186-Interruptedly FiG. 187.-Interruptedly pinnate leaf of the po- pinnate leaf of $A$ sritato. mouia Eupatoria [with connate stipules?.

In some cases the division into leaflets is repeated, and the leaf is then supradccompound. Thus we may have a bitcrnat leaf (Fig. 188), [in which each of the trifoliolate sections is again trifoliolate], a bipinnate (Fig. 190), and even 
a ter- to quinque-pinnate leaf (Fig. I89). In the bipinnate leaf, which is of very common occurrence, the leaflets which are

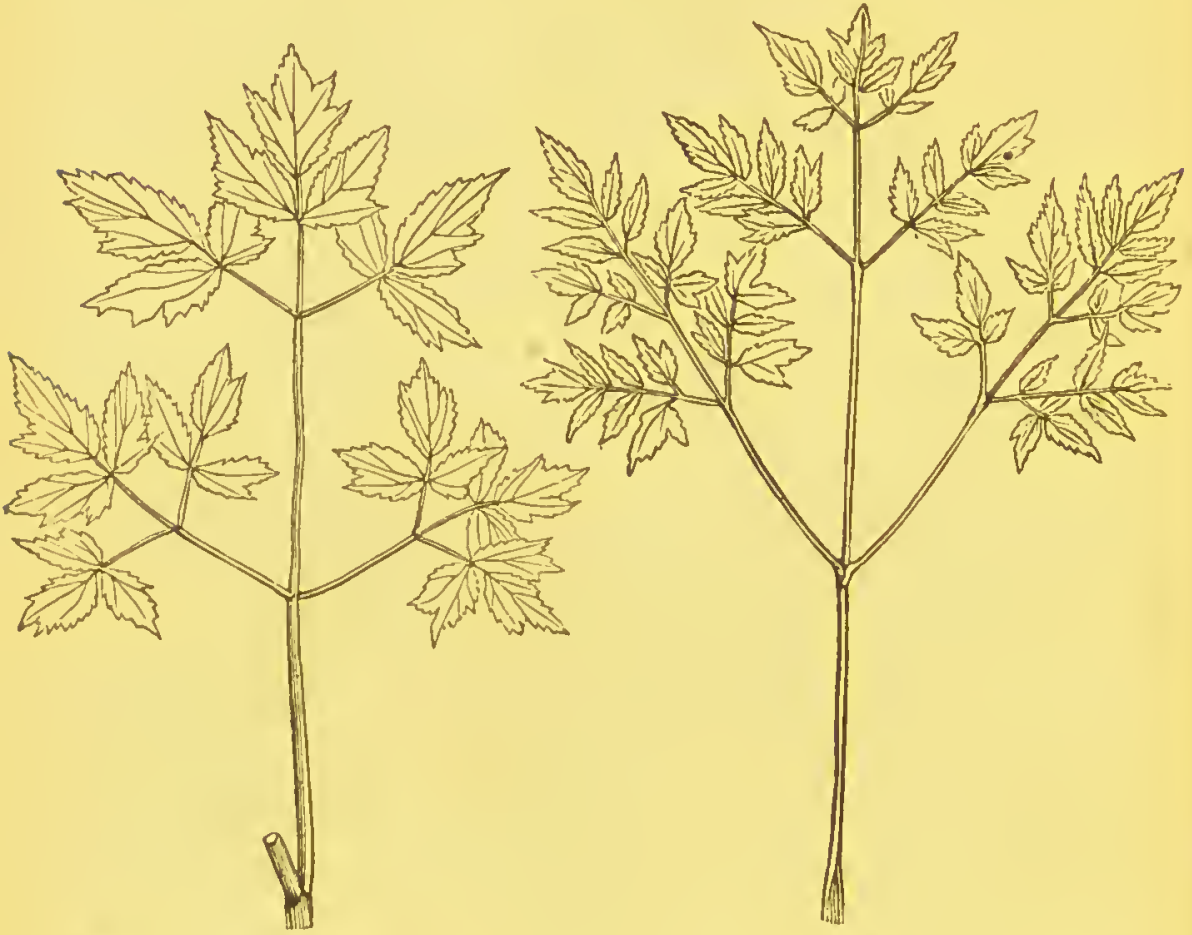

Fig. x88.-Biternate leaf of Actara spicata.

FIG. 189.-Terpinnate leaf of Thalictmus.

attached to the common rachis are termed the pinna, and the secondary leaflets the pinnules. ${ }^{1}$

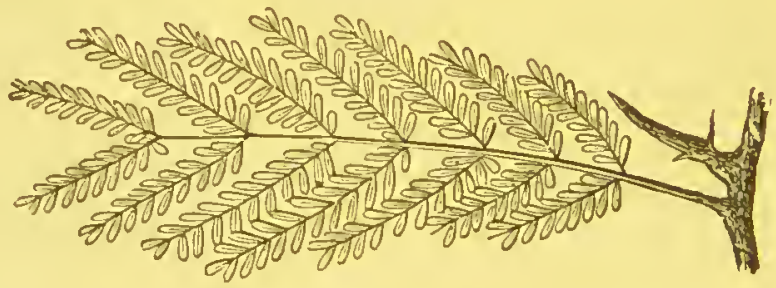

FIG. 19o.-Bipinnate leal of Gleditschia triacanthos.

1 [Several of the terms now defined, especially those relating to the form of leaves, are necessarily used in slightly different senses by different 
All the terms now defined in reference to the attachment, form, incision, and division of simple leaves apply equally to the leaflets of compound leaves.

The disposition and course of the ribs and veins, or the venation of leaves, is greatly dependent on the form of the leaf (or perhaps the converse is rather the case). The term principal nerve or mid-rib is given to the one which is most strongly developed, and which passes through the centre of the leaf; the larger branches which go out from it are the lateral ribs, and the smaller ramifications the veins (see Fig. I 8I, p. I02). If a leaf has only a single unbranched mid-rib, as in many Coniferæ, the venation is said to be simple. If the principal vein, when it enters the lamina of the leaf, divides at once into several branches, the terms palminerzed (Fig. I0I), pedati-

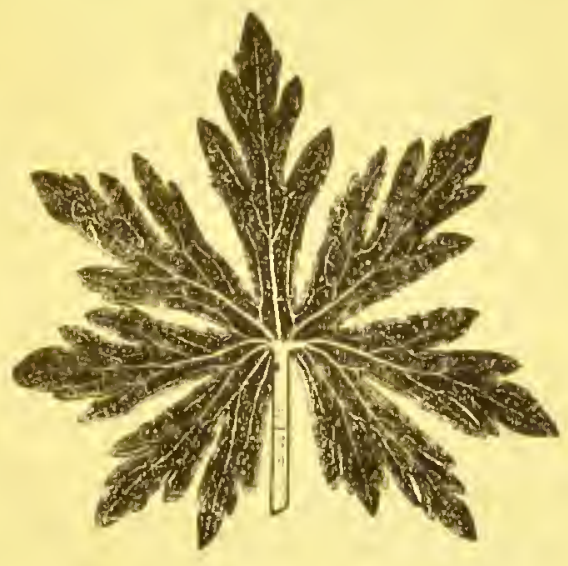
nemed (Fig. I83, p. IO2), or FIG. Igr - Palminerverl leaf of Geraniun peltinerzed (Fig. I62, p. 96), are given, according to the shape of the leaf. When the mid-rib runs through the leaf to its apex, sending out lateral branches from each side, the leaf is pinnatineried (Fig. $\mathrm{I}_{3}$, p. 97). When several nerves enter the leaf from the stem or petiole, they may be nearly straight and parallel to one another, as in Grasses, or somewhat curved as in the lily of the valley, but are said in either case to be parallcl-zeincd. The

writers. They may be combined in a variety of ways, as linenr-lanceolate, cordate-oyate, \&c. The following, not mentioned in the text, are olso in use among English writers: delloid, with three nearly equal angles; subulate, nearly cylindrical and awl-shaped; apiculate, ending in a short sharp point; cuspidale, with a slenderer sharp point. The margin is revolute when turned backwards on to the under side. -ED.] 
finest ramifications of veins are found almost without excep. tion in twining plants among Dicotyledons. ${ }^{1}$

The lamina is as a rule flat, rarely cylindrical (Fig. 192),

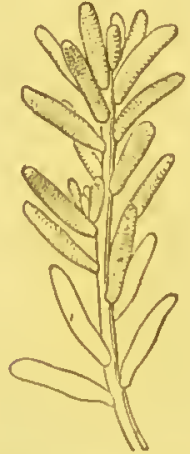

Fic. 102. - Cylindrical succulent leaf of the stonecrop, scdum acr.

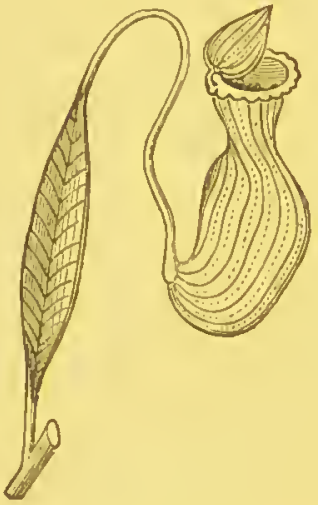

Fı. 193.- Ascidiform leaf of pitcherplant, Nifenthes.

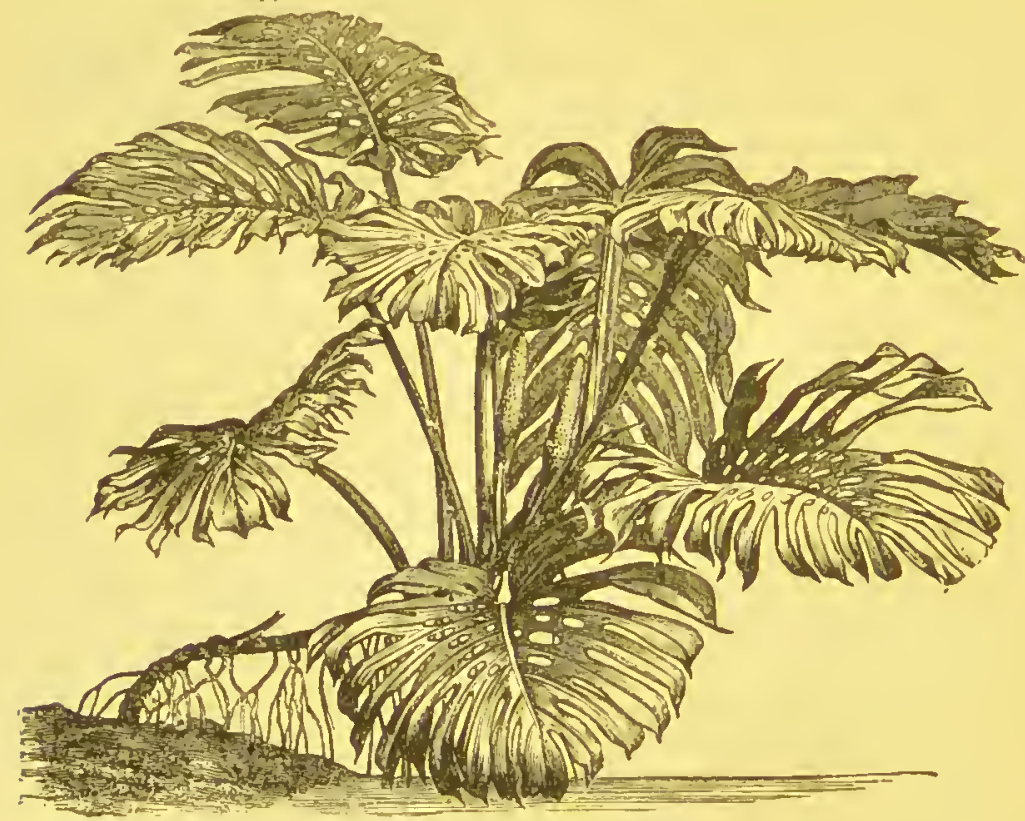

Fig. 194-Tornclia fragrnss, an Aroid, with perforated leaves.

1 [The parallel venation of the leaves is especially characteristic of Endogens or Monocotyledons; while all the other modes of rcation, comprised generally in the term reticulate or net-vcinet, are found nearly exclusively in Exogens or Dicutyledons. - ED.] 
or filiform as in the submerged leaves of Ramunculus aquatilis (Fig. I77, p. Iоo), fistulose as in Allium carinatum, inflated as in the onion, or even ascidiform, as in the case of the pitchers of Nepenthes (Fig. I93), [and a few other genera, the bladders of Utrialaria (Fig. 356, p. I84), \&c.] Occasionally the lamina is perforated (Fig. I94).

It is not uncommon to find on the same plant leaves of different forms (Fig. I 77, p. I00; Fig. I95), when the plant is said to be heterophyllous. This is especially the case with many water-plants, in which some of the leaves are submerged, while others rise above the water or float upon it, as in the arrowhead, Sngittaria sagittafolia, and water crowfoot, Ranunculus aquatilis. The leaves which grow from the lower part of the stem, or radical leaves, are frequently different in shape from the upper ones [or cauline leaves attacher to the stem].

With reference to their consistency, leaves are herbaceons [i.e. thin and flaccid], succulent (Fig. I02) as in the lettuce, coriaceous or leathery as in the box or holly, or fleshy as in Pinguicula.

The leaf is usually of

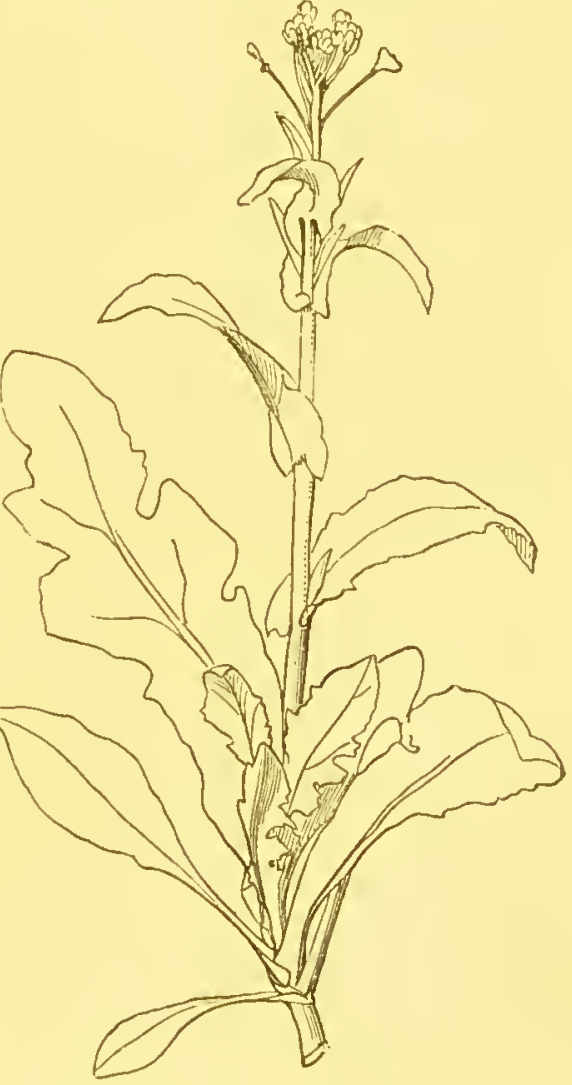

Fig. I95. - Heterophyllous leaves of shepherd's purse, capsella bursa-pasioris. symmetrical shape on each side of the mid-rib; but sometimes unsymmetrical or oblique (Fig. I56, p. 95), as in the lime or Begonia, one side being larger than the other. 
The length of life of leaves varies greatly. The leaves of the majority of plants in temperate climates fall off in the autumn [or are deciduous]; in so-called evergreen trees and shrubs they persist through the winter, and may even remain for several years, as in some species of Coniferæ.

The green colour which is characteristic of the greater number of leaves is due to a colouring matter contained in their cells, chlorophyll (see p. 24). In some etiolated [saprophytic or parasitic] plants, as Orobanche, it is wanting; in others the leaves are variegated or coloured white, red, or yellow, in patches. The colour of the leaves of many plants changes more or less in the course of the year. Thus the leaves of the grape-vine, which are at first green, often turn

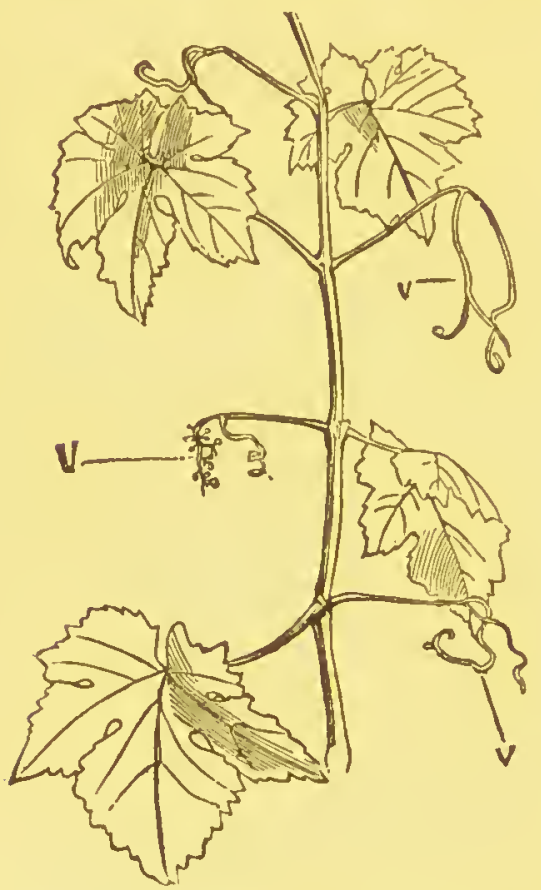

FIG. Ig6.-Stem-tendrils of the grape-vine: $v$ in the normal state; $v$ bearing a bunch of grapes. red in the autumn; while those of the copper-beech are reddest in the spring, and afterwards become more and more green.

\section{SUBSIDIARY ORGANS.}

Under this head are included a number of structures which may be regarded as appendages to the organs already described. They are in some cases modified parts of the stem or leaf, in others a special development of the epidermis which forms the outer covering of plants. Among them are tondrils or cirrhi, filiform structures which cling round neighbouring substances, and whose function is to enable weak plants to attach themselves to, and to climb up 
stronger plants. Accordingly as they belong to the stem as in the vine (Fig. 196 ), or to the leaf as in the tare, they are called stem-or leaf-tendrils. The same distinction is made between branch-spines as in the sloe (Fig. r97), and leafspines as in the holly (Fig. 172, p. 98); i.e. stiff and very sharp-pointed structures arising from the transformation of a stem or leaf, or a part of one of these organs, and which are therefore not mere epidermal growths. ${ }^{1}$ Prickles, although

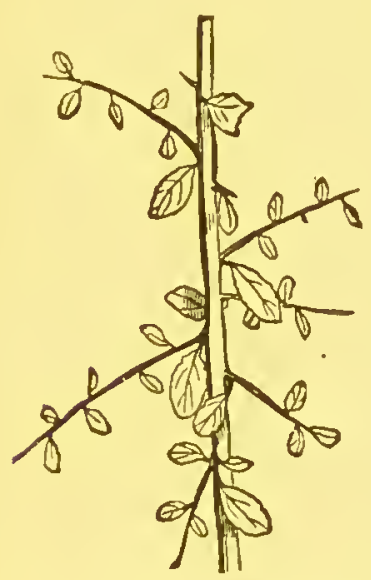

FIG. I97.-Dranch-spines of the sloe, Prusens spiuosn.

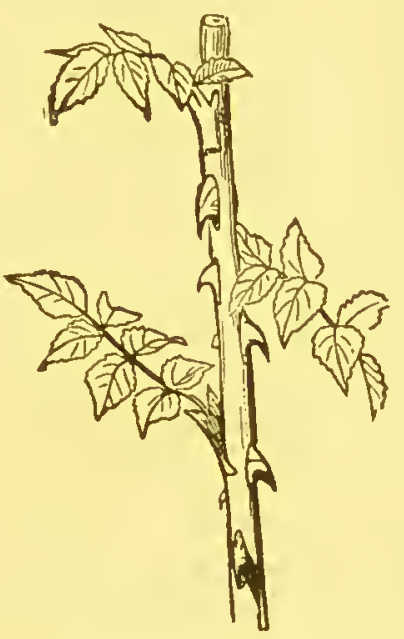

FIG. I99.-Prickles of the rose.

sharp-pointed like spines, are distinguished from them by belonging to the epidermis only, and therefore easily breaking off smoothly; which is never the case with spines; a good illustration is furnished by the rose (Fig. I9 8 ; see also p. 63). An important class of these subsidiary organs are hairs-delicate appendages of the epidermis which are

1 [Tendrils and spines may al;o both be metamorphosed stipules; the former is generally believerl to be the morphological nature of the tendrils in the Cucurbitacer; the latter is the case in the 'acacia-tree,' Robinia (Fig. I84, p. 103). In Lathyrus Apluaca (Fig. 146, p. 92), the whole of the leaf is eonverted into a tendril; but more frequently only the upper pintax of a compound leaf, as in many Leguminose, or the extencled mid-rib, as in Gloriosa. - ED.] 
sometimes very thinly scattered, when [if they are moderately stiff] the part which they cover is said to be setose or hispid, hirsute [when the hairs are longer], pubescent, or villous [when the hairs are thicker and softer, according as they are shorter or longer]; silky [when they are very long and delicate] as in the young leaves of the aspen; woolly as in some species of Primula; tomentose as on the underside of the leaves of the aspen, or floccose, as in Verbascum Thapsus [when they are very dense and interwoven, according to the coarseness of the hairs and the thickness of the coat which they form]. Sometimes, as in the stinging-nettle (Fig. 88, p. 62), the hair contains an acrid fluid, and is then called a sting ; if the fluid, on the other hand, is viscid [or oily], it is termed a giandular hair (Fig. 92, p. 63). Closely connected with these are glands, organs which do not assume the form of a hair, but, like glandular hairs, secrete a fluid which causes the surface to become viscous or glutinous as in Lychnis viscaria (see also p. 63). Mention should be made finally of scales [or peltate hairs], peculiar flattened hairlike structures, such as occur on the leaves of Elacagnuls (Fig. 9r, p. 63), and Hippophaë rhamnoides.

\section{THE FLOWER.}

The flower is the organ [or rather assemblage of organs] the purpose of which is the production of the seed. It is therefore the reproductive organ of the plant, and is morphologically a branchlet provided with leaves of peculiar form.

The more or less perfect development of the flowerstalk determines whether the flower is pedicellate (stalked) or sessile.

Some parts of the flower are essential, others nonessential, according as they are indispensable or not for its main purpose, the production of the seed. The non-essential parts, which are always exterior, form together the floral envelopes or perianth, and are separately the calyx and 
corolla, the former constituting an outer whorl, which is usually green, and the latter an inner whorl, which is usually coloured (i.e. not green), (Fig. 199). In other cases, how-

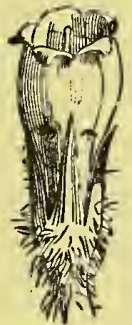

F1G. 199.-Flower of Symzphytum officinale, with both caly $x$ and corolla.

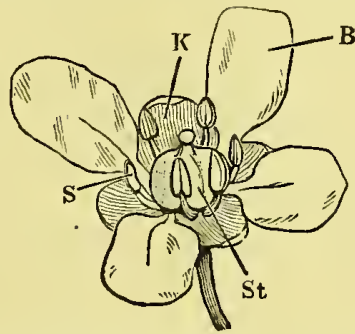

FIG. 200.-Flower of Sisymbrizm Alliaria (magnified); $\mathrm{k}$ calyx ; B corolla ; S stamens; St pistil.

ever, there is no such contrast between the two whorls. One may be entirely absent, as in the elm [or stinging nettle], or, if both are present, as in Liliaceæ, [Juncaceæ], and

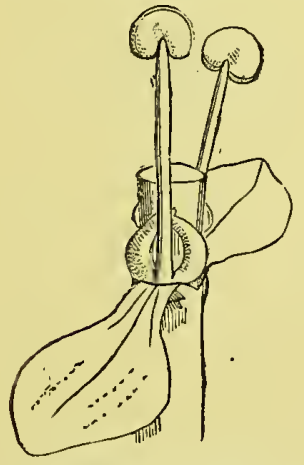

Fig. 201.-Staminate ( $\left.{ }^{\circ}\right)$ flower of Callitriche vema (greatly magnified) with two sickle-shaped bracts.

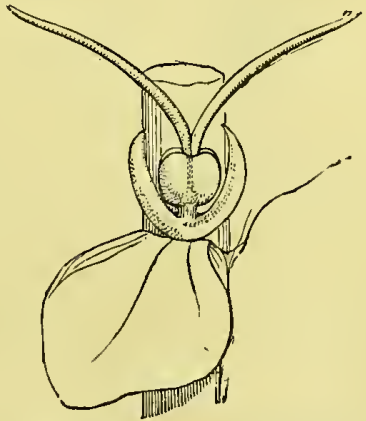

FIG.202.-Pistillate (Q) flower of Calli: triche verna (greatly magnified).

Orchideæ, they may not materially differ in colour or form ; and the term perianth is especially used in reference to these cases. The essential parts of the flower are the andracium or stamens, and the gynaceum or pistil (Fig. 200, S, St). 
The fruit, containing the seeds, is developed out of the latter or female organ, after fertilisation by the pollen formed in the stamens or male organs.

When all these four organs are present in the same flower, it is said to be complete or perfect ; if either is absent, incomplete or imperfect. [If calyx and corolla are both absent, the flower is said to be achlamydeous; if the calyx is present, but the corolla wanting, it is monochlamydeous or apetalous; while if both whorls are present, it is dichlamydeous.] Those flowers which possess both stamens and pistil are hermaphrodite or bisexual; those in which either stamens or pistil are wanting are diclinous or unisexual. If the stamens are present but the pistil absent, they are male or staminate (Fig. 20r); if on the other hand the pistil is present but the stamens absent, they are pistillate or female (Fig. 202);

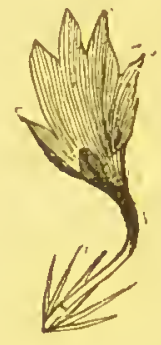

FIG. 203.-Neuter flower of Centaurea Cyanus.

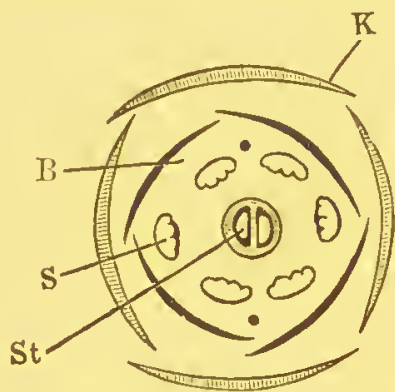

Fig. 204.-Floral diagram of a cruciferous flower; $\mathrm{K}$ calyx : B corolla ; s stamens: St bilocular ovary (see also Fig. 200).

while flowers which possess neither pistil nor stamens, as the outermost flowers of the capitula of the corn blue-bottle, Centaurea Cyanus (Fig. 203), are sterile or nenter. If the same plant bears both male and female flowers, the species and the flowers are said to be monacions; diacious when the male and female flowers are on different individuals, and hence some individuals are male, others female; while those plants in which male, female, and hermaphrodite flowers are all found on the same individual are said to be 
polygamous. Examples of monœcious plants occur in the oak, walnut, birch, and Callitriche ; of diœcious plants in the juniper and poplar; of polygamous in the maple, elm, and horse-chestnut.

The centre of a perfect flower is occupied by the pistil, around which are grouped first the stamens, next the corolla, and finally the calyx, arranged in whorls or spiral lines. The greatest diversity, however, prevails in the mutual position of the individual organs, which is best recognised by a longitudinal section of the flower, and by the floral diagram or cross section. In Fig. 204, for example, which represents

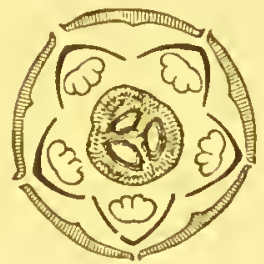

FIG. 205.-Diagram of the flower of Rhamnus Frangula; with five valvate sepals, five folded petals, five stamens opposite the petals, and a trilocular ovary.

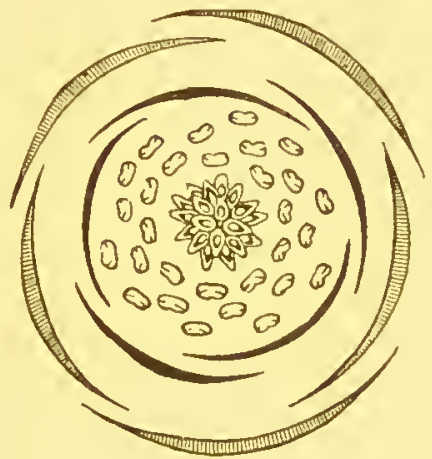

FIG. 206.-Diagram of the flower of Kanunculus acris: with five imbricate sepals, five imbricate petals alternate with the sepals (both quincuncial). a very- large number of stamens, and a large number of distinct carpels.

diagrammatically the cross section of a cruciferous flower, it is seen that the calyx, $\mathrm{K}$, consists of two whorls, each of two leaves, with alternate astivation; the corolla, $\mathrm{B}$, of one whorl of four leaves with imbricate æstivation; while the andrœcium, $\mathrm{s}$, also consists of two whorls, the outer one of two, the inner one of four stamens. The leaves of the corolla alternate with those of the calyx ; the stamens of the inner whorl stand in front of (in other words, are opposite to or superposed 
alternate with them. The diagrams Figs. 205, $206^{1}$ bring out analogous points of structure.

All the different parts of the flower frequently stand free on the base or receptacle of the flower, as in the various species of Ranunculus, but are often coherent or adherent to one another. Thus in the dead-nettle, borage, \&c., the stamens are adherent to the corolla, and in Daplone (Fig. 207) to the perianth; in the Malvaceæ (Fig. 275, P. I39) the

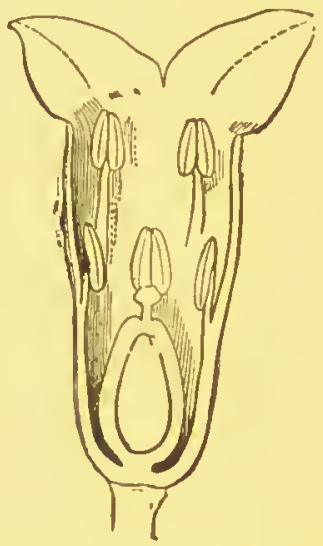

FIG. 207. - Longitudinal section through the flower of Daphne Laureola, showing the stamens adherent to the perianth.

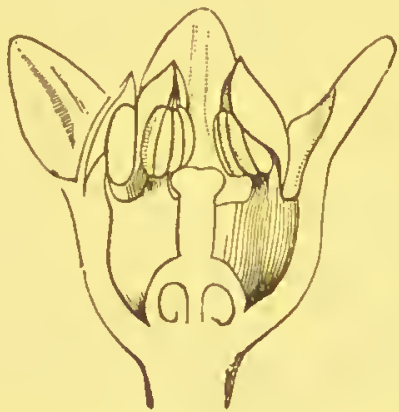

FIG. 208.-Longitudinal section through the flower of Rhamnzes Frangula, showing the lowel part of the calyx, corolla, and stamens adherent to one another.

filaments of the stamens are coherent in their lower part into a tube; in Orchideæ the single stamen is adherent to the pistil, \&c. When the calyx, corolla, and stamens adhere to one another at their base, the flower is said to be calycifloral (Fig. 208); thalamiftoral when the various parts stand free on the receptacle or thalamus (Fig. 209).

Special importance is attached to the relative positions of the perianth-whorls and stamens in relation to the pistil, or to their insertion; the ovary [the lower part of the pistil] being inferior or superior in relation to the superior or inferior calyx, corolla, and stamens. Thus the ovary is

In all the diagrams, the calyx is shaded a lighter colour than the corolla. 
superior or free, as in Ranunculus (Fig. 209) or Rhammus (Fig. 208), when the remaining parts of the flower are attached to or below its base, and are conversely inferior or hypogynous. The ovary on the other hand is inferior when the cther parts of the flower are attached to its upper part, and are therefore superior, adherent, or epi-

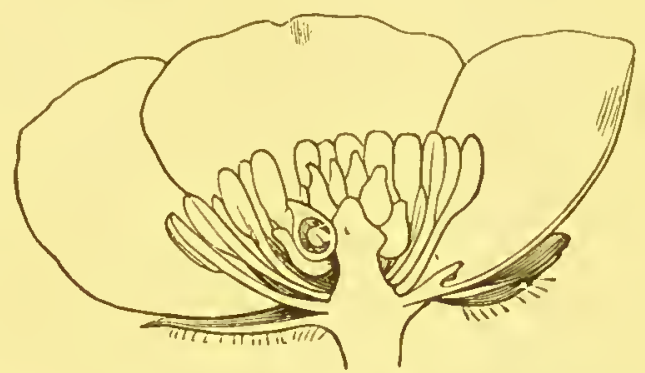

FIG. 209.-Longitudinal section through the flower of Ranunculus acris, showing the hypogynous calyx, corolla, and stamens.

gynous, as in Mesembryanthemum (Fig. 210). The ovary, finally, is half-inferior when the other parts of the flower are coherent at their base, and thus form a tube which sur-

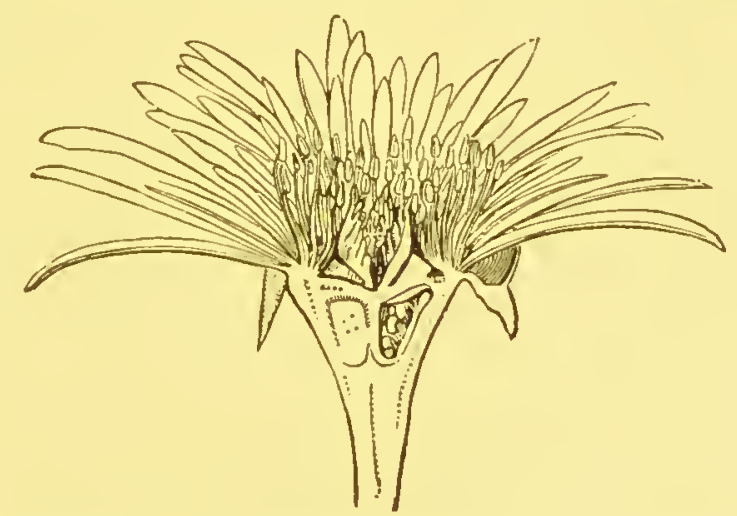

FIG. 210.-Longitudinal section through the fower of Mesembryanthemun falciforme, showing the epigynous calyx, corolla, and stamens.

rounds the free pistil, as in the rose ; the calyx, corolla, and stamens then having a half-superior or perigynous ${ }^{2}$ insertion.

1 Practically the term perigynous is used in English descriptive botany with reference to the stamens to express their union to the calyx; when attached to the corolla thcy are cpiptalous; epigynous when attached to the upper part of the ovary. An 'inferior' ovary is always the result of the adhesion to the wall of the ovary of a part or the whole 

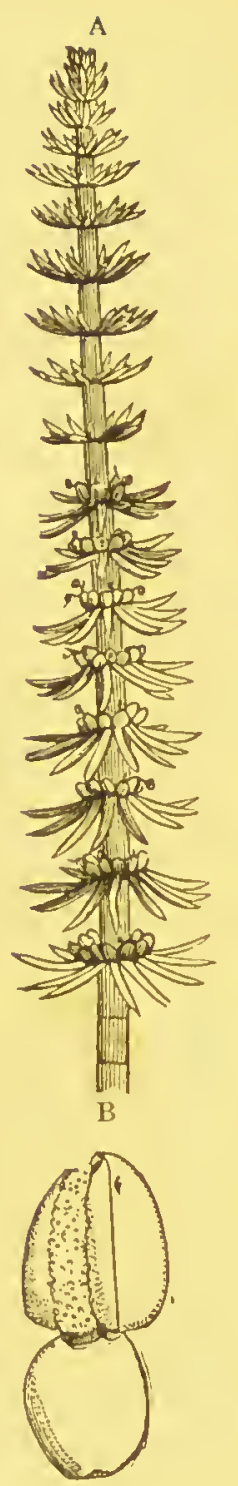

Fig. 211.-A Hippuris antgaris with verticillate inflorescence: B separate flower consisting of a pistil with a long wart-like stigma and a single stamen (magnified).
An additional point to note is that frequently the number of the different parts of the flower is not always the same in the same species. Thus in Adoxa Moschatellina and Monotropa hypopitys, the petals of the terminal flowers of the inflorescence are five in number ; of the lower flowers on the contrary four; in Atriplex the perianth of the female flowers is two-leaved, while that of the male and hermaphrodite flowers is three to fiveleaved.

\section{THE INFLORESCENCE.}

The flowers stand either solitary or grouped together according to a definite law, on branched or thickened flower-stalks. Such a group of flowers is termed an infloresccnce; [the common stalk of the inflorescence is then the pcduncle, the separate stalks of the individual flowers pedicels, and the axis of the inflorescence the rachis]. Solitary flowers are usually seated each in the axil of a leaf or bract as in the deadly nightshade, Atropa Belladonna, less often at the apex of the stem as in Paris quadrifolia, or of a scape as in the tulip. In some plants with verticillate leaves a single flower is produced in the

of the calyx; when the whole is adherent, the calyxlimb is then obsolete, as in many Umbelliferre; when only a portion, then the calyx-limb is said to be superior, or half-superior, as the case may be. The term cohesion is used to express the union of similar parts, as stamens with stamens, or petals with petals; adhesion the union of dissimilar parts, as stamens with corolla, or calyx with ovary. In Germn the same term is used for both.-ED.] 
axil of each of the leaves, when the flowers form a true zolhorl, as in Hippnris (Fig. 2I $\mathbf{r}$ ).

The common peduncle of the inflorescence is sometimes extremely abbreviated, the sessile or very shortly pedicelled flowers standing upon it very closely crowded, as in the clover (Fig. 212). The form of the inflorescence is then dependent on the nature of the termination of the peduncle.

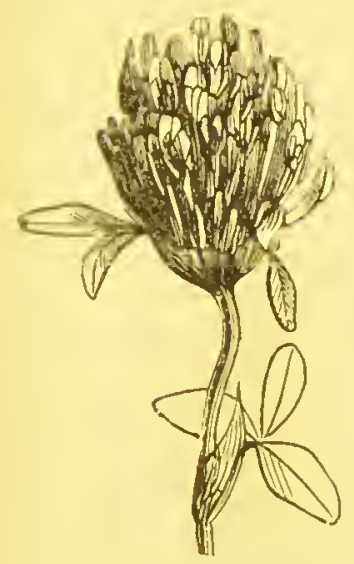

Hig. 212. - Abbreviated inforescence of clover.

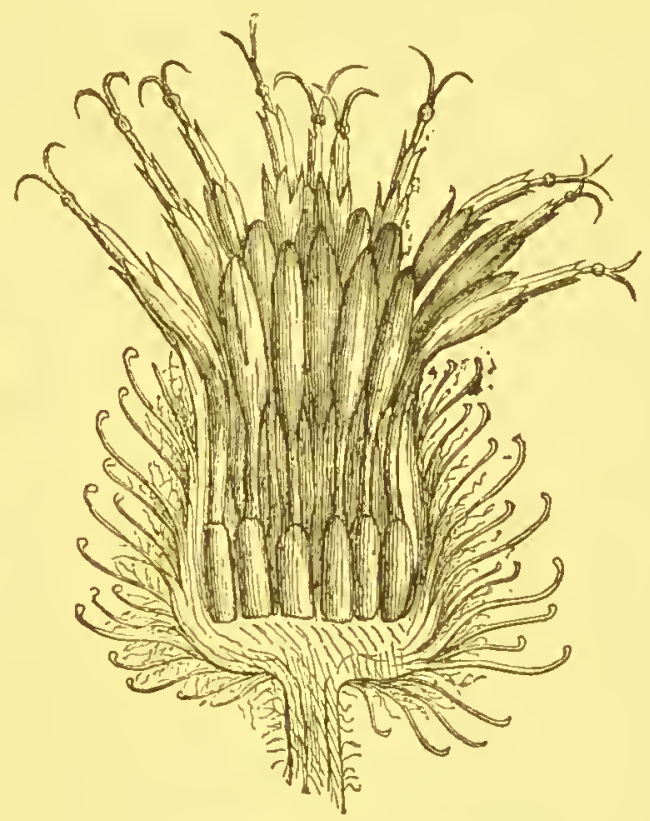

FIG. 213--Longitudinal section through the capitulum of the burdock, Arctium Lappa.

The common receptacle, or surface from which the inflorescence springs, is sometimes flattened out, and sometimes swollen into a more or less hemispherical form (Figs. 2I3, 2I4); these two variations being especially common in the order Compositæ, and characterising the capitulnm; or it is sometimes hollowed out into a pitcher-like form, as in the fig (Fig. 2I5), constituting a hypanthodinm; or the separate flowers are buried in the fleshy receptacle, when it becomes a cananthium, as in Dorstcnia (Fig. 2I6). The receptacle itself is usually solid, but may be hollow (Fig. 2 I4); 
it may be naked, or setose, i.e. clothed with bristles (Fig. 2 I 7), or covered with hair-like bracts or palece when it is palcacious

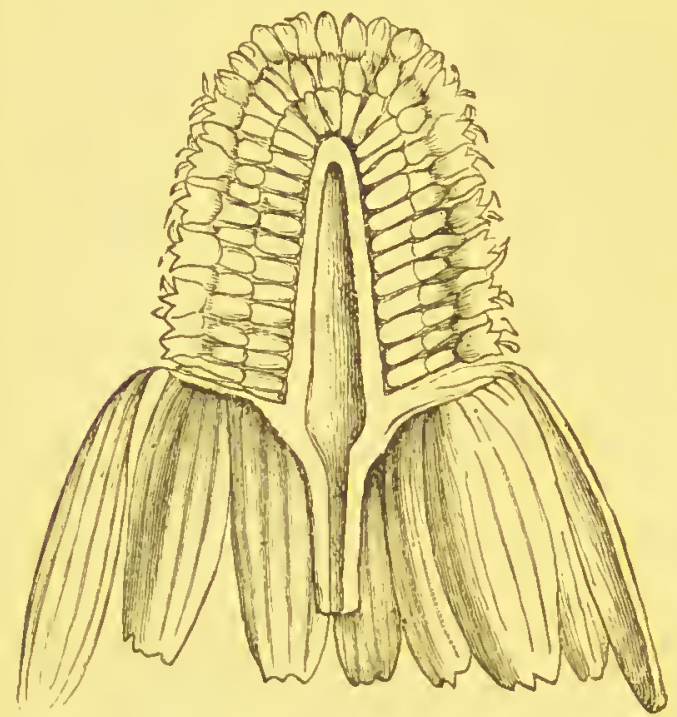

(Fig. 2 I 8 ), or fimbriated; or it may be pitted with small excavations. All these forms of receptacle occur in different genera of Compositæ. The capitulum is most commonly - in Compositæ [and Dipsacacex] always - enclosed at its base in

a common involucre, consisting of crowded bracts, sumetimes Frg. 214.-Longitudinal section through the raycel arranged in several capitulum of the chamomile with hollow rereptacle, whorls, and then
the outer fowers of the ray ligulate, the inner flowers whors of the disc tubular (magnitied).

I.

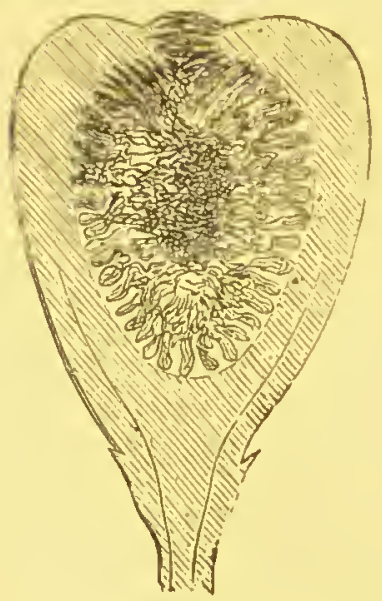

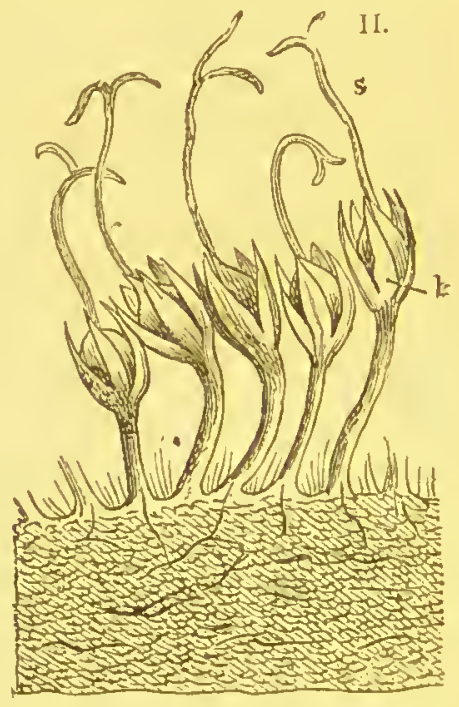

FIG. 215.-I. Longitudinal section through the lyypanthodium of a fig, exponing the flowers in its interior; 11. a piece greatly magnified, with five female fowers; $s$ pistil ; $b$ perianth. 
usually imbricate (Fig. 2I9). In many plants (especially Composita) in which the flowers are arranged in capitula,

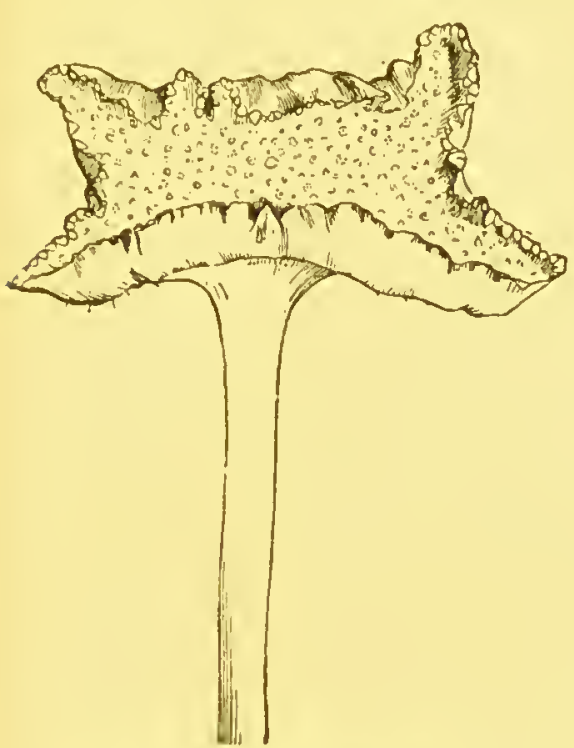

FiG. 216.-Fleshy conanthium of Dorstenia.

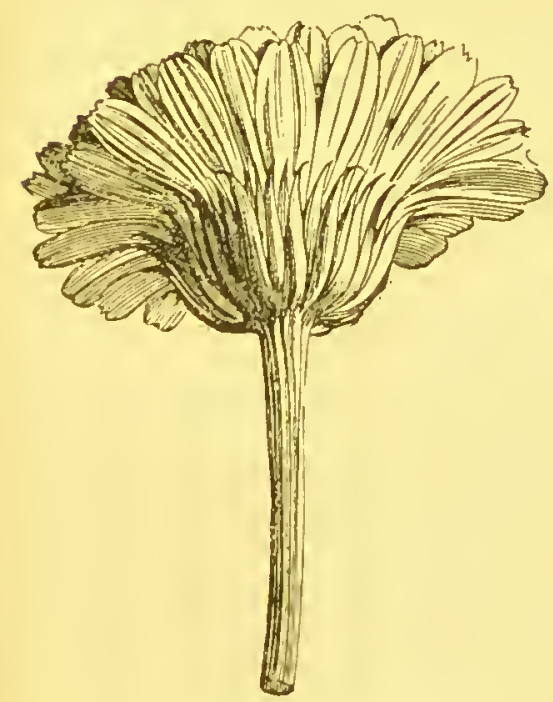

FIG. 219.-Capitulum of marigold, with imbricate involucre.

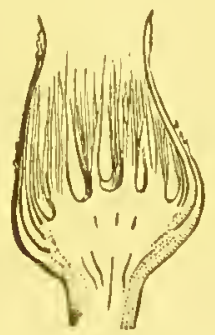

FiG. 2x7.- Common receptacle of Centanrea Cyanus with setose palea.

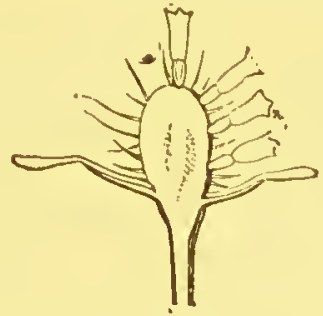

FiG. 218 . - Common receptacle of $A n$ themis arvensis with palea between the flowers.

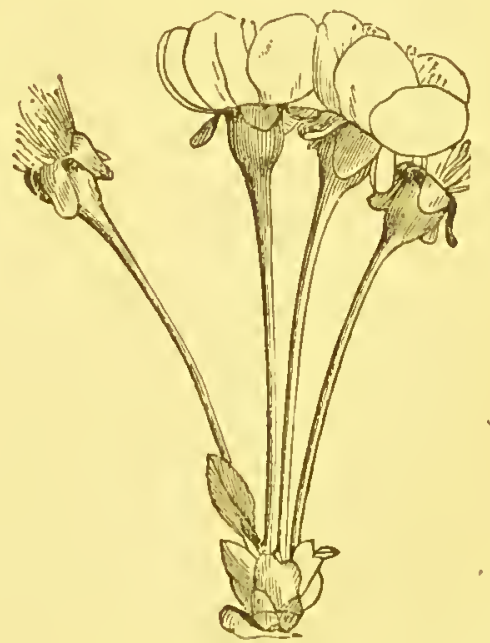

F'ik. 220.--Simple umbel of the cherry. 
the marginal flowers of each capitulum are larger and more conspicuous than the internal ones, and the capitulum is then said to be rayed [the outer flowers being termed flowers or florets of the ray, the inner ones flowers or florets of the disc], as in the chamomile (Fig. 2I4), single aster, marigold, \&c.

The $u m b e l$ resembles the capitulum in the fact of the stem terminating in a number of flowers, but each separate flower is stalked. The umbel is simple when the main stem or peduncle ends in a number of separate stalked flowers, as in the cherry (Fig. 220), compound when it branches into a number of secondary umbels or umbellules (Fig. 22I) [as in

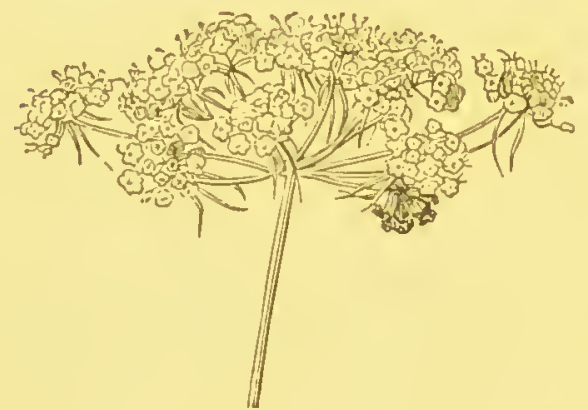

FIG. 221.-Compound umbel of fool's parsley, Fithusn cyurpium: common involucre wanting ; involucels of three leaves each. the majority of genera of Umbelliferr]. The main umbel is generally surrounded at its base by a whorl of bracts, again called an involucre, while the whorl surrounding each of the secondary umbels is an involucel or partial involucre. Either of the two may, however, be wanting, or may consist of a smaller or larger number of leaves. Thus the carrot has both involucre and involucels, each consisting of a large number of bracts; the fool's parsley, Ethusa cynapium (Fig. $22 \mathrm{x}$ ), has involucels, but no general involucre; the fennel neither one nor the other. The length of the separate pedicels may vary greatly, so that the umbel becomes spherical, hemispherical, or flat ; or it may be rayed like the capitulum [as in Heracleum, where the outer flowers of each umbellule are larger than the inner ones].

In the spike, the common peduncle or rachis bears a number of flowers, arranged, in the simple spike (Fig. 222) opposite one another, in whorls, or spirally, and sessile, or with only very short pedicels; while, in the compound spitic, 
these are replaced by small secondary spikelets, as in some grasses. The individual flowers may also be less or more crowded, according to the greater or less elongation of the rachis. A spike with a thick fleshy rachis, and enveloped in a large bract growing at its base, as in Arum or Calla, is

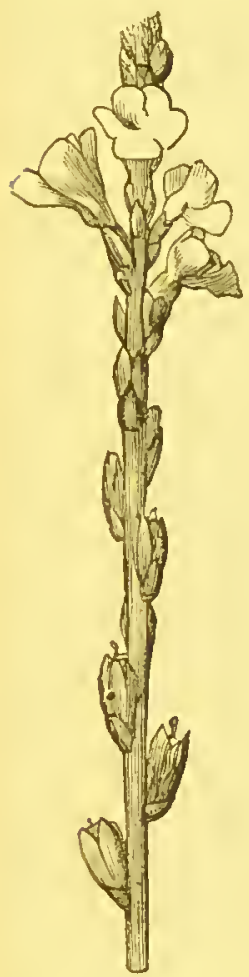

Fig. 222. - Simple spike of Verbence oficinalis.

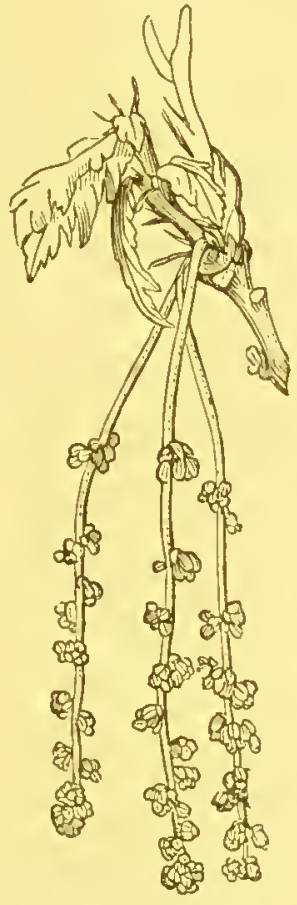

FIG. 223. - Catkin or amentum of the oak. termed a spadix, and the enveloping bract a spathe. A catkin or amentum is a crowded spike of unisexual flowers, with weak rachis (Fig. 223);

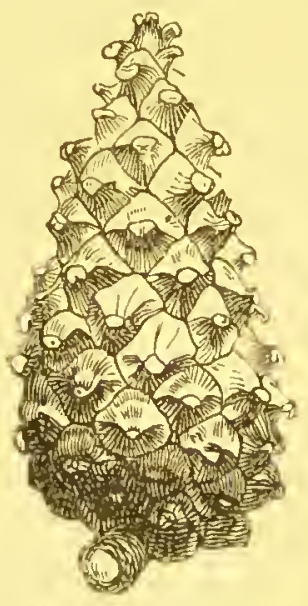

Fig. 224. - Cone of the Scolch fir.

when consisting of male flowers only it is deciduous; the male flowers of the oak, hazel, sweet chestnut, \&c., are in catkins; both male and female flowers of the willow, poplar, and birch. In the cone of many Coniferre (Fig. 224), the rachis and bracts which subtend the naked ovules have become more or less completely lignified; in the strobilus of the hop the bracts are persistent, large, and membranous. The raceme is distinguished from the spike by its separate 
flowers being stalked. A compound raceme or panicle, as in the oat, is distinguished from a simple raceme (Fig. 225) by the individual flowers on the rachis being replaced by secondary racemes; when very much branched [and pyramidal in shape] as in the lilac [or horse chestnut] it is called a thyrse. When the lower and outer flowers are borne on

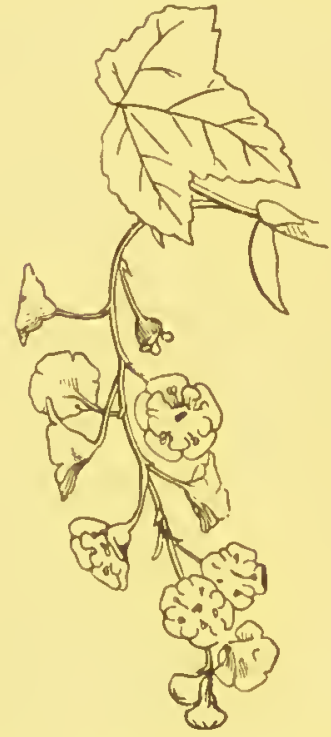

Fig. 225.- Simple raceme of the currant.

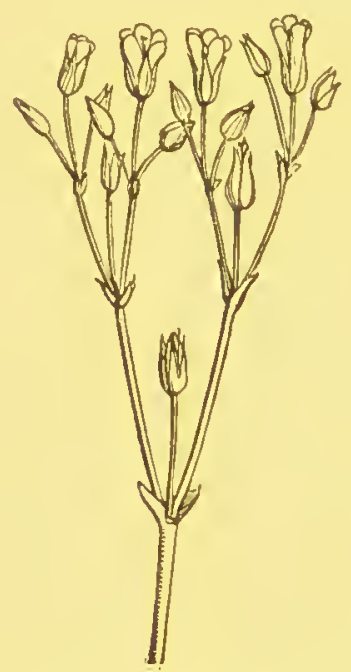

FiG. 226.-Dichotomous cyme of
Cerastiuzn.

pedicels which are so much longer than the upper and inner ones that the whole inflorescence is more or less nearly flatheaded, it becomes a corymb, as in the undeveloped raceme of many Crucifers [like the wall-flower, or in the elder]. In the inflorescences of many species of Juncus and Luzula the pedicels of the lower flowers are so greatly lengthened that they rise even above the upper ones, and the term anthela is then given to the inflorescence. The mode of development of the anthela corresponds to that of the sympodium (see p. 76). The panicle often passes over insensibly into the compound umbel. In the cyme two or more branches of equal strength spring from beneath a terminal flower; it 
is globular in the guelder-rose, flat-headed or corymbose in the laurustinus. Under this head should be included also the verticillastcr, frequently erroneously described as a whorl, a very common inflorescence in the Labiatæ, in which the flowers of two cymes, often but imperfectly developed and borne on opposite sides of the stem in

A

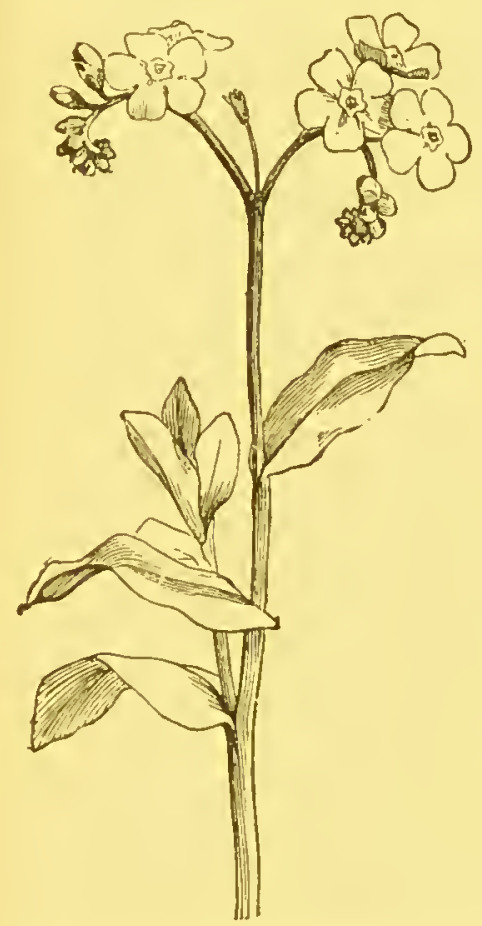

F!G. 227:- A, Cymose inflorescence of Nyosotis; B, diagrammatic representation of the order of development of the flowers in the scorpioid cyme.
B

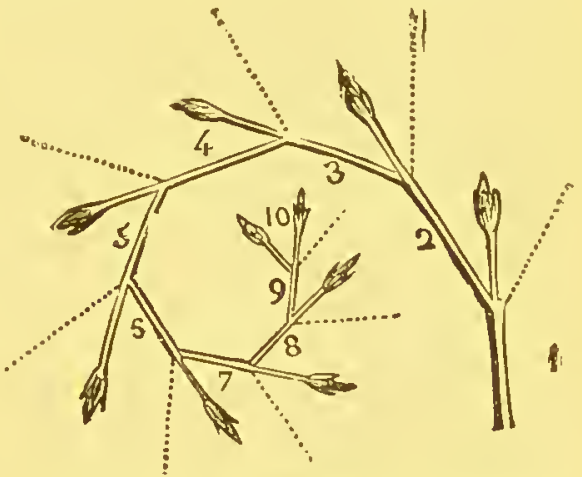

the axils of opposite leaves, appear as if encircling the stem. Similar undeveloped closely crowded cymes, termed glomeruli, occur in Valerianella. When a cyme is developed only on one side, and in the young state is rolled up in a circinate manner, it is called a scorpioid cyme, as in the forget-me-not (Fig. 227); [when always branching into two arms of equal strength, with a flower in the angle, as in most Caryophyllaceæ, it is a dichotomous cyme, Fig. 226]. The great variety of different kinds of inflorescence is increased and rendered more complicated by the combination of some of those here described. ${ }^{1}$

1 [The best primary classification of inflorescences is into ( 1 ) indefinite or centripetal, in which the lowest flower or that furthest from the 
THE CALYX.

The calyx is, in its most perfect form, the protecting envelope for the interior more delicate parts of the flower; and may therefore be compared to bud-scales. In some plants, as in the Umbelliferæ, it is but slightly developed, the calyx-limb being obsolete, and its teeth scarcely visible on the margin of the inferior ovary. ${ }^{1}$ The more perfectly developed calyx, which is generally green, consists usually of only a single whorl of leaves or sepals; less often, as in the strawberry (Fig. 228), of two; or occasionally, as in

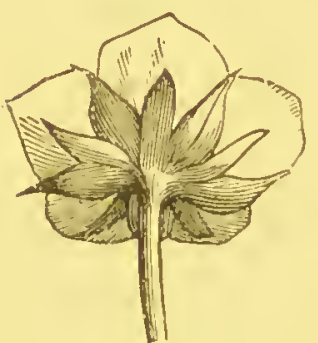

FIG. 228.-Flower of the strawberry, with calyx in two rows. Gossypium, of three whorls. In a few instances-among Dicotyledons in the fuchsia, larkspur, Tropecolum, \&c.--the calyx is coloured ; but the whole of the floral envelope might in these cases be spoken of as a perianth, as is usually the case with Monocotyledons.

The calyx is said to be gamosepalons or synsepalous [in older works on de. scriptive botany 'monosepalous'], when the leares of which it is composed are more or less coherent at the base; aposepalous or eleutherosepalous [in older works 'polysepalous '], when they are completely distinct. It may also be regular or irregular; but the irregular calyx is almost always symmetrical, ${ }^{2}$ that is, it can be divided into two

apex opens first, and then the rest in regular succession; and (2) definite or centrifugal, in which the order of clevelopment is the reverse, the central flower opening first. To the second class belong the cyme and its varieties ; to the first most of the other kinds of inflorescence. In the capitulum of some Dipsacacere we get a combination of the two. - Ev.]

1 See note, P. II 5 .

2 [This term is used in most English tert-books in a different sense, to express a relationship in number between the sepals, petals, and stamens. If these are the same in number, or a multiple of the same number, as in Saxifrasa, 5, 5, 5, or Fuchsia, 4, 4, 8, the flower is said to be 'symmetrical ;' if this is not the case, as in Cruciferre, 4, 4, 6, or Labiatx, 5, 5, 4, it is said to be 'unsymmetrical.'-ED.] 
parts, so that each one is exactly similar to the other reversed. The regular gamosepalous calyx may be rotate [or with the limb expanded like a wheel], turbinate or topshaped, urcelate or urn-shaped (Fig. 229), infundibuliform or funnel-shaped, tubular or cylindrical, inflated (Fig. 254, p. I32), [campanulate or bell-shaped], \&c. 'The margin or edge of the calyx may also be toothed, lobed, or incised, according to the depth to which it is cut. The number of teeth has also to be taken into account, when the calyx is said to be bifid, trifid, multifi, \&c. ; or in the case of aposepalous calices the number of separate sepals, when it is biscpalous,

I.

II.

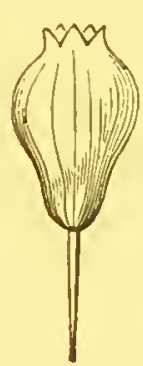

FIG. 229.-I. Turbinate; II. urceolate calyx (represented diagrammatically).

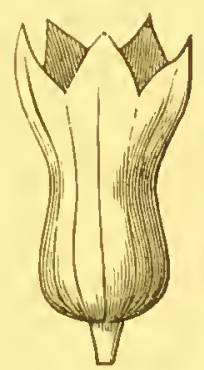
F1G. 230.-Bilabiate five-toothed calyx of Lamium.

trisepalous, polysepalous, \&c. Among irregular forms of the calyx an especially common one is the bilabiate, or twolipped (Fig. 230), a gamosepalous calyx divided by two deep incisions into an upper and lower division or lip [particularly characteristic of the order Labiatæ]; and not unfrequent are the spurred (Fig. 23I), fumished with a larger or shorter hollow appendage or spur [as in Tropceolum and Impatiens]; and the saccate (Fig. 232), which occurs frequently in Cruciferæ, and consists of four distinct sepals, two of which are gibbous at the base.

As respects its persistence, the calyx may be caducous, when it is thrown off at the time of expansion of the flower, as in the poppy (Fig. 233); deciduous, when it falls off at 
the same time as the corolla; or persistent [when it remains after the corolla has fallen]. The calyx generally leaves a smooth scar when it falls off; less often, as in Datura and

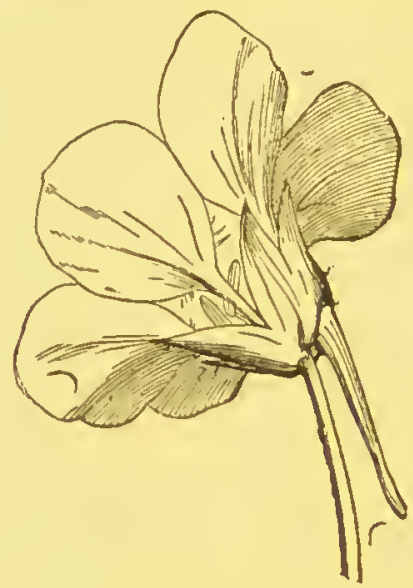

FIG. 231.-Spurred calyx of Trepreolumt.

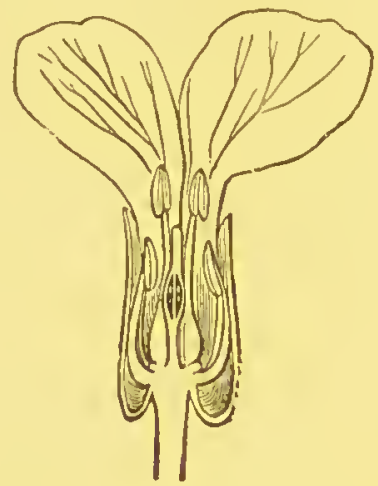

FIG. 232.-Saccate calyx of Lunaria.

Portulaca, the lower part remains attached like a frill. The persistent calyx often retains its form unchanged, as in the strawberry; but, sometimes, as in the winter-

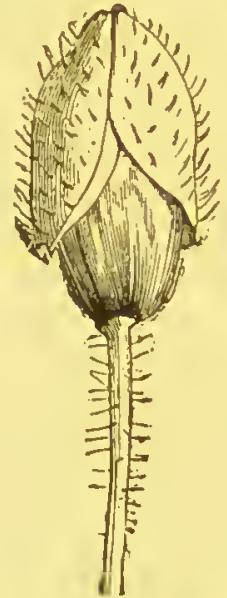

Fig. 233.-Caducous calyx of poppy.

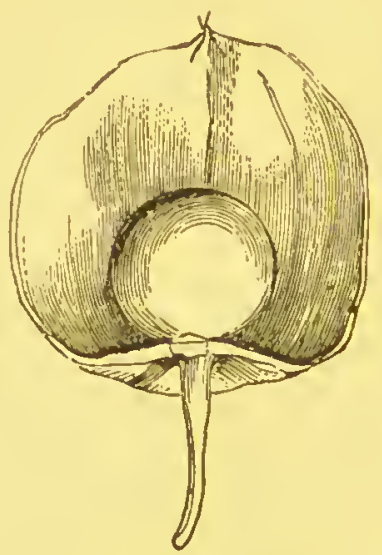

FIG. 234.-Longitudinal sectıon through the accrescent calyx of Physalis Alkckengi surrounding the fruit.

cherry, Physalis Alkckengi (Fig. 234), it increases in size [or is accrescent], and forms a membranous sack which envelopes 
the fruit. Sometimes it even takes part in the formation of the fruit, as in Trapa, the four horns of the fruit being here formed by the lignification of the calyx-teeth. ${ }^{1}$ Particularly noteworthy is the production of the pappus from the limb of the calyx. This peculiar form is especially characteristic of Compositæ; the calyx continues to grow after the withering of the corolla, and either a crown of simple hairs or pilose pappus (Figs, 235, 236), or a plumose pappus of branched hairs

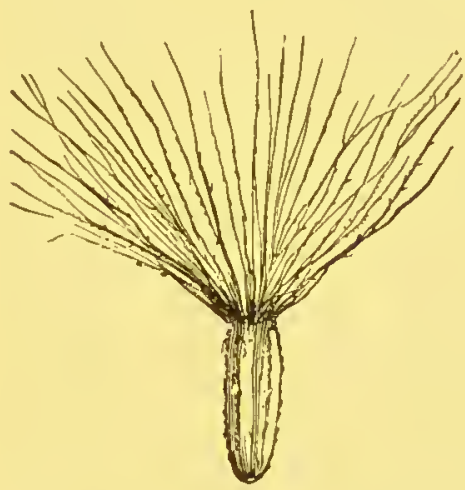

FIG. 235.-Pilose sessile pappus of Senecio.

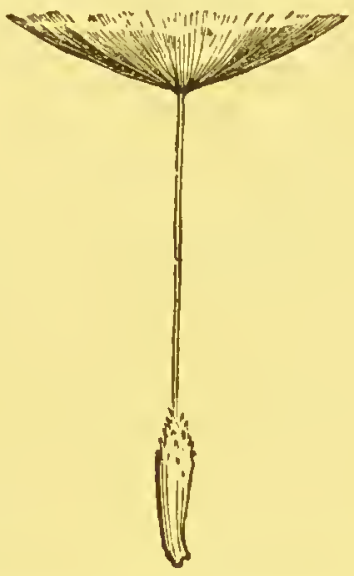

FIG. 236.-Pilose stipitate pappus of dandelion.

(Figs. 237, 238), is formed from its teeth, and subsequently crowns the fruit. The pappus may either be sessile as in the groundsel (Fig. 235), or stipitate as in the dan. delion (Fig. 236), from the development of the upper part of the calyx-tube, in the form of a stalk which bears the feathery crown. The pappus, again, may be dentate, or coronate (Fig. 239), the calyx-teeth remaining in the latter case undeveloped, and being transformed into small broad hairs which form, as it were, a crown to the fruit. In addition to the Compositæ, instances of a pappus occur in Valerianaceæ and Dipsacaceæ. The chicory, Cichorium

${ }^{1}$ [The fleshy calyx-tube-or, as some think, the receptacle-of the rose, apple, pear, \&c., mnites with the pistil to form a pseudocarp (see p. I46).-ED.] 
Intybus, furnishes an illustration of a coronate, the artichoke and Scorzonera of a plumose sessile, the goatsbeard, Trago-

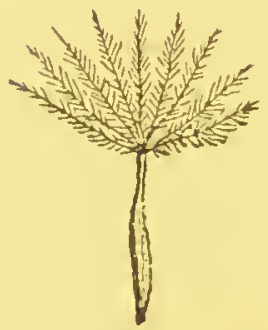

Fig. 237 - Plumose sessile pappus of Tragopogon.

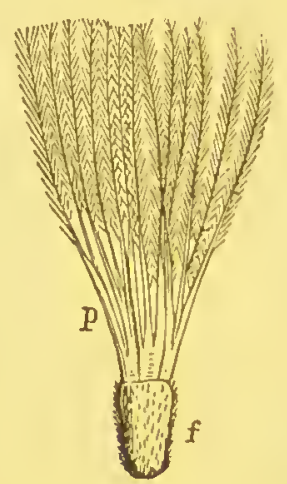

Fig. 238.-Pappus of Carlina vilgaris, the feathery rays united below into several bundles and coherent at the base into a ring.

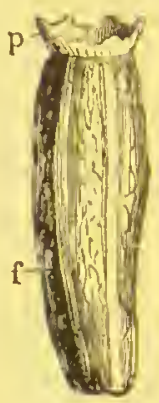

Fig. 239.-Fruit, $f$, of the tansy, Tanacctum antgare, surmounted by the coronate pappus, p.

pogon, of a plumose stipitate, the common thistle, Cnicus, of a pilose sessile, the dandelion of a pilose stipitate pappus.

\section{THE COROLLA.}

The leaves of which the corolla consists, or petals, are, as a rule, much more delicate than those of the calyx, and are usually coloured, i.e. white or some bright colour in contradistinction to green. The colour of the corolla is, however, of subordinate importance, and is often variable in the same plant. The corolla of Pulmonaria, for example, is red when it first opens, and afterwards becomes violet [that of Cobcea scandens changes gradually from pale-green to purple], while that of Hibiscus abelmoschus is white in the morning, pale red by mid-day, and rose-red in the evening. ${ }^{3}$

${ }^{1}$ [In many species also the colour varies in different indivicluals : thus the corolla of Campanula rotundifolia, usually blue, is occasionally white; that of Erica tctralix, usually rose-coloured, is also occasionally white; while that of Polygala vulyaris is indifferently white, blue, or rose-coloured._ED.] 
It is unusual for the corolla to be green ; in the grape-vine it is yellowish green. Certain plants, however, which have normally a bright-coloured corolla, produce occasionally a green one, as occurs in Hydrangea and Hesperis.

The corolla is gamopetalous or sympetalous [less correctly 'monopetalous'], when the petals are more or less coherent; apopetalous or cleutheropetalous [less correctly 'polypetalous'], when they are perfectly distinct; regular when they are all alike; irregular when one or more differs from the rest in size or form; but in the latter case the corolla is always symmetrical (see foot-note, p. 124).

The principal forms of the gamopetalous corolla are globose as in Frica tetralix (Fig. 240); urccolate or urn-shaped

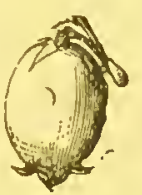

FIG. 240.-Globose corolla of Erica teiralix (magnified).

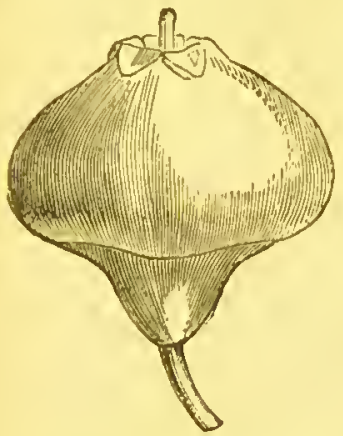

FIG. 241.-Urceolate corolla of Vaccinium Myrtillus (magnified). as in the bilberry (Fig. 24I); campainulate or bell-shaped as in Campanula (Fig. 242); infundibuliform or funnelshaped as in Convolvulus arvensis (Fig.

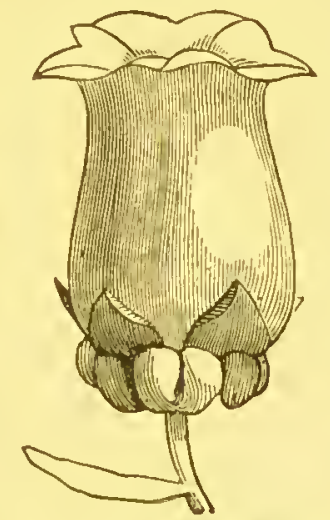

FIG. 242.-Campanulate corolla of the Canterbury bell.

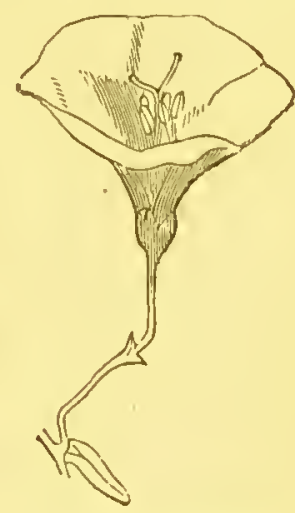

FIG. 243. - Infundibuliform corolla of Convolvulus areusis.

243); tubular as in the 'florets of the disc' of many Com. positæ (Fig. 244); rotate as in the borage (Fig. 245); hypo. crateriform or salver-shaped as in the jasmine (Fig. 247); ligulate or strap-shaped as in the 'florets of the ray' of many Compositæ (Fig. 246); bilabiate as in mest Labiatæ (Fig. 
248 ), where the corolla is divided into an upper and a lower lip, the former having two and the latter three teeth [representing the five petals]. When the two lips are widely sepa-

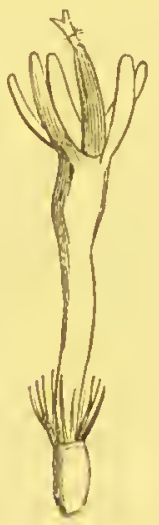

Fig. 244. - Tubular corolla from the disc of the capitulum of Centaurea Cyanus.

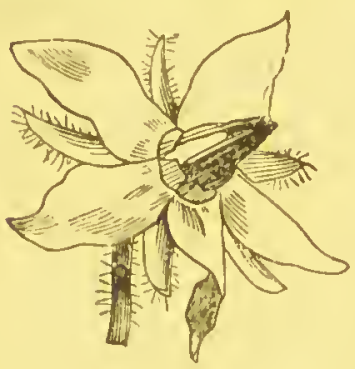

Fig. 245-Rotate corolla of Fig. 246.-Ligulate cothe borage, Borrago officinalis (magnified).

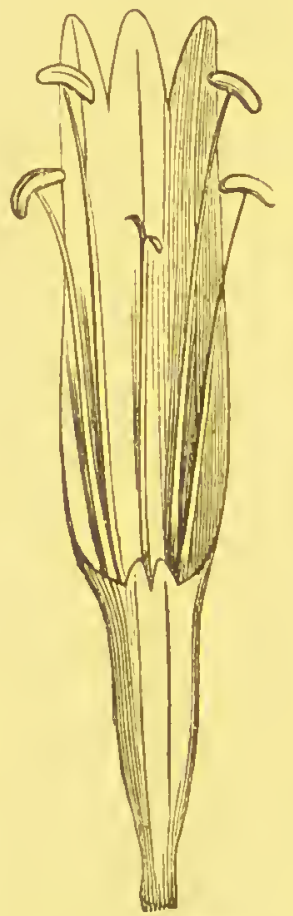

Fig. $246 .-$ Ligulate co-
rolla of Globularia $A(y-$ pum (magnified).

rated, as in the figure, the corolla is said to be ringent; while, if the mouth is closed by a cushion-like formation on the under: lip, called the palate,

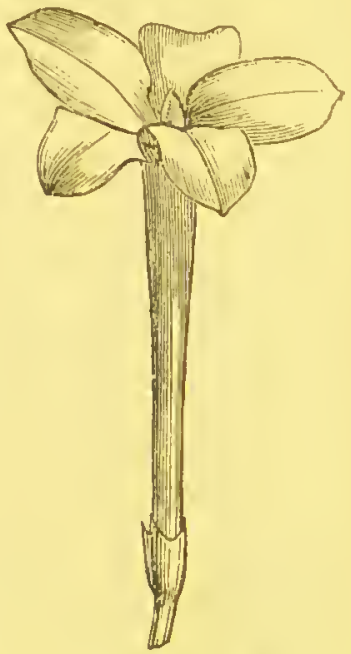

FIG. 247. - Hypocrateriform corolla of the jasmine (magnified).

as in Antirrhinum (Fig. 249), the corolla is said to be personate. ['The corolla, like the calyx, may be spurred, as

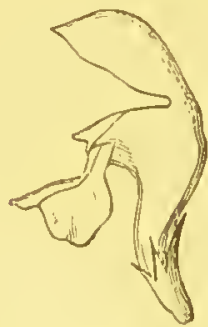

FIG. 248-Bilabiate ringent corolla of Lamium album.

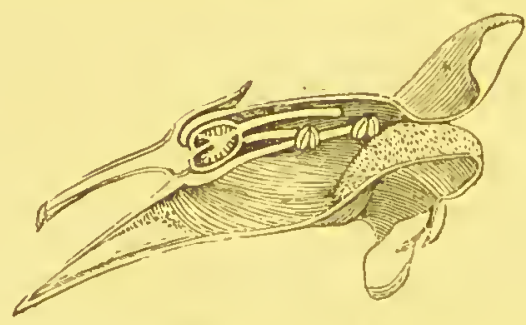

FIG. 249.-Bilabiate personate corolla of Antirrhinum majus. 
in Viola and many orchises, or hooded, as in the monkshood].

The form of the apopetalous, like that of the gamopetalous corolla, varies, and may be globose, campanulate, rotate, \&c.; but the most important point to note in it is the form and the relative position and number of the petals. As respects their form, they may be entire as in the apple; obcordate as in Athusa cynapium; toothed or fringed as in many Caryophyllaceæ (Fig. 250); fimbriate as in Dianthus

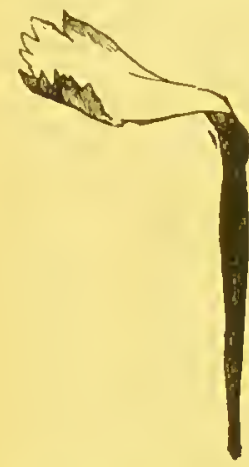

Fig. 250.-Unguiculate petal of Dianthzes, with toothed lamina.

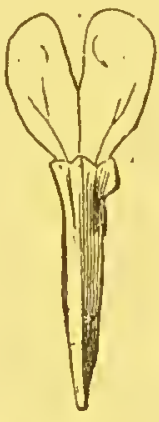

FIG. 251.-Bifid unguiculate petal of Lychnis, with ligule.

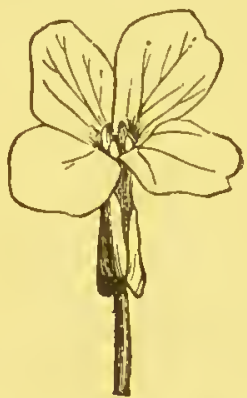

Fig. 252. - Cruciform flower of Lunaria with unguiculate petals.

plumarius; bifid as in Lychnis diuma (Fig. 25 I); unguiculate (Figs. 250-252), when the petals are very narrow in the lower part, which forms a claw or unguis, while comparatively broad in the upper part or lamina, \&c.

There are several forms of the apopetalous corolla which are of especially common occurrence, and therefore worthy of note [and which are frequently characteristic of large natural groups]: viz. the cruciform, papilionacenus, caryophyllaceous, rosaceous, and the less common but very remarkable mitræform. In the cruciform corolla (Fig. 252), characteristic of the large natural order of Cruciferæ, we find four unguiculate petals arranged in the form of a cross, and alternating with the four sepals. The papitionaceonis corolla (Fig. 253), confined to the division Papilionacex of the order 
Leguminosæ, consists of five petals, of which one, the standard or vexillum, the uppermost, is usually the largest; at its sides are the two wings or ala; while the lowermost

I.

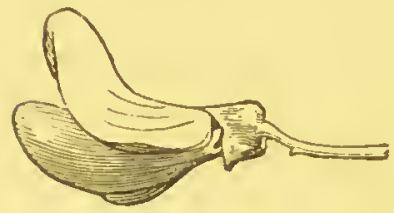

IV.

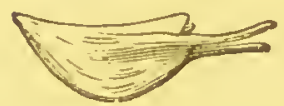

II.

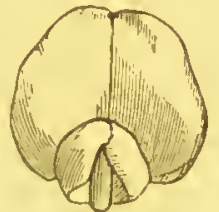

V.

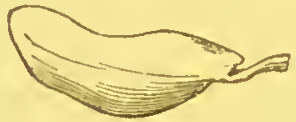

III.

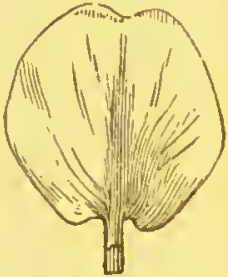

Fig. 253.-Papilionaceous corolla of laburnum: I. seen laterally; II. in front; III. standard; IV. keel ; V. left wing seen from without.

part of the corolla, the keel or carina, consists of two petals often more or less united above, and usually enclosing the stamens and pistil. The caryophyllaceous corolla (Figs. 254, 255) consists of five petals with long ungues attached to the

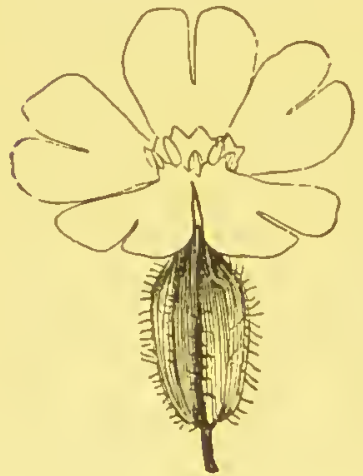

Fig. 254.-Caryophyllaceous corolla of Lychnis vespertina, with corona (magnitied).

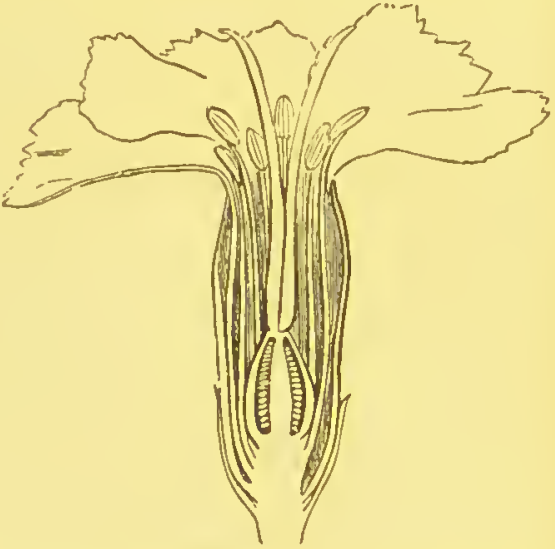

FiG. 255.-Longitudinal section through the caryophyllaceous corolla of Dianthus (magnified).

base of a gamosepalous [or sometimes aposepalous] calyx, [and each of the petals is often furnished with an appendage known as the ligule, (Fig 25I) and forming together the 
corona]. The rosaccous corolla (Fig. 256), consists of five petals which are not unguiculate, with perigynous adhesion, i.e. attached to that part of the urceolate or hypocrateriform calyx where the separate sepals spring from the coherent base, and is especially characteristic of a section of the order Rosacea. The mitraform corolla (Fig. 257) which occurs

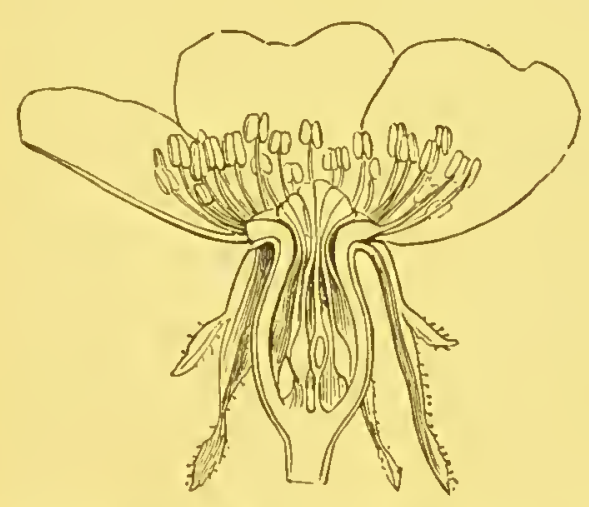

F1G. 256.-Longitudinal section through the rosaceous flower of the rose; the pistil seated in the base of the urceolate calyx.

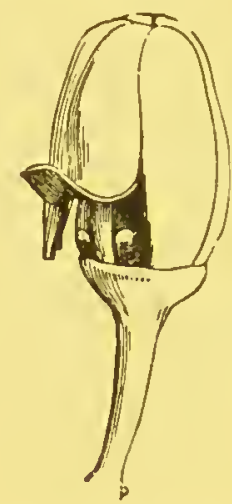

Fig. 257. - Mlitreform flower of the grape-vine (magnified).

in the grape vine, consists of five petals which are coherent at their tips, and become detached at their base on the expansion of the flower, thus covering the inner petals of the flower like a cap.

The petals usually break off when they fall by an articulation at their base, but often remain attached and withered, as in Campanula [when they are said to be marcescent]. The corolla never takes any part in the formation of the fruit, as is sometimes the case with the calyx.

\section{THE PERIANTH.}

When the Perianth (i.e. the two floral envelopes, the calyx and corolla) is green, as in the elm and Rumex (Figs. $258,259,260$ ), it is said to be sepaloid; when brightcoloured or white, as in Orchidex and Liliacere (Fig. 26r), it 
is petaloid; the dry scarious perianth of grasses is glumaceous; that of the catkins of many forest-trees scaly. Simi-

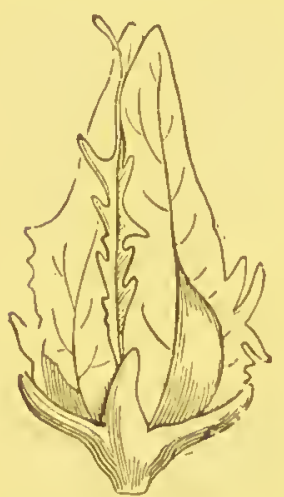

Fig. 258.-Double sepaloid perianth of $R u$. mex acetosn (magnified).

lar terms may be applied to the perianth as to the calyx and corolla, with respect to the form, size, number, and arrangement of its separate parts. It may be gamophyllous or symphyllous [' monophyllous '] on the one hand; or, on the other hand, apophyllous or eleutherophyllous ['polyphyllous ']. It may be deciduous, as in orchis, or persistent, and may then become accrescent and dry as in the hazel-nut, or succulent as in the mulberry. In the latter cases and some others, as Rumex and Hippophaë, it takes an impor-

I.

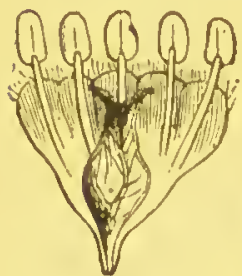

FIG. 259. - Longitudinal section through the sepaloid perianth of the elm (magnified).
II.

III.

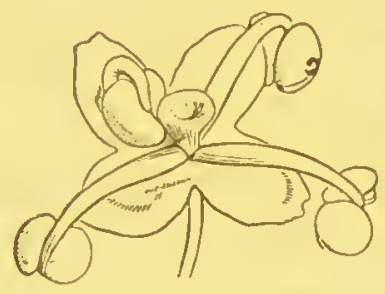

FIG. 260.-I. Staminate flower: II. pistillate flower: III. section of the fruit of the stinging-nettle, $U_{r}$ tica dioica (magnified).

tant part in the formation of the fruit. [Under this head come the palea and lodicules of grasses, and the perigynium of sedges.]

\section{SUBSIDIARY ORGANS OF THE FLOWER.}

By subsidiary organs are meant appendages to the flower of various kinds which cannot be included either among the floral envelopes or the essential organs of the flower.

The corona or paracorolla is a whorl of leaf-like or filiform organs, often brightly coloured, intervening between 
the perianth and the stamens, and sometimes attached to the one, sometimes to the other. In the narcissus (Fig. $26 \mathrm{r}$ ) it is coherent and bell - shaped, while in the passionflower it consists of a number of brightly coloured hairs; in Lychnis (Fig. 254, p. I32) it forms a small coronet at the base of the rotate lamina of the corolla ; in many Borragineæ (Fig. 262) it consists of five scales [or staminodes] which close up the throat of the corolla-tube. In the corolla of Lamium it assumes the form of a circle of hairs ; in

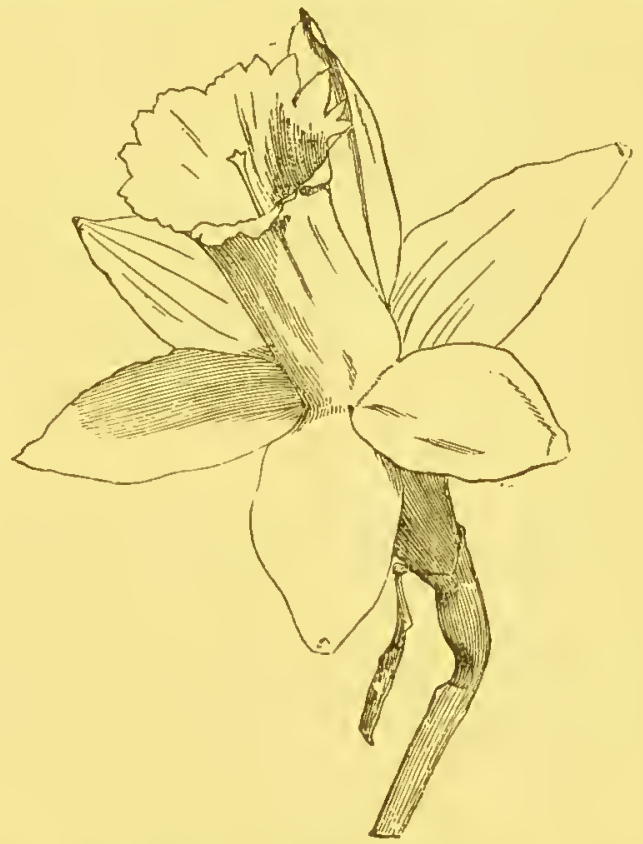

Fig. 26r.-Petaloid perianth of Narcissus, with 6partite limb and campanulate corona.

the grass of Parnassus (Fig. 263) it consists of five leaves which terminate at their apex in from nine to fifteen glandular bodies. The spur (Figs. 264, 266), which sometimes belongs to the calyx, Fig. 262. - Longitudinal section through the flower of sometimes to the the borage ; each bifid stamen bears the anther on corolla, is also fre-

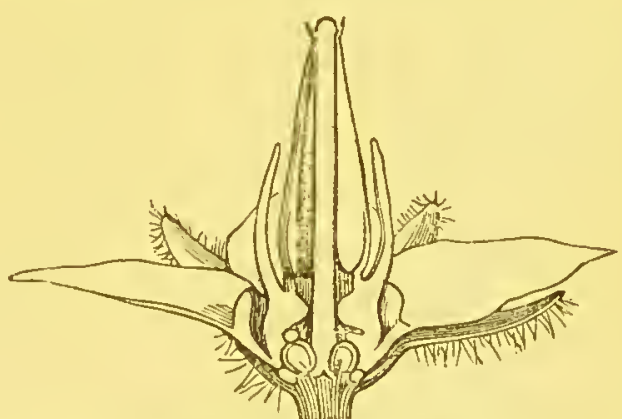
quently treated as a subsidiary organ.

The ncctaries must also be mentioned in this connection. 
They are the part of the flower which is specially constructed for the secretion of honey, and are of great importance in

I.

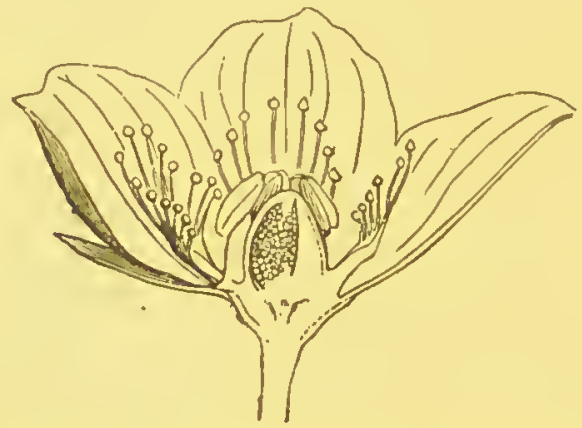

II

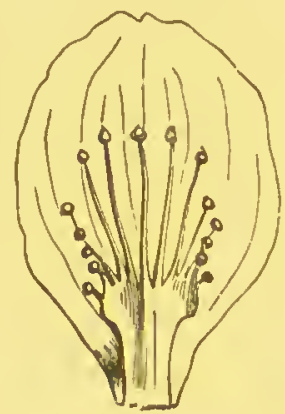

FIG. 263.-I. Longitudinal section through the flower of Parnassia falustris: II. one of the petals (magnified); a glandular scale belonging to the corona attached to it in front.

attracting insects to assist in fertilisation. Instances are afforded by the shallow pits at the base of the perianth-leaves.

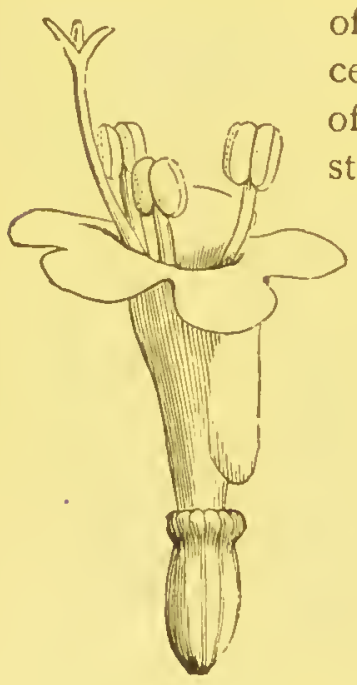

FIG. 264.-Spurred corolla of Valeriana (magnified). of the crown-imperial, the hollows concealed by scales at the base of the petals of Ranunculus, the glands between the stamens of the grape-vine (Fig. 265),

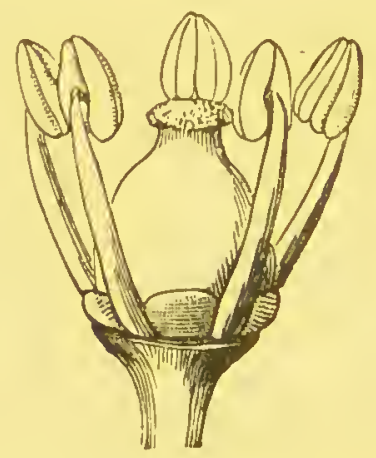

FiG. 265--Stamens and pistil of the grape-vine, with a honey-gland (nectary) between each pair of stamens (magnified).

[the spur of the columbine or larkspur (Fig. 266), and of many species of orchis, the appendages to two of the stamens. of Viola, \&c.]. 
Lastly, we must also include under this head barren stamens or staminodes, filiform bodies placed either within or without the perfect stamens, but not furnished, like them,

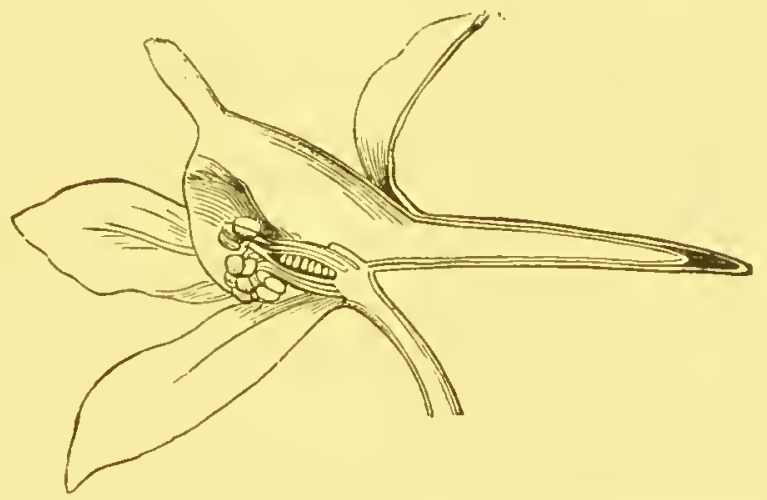

FIG. 266.-Longitudinal section of flower of larkspur, with spurred calyx and corolla (magnified).

with anthers at their apex. Examples occur in [the female flowers of] the bay Laumes nobilis, in Illecebrum, Erodium, Samolus, [the borage (Fig. 262) according to some], \&c.

\section{THE ANDRCECIUM OR STAMENS.}

The Stamens consist, in their most perfect form (Fig. 267), of a longer or shorter filiform stalk, the filament, which: bears at its apex the anther. The filament usually divides the anther into two halves, the anther-lobes. The part of the filament which is inserted between the anther-lobes is called the comective, and is sometimes divided into two arms, which are often greatly elongated, and are either of equal length, as in the horn-

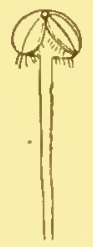

Fig. 267.-Stamen of FIG. 268.- Stamen Lamiun, with mo- of hornbeam, Carderately developed pinus Betulus, with connective (magni- branching connecfied).

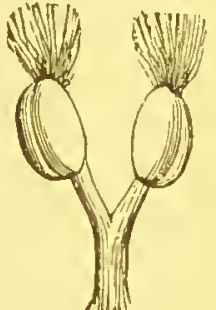

tive (magnıfied).

beam (Fig. 268), hazel-nut, alder, birch, and lime, or occasionally of very unequal length, as in Salvia (Fig. 269). 
The connective usually ends with the anther-lobes, and these latter are then placed at the extremity of the filament ;

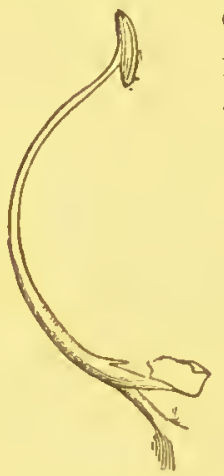

FIG. 269.- Stamen of Salvia, with connective branching into two arms of very unequal length : the right-hand arm bearor less often, it grows beyond the anther, as in Paris quadrifolia, where the anther appears to be attached to the middle of the stamen,

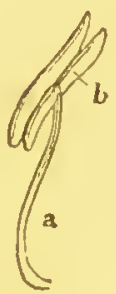

Fig. 270.-Stamen of wheat, with versatile anther $b$ lightly fixed at the extremity of the filament $a$ (magnified).

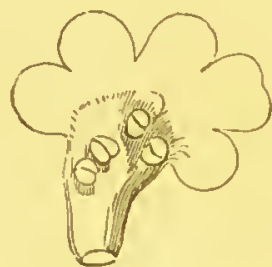

Iig. 27r.-Section of corolla of Verbens, with sessile epipetalous anthers (magnified).

[or the violet, where it forms the orange tip to the stamens]. Since the essential part of the stamen is the pollen, which is developed within the anther, the filament may be en-

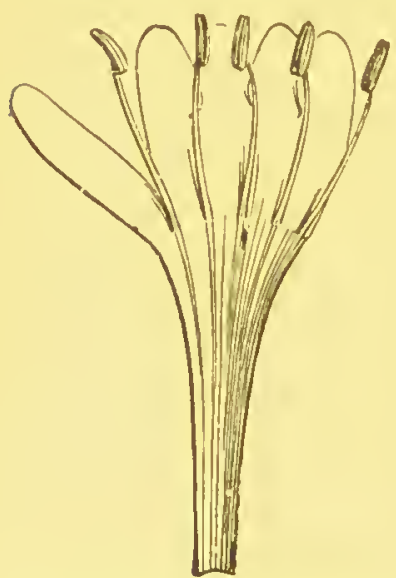

FIG. 272.-Section of corolla of honeysuckle, with epipetalous stamens. tirely wanting, as in Orchideæ, $V$ rrbena (Fig. 27r), [and Viola], when the anther is sald to be sessile. In the Grasses (Fig. 270), the anther is fixed transversely to the filament.

Of great importance in connection with classification are the mode of attachment and number of the stamens, as well as the relative lengths of the filaments. For example, with but few exceptions, all Labiatæ [Scrophulariaceæ, Verbenaceæ, Gesneraceæ, Acanthaceæ, and Bignoniacex] have two short and two long [didynamous] stamens \{Figs. 27I, 273); all Cruciferæ (Fig. 274) two sholt and four long [tetradynamous]. It must also be noticed whether all the 
filaments are distinct to their base or not. Sometimes the whole of the filaments are united into a tube or sheath

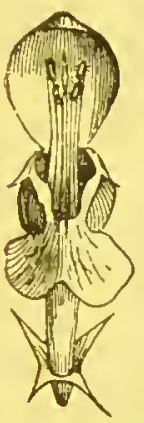

FIG. 273.-Flower of Lamium, with didynamous stamens.

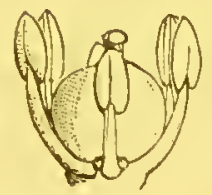

FIG. 274.-Pistil and tetradynamous stamens of Cochlearia.

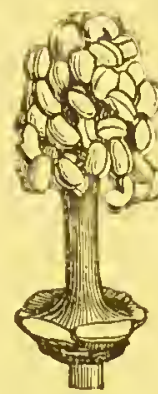

FIG. 275. - Monadelphous stamens of Mlalvo.

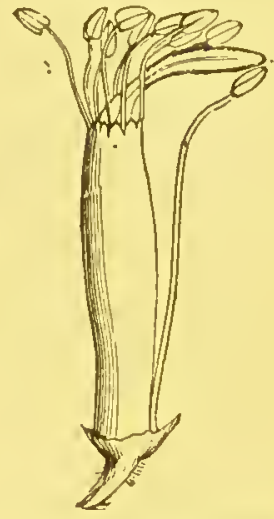

Fig.276.-Diadelphous stamens of Lathymis: nine filaments united into a sheath at the base; one free.

[monadelphous], as in Malvaceæ (Fig. 275) and many Leguminosæ; in other cases into two bundles [diadelphous], as in manyLeguminosæ (Fig. $276)$; or into a larger number [polyadelphous], as in the orange (Fig. 277) and Hyporicum. Again, when the filaments are perfectly
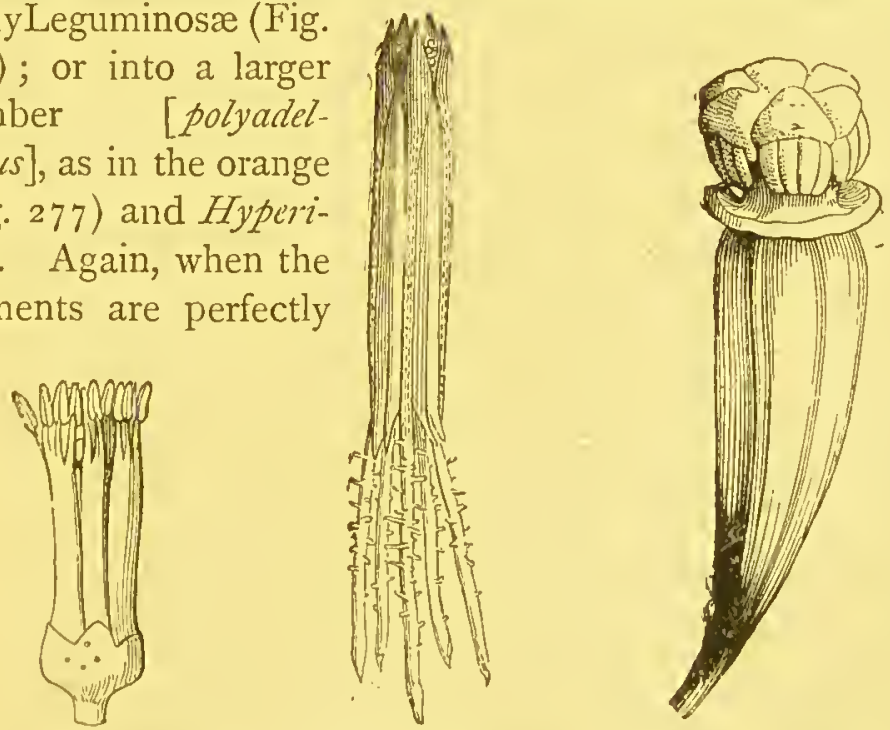

FIG. 277-Polyadelphous Fig. 278-Syngenesious stamens of orange (magnified). anthers of thistle: the filament free (magnified).
FIG. 279.-Stamens of Aristolochio sissile upon the stigma (magnified). 
distinct, the anthers may be coherent or united by their margins [syngenesious], as occurs in Compositæ (Fig. 278). Occasionally, the anthers are sessile upon the stigma [yynandrous], as in Orchider (Fig. 279). ${ }^{1}$

The pollen is formed in the cavities of the anther-lobes, which are termed loculi, and are most often two, more rarely

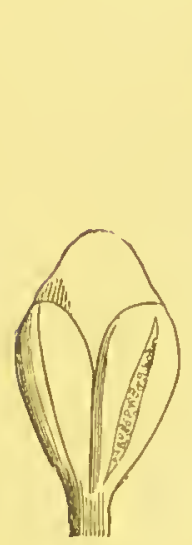

FIG. 280.-Stamen of Pinus syluestris with longitudinal dehiscence (magnitied).
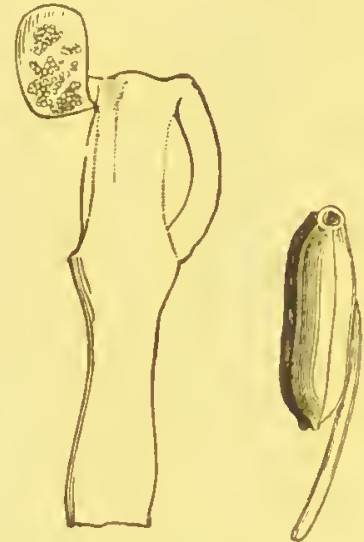

FIG. 28 r.-Sta- FIG. 2b2.,-stamen of bar- inen of Rlloberry, the an- dodendron, ther opening each antherby recurved lobe opening valves (mag- by a pore. nified).
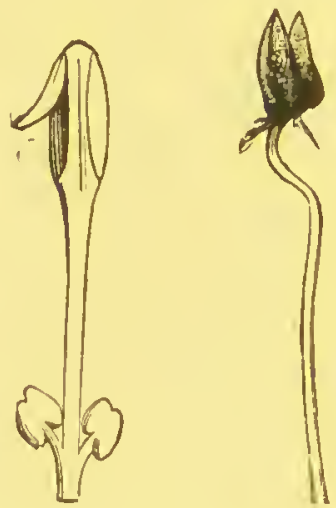

FIG. 283.-Sta- FIG. 284.-Stamen of bay, men of Erica, Lourus no. the anther bilis, with two opening by glands at the poresand bearbase of the ing two apfilament, the pendages at its anther opening by recurved valves. base (magnified).

one or four in number, the anther being then termed unilocular, bilocular, or quadrilocular. In most plants it consists of minute pollen-grains, entirely distinct from one another; less often, as in Orchideæ and Asclepiadeæ (Fig.

1 [As respects their adhesion or mode of attachment, stamens are hypogynous when growing directly from the receptacle beneath the ovary (Ranunculus, Cruciferx); perigynous when springing from the calyx (Rosa, Fuchsia); epipetalous from the corolla (Primula, Lamium) ; epigynous when attached to the upper part of the pistil (Umbelliferæ, Rubia.). With reference to the mode of attachment of the anther to the filament, the former is basifuxal or innate when attached by its base (heath, tulip); dorsifuxed or adnate when attached by its. back (onion, nyrtle); versatile, when, in the latter case, the attachment of the anther to the filament is very slender, as in most Grasses. (Fig. 270).-ED.] 
355 , p. $18_{3}$ ), they are united into a waxy mass [or pollinium]. On the maturity of the anthers, they burst open or dehisce in a manner which is well defined beforehand. This usually takes place by means of a longitudinal fissure in each anther-lobe (Fig. 280), longitudinal defiscence, most often on the inner side of the anther, facing the pistil, introrse, less frequently on the outer side facing the corolla, extrorse, as in Irideæ, [or precisely at the side, lateral, as in Ramunculus]. Less common modes of opening are the dehiscence by rearved valves, [when the side of the anther-lobe is turned back as on a hinge], as in Berberis and Laurus (Figs. $28 \mathrm{I}, 283$ ); and by pores (Figs. 282, 284), as in the Ericaceæ, Polygala, Solamum, \&c. ; [still less frequent is the transierse defiscence, as in Alchemilla.] In some cases, appendages of a peculiar structure, of a leaf-like or glandular nature, are

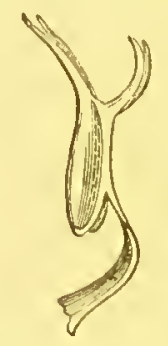
FIG. $285 .-$ Stamen of Vaccini$267 n$, with appendages at the base of the anther. attached to the filaments, as in Viola, the borage, onion, bay, \&c. (Fig. $2 \delta_{3}$ ), or to the anther, as in many Ericacex (Figs. 284,285 ). [Between the corolla and the stamens is sometimes an elevated ring known as the disc.]

The foliar nature of the stamens is especially well seen from the fact that very frequently-especially in many socalled double flowers-the stamens are converted into petals; or occasionally stamens are developed instead of

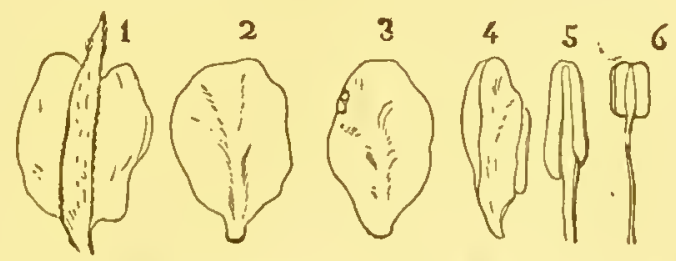

FiG. 286. - Stages of transition between the petals and stameris of Rosa centifolia.

petals, as is often seen in the shepherd's purse. It is also not uncommon to find in the same flower a gradual transition between the stamens and petals, as occurs normally in Nymphæaceæ and Rosa centifolia (Fig. 286). 


\section{THE GYNECEUM OR PISTIL.}

The Pistil consists, in its most perfect form (Fig. 287), of three parts:-the lowermost swollen part, a hollow cavity

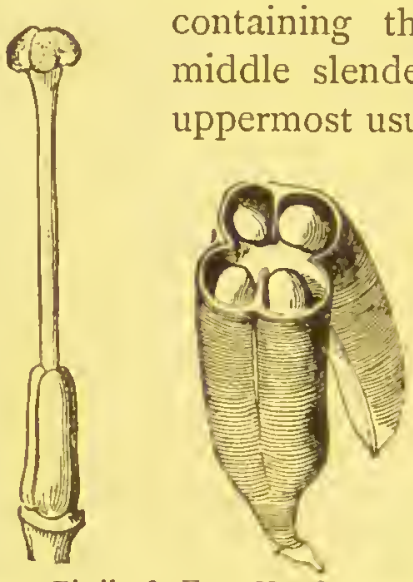
containing the ovules, is the ovary; the middle slenderer part is the style; and the uppermost usually thicker part is the stigma.

The pistil is composed of one or more organs of a foliar nature, the carpels; and their number is almost always indicated by the seams or sutures. on the outside of the ovary. A knowledge may thus be obtained of the constitution of the fruit, which is often characFig. 287.-Pistil of Fig. 288.-Legume teristic of whole families of
lily, with ovary, of Astragalus, style, and stigma. partly cut through. plants. Thus, from the structure of the legume (Fig. 288) it may be concluded that it consists of a single carpel; while in the same manner it is seen that the capsule of Colchicum (Fig. 289) is composed of three carpels.

If a suture faces the centre of the flower, it is called the rentral suture; while one facing the perianth is called the dorsal suture. It is common for the carpels of which a pistil consists to be coherent at the base while distinct in the upper part, and we have then a single ovary with several styles or stigmas, as in the apple. As a general rule the style and stigma are a prolongation of the mid-rib of the carpel, although exceptions occur, as in the Papaveracex. Pistils which consist of a single carpel are said to be monocarpellary [as in Leguminosæ and Primulacex]; when of two or more carpels bicarpellary, tricarpellary, polycarfellary, \&c. [If the carpels of which a pistil is composed are more or less completely welded together, it is syncarpons (Figs. $3^{13}, 320,323,326$ ); if quite distinct, it is apocarpons (Figs. 314, 315).] 
The style is not an essential part of the pistil, and is therefore not unfrequently wanting, as in the poppy (Fig. 294). When present it is usually placed at the summit of the ovary, terminal, but occasionally springs from its base, and is then lateral or basilar, as

A.

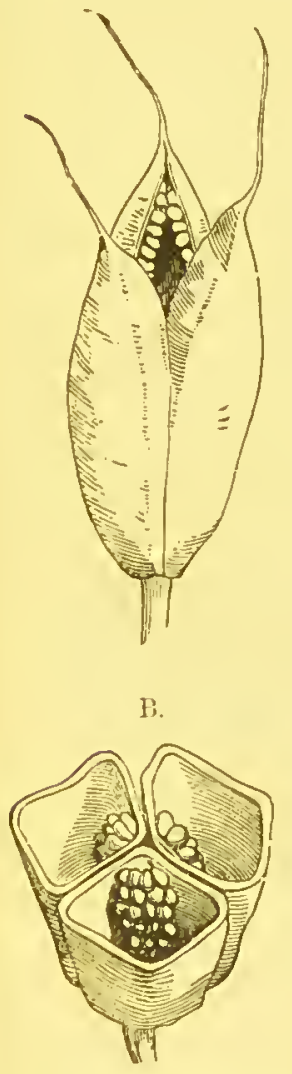

Fig. 289.- Capsule of Colchicums; A at the moment of dehiscence; B transverse section.

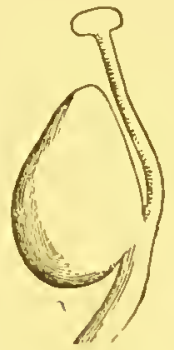

Fig. 290. - Basilar style of Alchemilla (magnified).

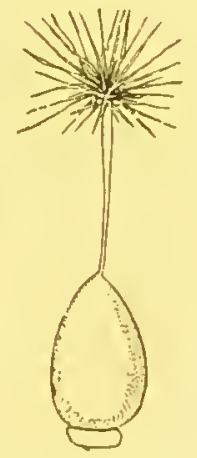

F1G. 291.-Pistil of Parictaria, with penicillate

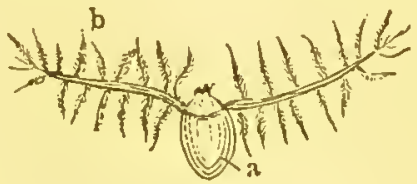
FIG. 292.-Pistil of Bromus ; $a$ ovary, $b$ plumose stigma (magnified).

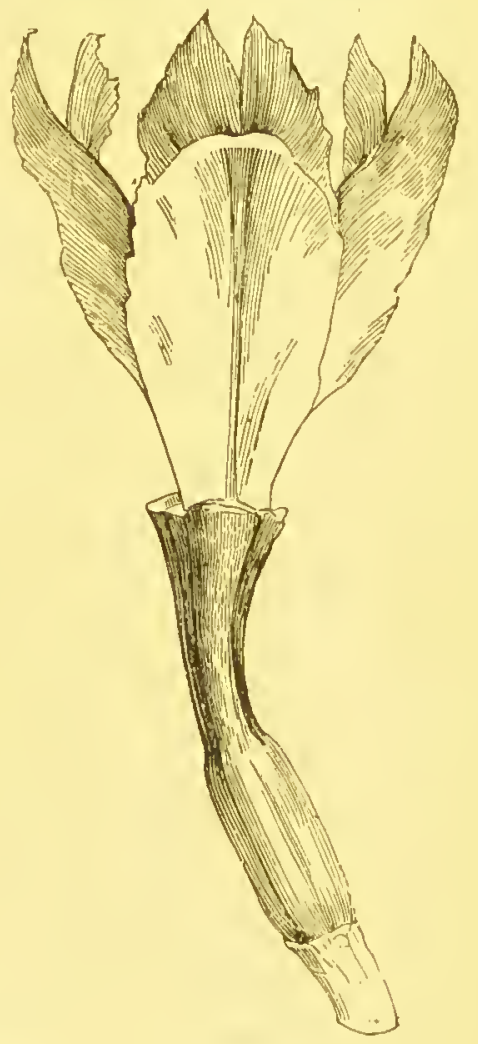

stigma (magnified). FIG. 293.--Petaloid stigmas of Iris.

in the strawberry and Bromus (Figs. 290, 292).

The purpose of the stigma is to serve for the detention of the pollen-grains; and it is therefore universally present, 
though it varies greatly in form. It may be capitate or buttonshaped (Fig. 287); penicillate or consisting of long slender arms (Fig. 291) ; plumose or feathery (Fig. 292); petaloid as in Iris (Fig, 293); peltate or shield-like as in the poppy (Fig.

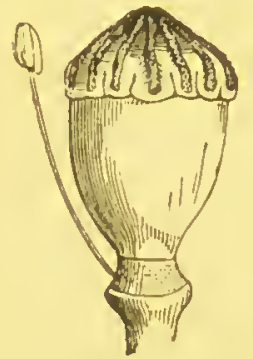

Fif. 294. - Peltare stigma of poppy, wilh hypogynous stamen. 294); filiform as in Luzula; papillose or covered with papillæ (Fig. 295), \&c.

The interior of the ovary is occupied by one or more cavities or loculi, [the walls which separate them being the septa or dissepiments]. Thus the ovary of Leguminosæ and Primulaceæ is unilocular (Figs. 296, 298); that of Scrophulariaceæ and most Cruciferæ bilocular (Fig. 297); that of the apple quinquelocular, \&c.

Within the loculi of the ovary are the ovules, the bodies which ultimately develope into the seeds. They are fixed to certain parts of the wall of the ovary termed the placenta ; and are either scssile (Fig. 298), or are attached to the end of a stalk or funiculus

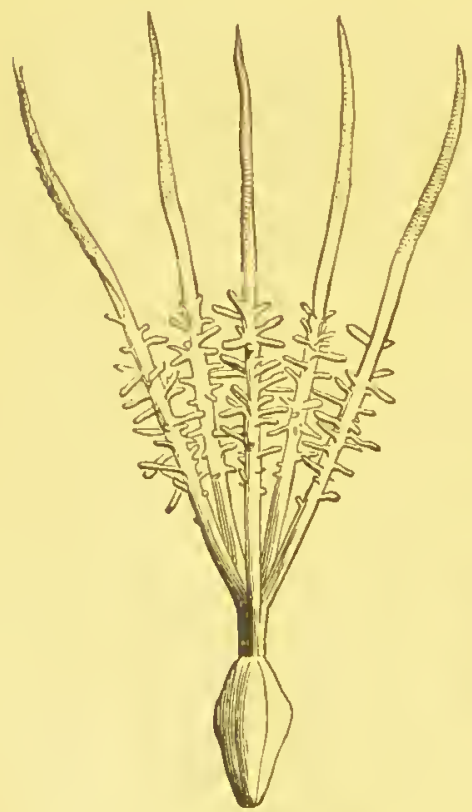

I'tG. 295. - Papillose stigma of Statice (magnified).

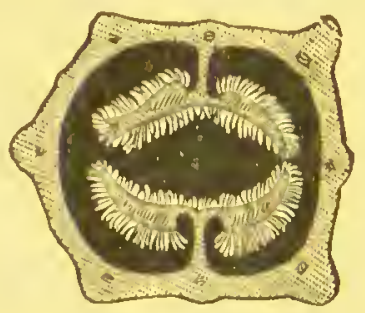

FIG. 296.-Unilocular ovary of Pcutaraflica (Gesneracex), with parietal placentæ (magnified).

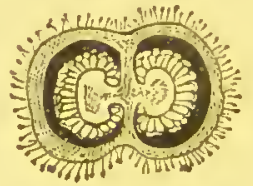

Fıc. 297.-Bilocular ovary of Antirrhinum, with axile placenta.

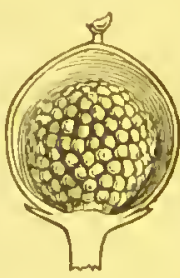

F1G. 298. - Unilocular ovary of Hottonic, with free centual placenta. 
(Fig. 299). In a few cases the whole of the interior wall of the ovary or of the loculi serves as a placenta, as in the poppy; or a single placenta stands in the centre of the unilocular ovary like a column, as in Primulacex [when the placentation is free central]; more often certain portions of the inner walls of the loculi, corresponding in number to the carpels and often projecting, bear the ovules, and are then called parietal placentæ [as in Viola or Ribes]; [or the ovules are attached to the common axis of all the loculi of a multi-

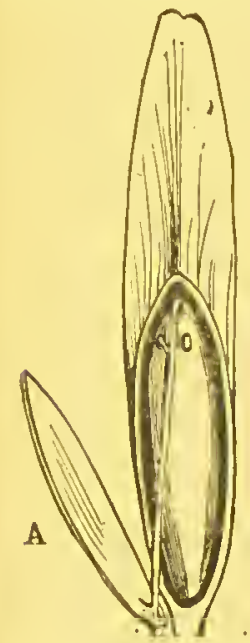

Fig. 299.-Ovary of the ash ; the single seed attached to a long funiculus, and still enclosed in locular ovary, as in the apple or Tris, when the placentation is axile.] As respects the mode of attachment of the ovules to the loculus, they may be either erect, [lateral], or pendulous.

I.

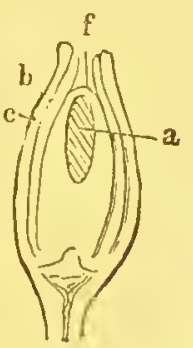

II.

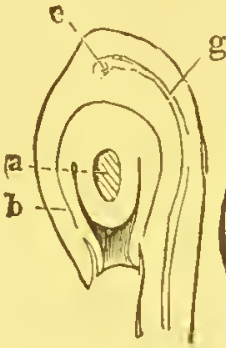

III.

FIG. 300.-I. Orthotropous : II. anatropous ; III. campylotropous ovule; $a$ nucellus with the embryo-sac coloured dark ; $b$ primine ; $c$ secundine ; $d e$ chalaza ; $f$ micropyle; $g$ raphe (represented diagrammatically). piece of the wall of the ovary.

If a section is madie through the longer axis of an ovule, and the surfaces examined under a magnifying-glass, it is seen that the ovule consists of a [cellular] mucellus (Fig. $300 \mathrm{a}$ ) enclosed in a single or more usually in a double coat or integument $(b, c)$, [the outer coat being designated the primine, the inner coat the secundine]. At the apex of the ovule is a small orifice through the integuments, called the micropyle or foramen; [and in the interior of the nucellus is a large cell called the cmbryo-sac]. With regard to their form, ovules may be classified into three kinds - the ortho- 
tropous (or atropous), in which the ovule and nucellus are straight, and the micropyle is exactly opposite the base of the ovule (Fig. $300, \mathrm{I}$.); campylotropous, in which the nucellus is curved so as to bring the micropyle near the base (Fig. 300, III.) ; and anatropous, where the ovule is itself inverted so as also to bring the micropyle near the base, but the nucellus remains straight (Fig. 300, II.). [The last is by far the most common form of the ovule; illustrations of the first are afforded by Polygonace ; of the second by Caryophyllaceæ. The point where the nucellus and integuments coalesce is called the chalaza; in the anatropous ovile this is at the opposite end to the hitum (the part of the ovule which is attached to the placenta), and is connected with it by a fibrovascular bundle, $g$, called the raphe].

\section{THE FRUIT.}

The fruit is the result of the development of the ovary; but is usually formed only after the fertilisation of the ovules, and, when mature, encloses the seeds which have developed from the ovules. Hence the product of an inflorescence, such as a bunch of grapes, is not properly a fruit, but rather a group of fruits, each separate berry or grape being a distinct fruit. Collections of fruits of this kind, resulting

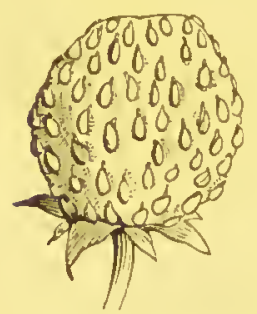
Fig. 301 . - Pseudo- psenducarps. The rose-hip, for example, is berry. the development of the calyx-tube, each little 'stone' which is enclosed in it being a mature ovary. The strawberry (Fig. 3OI) is also of this character, the succulent sapid mass being a portion of the receptacle which has become fleshy, while the small so-called 'seeds' which are imbedded in its 
surface are the actual fruits. The apple again is a pseudocarp [here termed a pome], the flesh being mainly developed out of the calyx-tube, 'which even when in flower is adherent to the ovary. In the spinach the perianth, in the oat the glumes, take part in the formation of the pseudocarp. Pseudocarps are sometimes formed not of simple, but of multiple fruits. Thus the mulberry (Fig. 302) is a pseudo-syncarp, resulting from the coalescence of the bracts with the perianth; and the same is the case also with the pineapple, the fig (Fig. 2 I5, p. II 8 ), the breadfruit, \&c.

Additional examples of the participation of the calyx or of the perianth in the production of the fruit have

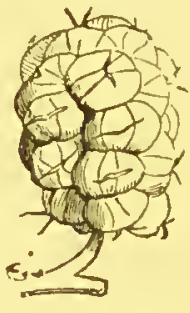

FIG. 302. - MIUItiple pseudocarp of the mulberry. already been adduced ( $p$ p. 126, I34). Mention has yet to be made of the husk in which the hazelnut is seated, this being the greatly 1.

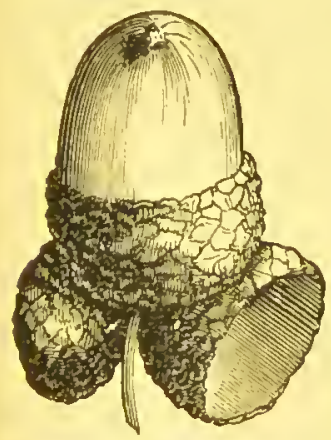
enlarged perianth; while on the other hand the cup or cupule of the oak, beech, and sweet chestnut arises from a cup-shaped organ

I I.

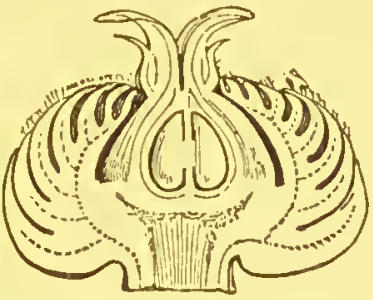

Fig. 303.-I. Acorn of Quercus sessilifiom with two empty cupules: II. longitudinal section through the fertilised pistillate flower, with the cupule in an early state.

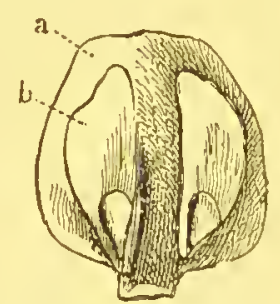

FIG. 304.- $n$ Scale of the Jarch-cone seen from above ; $b$ one of its two winged naked seed's, z.e. not enclosed in an ovary.

which is formed only after fertilisation between the ovary and the perianth, and produces leaves on its outer margin (Fig. 303).

Special reference must be made to the Coniferæ, in which there is no ovary, but only naked ovules (Fig. 304), and which therefore cannot form a true fruit. The class to which they belong are hence termed Gymnosperms or naked seeded. 
In observing a fruit, care must be taken to distinguish the wall of the cavity which encloses the seeds, or pericarp, which may. consist of several layers of a membranous, fleshy, or stony consistence (Fig. 305). The nature of the outermost layer or epicarp determines whether

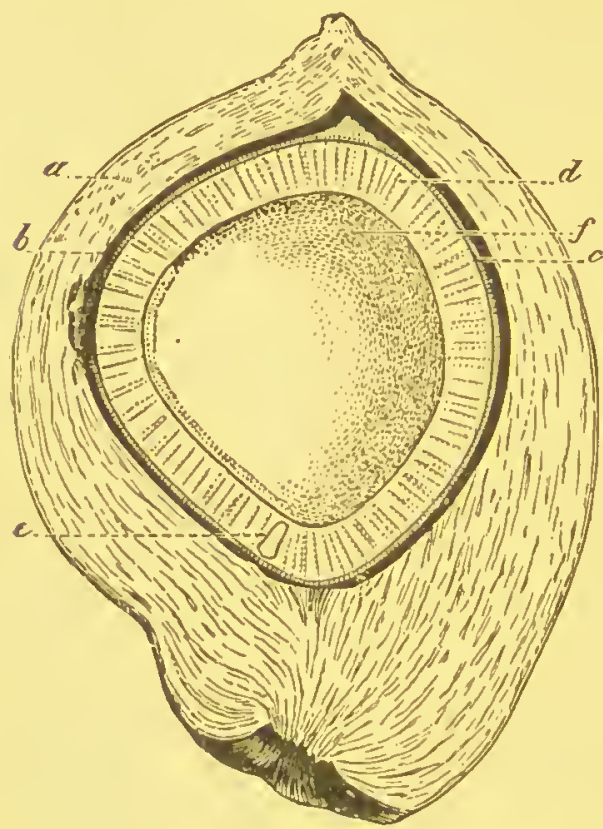

FIG. 305.-Longitudinal section of cocoa-nut ; $a$ epicarp : $b$ endocarp ; $c$ testa : $d$ endosperm or albumen ; $c$ embryo : $f$ cavity in the endosperm which contains the milk. the fruit has a smooth appearance like the cherry, rough like the peach, or spiny like the thorn-apple (Fig. 3 10, p. 150). The middle layer or mesocarp is often fleshy or succulent, and is then called the flesh or sarcocarp [as in the peach or cherry]. The innermost layer or endocarp is often very hard, and forms the stone or putamen of stone-fruit; it encloses the cavities of the fruit which correspond to the loculi of the ovary, and are still termed loculi. The number of these loculi generally corresponds to the number in the ovary, although one or more not unfrequently disappear in the course of development. Such a disappearance or abortion is the rule in the lime, in which the ovary is originally quinquelocular, in Isatis where it is bilocular, [and the oak where it is trilocu. lar], while in all these cases the fruit is ultimately unilocular.

Fruits may be divided into two primary classes, dchiscent and indehiscont; to the former belong the capsule and schizocarp ; to the latter the drupe, berry, and achene.

'The capsule bursts or dehisces when ripe, and allows the seeds to fall out. If this splitting takes place only at the 
sutures], is called a legume (Fig. 316), that of Cruciferæ [which is always bicarpellary, the seeds remaining attached
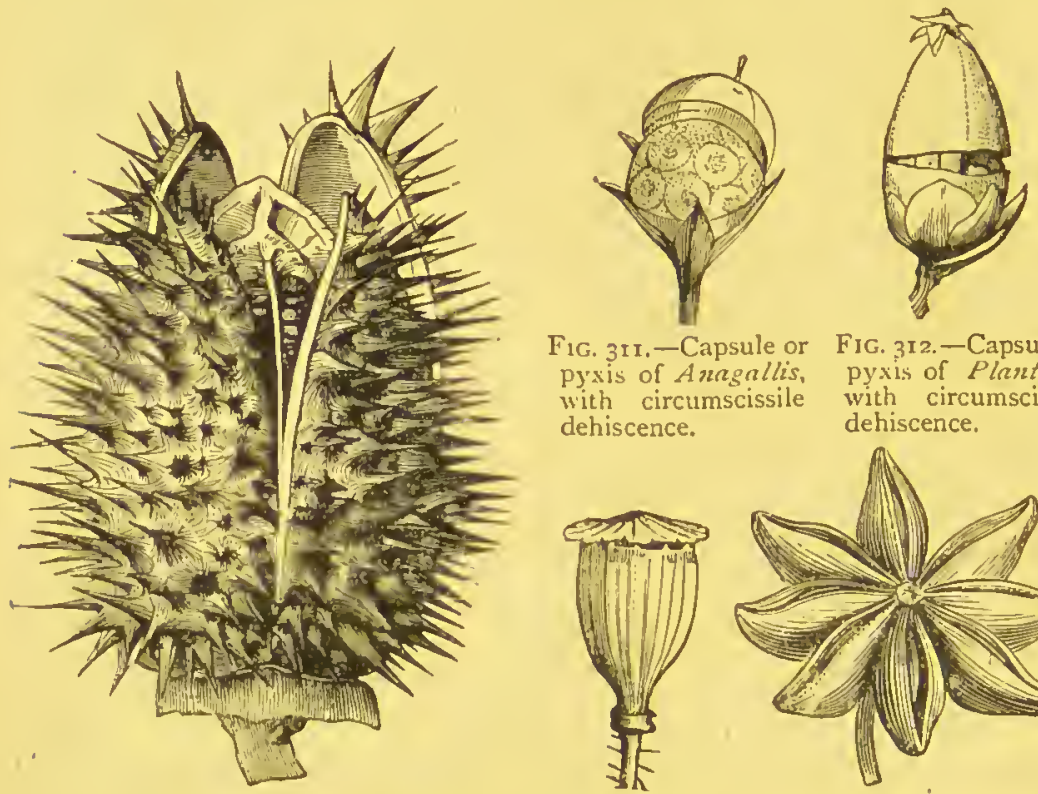

F1G. 3II.-Capsule or FIG. 3I2.-Capsule or pyxis of Anagallis, pyxis of Plantago. with circumscissile with circumscissile dehiscence.
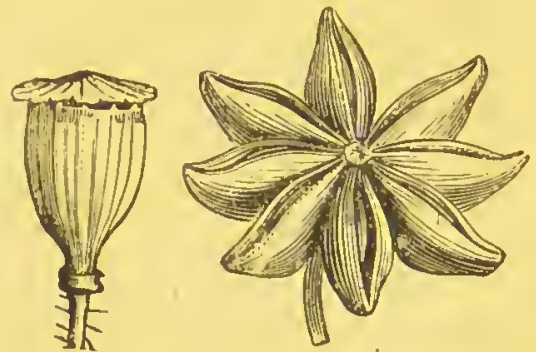

F1r. 310.--Septifragal capsule of Datura.

FIG. 313.-Capsule Frg. 314.-Fruit of Illicium of puppy dehiscing or star-anise, consisting by pores beneath the peltate stigma: of a number of follicles.

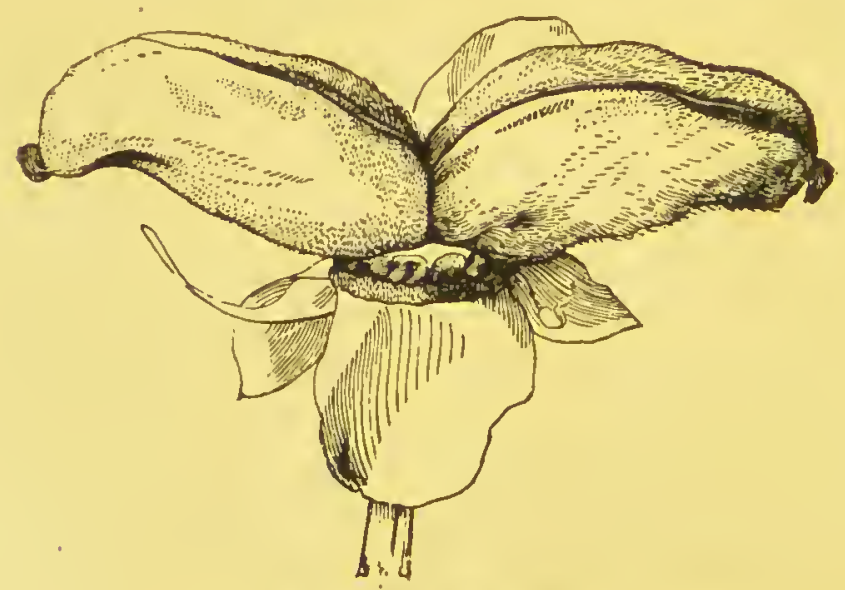

IitG. 315. - Fruit of peony, consisting of two follicles. 
to a false septum or replum] a siliqua [when much longer than broad, when only about as long as broad, a silicula (Fig. 3I 7)].

The schizocarp splits up, when ripe, into distinct pieces,

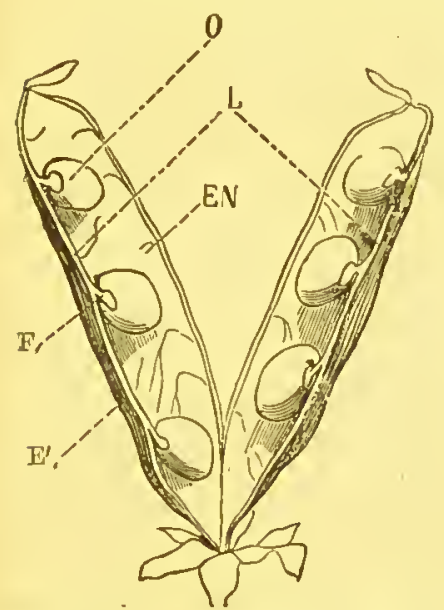

FIG. 336.-Legume of pea split lengthwise; $E$ outer, $E N$ inner layer of the pericarp; L placenta : $F$ funiculus; o seed. called mericarps. These last contain usually each a single seed, and as a rule remain closed, seldom opening to allow the seeds to escape in the manner of a

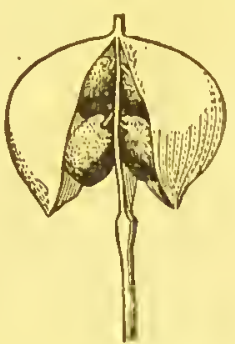

FIG. 317. - Silicula of Cochlearia open and showing the seeds at. tached to the replum.

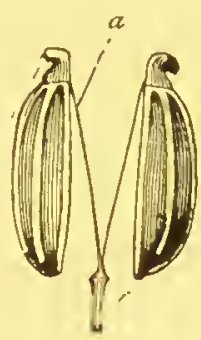

FIG. $318,-$ Cremocarp of the fennel; $a$ carpophore.

capsule. The splitting may be either longitudinal or transverse. In the former case the schizocarp may split into

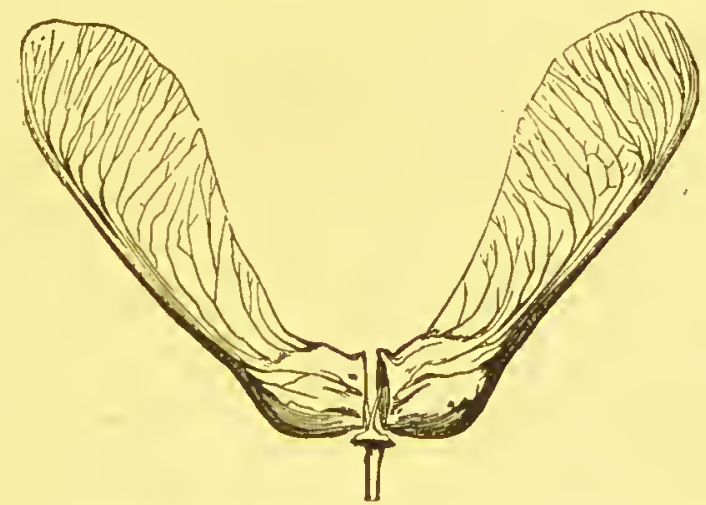

FIG. 319.-Bipartite schizocarp of the maple, consisting of two saniara.

two pieces, as occurs in Umbelliferæ [where it is termed a cremocarp], the mericarps separating at their lower part, and 
remaining attached at their apex to the filiform carpophore (Fig. 3I8), or in the maple (Fig. 319); or it may divide into three as in Euphorbia and Tropcolum (Fig. 320); or into four as in Labiatæ (Fig. 32I), [where they are often

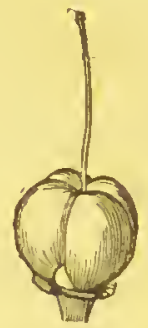

FIG. 320. - Tri- FIG. 321.-Quadripartite schizoearp of Tropecolume. partite schizocarp (carcerulus) of Ajugu, consisting of four nucules.
I.

II.

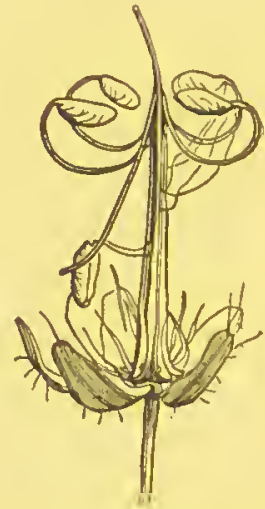

FIG. 322:- Quinquepartite schizocarp of Gernuium roberliunum: I. the immature pistil : Il. the mature fruit.

cailed mucules, and the entire schizocarp a carcerulus]; or into five as in Geranium (Fig. 322); or a larger number as in

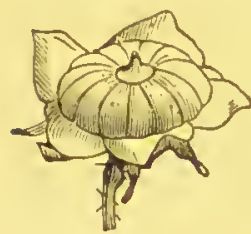

Fig. 323. - Multipartite schizocarp of Malva. Malva (Fig. 323). A transverse splitting of the schizocarp at right angles to the axis of the flower occurs in some Leguminosæ and Cruciferæ of the suborder Lomentaceæ, where the fruit is called a lomontum (Fig. 324).

Passing to indehiscent fruits :-in the drupe or stone-fruit the various layers of which the pericarp consists develope in a different manner, the mesocarp (sarcocarp) becoming softer and more succulent, the endocarp (putamen) harder, dry and roody, and forming the stone which encloses the kernel. The consistency of the mesocarp, however, differs greatly; in the peach, plum, and cherry (Fig. 325 I.) it is very soft and succulent; in the cocoa-nut (Fig. 305, p. 148 ) it is fibrous; 
in the almond and walnut, dry and almost leathery. The drupe usually contains a single stone, rarely more as in the medlar, when the separate sections of which it is composed are called pyrenes; it is usually unilocular, as in the peach,

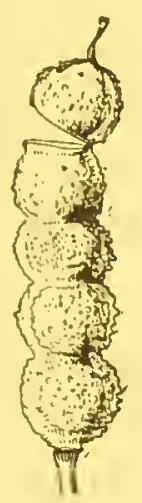

FIG. 324. - Iomentum of Hedysarum.

\section{I.}

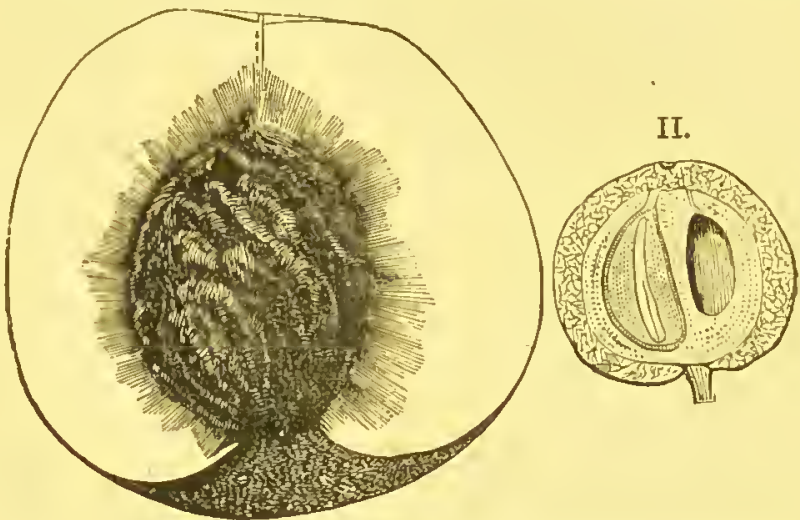

FIG. 325.-I. Longitudinal section through the unilocular drupe of the peach; II. through the bilocular drupe of Comns.

almond, and walnut, sometimes bilocular, as in the cornel (Fig. 325 II.) and coffee-berry.

In the berry all the layers of the pericarp are fleshy and succulent, as in the grape, currant, and gooseberry (Fig. $326)$; or the outer layers are harder, as in the citron and gourd, [the latter sometimes called a pepo]. The apple is a berrylike pseudocarp.

In the achene all the layers of the pericarp are dry and nearly similar. It almost invariably contains only a single seed, and is usually also from the first unilocular and with only one ovule, as in Grasses and Compositæ (Fig. 327); less frequently it becomes unilocular in the course of development, by the abortion

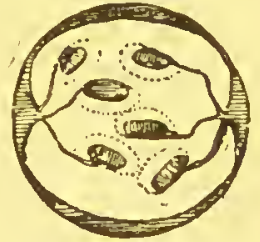

Fig. 326. - Transverse section through a gooseberry : the firmer outer layer of the pericarp encloses the succulent flesh: the seeds lie imbedded in the latter, and are at. tached by long funiculi to two opposite parietal placentæ. of some of the ovules and the disappearance of some of the loculi, as in the oak and alder. The pseudocarp of the 
rose contains several achenes. The fruit of the elm, ash, maple, \&c. (Fig. 319, p. 15I), known as a samara, is an achene

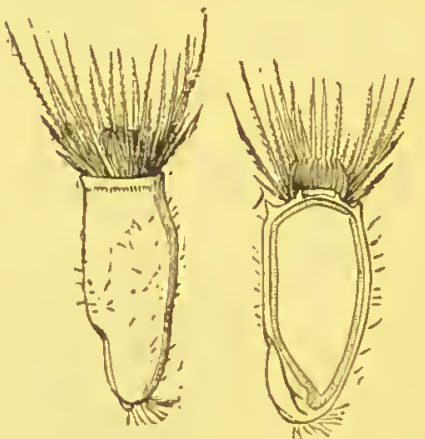

FIG. 327. - Achene or cypsela of Centuurea Cyanzs, entire and cut through lengthwise (magnified). [or schizocarp] with membranous appendages or wings [which enable it to be carried by the wind through the air]. ${ }^{1}$

\section{THE SEED.}

The seed or mature ovule is the organ by means of which the higher plants are chiefly propagated. It is connected with the placenta or part of the internal wall of the ovary to which it is attached by a more or less strongly developed stalk or funiculus (Fig. 326); when this is so short as to appear to be altogether absent, the seed is said to be sessile.

The arillus is an appendage springing from the point of attachment of the seed to the placenta or hilum, from

I.

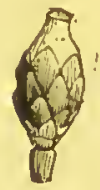

II.

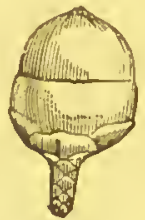

III.

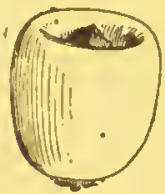

IV.

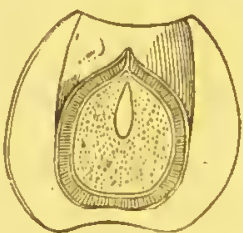

FIG. 328.-I., II., III., Development of the arillus of the yew: IV. longitudinal section through the ripe seed.

whence it rises up and envelopes it. In the ripe seed of the willow it is split up into long silky hairs; in the nutmeg it

1 [The nut (Fig. 485, p. 380) and glans (Fig. 303, p. 147) are oneseeded achenes resulting by abortion from a trilocular ovary, in which the epicarp is more or less lignified. The caryopsis, characteristic of Grasses, is an achene in which the membranous pericarp adheres closely to the seed ; the inferior achene of Composite is sometimes called a cypsela. The hesperidium, as in the orange, is a multilocular berry in which there is a remarkable development of succulent cells Jrom the endocarp. -ED.] 
forms the substance known in commerce as mace: in the yew (Fig. 328), it forms a drupaceous pseudo-berry. ${ }^{1}$ Appendages of other kinds to the seed occur in the form

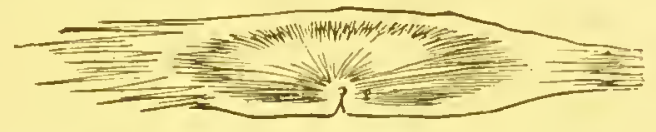

FIG. 329.-Winged seed of Bignonia Catalpa.

of wings, as in Bignoniacere (Fig. 329), and Coniferæ (Fig. 304 , p. 147), [in the latter case the wing does not belong to the testa, but to the wnody scale to which the seed is attached], or hairs, as in Polemoniaceæ, \&c. (Fig. 330).

The seed consists of an integument and a nucellus, the first being formed from the integuments, the last from the nucellus of the ovule.

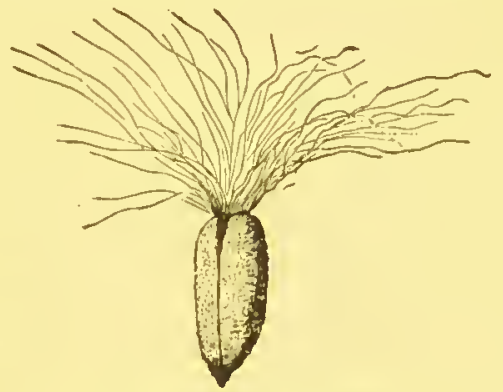

'The integument consists Frg. 330.-Ripe seed of Epilobium, with of an outer and an inner layer, the former being sometimes called the testa, and the latter the tegmen. In the walnut the outer layer is yellow and

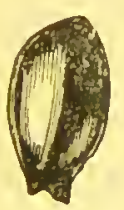

FIG. 33 r. Smooth seed of Aquilegia (magnified).

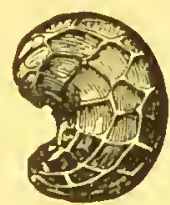

FiG. 332.-Reticulated seed of , poppy (magnified).
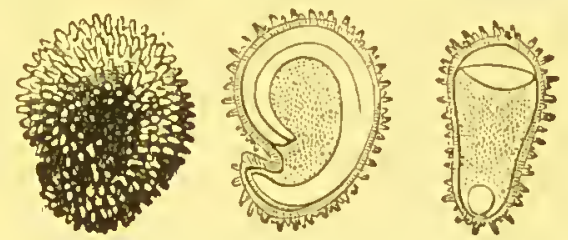

FIG. 333.-Spiny seed of Stellaria, entire and cut through, both lengthwise and transversely, showing the campylotropous form, the curved embryo surrounling a copious endosperm (magnified).

1 [The term aril is, strictly speaking, confined to a structure of this kind which springs from the lilum, as in Passifiora, Taxus, Nymphan, \&c. A similar structure, originating at or near the micropyle, as in Euonymus, Euphorbia, Polygala, \&c., is a false aril or arillode; if from the testa, independent of the micropyle or funicle, as in Chelidonizm, Violu, \&c., a strophiole or caruncle. - ED.] 
bitter; the inner layer thin and white. The testa is often leathery, crustaceous, or even stony [as in the Brazil-nut]; and is either smooth (Fig. 33I), or with pit-like depressions. (Fig. 332), or covered with spines (Fig. 333), and may be white or coloured.

The mucellus of the seed consists essentially of an embryo, in addition to which is found in the majority of seeds an albumpn or endosperm (Fig. 333). Seeds are therefore distinguished into albuminous and exalbuminous. The embryo in its simplest form (Fig. 334), as in orchids, Orobanche,

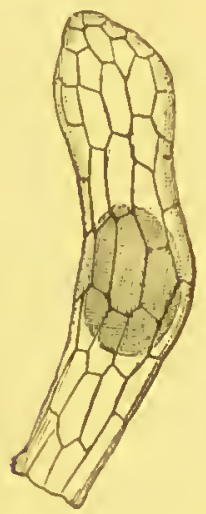

FIG. 334. - Globular embryo of Pyrola, with reticulated testa (magnified). Monotropa, and Cuscuta, is a spherical body; but as a rule consists of an axis (Figs. 97-99, pp. 70, $7 \mathrm{I}$ ) and one or more leaves. The axis is differentiated at its apex into a plumule, distinct from the lower end or radicle. The leaves of the embryo are in most plants very characteristic, and different in form from the foliage-leaves which are subsequently developed, and bear the name of seed-leazes or cotyledons. They are sometimes thin and leaf-like, sometimes thick and fleshy. The green colour which many cotyledons assume as soon as they rise above the ground after germination is only developed under the influence of light; it is not found while they are still enclosed in the testa. The thicker and more fleshy cotyledons which often occupy the greater part of the seed, as in Leguminosæ, have scarcely anything in common with the later foliage-leaves of the plant, and generally remain underground after germination. Dependent . on the number of cotyledons, plants are divided primarily into Dicotyledones with two, Monocotyledones with only one, and Acotyledones [flowerless plants], without any. A larger number of cotyledons than two is rare, and is peculiar to certain Coniferæ (Fig. 335). In a few cases, as the 
pea and bean (Fig. 98, p. 70), the embryo contains a few other leaves besides the cotyledons.

The relative position of the different parts of the embryo requires special notice. The most common arrangement is that found in Crucifer:e, where the embryo is pleirortizal, the cotyledons lying flat one upon another, and the radicle upon the line which separates them (Fig. 336). In the notorlizal embryo (Fig. 337), the radicle lies upon the back of one of the cotyledons, which again lie flat one upon another. The embryo is orthoplozic (Fig. $338)$ when the radicle lies in the hollow channel of

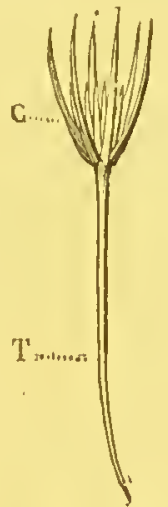

Fig: $33.5 .-\mathrm{Em}$ bryo of Scotch fir, with six cotyledons, $c$.

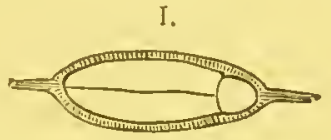

II.

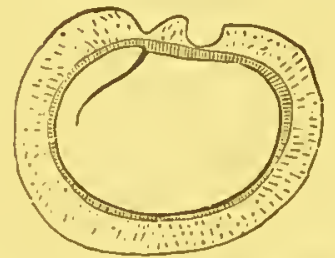

FIG. 336. - Pleurorhizal embryo of Lumariz; 1 . transverse ; II. longitudinal section through the seed (magnified). the folded cotyledons. In the spiral embryo (Fig. 339),

I.

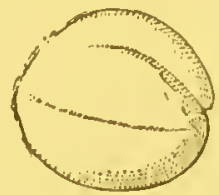

II.

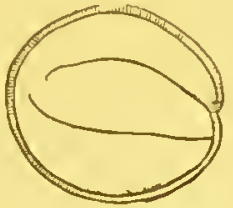

III.

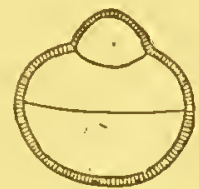

FIG. 337.-Seed of Nesler paniculata: I. entire; II., IIT., sections in two different directions showing the notorhizal embryo (mngnified).

I.

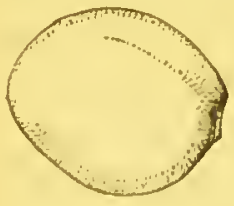

Fic. 338-Seed of Emen satiza: I., entire: II., IIl., sections in two different directions showing the orthoplozic embryo (magnified).

II.
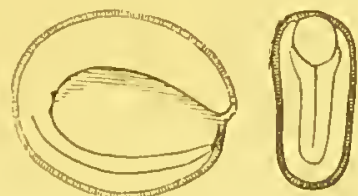

III. the cotyledons are laid flat upon one another and coiled spirally. Occasionally the embryo is doubly spiral.

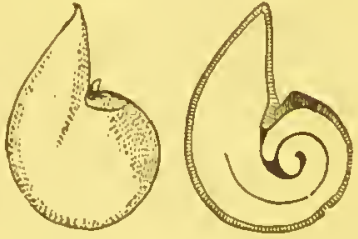

F1C. 339.-Spiral embryo of Bunias Emicago (magnified). 
The position of the embryo in the endosperm also varies in different plants. It sometimes lies in the middle of the endosperm, when the latter is said to be peripheric (Fig. 340), as in Iris; sometimes outside it, when it is said to be

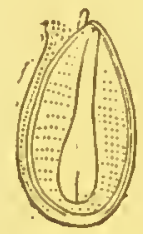

FIG. 340. - Peripheric endosperm surround. ing the central embryo in the pansy (magnified).

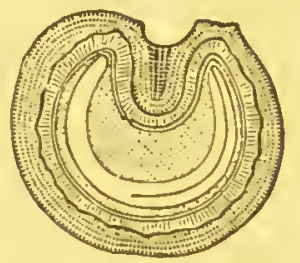

FIG. 34I. - Lateral embryo of Menispermum conadense (magnified).

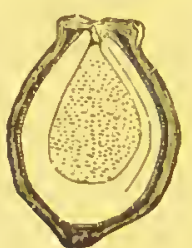

FIG. 342. - Peripheric embryo surrounding the central endosperm in Mirabilis Falapa (magnified).

opposite the lateral endosperm (Fig. 34I); or peripheric and the endosperm central (Fig. 342). The texture of the endosperm also varies greatly; in the cereal grasses it is. farinaceous or starchy, in the coffee-berry cartilaginous, in the vegetable ivory, Phytelephas, hard and white like ivory.

\section{CHAPTER V.}

THE LIFE OF THE PLANT.

THE life of a plant is in general apparently much more simple than that of an animal. Its vital phenomena are, however, in both cases, the result of the concurrence of two factors-its internal structure with the faculties belonging to this structure, and its external environment.

The theory is founded on a number of delicate experiments which cannot here be described, that.all organised parts of plants consist of minute, solid, and crystalline particles called molecules or micella, which cannot, however, be distinguished by the most powerful lenses. This hypothesis does not assume that the molecules must always be spherical ; they are often, on the contrary, supposed to have a crystalline structure. The adjacent molecules are not united by any solid 
connection, but are isolated one from another, and the reason of the solid condition of a body is that its molecules have a mutual attraction for one another; and the stronger this attraction, the more firm and solid is the body which they compose. Every molecule is in its natural state surrounded by a layer of water, so that they are com. pletely separated from one another on ail sides. Within certain limits. a portion of their watery contents can be removed from organised structures, or they can take up fresh quantities, without being thereby destroyed or killed. Loss of water or desiccation causes a contraction, the absorption of water an increase or swelling of the borly. The molecules of one and the same organised body separated by envelopes of water always differ chemically, so that molecules of a different chemical nature are found in the midst of and beside one another at every point that can be perceived by the microscope.

THE MOVEMENT OF WATER IN PLANTS.

It follows as a necessary consequence from the structure of organised bodies, that life is impossible in the most minute particles of the plant without access of water. The plant also requires water for the formation of organic substances out of the inorganic food-materials which it takes up, and furthermore, for the solution of solid substances stored up in it, the reserve-materials, which must be dissolved and transported to other places, where they are consumed. In addition to this the leaves lose in a short time a considerable portion of the water of their cell-sap by evaporation. In order to meet all these requirements, it is necessary that continuous currents of water should pass through the plant, and should be directed towards those parts where the plant requires it. The water, therefore, which is sucked up by the root-hairs flows through the roots like a system of rivulets, combining into larger streams or into a single current; and these then again ramify like the stem, and distribute themselves to the most delicate parts of the leaves, where the water again disappears in the form of vapour, by transpiration. It has been ascertained that 
in actively growing plants the quantity of water thus absorbed often amounts in a few days to many times the weight and volume of the whole plant. In true woody trees and shrubs, belonging to the Dicotyledons and Conifers, the less lignified portion of the alburnum serves especially as

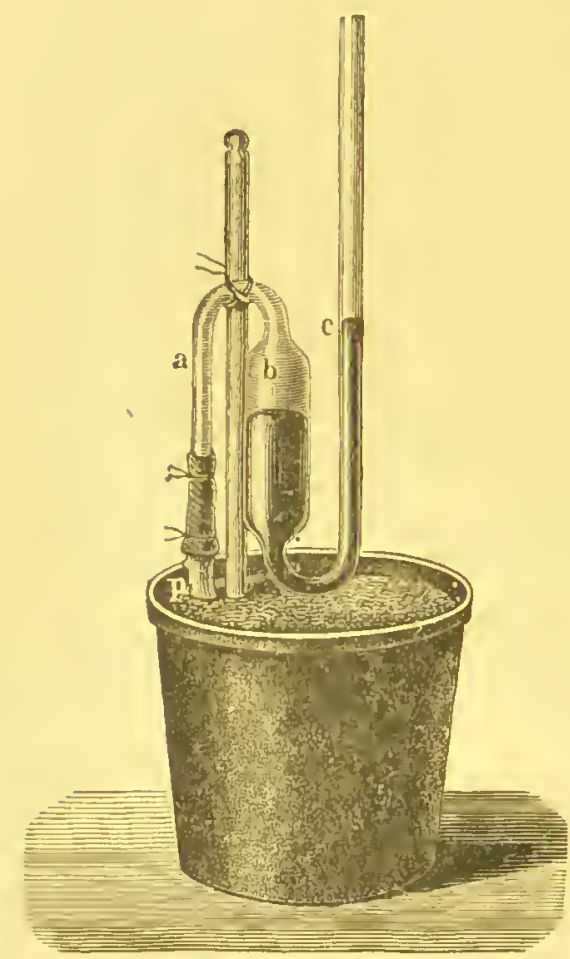

FIG. 343.-Apparatus for measuring the root. pressure. A inanometer, $a, b, c$, is fixed into the upper part of the plant $p$ growing in a pot, the top having beer cut off. The difference in the height of the mercury in the two arms $b$ and $c$ indicates the intensity of the pressure by which the water sucked up by the roots is forced out at the cut section. the conduit for this powerful stream; in Monocotyledons, treeferns, and many herbaceous Dicotyledons, the woody parts of the vascular bundles. But the current is not confined to these parts, occurring also, though less actively, in the unlignified tissues, and in the substance of the cell-wall itself. The chief causes of these great movements of water are : capillarity, and diffusion or osmose. Acting in conjunction with this force is the root-pressure. The roots absorb a greater quantity of water than the plant requires; and this, therefore, exercises a pressure which drives the water that has been already absorbed higher and higher up the stem ; and often, as in Grasses, Aroidex, \&c., even causes it to exude in drops at the margins and tips of the leaves. Experiments on the intensity of the root-pressure, performed 
by cutting off the upper part of the stem, and attaching a manometer to the section, show that it is sufficiently powerful to balance a column of water more than ten metres in height (Fig. 343).

The organs of transpiration are the leaves, which allow of the escape through their stomata of the aqueous vapour that has accumulated in the intercellular spaces. The amount of transpiration depends on the moisture of the air, on the intensity of light, on the temperature, on concussions to which the plant is subject, and on the age and size of the leaves. It has not yet been ascertained how all these forces act; observation has nevertheless shown that the stomata are closed at night and open in the day-time under favourable circumstances, i.e. when the atmosphere is not too moist, and under the influence of light and warmth.

If the loss of water by transpiration from the leaves is greater than the quantity supplied by the roots, the conducting parts becone first of all deficient in it; and when at length the evaporation from the more delicate organs can no longer be compensated, they lose their stiffness and hang down from their own weight, or in other words wither. This condition is caused at an earlier period in herbaceous plants than in succulent plants or trees which possess large reservoirs of water in their stens.

[The fluid which is contained in the alburnum of Dicotyledons is of a watery character, containing dextrine and sugar, but not starch, chlorophyll, or any colouring matter. It may also contain matters dissolved out in its course through the tissues, as well as mineral salts absorbed by the roots. This fluid is called crude sap, and occurs in special abundance in the spring. At this season it flows freely out from incisions made in the bark, as in the process known as the 'bleeding' of vines, \&c. In the leaves this crude sap becomes converted into elaborated sap, which, in its descending current, produces the cambium and other formative tissues.]

\section{ASSIMILATION AND METASTASIS.}

The life of the plant is associated with a continual consumption of plastic substances, which are of service to it as formative materials for the growth of cells already in existence, and for the production of new ones. A number of the sources of force in the plant are being continually lost through these processes, because many of these forniative 
substances then cease to exercise their chemical influence on one another. If the plant is not to perish from the deficiency thus occasioned of formative materials and of sources of force, or, as it were, to be starved, it must be supplied with nutrient substances, i.e. with chemical compounds which contain the substances that it requires. Only in comparatively few cases is a chemical compound absorbed into the plant which will be useful to it without change; as a rule, it is only the separate elements which are indispensable, and are on that account taken up out of their compounds. Those elements which are indispensable for the entire processes of vegetation are called the mutrient substances of the plant.

If we pass in review the elements which play this part in the vegetable kingdom, we find that the list comprises carbon, oxygen, nitrogen, hydrogen, and sulphur, because these enter into the composition of protoplasm, and are consequently necessary for the formation of every vegetable cell. 'To them must also be added iron, calcium, potassium, magnesium, and phosphorus, because no instance is at present known of a plant retaining its normal state of health if deprived of any one of these elements. Sodium and chlorine must also probably be included. In addition to these universally distributed nutrient materials, the growth of some plants is also dependent on the presence of other special elements; although we have no exact knowledge of the part which they play, and are unable to state positively that they are indispensable. Thus Viola calaminaria and some other plants always contain zinc, and will only grow on soil which contains that element.

The organ by means of which the nutrient substances are taken up is, in the lower plants, the entire surface; in the higher plants this function is specially assigned to the root, which is constructed for this purpose. In the case of roots which penetrate into the soil, only the youngest parts, with their delicate root-hairs and papilla, can perform this function; but in the aërial roots of some 
plants, which are provided with a great number of hairs or with a root-sheath, the whole surface of the root appears to possess the power of absorbing nutrient substances in the form of vapour.

In addition to the roots, the higher plants possess also in the leaves organs which are adapted for the absorption of nutrient substances in a gaseous condition. But experimental observation has shown that the leaves, under ordinary circumstances, do not absorb fluid nutriment, either in the form of drops or of vapour, so as to carry it to the other parts of the plant.

Since the nutrient substances must pass through the chosed walls of the cells in order to reach their interior, it follows that they must be present in a dissolved fluid or gaseous form. They are then received into the cells adapted for this purpose by means of osmose; since there are in general two fluids, the cell-sap and the water absorbed from the soil, capable of mixing with one another, and separated only by the permeable cell-wall. 'The absorption of nutriment is, therefore, only a mixing of two fluids of different densities.

The terms osmose, diosmose, and diffission have been given to the mingling of fluids through a permeable partition-wall, i.e. one which lias no visible perforations. If, for example, a vessel closed below by an animal membrane (Fig. $344 b$ ) is filled with a concentrated solution of cupric sulphate (blue vitriol), and is then immersed in a vessel filled with water (n), the water will pass gradually through the bladder into the vessel $b$, and the fluid will rise in a tube $r$ attached to it, whilc the level at $n$ falls. If, on the contrary, the cupric sulphate wcre placed outside, and the water within the vessel $b$, the fluid would fall in the tube $r$, while the level $n$ would rise. In both cases a small quantity of the cupric sulphate also passes through the bladdcr into the watcr, as may be secn by its colouration, but a very much larger quantity of water passes the other way. The process will continuc until the two fluids on each side of the bladder have become homogeneous. The cause of the incrcase of the fluid on one side, and the decrease on the othcr side of the bladder, is that the watcr passes more easily through it than the solution of cupric sulphate docs. But in other cases a very considerable 
interchange of the two fluids may take place without its being perceptible ; viz. when they are of the same colour and pass through the partition-wall in equal quantities. When two fluids are capable of diffusion--

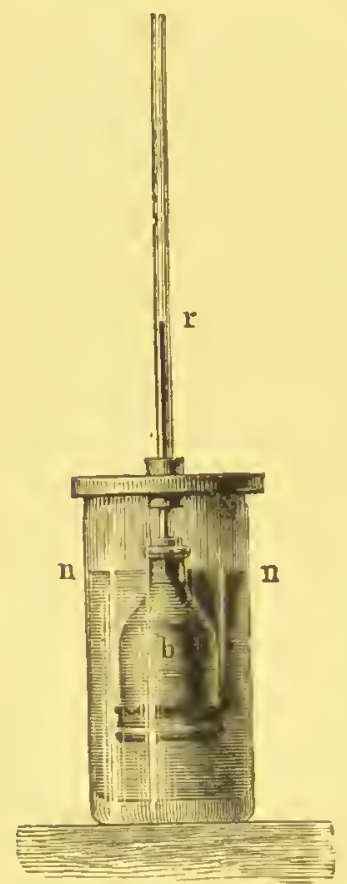

FIG. 344.-Apparatus for measuring osmose : $b$ a vessel filled with cupric sulphate closed below by a permeable membrane, and placed in a vessel of water. As the water passes through the bladder to mingle with the cupric sulphate the level of the fiuid will rise in the tube $r$ in connection with the vessel $b$, but will fall at $n$ in the outer vessel. which is not always the case-a greater quantity of the less concentrated or lighter fluid usually passes through than of the more concentrated or denser. Cell-walls act in the plant exactly like an animal bladder in the instance adduced. In the process just described, the current which passes into an enclosed space such as a cell is. termed an endosmotic, that which passes in an opposite direction an exosmotic current.

Since the cell-sap is much richer in substances which cause osmose [or is of a greater specific gravity] than the moisture of the soil, which contains in solution only a small quantity of salts, gases, \&c., a considerable endosmotic current is set up of the absorbed moisture into the cell, while only a very small quantity of the cell-sap passes out into the ground. This last process has, however, nothing in common with the elimination of products of excretion which takes place in animals; its purpose is rather to render soluble the insoluble constituents of the soil, and thus to enable the plant to absorb them in the water which it takes up. The membranes of the apices of roothairs of plants which are still in active growth are so delicate that, in obedience to the force of gravitation, they come into intimate contact with all the unevennesses of the adjacent solid particles, and afterwards, by the hardening of the membrane, actually unite with them (Fig. 345). And since experiment has shown that the cell-sap is almost always acid, its passage into the ground causes the 
particles of soil with which the roothairs have united to be gradually dissolved at the points of union, so that they can then be taken up into the plant.

WWith regard to plants growing in the soil, the nutrient power of the roots is greatly increased by the singular property of the circumnutation of the rootlets, discovered by Darwin, by means of which their tips are constantly brought into contact with fresh particles of soil.]

The mode of nutrition of parasites is different from this. The roots of the more highly organised parasites, such as the mistletoe and the broom-rape, Orobanche, penetrate into another plant which is termed their host (Fig. 346), and take up from it nutrient substances which have already been to a certain

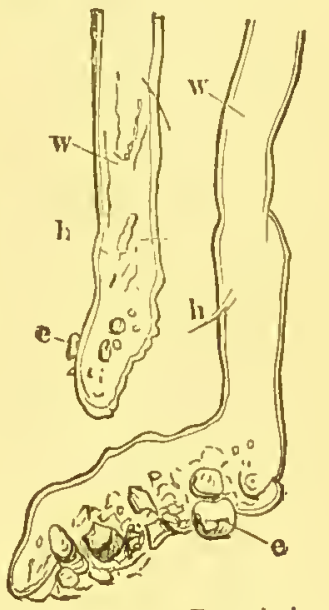

FIG. 345.-TU Root-hairs of a seedling of wheat growing in loam, which have taken up minute stones and particles of soil $e ; h$ smaller roothairs. $(x 800$. extent assimilated. The lower parasites, such as certain Fungi, on the other hand, pierce by their cells the membranes of other cells, in order to live in and on them (Fig. 347). The mode of absorption of food-material and of the nutrition of saprophytes [or plants which live on decaying organic substances], such as Monotropa Hypopitys and certain Orchider, is still in doubt. The characteristic of these plants is that their absorptive organs take up certain products of the decomposition of organic substances, termed humus, and bring them again into requisition for nutrition, after undergoing some change.

Plants do not absorb the nutrient substances which are adapted to them unless presented to them in a suitable form; they do not for example, imbibe the free nitrogen of the atmosphere. Experiments, in to the details of which we cannot enter, have given on this point the following results :-

The source of the carbon in those plants which contain 

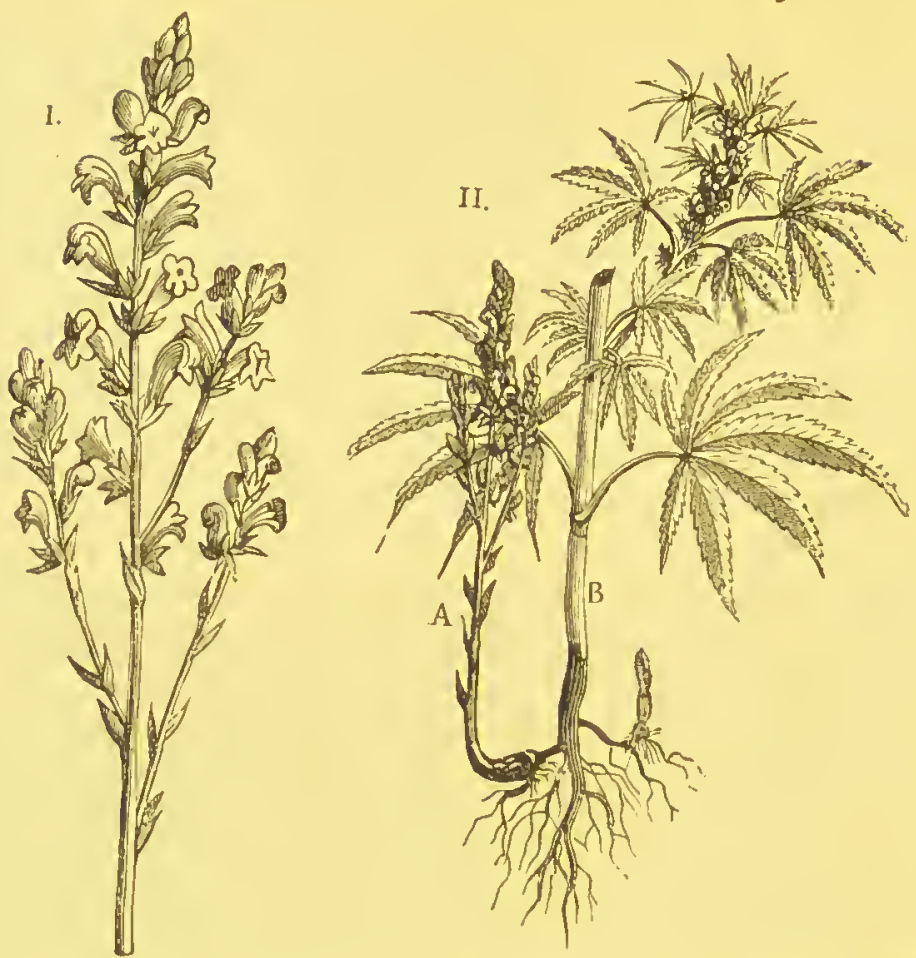

FIG. 346.-I. Orobanche ramosa (about one-third natural size); II. the same plant A parasitic upon the roots of a plant of hemp B (greatly reduced).

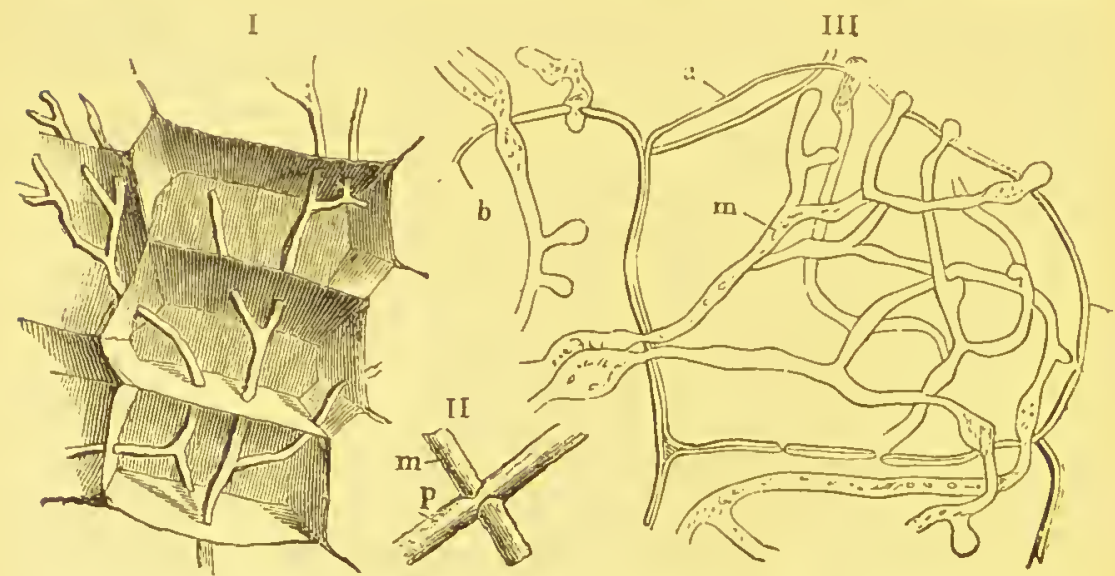

FIG. 347.-I. Diagram in perspective of the mnde in which a Fungus-hypha penetrates through several cells; II. point at which a Fungus-hypha $p$ has pierced through a cell-wall $m$; III, $a$ parenchymatous cell from a rotten turnip $b$ part of an adjacent cell ; both cells are penetrated by Fungus-hypha, $m$; a Fungushypha is in the act of piercing into cell $b .(x 200$. 
chlorophyll, and which are not parasitic, is mainly, if not exclusively, the absorption of carbon dioxide (carbonic acid gas) by those parts which contain chlorophyll, and its decomposition under the influence of light, the carbon being retained and the oxyger again given off. It is indisputable that in certain cases the humus can also contribute a supply of carbon for the nutrition of the plant; but the fact that in a soil which has not been affected by cultivation, as in a primeval forest, the stratum of humus does not diminish, but rather constantly increases, notwithstanding its continual decay and its consumption by plants and animals, shows that a much greater quantity of carbon must be derived from the atmosphere than from the soil.

Hydrogen, which, like carbon, is present in every organic compound, enters into non-nitrogenous combinations only through the decomposition of water; in those which contain nitrogen possibly also by the absorption of ammonia.

Oxygen is taken up into plants along with the elements already mentioned, the substances in which they occur being of such a nature that a large portion of their oxygen must be given off before they can be of any further use to the plant. The decomposition of the carbon dioxide of the atmosphere is a remarkable illustration of this. But, notwithstanding this excess of oxygen in the plant, the oxygen of the atmosphere is also absorbed; not, however, in order to form a part of any permanent compound, but, on the contrary, in order to decompose the substances contained in the plant, to deprive them of at least a part of their carbon, and to be again evolved as carbon dioxide. This process, the true respiration of plants, is very important; since it is always taking place in all living cells without exception; and the action of the inhaled oxygen is a necessary condition of the life of the protoplasm, and therefore of the plant. In relation to this, the experimental fact is of the greatest importance, that plants placed in pure carbon dioxide are suffocated, just as animals are. In some flowers 
and inflorescences, the production of carbon dioxide by the inhalation of oxygen is very energetic; and since the radiation of the heat produced by the oxidation is in these cases insignificant, from the surface being comparatively small or the parts protected by enveloping sheaths, very. considerable elevations of temperature can be observed. At the time of the fertilisation of the spadices of Aroider, an elevation of temperature amounting to as much as $10^{\circ} \mathrm{C}$. has been detected; and in the flowers of Cucurbitaceæ and of Victoria regia similar elevations have been observed, though to a smaller extent. Respiration is a process diametrically opposite to the process of assimilation which takes place in the cells that contain chloropliyll, and which consists in the absorption and subsequent decomposition of carbon dioxide, although this latter has also been described under the same name, a use of terms as incorrect as if we were to speak of an animal inhaling its food.

The free nitrogen of the atmosphere enters the plant through the stomata, and also by the process of osmose, but does not serve for nutrition; for the purpose of nutrition this element must be presented to the plant in the form of nitric acid or of an ammoniacal salt. Whether non-parasitic plants absorb nitrogen also in the form of certain organic compounds is still undetermined.

The only conceivable source of sulphur is the sulphuric acid of the sulphates present in the soil. It probably enters the plant only in the form of calcium sulphate, which is decomposed by the oxalic acid formed in the plant itself; this being the source, on the one hand, of the calcium oxalate, which so commonly occurs in plants [in the form of raphides], while on the other hand the sulphuric acid gives up its sulphur in the production of protoplasm and generally of albuminoids.

It is evident that the remaining nutrient substances can only enter the plant by the process of diffusion, and in general in the form of soluble salts; but their relations to the life of the plant are still obscure. With regard to iron 
we can form some judgment, since we know that its presence is necessary for the production of chlorophyll. Plants which grow in soil destitute of iron do not become green, but remain bleached or etiolated until enabled to do so by the addition of iron to the soil; though it is doubtful whether chlorophyll contains iron as one of its essential ingredients. Since etiolated plants, owing to the absence of chlorophyll, are unable to absorb carbon dioxide, they can live only for a short time, and soon perish. The salts of iron present in the soil afford the necessary supply of this element for vegetation. Phosphoric acid appears to stand in a certain relation to the production of albuminoids, or at least, is invariably found in association with them; and in many seeds there is a constant relationship between the weight of the phosphoric acid and that of the nitrogen contained in them. With respect to potassium, similar general relationships to starch, sugar, and cellulose are not improbable; and it is known that the amount of potassium in any part of a plant varies with the rapidity and energy of its growth. But in what form phosphoric acid and potassium enter the plant, and what their special functions are, is still unknown. Silicic acid, which constitutes the greater part of the ash in many plants, as, for instance, the stems of cereals, cannot be considered a nutrient substance in the same sense as those already described; since it has been proved by experiment that it is not absolutely necessary to the growth of these plants, and its presence appears to be only a favourable condition to their perfect development. Iodine is taken out of the sea-water by marine plants.

[The remarkable phenomena connected with Camivorous Plants have only recently been fully investigated. A few plants belonging to widely separated natural orders, the best known of which are Drosera, Dionaa, Pinguicula, Nepenthes, and Sarracenia, have the remarkable power of absorbing through their leaves substances containing nitrogen, by a process of true digestion, precisely analogous to the digestion of animals, due to the presence of a ferment identical with pepsin. The 
singular movements of some organs connected with this process will be referred to hereafter : they afford in some cases an extraordinarily delicate test for the presence of nitrogen. The phenomenon is accompanied by remarkable changes in the form and appearance of the protoplasm-body in the cells contiguous to those which are directly concerned in the absorption of the nutrient matter.]

If plants are grown in fluids which contain all the substances necessary for their life, it is found that these substances are not taken up in quantities dependent on the concentration of the fluid, nor on the proportion of the various substances contained in it ; but that different species of plants, on the contrary, supply their needs from the same fluid in different ways. In consequence of this phenomenon, which depends on causes at present unknown, a quantitative 'selective power' has been ascribed to plants. With reference to the peculiarity that-setting aside nitrogenous food-materials-different species take up in preference different nutrient substances, plants may be distinguished as calcareous, alkaline, siliceous, \&c. Leguminosæ, for example, are specially dependent on lime, potatoes and turnips on potash, all plants in which the seed is remarkably developed on phosphoric acid, cereals and grasses generally on silica, \&c.

The cultivation of crops withdraws from the soil immense quantities of substances; so that sooner or later the moment must arrive when the produce will diminish, and at length altogether cease, unless those constituents of the soil which the crops have withdrawn from it be replaced. The object of the agriculturist must therefore be so to. work his ground that the soil never becomes exhausted, but that heshall constantly obtain abundant crops and an adequate interest on his capital, the soil. There are two modes of securing this : by a carefully selected succession of different crops, and by manures. He must of course in addition depend on a suitable mechanical working, loosening, and irrigating of the ground.

In consequence of the selective power of plants, a succession of a number of crops of an alkaline plant causes the soil to become for a time-and at length when all the alkalies have been consumcd, pcr- 
manently - unproductive for plants of this description. But while the alkaline plant has the power of withdrawing an unusual proportion of alkalies from the soil, it leaves all the other nutrient substances com. paratively untouched. These substances therefore accumulate in the soil, the small consumption of them being outweighed by the decomposing influence of the atmosphere, which is constantly reducing to a soluble condition small quantities of soil, and thus rendering their constituents available for nutrition. The substances which are thus made available for the plant are retained by fertile soils, and thus their solu. tion by rain, \&c. ensured for at least a sufficient time for the whole of the soil to become completely saturated by them. It is, therefore, essential to good agriculture that the crop of the alkaline plant should be followed by one of another lind, say a siliceous plant; and thus a well-chosen succession of different crops will remove from the soil one substance after another. This rotation must be continued until the substances first withdrawn are restored in such proportion and distribution that the same series of crops may again be grown. In former times the influence of the atmosphere on the soil was utilised by cultivating only a portion of the soil, the rest being left untilled or fallow; but it is now acknowledged that this mode of agriculture is not economical. In those districts where it pays to cultivate large tracts of land, no considerable portion is now left fallow; but the object is, by a good rotation of crops, to use up as equally as possible all the constituents of the soil. Even under the best system of agriculture, however, the soil must become gradually exhausted, and this exhaustion must be artificially counteracted. This purpose is effected by a scientific system of manuring, by which those substances are supplied to the soil of which it has most need. According to circumstances the most various organic and inorganic substances may be employed as. manures. If, for example, there is a deficiency of nitrogenous substances, an addition of nitrates or guano is made. We cannot here enter further on the physical changes in the constitution of the soil, often so advantageous or even indispensable to vegetation, caused by the rotation of crops and by manuring. Care must on the other hand be taken not to impart to the soil such substances as are injurious to. vegetation. Manuring with chlorides such as sodium chloride (comnon salt), for example, while increasing the weight of root-crops, has a decidedly injurious effect on their quality.

The nutrient substances taken up by plants are, however, by no means adapted, in the raw state, to take part in the construction of any vegetable structures; they must, on 
the contrary, undergo important transformations, and become clianged into organic compounds suitable for nutrition. This process of assimilation may be compared to the digestion of food by animals, i.c. to its conversion into blood; but still differs greatly from that process, since the animal takes up organic compounds already existing as such, which have only to undergo change, while plants have to construct more highly complicated out of simpler compounds, or, possibly, even out of their constituent elements. The fact that the compounds which are absorbed into the plant are usually very rich in oxygen, while the substance of the plant itself contains only a small proportion of that element, shows that assimilation must be a process of deoxidation or of elimination of oxygen. It can, therefore, take place only in those cells which contain chlorophyll, and under the influence of light; because it is only in those parts of the plant, and only under the action of sufficient light, that oxygen is given off. The leaves are, therefore, the principal organs of assimilation.

It is not at present possible to follow step by step the process of assimilation; it seems to depend mainly on the following forces : ( I) the evaporation of the water contained in the nutrient sap by transpiration; (2) the decomposition of carbon dioxide and the fixation of carbon; (3) the formation of albuminoids which are essential for the production of protoplasm and chlorophyll ; 4 ) the formation of the substances from which cellulose is produced, viz. starch, the different kinds of sugar, oil, and inulin.

Since the growth of plants can take place only at the expense of assimilated substances, it is of the highest importance that a number of the products of assimilation should be transported from the places where they are produced, and made to take their part in the vital processes of the plant; and they have therefore to be stored up at certain points, in order to serve, as required, as rescrec-matcrials. Some of these reserve-materials are, for example, again dis- 


\section{The Life of the Plant.}

solved in the spring at the commencement of the period of vegetation, and thein employed in the production of new organs, especially the leaves.

The decomposition of the carbon dioxide contained in the atmosphere is the main source of the carbon requred for building up the tissues of plants. Only those cells which contain chlorophyll, and then only under the influence of sunlight, have the power of decomposing the carbon dioxide which they take up, and of producing organic compounds out of its elements and those of water, with elimination of an equal volume of oxygen, or in other words of assimilating. It is highly probable that in this process the carbon dioxide loses only one half of its oxygen, the other half of the oxygen which is evolved resulting from the decomposition of water. It is only living chlorophyll that has the power of decomposing the carbon dioxide; and in general both sides of the leaf take part in this process, though with different energy. Light and beat are absolutely necessary for it ; a small deficiency of heat may be compensated by more intense light, but there are limits which cannot be passed (see Fig. 373, p. 213). Plants which do not contain chlorophyll have no powver of decomposing carbon dioxide, and hence of assimilating; they must therefore obtain their nutriment from substances already assimilated; and hence grow either on or in animals or other plants as parasites, and obtain their nutriment from them, or live [as saprophytes] on organic substances actually undergoing.lecomposition, and absorb their organic constituents before they are completely decomposed.

The mode of formation of albuminoits is still unknown; it has not even been accurately ascertained at what spot they are produced. The most probable solution is that they are formed at those spots where calcium oxalate is stored up, because this salt is formed by the decomposition of calcium sulphate, the sulphur of which passes over into the albuminoids (See p. I68).

Neither is it yet known how cellulose is formed, although access of atmospheric oxygen appears essential to its production. It is tolerably certain that starch, sugar, inulin, and oil are the materials out of which the protoplasm constructs the cell-wall ; at least substances of this description which are stored up in the cells always disappear when an energetic formation of cellulose is going on.

Starch is invariably formed originally within the grains of chlorophyll. Light is necessary for this ; but the very small intensity of light which suffices for the formation of chlorophyll is not sufficient for that of starch or of the drops of oil which sometimes replace it. In direct sunshine starch is produced in the green parts of plants almost at the very. 
moment in which the rays of light fall upon them; and in cliffused daylight after a short time. Plants grown in the dark, and therefore etiolated, develope chlorophyll first when exposed to light, and then starch in the cllorophyll-grains. In the dark, starch is transformed into - other nearly related but soluble substances, such as sugar, dextrin, \&c., which become distributed through the whole plant, and is again fixed in the form of starch as a reserve-material at particular places, as in the grains of cereals, the tubers of the potato, \&c. Whether or to what extent the nitrogenous constituents assist in these processes is still unknown.

The processes of life cannot be conceived as going on, even in unicellular plants, without a continual movement of those substances which are necessary to their life. In the most simply organised plants these processes are simple, but become more complicated as we ascend in the scale.

The direction in which the assimilated substances move varies according to the vital needs of the plant. They can be transported from the places where they are formed directly to those where they are required, or to reservoirs of reserve-material, where they are stored up until they are again carried to the parts where they are consumed. Hence perennial plants have their chief reservoirs in their stems, rhizomes, bulbs, or tubers; while those which do not bear fruit more than once have the greater part of their assimilated substances stored up in their seerls.

It may be taken as nearly certain that in plants higher in the scale than Mosses, in most if not in all cases, the transport of the assimilated nutrient sap takes place through two forms of tissue. The soft-bast is chiefly, though not exclusively, the conducting tissue of the albuminous mucilaginous alkaline compounds; while the parenchyma, both of the cortex and of the pith, is the chief agent in the conduction of non-nitrogenous substances, such as starch, sugar, inulin, oils, and acids. The laticiferous and the utricular vessels also contain reserve-materials of a different kind, which can be made use of when required ; but the movement of the fluids contained in them is more sluggish than in a small-celled tissue. 
The experiments of Hanstein were the first to prove this print. From the cut branches of various dicotyledonous plants he removed, above the cut surface, a circular piece of bark, and then placed the branch in water. The result was that in those species which possess no isolated vascular bundles, no cambium cells, and no sieve-tubes in the medullary sheath, no roots sprang from below the place from which the bark had been removed, or at least very few in proportion to the size of the piece of bark below; while above that part a large number of strong roots were formed (Fig. 348). In those plants, on the other hand, like Alirabilis falapa and Amaranthus sanguineus, which have isolated vascular bundles in the pith, or, like Nerium Oleander and Solanum Dulcamara, cambium-bundles or sieve-tubes, an abundance of roots were formed even below the part where the bark had been removed. The conclusion is unavoidable that substances essential to nutrition are conducted only through the elongated cambiumor sieve-tube cells. In these cellbundles, however, non-nitrogenous substances occur only exceptionally, that is only at periods when large quantities must be transported in a short time; and in many plants they are never found there. The conclusion may hence be drawn that other groups of cells besides the elongated ones also take part in the transport of the

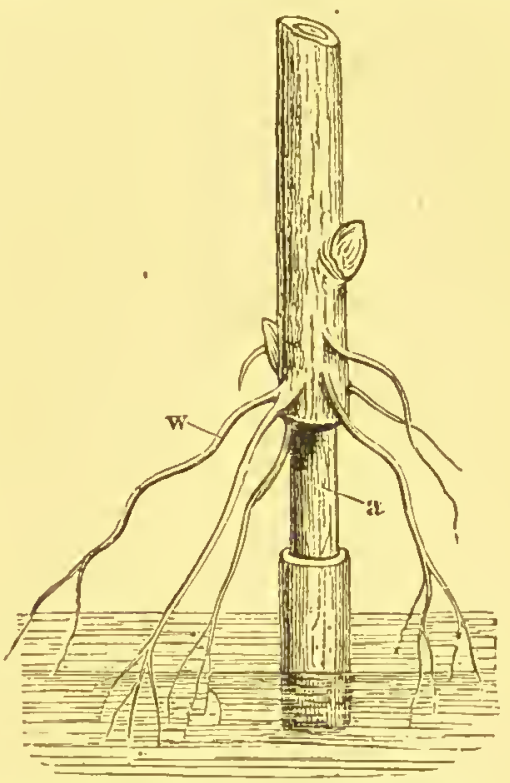

FIG. 348.-A cutting from which a ring of L. .rk has been removed placed in water; from above this place $a$ adventitious roots $w$ are developed. assimilated sap ; and these are most probably certain groups of parenchymatous cells which are distinguished by containing very fine-grained starch, and which can be recognised at once by this.

It follows from what has been said that the old view of an ascending sap in the spring and a descending current in the autumn, must be modified; that the sap certainly rises in the spring after the close of the winter's period of rest; but that this ascending current continues through the whole period of growth, as does also the descending current; and that, as need arises in the plant, horizontal currents also pass through its tissues. The old comparison between the circulation 
of the blood in animals and that of the sap in plants must therefore be entirely abandoned.

If now we inquire what are the causes of the movements of the assimilated nutrient sap, it is impossible to give a defmite answer, because the action of organised and living protoplasm introduces indeterminable factors. It may, however, be assumed that the law of diffusion in its widest sense is one cause of these currents. The movement in cells enclosed on all sides is brought about by two causes: the fore of osmose and the tension of the tissues, that is the force exercised on the conducting cells by the surrounding ones. The movement of the sap can take place more readily in intercommunicating tubes than in closed cells, as is seen in laticiferous vessels and sieve-tubes. Thus, for example, in the celandine, Chelidonium majus, the slight rise in temperature caused by the approach of the hand at the distance of an inch is sufficient to cause a current of latex towards the colder parts which may be perceived under the microscope. This movement is obviously occasioned by the pressure or tension which the swelling of the neighbouring cells exercises on the thin-walled laticiferous vessels. Other forces besides those already mentioned operate in these tubes, especially the curvatures and torsions of particular parts of the plant occasioned by the influence of light, gravitation, and the wind.

The products of assimilation, when transferred to other cells, and when brought into actual use, undergo a variety of changes which are included under the term metastasis or metabolism. Thus when the starch formed in the leaves of the potato is to be transferred into the tubers as a reservematerial, it must first be transformed into a soluble substance, viz. glucose. This glucose is distributed through the conducting tissues ; and being again transformed into starch in the cells of the tuber, all the starch gradually collects in these organs. By the close of the period of growth, all the chlorophyll-grains are also dissolved and carried in to the permanent organs, together with all the other substances which are subsequently to be employed. Many products of metastasis are of no further use in the construction of new cells, but remain stored up and inactive at the spots where they are produced. These are termed secondary products of metastasis, and comprise the volatile oils, resin, caoutchouc, 


\section{The Life of the Plant.}

gum-like substances, tannin, pigments, acids, alkaloids, wax, pectin, \&c. Other substances, known as degradation-products, are produced only by subsequent changes in the substance of organised structures; such are the mucilage of quince-seeds and linseed, and perhaps also lignin and cork (see p. 23).

The object of the processes of assimilation and metastasis, the nutrition of cells already existing and the formation of new ones, is at present known only in its most general features. The little that is known consists of the laws of cell-formation already mentioned, and of the fact that the cell-wall grows by intussusception, that is, by the formation of fresh molecules between those already in existence.

\section{REPRODUCTION.}

The great office assigned to vegetation of covering the surface of the earth with forms of organic life, and transforming inorganic into organic substances in order to support the life of man and other animals, requires that plants be endowed in a remarkable manner with the power of reproduction, that is, of producing individuals of the same species, in order that the short duration of all earthly life may not result in the world being soon deprived of its covering of vegetation, and all life perishing in consequence. For this purpose, particular cells of the plant begin, at definite times. an independent growth, and thus carry on a life of their own, often not in comnection with the parent plant. Such cells are called reproductive cells, and the plant which results from one of them constitutes a distinct generation. The successive generations are only rarely, as in some Algæ and Fungi, alike; as a rule, generations of a different kind follow one another. For example, a generation of the kind a will produce one of the kind $\mathrm{B}$, and this again one of the kind $\mathrm{A}$. 'This kind of development is called an alternation of generalions. 
Processes of reproduction are, again, of two essentially different kinds. While one class or group of reproductive cells are capable, without further preparation, of giving rise to a new plant, another class only have this power imparted to. them by other cells which stand to them in a relation of contrast. The former kind are termed in general non-sexual reproductive cells, the latter germ-cells or oospheres.

Reproduction by non-sexual reproductive cells [non-sexual reproduction] occurs in a variety of modifications, some less, some more perfect, and is variously termed reproduction by spores, gemma, bulbils, conidia, buds, gonidia, \&c.

The most common mode of multiplication in the lower plants is by means of spores. This term may, in general, be applied to all those simple reproductive cells which arise without any process of sexual union. In by far the greater number of cases they are simple cells enclosed in a single or double cell-wall, and formed at particular places, very commonly in special receptacles to which the name sporangia is given. The great variety that prevails in the form, function, permanence, and mode of formation of spores has led to the use of a number of special terms, of which those in most common use will be hereafter mentioned and explained. (See e.g. Figs. 394, 395, 400, 402.)

Conidia are scarcely distinguishable from spores; the term is applied especially to the non-sexual reproductive cells of certain groups of Fungi; they are always naked, never enclosed in a sporangium.

Gonidia are reproductive organs consisting of chlorophyllaceous cells; they are peculiar to Lichens, and are regarded as a peculiar form of lowly developed Algre. (See Figs. 4r 2, 4I3, pp. 287, 288.)

In gemme the cells are united into regular groups, and only in this condition detach themselves from the parent plant. They occur especially in the Muscineæ. In the Hepaticæ they are developed in special bowl-shaped conceptacles (Fig. 349); in Mosses, on the contrary, on the 
stem, rhizoids, leaves, and in short on all parts of the plant.

Special interest attaches to the mode of reproduction by means of buds. These are larger assemblages of dissimilar cells, and are moderately highly organised germs of new plants, inasmuch as they already consist of axial and foliar organs. They are also not distributed irregularly over the parent plant, like the reproductive organs already mentioned,

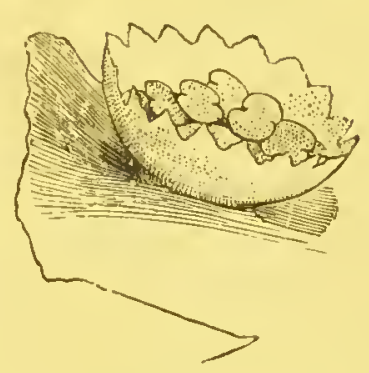

FIG. 349.--Conceptacle containing gemma of a Liverwort, Mlarclantia polymorpha (magnified).

but are usually attached to definite positions, being found most commonly in the axils of leaves. The mode of reproduction by buds is of the highest practical importance, and is made use of by gardeners in a great variety of ways, since by this means not only is the species but the particular variety propagated, which is not always the case in reproduction by seeds. To this class belong reproduction by bulbils, runners, cuttings, grafting, layering, and budding. In these processes, so different in their external appearance, reproduction depends simply on the further development of buds which have become spontaneously detached from the parent plant, or artificially separated from it.

Bulbils are endowed in a high degree with the power of independent life ; they become spontaneously detached from the parent plant, and, when they fall to the ground, continue to grow like seedlings. They occur especially in bulbous plants; in the hyacinth, for example, in the axils of the bulb-scales (Fig. I 22, P. 82), in some lilies in the axils of the

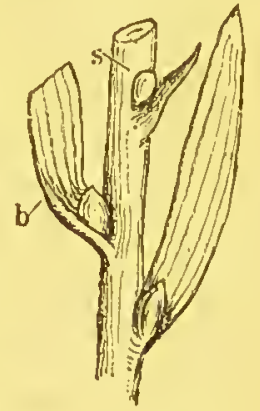

Fig. 350.-Stem of Lilizem bulbifemin; $s$ bulbils developed in the axils of the leaves b. foliage-leaves (Fig. 350), and in some species of Allium within the inflorescence. More rarely they are found on the 
surface of the leaf, as in Cardamine pratensis, [Bryophyllum], and some Ferns.

Multiplication by the division of underground [or aërial] stems, as in the Aster and couch-grass, Triticum repens, and by mnners, as in the strawberry, is so simple and so well known as not to require further description.

While in all the cases already described buds which

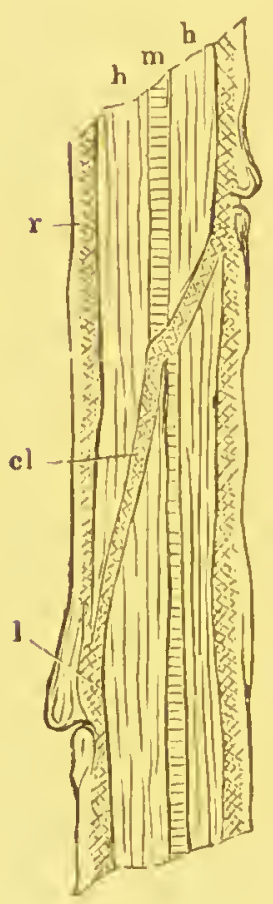

Fig. 351. - Diagrammatic representation of a longitudinal section through a graft ; $c l$ the callus; $r$ bark: $m$ pith. have separated spontaneously from the plant have at once a power of new growth; in cuttings, grafts, layers, and buddings, on the other hand, the wound caused by an artificial and violent separation must first heal. The formative cambium is. excited into activity, masses of succulent cells are formed, swell up to a certain extent between the innermost layer of

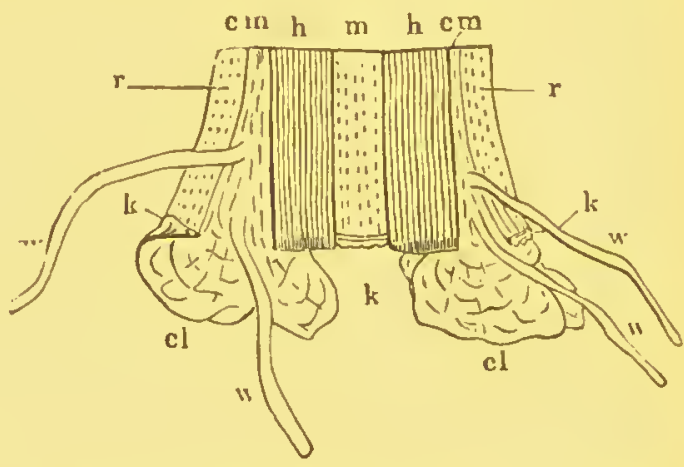

Fig. 352.-Diagrammatic representation of a longitudinal section through the lower end of a curting: $c t$ the callus; $c m$ cambium; $h$ wood ; $k$ cork $m$ pith : $r$ bark; $z u$ roots.

bark and the wooa, and spread laterally over the cut ends of both xylem and phloën, these latter taking no part in the formation of new tissue (Fig. 352). Thus is formed a spongy, cartilaginous, succulent cushion of tissue, known to gardeners as a callus. At the same time the outer wounded parts of the bark, and sometimes also the pith, are 
protected from further injury by a newly formed cork-tissue. In cuttings (Fig. $35^{2}$ ), i.e. cut branches planted in the earth, the roots are developed either through the tissue of the callus or near it, but always directly from the cambium. In grafting, layering, and budding, the cambium plays the same

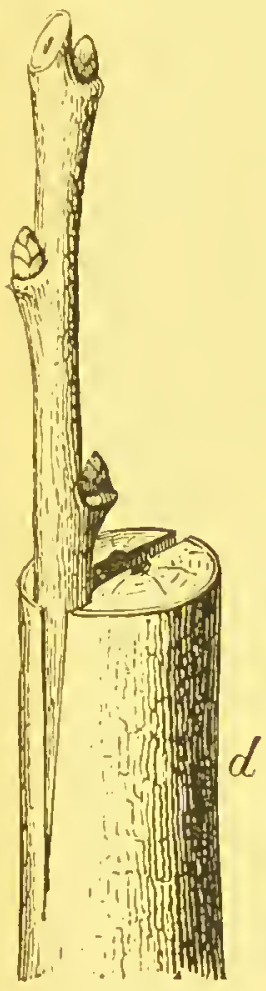

FiG. 353.-Grafting ; $d$ the stock to which the graft is attached. part as in the cutting, giving rise to the recuperative mass of healing tissue, or callus. This forces itself into the injured space between the bark and the wood (Fig. $35 \mathrm{I})$, fills it up in all directions, covers up the dead parts of the tissue, and causes those parts that are still active to coalesce with one another. The various modifications of this process are of greater interest from a practical than a scientific point of view. In grafting (Figs. 35 I, 3.53), a branch of a superior variety is planted on a stock
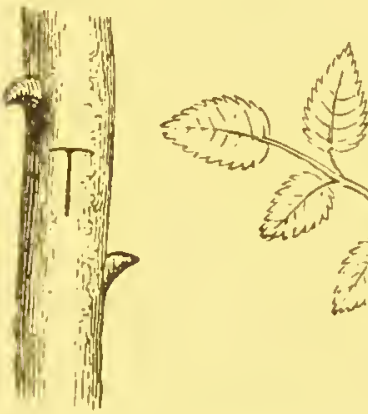

倍

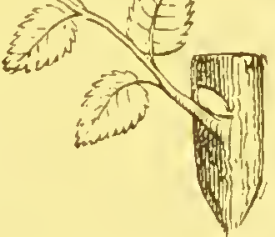

FiG. 354.-The various elements in the process of budding.

of a wild variety. In budding, a bud to which a piece of the bark is still attached is inserted into a $\mathrm{T}$-shaped incision beneath the bark of the stock (Fig. 354). In all cases the wounded part must be protected externally by wrapping round with bast and covering up with cotton-wool or some other substance from the injurious influence of the atmosphere. In these various processes the point of junction between the stock and the graft forms a boundary-line; all the parts 
developed above this line belong to the latter; all those beneath it to the stock. The graft is developed altogether spontaneously, without undergoing any essential change from the stock ${ }^{1}$; while the stock, if the buds formed on it are allowed to grow, developes its own proper leaves, flowers, and fruit.

This independent growth of a bud in contact with the stock of another plant takes place, however, only when the two belong to nearly related species. The peach can be grafted on a plum-stock, but not the rose on an oak.

Reproduction by means of oospheres or germ-cells is essentially different from the modes already described ; since here cells of two different kinds are necessary to produce the new plant by their mutual action the one on the other, the cells of each kind having no power of propagation in themselves alone. This process of mutual action is called fertilisation or impregnation, and involves a distinction between the fertilising or male, and the fertilised or female element; it is hence also known as sexual reproduction. The female element becomes, after fertilisation, the germ of the future plant.

Of the various processes of fertilisation we can here only describe that which is characteristic of all flowering plants or Phanerogams. The organs of reproduction-the male pollen, and the female ovule-are in them collected in the flower, and form its essential constituents, and fertilisation consists in the pollen exercising an influence on the ovule, by which a further development is induced in the latter. In those plants in which the ovules are enclosed in an ovary (Angiosperms) it is necessary that the pollen should, in the first place, fall upon the stigma. The period of maturity of the pollen and of the capacity of the ovule for fertilisation generally coincides with that of the expansion of the flower.

' [The graft and the stock do, however, exercise a certain amount of reciprocal influence the one on the other; and in certain cases hybrids or intermediate forms between the two are produced. - ED.] 
The anthers then open, and the pollen-grains (Fig. 355) are carried to the stigma, either by the wind [anemophitous], or by the agency of insects [entomophilous], or by peculiar movements (see pp. 203, 205) of the stamens or carpels, and remain attached to it in consequence of its exuding a viscid fluid. If we consider the immense number of pollengrains produced in any individual flower, and in addition the fact that a single one of these grains suffices for the

A

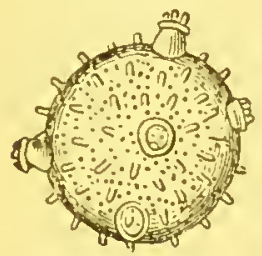

B

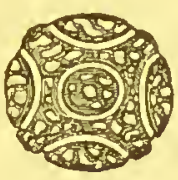

C

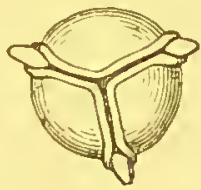

D

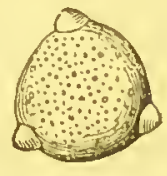

fertilisation of an ovule, it would appear at first sight as if ample provision were made in the majority of plants for this first act in the process of fertilisation, especially if attention is directed to the relative positions of the anthers and stigma. . Thus, for example, in most plants with pendent flowers, such as the fuchsia, the anthers are always placed higher than the long-styled stigma, so that in the act of pollination, that is, the dispersal of the pollen, some pollen-grains must almost inevitably become attached to the stigma.

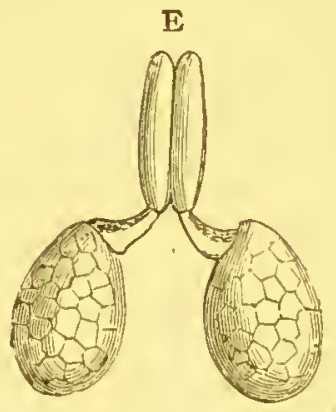

FIG. 355.-- Pollen-grains ; A Cucurbita: B Passiflora: c Cuphea platycentra ; D Dipsacus Finllonum: E pollenmasses (pollinia) of $C_{y \prime \prime}$ anchum vincetoxicum (Asclepiadeæ). But in spite of the frequent occurrence of such favourable arrangements, there are many cases in which fertilisation is impossible without foreign aid, as in the Orchideæ and Asclepiadeæ (Fig. 355 E), in which the pollen-grains are firmly united together by a viscid substance into a pollınium, and lie undisturbed in the open anthers. In these cases assistance is given by the host of insects which, in their search for honey, fly busily from flower to flower, 
penetrate to the nectaries, and unintentionally and unknowingly carry the fertilising pollen from one flower to another. In a large number of flowers, as, for instance, the Leguminosæ, other contrivances are also found, by mears of which the pollen is conveyed to particular parts of the bodies of the insects in their search for honey, viz. to those which must come into contact with the stigma when the insect visits the next flower. And since many insects, and especially bees-the most efficacious class in the fertilisation of flowers-habitually visit in succession a great number of flowers of the same kind, the pollen is not, as a rule, wasted by being carried to a flower of a different species. Too great importance cannot be attached to this function of insects; and many exotic plants, such as the vanilla, were long cultivated in our hot-houses without producing fruit, because the insects required for their fertilisation were wanting, until their place was supplied by artificial pollination.

In particular cases, in which fertilisation would otherwise be impossible, other special contrivances are found, especially in water-plants. When the pollen-grains come into contact with water, with a very few exceptions (as in Ceratophyllium and Zostera), they alsorb so much as to cause them to burst, or to occasion the escape of their contents from one of their pores so quickly that they perish. In order to prevent

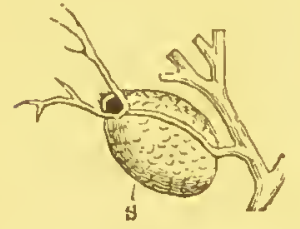

Fig. 356. $-s$ Pladder from a leaf of Utricularia vulgaris. $\left(x_{4}\right)$. this injurious effect it is almost invariably the case that submerged plants raise their flowers above the water, as in Sagittaria and Hydrocharis. In Utricularia (Fig. 356) the bladders on the leaves, which are previously empty, become filled with air at the time of fertilisation, raising the whole plant to the surface of the water, while it again sinkis at the close of the period of flowering. The most remarkable case is, however, presented by Vallisneria spiralis. The male flowers are seated on very short pedicels at the base of the leaves, often several feet below the surface of the water; the female flowers on the contrary on very long pedicels, which at a particular time become greatly elongated and raise the flowers to the surface of the water. The male flowers then become detached from their pedicels, rise to the surface, are floated among the female flowers, and fertilise them. After this has been accom- 
plished the pedicel of the female flower coils up spirally, and the fruit ripens beneath the water.

Notwithstanding that appearances would seem to point to the pistil being always pollinated by the stamens which surround it, more exact olservation has nevertheless shown that self-fertilisation of this nature does not, as a rule, take place, but that on the other hand cross-fortilisa. tion, i.e. a crossing between different flowers on the same plant, or between flowers on different plants of the same species, is much more frequently actually found in nature. Illustrations of this law are found in the phenomena of dichogamy and heterostylism, which are found to occur in so many plants.

By dichogamy is meant the maturing at different times of the reprocluclive organs.in a hermaphrodite flower. Dichogamous flowers are either proterandrous, when the pollen escapes from the anthers before the stigma in the same flower is ready for pollination, or protero. synous, when the stigma has lost its capacity for pollination before the pollen is mature, so that its pollination must depend on the pollen of older flowers. Most species of Geranium, Pelargouizm, Malva, Umbellifere, Compositæ, and Campanulacer, are proterandrous; while among proterogynous plants [which are much Icss common] may be mentioned species of Magnolia, Aristolochia, [Scrophularia, Plan$\operatorname{tag} o], \delta . c$.

Heterostylism consists in different flowers belonging to the same species having staI. II. mens and pistils (styles) of different lengths. Thus, for example, in the cowslip [and primrose], Linum pereune, and Pulmonaria officinalis (Fig. 357), two clifferent forms occur, the long-styled (I.), and the shortstyled (II.). This diffcrence in the form of the repro-

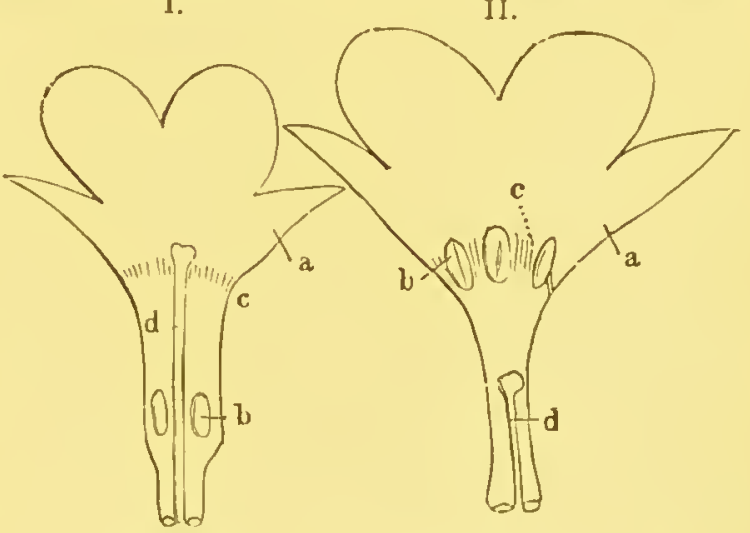

FIG. 357.-Dimorphic fower of Pulmonaria: I. long-styled ; II. short-styled form. $a$ corolla ; $b$ anthers; $c$ ring of
hairs; $d$ pistil. ductive organs is existence of Oxalis]. Oralis]. In plants in which this arrangement occurs, fertilisation, 
or the production of fertile seeds is, as a rule, effected only by the union of the reproductive organs which stand at the same height, and which are therefore always found in different fowers (Fig. 357 1. $b$ and II. $d$, and I. $d$ and II. $b$ ); [it is obvious that this will easily be brought about by the agency of insects. In many cases the stigma is absolutely sterile to pollen from the same flower; while in others pollen from a different flower is prepotent over that from the same flower.] Finally, the circumstance is specially noteworthy that in some Orchiclex the pollination of the stigma by pollen-grains from the same flower is actually poisonous, having a fatally injurious effect on the whole flower.

[Not a few examples are known of plants producing two kinds of flowers, one kind with conspicuous corolla, which may or may not be fertile; the other kind, known as cleistogamic, closed, with the corolla wanting or very imperfect, always fertile and self-fertilised. Very good examples occur in the sweet violet and common dog-violet.]

When pollination has been fully accomplished, the pollengrain, excited by the viscid fluid exuded by the stigma, puts.

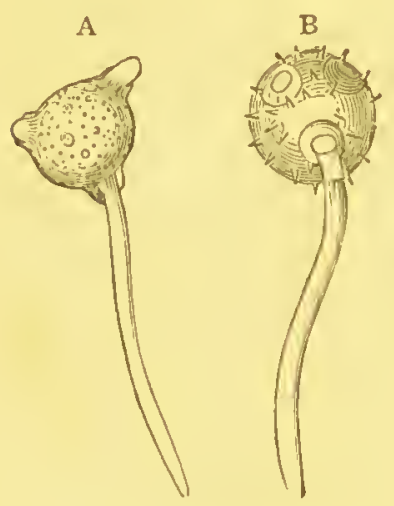

FIG. 358.-Pollen.grains putting out their pollen-tubes; A Dip. sacus Fullonum; B Cucur. bita. out one or more long tubes, the pollen-tubes (Fig. 358). [The pollengrain of Angiosperms is now known -at least in a large number of cases - not to be unicellular, as previously supposed, but to resemble that of Gymnosperms in consisting of one large and several very much smaller cells. The large cell contains a fluid known as the fovilla, and very commonly two nuclei, and from it alone the pollentube is formed. The pollen-grain is invested by two coats, an inner coat, the intine, composed of cellulose, and an outer cuticularised coat, the extine, which is very commonly furrowed, warty, or spiny. The extine is either thin or entirely wanting at certain spots, beneath which the intine is exceptionally thick. The pollen-tube is formed from these accumulations of cellulose in the intine bursting through the weaks spots in the extine.] It penetrates through the conducting tissue 
of the style, and reaches the interior of the cavity of the ovary, often in a few hours. There it comes into contact with an ovule and attaches itself closely to it (Fig. 359). One of the cells of the nucellus of the ovule has, in the meantime, grown much larger than the rest, and has pressed aside and absorbed the surrounding tissue. This is the embryo-sac, [the mother-cell of the oosphere, containing one large nucleus, which is originally towards its lower end, i.e. away from the micropyle. As the embryo-sac increases in size before fertilisation, this nucleus divides, and the two daughter-nuclei travel to opposite ends of the sac, a large central vacuole being formed. Each of these nuclei again divides, and there are now four at

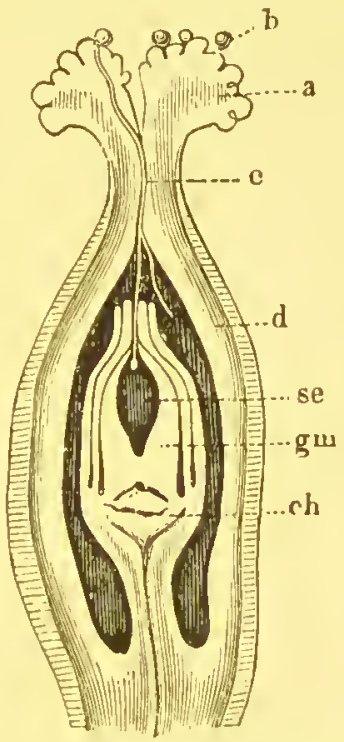

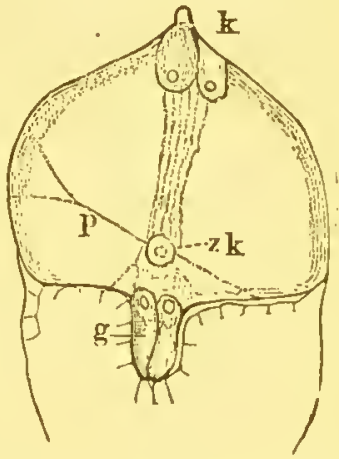

FIG. 360. - Upper part of the nucellus of the ovule of Crocus: $p$ the embryo-sac with its nucleus $z k$; $k$ the embryonic vesicles: $g$ the antipodal cells. $(\times 75)$.

FIG. 359.-Longitudinal section through the uni-ovular ovary of Polygonum Convolvulus at the time of flowering : $a$ stigma; $b$ pollen-grains; $c$ pollen-tube : $d$ wall of the ovary; $g m$ the erect orthotropous ovule; se its embryo-sac; $c h$ chalaza: two pollen-tubes have penetrated through the conducting tissue of the style, one of which has entered the micropyle of the ovule, the other not. $\left(x 4_{0}.\right)$

each end of the sac, constituting the polar nuclei. Subsequently two of these, one from each end, approach and coalesce, constituting the permanent nucleus of the embryosac. The nuclei at the basal end of the sac soon become invested with cell-walls, and are called the antipodal cells (Fig. $360, g$ ) ; their function is unknown, and they soon disappear. Those at the upper end of the sac are the germinal or embryonic vesicles, or the ego-apparatus (Fig. $360, k$ ). Two of these, lying nearest to the apex of the sac, have been 
termed the synergida ; they are surrounded by a protoplasmic membrane, but not by a coat of cellulose. In some cases

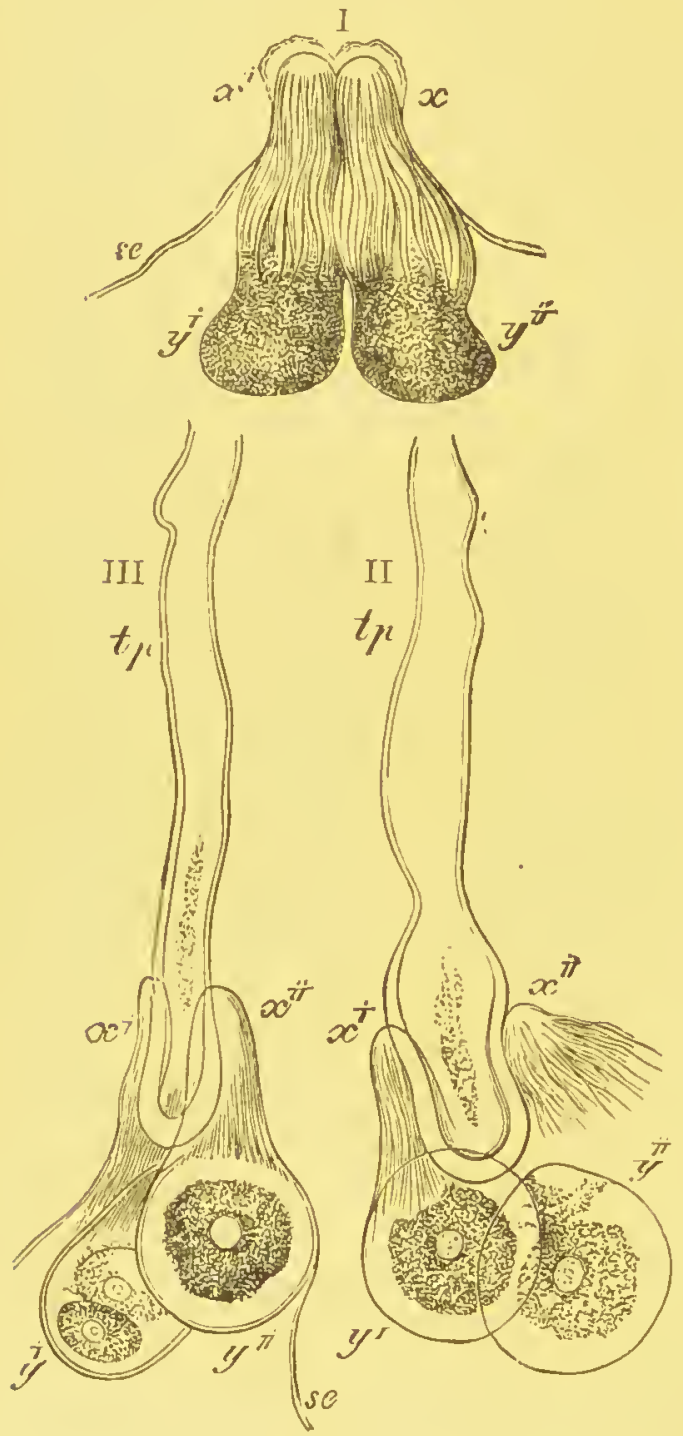

I.

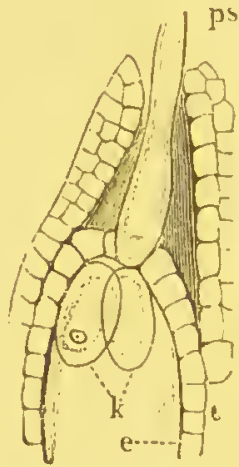

II.

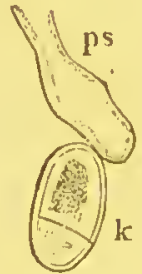

Fig. 362. - Fertilisation of Canna: I. apex of the embryo-sac $\mathcal{E}$ at the tıme when the pollen tube fs has just come into contact with the. embryonic vesicles $k$; II. fertilised embryonic vesicle separated. ( $x$ 200.)

FIG. 36r. - The process of fertilisation in Gladiolus segctum: I. the two embryonic vesicles at the apex of the embryo-sac: $x^{\prime} \cdot x^{\prime \prime}$ the filiform apparatus; $y^{\prime} y^{\prime \prime}$ the balls of protoplasn ready for fertilisation; se the wall of the embryo-sac. II. a pollen-tube to which has just fertilised the two embryonic vesicles in contace with it ; the cell-walls which surround the balls of protoplasm are still very thin. III. a somewhat later stage ; the cell-walls are thicker; the fertilised vesicle $y^{\prime}$ is beginning to develope and to divide into two. ( $x$ 400.) 
the elongated superior ends of these cells present a longitudinal striation, termed the filiform apparatus (Fig. 36r I. $x^{\prime} x^{\prime \prime}$ ), and supposed by Schacht to play an essential part in impregnation. The third of the germinal vesicles, lower down and somewhat lateral in position, is the oosphere or ovum-cell, and its nucleus is the sister-nucleus to the polar nuclei which coalesce to form the permanent nucleus of the embryo-sac. Occasionally two of the embryonic vesicles are fertilised and produce perfect embryos, affording instances of polyembryony.]

Of the numerous pollen-tubes which, as a rule, reach the ovule, one penetrates through the micropyle, and reaches the embryo-sac either directly or by forcing aside the tissue which still lies above it. At the apex of the embryo-sac the pollen-tube comes into contact with the embryonic vesicles, and fertilises one of them, the oosphere (Figs. $3^{61,} 3^{62}$ ), the others, as a rule, entirely disappearing. Immediately after fertilisation, the fertilised embryonic vesicle, which was before naked, becomes clothed with a cell-wall of cellulose, and begins at once to develope. It is now known as the oosperm. This divides, at first, into two cells, the upper one of which becomes the suspensor or pro-embryo, while the lower one developes, - by frequent division and growth, into the embryo (Fig. 363). The suspensor is sometimes longer, as in Borragineæ, Cruciferæ, Labiatæ, and Scrophulariacex, or shorter,

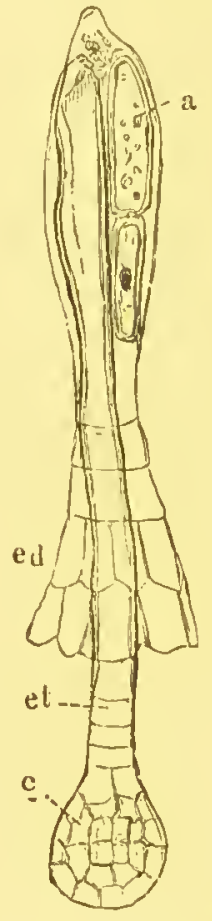

FIG. 363. - Formation of the embryo of Heliotropizem: $c d$ endosperm: $e t$ suspensor ; $e$ rudiment of the embryo, its enveloping mem. brane being already formed : a cells developed out of the other embryonic vesicle. as in Polygonacer, and in Potamogeton consists of a single globular cell ; occasionally it is composed of pairs of cells lying side by side; sometimes it is entirely wanting. In the I,eguminose each cell of the suspensor frequently contains several nuclei, sometimes as many as thirty. 
The radicular end of the embryo is always developed first on the suspensor, and hence the radicle of the mature embryo is almost always turned towards the micropyle. During its growth the embryo is almost always, except in Orchidex,

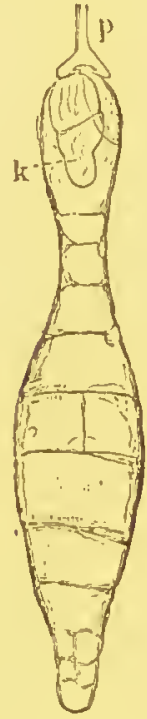

FIG. 364.-Separated embryo-sac of Heliotro. fium, the endosperm consisting of a long row of cells : one of the cells in the middle has already divided transversely : $p$ pollen-tube : $k$ rudiment of the embryo.

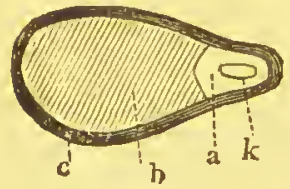

FIG. 365. - Longitudinal section through a seed of Nymphac: $c$ testa; $b$ perisperm : $a$ endosperm; is embryo. nourished by a tissue developed in the embryo-sac (Fig. 364), and termed the albumen or endosperm. The formation of this tissue, which takes place by free-cell formation, commences while the suspensor is developing. When the embryo-sac has ceased to grow, the endosperm-cells become vacuolated, and invested by walls of cellulose. In this condition a communication has been observed between the contents of adjacent cells by protoplasmic threads passing through the cell-walls. The endosperm is occasionally reduced to only a single row of cells, and in Canna is said to be entirely wanting. In some very large embryo-sacs the centre is filled with a watery fluid, forming the 'milk' of the cocoa-nut. The function of the endosperm is to supply the growing embryo with nutriment, though some is also derived from the nucellus through the suspensor. In some cases the endosperm is thus ultimately entirely consumed, and the mature seed is then said to be exalbuminous; if a portion of it is left, it is albuminous. When a portion still remains of the tissue of the nucellus itself, this is called the perisperm. Cannaceæ have a perisperm, but no endosperm, while Nymphæaceæ (Fig. 365) have both. The cells of these tissues are finally filled with a quantity of nutrient substances of all kinds, which serve for the nutrition of the young plant when germinating. 
The processes concerned in fertilisation and the formation of the embryo in Gymnosperms (Coniferæ and Cycadex) differ somewhat from that now described. The pollen-grain, always carried by the wind, falls directly upon the micropyle of the ovule, the pollen-tube being developed from one of its daughter-cells (Fig. 366). The embryo-sac, at least in Coniferæ, is filled up, even before pollination, with endosperm-cells, which, however, have only a transitory existence. After some weeks, or often only after some months, they are again absorbed, a fresh development of endosperm taking

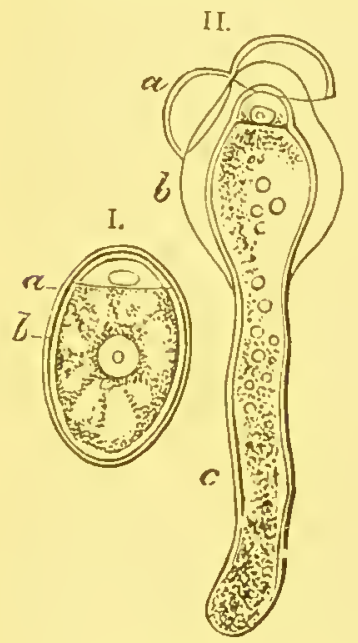

Frg. 366.-Fertilisation of Cupressus sempervircns (Coniferæ) : I. a pollen. grain with its two cells; $a$ extine ; $b$ intine: II. pollen-grain in which the pollen-tube $c$ has been formed. $(\times 300$.

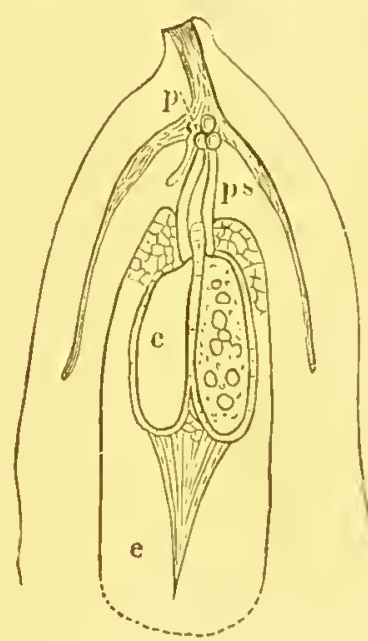

FIG. $367 .-$ Fertilisation of Abics $c x$ cclsa: $p$ pollen-grains : $p s$ pollentubes $c$ two corpuscisles in the em. bryo-sac $c . \quad(+60$.

its place. In this latter, towards its apex, are formed, after pollination has taken place, a few cells of larger size than the rest, the secondary embryo-sacs or corpuscules ${ }^{1}$ (Fig. $3^{6} 7$ ), the number of which differs in different genera. After some time each of them splits up by a partition-wall into

${ }^{1}$ Sometimes called archegonia, from their resemblance in structure ancl function to these organs in Vascular Cryptogams, to the central cell of which they are homologous. 
two cells, a smaller upper one, the neck-cell, and a larger lower one, the central cell. The first forms the neck, either remaining simple or splitting up into several contiguous. cells. In the central cell is developed a large oosphere, which is surrounded by the neighbouring tissue of the endosperm as a peculiar enveloping layer of cells. There are no synergidæe or antipodal cells. At the time of pollination the ovule exudes a drop of viscid fluid. This excites the emission of the pollen-tube, which now advances to the corpuscules, becomes closely applied to several of them, or penetrates into the neck of a single one, often even into the central cell, and transfers its contents to the oosphere. The oosphere now breaks up in its lower part, in Cupressinex, into several cells lying one over another; or, in Abietinex, a layer of cells is developed there by repeated cell-divisions. These cells divide further, and form the pro-embryos, which in the course of their development break through the embryo-sac, an embryo being formed at the lower end of each. As a rule only one rudimentary embryo in each ovule attains perfection.

The germination of many seeds takes place as soon as they escape from the fruit and attain favourable conditions of moisture and warmth; in others, on the contrary, a period of rest seems to be necessary in order for them to ripen, i.e. to become capable of germination, by slow changes, probably of a chemical nature. The radicle of a seed of the willow pierces the testa as soon as twelve hours after sowing; and if it is allowed to remain dry for only twelve days it loses its capacity for germination. The seeds of the elm, poplar, coffee, and many Lauracer also germinate only when they have been kept fresh and have not dried up; while that of the mistletoe often germinates even while still inside the fruit. Fresh seeds in general germinate more quickly and easily than old ones. Seeds which contain starch may, on the contrary, retain their power of germination for many years, if kept dry. The temperature 
rises during the germination of seeds, in consequence of the absorption of water and formation of carbon dioxide.

In order for germination to take place, it is essential that the temperature should fluctuate only between certain limits, which, as might be expected, vary greatly in the case of different plants. In the case of wheat, for example, the lower and upper limits are $5^{\circ}$ and $43^{\circ} \mathrm{C}$.; for barley $5^{\circ}$ and

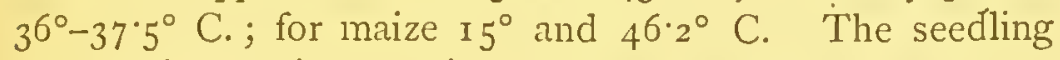
derives its earliest nutriment from the
seed, and especially from the cotyledons, or, when there is endosperm, from it also through the medium of the cotyledons. The radicle first emerges from the seed, and after it the plumule. The radicle is, in Dicotyledonous plants, a direct prolongation of the axis of the embryo, and, therefore, a tap-root; while in Monocotyledons, on the other hand, the radicular end of the embryo never becomes a primary root; a number of adventitious roots are, on the contrary, developed (see Fig. 105, P. 74), and it is only rarely (Fig. 368) that the radicular end of the embryo elongates into a protuberance which soon perishes. In respect to the cotyledons also, there are two modes of germination. 'They either remain

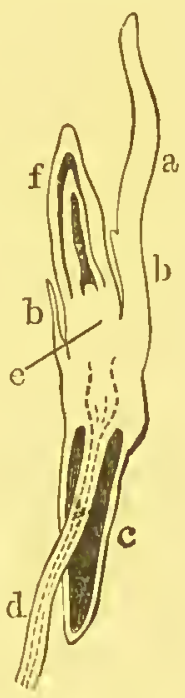

FIG. 368.-Germination of the oat : $a$ cotyle. don ; $e$ axis of the embryo: $d$ racicle : $f$ plu mule $(x 6)$.

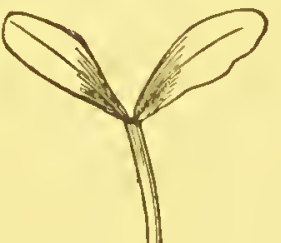
beneath the soil still enclosed in the testa, (Fig. 369 ), or they rise above ground and throw off the testa (Fig. 370). The single cotyledon of Monocotyledons almost always remains beneath the surface, as also do those of "the oat 
and sweet chestnut, while in other Dicotyledons, as the beech, birch, and lime, they emerge from the soil. 'The

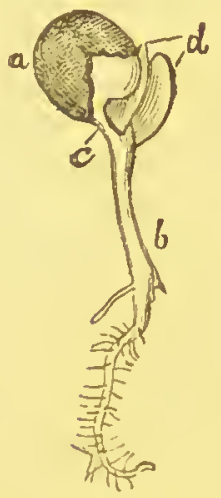

FIG. 370.-Germinating seed of cabbage : l- axis: $c, d$ the two cotyledons which have risen above the soil, the testa $a$ not veing vet completely thrown off $\left(x_{4}\right)$. plumule of Monocotyledons consists of superimposed leaves of a sheath-like or cornet-like character (Fig. 368); while in Dicotyledons the cotyledons. when they separate, are green and leaf-like.

In all modes of reproduction the pro. perties of the parent plant are transmitted to its descendants. When reproduction is effected by asexual cells, this is altogether the case ; but when the reproductive cells are fertilised oospheres, only so far as to maintain the character of the specics. When the fertilising (male) and the fertilised (fenale) cell are derived from plants which belong to different species, fertilisation can take place only if the two species are very nearly related to one another. An individual resulting from impregnation of this character is a hybrid; and it is determined by a number of circumstances, some of which are still unknown, which of the two parent species the hybrid most nearly resembles. Hybrids resulting in this manner fiom the crossing of two species not unfrequently occur in nature; but their power of propagation is commonly defective, and they are often altogether infertile.

In systematic botany hybrids are distinguished by names compounded of those of their parent-species, the name being placed first of the one which it most resembles. Thus between Mcntha rotundifolia and $M$. sylvestris, two hybrids are linown, $M$. rotundifolio-syliestris and $M$. sylevestri-rotundifolia, the former of which most nearly resembles M. rotundifolin, the later $M$. sylvestris. ${ }^{1}$

${ }^{1}$ [A more usual and preferable practice is to place the name of the male parent first. of the female parent last. Thus Mtulharotumafoliosyluestris would be the result of the fertilisation of M. sylicstris by $M$. 
Fertilisation is easier between different varieties of the same species than between different species, the result being in this case termed a variety-hylbid. The stamens are often replaced in them by petals, thus forming what are called double sterile flowers, on which account they are not gene. rally so well calculated for propagation as species-hybrids.

It is easily understood that agriculture, and especially horticulture, takes advantage of these peculiarities in order to call into existence varieties of plants cultivated for their usefulness or their beauty.

The subject of fertilisation is incomplete without a description of the mode of reproduction of Cryptogams by means of oospheres. But as an account of the very numerous modifications of this process must necessarily be given under the separate classes, the whole subject is deferred till the section on classification.

PHENOMENA OF MOVEMENT.

Motion is an essential condition of life. The plant, therefore, like the animal, exhibits phenomena of motion; but since the former finds conditions suitable for existence on all sides, these phenomena are in general less strongly manifested than in the case of the latter. It is not necessary here to allude to those movements of a passive character which the plant performs under the influence of wind or wave, or when bent to the ground beneath the weight of its fruit, rising again subsequently to an erect position; in short, to those movements which are imparted to it by the obvious action of mechanical forces. Those only will be referred to which are inseparable from life, and are a direct result of the vital processes.

It is impossible to give a minute account of all these various phenomena of movement; but they will at least be made somcwhat more

rotundifolin, $M$. sylerstri-rolumdifolia the result of the fertilisation of $M$. rotusedifolia by $M$. sylvestris. - L.D.] 
intelligible by observing those forces which are inherent in plants from the mode of their construction out of cells, as well as from the molecular structure of their organised parts.

Chemical processes in the interior of the growing structure arc always connected with growth by intussusception, as this process has already been described (see p. 15). Thus the nutrient fluid which forces its way into the cells from without by the action of osmose, contains, it is true, material for the formation of molecules of a clefinite chemical composition ; but this material is chemically different from the molecules which it nourishes. Thus starch-grains are produced out of a fluid which does not contain any starch in solution; the cell-wall is formed by the secretion of substances out of the protoplasm which are not dissolved cellulose; the colouring matter of the chlorophyll is first formed in the interior of the chlorophyll-bodies, \&c. Growth by intussusception is therefore connected not only with a continual disturbance of molecular equilibrium, but also with chemical processes in the interior of the growing structure. Chemical combinations of the most various character must therefore take place between the molecules of the organised body, and act and react upon one another.

It is certain that growth can only take place so long as the growing parts of the cell are permeated by atmospheric air, and that the oxygen of the atmosphere decomposes the compounds within the organised structure. ${ }^{1}$ The formation and evolution of carbon dioxide is therefore a necessary accompaniment of growth ; and not only is the equilibrium of chemical forces thus being continually disturbed, but heat is also necessarily produced, and electrical action may perhaps also come into play.

By the chemical processes which have been partially described in detail when treating of nutrition, by the influence of heat, and perhaps also by electrical action, forces of considerable magnitude are set free in the interior of the plant, which set in motion its smallest particles (atoms or molecules), and thus represent a definite amount of work within the growing organised body, which is probably often enormous. ${ }^{2}$ And herein we have an essential characteristic of all organisation and of

1 See p. 167, on the process of respiration.

2 The temperature of dry grains of starch, when they absorb water of the samc temperature, rises $2^{\circ}$ or $3^{\circ} \mathrm{C}$.; while boiling water is only raised in temperature about $0^{\circ} 078^{\circ} \mathrm{C}$. by a pressure of ten atmospheres. Since, as experiment has shown, the rise in temperature on absorption depends on an increase in density of the water, these stalemcnts will give some idea of the enormous force with which the absorption takes place. 
life, viz. that organised structures are capable of a continual internal change; and that so long as they are in contact with water and with atmospheric air, only a portion of their forccs can be in equilibrium in their interior; in short, that they are in continual internal movement. The whole organism forms, therefore, a framework, between and in the molecules of which forces are constantly being set free by chemical changes, which forces again occasion further changes. This is essentially dependent on the pcculiar molecular structure which allows that at every point in the intcrior substances penetrate from without and are absorbed in the liquid or gaseous state, and can again be expelled. This internal changeableness attains its highest grade in the chlorophyll-bodies and the protoplasm. In the former, chemical changes take place with great energy and force under the influence of light, such as the formation of the green colouring matter and of starch; while the absence of light at once sets up other chemical processes, which terminate only with the complete destruction of the whole of the chlorophyll-body.

Besides the chemical and physical forces, others are also set free in plants by the mutual action on one another of their cells, which are manifested in a tension of the tissues or of the cells with respect to one another.

Every part of the plant consists of external and internal layers whose growth proceeds, at least for a time, with a different rapidity in the same direction. A necessary consequence of this unequal energy of growth is a corresponding tension of the different layers with respect to one another; because those which are growing more quickly are prevented from expanding as much as their growth requires, and hence exercise a pressure on the layers that grow more slowly, which these seek to counteract by their elasticity. Such tensions of the layers causcd by unequal growth may still continue after growth has ceased; but they may also be dcstroyed by a change in the relative rates of growth. The existence and the nature of the tension can be easily shown by separating the layers from one annther; those which had grown more quickly, and were therefore previously compressed, will expand; those which had grown more slowly and which were therefore pieviously stretched to more than their natural length, will now contract elastically; the former become longer, the latter shorter, than before their separation. A partial separation of the tissucs is often sufficient to show this. If, for example, any rapidly growing stem is cut longitudinally into four pieces cross-wise, the pieces curve concavely outwards and convexly on their inner side, in consequence of the internal layers extending while the outer layers contract. These tensions caused by the unequal growth in length of different layers of tissue act chiefly in the 
direction of the axis of the growing structure, and are therefore called longrizudinal tensions. But when, after growth in length has ccased, a permanent increase in thickness takes place, as for instance in the case of the stems of forest-trees, then this increase in thickness is accompanied by a transerse tension in the radial and tangential directions. This is generally caused by the cortical tissue growing more slowly than the wood; and this, as has: already been shown, causes the bark to become too small for the wood, and hence to compress it considerably; no inconsiderable pressure being exerted, on the other hand, by the wood on the bark. This can be easily shown by stripping a ring of bark from a stem, and slitting it up one side, when it contracts, and will no longer enclose the wood, its edges gaping apart.

Tensions of different layers do not occur only in tissues, but also in the cell-walls of individual cells; and it is then usually the ontermost layers of the cell-wall which are stretched by the inner ones, while these latter are correspondingly compressed by the elasticity of the outer layers.

The turgitity of the cell, or the pressure exercised by the cell-sap on the cnveloping cell-wall, must be carefully distinguished from the tension of the layers of tissue. Turgidity is caused by the substances dissolved in the cell-sap attracting the water which surrounds the cell by the force of enciosmose; the water accumulates within the cellcavity by endosmotic attraction, and, exerting a pressure on the inside of the cell-wall, places it in a condition of greater or less tension.

The final result of the growth of the cell-wall caused by the various forces enumerated-its extensibility and elasticity, and the turgidity of the cell-is a measure of the rigidity or flaccidity of the plant or part of the plant. The total tension, for instance, is diminished, and the part becomes more flexible, when the turgidity decreases from loss of waler, or when the elasticity of the stretched cell-walls aiminishes, or when the cell-walls become more extensible, or, finally, when the inequality of the growth of the different layers of tissue diminishes. When a change of this kind talies place on all sides, the part of the plant will become shorter or longer according as the tension diminishes or increases; but if it takes place on one side only, a corresponding curvature is caused.

To complete the account of the forces at work in the plant, we must add to those already mentioned, which are peculiar to the molecular structure of their organised parts and to the phenomena of tension, others which are set free by the movement of water and of gases within the plant. Sufficient reference has already been macle to the former under the head of nutrition. The latter class of movements is casily 


\section{The Life of the Plant.}

explained by the continual interchange, through the medium of the stomata, of the gases formed in the intercellular spaces with the external air, and by the fact that in growing plants gases are continually passing in and out of the cells by the force of diffusion. A large number of very remarkable movements of plants and of parts of plants are at least to some extent explained by the co-operation of these forces; but a large number of others still require further investigation.

The wonderful properties of protoplasm, to which attention has already been directed, culminate in its spontaneous. motility, in its capacity of assuming different forms, of changing its outline and its internal condition, and of thus. calling into activity internal forces without any corresponding impulses being observed to act upon it from without. Good examples of this capacity are afforded by the circllation which occurs in the filaments of the stamens of Tradescantia, the stinging-hairs of the nettle, \&c. 'The movement of the protoplasm in these cells is apparently not subject to any definite law, sometimes advancing, sometimes. retreating, and sometimes suddenly ceasing. The protoplasm often makes for itself new courses in the cell-sap; but its motion appears to be dependent on the nucleus, round which it always flows, and often carries it along with it. When the protoplasm within a cell possesses this power of motility, it is not extraordinary that cells destitute of a cell-wall (primordial cells) should have the power of moving from place to place; and, in fact, the naked primordial cells of the Myxomycetes, which are termed plasmodia, are endowed with the faculty of moving like an animal, and even, in the case of Ethalium - the so-called 'flowers of tan'-of creeping to the distance or height of several feet, as if endowed with voluntary power. It is, therefore, not to be wondered at that even till quite recently these organisms were considered. to be animals; while at present they are assigned to an abnormal section of Fungi, to which class they are allied by the mode of formation of their spores. The rapidity of these 'streaming' movements varies greatly; the maximum appears 
to occur in Didymium Serpula, where a rate of Io millimetres in a minute has been observed.

The antherozoids and zoospores (swarmspores) of many Cryptogams were long considered to belong to the animal kingdom; and they actually show so close a resemblance to animals that they might well have been described as plants at the moment of their transformation into animals. The zoospores of Algæ are particles of protoplasm which break through the walls of the cells in which they are formed, and swim about for a time in water like animals. It is only since it has been ascertained that they give birth, after a shorter or longer perind of rest, to a plant of the same species as that from which they sprang, that their vegetable nature

I.

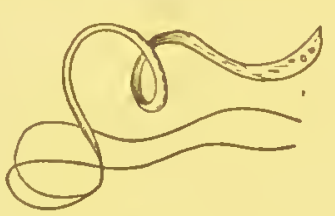

II.

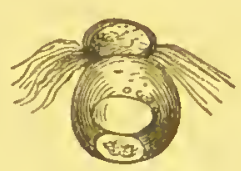

FIG. 371. -Antherozoids : I. of Nitella syncarpa (Characex, $\times 500)$; II. of (Edogonium gemelliparum (Algæ, $\times$ 800).

has been absolutely determined. The internal forces by which these zoospores (Fig. 386, p. 254), and the antherozoids (Fig. 37 I) which are endowed with motion of a similar nature, are enabled to perform their movements, are still unknown; but they are certainly connected with the vibratile cilia, or minute threads of protoplasm of different lengths and variable number, the vibrations of which set the body in motion. But it must be admitted to be a most wonderful contrivance for the maintenance and propagation of a number of vegetable organisms.

Neither zoospores nor antherozoids are provided with a cell-wall-or, at all events, with only an extremely delicate one-during their period of motility. Still more remarkable than these must, therefore, be considered the movements of the Diatomaceæ, [Desmidiex], Oscillatoriex, Bacteria, and some other organisms which are enclosed in a complete cell- 


\section{The Life of the Plant.}

wall, or even in a hard siliceous coating, as in the case of the Diatomacer. The Oscillatoriex consist of long filaments which often oscillate rapidly; and the Spirulinex are filaments of similar form which coil about in a great variety of ways. The cause of their movements has not been ascertained.

Circumnutation is the term given to those curvatures which cause parts of plants that are growing in length to assume successively different directions without any apparent external cause. Examples are furnished by the flowering scapes of the onion, which, before they attain their ultimate length, bend slowly first to one side and then to another; or, still better, by climbing stems. In these, such as the hop and the scarlet-runner, the first internodes do not twine; but when the apex of the stem hangs down in consequence of its weight, it begins to revolve in a circle, and thus to approach the support which it afterwards embraces. The earlier coils are hence looser than the later ones, which embrace the support more closely. These curvatures of circumnutation appear, in general, to take place at the spots where the tension of the tissues is the greatest, and to be caused by the growth in length being greatest first on one and then on the other side. The twining of tendrils is due to a similar property of circumnutation, combined with a sensitiveness to be mentioned hereafter.

Parts of plants which are growing in length sometimes become, by long-continued close contact with a solid body, firmly attached or adherent to it. Instances are afforded in the adhesion of pollen tubes to the stigmatic hairs and to the internal wall of the ovary; and in the climbing and turning of the tendrils of many plants round slender supports.

Tissues in a state of tension become relaxed by concussion. Parts of a great number of plants, when in a state of active growth, undergo a diminution of the elasticity of their tense tissues by violent shaking, repeated bending, a blow on one side, or sometimes even simply by stretching, 
the tissues thus becoming flaccid, and the parts lecoming elongated and bent. These facts can easily be established by experiment, very clearly by simple observation of rapidly growing plants shaken by violent winds, when, though apparently injured, they are not generally so in reality. In other cases of a similar kind the extensibility of the parenchyma is diminished, and a flaccidity, shortening, and curvature of the organs occasioned. These changes are probably the cause of the movements of irritability, as it is termed, of some leaves; although these phenomena may also be due to other causes, such as electrical shocks or currents. The most remarkable instance occurs in the leaves of the sensitive plant, Mimosa pudica. The bipinnate leaves of this plant are united to the stem by an articulation, as also are the four pinnæ and the separate leaflets to their petioles (see Fig. 5I 7, P. 403). The primary petiole has the greatest scope for movement, since it can rise or fall to the extent of a semicircle. The pinnæ move upwards and laterally, so that they lie upon one another like parts of a fan. The secondary pinmules move upwards, and close up like the wings of a butterfly at rest. The sensitive plant closes its leaves spontaneously in the evening, and also in the day-time when excited by any irritation. This irritability is only manifested when the temperature of the surrounding air is above $15^{\circ} \mathrm{C}$. ; it is still weak between $\mathrm{r} 6^{\circ}$ and $\mathrm{I} 8^{\circ}$, and appears to reach its maximum at $30^{\circ} \mathrm{C}$. At that temperature the plant is so sensitive that the movement is communicated to a number of leaflets almost simultaneously; while, when the sensitiveness is less, the movement advances regularly from the irritated spot. The closed leaflets again assume their normal position when the irritation ceases, if it has not been too strong and consequently had an injurious effect; and this takes place sooner or later according to the vigour of the plant, commencing sometimes in as short a time as five minutes. Poisons. often kiil the sensitive plant; anæsthetics, such as ether 
or chloroform, usually temporarily paralyse it; and ccristant repetition of the irritation is followed by a diminution for a time of its sensitiveness. It is probable that the tissue of the lower side of the pulvinus, or mass of succulent tissue found at the articulation, contracts after irritation such as that produced by simple contact, its cells losing a large portion of their cell-sap, and thus becoming less turgid, and giving space for the expansion of the tissue of the upper side. A depression is thus caused of the leaf which is attached to the articulation ; and this is not counteracted by the vascular bundles in the pulvinus in consequence of their flexibility. A fresh flow of sap into the part of the tissue which was previously emptied then causes a fresh elevation of the leaf. [There can be little doubt that the motility of the leaves of Mimosa is connected with the continuity of protoplasm recently discovered in the cells of the motile organ.]

Venus's fly-trap, Dioncea muscipula (Fig. 372), manifests a similar irritability. On each half of the upper side of the leaf, through which passes a strong mid-rib, are three small bristles; and when one of these bristles is irritated, the two halves of the leaf close together, and remain closed until the irritation has ceased. If, therefore, a small insect, such as a fly, settles upon the leaf, it becomes shut in, and is retained between the halves of the leaf until it is dead and no longer exercises any irritation upon it. One of the best examples of irritability is furnished by the various species of Drosera or sundew. The margin and upper side of the leaf are furnished with numerous red glandular hairs or 'tentacles.' The club-shaped head of these hairs exudes a viscid fluid, in which any insect that alights on the leaf becomes imprisoned. As soon as the insect is captured, the tentacles begin to bend over from all sides towards it, until it is completely enclosed by the club-shaped heads of all the tentacles of the leaf. There can be no doubt that the object of the movements, both in this case and in that of Dionaa, is the digestion of the soft portions of the body of the insect by 
means of special glands, since the movements are accompanied by the excretion of a digestive ferment identical with animal pepsin; and experiments have proved that

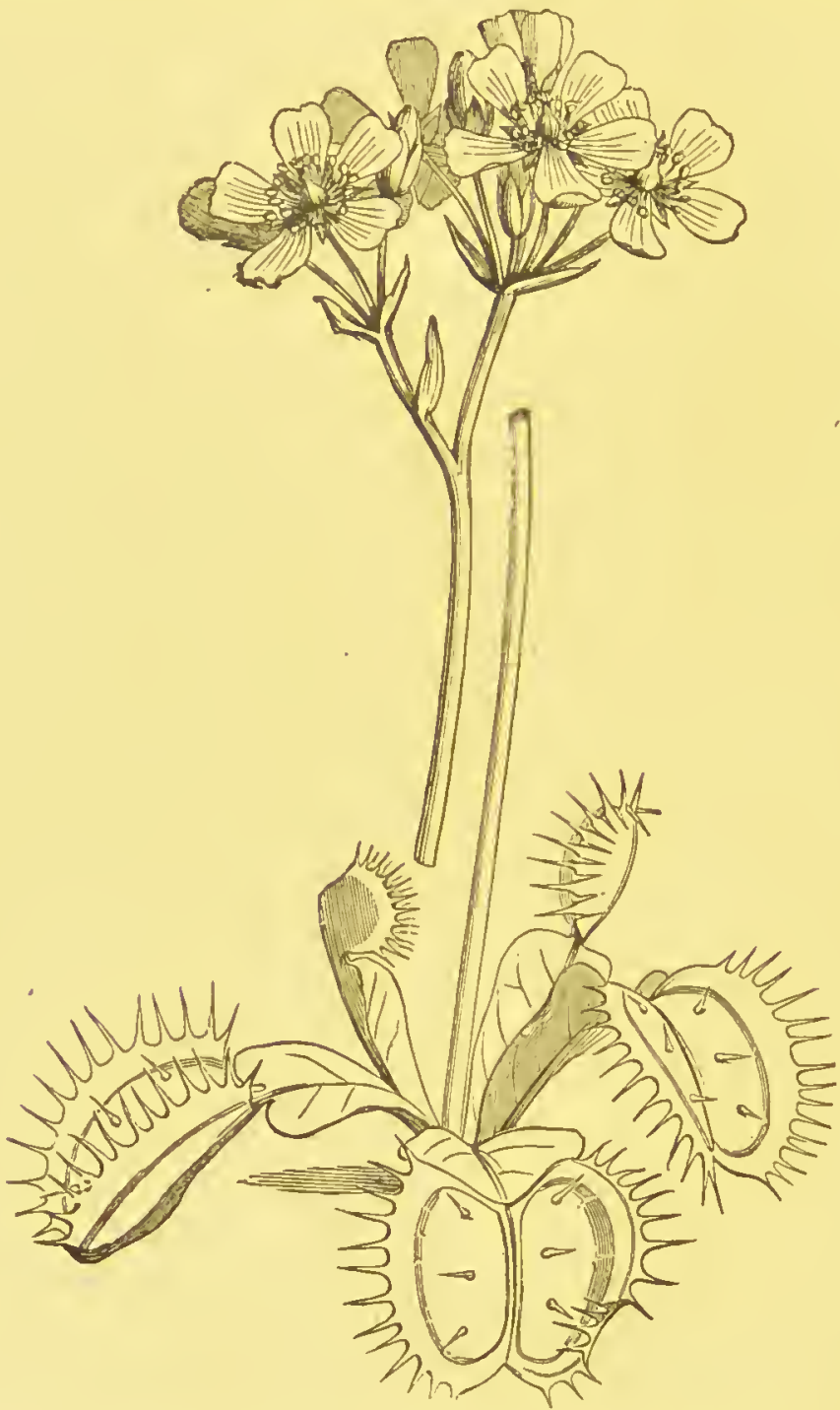

FIG. 372.-Venus's fly-trap, Dionaa mzuscipula (natural size).

plants provided with food of this nature flourish better and produce a larger number of seeds than those which derive their nutriment through the root only. Any substance con- 


\section{The Life of the Plant.}

taining nitrogen serves to stimulate the movements of the tentacles of Drosera.

The stamens of many Compositæ, such as Centaurea, contract when irritated before pollination. The stamens of Berberis, when touched on the inner side, spring violently against the pistil, and place their anthers in contact with the stigma. The stamens of the grass of Parnassus, Parnassia palustris, lengthen in succession, and place their anthers on the stigma.

The stigmas of some plants, as Bignonia, Gratiola, Martinia, [Mimulus], \&c., which are expanded at the time of pollination, close on contact. A similar phenomenon is exhibited by the stigmas of Torenia asiatica, which close immediately after pollination, open again in a few days, but are then insensitive to further contact. Movements of this nature are all closely connected with the sustenance and propagation of the plant.

Closely connected with these movements are those belonging to tendrils and tendril-like organs. In their early state, before they have coiled up backwards or have clung to a support, these organs are sensitive to simple and slight contact or to very light rubbing, the side on which they are touched becoming, after some minutes, concavely curved. The bent tendril subsequently straightens itself, and is then again irritable. Bent tendrils are sensitive only on the concave side.

Those parts of plants in which there is generally a tension of the tissues exhibit a constant increase and decrease in the degree of tension. Under the ordinary conditions of life, in which plants are subject to the alternation of day and night, the intensity of the tension declines from morning till noon, and rises during the night, attaining its maximum in the morning. The most beautiful illustration of a movement of this nature, and the most independent of external influence, is furnished by the telegraph-plant, Desmodium gyrans, a southern Asiatic shrub. The leaves of this plant are trifoliolate, the central and largest of the three 
leaflets moving only in sunshine, and assuming besides different positions by day and by night; while the lateral leaflets, which are about one-sixth the size of the middle one, perform almost uninterrupted oscillations whenever the temperature exceeds $22^{\circ} \mathrm{C}$., their apices describing an ellipse. These oscillations, which are often very active, so as to recur several times in a minute, do not, however, proceed uninterruptedly, but spasmodically, as if the plant were continually acquiring new strength, or overcoming an obstacle. Other species of the same genus show similar but less active movements. These movements always result from a periodical alternate lengthening and shortening, first of one, then of the other side of the motile organ. Similar movements, but of less intensity, are exhibited by the leaflets of the red clover, the wood-sorrel, and many other plants. Those of the red clover alter their position by as much as $90^{\circ}$ in the course of two or three hours, when placed in the dark.

Periodical movements are manifested in many other plants, especially in a strong curving upwards and downwards of the part, and then bring about what are commonly known as the diumal and noctumal, or waking and sleeping positions. These phenomena are exhibited especially in the trifoliolate and pinnate leaves of many Leguminosie and Oxalideæ, which at night depress their common petioles or the laminæ of the leaflets, the latter lying or closing upon one another in a variety of ways. The flowers of some other plants, as, for instance, Hemerocallis, close regularly in the evening, and open in the morning. Others, again, like the marigold, vary according to the weather ; in clear, dry weather, they expand their capitula between six and eight in the morning, and close them between four and six in the afternoon; whilst when the sky is perfectly cloudy, or in rainy weather, they remain altogether closed.

These periodical movements are often confounded with the curvatures of periodically motile organs, caused by their exposure alternately to a greater and less intensity of light. Thus, for example, sudden removal of light causes the 


\section{The Life of the Plant.}

leaflets of the bean to be depressed, those of the clover to be bent sideways; while sudden exposure to light, or increase in its intensity, produces the opposite effect. The leaves of Oxalis, on the other hand, assume the nocturnal position in direct sunlight. Curvatures of this nature, caused by light, are cailed paratonic.

While paratonic curvatures are caused only by the presence or absence of light, and are independent of the direction in which the light falls upon the plant, the contrary is the case with heliotropic curvatures, which occur only on the side from which the strongest illumination comes. If the side which faces the source of light curves concavely, the effort after light, or heliotropism, is said to be positize ; if convexly, it is negative. The former phenomenon is exhibited by most internodes of erect stems which are in active growth, and especially by petioles, which by this means place the surface of the leaf in such a position that it will receive the greatest possible amount of light. It may be seen very strikingly in plants grown in a window, which at length become quite crooked, from their young parts which face the light becoming rigid in this position. Comparatively few parts of plants are negatively heliotropic; examples occur in the tendrils of the grape-vine, and in older branches of the ivy, which by this means become firmly adpressed to their support. Heliotropic curvature does not contract the part of the plant; but in positive heliotropism the shaded side elongates from more active growth more rapidly than the side which faces the light; [in negative heliotropism the reverse].

One other phenomenon must be mentioned in this connection, ziz., that known as geotropism, or the tendency to grow away from or towards the centre of the earth. Parts of plants which are still growing in length tend to place themselves in such a position that the direction of their growth is vertical, or coincides with the direction of the force of gravitation. If the growing part consists of tissues 
in which there is no tension, as is the case with roots, it will simply follow the direction of gravitation, and its apex will direct itself vertically downwards. But when the growing part consists of layers of tissue in a state of tension, a change takes place in the tenșion of the tissues and in the direction of growth, which causes the under side of the curved part to grow more vigorously than the upper side, and consequently tends to force the apex upwards. The erect growth. of most stems is a result of this force of geotropism.

\section{GENERAL CONDITIONS OF PLANT-LIFE. ${ }^{1}$}

Very little is at present known with regard to the general bearing of plants as respects heat; for example, with regard to their power of conducting heat, or to the changes in volume of masses of tissue and individual cells through the influence of temperature; but somewhat more on the influence of different degrees of temperature on the various vital phenomena of plants. On this point the following important laws have been established :-All functions of the organs of a plant are brought into play only when the temperature rises to a certain height above the freezing-point of the sap. When the temperature begins to rise above this lower limit, the functions begin to be exercised with an increasingly greater energy, until at a certain height the point of the greatest vital activity is attained. With a further increase of temperature above this point, both the rapidity and the energy of the functions again decrease, until, at length, they completely cease at a definite maximum of temperature, which can apparently never be nermanently higher than $50^{\circ} \mathrm{C}$.

Beneath a covering of snow, or at a temperature below zero C., scarcely anything grows. The few perennial plants which blossom with us in

1 This section is taken in the main from Sachs's 'extoook of Botany", Book III., chap. iii. 
the winter, as the Christmas rose and hepatica, freeze when the temperature falls below zero at any stage of their growth, which begins again as soon as they thaw. The extraordinarily rapid growth of Alpine and Arctic plants in spring depends on a long anterior development of their floral organs in the preceding autumn. The green sods and the great number of leafy plants which appear as soon as snow melts, only show that the number of evergreen plants is larger than is generally supposed. Growth is entirely dependent on the temperature of the atmosphere; hence the blooming of willows and rhododendrons whose roots and stems are still frozen, as well as the development of the so-called 'red snow,' Palmella nivalis, on the surface of the snow. Neither the lowest nor the highest temperature at-which plants can exist has yet been determined. It would appear, however, that water must not be above $40^{\circ} \mathrm{C}$. for plants to be able to live in it. Plants living in the air, on the other hand, will endure for some time a temperature of from $48^{\circ}$ to $49^{\circ} \mathrm{C}$. ; at $5 \mathrm{I}^{\circ}$ they are killed in from 10 to 30 minutes.

The growth of the embryo at the expense of the reserve-materials stored up in it, begins, with wheat and barley, at about $5^{\circ} \mathrm{C}$.; with the scarlet-runner and maize at $9^{\circ} .4$; with the pumplin, Cucurbita Pepo, not below $13^{\circ} .7 \mathrm{C}$. But when the reserve-materials have been consumed, a higher temperature is apparently always necessary to enable growth to proceed by means of freshly assimilated material. The highest temperature at which germination can take place is about $42^{\circ} \mathrm{C}$. for the scarlet-runner, maize, and pumpkin ; $37^{\circ}$ to $38^{\circ} \mathrm{C}$. for wheat, barley, and peas.

'T'he lowest temperature at which the chlorophyll-bodies turn green is above $6^{\circ} \mathrm{C}$. in the scarlet-runner and maize; between $7^{\circ}$ and $11^{\circ}$ C. for Pinus pinea; and the highest at which leaves already formed and still yellow turn green is above $33^{\circ} \mathrm{C}$. The cold of winter often occasions a winter-colouring in evergreen plants. This is caused:(I) by a brown colouring, in consequence of a peculiar transformation of the blue-green constituent of chlorophyll, as in Coniferæ and the box; (2) by a red colouring, in consequence of the formation of a red pigment soluble in water and imbedded in balls of tamin, as in Mahonia; (3) by a change in colour of the chlorophyll itself by the shifting and collecting into masses of the grains of chlorophyll; this occurs in all plants. A higher temperature restores the normal condition.

The exhalation of oxygen and consequent assimilation begin, in

${ }^{1}$ [A few Algæ of low organisation appear to be able to withstand a temperature of nearly or quite boiling water; as do also some Fungi, Bacteria, and fungus-spores.-ED]. 
the case of Potamogeton, between $10^{\circ}$ and $15^{\circ} \mathrm{C}$; in Vallisneria above $6^{\circ} \mathrm{C}$.

The sensitiveness and periodical movements of the leaves of the sensitive plant do not begin till the temperature of the surrounding air exceeds $15^{\circ} \mathrm{C}$. ; the rapid periortical movements of the lateral leaflets of the leaf of Desmodium syrans only at a temperature above $22^{\circ} \mathrm{C}$. The action of higher temperatures on the sensitiveness of the leaves of Mimosa depends on the continuance of the warmth; in air of $40^{\circ}$ C. they become rigid within an hour; at $45^{\circ} \mathrm{C}$. within half an hour; at $50^{\circ} \mathrm{C}$. in a few minutes, but may again become sensitive when the temperature falls. A temperature of $52^{2} \mathrm{C}$. causes permanent loss of motility and death.

The lower limit of temperature for the motility of the protoplasm in Nitclla syncarpa is zero ; for the hairs of the pumpkin $10^{\circ}$ to $1 \mathrm{I}^{\circ} \mathrm{C}$. The upper limit is $37^{\circ} \mathrm{C}$. in the former case; in the latter the current is arrested within two minutes when immersed in water of $46^{\circ}$ or $47^{\circ} \mathrm{C}$.; in water above that temperature within a minute; in the air, exposure to a temperature of $49^{\circ}$ or $50^{\circ} \mathrm{C}$. for ten minutes does not stop the current.

The absorption of water through the roots is also subject to certain limits of temperature. The roots of the tobacco and pumpkin, for example, do not absorb sufficient water in a moist soil of from $3^{\circ}$ to $5^{\circ}$ C. to replace the small loss caused by evaporation, the leaves hanging in a flaccid condition in consequence of the cessation of their turgidity.

The rapidity and intensity of the vital functions are not in proportion to the increase of temperature. The rate of growth of the roots of a seedling of maize attains its maximum at $27^{\circ} \cdot 2 \mathrm{C}$. ; of the pea, wheat, and barley at $22^{\circ} .8 \mathrm{C}$. The sensitiveness of the leaves of Mimosa reaches its maximum at $30^{\circ} \mathrm{C}$; the rapidity of the movement of the protoplasm in Nitclla syncarpa at $37^{\circ} \mathrm{C}$.

If the limits of temperature mentioned above are passed, the vital functions of the plant may simply come to rest, as is the case with perennial plants during the winter season; or permanent changes are brought about in the plant or in parts of it, resulting in injury or death. The fatal injury inflicted on cells, both by too high a temperature and by freezing, is a consequence of their containing water.

Air-dry peas can resist a temperature of over $70^{\circ} \mathrm{C}$. for above an hour without losing their power of germination; soaked in water for an hour and exposed to a temperature of $53^{\circ}$ or $54^{\circ} \mathrm{C}$, they are 
lilled. The cause of death may be partly the coagulation of the albuminoids, while the decomposition of the cell-wall is perceptible only at higher temperatures. Air-dry seeds appear to be able to withstand any degree of cold without injury to their power of germination. The winter-buds of woody plants, the cells of which contain a great quantity of reserve-materials but only a small quantity of water, withstand the cold of winter and frequent rapid thawing; while the succulent leaves at the time of their unfolding in the spring succumb to a slight night-frost. Many plants, such as Lichens, Mosses, Fungi of a leathery texture, the mistletoe, and some others, appear never to freeze; while, on the other hand, many flowering plants from a southern climate are killed by rapid changes of temperature near the freezing point. Whether the tissue of a plant can be killed simply by the solidifying of the water of its cellsap into crystals of ice is uncertain; while, on the other hand, it is unquestionable that in a great number of plants death is caused only by the mode in which the thawing takes place. The same tissue which retains its vitality if thawed slowly after freezing, becomes decomposed if thawed rapidly after exposure to the same degree of cold; so that death is evidently in this instance the result not of the freezing but of the tharving. Moreover, the lower the temperature at which the freezing took place, the sooner is the plant killed by the freezing as well as by the thawing. A common but not invariable result of the freezing of the cell-sap is that internal cells or layers of tissue are ruptured; but these internal rupturings do not, as was once supposed, always cause death ; they have as little to do with the destruction of the life of the cells by cold as the splitting of the branches of the trees caused by frost, which, when the temperature falls very low, is produced by the contraction of the bark and outer layers of wood, the crevices again closing when the temperature rises. The phenomena of freezing are, however, at present but imperfectly understood.

The entire life of the plant depends on the action of light on the cells which contain chlorophyll, since this action is essential to the formation of new organic compounds out of the absorbed nutrient substances. But when a certain quantity of assimilated substance has been produced under the influence of light, a long series of vegetative processes may be carried on at its expense without any further direct action of light.

The growth of new organs and the metastasis connecterl with it which takes place in the parts that do not contain chlorophyll, and 
which is maintained by the process of respiration, is to a certain extent independent of light, as is shown by the germination in the dark of seeds, tubers, and bulbs. But even leafy plants which have accumulated a sufficient quantity of reserve-material in the light, put out shoots, and even flowers and fruits, when placed in the dark. If, for example, the growing end of a branch of a green-leaved plant, such as a pumpkin or Troprolum, is made to grow into an opaque receptacle, the grcen leaves remaining still exposed to light, the buds will continue to develope in the dark, and new leaves and fowers to be formed which attain their full size and colour, the latter even producing fruits and fertile seeds. It is only rarely that the seclusion from light produces any perceptible effect on the development of the plant; though sometimes the flowers which are produced in the dark have an abnormally light colour. All this takes place at the expense of the food-material conveyed to them through the stem, which had been previously assimilated by the leaves exposed to light. In the same manner the underground parts of parasitic plants, or those otherwise secluded from the influence of light, carry on their existence to a certain extent independent of light; but are nevertheless indirectly dependcnt upon it, because they are nourished by substances which could only be formed under the influence of light. The earliest development of the plant seems to be even promoted by the absence of light or hy shade. Thus, for example, roots are formed on the stems of Cactus, Tropreolum, \&c. which grow in the dark, where they would never be formed in the light. The lower Algæ assimilate in the day-time, and form zoospores in the night, or, when placed in the dark, even in the day-time. The movement of the protoplasm on which the formation of the zoospores depends is not caused directly by the influence of light, but is rather interrupted by it. The direction of the movements of the zoospores stands, however, in some definite relation to light, their anterior end being always turned towards it. It has, nevertheless, been observed in some cases that they have a tendency to collect where there is a medium intensity of light, avoiding both deep shade and bright sunlight. The chlorophyll-bndies enclosed within cells are subject, in some plants, as Sagittaria sagittafolia, to a change of position, being carried by the currents of protoplasm to the region of brightest light. Finally the normal habit of plants is altogether determined by the direct influence of light. The internodes of the sten:s of bleached or etiolated plants grown in the dark are often elongated to ten or twenty times their ordinary length; while leaves of Dicotyledons and Ferns, which are normally broad and branched, remain, when grown in the dark, remarkably small. Under these circumstances the lamina of the leaf of Tropaolum attains scarcely from $\frac{1}{30}$ to $\frac{1}{20}$ of its 
normal size; the leaves of Ferns do not even unfold, and attain only $\frac{1}{100}$ or even $\frac{1}{1000}$ of their normal superficial development in the light.

White daylight consists of a mixture of rays of light, differing in their colour and their refrangibility; and it might be expected that the action of the different rays on the vital processes of the plant would not be the same. This is illustrated by the accompanying diagram (Fig. 373).

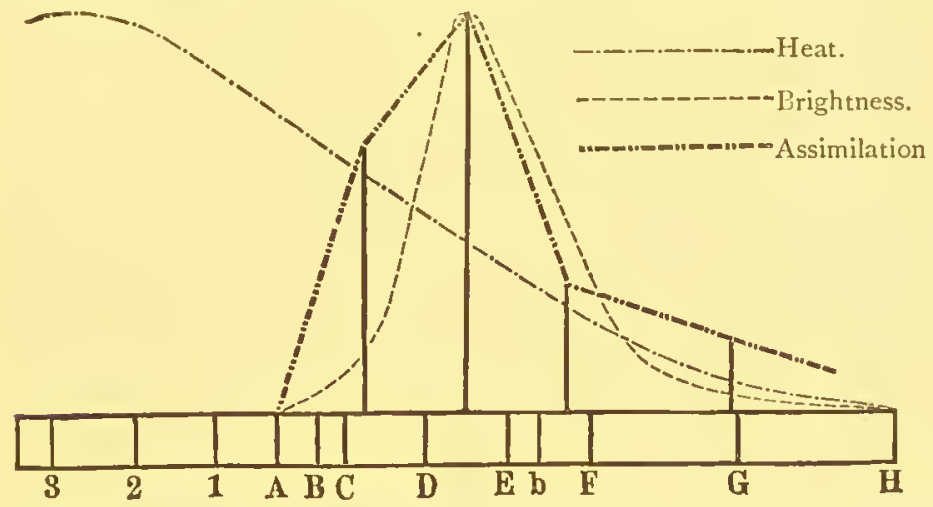

FIG. 373.-Diagrammatic representation of the efficacy of rays of light of different refrangibility in causing evolution of oxygen, compared with their brightness and heating power. The solar spectrum A $\mathrm{H}$ serves as a base on which Fraunhofer's lines are indicated: $A$ and $B$ lie in the red light, $C$ on the border of the orange, D in the yellow, $\mathrm{E}$ in the green, $\mathrm{F}$ in the blue on the border of the green, $\mathrm{G}$ on the border of the indigo and violet. $\mathrm{H}$ in the violet. The height of the three curves, of Heat, Brightness, and Assimilation, at any point, represents the intensity of the action. Thus assimilation is still slight at $\mathrm{G}$ on the border of the violet and indigo, and attains its maximum between $\mathrm{D}$ and $\mathrm{E}$ on the border of the yellow and green, then diminishing, and ceasing at $\mathrm{A}$ on the border of the red light. It is seen that the process of assimilation nearly coincides with the subjective brightness as shown in the colours of the spectrum, while the curve of heating power takes a totally different course and attains its maximum at a point where the eye is unable to perceive any light, and where no process of assimilation goes on in the plant.

The most important chemical process in the plant, the decomposition of carbon dioxide in the cells which contain chlorophyll and the elimination of uxygen resulting from it, proceeds almost as energetically as in white daylight, in a mixture of orangc, yellow, and green light which acts only slightly and very slowly on photographic paper. Blue, violet, and the ultra-violet rays, on the contrary, which at once colour photographic paper a deep brown, have no or very little effect on the elimination of oxygen. ${ }^{1}$ The samc relationship towards light has been shown

1 It is an established mode of expression to speak of the blue, violet, and ultra-violet rays as the chemically active, because they are cfficient 
to exist in the formation of starch in the grains of chlorophyll in the case of some Algx; and the starch already formed in the chlorophyll even disappears in a mixed blue light as in the dark. The green colour of Monocotyledons and Dicotyledons may be produced by rays belonging to all parts of the spectrum; but the action of the yellow rays is by far the most powerful; the red and the green have less power, while the blue, violet, and ultra-violet act very slowly. The action of light on the change in the tension of the tissues by which positive heliotropic curvatures are brought about, belongs to the more refrangible (blue and violet) rays; the red and orange appear to be altogether inefficient. The same is the case with paratonic irritation and the periodical movements of the leaves of various plants, as the scarlet-runner and Oxalis. On the movement of zoospores the less refrangible (red and orange) rays act like darkness, while the direction of the movement is determined by the blue and by the still more refrangible violet and ultra-violet rays.

Light from other sources than the sun, as that of lamps of various kinds or of a body glowing in an electric current (lime-light), appears, from observation, to have the same effect as sunlight, provided that the intensity and refrangibility of the rays are the same. This is especially the case with the electric light.

The chemical processes within the cells of a plant, the molecular movements connected with growth, and the internal changes on which the activity of the protoplasm depends-whether exhibited in the formation of new cells or in motility-are probably connected with disturbances of the electrical equilibrium. The fluids of different chemical properties in adjoining cells, the diffusion of salts from cell to cell, their decomposition, the evolution of oxygen from cells containing cllorophyll, the formation of carbon dioxide in growing organs, and the process of transpiration:-all these vital processes must produce electrical currents; although this fact has not yet been experimentally determined or accurately investigater. It has, however, been established that the internal tissue of land-plants is always electro-negative to the strongly cuticularised surface, and that a similar relationship subsists between the surface of roots saturated with sap and the surface of the stem and leaves. Electrical currents which are not too strong only temporarily arrest the motility of protoplasm and the movements of the sensitive parts of plants, while stronger currents destroy the life of the protoplasm, and hence of the plant.

in the combination of chlorine and hydrogen into hydrochloric acid, the colouring of photographic paper, \&c. But with reference to the vital processes of the plant this term is inaccurate, and ought to be abandoncd. 


\section{The Life of the Plant.}

Since gravitation acts uninterruptedly on every part of the plant, all the parts must be so contrived as to diminish the influence of this force; and we find, in fact, in the organisation of the plant, a number of contrivances for this purpose. The firmness and elasticity of the wood of erect stems; the uniform distribution on all sides of the weight of the foliage and of the branches; climbing and twining internodes which are sensitive to contact, and the various othcr contrivances that enable slender stems to climb which could not otherwise maintain themselves in an erect position under the weight of their leaves; the floating apparatus of floating plants, such as the air-bladders in the fronds of Fucues and in the leaf-stalk of Trapa, and those of Uiricularia (Fig. 356, p. I84), the floating apparatus, such as the pappus or wings, of many seeds and fruits; and a number of other specialities of organisation, all serve to counteract the weight of the plant, and to prevent its sinking to the ground where this would be unfavourable to the other functions of the plant. L'nder the head of the tension of tissues it has alraady been mentioned that young and weak plants in which there is no tension tend to grow downwwards in accordance with the force of gravitation; while those in which there is tension lave a tendency to grow erect; and this is the reason why roots in general grow downwards and stems upwards. But the influence of gravitation on plants is not yet exhausted, since it opposes a resistance to all internal movements, such as those of water and of the cell-sap whenever their direction is upwards, which resistance the plant must overcome by its intermal forces. Light and gravitation are the forces which give to the separate parts of plants, such as the stem and leaves, their normal position, whether erect or horizontal, and therefore, along with the arrangements of the buds and leaves, impart to plants what is termed their Habit.

From the infinite variety of the conditions of life, it is evident that plants must possess a certain power of adaptation to their external conditions.

This is seen especially clearly in amphibious plants, which live sometimes in watcr, sometimes on dry ground ; and in climbing plants. Thus for example, the terrestrial form of Polygonum amphibizm, with its erect stem and shortly-stalked narrow hispid leaves, is easily transformed, by simply transplanting into water, into the floating form with foating long-stalked glabrous leaves. The branches of the terrestrial form then soon ccase to grow, their leaves dry up, and the new plant of the floating form is dcveloped from the rhizome. 
ABNORMAL VITAL PHENOMENA AND CONSEQUENT ABNORMAL DEVELOPMENTS.

That section of botany which treats of the abnormal vital phenomena and the consequent abnormal developments of plants, is called Vegetable Pathology; and may be divided into two subdivisions, Teratology or the study of malformations, and Nosology or the diseases of plants. The former is concerned with deviations from ordinary structure in the organs of the plant, the latter with variations in the vital functions. This whole subject, therefore, independently of its practical importance, is also of great scientific interest, the former part especially in relation to morphology, the latter to physiology. It is, however, impossible to draw any sharp line of demarcation between malformation and disease, and often one cannot be conceived without the other.

The causes of the phenomena now under consideration lie in a want of conformity of the plant, partly to the conditions of its environment, partly to those of other plants, and partly also in injuries inflicted by animals. In a certain sense also, treatment by man may be a source of abnormal vital phenomena; inasmuch as he prescribes the conditions in which the plant shall grow. Most cultivated plants live in conditions which were foreign to their uncultivated ancestors, and they have frequently undergone such change that their parentage cannot be recognised. It is, indeed, often the object of cultivation to cause such deviations. Thus, the brussels-sprout is cultivated on account of the monstrous edible thickening of the stem, and the cauliflower on account of its peculiarly metamorphosed inflorescence. A very high cultivation produces, however, other modifications besides those aimed at, and less desirable in themselves. Thus, there is no doubt that the cultivation of fruit-trees has resulted in an enfeeblement of their vege- 
tative organs, and a shortening of the duration of their lives. The same is the case with those plants which man has transplanted from warmer to colder climates or the reverse, or has attempted to acclimatise. In order to understand this, it is only necessary to observe the weakly specimens of tropical plants in our conservatories, and to compare with them drawings made in the primeval forests of their native country. In short, it may be assumed that all cultivated plants are, to a certain extent, disposed to deviate from their ordinary structure; and it cannot, therefore, be wondered at, that they are especially liable to malformations and diseases.

Attention must first be directed to those deviations which are caused by atmospheric influences, or by the nature of the soil. Light, warmth, and moisture, as well as the nature and chemical composition of the soil, are here the active factors; but as to how these act very little is at present known, except what has already been said in the section on the general conditions of plant life (see p. 208). The changes brought about by these influences affect the size and number, the arrangement and shape of the individual organs, in short, the external form of the plant; but they also cause an abnormal activity of cells, from which results a more or less complete disturbance of metastasis and of the processes of life.

The change in size may be partly due to abortion, partly to an abnormal increase in size of the organs. The abortion of the primary axis shows itself, as a rule, only in the form of dwarfing, that of larger or smaller branches occurs in its purest form in the production of spines. Several families of plants, such as the Rosaceæ, are especially distinguished by the frequency of branch-spines whenever the species grow on sterile ground. Like the branches, the leaves can also degenerate into spines. Thus, many species of Berberideæ and Grossulariex develope spines in the place of particular leaves; and these often, as in the gooseberry, 
remind one in their form of the three or five-lobed leaf. The abortion of leaves does not, however, always lead to the production of spines. In many species of acacia the lamina is so little developed, that nothing remains but the petiole, which is then called a phyllode (Fig. I 43, p. 90); and in some species this transformation of the leaf is so common that it can scarcely be considered as abnormal. All these peculiarities, so far as they are not hereditary, i.e. transmitted through the seed, are due to the poverty of the soil. As poverty of soil leads to abortion, so an unusual increase in development of the axial or foliar organs is usually the result of too powerful nutrition; either the transmission of nutrient substances from the soil is in itself too abundant, or a want of due proportion between the parts above and below the surface is caused by too vigorous cutting away of branches or leaves. The latter course is generally pursued by gardeners, who aim at obtaining unusually large fruits or flowers by cutting away blossoms, young fruits, leafy shoots, \&c. Finally, it has already been stated that an unusual development of the stem may result from a deficiency of light; and this is always the case in the etiolated parts of many plants.

Abnormalities in the number of organs are not uncommon. In the clover, for example, an increase in the number of leaflets of the normally trifoliolate leaf is frequent. In the dédoublement or 'doubling' of flowers again, to which more particular reference wll be made hereafter, in addition to the transformation of one of the floral organs into another, as stamens into petals, there is generally also a multiplication of the floral whorls; for example, in place of a single whorl of stamens, two whorls of petals, \&c., as happens in the pink, which has normally only five petals and ten stamens, but when double, often twenty or more petals. The change in the relative number of parts is not however, always in the way of increase, but as often, perhaps, of a diminution of the number of the organs concerned. 
Every part of the plant has, when young, the power of adhering to others in its growth, and does actually do so. whenever its formative tissue or cambium comes into contact with that of other parts. This fact, so important for the processes of grafting, budding, \&c., is also of some importance in this connection, because very peculiar malformations often result from such adhesions in growith between neighbouring plants or parts of plants. It is very common, for instance, to find the pinnæ of Gleditsitic tria. canthos united with one another in such a manner that the bipinnate leaf becomes a simply pinnate or even a simple leaf. Separations of organs which are normally united in their growth also sometimes occur. If, for example, a mallow is made by prolonged cultivation to become double, this change begins by the filaments which were previously united into a single bundle separating from one another, each stamen then becoming transformed into one or more petals.

Of much greater importance than changes in the number, size, and position of the parts of plants, are those which relate to their form. The most common and interesting change of this kind in the stem is the phenomenon known as fasciation. This consists either in the stem becoming flattened, and hence assuming a ribbon-like form, or in its beginning to divide irregularly into a number of branches, which at once coalesce laterally with the main branch, [or from the cohesion of a number of buds]. Fasciation occurs especially in ground that has been excessively manured, and hence very commonly in cultivated plants. In them it is often inherited through the seeds, as, for example, in the garden-plant known as 'coxcomb,' Celosia cristata, and in the cauliflower, in which the thickened fleshy branches of the inflorescence have coalesced to form. a head or mass covered in the upper part with ahortive flowers. As in the last case, abortion is almost always associated with fasciation. For while the fasciated part of the 
stem becomes itself inordinately developed, the buds which are normally produced on it in large numbers either remain altogether dormant, or give rise to weak immature organs or a few fasciated or, less often, separate branches. The terminal bud almost invariably ultimately Gisappears. Fasciation is frequently associated with curvatures, causing the production of peculiar forms resembling sickles or crosiers, as is not uncommon in the willow and ash.

Far more numerous are the changes in form which affect the leaves. These may be classified into Metamorphosis of Leaves, Peloric Formations, and true Changes of Form.

Goethe was the first to propound the theory, though somewhat poetically, that all the organs of the higher plants can be referred back to a single, or at least, to a very small number of fundamental forms ; that, in fact, every organ is either axial (stem), or foliar (leaf), or is compounded of these two. That this is actually the case is shown, not only by the history of development, but also by a close investigation of those abnormal processes which are called metamorphosis. According to Goethe a foliar organ must be considered the more highly developed the higher it stands on the axis of the plant, the nearer therefore it is to the centre of the flower; and an ascending series can be constructed as follows:-Leaf-spine [Scale-leaf], Foliage-leaf, Bract, Sepal, Petal, Stamen, Carpel. The metamorphosis may be either progressive or retrogressive, according as the transformation of the foliar organs takes place in the direction of a higher or lower member of the series. Instances of retrogressive metamorphosis are furnished by the production of leaf-spines and leaf-tendrils already mentioned, which may be considered as consisting essentially in an abortion of the lamina and a reduction of the leaf to the lignified petiole or mid-rib. Equally common is the retrogression of bracts to the form of foliage-leaves; as in the spathe of Aroider, which often has a leaf-like form. The retrogression of 
sepals into bracts or foliage-leaves is still more frequent, a common and beautiful example of which occurs in the calyx of the rose. One of the best known instances of metamorphosis of the reproductive organs into perianth-leaves is furnished in the case of the common garden tulip, in which the three carpels and the six stamens are all transformed into. ordinary petals; [and the same is the case with the greater number of double flowers, as the rose, camellia, pink, \&c.]. That these leaves are actually lower stages of development of the organs, is shown very clearly in an imperfectly double tulip, in which some of the leaves are divided through their mid-rib into two altogether unlike halves, a half-stamen and a half-petal. These imperfect transformations are also frequently seen in the peony and the water-lilies (Nymphriceæ)-[in the case of the white water-lily, Nymphaca alba. even in the wild state]-these instances affording convincing proof that the 'doubling' of flowers is due to retrogressive metamorphosis. It has already been mentioned that this metamorphosis is very commonly accompanied by an increase in the number of parts of the flower; and it is not surprising that such retrogressions should also be associated with abortion. Perfectly double flowers are of course sterile; but even when the metamorphosis affects the stamens only, the pistil is in that case also always less perfectly developed, and less or even not at all capable of being. fertilised by pollen from other flowers. In many cases the doubling is only apparent, as in the cultivated Compositæ, such as the aster and dahlia, in which the altered appearance is produced by the transformation of the yellow tubular flowers of the disc into ligulate flowers of a different colour; but sometimes only by the increase in size and change in colour of the tubular flowers. In this case also. the transformation is usually associated with sterility. When the retrogressive metamorphosis goes back still further than in the doubling of flowers, the brightly coloured. petals lose their colour, and the flower becomes green. 
Such instances of chloranthy are common in the Leguminosæ, and especially in clover.

Instances of progressive metamorphosis are much less common, though a number are to be met with. The most common example is the metamorphosis of petals into stamens. It is not uncommon to find the shepherd's purse, Capsella bursa-pastoris, with ten stamens and no petals, the normal number being four petals and six stamens. A metamorphosis of stamens into carpels is also not unusual in willows, making them apparently monœcious, whereas they are normally diœcious.

Changes of form arising from the metamorphosis of whole parts of plants may be divided into four groups :- the solution of flowers or Antholysis, Prolification, Gemmation, and the Metamorphosis of Buds. By antholysis is meant those separations of the parts of the tiower by which their relative number and position are so altered that the normal construction is completely concealed. Prolification is the elongation of the apex of the floral axis above the flower, where it bears fresh buds, leaves, and flowers, as occurs normally in the syncarp of the pine-apple, and not unfrequently in roses [and pears]. Gemmation is the production of buds in the axils of the floral leaves, which then develope into new flowers or inflorescences, as is not unfrequently the case in the capitula of Scabiosa and Dipsacus. Finally, it is not uncommon for leaf- or flower-buds to be transformed into fleshy bodies with small scale-like leaves and a very short fleshy axis. These buds, which often serve as a reservoir for the reception of assimilated reserve-materials, very commonly grow, when detached from their parent-plants, into independent plants. Species in which this phenomenon commonly occurs [as Polygonum viviparmm, Poa vivipara, \&c.], are called viziparous. In the above and some other species it occurs normally, and is not uncommon in many natural orders, as Liliacex, Gramineæ, Cyperaceæ, and Juncaceæ. The buds in the axils of 
the leaves of Lilium bulbiferum (Fig. 350, p. I79) and in the inflorescence of many species of Allium come under this head.

Closely connected with metamorphosis is peloria, or the abnormal regularity of flowers usually irregular but symmetrical, i.e. so constructed that there is only one line by which they can be divided into two similar parts. This phenomenon is most common in Gramineæ, Leguminosæ, Labiatæ, Scrophulariaceæ, and Violaceæ. In the common toadflax, Linaria zulgaris, for example, in which the perso-. nate bi-labiate corolla runs out into a spur, the terminal flower of the raceme not unfrequently exhibits complete peloria, i.e. has a regular margin, and five spurs at equal distances from one another. In Compositæ, peloria frequently takes the form of a conversion of the ligulate into tubular flowers.

The last class to be mentioned is the change in the external form of leaves, the result of an irregular accession or suppression of growth from disease. Deviations from a symmetry between the right and left side of the leaf occur normally in some plants, as the various species of Regonia [and lime], and occasionally in almost all plants. The relationship between the length and breadth of the leaf is also often disturbed. A difference frequently occurs between the intensity of growth of the vascular bundles and of the parenchymatous tissue (mesophyll) which occupies the space between them. When the vascular bundles grow more vigorously than the parenchyma, the latter is ruptured, and the leaves become perforated or slit, as is always the case in old leaves of the banana [and in some Aroidex, Fig. r94, p. ro6]. When, on the other hand, the growth of the parenchyma exceeds that of the vascular bundles, the leaves become crumpled, as in many garden-plants such as endive, parsley, \&c. More rarely, outgrowths are developed on the surface of the leaf, which themselves assume a leaf-like form.

In all the cases hitherto mentioned we have treated only of changes in form. But diseases are also caused through 
the influence of the soil, depending on an abnorrnai transformation of those substances out of which the tissue of the plant is constructed. These constitute what are called secretional diseases, in which cellulose is transformed into gum, resin, or manna. These diseases are, properly speaking, only excessively vigorous phenomena of vital functions which in many plants are quite normal. It is remarkable that effusions of sap of this nature are often the result only of external injury, and are commonly increased by removing the substance excreted, as in the production of resin.

The consideration of secretional diseases leads to that of diseases of decomposition. These diseases, which are frequently confounded or blended with the former-known generically as gangrene or canker-are processes of decay in which the cellulose is transformed into a muddy fluid, a brown humus-like powder, or a carbonaceous mass, such as never occurs in a normal state. Decompositions of this nature are promoted, or, perhaps, are first caused, by swarms of low inicroscopic organisms, Fungi and Alga, which find in the dissolution of the organic substance a favourable substratum for their development. It is impossible to enter in this place on a more minute discussion of the processes of fermentation, decay, and putrefaction, and of the points. which are still in dispute as to the part played by the organisms which always accompany these processes, and as. to their systematic position. It is, however, certain that diseases of this kind are characterised by the presence of organisms, and are by this distinguished from secretional diseases. In reference to the external form in which they present themselves, a distinction is to be drawn between moist and dry gangrene, according as the product of decomposition of the cellulose is a fluid or a solid substance. The latter form very commonly first attacks the innermost layers of wood, which may be, according to the colour of the substance formed, red or white. Plants attacked by decay may 
still live a long time under certain circumstances, and may have a perfectly sound appearance on the outside, until the disease reaches the cambium-layer, when they quickly perish. The decomposition of cellulose does not, however, always begin inside the plant; it may also penetrate from without, at spots which have become diseased from external injury.

Diseases of another class, produced by vegetable parasites, that is by plants which. derive their nourishment from the living tissue of the plants they inhabit, are in general less obscure than those which were last described.

Among these parasites are certain Fungi (Fig. 374), which are of the greatest practical importance. The ques-

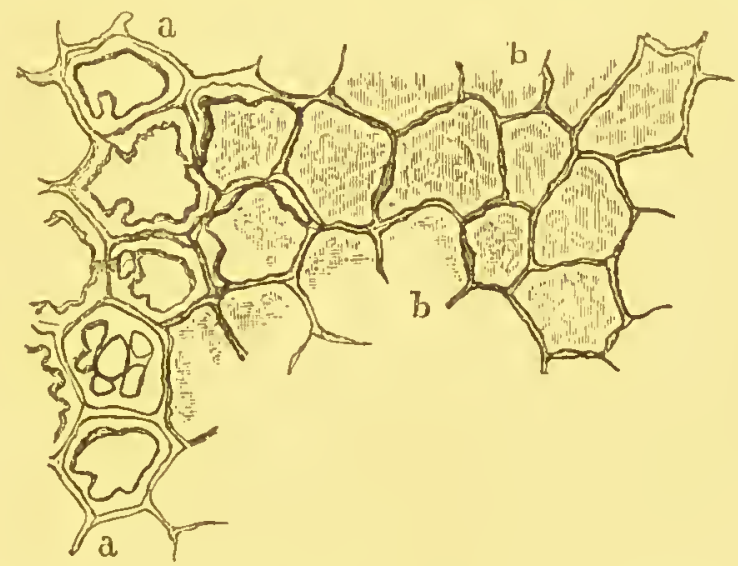

FIG. 374,-Destruction of the cell-wall caused by a Fungus : transverse section of the wood of a beech; at $a, a$ the destruction of the secondary layers is still in progress : at $b, b$ the entire cell-wall has been destroyed with the exception of a larger or smaller residue of the primary layer, and the cell-cavity filled with
an amorphous substance.

tion which has often and for a long time been discussed respecting these plants, whether they are the cause or only the accompaniment of the disease, has now been decided in favour of the former alternative, since it has been proved that the organisms in question are well-defined species of Fungus, and that the same organism is always found to accompany the same disease. In addition to this, it has been 
proved by a number of observations and careful experiments, that these diseases are contagious, and that healthy plants become subject to a particular disease when the spores of that Fungus are sown upon them which always. occurs in connection with that disease; and that, finally, the best means for preserving or restoring the health of the plant are those by which the spores of the Fungus are destroyed. This does not, however, prevent other Fungi occurring as accompaniments of the particular disease besides the one to whose attacks it is due.

Among the most important of the diseases of this nature to which cultivated crops are liable is the rust or mildew" of cereals. This term is appropriately given to a disease in which, at least at first, reddish masses of a brown rust-like dust break out from the internal tissue of the plant. It is most common on barley, wheat, and oats, less so on rye and wild grasses. Since it chiefly attacks the vegetative parts, the leaves and succulent stems, and but rarely the seeds, the injury caused by it consists mainly in a deterioration of the straw ; but the grains are also of inferior quality, when the parts which contain chlorophyll, and which consequently assimilate, are attacked at an early stage. The species of mildew which infest cereal crops are mainly two, Puccinia graminis (Fig. 400, p. 277) and P. coronata. The very remarkable course of development of the latter will be afterwards more exactly described when speaking of Fungi.

Smut shows itself first on the organs of fructification, the epidermis of which is irregularly ruptured in a great number of places, a black dust then appearing through the slits. It attacks the different parts of the flower in a very unequal degree. The whole of the parenchymatous tissue is often destroyed; and this occurs to so great an extent in winterbarley, that of the whole ear the common rachis of the inflorescence alone remains, while frequently, as in oats, the seed only is destroyed, the paler remaining unaffected. Especially in the last stage of the disease, the masses of 
dust also emerge from the culms beneath the flowers, as well as from the leaves. Rye and wheat are also subject to this disease, wild grasses less so. It is caused by the attacks of a Fungus, Ustilago carbo, the black masses consisting of its emerging spores which project between the paleæ, the mycelial threads obtaining their nutriment from the interior of the parenchymatous cells.

The smut of maize and millet are of a similar character. In the former swellings the size of the fist or even of the head are formed in the diseased part, between the cells of which the filaments of the Fungus which produces the disease, Ustilago maydis, are easily found. The millet-smut, caused by Ustilago destruens, destroys the whole of the flower even within the leaf-sheaths.

Bunt is a disease which attacks all kinds of wheat, but the varieties of spelt have less to fear from it than other sorts, and winter- less than summer-wheat. The Fungus which produces this disease, Tilletia caries, fills up with its spores the whole of the ovary, and replaces it by an elongated, black, greasy body of a disagreeable odour. The mycelium is easily found in the parenchyma of the flower.

Ergot is another Fungus of this kind, which attacks the inflorescence of grasses, and especially of cereal crops, appearing in the place of the fruit in the form of an enormously large grain among those that are still healthy. In form it resembles, therefore, the grain which it attacks ; in rye, for example, it is obtusely triangular, and in Phragnites flatly compressed. It is the 'sclerotium' of a Fungus which grows from the base of the ovary, and soon detaches it from its point of attachment, raises it up and then encloses it or presses it aside. Ergot, although it seldom occurs in any great quantity, is one of the most dangerous vegetable parasites of cereal crops, since it contains a powerful poison, on account of which it is valuable in medicine, but which renders the meal quite useless when ground 
with it. The various stages of development of the ergot of rye received a number of different names before their connection with one another had been ascertained. Thus the delicate mycelium from which ergot originally springs has been called Sphacelia segetum, the ergot itself Sclerotium clavns, Secale cornutum [or 'spurred rye'], and the fructification which developes from it (Fig. 375) Claviceps pur-

B.

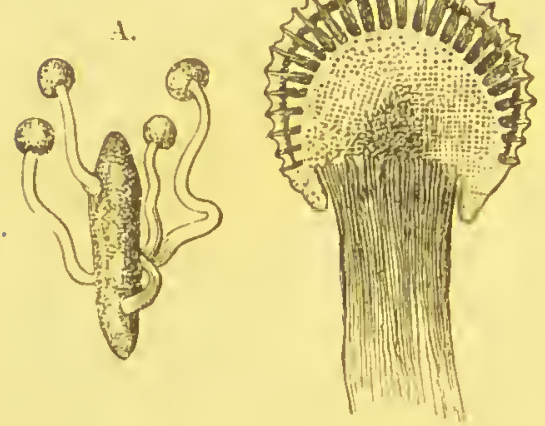

FIG. 375. - Ergot; A, with four fructifications (natural size); $\mathrm{B}$, longitudinal section through a fructification with its perthecia. (Magnified.)

purea; the last being the name now given to the Fungus.

Mention must also be made of a number of diseases about which but little is yet known, and which have this in common, that they appear as black velvety coatings on the leaves, and especially on their upper side. There seems to be frequently, but not invariably, a connection of alternation between the "honey-dew" caused by aphides and these diseases, the aphides encouraging the settlement of the Fungi, Saccharomyces and Cladosporizm, which give rise to the latter.

A similar appearance is presented by vines attacked by the vine-mildew, Erysiphe Tuckeri. The course of this disease is, in its essential points, as follows :-A delicate white shining growth is seen, as a rule after the blooming-time, and at first on the under side of the leaves, then on all the young parts of the vine (Fig. 376), which finally invests these parts more and more completely, without, however, penetrating into the interior, as it only puts out short organs of attachment here and there. These drain the

1 Honey-dew is a sweet juice exuded by varions species of Aphis; [or believed by some to be an exudation from the leaf itsel]]. 


\section{The Life of the Plant.}

epidermis; the grapes remain small, and finaily burst, the fleshy interior being forced out of one or two intersecting clefts.

The English gardener Tucker was the first to remark, in the year I 845 , the Fungus which was named after him, but without recognising its nature. The disease appeared at Versailles in 1850 ; and in $185 \mathrm{I}$ under various conditions, and in widely scattered districts, in France, Italy, and Germany. In Madeira, the vine, which had been cultivated since the fifteenth century, was attacked in $\mathrm{I}_{52} 2$; in several succeeding years the crop completely failed; and this induced the inhabitants to abandon the cultivation of the grape for that of the more profitable

A

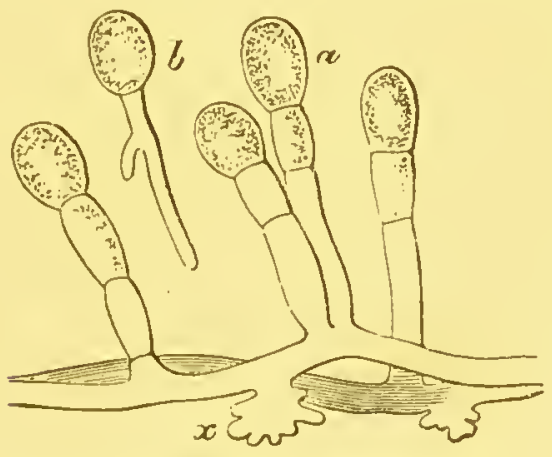

B

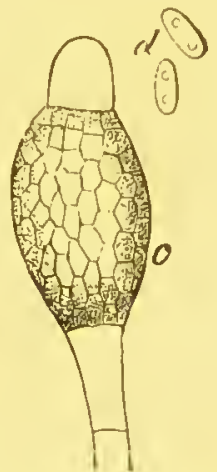

FIG. 376.-The vine-mildew : A, the fungus Erysiphe Tuckeri; $a$ the conidiospores becoming detached; $x$ the organs of attachment, or haustoria ; $b$ a germinating spore $(x+400)$. B, $c$ a fungus (Cicinnobulus Cesatii) parasitic on the Erysiphe, and formerly regarded as a special mode of reproduction of it $; d$ its spores ( $x 450$.)

sugar-cane; so that for twenty years after I ${ }_{5}$ I scarcely any Madeira wine was produced. From that time the disease, favoured by damp warm weather, has spread locally to the whole of Europe, no remedy having been up to the present time discovered for it.

Next to the vine-disease the plum-disease is one of the most destructive parasitic diseases of the different kinds of stone-fruit. The malformations produced by it, and known under the name of 'pods' and 'pockets,' are distinguished from the dark juicy fruit covered with a bluish bloom by their greater length and flatness, by the want of the hard stone, and by their invariably lighter colour. The prema- 
turely ripe fruits fall off and are worthless. The cause of the disease is a Fungus, Exoascus Pruni.

The Potato-disease makes its appearance first on the

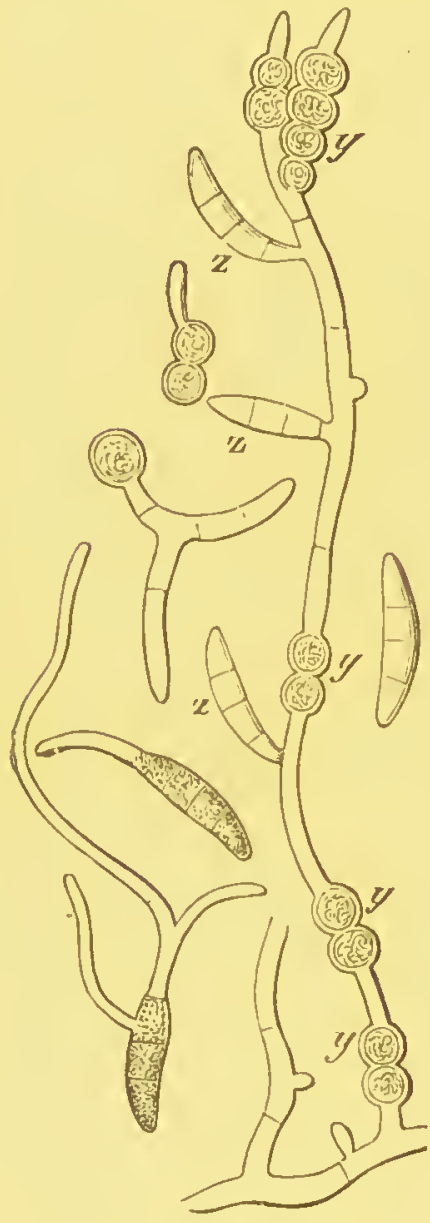

EIG. 377.-Fungus-filaments from a rotten potato, together with the spherical spores $y$ called Oidium violaceum, and the long ish multicellular spores $z$ of Frisisporium Solani; young plants are germinating from both forms. (This tungus very commonly accompanies, but is not the cause of, the discase. $\times 400$.) green parts of the plant, forming brown spots on the leaves and stems, usually in July and August. A short time afterwards the tubers are found to be diseased, and begin to decay. The decomposition is either moist and of a disagreeable odour, or ends in a drying up of the tissue; the former kind being generally described as the true potato-disease, although the two forms pass into one another. It is only rarely that the decay of the tubers precedes the sickening of the plant itself. The parasite which causes this disease is also a Fungus, Phytophthora infestans (Fig. 397, p. 273). It penetrates the tissue of the leaf, its conidia-bearing flaments projecting through the stomata. The tissue of the leaf dies under its influence, and the tubers which are subsequently attacked also decay (Fig. 377).

The true potato-disease broke out about the year 1830 , and spread with terrible rapidity during the next ten years ; and has never since entirely disappeared. Its study suggested a variety of causes: among the rest damp weather, too strong manuring, and the cutting up of the 'seed-potatoes.'

A peculiar disease, also caused by a Fungus, but which 
has not yet been sufficiently investigated, is one of considerable practical importance, the beet-disease. It shows itself sometimes in the winter, its presence being manifested by the root becoming light-brown and transparent from without inwards.

The diseases to which bulbs are subject have been but little studied. In the ring-disease, called also the hyacinth-pest, rust-coloured spots spread from the disc over the scales, advancing from below upwards. The innermost scales are first attacked, the leaves turn yellow, the flowerstalk decays, and finally the whole bulb degenerates into a muddy mass. The so-called white smut consists in the bulbs rotting from above downwards under the influence of a white slime.

Besides the diseases already named, there are many others of less practical importance caused by parasites. Of these causes of disease, phanerogamic parasites are in general less injurious than cryptogamic. Of the former there are only a very few natives of Europe, the mistletoe (Viscum album), Loranthus europaus, Lathraa squamaria, the dodders (species of Cuscuta), the various species of Orobanche, Monotropa Hypopitys, and Thesium humifusum.

The mistletoe usually grows on the apple, but also on other trees. It weakens the trees which it attacks by the penetration of its sucking-roots (Fig. 378 r.), and causes the formation of knots, sometimes killing the branch on which it grows, or even the whole tree.

The various species of Cuscuta (dodder) germinate in the ground, and only subsequently strike their roots into the neighbouring ' host:' but they also develope above ground their 'haustoria' or sucking-roots at those spots where they come into contact with the plants which they embrace. $C$. europae grows readily on hedges and thickets, and attacks the hop, [stinging-nettle], hemp, and other herbaceous [and shrubby] plants. C. epilinum is exceedingly destructive to fiax. C. Trifolii (Fig. 378 I r.) is especially injurious to fields 
of clover and lucerne, spreading itself centrifugally from. single points, and entirely destroying the vegetation. $C$. epithymum is indigenous, chiefly on gorse and heather.

Of the species of Orobanche or broomrape, which mostly grow on the roots of wild plants, the only ones of practical importance are O. minor and ramosa.
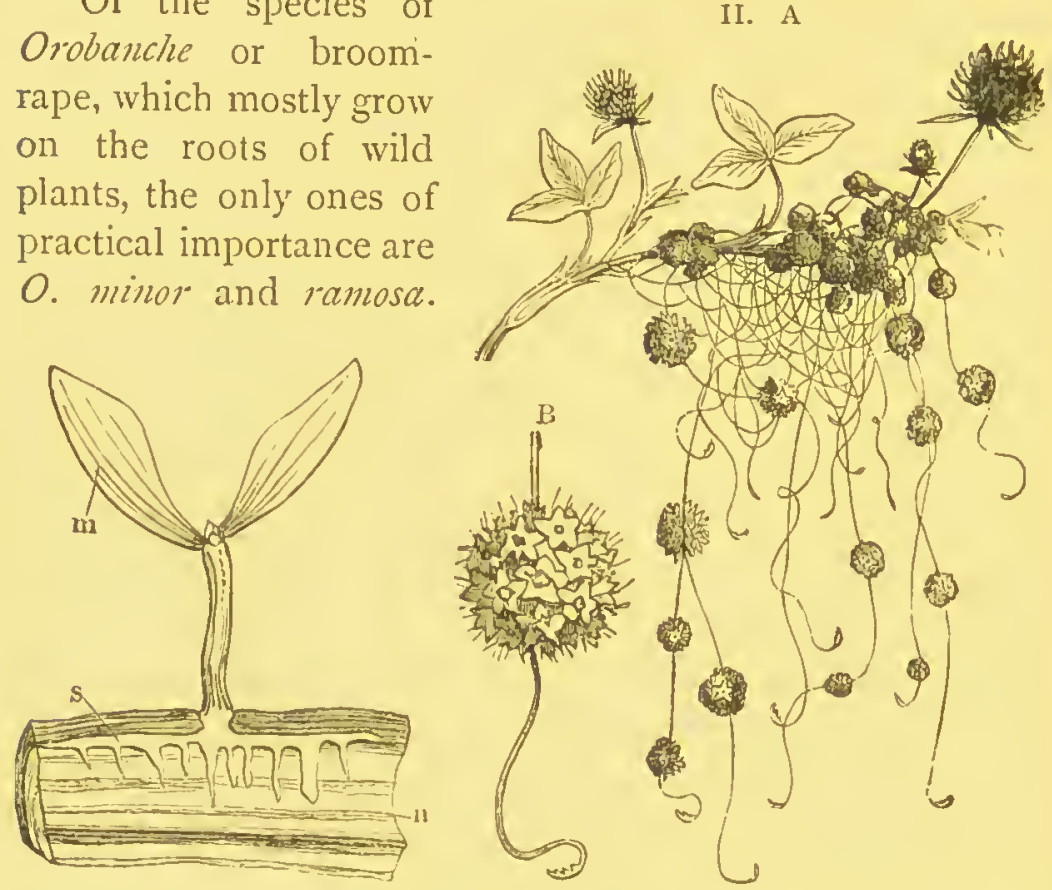

FIG. 378.-I. $u$ a piece of a branch of an apple-tree cut through lengthwise, into which a young mistletoe-plant $m$ has driven its sucking-roots $s$ (reduced); 1 I. Cuscuta Trifolii: A, parasitic upon clover (reduced); $\mathbf{B}$, a separate inflorescence (natural size).

The former occurs especially on clover, while the latter mostly attacks hemp, but also tobacco and nightshade (Solimum); (see Fig. 346, p. I66).

The remaining phanerogamic parasites named above have but little scientific interest; to them may be added the various species of Melampynum, Rhinanthus, and Pedicularis. No further notice is required of the phanerogamic parasites of tropical and subtropical primeval forests, \&c., belonging to the natural orders Balanophoraceæ, Rafflesiacea, Loranthacee, \&c.

Besides these parasites, there are various flowering plants 
which are injurious as weeds, depriving other plants of light and nourishment and therefore of the most essential conditions of life, or themselves stunting them in their growth by climbing over or twining round them, and dragging them to the ground.

Reference must finally be made to epiphytes, or those plants which only grow on other plants without deriving nutriment from their tissues. Plants of this class which occur in our zone, for example, many Mosses and Lichens [and some Ferns], can scarcely be considered as pathogenous.

The injuries which plants receive from animals are extremely numerous and various. When the injury is to the root, it results in an insufficient supply of nutriment to the plant; when, on the other hand, it is the leaves that suffer, the absorbed food-materials are not assimilated in sufficient quantity, and the plant suffers from weakness or exhaustion. Injuries to the bark cause 'bleeding,' gangrene, or decay. There are also a number of animals that live in or on plants, which, without visibly injuring them externally, cause an irritation in the parts of the tissue affected which results in morbid phenomena. It is common, for example, to see the leaves of the hop, cabbage, and other plants, crumpled up into blisters and rendered unhealthy by the attacks of some species of aphis on the under side. The form of these abnormal productions is usually so characteristic that it is possible from them to determine the animal by which they are caused, and vice versâ. Thus, aphides, which lay their eggs in the plant, cause blister-like swellings, in which the larva live until the period of their metamorphosis, at the expense of the plant. The structures which they produce, and which are generally not injurious, are sufficiently well known in the lime, hazel, elm, and other trees and shrubs. Willow-galls and rose-galls are a somewhat higher form of these bodies. The former are produced especially on willows by the puncture of the Cecidomyia 
strobitina in the leaf-buds, which causes arrest of growth, the stem scarcely developing, and the leaves becoming
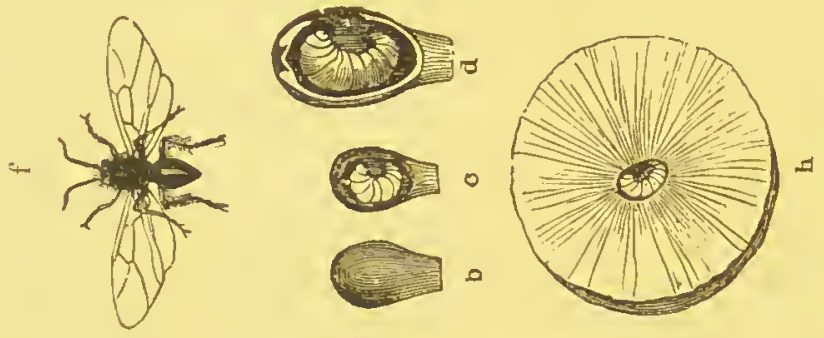

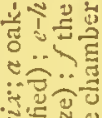

-

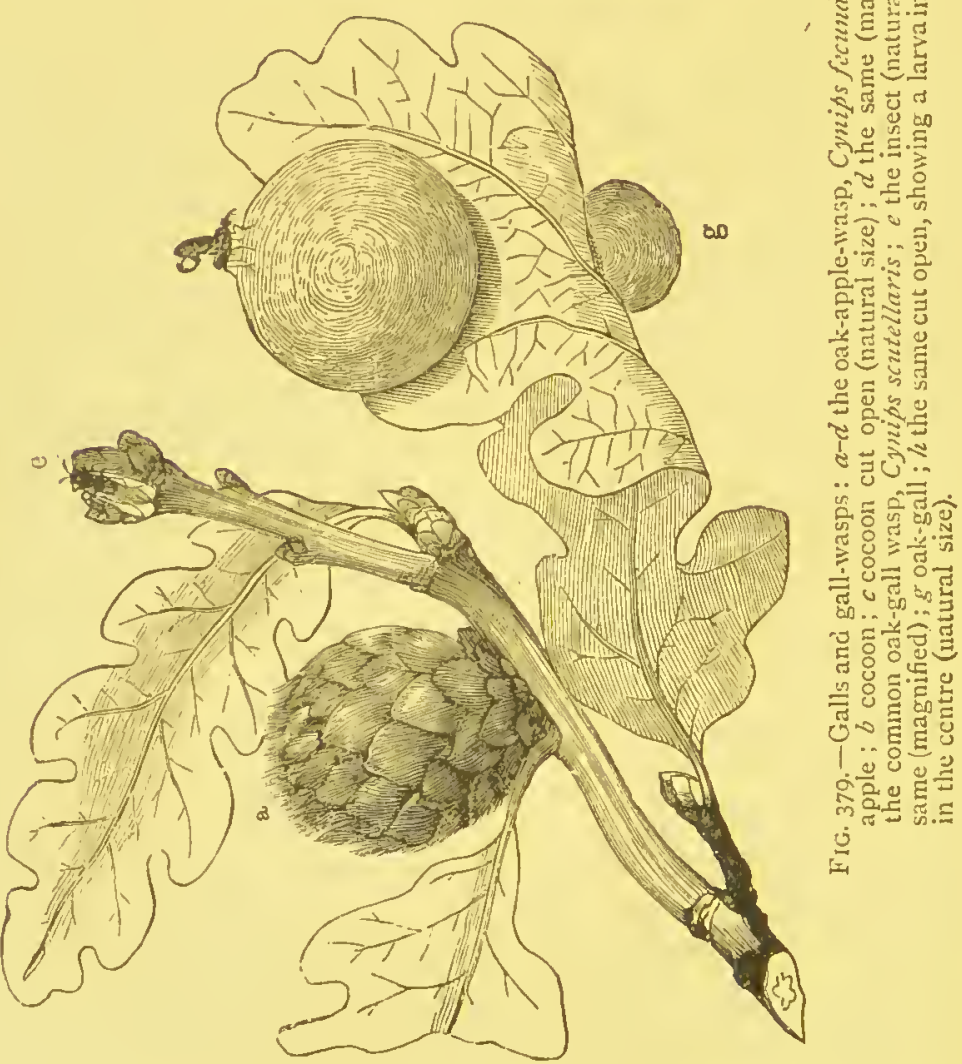

ษ

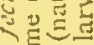

空㟧 的

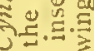

ㄴ..ำ

过..

ㄴ.?

론

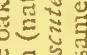

$\triangle \approx$

$\because 0 \div$

जु‥

जि

证

邻露的可

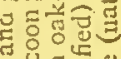

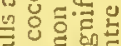
ㅇ.. है

원

लि

可

crowded together into a close rosette. The rose-gall is caused by Rhodites Rose laying its eggs in the branch, the stem then swelling up to a considerable size from the exu- 
berant growth of the parenchyma, while the leaves are produced in ordinary numbers, but with scarcely any parenchyma between their fibro-vascular bundles, causing the misshapen branch to appear as if covered with moss. The highest form of development of these structures is seen in the true galls, the production of which is due to punctures made in the leaves, flowers, fruits, buds, and young bark by the female gall-wasp, belonging to various species of Cynips, which then lays its eggs in the wound. The various kinds of gall are most abundant on the oak-tree, on which the itotal number of species that have been observed is upwards of 150 . The best known is the common oak-gall, produced by the puncture of Cynips scutellaris on the under side of the leaf (Fig. 379). ${ }^{\mathrm{I}}$ As morbid phenomena galls are usually of but small significance. Whether they are regarded as the nidus of a number of useful insects, or, many of them, as articles of considerable value in commerce, their usefulness greatly exceeds the injury which they inflict on the plant.

It would occupy too much space to enumerate those animals which are hurtful to the plant by the extemal injuries inflicted by feeding on them, \&c. The part which insects play in this respect is well known to every observer of nature.

\section{AGE AND DEATH OF PLANTS.}

If the life of a plant is not shortened by any disease, and if no animal or man appropriates it to its own purpose, gathers it, and kills it, its term of life is still usually limited. Some die after they have once produced fruit [monocarpic plants], one or two years [amnual or biennial plants] being required for their development; while others [polycarpic plants] produce fruit many times and live for many years, attaining sometimes an enormous age. The silver-nir sel-

' [Oak-spangles are smaller, flat bodies, produced also on the under side of oak-leaves by the attacks of an insect, Diplolepis lenticularis. 
dom flowers under thirty or forty years; the Scotch fir and larch, on the other hand, produce cones in ten or twelve years; the oak and beech, again, only flowering when they have attained a considerable age. The Scotch and spruce-fir attain their full height, as a rule, in from so to roo years, while the silver-fir requires a longer period. The annual rings of the beech usually become less distinct after I $_{30}$ or I 50 years, while the regular increase of the oak in girth does not diminish till it is 150 or even 200 years old; and in the sweet chestnut the increase continues for at least double that period in the south of Europe. Probably the oldest lime-tree in Germany, at Neustadt on the Kocher, was celebrated in song as long ago as the year r408; and the silver-firs on the Wurzelberg in the forest of Thuringia must be, from the number of the annual rings in one of the oldest trunks, 600 years old. The age of an oak at Breslau, more than 13 metres in girth at a height of 26 metres, is estimated at 700 years. The old rose-stock in the crypt of the cathedral at Hildesheim was planted, according to tradition, by Louis the Pious; and the old dragon's-blood tree at Orotava in Teneriffe, is said to have been as vigorousand even to have been hollow-in I 402, when the island was taken by the Spaniards, as in 1868 , when it was blown down in a storm. All previous conceptions of the size and age of trees are enormously exceeded by the facts ascertained respecting the Sequoia (Wellingtonia) gigantea, the 'mammoth-tree' of California, the largest measured specimen of which gives a diameter of 10 and a height of 120 metres, and, judging from the number of its annual rings, an age of from 3,000 to 4,000 years. The bread-fruit-tree is said to attain an age of from 5,000 to 6,000 years; that of the gigantic species of Eucalyptus of Australia, from $\mathrm{r}_{3} 0$ to I60 (?) metres in height, has not been ascertained. 


\section{CHAPTER VI.}

\section{SPECIAL MORPHOLOGY AND CLASSIFICATION.}

FuEN the most superficial observation of the vegetable world is sufficient to show that no form exists on the earth as a single individual, but that each is repeated with very slight variations. These variations, however, refer only to the size, colour, degree of hairiness, and other external character of the separate organs, to the number of branches, leaves, and flowers, in short to points so unessential that the same name is naturally given to all these similar individuals. Closely connected with this is the additional fact that new individuals which spring from seeds resemble exactly the individuals which produced the seeds, with the exception again of slight and unimportant variations. The entire collection of those plants which thus coincide in all essential characteristics, and of all those which are descended from the same parent, is called a Species. But a species remains unchanged, even within the limits defined by essential characteristics, only as long as the vital conditions remain the same. When these are altered by change of climate or food, or of relationship towards other organisms, whether man, animals, or other plants, even some of these characters gradually disappear, and are replaced by others. A species is therefore only an assemblage of forms which resemble one another for the time being, and is not a type rigidly defined by nature.

Dependent on changes produced by cultivation, a species is divided into Sub-species; and when the characters are hereditarily transmitted with constancy through the seed, into Races. Variations within the same race are called $V$ arieties, and these again are divided into Sub-varieties.

All species which agree in the essential characters of 
their organs of reproduction-the parts of the flower, seeds, spores, \&c.-form together a Genus. The different species belonging to the same genus may differ very considerably in their vegetative organs; but the slighter these differences the more natural is the genus.

Since the time of Linnæus two names have been given to every plant, a generic and a specific name, the generic name being placed first, and the specific name last. Thus the cucumber is Cucumis sativus, the melon Cucumis melo, both belonging to the genus Cucumis.

Since the conception of a genus is defined arbitrarily, according to the individual view of each naturalist, and that of a species is no more natural, it has come to pass in the course of time that one and the same plant has received several specific and generic names, or that the same name has been given to different plants. In order to distinguish clearly the particular plant meant, it is usual to append to its name that of the botanist who first bestowed it. Thus by the phrase Conium maculatum Linn., is meant that Linnæus was the first to give this name to the common hemlock. In the present work the name of the authority will not be given, because only those plants will be mentioned with respect to which there will be little danger of a mistake as to the species intendect.

For the purpose of obtaining a general view of the enormous number of plants, and their mutual similarities or relationships, their classification into genera is not sufficient. Those genera which are nearly related, i.e. which resemble one another in the form and mode of arrangement of their organs of reproduction, are collected into Families; these into Orders; and these again into Classes. Several classes go to make up a Sub-kingdom, and the whole collection of sub-kingdoms constitutes the Vegetable Kingdom. Since, where the relationships are complicated, it is often necessary to distinguish steps even intermediate between these, it is usual to arrange the orders which make up a class into Series, the genera which make up a family into Tribes, and the species which make up a genus into Sections. To denote still further sub-divisions, the prefix 'sub' may be placed before any of the terms mentioned, so as to mark 


\section{Special Morphology and Classification.}

still further intermediate grades; thus a Sub-family is a grade between family and tribe, a Sub-tribe a grade between tribe and genus, \&c.

The system of classification ${ }^{1}$ at present in use has gradually grown up from a combination of those proposed by Jussieu, De Candolle, Endlicher, Lindley, Bentham, and other systematists. The vegetable kingdom is first divided into two great sections, Cryptogamia and Phanerogamia, the former being destitute of flowers containing anthers and orules, the latter having these organs.

Cryptogamia are again divided into four groups or subdivisions, viz.:-

I. Thallophytes or Leafless Cellular Cryptogams. Plants which have no leaves and no vascular tissue, but are constructed of cells only. There are, however, certain transitional forms which must not be overlooked between these and the leafy Cryptogams. To this sub-division belong: I, Protophyta ; 2, Algä; 3, Fungi. It is impossible to lay down accurate lines of demarcation between these three classes; but it may be stated broadly that Algæ contain chlorophyll, and are therefore able to avail themselves of inorganic food-materials ; while Fungi contain no chlorophyll, and are therefore not able to make use of absorbed unassimilated food-materials, but are compelled to live as parasites on other organisms, or on organic remains. The lowest forms of vegetable life, unicellular organisms, with no known mode of sexual reproduction, whether containing chlorophyll or not, make up the Protophyta.

1 [In order to adapt this section to the requirements of candidates for the London University Examinations, very considerable alterations have been introduced in the mode of classification adopted in the original, and the descriptions of particular forms have been amplified. No full unanimity has yet been arrived at with respect to the hest system of classification of Cryptogams, especially of the lower Thallophytes, the life-history of some of which is still but imperfectly known. I have here followed, both in classification and in terminology, the last edition of Henfrey's 'Elementary Course of Botany,' the descriptions of the groups being largely borrowed from that work.--ED.] 
2. Charales. Submerged water-plants readily recognised externally by their organs of reproduction, and by their verticillately branched vegetative organs. Their distinguishing characteristic lies in the peculiar phenoniena connected with their mode of sexual reproduction (Figs. 4I8-420, pp. 292, 293). They consist of a single class only, the Characea.

3. Muscines. We have here a distinctly marked alternation of generations. From the spore is developed either directly (in most Hepaticæ) or indirectly, as the lateral branch of a so-called prothallium (in some Hepaticæ and all Musci), a plant which bears the organs of reproduction; this is the first [sexual] generation. The result of fertilisation is the second [non-sexual] generation, a fruit-like structure, the sporogonium, in which the spores are formed. This group is divided into two classes: I, Hepatica, and 2, Musci, of which the former has capsular sporogonia, usually opening with valves, and containing, in addition to the spores, claters, i.e. elongated spirally thickened cells (Fig. 422, III. p. 297) [the object of which is to assist the dissemination of the spores]; while the sporogonia of Musci have usually a removable lid or operculum and do not contain elaters. In the Musci and the higher Hepaticæ we have, for the first time, a differentiation of the vegetative structure into distinct stem and leaves.

4. Vascular Cryptogans. These possess true vessels, and are also characterised by the development from the spore of a leafless prothallium of small size, bearing the oospheres from which, after fertilisation, the spore-bearing plant is produced. The former is, therefore, the sexual, the latter the nonsexual generation. They are classified into two series-the Isosporous and the Heterosporous. The former produce only one kind of spore; the prothallium, which is developed from this, grows for a considerable time independently of the spore, and bears both the male and female organs of reproduction [antheridia and archegronia]. 'The 


\section{Special Morphology and Classifucation.}

Heterosporous Vascular Cryptogams produce, on the contrary, two kinds of spores, larger or megaspores (often called 'macrospores'), and smaller or microspores. From the former arise prothallia, on which the oospheres are developed; while the latter produce only a slight trace of prothallium, and almost immediately the male elements, the spermatozoids or antherozoids. The Isosporous Vascular Cryptogams are divided into three classes : 1 . Filicales. The prothallium is usually above-ground and green; the sporangia are epidermal structures (trichomes) of the leaves. 2. Equisetales. The prothallium is above-ground and green ; the verticillate leaves are provided with sheaths; the sporangia are formed several together on the margin of peltate scales, which form a terminal fructification. 3. Lycopodiales. The prothallium is above-ground and green; the leaves are small and very closely imbricate; the sporangia being formed in their axils. The Heterosporous Vascular Cryptogams include the two remaining classes:-4. Rhizocarpece. The sporangia are formed in considerable numbers in the interior of hollow capsules, the sporocarps, and contain either a single megaspore or a number of microspores. 5. Selaginellates. The sporangia are produced singly on the upper side and near the base of the leaf. The megasporangia contain a small number of megaspores, the microsporangia a large number of microspores.

Phanerogamia or Flowering Plants are classified into two divisions:--I. Gymnospermia, in which the ovules are naked, i.e. not enclosed in an ovary; and 2. Angiospermin, in which they are so enclosed. The alternation of generations is in them concealed in the formation of the seed. The pollen-grain corresponds to the microspore, and the embryosac to the megaspore of the Heterosporous Vascular Cryptogams. Gymnosperms comprise the Cycadea, which have a simple stem and pinnate leaves; the Coniferce, with branched stem and simple usually acicular leaves; and the Gnetacea. Angiosperms are divided into two classes, Monocotyledones 
and Dicotyledones. In the former the embryo has only a single cotyledon, the vascular bundles of the stem are dispersed, the leaves are usually parallel-veined, and the prevalent number in the parts of the flower is 3 . In Dicotyledons the embryo has almost always two opposite cotyledons, the vascular bundles are united in the stem into a more or less complete ring, surrounding a central (axial) pith, the leaves are net-veined, and the prevalent number in the parts of the flower is 5 [or 4 ].

\section{CRYPTOGAMIA, OR FLOWERLESS PLANTS.}

THALLOPHYTES.

\section{Class I. Protopliyta.}

Under this class are comprised the simplest forms of vegetable life, whether containing chlorophyll or not, in which all the functions of life, both nutritive and vegetative, are performed by a single cell. It follows that there can be no mode of sexual reproduction, consisting in the coalescence of the contents of a male and female cell. The cells are always microscopic, and a number are frequently enclosed together in a common gelatinous envelope (Fig. 59, p. 37). When free, they are often endowed with spontaneous motions of various kinds. The Protophyta are divided into two sub-classes, according as they contain chlorophyll or not.

\section{Sub-class I. Protophyce⿸ or Phycochronacede.}

The cells contain chlorophyll, either pure, or coloured by a bluish pigment (phycocyanin). They are either isolated, and then frequently provided with vibratile cilia, or united together in colonies by a gelatinous envelope; or they are elongated filaments, sometimes divided by extremely delicate transverse septa, and endowed with a slow undulating motion. The following families are moderately well defined :-

CHROOCOCCACE/E are probably the lowest forms of vegetable life, living either isolated or in colonies, imbedded in a transparent jelly, destitute of cilia, abundant in fresh water (Fig. 8, p. II). 
Palmellace $E$ or Protococcace.. Green unicellular organisms, occurring in three stages: (I) the protococcus form, naked ciliated cells, swimming free in water; $(2)$ the ency'sted condition, also free, but clothed with a cell-wall, and destitute of cilia ; (3) the palmella condition, associated in colonies which are invested with a common gelatinous envelope (Fig. 59, p. 37). Protococcus viridis is an extremely common object in rain-water. It is found very abundantly in the mud where rain-water collects, and in similar situations. In its most ordinary form, each individual consists of a single, nearly spheroidal, cell from ${ }^{\circ} 003$ to $\cdot 0000 \mathrm{I}$ inch in diameter, and varying in colour from bright green to bright red, according to the relative proportion of a green and a red colouring matter diffused throughout the protoplasmi or occurring in the form of granules. In this form it multiplies with great rapidity by fission, i.e. by simple cell-division; and is also stated occasionally to increase by gemmation or budding. The individual Protococcus performs all the functions of an ordinary vegetable cell, respiring, i.e. absorbing oxygen and giving off carbon dioxide in the dark, in consequence of the oxidation of its substance, and probably also in the day-time, although the process is then concealed by the opposite process of nutrition, or the decomposition of carbon dioxide and elimination of oxygen, which is effected by the chlorophyll under the influence of sunlight. The change to the active condition takes place in the following way. The protoplasm withdraws itself from the cell-wall at all but two points, where it protrudes through the wall in the form of long vibratile cilia, by the motion of which it is propelled through the water. The cilia are extremely delicate, and are invisible except when moving very slowly, or when artificially coloured by some reagent, as iodine, which, however, kills the plant. In this condition it sometimes loses its cell-wall, and swims about as a naked primordial cell. Eventually, however, it loses its cilia, clothes itself with a coat of cellulose, and becomes quiescent. 
In this state it may retain its vitality when dried up, even for years ; and will then resume its activity when again placed in water.

Palmella nivalis, appearing suddenly in enormous quantities on Arctic snow-fields, is the substance known as 'red snow.' $P$. cruenta often forms red patches resembling coagulated blood on stones and rocks.

The NOSTOCACEE consist of curved moniliform filaments of cells imbedded in jelly, one species, Nostoc commune, being common on dry ground. The ordinary small cells are replaced here and therc by larger cells known as heterocysts, the function of which is unlinown. Rcproduction takes place by portions of the filaments between the heterocysts becoming detached, escaping from the cnveloping jelly, and dividing into fresh filaments. Some specics of Nostoc are endophytic, living within the cclls of other living plants.

The OscillatoRIE $E$ are very common objerts in running or stagnant fresh water. They consist of cylndrical filaments, enveloped in a gelatinous sheath, sometimes divided by very delicate transverse septa into disc-like cells, which readily separate. The only mode of reproduction known is by the detachment of portions of the filament, known as hormogonia, which carry on an independent existence, and develope into new filaments. In both the Oscillatoriex and the Nostocacex the cell-contents are of a bluish-green colour, from the presence of phycocyanin in the cell-sap. The Oscillatoriex are endowed with a constant oscillating motion of the filaments.

The Rivulariee form soft greenish-blue lumps of jelly, which swim about in stagnant water, or grow attached to watcr plants. Within the gelatinous envclope are very slender moniliform filaments of roundish cells, running out at the extremity into a long hyaline hair, the basal cell being a much larger heterocyst. Reproduction is effected by special cells separating from the rest, becoming invested in a firm cell-wall, and remaining in this condition for some time as restingspores. A new colony is then produced by cell-division.

The Scytonenef are nearly allied to the Rirularica, forming branched filaments enclosed in a thick gclatinous cnvclope. 


\section{Sub-class II. Protomycetes.}

The cells are isolated or associated in colonies, and do not contain chlorophyll. They are therefore incapable of carrying on an independent existence, and live only in organic fluids, where they occasion putrefaction or fermentation. They are not endowed with cilia, but have in some cases an apparently spontaneous power of motion. The Protomycetes are reproduced by cell-division (gemmation) or free cellformation. They are divided into two well-marked families :-

The Schizomycetes, or Bacteriaceæ, are extremely minute unicellular organisms, occurring in enormous quantities in all organic solutions where decay is going on, of which process they are the invariable accompaniment, if not the cause. The number of distinct forms that have been described as belonging to the Schizomycetes is very large; but to what extent these are different conditions of development of the same organism is still in doubt. They may be conveniently arranged under the following heads, viz.:-

I. Micrococcus. Globular and extremely minute.

2. Bacterium. Short straight rods.

3. Bacillus. Longer straight rods.

4. Vibrio. Curved rods.

5. Leptothrix. Straight filaments.

6. Spirillum. Curved filaments.

7. Zoogloa. Colonies of globular cells imbedded in mucilage.

The rods and filaments are characterised by the ease with which they break up into separate segments as soon as they come into contact with the atmosphere, from which circumstance the class has received its name. They multiply in this way, by simple division ; but in the case of Bacillus,

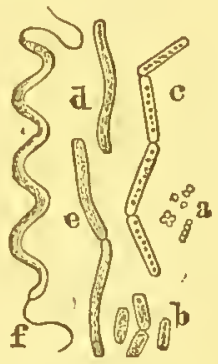

Fig. $380 .-$ Bacteria : a Micrococcus prodigiosies ; 6 Bacterium Lineola: c Bacillzes Ulna; d Vibrio Rugula: $e$ the same, dividing : $f$ Spirillum volutans. the formation of endogenous spores has also been observed. All the forms except Micrococcus and Zoogloa are endowed with rapid vibratory motions by means of cilia attached to the extremities, which can only be made out by the 


\section{highest powers of the microscope, and with the assistance of staining reagents.}

The SCHIZOMYceTES usually grow in water, splitting up the nitrogenous compounds which are contained in it into ammonia, which supplies them with nutriment, and other substances which arise as secondary products of decomposition. Such decompositions of nitrogenous substances are known as putrefaction, and the chief or sole agent in this decomposition is the organism known as Bacterium Termo. Solid nitrogenous compounds which are insoluble in water are rendered fluid by the agency of bacteria. As soon as the nitrogenous substances in the substratum are entirely consumed, the bacteria gradually cease multiplying, and pass over from their motile to their stationary condition, usually secreting at the same time an intercellular substance, and congregating into gelatinous colonies. In this state, when they are known as Zooglna, they still continue to grow, divide, and, under certain circumstances, again to become active. Those bacteria which develope in damp air on nitrogenous nutrient substances also form gelatinous masses; they often produce, as secondary products of their process of assimilation, red, violet, yellow, green, and brown colouring substances.

When water which contains living bacteria is evaporated, a great number of these organisms are carried into the air, and in particular the most minute globular forms, the Micrococci. The germs of bacteria which, in consequence, rise into the air whenever putrefying fluids are evaporated, are carried down everywhere by rain, are sucked in with the air in breathing, and hence become causes of putrefaction in all nitrogenous substances exposed to the air, since their vitality is not lost in the atmosphere. Of this nature are many and possibly all causes of putrefaction and the propagators of contagious diseases. These latter are mostly immotile globular bacteria (Spharobacteria), often united together into clusters, drinking-water being usually considered the medium of their propagation. The blood of animals attacked by contagious diseases generally contains, a considerable time before their death, a prodigious number of bacteria — straight, rigid, cylindrical rods which are bent at an obtuse angle in one or two places, extremely slender, and usually not more than from 004 to $012 \mathrm{~mm}$. in length. In the intestines, excrements, and vomit of cholera patients are found, at least at the commencement of the attack and possibly as its cause, enormous quantities of organisms of this nature. Under the Schizonycetes must also be included Leptothrix buccalis, an organism which always occurs in the mouth, especially in the morning, but is in general 


\section{Special Morpltology and Classification.}

without any pathogenous significance. It consists of extremely clelicate transparent filaments, which, nevertheless, appear to be composed of separate cells, since they break up into sharply defined pieces simply on being touched. The cube-shaped cells of Sarcina ventriculi are commonly found in the gastric juice of man. To this class belongs also the substance known as Monas (Micrococcus) prodigiosa, closely resembling the red corpuscules of the blood, which sometimes appears in prodigious quantities on bread and similar substances. The disease caused by Achorion Schenbeinii, called 'favus,' usually attacks the part of the head of man which is covered with hair, and produces there the characteristic straw-coloured crab's-eye-shaped incrustations; and since its spores grow into the hair, this obstinate disease ends in complete and permanent loss of hair. The spores of Trichophyton tonsurans penetrate in enormous numbers into the hairs, make them brittle, and cause them to break off at the skin. All these diseases, as well as others which might be added, are contagious. Bacillus anthracis is the cause of 'charbon 'in animals ; B. tuberculosis is supposed to be the pathogenous agent in phthisis; Micrococcus vaccinee is the active element of vaccine lymph ; $M$. diphtheriticus is always found in diphtheritic membranes. The foot-rot, the cholera of fowls, and many other diseases which attack man and other animals, are also due to the effects of specific bacteria.

Certain kinds of fermentation are also due to these organisms. Bacillus amylobacter is capable of acting on starch in a manner analogous to diastase, converting it into glucose ; or breaking up it or other carbohydrates into butyric acid, carbon dioxide, hydrogen, \&c., and is thus the cause of butyric fermentation. Micrococcus urece is the ammoniacal ferment of urine, splitting up the urea into ammonium carbonate and hydrogen. The acetic fermentation is due to Bacterizun aceti, which converts alcohol into acetic acid. Lactic fermentation is due to Bacterizm lactis, which changes the sugar of millk into lactic acid. The importance of these organisms in the study of pathology cannot be over-estimated.

The Saccharomycetes consist of minute isolated cells, reproduced by the mode of cell-division known as gemmation, as well as by endogenous spore-formation. They are not endowed with cilia or with spontaneous motion. They are the sole cause of alcoholic fermentation.

Saccharomyces or Tomla cerevisice is the ordinary Yeast of beer, a brownish fluid which possesses the property of 
causing in any solution which contains sugar the change known as Fermentation, that is, the conversion of the sugar into alcohol, which remains in the fluid, and carbon dioxide, which is given off in the form of bubbles. Yeast, when evaporated at a low temperature, is reduced to a powdery mass, which retains for a considerable period its property of fermenting saccharine fluids. Fermentation is prevented by boiling either the yeast or the saccharine fluid, or by previously straining the yeast through a very fine filter, such as porous earthenware; nor does any change take place if, after boiling the fluid, it is allowed to come into contact only with air which has been passed through cotton-wool. Hence it is concluded that the fermentation is caused by a solid substance contained in the yeast, which cannot pass through the earthenware or cotton-wool. Examined under a low magnifying power, yeast is found to contain a number of nearly spherical transparent granules, averaging about .0003 of an inch in diameter, each of which is a Saccharomyces. Each individual is an ordinary vegetable cell, usually containing a vacuole, but it is doubtful whether there is a nucleus; and the cells are either solitary or associated in heaps or strings. It consists of carbon, hydrogen, oxygen, nitrogen, sulphur, phosphorus, potassium, magnesium, and calcium ; the last four in very small quantities. Its chief proximate constituents are (I) a protein-compound analogous to casein; (2) cellulose; (3) oil;. (4) water; the larger part of the mineral substances being contained in the protoplasm. The Saccharomyces is the sole cause of fermentation in the sugar, and is believed to be always present in the air in the form of invisible dust. If a small quantity of yeast is added to a large quantity of a clear saccharine fluid, and the fluid kept warm, it will gradually become more and more turbid, and a scum of yeast will collect, containing a prodigous quantity of Saccharomyces-cells. The ordinary mode of reproduction is by what is termed gemmation (Fig. 38I), each cell giving rise to minute protuberances, 


\section{Special Morphology and Classification.}

which grow rapidly, attain the size of the parent-cell, are separated by a septum of cellulose, and eventually become
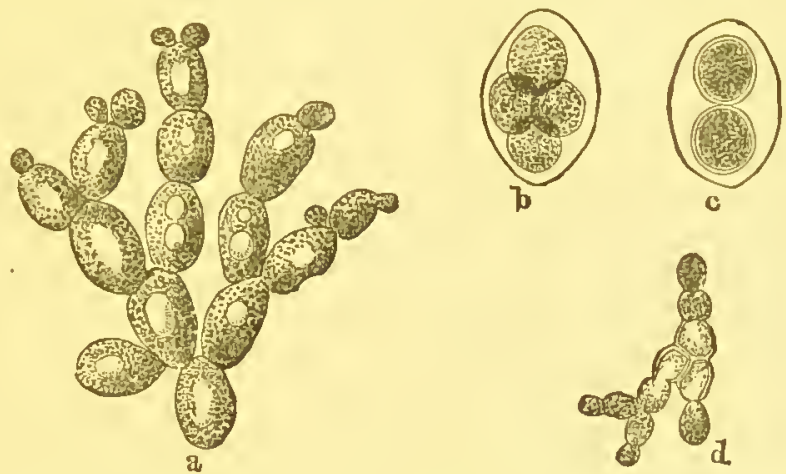

Fic. 381.-Reproduction of Saccharomyces cerevisia: $a$ increase by gemmation i) by endogenous free-cell formation; $c$ two fully formed spores; $d$ a spore increasing by gemmation. ( $x$ I000).

detached, but not generally until they have themselves developed a second generation of buds. They very commonly adhere together in the form of heaps or strings. A second, but rarer, mode of multiplication is the formation of spores by endogenous free-cell formation, the protoplasm of a cell dividing into usually four masses, each of which surrounds itself by a cell-wall; and the daughter-cells are eventually set free by the dissolution of the wall of the parentcell. In order to show that the substances of which the Saccharomyces consists, protein, cellulose, and oil, were not present in the nutrient fluid, but have been manufactured by the yeast-fungus out of it, it is best to take a nutrient fluid of definite chemical composition, a convenient one being that known as 'Pasteur's solution.' I The power of constructing protein out of such a substance as ammonium tartrate, and the investment of the protoplasm by a continuous coat of cellulose, are the chief properties which determine the Saccharomyces to be a vegetable. It allies

1 Potassium phosphate, 2 parts ; calcium phosphate, 2 parts ; magnesium sulphate, 2 parts ; ammonium tartrate, Ioo parts; cane sugar, I, 500 parts ; water, 8,394 parts. 
itself to Fungi in containing neither starch nor chlorophyll, and having consequently no power of decomposing carbon dioxide. In the process of fermentation nearly the whole of the sugar is converted into an equal weight of alcohol and carbon dioxide ; but a sniall quantity of glycerine and succinic acid are also produced; and one or two per cent. is not yet accounted for, but may perhaps be assimilated by the Saccharomyces. It will grow and multiply actively in a solution in which sugar and ammonium nitrate replace the ammonium tartrate; and in this case the carbon must be obtained from the sugar. Although oxygen is essential to its life, it will live in saccharine solutions which contain no. free oxygen, appearing, under these circumstances, to get its. oxygen also from the sugar. It will also flourish in solutions in which the ammonium tartrate is replaced by sugar and pepsin, in which case the nitrogen of the protein-compounds must be derived from the pepsin.

The mode of multiplication of Saccharomyces by the endogenous. formation of spores has led some authors to regard them as the lowest members of the group of ascomycetous Fungi.

Saccharomyces cerevisie occurs in two distinct forms, known as 'high' and 'low' yeast. There are also a number of other species, more or less nearly related to one another, some of which accompany other kinds of fermentation, while others are pathogenous in man or other animals. S. ellipsoideus, Pastorianus, and apiculatus occur in the fermentation of wine; S. glutinis causes starch to ferment; S. Mycoderma (Mycoderma vini) forms the 'mould' on beer and wine, and also accompanies acetic fermentation; $S$. (Oidium) allicans appears to be the cause of the disease known as 'thrush.'

\section{Class II. Alga.}

Algæ are submerged water plants, growing in fresh, brackish, or salt water, or at least in very damp situations, entirely cellular, and without any distinction of stem and branches, but always containing chlorophyll, and therefore capable of carrying on an independent existence. Reproduction takes place either (I) non-sexually, which may be 
by simple fission or cell-division, as in the case of the desmids and some other lower forms, or by spores, which are either motionless, and are then usually tetraspores (Fig. $3^{82}$ ), formed in groups of four within a sporangium, or zoospores (Fig. 82, p. 56, and Fig. 386, p. 254), endowed with apparently spontaneous motion by means of vibratile cilia; or (2) sexually, and then assumes two forms: the union of apparently similar cells, conjugation (Fig. 54, p. 32, and Fig. 383, p. 257), or the fecundation of a female cell, oosphere, by a male protoplasmic body, antherozoid, and the consequent production of an oosperm (Figs. $385-387$ ).

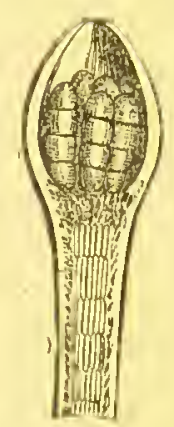

Fig. $3^{82 .}$ - Tetraspores of Corallina cupressina, enclosed in the tetrasporangium cut open.

Algæ vary very greatly in size, from the microscopic unicellular diatoms and desmids to the gigantic seaweeds likc Macrocystis (Fig. 391, p. 262), which attains a length of $I, 000$ feet. The important points of distinction between the different forms lie either in the degree of development of the individual cells, or in the mode in which they combine. Even among the Unicellular Algæ the greatest varicty of forms is found, from the rooting spherical cell of Botrydiztm (Fig. Sr, p. 55), to the species of Caulerpa (Fig. 383) of tropical seas, two feet in length, and simulating the appearance of stem, leaves, and roots. Sometimes the single cell branches copiously, its branches beconing most intimately connected with one another in such a peculiar way that a tissue-like structure is produced, as in Coleochete scutata, and a section through the whole presents the appearance of a number of cellcavities, where we have actually only protuberances of a single cell. Sometimes thesc protuberances lie in such regular layers one over another, that a transverse section might be imagined to exhilit one medullary and two cortical layers, as in Udotea cyathiformis. The Multicellular Algxe are eithcr filiform, the cells arranged in a row or thread (Fig. 54, p. 32); or the cells form a flat surface or single layer only one cell thick (Fig. 82, p. 56); or, finally, a solid mass of cclls in three directions. Within thcse three classes even a greater variety of form prevails than in the Unicellular Algæ; some of the larger species of Ficcus, for examplc, often bcaring a resemblance to branched trees. In the massive algx it is very common for there to be a differentiation 
to this extent into epidermal and fundamental tissues, that the outermost layers consist of smaller cells with thicker walls, while the interior cells are often much larger, and sometimes of great length. This is, however, correctly described only as a pseudo-parenchyma; there is nothing of the nature of primary parenchyma or cambium; and the

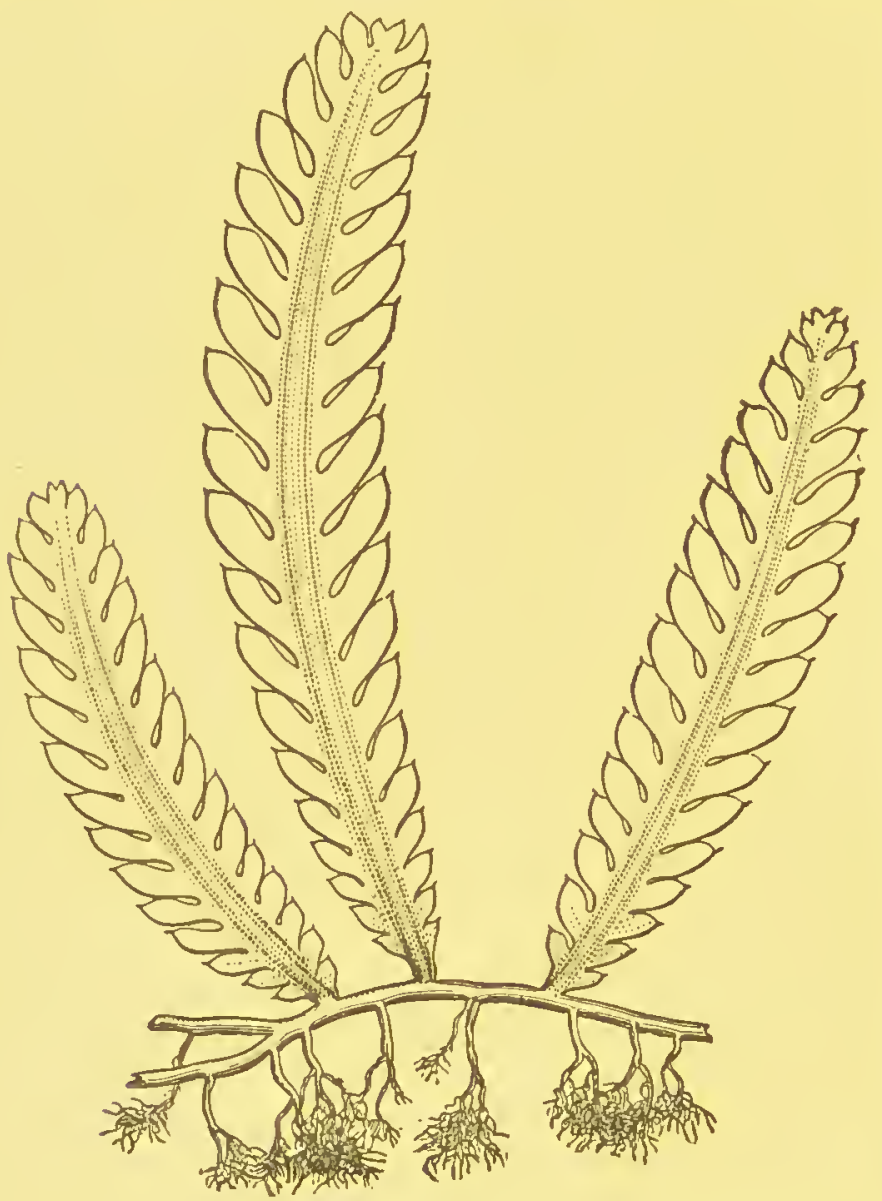

F1G. 383.-Caulerpa taxifolia, a marine Unicellular Alga (natural size).

entire process of growth is governed by a single apical cell. True roots provided with a root-cap are also altogether wanting.

The cell-walls of Algæ usually consist of ordinary unlignified cellulose, which is coloured blue by iodine and sulphuric acid; but they have a great disposition to be converted into a mucilaginous substance, 
eatusing the entire organism sometimes to beeome surrounded by a gelatinous envelope, while in other eases a stalk-like mass of jelly eonneets the Alga with others of the same kind, or fixes it to its substratum. Many are ealeareous, and the ealeium earbonate is, in some eases, as Corallina, deposited in the eell-wall; while in others, as Cymopolic, it is exereted into the intereellular spaees. The eell-walls of the Diatomaeer form, in eonsequenee of the deposition in them of siliea, netual eoats of mail, whieh are not destroyed either by deeay or at a red heat. Although the diatoms are at most $\mathrm{O}^{\circ} \mathrm{I} \mathrm{mm}$. in diameter, these silieeous eoatings form strata whieh are not without importanee in building up the erust of the globe, as in the ease of emery and infusorial earth (Fig. 38, p. 22, and Fig. 384).

The eells of Algre often eontain stareh and oil. The presenee of ehlorophyll is of speeial importanee; and this is invariable, although often eoneealed by pigments of various eolours. These eombinations of eolours are remarkably eonstant in large natural groups. Thus the Diatomaeex exhibit a yellow eolour, the Fueaeex a brown or olive, and the Floridex a beautiful rose-red. Both the ehlorophyll and the other colouring matters sometimes form granules in the living eells, sometimes broad bands often eurved spirally, as in Spirogyra (Fig. 4I, p. 25), sometimes elegant dises, the forms of whieh are eharaeteristic of partieular genera. It is also not uneommon for the ehlorophyll-grains to be imbedded in coloured fluids. On the death of the plant these eolouring matters eommonly undergo a ehange, so that, when dried, Algæ seldom rotain the beautiful eolours of the living plant.

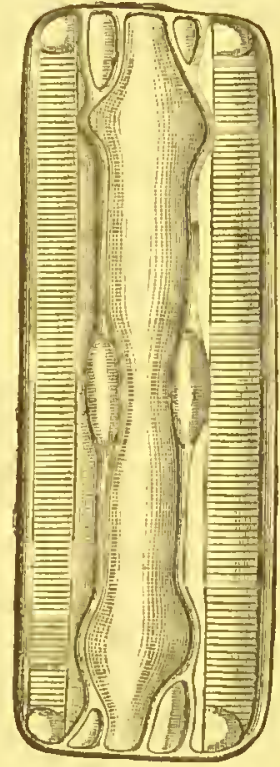

FIG. $384 .-$ Grammatophora subtilissima, a diatom $(X 1550)$.

In the formation of zoospores or swarmspores, one or more naked primordial eells are formed by free-eell formation in a particular eell of the parent plant; these beeome free by rupturing its eell-wall, and then swim about in the water for a longer or shorter tinie by means of two, four, or a larger number of vibratile eilia with whieh they are provided. They are mieroseopie and destitute of a eell-wall; but, after gradually eoming to rest, develope a eell-wall of eellulose, and then grow into a new Alga. They oeeur in both freshwater and marine Algre, Vaucheria, Eidogonium, \&e. Oeeasionally two zoospores, one of whieh exeeeds the other in size many times, eoalesee, the produet of their union being 


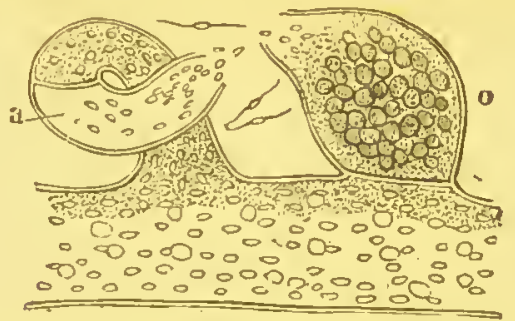

FIG. $3^{8}$. - Paucheria sessilis: portion of filament with organs of reproduction. The

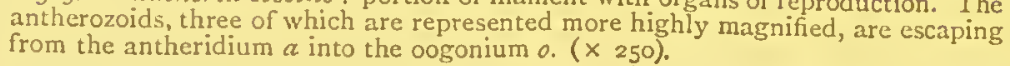

I.

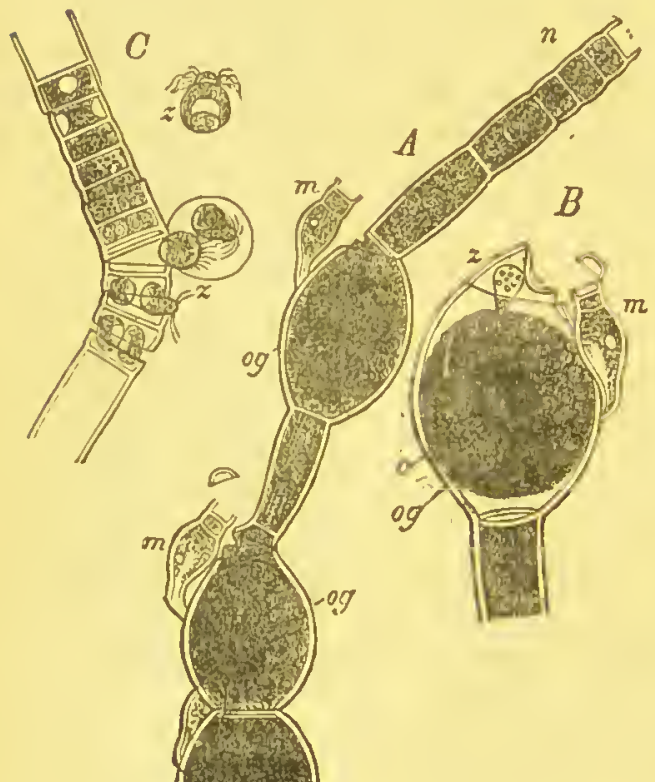

II.
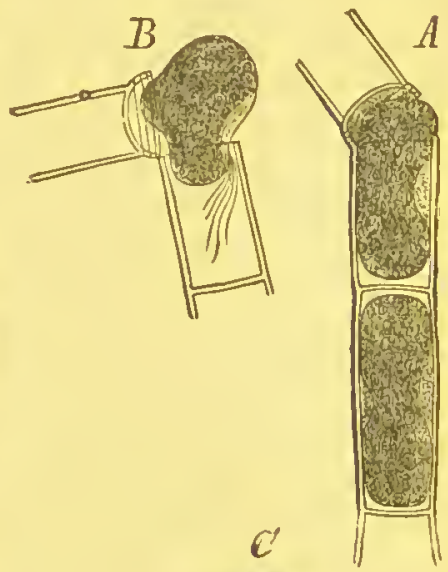

Fig. 386.-I. A, Filament of Edogorinm ciliatum: $n$ cells which produce the zoospores: 05 oogonium with dwarfmale $n ; B$, oogonium at the moment of impregnation; 0 oosphere; $z$ anthero\%oid in the act of entering; $m$ dwarf-male; c, O.gemilliparum: piece of a filament in which the zoospores $z$ are being formed, from which the dwarf-males are produced $(x 250)$. II, Zoospores of (E) dogonizm: A, before escape from their mother-cell : B, in the act of escaping; c, when set free. (After Pringsheim.)

a single reproductive cell, as in Pandorina and Ulothrix. This may be regarded as a mode of conjugation constituting a connecting link between the modes of reproduction by zoospores and by 


\section{Special Morphology and Classification.}

oospheres. The highest form of sexual reproduction in Algre is that in which the two cells which share in the proccss are unlike. The fcrtilising or male body is in these cases termed a spermatozoid, antherosoid, or sperm-cell ; the mass of protoplasm which has to be fertilised, female cell, an oosphere or germ-ccll. The latter are many (often several hundred) times larger than the former. The antherozoids are first formed in a cell which is called an antheridizum, and the oosphere is the result of the contraction of the protoplasm of a special cell termed the oogonizum. In Vaucheria (Fig. $3^{85}$ ) a number of elongated antherozoids are formed in the antheridia, 'here called 'horns'; these penetrate into the oogonium through an opening formed in its cell-wall at the period of its maturity, and finally reach the oosphere. The latter clothes itself, after fertilisation, with a membrane of cellulose, and bccomes the oosperm. This assumes the form of a resting-spore, which docs not germinate at once, but is set free when the alga itself decays, sinks to the ground, remains dormant through the winter, and germinates in the spring. In Edogonizum (Fig. 386) the oogonium is a cell of the filament itself. The multicellular antheridium or ' $\mathrm{dwarf}$ male' is formed from a peculiar zoospore or androspore, which attaches itself to the oogonium. Only a single antherozoid is formed in cach cell of the antheridium, which escapes through a slit and forces itself into the oogonium through an opening formed at the same time in its cell-wall, and finally reaches the oosphere, which then developes into an oosperm. In the Florider the antherozoids are unprovided with cilia, and are only moved about passively in the water; they attach themselves to a hair-like cell, the trichogyne, emptying their contents into it. The result of this impregnation is scen sometimes at the base of the trichogyne (in Nemaleon, Fig. 387 ), sometimes in adjoining cells (in the Ceramiacer), sometimes (in Dudresnaya) in altogether different branches, on which cystocarps are formed, which contain the carposperms.

Alge are rarely true parasites, although they very commonly inhabi the surface of other plants; they much more often obtain their food by 
direct assimilation. They may be classified accorcling to their habitat into Fresh-water and Marine Algre. The former are mostly green, and are found plentifully in any stagnant water or ditch in the spring and summer, and not unfrequently contribute, by their process of vegetation, to the removal of substances decaying in the water. The red, green, and brown marine Algre are larger and of much greater beauty; some.

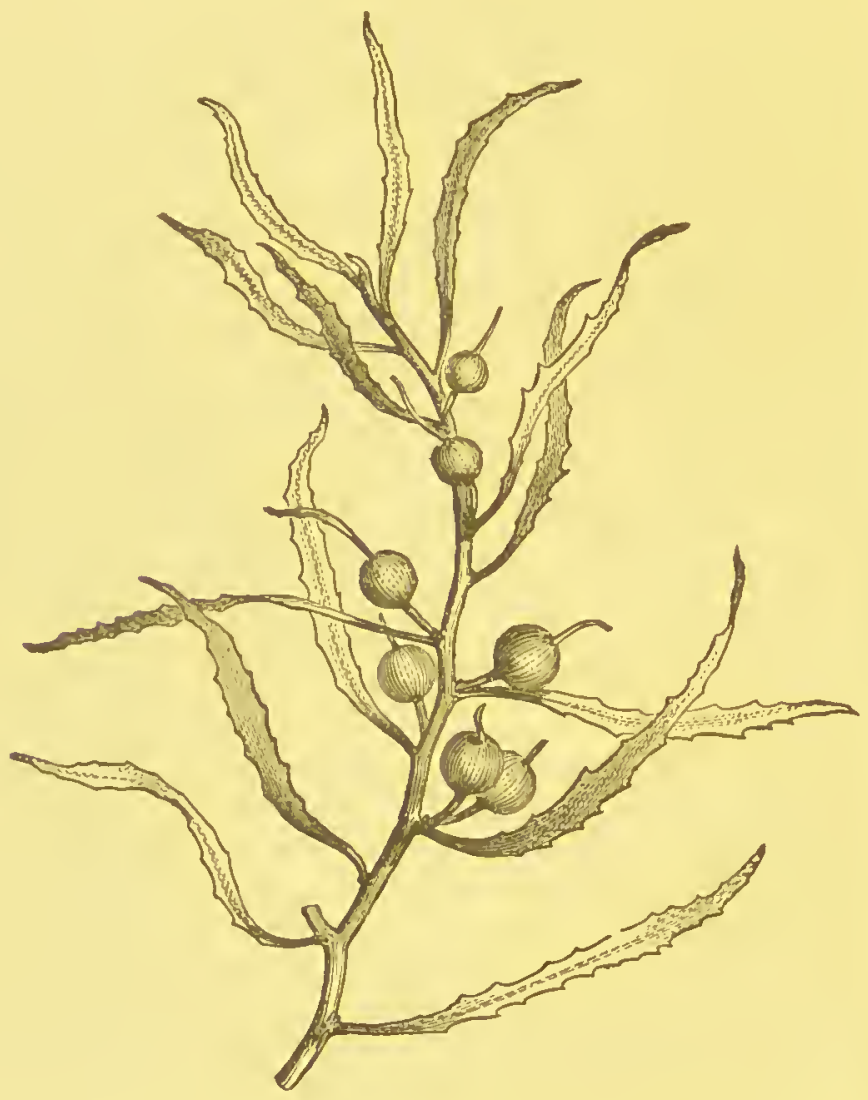

FIG. 388.-The gulf-weed, Sargassum baccifermm, with globular berry-like air-bladders (natural size).

of these live only in the breakers, others only on the quiet bed of the ocean. They very often occur in great masses; the largest of these is the 'sargasso sea,' which occupies several thousand square miles in the Atlantic between $19^{\circ}$ and $34^{\circ} \mathrm{N}$. lat. and $34^{\circ}$ and $36^{\circ} \mathrm{W}$. long., the surface of the sea being covered with detached sterile masses of the 'gulf weed,' Sargassum bacciferum (Fig. 3S8). 


\section{Special Morphology and Classification.}

The gelatinous substance of the cell-walls gives to several kinds of Algre the property of being used as articles of diet, such as the species of Laminaria and Ulva (green laver) on the coasts of Scotland and Ireland, and the 'carrageen moss' which is obtained from Spharococcus crispus and mammillosus. The ashes of the larger marine Algae were at one time largely employed, as kelp, in the manufacture of alkali, and still are for that of iodine. Gigartina helminthochortos furnishes 'worm·moss,' but is usually adulterated with other seaweeds.

The most convenient classification of Algæ is into three sub-classes, dependent on their mode of sexual reproduction.

\section{Sub.class I. ZYGOPHYCEÆ.}

In the Zygophycer the cells which coalesce in the act of fecundation are only with difficulty distinguishable from one another. This mode of reproduction is known as conjugation, and the product of coalescence is a zygosperm. The conjugating cells may be motionless, or may be possessed of vibratile cilia giving them a power of independent motion, when they are indistinguishable from zoospores.

In the following families of Zygophycex, conjugation talkes place between naked ciliated masses of protoplasm resembling zoospores.

The Ulvace E (Fig. 82, p. 56) are green fresh-water or marine Algx, in which the thallus consists of a single layer of cells, which is expanded either into the form of a ribbon-like plate or that of a tube. Reproduction is effected by cell-division, or the conjugation of motile ciliated primordial cells.

The Confervaces are green or coloured fresh-water Algæ, consisting of branched or unbranched filaments, densely filled with granular chlorophyll. 'They are among the most abundant vegetable organisms in running, but especially in stagnant water, rapidly filling the water with masses of dark-green filaments. They are reproduced nonsexually by zoospores, but in a few instances conjugation has been observed between motile ciliated bodies resembling the zoospores in everything except their much smaller size.

The Siphonocladace $\approx$ are fresh-water Algæ composed of a single much-branched cell, varying from a very simple form in Botrydizun (Fig. 8I, p. 55) to one of great complexity in Caulerpa (Fig. $38_{3}$, 
p. 252) and similar genera, mostly natives of warm seas. They are remarkable from the large number of nuclei contained in a single cell.

The PANDORINEÆ are fresh-water organisms consisting of a single cell, or of a number united symmetrically into a cell-family enclosed in a gelatinous envelope, each cell being provided with a pair of cilia. Reproduction takes place by cell-division or the conjugation of ciliated cells.

To the Zygophycer belong also the beautiful Hydrodictyon or water-net, Pediastrum (Fig. 58, p. 37), common in fresh water, and Ulothrix; but it is difficult to classify these genera more exactly.

The CoNJUgATæ are unicellular or filamentous Algæ, in which conjugation takes place between the ordinary unciliated cells. They comprise three distinct orders :-

I. The Zygnemacea are fresh-water Algæe of great beauty, consisting of unbranched filaments of cells, often of large size, displaying an evident nucleus, and with the chlorophyll arranged in spiral bands (Fig. 4I, p. 25), stars, or a thin axile plate. The process of conjugation, the only mode of reproduction known, may be well watched in Spirogyra (Fig. 54, p. 32). When the process is about to commence, the cells of two fllaments, lying side by side, put out protuberances, each on the side nearest its neighbour. These protuberances elongate until they meet; the septum at the point of union disappears, an open channel being thus formed connecting each cell of one filament with a corresponding cell of the other filament. The protoplasmic contents of each of the two cells have, in the meantime, retired from the wall, the chlorophyll losing its spiral arrangement, and have become condensed into an ovoid mass ; then the whole contents of one cell pass through the connecting tube into the other cell. Thus is formed a globular or oval body, the zygosperm, which developes two or three coats of cellulose, escapes from the parent-cell by the decay of the filament, and continues for a time in a state of rest, as a so-called 'resting-spore.' After a time, usually in the spring succeeding its formation, the zygosperm germinates, the inner cell-wall bursting through 
the outer one, and developing into a filament like the parent. As a rule, all the cells of one of the two filaments pass into those of the other, and not some in one direction, some in the other. The cells of the active filament are also generally somewhat smaller than those of the passive filament; the former may be regarded as a male, the latter as a female filament. Occasionally the cells of one male filament conjugate with those of several female ones; and a process of lateral conjugation has been observed between two adjacent cells of the same filament.

2 The Desmidiece (Fig. II, p. I2) are unicellular organisms, occurring isolated in fresh water, of symmetrical figure, and containing chlorophyll arranged in symmetrical plates and bands. They vary greatly in form and size, and are very common objects in stagnant and running water, and are among the most beautiful of microscopic objects. They have two modes of reproduction : by division and by conjugation. A good example of the former is afforded by one of the commonest and most beautiful genera, Cosmarium. The two somewhat unequal halves of the cell gradually separate from one another, leaving a connecting band, which is ultimately divided midway by a septum. Each half of this band gradually assumes the form of a half-cell, and, together with the half of the parent cell with which it was in connection, constiiutes a new individual. Finally, the two individuals completely separate from one another. Conjugation (Fig. 389 ) is effected by cells which appear as if about to divide approaching one another in pairs; a fracture of the external cell-wall then takes place

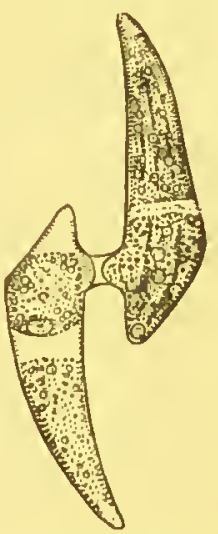

FIG. 389. - Conjugation of Closterium Linula, a desmid (greatly magnified). at the usual line of division, and the contents of each cell, bounded by the parietal utricle, escape, and coalesce into a zygosperm, which assumes a roundish form, and becomes 
invested with an ultimately double coat of cellulose, which is often beautifully covered with spines. Its contents change from green to brown or yellow, and it developes into a new individual after going through a period of rest.

3. The Diatomacea or Bacillariea are microscopic unicellular organisms, occurring in great quantities in fresh, brackish, or salt water, and on damp ground, invested with a very hard but thin and transparent siliceous coat, and this again often in a gelatinous envelope enclosing single individuals or groups attached together (Fig. 390). They are always of more or less symmetrical figure; the green colour of the chlorophyll is masked by a brown or olive pigment known as diatomin, and they are frequently endowed with apparently spontaneous movements, the source of which is not yet fully explained. Each individual is composed of two similar halves or valves, known as frustules, and from the symmetry of their form, and the fineness and regularity of the stria-

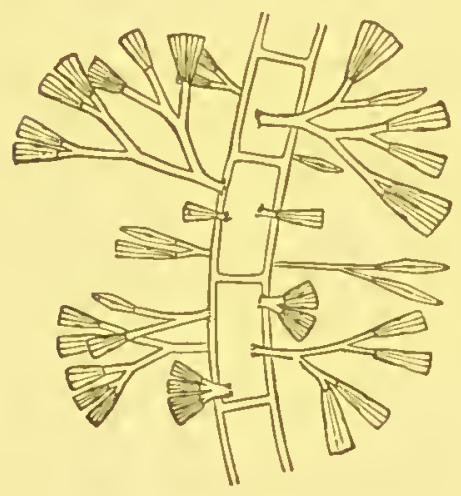

Fig. 390.-Gompironema hyalinum, a social Diatom, attached to a thread of a Conferva (greatly magnified).

tions on their thin transparent siliceous coat (Fig. 38, p. 22), they are extremely beautiful microscopic objects. The two halves of each frustule fit into one another like the halves of a pasteboard box. Diatoms are propagated by repeated bipartition; but the diameter of the successive generations gradually diminishes until at length it attains a minimum. This process is then interrupted by the formation of larger cells or auxospores, and individuals are produced which reach the maximum size of the species, but in other respects exactly resemble their parent-cells. In these the process of bipartition is then again commenced. In some genera a 
true process of conjugation has also been observed, a zy'gosperm being produced as the result of the coalescence of two different individuals which have previously been enclosed in a gelatinous envelope.

\section{Sull-class II. OOPHYCEA.}

In this sub-class we have a distinct advance in type from the Zoophycer in a distinct differentiation of the sexual cells. The male element is always a primordial ciliated mass of protoplasm, an antherosoid or spermatozoid; the female element or oosphere is contained within a simple cell or oogonizum, and the product of fertilisation is known as an oosperm. The group consists of several families not closely connected with one another genetically.

In the VOLVOCINE⿸ each family consists of a colony of cells or canobium, which, in the case of Volvox globator, a common very beautiful microscopic object in the standing water of pools, is nearly globular, and swims about with great velocity. Its appearance is that of a transparent membranous hollow sac studded with green points, and carried about by the motion of a large number of vibratile cilia, which project through the common envelope of the cœnobium. A pair of these cilia is attached to each of the green internal corpuscules, which resemble zoospores. Each of these bodies is a young individual, which developes into a new colony within the parent-colony, the daughter-colonies finally escaping by the dissolution of the common semimucilaginous envelope. A second non-sexual mode of reproduction is by the formation of resting-spores. Volvox is also reproduced sexually by the formation within the colony of male and female cells, antheridia and.oogonia, impregnation taking place within the common envelope, from which the fertilised oosperms finally escape.

The Vaucheriacese or Siphonere present a certain resemblance to the Siphonocladacer, the whole organism consisting of a single, often much branched and greatly elongated cell, undivided except when the sexual organs are about to be formed. The mode of reproduction is well 
themselves to a definite spot of the female plant, on or near the oogonium, where they germinate, producing very small male plants, the 'dwart males' or micrandres, each consisting only of a single antheridial cell, which gives birth to ordinary antherozoids. The cells of Ed logonizum present a remarkable appearance from the phenomenon known as 'intercalary surface growth' (II. B), in which a number of annular deposits of cellulose are formed in succession below the upper septum of each cell, giving the appearance of a series of caps.

The Phrospores are olive or brown seaweeds, frequently of gigantic size (Fig. 39I), with a foliaceous shrubby, often, much. branched thallus, which is some. times coriaceous. The only mode of reproduction at present known in them is by means of zoospores.

The Fucace£ are large brown or olive-coloured seaweeds, often many feet long, as in Sargassum (Fig. 388, p. 256), and of a cartilaginous texture, forming leaf-like or stem-like fronds. They are attached to stones [or other Algæ] by a branched attachment-disc. Their branches, which are often beautifully dichotomous, all lie in one plane, or can be reduced to one without violence to the plant. From the dead plant cold fresh water extracts a fine buff pigment. They very commonly form air-cavities in the
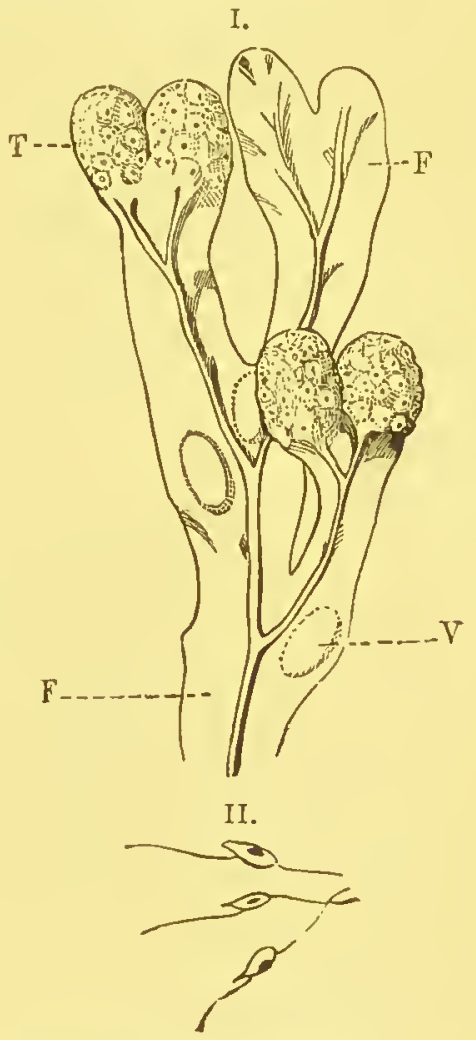

FIG. 392.-Fucus vesiculosus: I. F thallus : $T$ fructification; $v$ airbladder (natural size). II. anther. ozoids (greatly magnified).

interior of the tissue, or occasionally elevated on distinct stalks, as in the gulf-weed, which swell outwards like bladders and serve as swimming-bladders, as in the common bladder-wrack, Fuczs vesiculosus (Fig. 392). The thallus of 
the frond is frequently highly developed, and, though strictly cellular, displays a distinct cortical layer. This swells up greatly and becomes slimy in fresh water. The sexual cells are in distinct chambers or conceptacles in the same or different individuals. The female conceptacles

I.

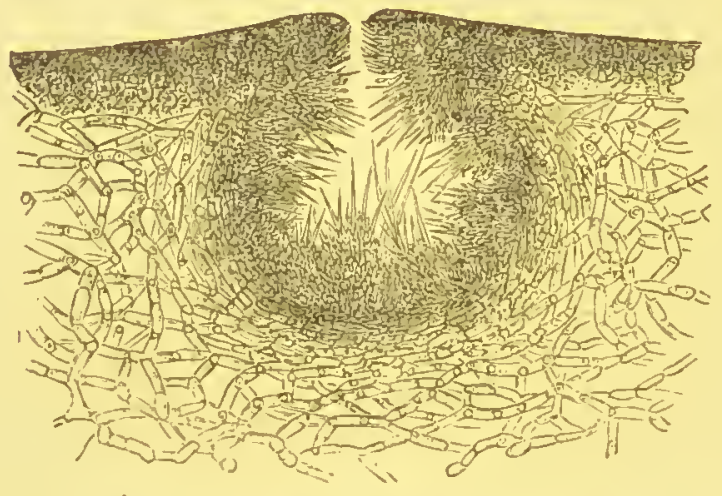

II.

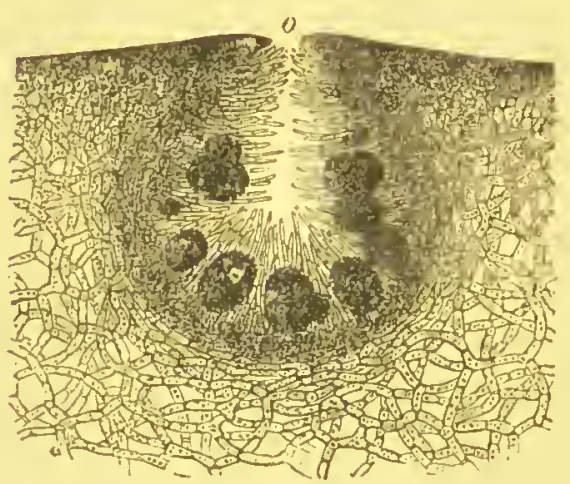

FIG. 393.-Fucus vcsiculosus: I. Section of male conceptacle, with branched hairs bearing the antheridia. II. The same : section of female conceptacle, with oogonia ; o mouth through which the oospheres escape. (After Thuret).

(Fig. 393 II.) are at first lined with filaments, some of which remain permanently in that condition, and are known as paraphyses; they sometimes project through the opening of the conceptacle. Others enlarge into sacs, the oogonia, the protoplasm of which divides into two, four, or eight oospheres, of comparatively large size. In the male concep- 
tacles (I.) similar filaments develope into branched sacs, the antheridia, from which escape the very minute antherozoids. In some instances oogonia and antheridia are found in the same conceptacle. When ripe, both organs discharge their contents through openings of the conceptacles into the surrounding water. Here a large number of the minute motile antherozoids crowd round the oospheres, coalescing with them, and thus impregnating them and inciting them to develope into oosperms. This process is indicated by the discharge from the mouths of the conceptacles of a drop of an orange fluid. No non-sexual mode of propagation is known in the Fucaceæ.

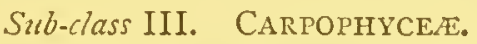

In the Carpophycee the male element is a motile or immotile antherozoid. The female organ containing the oosphere is a multicellular or occasionally unicellular body, the carpogonizm; the result of impregnation is a carposperm, enclosed in a more or less complicated structure, the cystocarp. Except in the simplest forms, other cells besides the actual male and female cells take an indirect part in the process of impregnation, which is hence frequently a complicated one.

The Coleoch жтеж are small green fresh-water Algæ, forming disclike or hemispherical patches on submerged water-plants, the sides of aquaria, \&c., some of the cells of which are prolonged into long hairs. The carpogonium contains only a single carposperm, and the cystocarp is of simple structure. There is also a non-sexual reproduction by zoospores.

The FLORIDE $\approx$ are marine, rarely fresh-water, Algæ, often of great beauty, including all the red sea-weeds. The red colouring matter, known as rhodospermin, is soluble in cold water, and exhibits beautiful phosphorescence. In the corallines of our coasts the frond acquires a stony character from the deposition of carbonate of lime. The Melobesiace are small flat incrustations on marine rocks. The thallus or frond of the higher forms is termed monosiphonous or polysiphonous according as it consists of a single or of several parallel filaments of cells, and a rudimentary differentiation 
is exhibited between an epidermal layer and internal spongy pseudo-parenchyma. No zoospores are known in the Floridex; non-sexual reproduction takes place by tetraspores (Fig. 382, p. 25r), collections of four spores formed by a double bipartition of the contents of the parent-cell or tetrasporangizm; these are often formed on metamorphosed branches of the frond known as stichidia. The antherozoids are motionless unciliated primordial cells, which are carried passively by currents of water to the apex of a long hair-like tube, the trichogyne or trichogonium, a prolongation of the cell which contains the oosphere, sometimes carried by a special lateral row of cells, the trichophore (Fig. 387 , p. 255). The oospheres are produced in other cells near the trichophore. In the most complex forms, such as Dudresnaya, the cystocarps are even formed on different branches from the trichophore, and a single trichogyne may assist in the production of a number of cystocarps. A still more complicated process has recently been described in the case of some Florider, consisting in a double process of impregnation, first of the oosphere within the carpogonium by an antherozoid, secondly of one or more 'auxiliary cells' by the carposperm, the auxiliary cell thus fertilised finally developing into the cystocarp. The carposperms are usually more or less imbedded in a jelly within the cystocarp ; they are either solitary, or are collected into a larger or smaller mass, known as a 'nucleus.' Florideæ are either monœcious or dicecious. The fronds of many species, as Callithamnion, display a continuity of protoplasm.

\section{Class III. Fungi.}

The elements of which the vegetative parts of Fungi that do not subserve the process of reproduction consist, are hypha, or filaments of cells destitute of chlorophyll, which usually branch repeatedly by lateral ramification, and grow only at their apices. In the simplest fungi the entire 
vegetative portion consists of a single undivided cell; while in the Mould-fungi it is composed of a single often much branched filament of cells. Even in the highest forms the filaments either run parallel to one another, or in an irregularly complicated mass, but often forming structures of an externally definite form characteristic of particular species. Sometimes the hyphæ are compacted at particular parts into a dense parenchymatous structure, known as a pseudo-parenchyma, as in the larger fungi, of which it forms the main mass. The various modes of reproduction in Fungi are closely analogous to those in Algæ. Non-sexual reproduction takes place either by motile ciliated zoospores, or by unciliated spores of various kinds, which are termed, according to their mode of origin, basidiospores, ascospores, uredospores, teleutospores, \&c. Sexual propagation is effected by conjugation, or by the fecundation of a female oosphere by motile antherozoids. A more distinct altemation of generations is displayed in some classes of Fungi than in Algæ, and in the Lichens we have the most remarkable instance in the vegetable kingdom of the singular phenomenon of symbiosis or commensalism.

The cell.wall of fungi consists of cellulose, which, however, is only very rarely coloured blue by iodine and sulphuric acid, and is therefore considered a special modification, under the name funguss-cellulose. Very often the outer layers of the cell-wall swell up and pass over into. a gelatinous or mucilaginous condition. The cells of fungi contain neither starch-grains nor chlorophyll ; their characteristic contents are a fatty oil. Calcium oxalate is very commonly found on the surface of the cells, very rarely in their interior.

The thallus of fungi consists of two principal parts, the mycelium and the fructification. The former is developed at once on germination, and either consists of simple hyphr, or forms loose flocculent masses, branching bundles, pellicular expansions (as Penicillium when growing on fluids), or, finally, compact tuberous masses, the sclerotia, as in ergot.

The fructification is, as a rule, the most conspicuous part of the fungus, and is popularly regarcled as the whole, as in the mushrooms. Fertile hypha, consisting of only a single filament, usually erect, are distinguished from true fructifications of a compound structure, 
In the fertile hyphæ the terminal cells of the principal filament and its ramifications become the mother-cells of the reproductive cells or spores, their growth as a rule then ceasing. A fresh growth of the lower portion, however, frequently begins after the ripening of the first spores, which soon again terminates with a new formation of reproductive organs, the process being sometimes repeated after a time. The fructification varies greatly in its external form; but the procluction of spores is almost always limited to a particular part, the hymenizm, which assumes very different forms in the different groups.

Reproduction by spores is by far the most common mode among fungi. The spores, however, vary greatly in their form and mode of formation; in some species two, three, or even four forms have been observed, forming a single cycle of development. Their mode of formation is of three principal different kinds :-

1. By Division; i.e. by the contents of a sporangium breaking up entirely into spores (Fig. 395), or being transformed by segmentation into a sporidesmium.

2. On basidia; i.e. on the apex, or on the more filiform or pointed protuberances, sterigmata, of special cells. Such spores are called basidiospores, acrospores, or ectospores; and they may either be formed simultaneously or may become detached successively. The former mode occurs in the Agaricini (Fig. 400 11., p. 280); the latter in Penicillium (Fig 1, p. 7). Those that become detached in succession, or abstricted, usually form threads, the younger spores placed on the apex of older ones, and the oldest on the basidium. In a few cases, as Cystopus and Peronospora, sporangia are formed instead of spores on the basidia. Spores which become abstricted in this way from the apex of filaments have been termed conidia; if formed in special receptacles or pycnidia, they are stylospores.

3. In asci or thecre (Fig. 404, p. 282). The spores, here called ascospores, are usually formed simultaneously in definite number (in most species eight), in the interior of a sac-like cell, the ascus, which they do not entirely fill up. The asci are usually surrounded by paraphyses, i.e. unbranched unicellular or multicellular hairs which are formed beside them, usually in large numbers and running in the same direction. Special receptacles in which asci are formed are called perithecia (Fig. 403, p. 282).

The zoospores or swarmspores break through the wall of the cell in which they are formed, and which is called a zoosporangizm; and then swim about for some hours, or even days, as if endowed with voluntary power of motion, by means of their vibratile cilia; after which they become fixed and develope into new plants (Fig. 399, 


\section{Special Morphology and Classification.}

p. 275). The greater number of spores, however, are not endowed. with motion of this kind. In some instances they germinate immediately after attaining maturity ; in other cases, where they have thicker coats, only after a definite longer time, so that they appear especially adapted for hibernation, and are termed resting-spores. Differences also exist in the mode of germination, many spores developing at once into a new plant, while others first produce spores of a second order, or sporidia, which then put out sacs or pro-mycelia (Fig. 400 IV., p. 277), and these either repeat the same process or develope into. perfect plants.

Sexual reproduction by means of the fecundation of oospheres by antherozoids is much less widely distributed among Fungi than among. Algx.

Fungi may be conveniently divided into three sub-classes, dependent on their mode of sexual reproduction, and to a certain extent parallel to those of Algæ. But to these must be added a fourth sub-class, altogether anomalous in structure, and the retention of which in the. class of Fungi is not altogether free from doubt, viz.:-

\section{Sub-class I. (?) Myxomycetes.}

The Myxomycetes (Fig. 394) are distinguished from all other plants by the fact of their cells being without a cellwall during the whole of their vegetative period. It is only when their protoplasm comes to rest, or their growth has. ceased on the formation of the fructification, that the protoplasm breaks up into small cells provided with a cell-wall, but not forming a true tissue. They live on decaying and putrefying vegetable substances. In its membraneless condition the mass of protoplasm, or plasmodium, displays an extraordinary motility ; and then, independently of the currents in its interior, the whole mass creeps over or in its substratum with a remarkable amœba-like motion. The plasmodium is of a slimy or creamy appearance, and contains a number of net-like anastomosing channels, along. which move constant currents of protoplasm, carrying foreign bodies, as spores, granules of starch, \&c. But when the plasmodium passes over into the fructifying state, it comes to rest, and breaks up into large receptacles or sporangia, 
filled with small spores, formed by free cell-formation, and often accompanied by a reticulation of thin-walled tubes opening into one another, a hair-like weft termed a capillitium. Round each of these tubes there frequently runs a spiral thickening band. In the simplest forms, as Dictyostelium, the spores are not enclosed in a sporangium. The contents of the spore, now provided with a cell-wall, break up on germination into a number of zoospores, known as

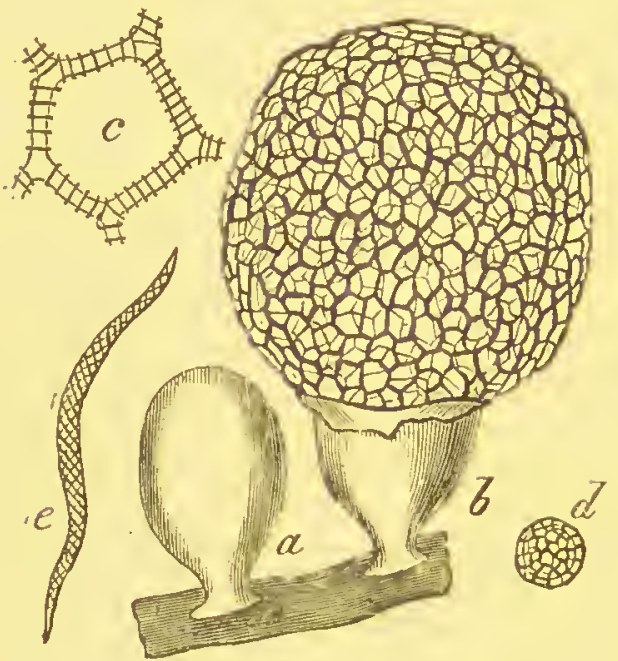

FtG. 394.-Arcyria incarnata: a closed ; $b$ de. hiscent sporangium with the expanded capillitium $(X 20): c$ a portion of the capillitium $(x 200), d$ spore $(x 400)$; $e$ thread of capillitium of Triclia clavata, with spiral thickening. myxamaba, provided with a nucleus and vacuole, and endowed with a remarkable amœboid motion, due ro peculiar retractile appendages known as pseudopodia. These swarming bodies mul. tiply by division during - two or three days ; and then a new process begins, two or more coalescing into a homogeneous mass of protoplasm or plasmodium, which again moves about in an amœeboid

manner. The plasmodium often creeps about for the space of a foot, the motion being caused by the projection at its margin of arm-like protuberances, which increase in size by fresh masses of protoplasm flowing into them. When this takes place for some time in one direction, the whole plasmodium has in this way shifted its place. These processes usually occupy a few hours ; in the so-called 'flowers of tan,' Ethatium septicum, one or two hours is sufficient for the still motile plasmodium to become changed into sporangia. When the vital conditions are unfavourable, the myxamœba 
and the young plasmodia become surrounded by a membrane, or encysted, and, if kept dry, remain in this condition for months without losing their power of life; when placed in water they recur to the motile condition. Mature plasmodia pass into the resting state when the amount of moisture or the temperature is low, forming a sieve-like plate or irregular tuberous body, and finally break up into a large number of round or polyhedral cells of a diameter of 0.025 to $0.033 \mathrm{~mm}$., and of a waxy or brittle texture. When placed in water the cell-walls which had been formed are again absorbed, and the plasmodia re-assume their motile condition.

Sub-class II. ZyGonycetes.

In this sub-class the mycelium consists of a single branching filament, which is septated only when about to produce organs of reproduction. Non-sexual reproduction takes place by motionless spores enclosed in a sporangizm, sexual reproduction by the conjugation of two branches of the mycelium, and the consequent production of a zygosperm. The Zygomycetes include only one well-marked family.

The Mucorini (Figs. 395, 396) are common mouldfungi, growing on living plants, decaying vegetable substances, or the surface of organic solutions. In Mucor, one of the commonest forms of mould, the spores are produced within sporangia, roundish heads borne at the extremity of filaments which rise vertically into the air from the hyphæ, and which are known as sporangiophores. The wall of the sporangium is rough from minute particles of calcium oxalate. The sporangium is easily ruptured, dispersing the spores; the greater part of its wall then disappears, but a small collar frequently adheres to the filament. The cavity of the filament does not communicate with that of the sporangium, but is separated from it by a partition which bulges into the cavity of the sporangium, forming a central pillar or projection, and termed the columella. The spores, on germinating, give rise to ordinary unseptated mycelial filaments. From these the sporangiophores are given off 
vertically; the free end dilates into a rounded head which developes into the sporangium, and is separated by a septum

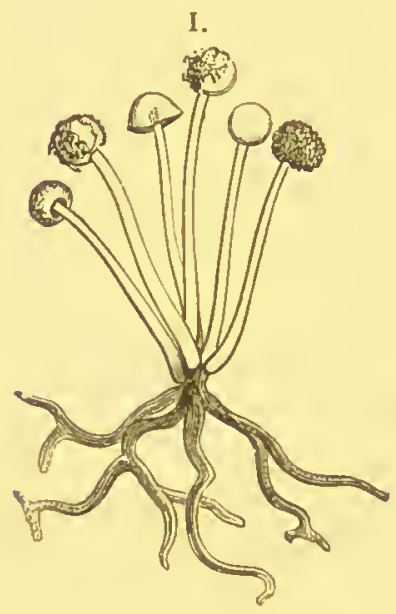

FIG. 395. - Mucor mucedo: 1. an entire plant with six sporangia in different stages of development (strongly magnified); II. single sporangium with spores $b(\times 200)$.

which constitutes the columella. The protoplasm in the sporangium becomes gradually separated into a number of masses by free cellformation, each of which secretes a cellulose coat, and becomes a spore.

II.

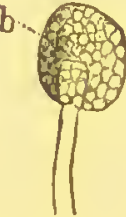

In addition to the ordinary spores, interior non-sexual reproductive bodies, or chlamydospores, are sometimes formed within the mycelial filaments. Mucor is also propagated sexually by conjugation, i.e. by the production of zygosperms. When two filaments come into contact, each puts out, in the direction of the other, a cylindrical protuberance resembling the filament itself (Fig.

II.

III.

IV.
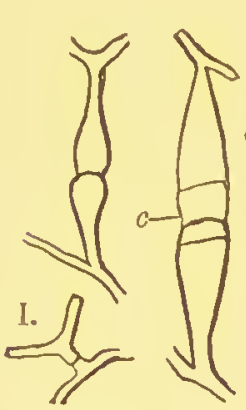

V.

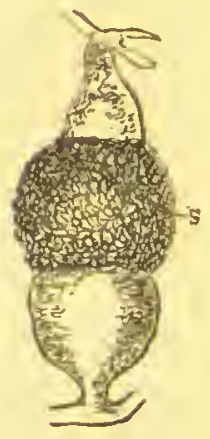

FIG. 396.-Formation of the zygosperm of Mucor mucedo: I.-V. successive stages of development; $V . s$ the mature zygosperm $(x 60)$. 396). These two protuberances become closely adpressed to one another by their ends, and grow into a club-shaped body, in which a quantity of protoplasm collects. When both have attained a certain size, a conjugating cell (c) becomes separated at the upper end of each, the two conjugating cells being usually of unequal size; the partitionwall between the two soon disappears, and they unite to form 
the zygosperm. The cell-wall of the zygosperm becomes separated into two layers, an outer one of a darker hue, cuticularised, and often spiny, the exospore, and an inner colourless layer of pure cellulose, the endospore. The germination of the zygosperm, which takes place only after a period of rest, resembles that of a spore.

The CHytridiacese are very minute organisms of simple structure and uncertain position, parasitic on or very frequently endophytic in flowering plants, algæ, or other fungi. They produce zoospores, which have often been mistaken for those of the host; and they are said also to be reproduced by conjugation. Nearly allied to them are the Piptocepilalide.

\section{Sul-class III. OOMYCETES.}

The mode of sexual reproduction is here, as in the Oophycex, the fecundation of an oosphere contained in an oogonizum, by motile ciliated antherozoids, and the consequent production of an oosperm. The non-sexual reproductive organs are either motile zoospores or motionless conidia. On germination the oosperms give birth either to sporangia, to conidia, or to zoosporangia, thus displaying an alternation of generations.

\section{The PERono-} SPOREE are fungi parasitic on living Phanerogams, the tissues of which they attack and destroy. The myce-

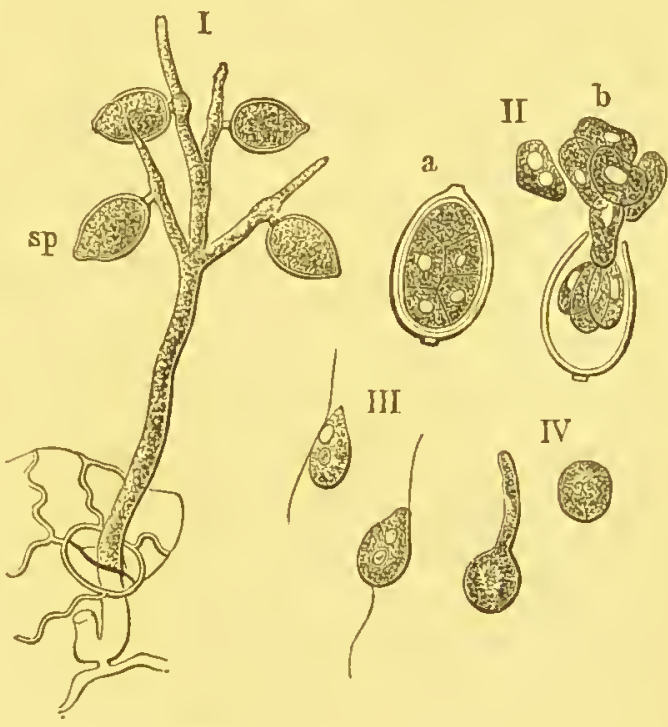

.FIG. 397.-Phytophthora infestans: I, a fertile branch growing out of a stoma, bearing four mature conidia : I1. zoospores emerging from a conidium; III. escaped zoospores; IV. zoospores germinating. (I. $\times 200$;

lium, ramifying through the tissue of the host, puts out conidiophores (Fig. 397), erect branches, appearing above 
the surface of the host, which agan branch and bear the conidia. These are either simple spores, which, on germinating, directly produce a mycelium, or they are zoosporangia, their contents breaking up into zoospores, each of which gives birth to a mycelium. The process of sexual reproduction is nearly identical with that in the Saprolegniex (Fig. 398). The female cells or oogonia are spherical, full of protoplasm, and usually terminal. Their protoplasm collects into one or more globular masses, the oospheres,

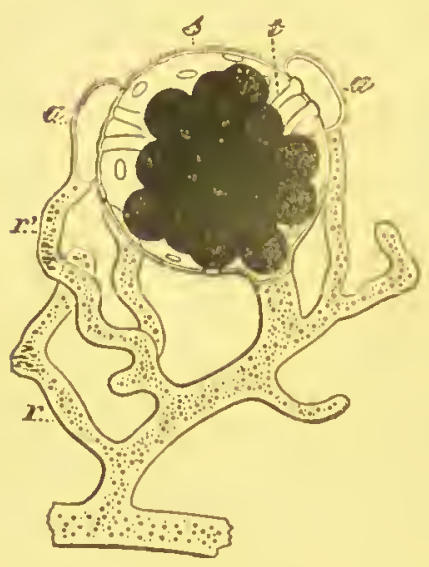

FIG. 398.-Process of impregnation of Saprolegnia monoica : a $a$ antheridia ; $t$ fertilising tubes which penetrate into the oogonium $s$ : $r \cdot$ mycelial filaments. which have at first a smooth surface, but no cell-wall. During the formation of the oogonium slender branches from its pedicel or from neighbouring filaments grow out towards it. The upper' end of one or more of these branches becomes firmly adherent to the oogonium, no longer grows, swells up somewhat, and becomes separated by a septum into an independent cell, the fertilising antheridium. As soon as both the oogonium and antheridium have attained their full size, and the oosphere is at least in process of formation, the antheridium puts out one or more beak-like protuberances, the fertilising tubes, which pierce the wall of the oogonium. In the Saprolegniere these tubes give way at the end, and inject their contents-minute motile bodies scarcely $.002 \mathrm{~mm}$. in size, the antherozoids -into the oogonium. In the Peronosporex, on the contrary, the fertilising tubes do not burst, but only touch with their apex the oospheres, which then become covered with a cell-wall of cellulose, and develope into the unicellular oosperms. The germinating oosperm again gives rise, after a long period of rest, to 
a mycelium, which bears first conidia, and afterwards the sexual organs. Or in oiher instances the contents of the oosperm break up into zoospores. Again, the germinating oosperm may produce a germinating filament or pro-mycelium, from which the new mycelium is developed. The

L

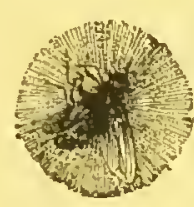

II.

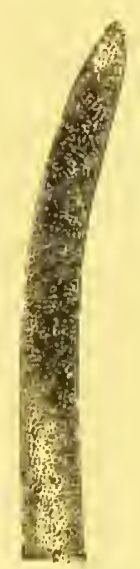

III.

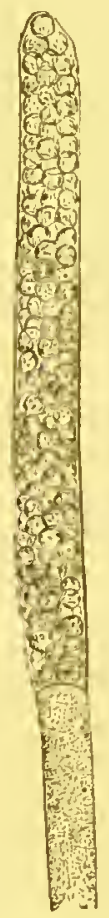

IV.

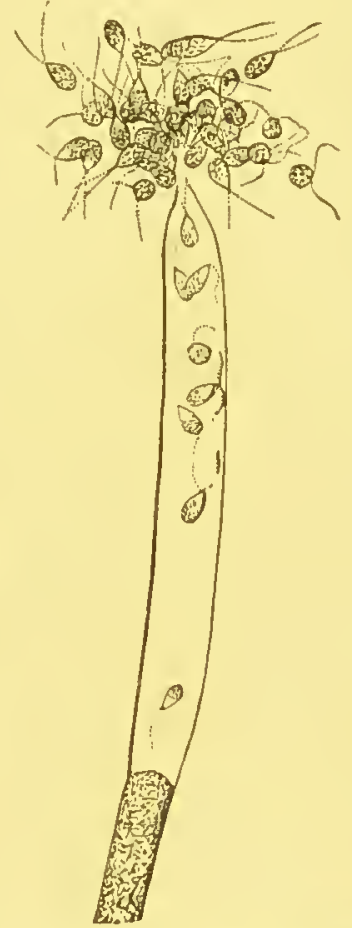

FiG 399.-I. Fly which has putrefied in water and become surrounded by the filaments of Saprolepnia ferax (natural size); II. end of one of these filaments. (greatly magnified): 111. protoplasm of the end of the filament collecting into globular masses : IV. biciliate zoospores produced from the protoplasm escaping from the cell $(x 300)$.

mycelium of Cystopus, an extremely common parasite, especially on Cruciferæ, is provided with numerous organs called haustoria, which penetrate the cell-walls of the host, and extract the nutriment for the use of the parasite. The Peronosporea are among the most destructive parasites to living plants. Phytophthora infestans (Fig. 397) is the well-known 
potato-blight. The zoospores penetrate into the mesophyll of the leaves through the stomata, especially in wet weather, and grow rapidly; the mycelium rapidly depriving the leaves of their food-supply, causes decay of the haulm and tubers. (See also p. 230.)

The SaprolegnieÆ (Figs. 398, 399) are nearly allied to the Peronosporex, but grow for the most part in water, and chiefly on the deacl bodies of insects. The two modes of reproduction, sexual and nonsexual, are similar, but many of the Saprolegniere are diœcious, the male and female organs being produced only on different plants. Parthenogenesis, or the production of fertile oosperms without the action of antherozoids, occurs in Saprolegnia and Achlya. Saprolegnia ferax is the parasite so extremely destructive to salmon.

The ENTOMOPHTHOREA form a small group, apparently interme. cliate between the Saprolegniex and Mucorini. To it belongs Empusa masca, which covers with a flocculent growth the hodies of flies decaying in water.

\section{Sub-class IV. CARPOMYCETES.}

In some families belonging to this class the fructification is a cysto. carp, corresponding, to a certain extent, to that in the Carpophycex, and results from the action of a male organ or pollinodium on a female organ or carpogonizum. In others no sexual mode of reproduction is known, and these are only referred hypothetically to this sub-class. Non-sexual propagation takes place by motionless spores or conidia; zoospores do not occur.

The Reidiomycetes (or Hypodermix) are made up of the two families Uredinex and Ustilaginex, and are noteworthy as displaying the most remarkable illustration of alternation of gencrations in the vegetable kingdom.

The most familiar instance of this alternation of generations occurs in some UREDINEE, as in the common 'rust ' of corn, Puccinia graminis (see also p. 226). The resting-spores, or teleutospores (Fig. 400, II., III.), of this Fungus-thickwalled spores situated at the apex of filiform basidia, either singly or in pairs-produce on germination a pro-mycelium which bears three or four sporidia (Fig. 400, Iv.). These produce first spermogonia (Fig. 400, I.), narrow-necked sacs containing minute bodies, the spermatia, which are believed 
to be male organs that have lost their function, no female organs having at present been detected in these fungi ; then cup-shaped organs which were at one time described as a distinct species under the name Ecidium. The acidiospores
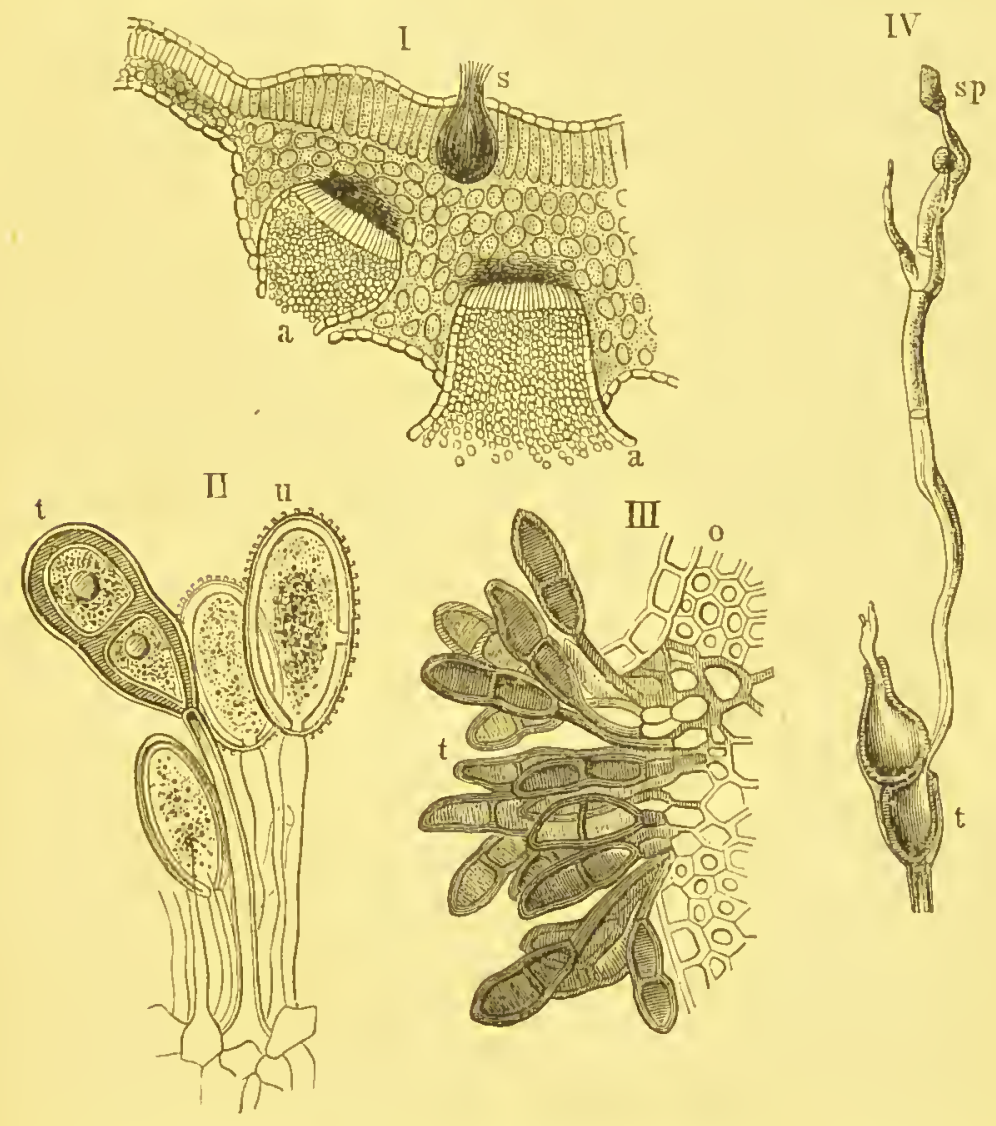

FIG. 400.-Puccinia graminis: 1. Transverse section of leaf of barberry with a spermogonium $s$, and two ascidia $a$; II. part of a 'rust-spot' from a grass-leaf with three uredospores $u$, and a telentospore $t: 11 \mathrm{I}$. tuft of teleutospores $t$ from a grass-leaf : $o$ the ruptured epidermi : IV. germinating teleutospore putting out a pro-mycelium, which bears two sporidia sp. (1. $x$ about 30 : II. about 300 ; III. 200; IV. 300). (After De Bary).

formed in these organs give rise to resting-spores, or produce the uredospores (Fig. 400, II.), out of which nothing but fresh uredospores arise. The form of the Uredinea which produces the uredospores was also formerly regarded 
as a distinct genus under the name Uredo. The acidia consist of round or oval receptacles, at the base of which is the hymenium, consisting of club-shaped basidia, each of which produces a series of æcidiospores. These are liberated by the bursting of the peridium, or layer of pseudoparenchyma which immediately surrounds the acidium; and put out their germinating filaments through the stomata of the host-plant. On these are produced either uredospores, round or oval conidia, or teleutospores, which commence the cycle of generations afresh. In the Uredinea this alternation of generations is connected with a change of the ' host' on or in which they live. 'Thus, the restingspores of Puccinia hibernate on the haulms of grasses; while the germinating filaments developed by the sporidia which are produced from them in the spring never germinate on grass, but penetrate into the epidermal cells of the leaves of the barberry, and rapidly develope there into the Fungus previously known as Acidium Berberidis. The spores of this form again, when they enter the stomata in the leaves of suitable grasses, produce in them, and in them only, the mycelium of the Puccinia, which bears uredospores and resting-spores.

The USTILAGINEA resemble the Ureclinere in the general facts of their life-history. They are parasites very destructive in their operation, especially to grasses. Many of the well-known diseases of cereal crops, such as 'smut,' are due to their attacks. (See also p. 226.)

The BAsidiomycetes include the largest and best-known Fungi. The hymenium or reproductive portion consists of several layers of cells, in which some individual cells, much larger than the rest, are known as basidia. From these are abstricted the basidiospores, always produced in fours from the apex of the basidia. These reproduce the fungus directly, and no sexual mode of reproduction is known. The mycelium is composed of septated hyphæ; this puts up the large massive fructification which bears the hymenia, often consisting of closely packed and interwoven hyphx, 
constituting a psendo-parenchyma. The hymenium may be either exposed on the surface of the fructification, when it is gymnocarpons, or it lines internal cavities, when it is angiocarpous.

A familiar example of the Hymenomycetes is furnished by the common mushroom, Agaricus campestris, belonging to the family Agaricini of the order Hymenomycetes. The basidiospores are here formed only on delicate plates

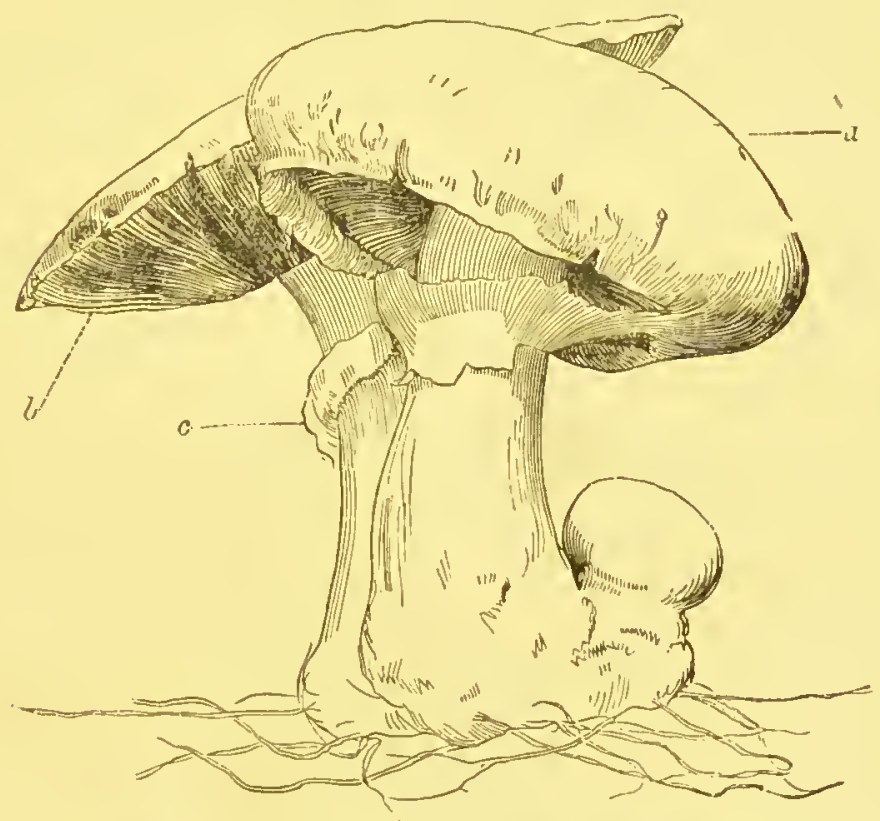

Fig. 40r.-Mushroom, Agaricus campestris : one young globular and two mature fructifications, $a$ pileus ; $b$ lamella ; $c$ annulus (natural size).

or lamella on the under side of the pilens or cap-shaped fructification, which is elevated on a stalk or stipes. In many fungi this fructification is naked ; in others the lower side of the pileus is covered with a membrane which is ruptured when near maturity (Fig. 40r) (velum partiale or anmulus); or often the pileus and stalk are both enveloped in such a membrane (ielum universale), or occasionally both are present (Fig. 402 I. .). Among the basidia are frequently 

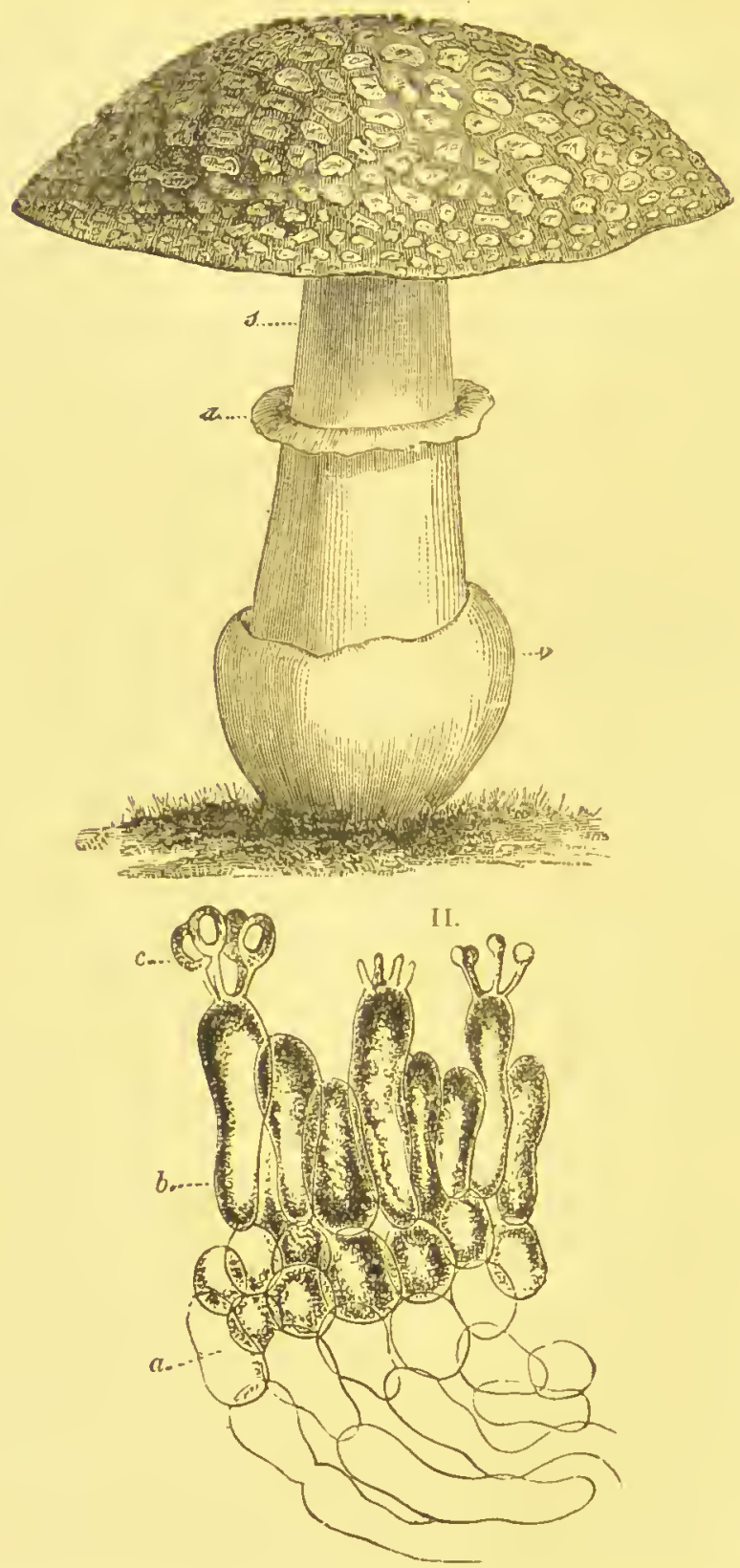

Fig. 402.-I. Agaricus rubesrens: the fructification (natural size): s stipes; v vclust universale, a velume partiale or annulus. II. Part of a longitudinal section through the hymenium of another species; a psetudo-parenchyma; $b$ hj'menium: $c$ basidiospores. ( $x$ 400.) 
to be found other greatly enlarged cells, the cystidia, the function of which is unknown, but which are possibly barren basidia. In another order, the Gasteromycetes, including Phallus and Clathrus, the hymenium, to which the term gleba is also given in these cases, is distributed into chambers, and is enclosed in an outer layer of pseudo-parenchyma, the peridium.

It is believed by many that the fructification of the Basidiomycetes is the product of a still undetected process of impregnation between sexual organs occurring on the mycelium.

The form of the hymenium differs in different families of the Hymenomycetes. In the Agaricini it is spread over the surface of lamellæ on the under side of the pileus; in the Polyporei (Polyporzis, Boletus, \&c.) it is spread over the cavity of tubes or pores; in the Hydnacex over teeth or spines. The Tremellini are distinguished by their jelly-like substance.

Several of the Hymenomycetes display the phenomenon of phosphorescence, due to slow decay and oxidation, either in their mycelium or fructification. The peculiar structures known as 'rhizomorphs,' common in damp cellars, are the long flocculent persistent mycelium of several species of Agaricus.

A number of the Hymenomycetes, as Agaricus campestris the common mushroom, $A$. casarezs, $A$. procerus the 'parasol-mushroom,' A. prunulus the 'plum-mushroom,' $A$. deliciosus, Boletus edulis, Cantharellus cibarius the 'edible chantarelle,' \&c., are edible; while others, as Agaricus muscarizus the 'fly amanita,'A. emeticus, \&c., are poisonous. Merulizus lacrymans is the dry-rot so destructive to timber. Among officinal species are Boletus laricis and Polyporus fomentarizus, which yields the 'amadou' of commerce. Among the more common Gasteromycetes are Lycoperdon bovista the 'puff-ball,' and Phallus impudicus the 'stink-horn.'

The Ascomycetes are a very numerous class of fungi, growing usually either on dead or decaying vegetable matter, and distinguished by the formation of ascospores, by free cell-formation, within special sacs or asci. Other nonsexual reproductive cells are conidia, produced in the 
ordinary way on conidiophores, and sometimes supported on

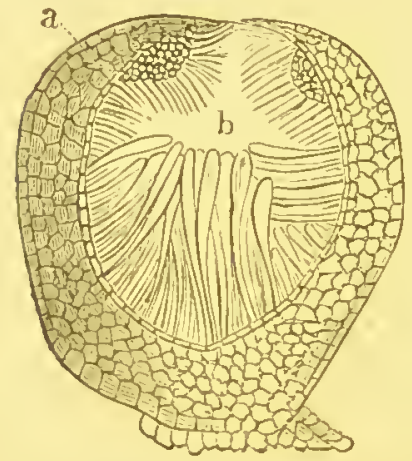

FIG. 403. - Nectria inaurata (Spheriaceæ): a mature perithecium; $b$ asci ( $x$ about 150 ). basal cells known as sterigmata; and stylospores, produced internally in special receptacles, the pycnidia. Bodies known as spermatia are also found, within spermogonia, which are believed to be male sexual cells that have lost their function; they appear to have no power of germination. The asci are often enclosed in a special layer of pseudo-parenchyma, the perithecimm (Fig. 403); and the asci are not unfrequently accompanied by barren filaments, the paraphyses. If the fructification or collection of asci is completely open, it is known as an apothecium. In a large number of the Ascomycetes no sexual organs have at present

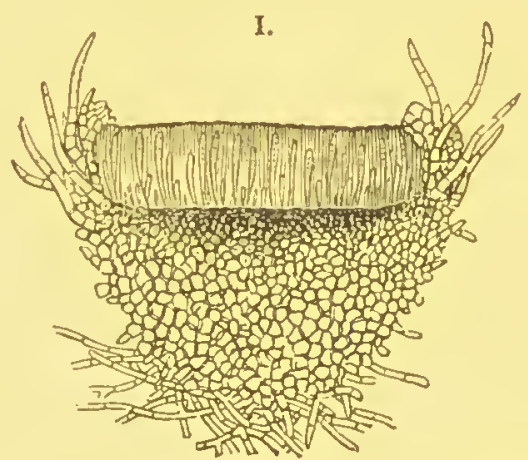

II.

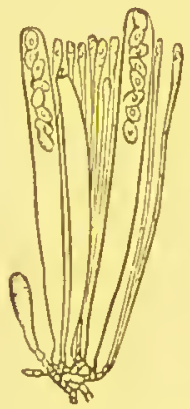

FIG. 404.-1. Transverse section through the fructification of Ascobolus pulcherrinues (magnified): II. a part of a fructification consisting of asci containing ascospores in various stages of development, and paraphyses (more strongly magnified).

been detected, as is the case universally with the Hymenomycetes; in others, as in the Discomycetes, (Figs. 403, 404), the fructification is the result of the fertilisation of a carpogonium by a pollinodium. Each of these organs consists of a series of short crooked cells arising on neigh- 


\section{Special Morplology and Classification.}

bouring branches of the mycelium. Fecundation is effected by the pollinodium coiling itself round the carpogonium, and passing into it the protoplasmic contents of its cells. One of the cells of the carpogonium then developes into the 'ascogonium' or 'scolecite'; this puts out numerous hyphæ, on which are borne the asci. The ascospores being always produced by repeated bipartition (free cell-formation) of the contents of the ascus, their number is always some power of 2, the most usual being 8 . The ascospores have always a double coat : an exospore, cuticularised and often warty, and an endospore of pure cellulose. On germination they produce a mycelium. Many of the Ascomycetes produce sclerotia, dense masses of hyphr, enveloped in an indurated 'rind' or 'cortex.' They are the resting condition of the fungus, and develop a mycelium on germination.

Some of the Discomycetes are large conspicuous fungi, as for example the edible morel (Fig. 405), others, like the various species of Peziza, are smaller,

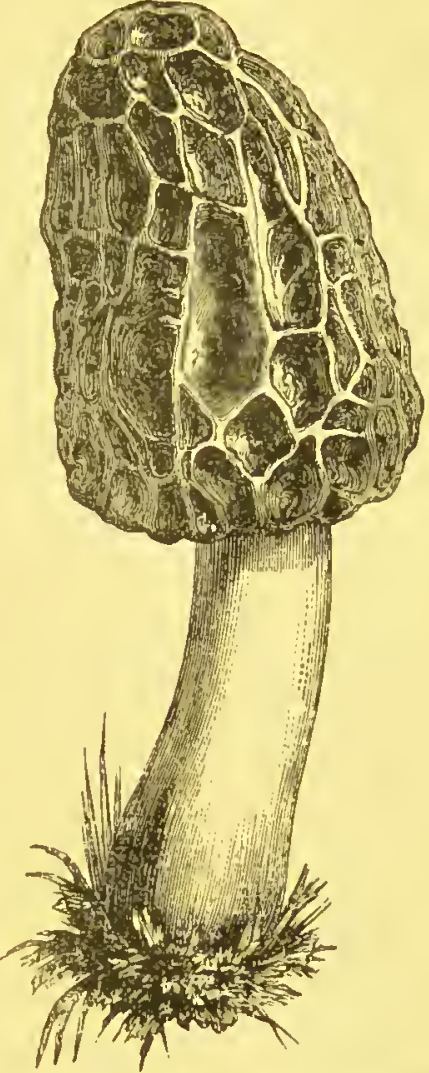

Fig. 405.-The morel, Morchella esculcuta (natural size). often very beautiful objects, growing on garden paths, dead leaves, \&c. The disease known as 'muscardine' which attacks the larva of the silkworm moth, is the 'botrytis' form of a Peziza (formerly called Botrytis bassiana), producing conidia as its only reproductive organs. The sclerotia of other species are exceedingly destructive to clover and other crops. To another order of the Ascomycetes, the Tuberacex, belongs the edible trufle, Tuber astivum (Fig. 406), the edible portion or fructification being produced only underground. 
Many of the commonest kinds of mould, such as the ordinary blue mould of cheese, \&c., are fungi belonging to the genera Penicillium and Aspergillzs, lowly developed forms of the Ascomycetes.

II.
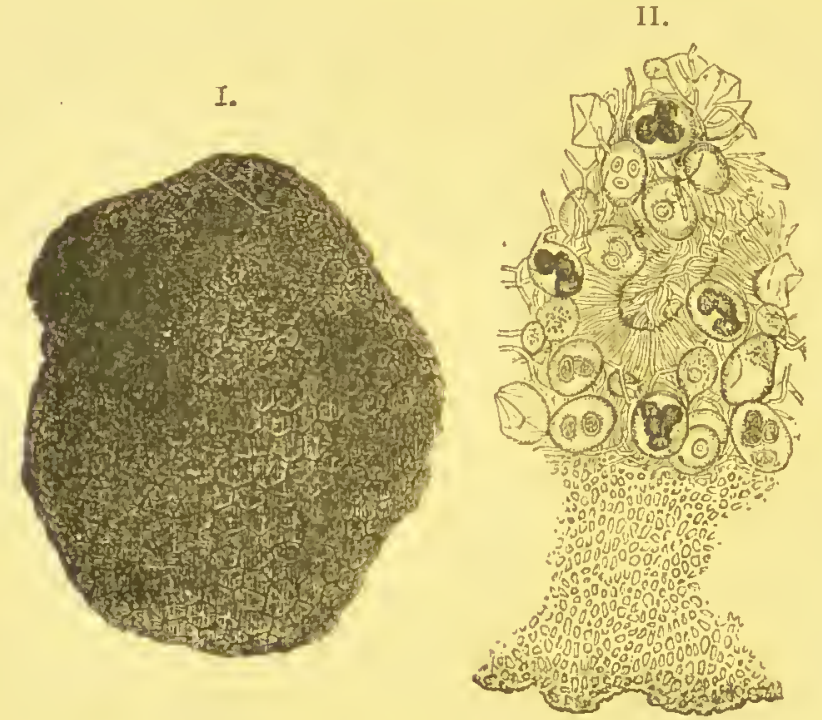

111.

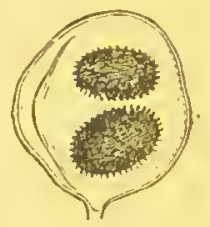

FIG. 406-Truffle, Tuber melanosponm: 1. fructification (the part that is eaten);

II. a part of the fructification with ascospores in different stages of maturity, the outer cortical layer or perithecium below (strongly magnified); III. ascus with two spores (more strongly magnified).

In Penicillinm, one of the commonest forms of these moulds (see Fig. I, p. 7), both the concealed part or mycelium, and that portion which is exposed to the atmosphere, the aerial hyphe, consist of cells which agree in every essential point (except the absence of a nucleus) with the typical cell, varying only in size and form. The only reproductive bodies seen here are conidia, that is, ordinary cells of a spherical form produced at the ends of the aërial hyphæ, and detached in succession. They are true spores. They have the same property as the Saccharomyces cells, of retaining their vitality for a long period when dried; and, from their extreme lightness, are in this form disseminated with the greatest facility through the air. On reaching a nutrient substratum they germinate. A bulging makes its appearance at one or more points of the cell-wall, and the cell 
rapidly lengthens in one or more directions, and becomes a radiating and branched, but still unicellular, hypha. Subsequently the protoplasm divides transversely, septa of cellulose are formed, and the hypha becomes multicellular. Some branches of the hyphæe extend downwards, forming the mycelium, while others direct themselves upwards, and constitute the aërial hyphæ, which break up into conidia. Under ordinary circumstances the conidia are the only reproductive organs of Penicillizm and Aspergillus; but, as with other Tuberaceæ, when in entire darkness, sexual fructifications are produced. Under these conditions the ascogonium, after it has begun to germinate, remains for a long time in a sclerotoid state. But when germination is induced by artificial means, the ascophorous hyphe separate themselves from the sclerotium, and form asci, in each of which are four ascospores. These germinate and produce a mycelium, which again bears conidia.

Another parasitic fungi, the Claviceps purpurea, the cause of 'ergot' of rye (see Fig. 375, p. 228), belongs to the Pyrenomycetes, another order of Ascomycetes; the medicinal ergot being a sclerotium formed in the ovary of the grass (see also p. 227). Erysiphle Tuckeri (Fig. 376, p. 229), formerly known as 'oidium,' is the cause of the well-known vine-mildew (see also p. 228).

LiCHENS (Figs. 407-4I7) should properly be regarded, not as a separate section of the Ascomycetes, or even of Fungi, but as a peculiar condition of growth of many fungi, chiefly belonging to the Ascomycetes. They usually consist, when mature, of a well-developed layer of tissue, the thallus, composed, like that of Fungi, of interwoven hyphæ, which form a fibrous pseudo-parenchyma. Imbedded in this thallus are round or oval cells of a green or blue-green colour, the gonidia. Three types of structure of the thallus may generally be distinguished : the Stratified, the Pictorial, and the Gelatinous. If the gonidia are irregularly distributed throughout the thallus, it is said to be homoiomerous; if they are arranged in definite layers, it is heteromerous. 


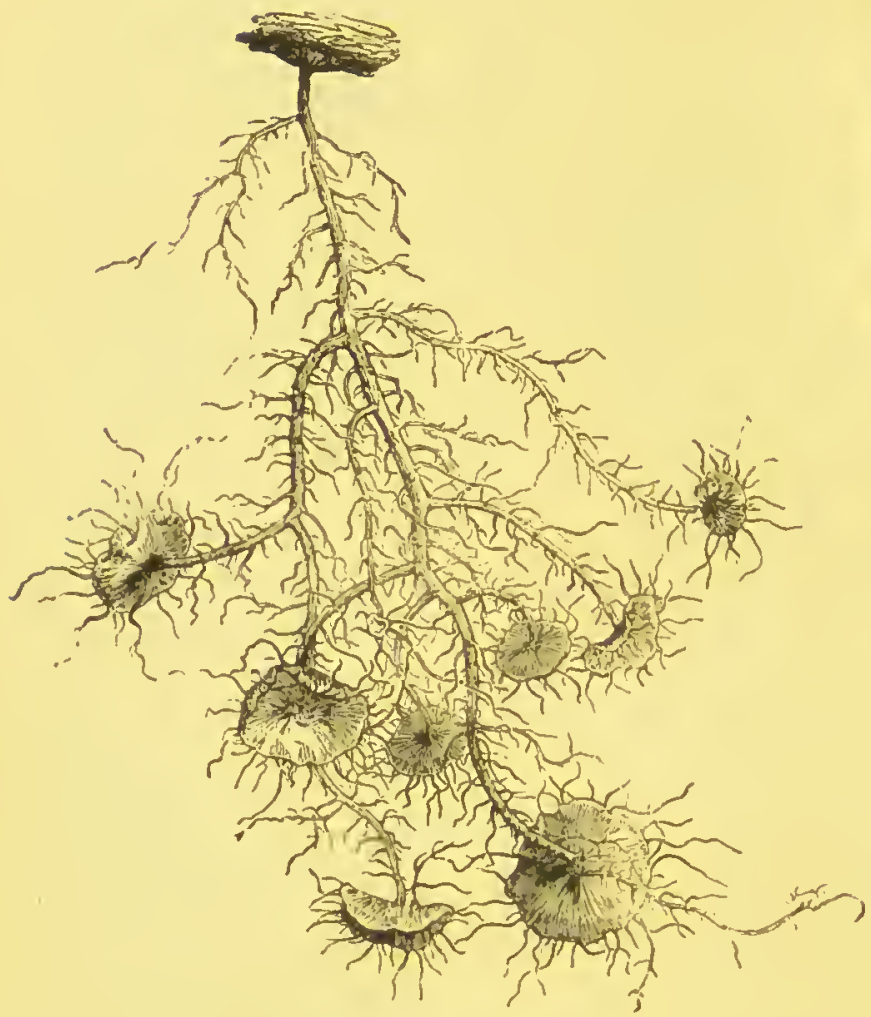

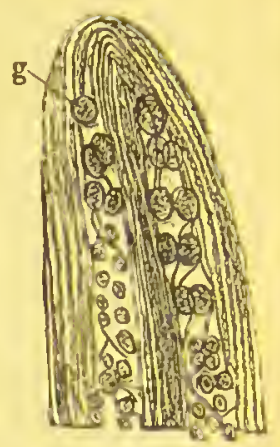

FIG.408.--Longitudinal section through the middle of the apex of the thallus; the cortex, the gonidial layer $\xi$, and the medulla are clearly distinguishable $\left(x_{5}{ }_{5}\right)$.

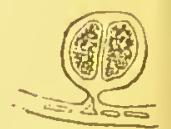

FiG. 409. - A single goni$\operatorname{dium}(x 700)$.

FIG. 407.-Usnea barbata: natural size, with the spoon-shaped apothecia.
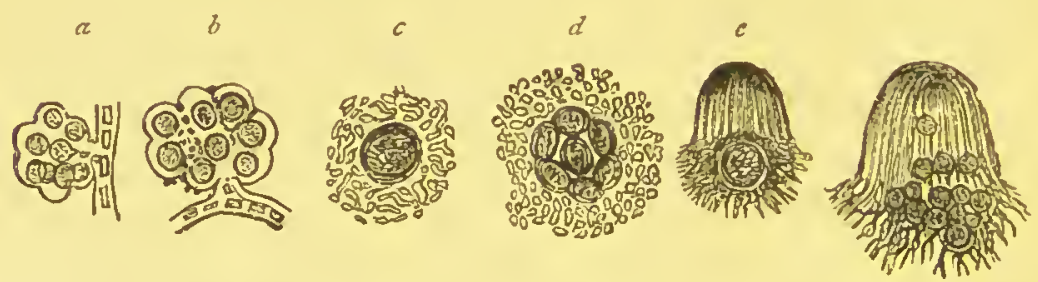

FIG. 410.-Development of the soredia : $a$ gonidial group of eight cells $: b$ a similar group in a more advanced stage of developinent : $c$ longitudinal section of a mature soredium: $d$ the same with the gonidia more distinctly separated, $c$ a germinating soredium; $f$ the same further developed $(x 500-700)$. 
Sections through the thallus of the Stratified Lichens (Fig. 408) almost always show two distinct layers of tissue, a comparatively thin, usually transparent but close outer layer or cortex, and an inner looser hyphal layer enclosed by the former, the medulla. The two layers are, however, formed of ramifications of the same hyphæ. At the line where they meet, the gonidia almost always constitute a zone of variable thickness, the gonidial layer (Fig. $408 \mathrm{~g}$ ). In the Fruticose Lichens the cortex commonly constitutes a layer of uniform thickness all round; while in the Foliaceous forms it is usually different on the upper surface exposed to the light, and on the under surface. The thallus of the Crustaceous Lichens presents an affinity to the latter form in being fixed to the substratum by capillary or bristle-like rhizines, so that it cannot be removed without injury.

The Pictorial Lichens or Graphideæ form thin patch-like incrustations on stones and the bark of trees (Fig. 4II).

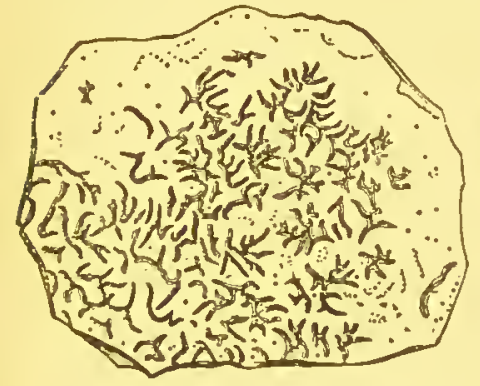

FIG. 4Ir.-Graphis elegans, a Pictorial Lichen (natural size).

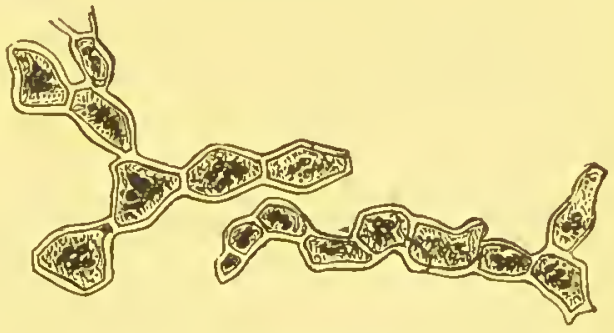

FIG. 4r2.-Chain of gonidia of a Pictorial Lichen, Graphis scripta ( $\times 390)$.

The chief peculiarity of their thallus consists in the nature of their gonidia, which are often united into many-celled alga-like rows of cells (Fig. 4I2), increasing in length by division of the terminal cell.

The thallus of the Gelatinous Lichens (Fig. 413) has a leaf-like or an arborescent form, or consists of granules which constitute an incrustation. When dry it is cartilaginous or brittle, and then absorbs water eagerly, swelling up 
into a gelatinous body. Sections (Fig. 4I3 I.) show that it consists of gonidia and narrow filaments of cells imbedded in an apparently homogeneous jelly. 'The contents of the cells are always colourless and invisible, and apparently contain no organised constituents such as grains of starch. The cell-walls of many Lichens (as, e.g., the so-called 'Iceland moss,' Cetraria islandica) swell up, when boiled in water, into a homogeneous jelly, forming the so-called 'moss or lichen-starch,' or lichenin.

I.

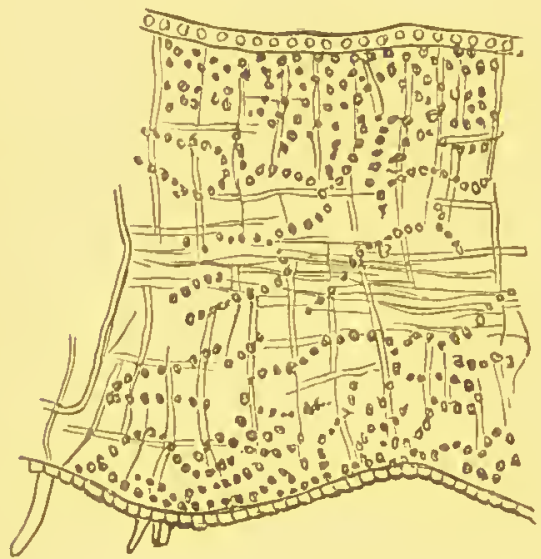

11 .

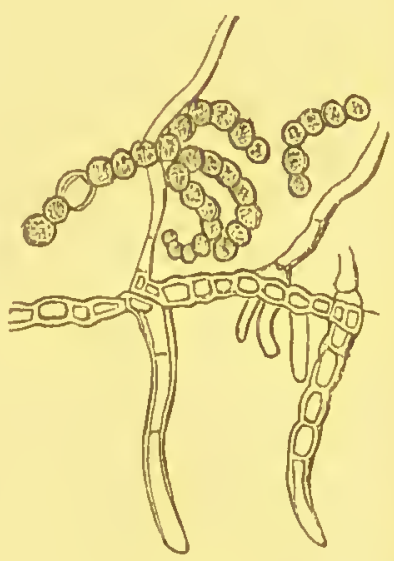

Fig. 413. -1. I ongitudinal section through the thallus of a Gelatinous Lichen, Mazlotinem Hildenbrandii $(x, 100)$ : 11. piece of a very thin section through the under side with moniliform chains of gonidia (after De Bary, $\times 390$ ).

Among the non-sexual organs of reproduction of Lichens are the soredia (Fig. 4IO), which are developed in the gonidial layer; groups of gonidia become enclosed in peculiar fibrous envelopes, and, when so completely inwoven, grow rapidly, and thus exercise a pressure on the cortex which ruptures it. The soredia which protrude through the crevices caused in this way increase in the same manner or develope into new individuals. In addition, Lichens are also provided with stylospores contained in pycnidia.

True sexual organs of reproduction occur in Lichens, namely a carpogonium, fertilised by spermatia contained in 
spermogonia; but although these organs are general in all the groups, it is only in the Collemacer that the actual process of impregnation has been observed. The carpogonium consists of two parts, a straight trichogyne, and a coiled ascogonium. The point of the trichogonium protrudes through the surface of the thallus, in which the rest of the thallus is imbedded, the spermatia are carried to it by currents of water, and, passing through it to the ascogonium, fertilise the oosphere contained in the latter. From the ascogonium are then developed barren paraphyses, and ascophorous hypha, which bear the asci. The receptacle

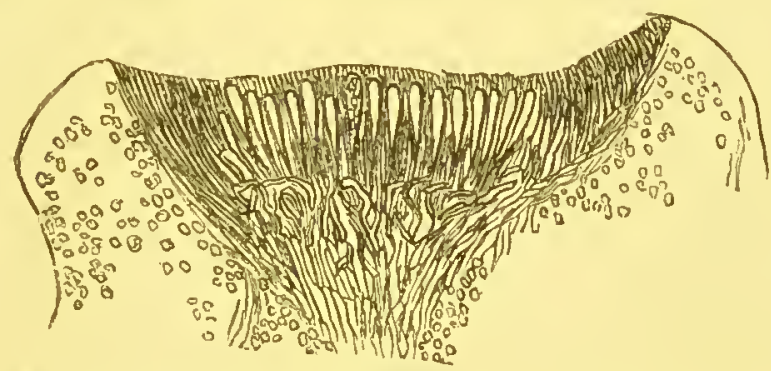

FIG. 414.-Vertical section through the middle of a young apothecium of Lecanora subfusca; the club-shaped asci are developed at the apex of the ascophorous hyphæ, and lie imbedded in the hymenium; the layers at each side contain spherical gonidia ( $x$ IOJ).

which contains the asci is either an open apothecium (Figs. 407, P、286; 4I4), like that of the Discomycetes, when the lichen is said to be gymnocarpous, or a closed perithecium, like that of the Pyrenomycetes, when it is angiocarpous. The development of the apothecia always begins in the interior of the thallus. When mature they consist of the external tissue or excipulum ; of a layer in which larger and stouter hyphal filaments are developed than those found in the remainder of the tissue, the ascophorous hyphæ or subhymenial layer ; and of the true hymenial layer, composed of parallel hyphæ or paraphyses and of the asci. These latter usually contain eight ascospores formed simultaneously.

The compound nature of Lichens, due to a symbiosis of a Fungus and an Alga, may now be said to be completely 
established. The gonidia are groups of Algæ, or rather of chlorophyllaceous Protophyta, belonging either to the Palmellacex or the Nostocacex. The whole of the rest of the Lichen, including the sexual organs, belongs to a Fungus which carries on a kind of parasitic existence on the gonidia, and which belongs in the great majority of cases to the Ascomycetes, rarely to the Hymenomycetes. The gonidia can be detached from the thallus, and will then carry on an independent existence, resembling in all respects that of the green organisms named; and in a few instances, as

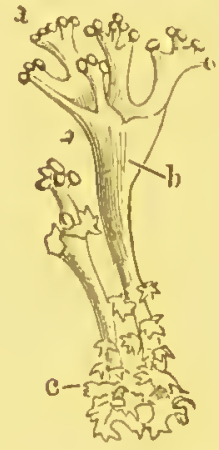

FIG. 415.-Cladonia digitata, a Fruticose Lichen : $a$ apothecia ; $b$ cup ; $c$ foliaceous thallus (natu. ral size).

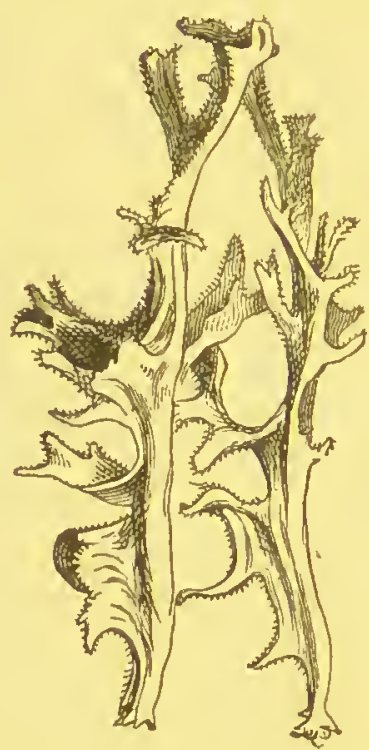

FIG. 4I6.-Cetraria islandica, a Fruticose Lichen: the margin of the thallus is fringed, and bears spermogonia on the edge of the fringe ; there are no apothecia.

that of Collema glaucescens, the perfect Lichen has been constructed synthetically, by causing the spores of the Fungus to germinate in contact with the Alga.

Lichens are classified as under, viz. :-

I. Lichens with a stratified thallus :-Heteromerous Lichexs.

I. Fruticose Lichens; thallus more or less arborescent in form (Figs. 407-410, p. $286 ; 415,416$ ).

2. Foliaceous Lichens: thallus leaf-like (Fig. 4I7).

3. Crustaceous Lichens: thallus crustaceous. 
II. Lichens with unstratified thallus:-Homoromerous Lichens.

I. Gelatinous Lichens: thallus gelatinous (Fig. 4I3, p. 288).

2. PICTORIAL Lichens : thallus forming a very thin irregular incrustation (Figs. 4I I, 4I2, p. 287).

The gelatinous lichenin, characteristic of many Lichens, renders them useful as articles of food to northern nations and their domestic animals, or as medicinal products. Of this character are the so-called 'Iceland moss' Cetraria islandica, (Fig. 4I6), the 'rein-deer moss' Cladonia rangiferina, and Sticta pulmonacea. Parmelia parietina is also used as a febrifuge, from its containing a bitter principle, which is present also in other kinds. Several other Lichens, as Roccella tinctoria, Lecanora tartarea, Variolaria dealbata, Gyrophora pustulata, and Lecanora atra are also important

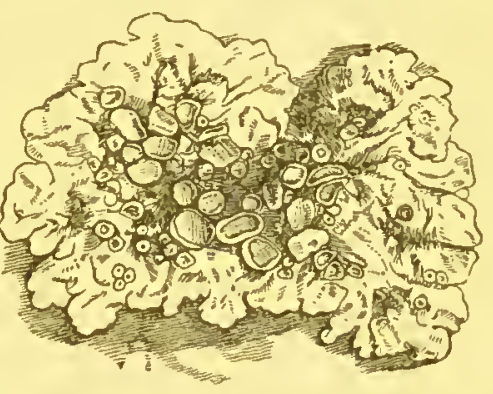

FIG. 4I7.-Parmelia tiliacea a Foliaceous Lichen, with apothecia. articles of commerce, in consequence of a pigment which is blue or red according to the imode in which it has been prepared, and which is known as orchil, litmus, and cudbear.

Lichens are most abundant in the colder regions of the globe, and occur on the utmost limits of vegetation. From this circumstance, and from the ease with which they grow where the means of living are extremely scanty - some of them flourishing on bare hard rocks, and others even thriving on glass and iron-they are of considerable importance in the economy of Nature.

\section{CHARALES.}

\section{Class IV. Characece.}

The Characeæ present in their structure and development a transition from Algæ to Muscineæ; for, although very similar in habit to many Algæ, and therefore at one time included in that class, they are nevertheless really more nearly allied to Mosses, not only in their mode of germination, but because they are Acrogens in contradistinction to Thallogens. They grow in fresh water, and consist of cellular filaments, which are branched in a verticillate 
manner at regular intervals (Fig. 4I8 I.). There are only two genera, Chara and Nitella. known as 'Brittle-worts,'
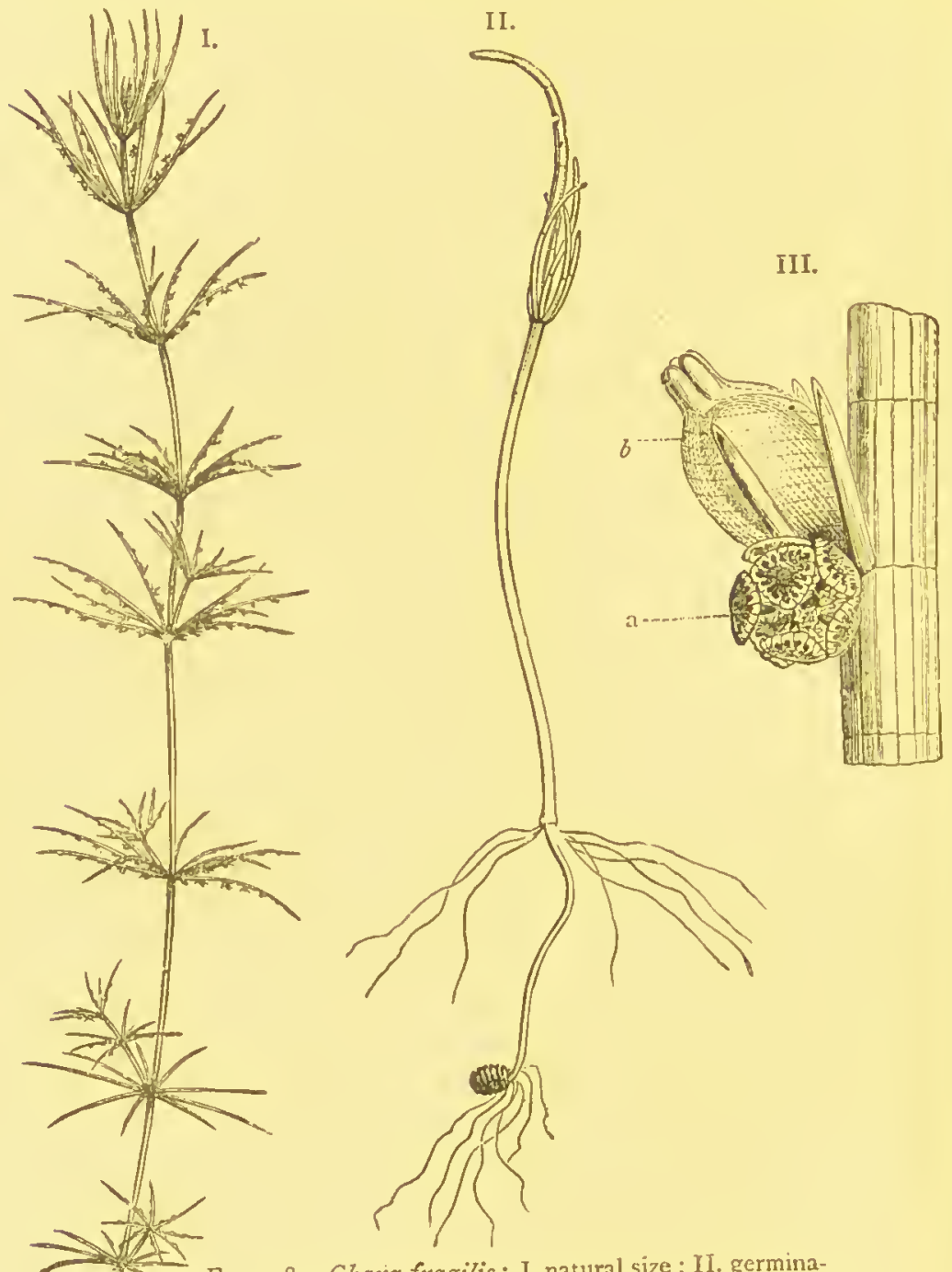

1 FIG. 4I8.-Charafragilis: I. natural size; II. germinating spore (magnified); the lower part as far as the second whorl of roots is the prothallium; III. part of a fertile branch (more strongly magnified); beneath the ovoid archegonium $b$ is the spherical antheridium $a$.

including a considerable number of species distributed over the whole globe. In Nitella each internode consists of only 
a single cell, while in the stem of Chara there is a central or axial cell, surrounded in a spiral manner by other cells, which form a cortex. Multiplication takes place partly by single cells becoming detached, partly by impregnation. In some species, as Chara hispida (Fig. 4I9) an antheridium or

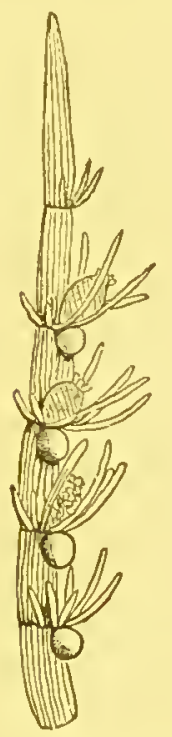

FIG. 419.-Fertile branch of Chara lispida (mag. nified).
I.

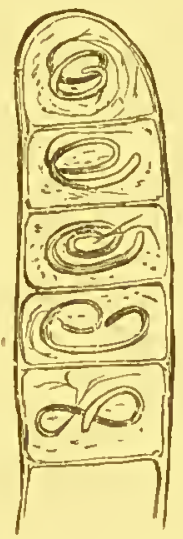

II.

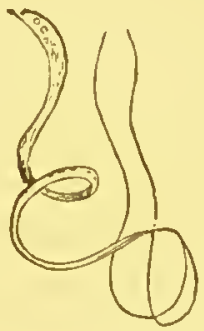

'globule' and a female organ called the 'nucule' stand beneath a lateral branch; in other species the two organs, which may be recognised in an immature condition as small red knobs on the plant, are found on different individuals. The antheridium (Fig. $4 \mathrm{I} 8 \mathrm{III} ., a$ ) is a sessile globular body, and consists of eight cortical cells which open when ripe. In the interior are a number of cellular filaments (Fig. 420 I.), coiled round one another, from each separate cell of which is developed an antherozoid or spermatozoid (Fig. 420 II.). The archegonium (Fig. 4I $8 \mathrm{III} ., b$ ) consists of an axial row of cells which is closely surrounded by five tubes coiled spirally round it. The oosperm is developed, as the result of impregnation, from the large apical cell of the inner axial row, 
the oosphere. In the autumn, when the annual plant dies down, the oosperm falls to the bottom of the water, the young plant developing from it in the spring. The first algoid cells of the young plant are considered a prothallium, on which the plant itself grows as a lateral branch (Fig. 4I 8 II.). The process of impregnation itself takes place in this manner. At the moment of maturity the neck of the five peripheral tubes of the archegoniun becomes loosened, and between the five clefts thus formed antherozoids penetrate into the oosphere. The Characeæ have no economical or medicinal value, but are of importance in respect to our knowledge of the life of plants.

[Several species of Chara are common in freshwater ditches, ponds, and streams, forming tangled masses, easily distinguished from Algæ by the verticillate arrangement of the branches, and by the gritty nature of the whole plant caused by the deposition of calcareous matter; when decaying the plant emits an offensive smell, resembling that of sulphuretted hydrogen. Nitella is not so abundant, and is destitute of the calcareous incrustation. The plant is, in each case, fixed in the soil by slender root-filaments or rhizoids.

The central or axial cell of each internode in Chara is very large compared with the size of the cells which surround it, and which form the cortical layer. Each node consists of a transverse plate of small cells resembling those of the cortical layer, and separating the internodal cells from one another. The branches and secondary branches (sometimes called leaves) resemble the stem in structure, the latter always ending in a much-elongated pointed cell. The apex of the stem forms a compact terminal bud, beneath which the internodes become gradually longer as you approach the base of the stem. Growth, i.c. the formation of new nodes and internodes, takes place immediately beneath this terminal bud, new rhizoids being first formed, and then branches bearing in their axils the reproductive organs, which are easily made out as minute orange-red 
bodies. A vegetative mode of reproduction sometimes takes place by means of bulbils, which become detached. The growing point, which occupies the centre of the terminal bud, consists of two cells lying one above another; while beneath the lower of these is another cell which divides longitudinally, and developes into the cellular transverse partition or node. Below this again is a single elongated internodal cell, and beneath this again a rudimentary node, and so on. The internodal cells increase in size, but never divide. The leaves or lateral branches, on the other hand, are developed from outgrowths of some of the peripheral cells of the node. The cortical layer which surrounds each internode is developed, not from the internodal cell, but by continual growth and division of the peripheral nodal cells, which from the first overlap the internode, and gradually assume a spiral arrangement. The cells of Chara always contain a nucleus, and afford a remarkably good illustration of the phenomena of rotation (see p. ro). This movement is exhibited especially in the inner layer of protoplasm next the central vacuole, the nucleus being carried round in the stream; while the outermost layer which includes the chlorophyll-grains is quite motionless.

The eight cortical cells of which the wall of the antheridium or 'globule' consists, are sometimes called shields; the four nearer the base are four-sided, the four nearer the apex three-sided. From the middle of the inner face of each shield a cylindrical cell, termed a manubrium, projects inwards, nearly to the centre of the antheridium; and at the extremity of each manubrium is a roundish hyaline cell, the head or capitulum. The shields, manubria, and capitula form therefore together twenty-four cells, which, together with the pedicel-cell of the antheridium, constitute its framework. Each capitulum bears six smaller cells, secondary heads or capitula; and from each of these grow four long whip-shaped filaments, the number of which therefore is about 200. Each of these 200 filaments divides transversely into from 100 to 200 cells, and in each of these 
cells an antherozoid is produced (Fig. 420, I. II.), provided with two cilia, by means of which it moves rapidly about when it escapes, by the separation of the shields and rupture of the parent-cell. The number of antherozoids produced by a single antheridium may therefore be from 20,000 to 40,000 .

The Characeæ do not exhibit any true alternation of generations; the fertilised oosphere germinating directly in the soil, without the intervention of a non-sexual generation. The young plant is developed from the growth of a single cell of the prothallium, situated at some distance below its free extremity; this cell gives rise to a set of leaves, among which a bud appears which grows into a new Chara.-ED.]

\section{MUSCINEA.}

\section{Class V. Hepatica.}

The Hepaticæ or Liverworts are elegant delicate plants, usually of a bright green colour, which form a beautiful

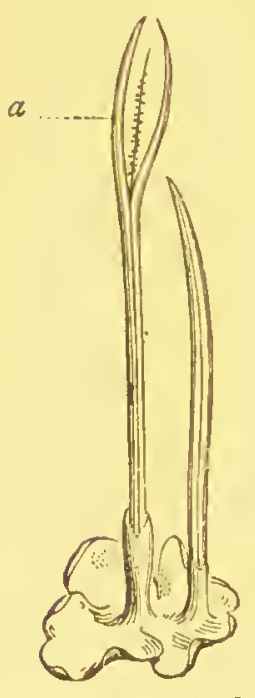

Fig. 421.-Antho. ceros lievis: $a$ a burst sporogonium. transition from the Thallogens to the Acrogens. Many of them, as Anthoceros (Fig. $42 \mathrm{r}$ ), are true Thallogens, having no leaves, and are included in the class only on account of their mode of reproduction. Some bear a great external resemblance to certain Lichens; and in others the true leaves are only represented by scales. These forms, the Thalloid or Frondose Hepatica (Fig. 422), are contrasted with the Foliose forms; but even in these latter the leaves never have so much as a mid-rib, even when the stem contains vascular bundles of low organisation in the form of cambium - strings. Often, especially in Jungermannia (Fig. 423), the leaves stand in two rows, running in right- or left-handed spirals. In some genera with stems creeping on the earth or on the bark of trees, besides these larger 
leaves, which are all on the upper side, there is a third row of smaller leaves (Figs. 424 II., 425), the ampligastria, adpressed to the under side of the stem. The Hepatica

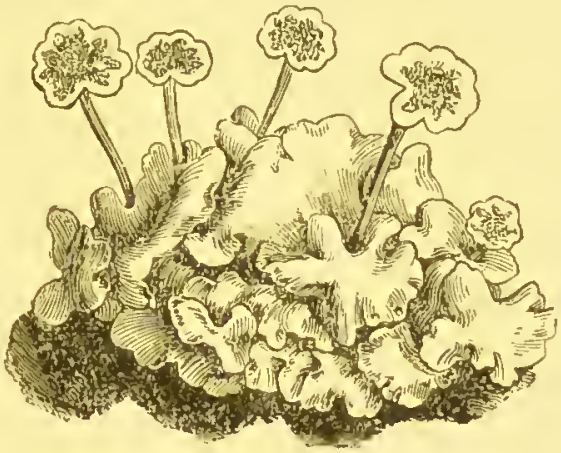

II.

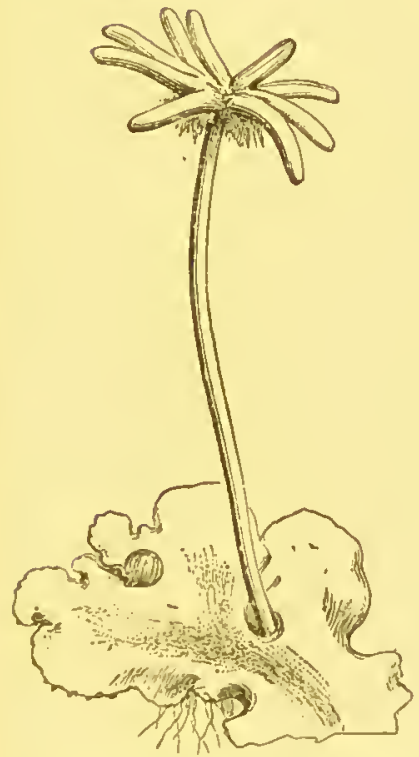

III.

IV.

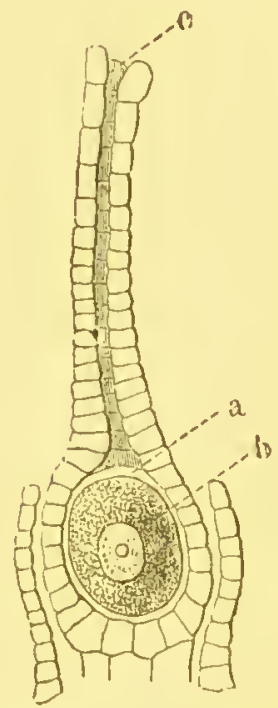

F1G. 422.-Marchantia polymorbha: I. thallus with five antheridial receptacles (natural size): 11. thallus with an archegonial receptacle (natural size); III. elater-cell with a continuous doubly spiral thread or elater $(x 200)$; IV. archegonium; $a$ central cell, $b$ oosphere with nucleus, $c$ neck $(x 200)$.

never have true roots; rhizoids replace them both in position and in function. 
The internal structure of the stem is extremely simple. In the Foliose Hepaticæ it consists of an elongated parenchyma more strongly thickened externally, and thus forming

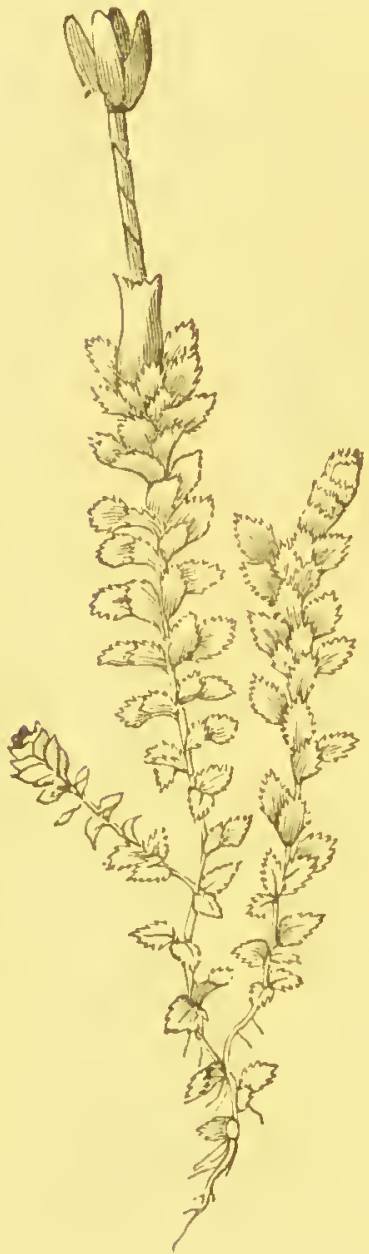

FIG. 423.- Fungermanuia uemorosa ( $\times$ ro).

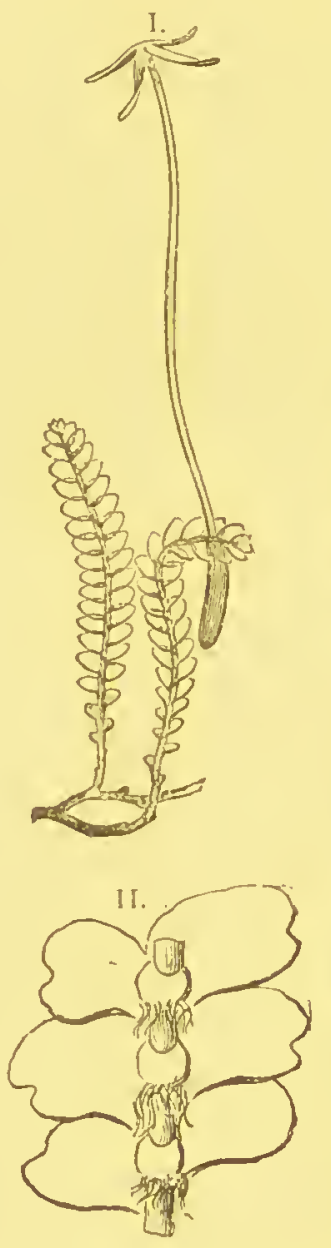

FIG. 424.-I. Calypogcia Trichomanis; 11 . under side of the stem with amphigastria (nagnified).

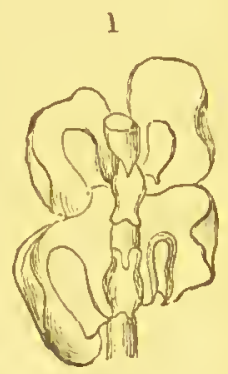

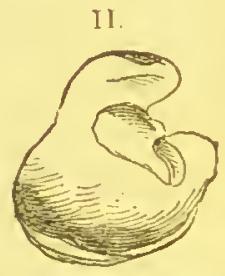

Fig. 425.-I. Under side of the stem of Frullania In. marisci with the amphigastria and true leaves (mag. nified); 11. leaf of Frullavia tilatata (magnified).

a cortical layer passing over gradually into the central tissue. The Thalloid Hepatica, on the contrary, have a well- 
marked epidermis, in which are a few scattered stomata, and which puts out rhizoids from its under side. In the most highly developed order, the Marchantieæ, we find the first rudiments of vascular bundles, in the form of elongated cells containing little or no chlorophyll but often crystals. The leaves consist of a single layer of uniform tabular cells.

There are two modes of reproduction: by fertilised oospheres, and by asexual buds or gennne. The latter are groups of cells which become detached from the plant, and, under favourable circumstances, develope into new individuals. In the Thalloid Hepaticæ they are usually found at the bottom of saucer- or spoon-shaped organs, the cupules (Fig. 349, p. I79); in other families they arise on the margin of the leaves or at the apex of the stem.

The sexual organs arise on the stem of the mature plant; some species being monœcious, and others diœcious. The male organ, or antheridium, is a stalked, usually spherical body, consisting of a cellular envelope or coat, and an internal portion formed of delicate cells. These last escape when the organ is mature, a spermatozoid or antherozoid having previously been developed in each cell, consisting of a spirally coiled thread furnished at the end with two long vibratile hairs or cilia. The female organ, or archegonium (Fig. 422 IV.) is a flask-shaped organ, enclosing near its base a large central cell. A canal leading to the central cell is formed in the neck of the archegonium by the disappearance of the septa of the axial bundle of cells, the canal-cells; the canal appears to be at first closed outwardly, but opens at the period of maturity by the separation of the apical cells, and thus gives access to the antherozoids. Before the antherozoids reach the central cell, the oosphere has been formed in the latter by free cell-formation, and gradually increases to such a size as completely to fill up the central cell, the sporogonium being developed from it after impreg- 
nation. The rudiment of this organ is first of all surrounded by a cell-wall, and then gradually developes-under the shelter of the archegonium, which grows with it and which is from this time called the calyptra-and developes into the stalked sporogonium. The sporogonium does not anywhere unite in its growth with the vegetative structure, even when its pedicel penetrates into its tissue. When mature, the sporogonium, elevated by the sudden and rapid increase in length of the pedicel or seta, ruptures the calyptra, opens, and allows the escape of a great number of spores. As a rule, several archegonia are grouped together into a female or archegonial receptacle, and several antheridia into a male or antheridial receptacle. The archegonium is sometimes surrounded by a so-called 'calyx' [or perichatium], consisting of several connate leaves. In the sporogonia of the Hepaticæe there usually occur, in addition to the spores, also peculiar elongated cells termed elaters, furnished with a brown spiral band, which is sometimes simple, as in Frullania, sometimes double (Fig. 422 III.). Rarely, as in Anthoceros, a row of cells or columella remains in addition in the axis of the sporogonium (Fig. 42I). The sporogonium usually opens with four, in Anthoceros with two valves; in the Ricciex it bursts irregularly. On germination the spore first puts out an irregular, often filiform, structure, the prothallium, on which the bud is produced from which the young plant arises. The course of development of the Hepaticæ shows a clearly marked alternation of generations. The first (sexual) generation begins with the germinating spore, and closes with the act of fertilisation; the second (asexual) generation consists of the sporogonium.

The Hepatica are classified into four families :-

I. RICCIE\&. The thallus is expanded flat and floats on water; the antheridia and archegonia are imbedded in the thallus, and do not project above it ; the sporogonium dehisces irregularly, and contains no elaters.

2. Axthocerotes. The thallus is expanded flat; the pod-like 
stalked sporogonium has a columella; [the claters have no spital bands] (Fig. 42I, p. 296).

3. Marchanties. The flat corinceous thallus is branched clichotomously [and possesses a micl-rib; it is charactcriscd by stomata of remarkable complexity]. The sporogonia are collected on a stallied organ or archegonial receptacle, and burst into four valves; [they contain elaters] (Fig. 422, p. 297).

4. JUNGERMANNIE $\cong$. [The vegctative structure is usually differentiated into a stem and distinct leaves]; the sporogonium bursts into four valves [and contains elaters] (Fig. 423, p. 298).

The Hepatica are distributed throughout the world, but are of no economical importance.

\section{Class VI. Musci.}

The Musci or Mosses are nearly related to the Hepaticæ; but are in general of a higher type, no longer possessing any of the characteristic features of Thallogens, but having a cylindrical stem covered with leaves (Figs. 427, 434). The stem of the order known as Sphagnaceæ is divided by narrow elongated cells, which are often lignified, into a central large-celled axial and a looser cortical portion consisting of only a few cells (Fig. 426 r.). True vascular bundles are altogether wanting, but in most other families of Mosses there is in the centre of the stem an axis of simple structure, which does not contain true vessels, but which is often described as a vascular bundle (Fig. 426 II.). This often consists only of a few thick- or thin-walled cells, not sharply distinguished from the parenchyma of the stem, which serve for the conduction of the sap, and therefore perform the function of a vascular bundle. In some Mosses there are, however, cells with thicker walls, on which may be seen a very delicate spiral striation, and which therefore, altogether call to mind a vascular bundle. These are sometimes central; but sometimes, as in Polytrichum, give place to a central medulla. Lateral branches from these bundles sometimes pass into the leaves as veins. The leaves are often narrow, of very thin or even membranous texture, and 
I.

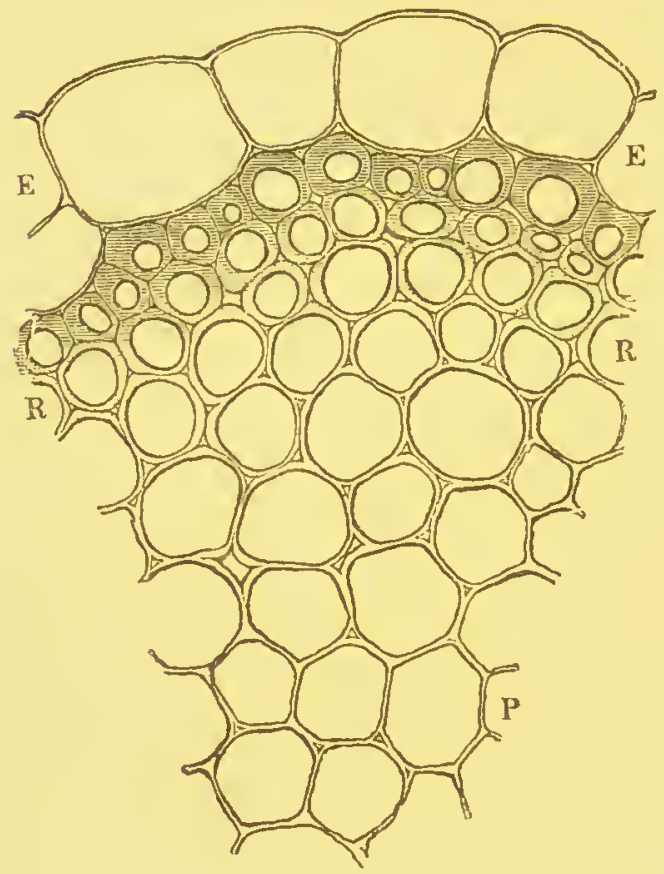

II.

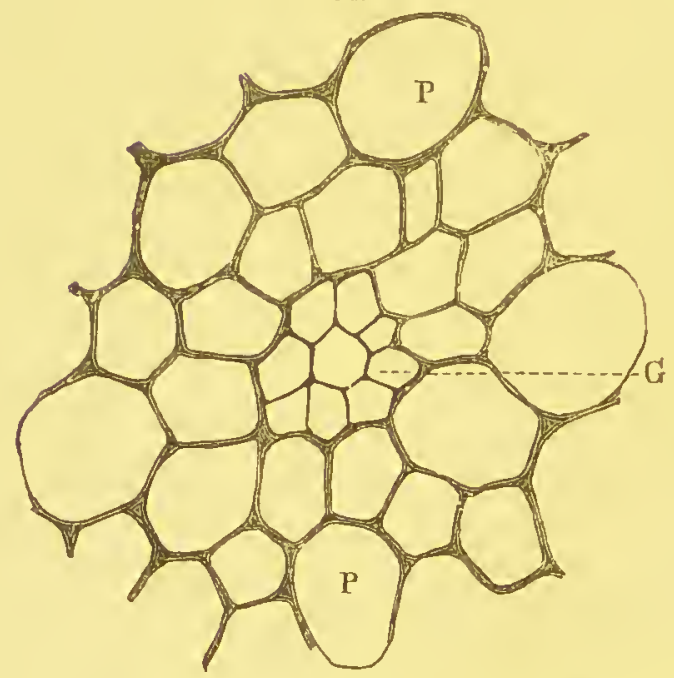

FIG. 426.-I. Part of a transverse section through the stem of Sthagnum cymbifolinm : E epidermal cells; R thickened and coloured cortical cells : p parenchyma of the stem $(\times 320)$; II: central portion of a transverse section through the stem of Climacizum dendroides: $G$ central axis; $P$ brown parenchyma of the stem $\left(x 4_{400}\right)$. 
of simple structure. They usually consist, with the exception of the veins, of only a single layer of parenchymatous cells;
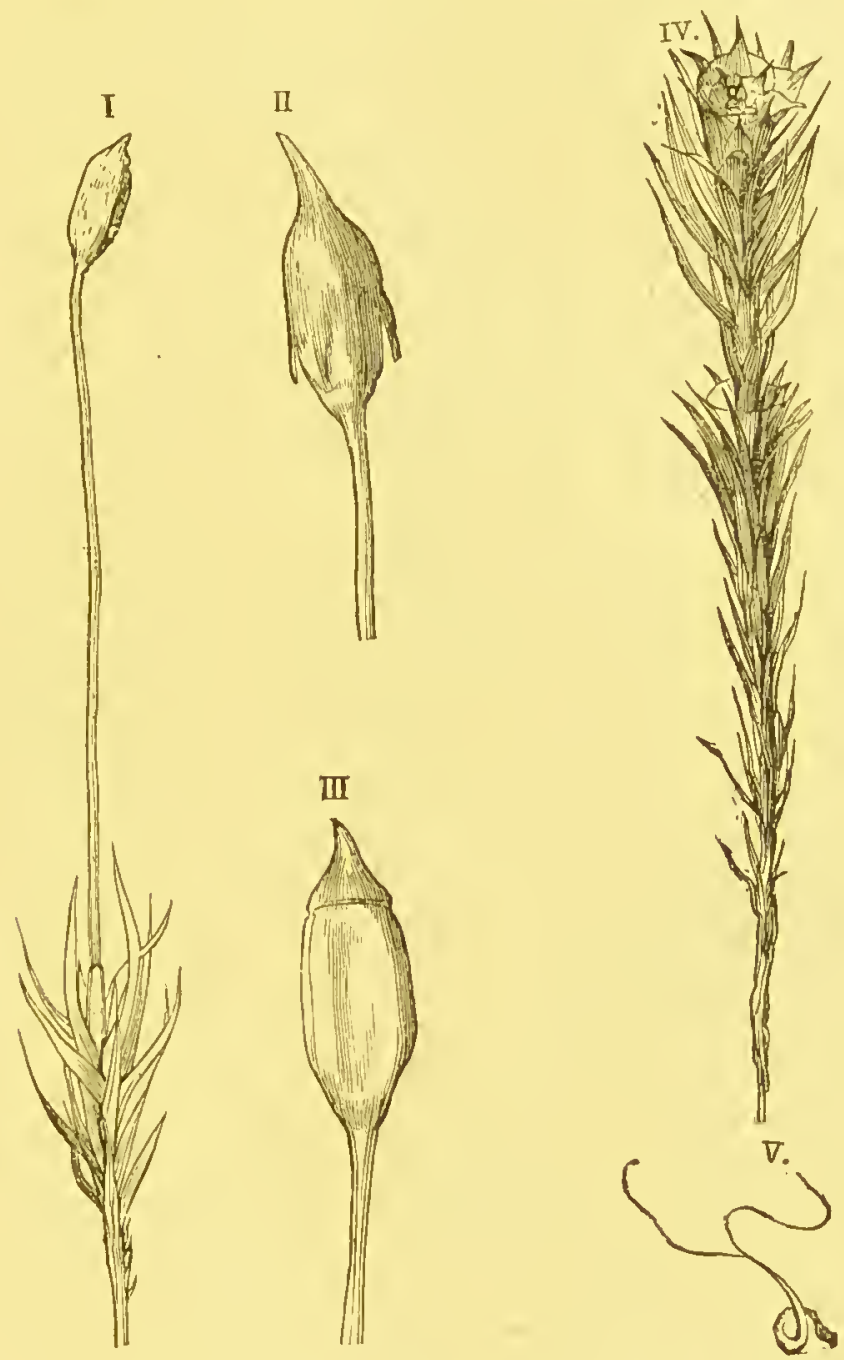

FIG. 42\%.-Hair-moss Polytrichum commune: I. plant with sporangium (mag. nified); 1I. sporangium with calyptra, III. without calyptra (magnified); 1V. plant with perigonium surrounding the antheridial receptacle, and exhibiting prolification (magnified); V. antherozoid ( $x$ rooo).

but exceptions occur in the case of Splagmem and other Mosses. In Polytrichum the surface also has cells pro- 
vided with peculiar lamellæ; otherwise there is, as a rule, no special epidermal tissue with stomata, hairs, \&c., even when this is found on the stem and reproductive organs. There are never true roots; the nutriment being absorbed through rhizoids. At the apex of the stem, or growing laterally on it, are often several leaves of a somewhat different form to the rest, forming the perigonium, a kind of envelope which protects the organs of reproduction growing within it (Fig. 427, IV.).

The organs of reproduction at first altogether resemble those of the Hepaticæ; but in the course of their development the following differences arise:--The archegonium of Mosses is ruptured by the young sporogonium, and usually in such a way that the lower part remains as a sheath or z'aginule, while the remainder is elevated in the form of a cap or calyptra, surmounting the capsular 'fruit,' the urn, theca, or sporangium; and is finally carried away by the wind, rain, or other accident. The axis of the sporangium is occupied by a central column or columella, around which the unicellular spores are formed. In order to allow these to escape, the sporangium, which varies greatly in form in the different genera, opens by means of a lid or operculum; less often, in the Andreæaceæ (Fig. 429), by four longitudinal slits, or, in the Phascaceæ, irregularly. The opening resulting from the operculum being thrown off is variable in form; its margin is either smooth (gymnostomous), or is furnished with two rows of cilia or teeth of beautiful form, constituting together the peristome (Fig. 430), the nature of which furnishes a character for the classification of the genera. The antheridia are usually in groups, and are surrounded by an envelope of peculiar leaves, the pcrigonium (Fig. 427 IV.). Among the antheridia are filiform structures-possibly abortive leaves-the parapliyses. [The antheridia produce a number of extremely minute antherozoids (Figs. 427 v., 428).] On germination the spore puts out first of all a prothallium, which is usually filiform, when 
it is called a protonema; and on it the young plant is developed.

Besides the reproduction by spores, Mosses are also propagated non-sexually by gemme, and by special shoots known

II.

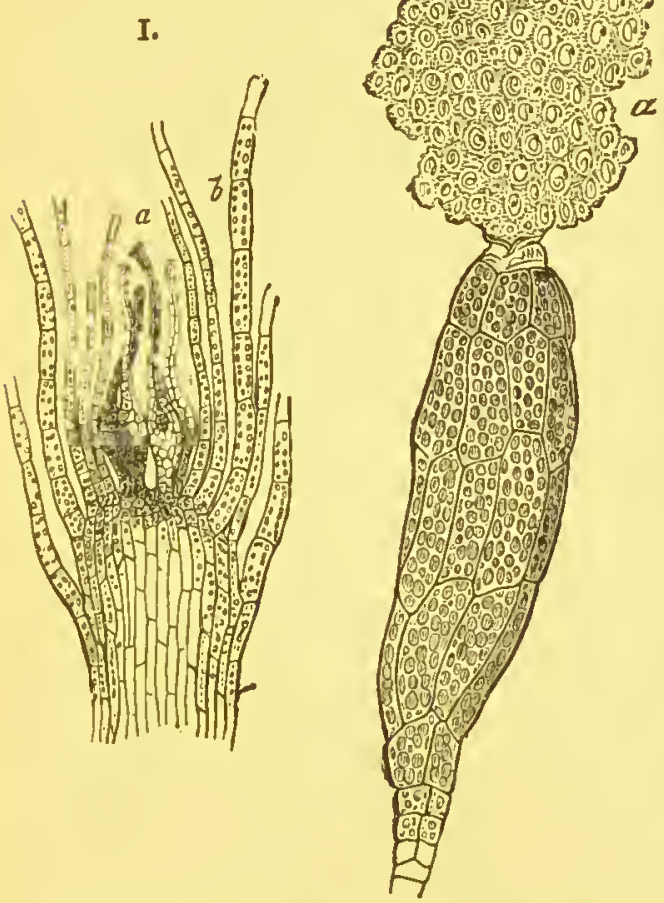

FrG. 428.-Funaria hygrometrica: I. longitudinal section through the upper part of a plant with arche. gonia $a$ and leaves $b(x, 400)$; II. antheridium bursting, and allowing the antherozoids $a$ to escape $(\times 350)$.

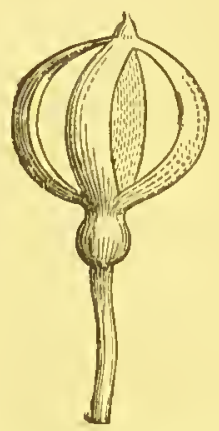

FIG. 429.-Andrecea alpestris: sporangium bursting into four valves.

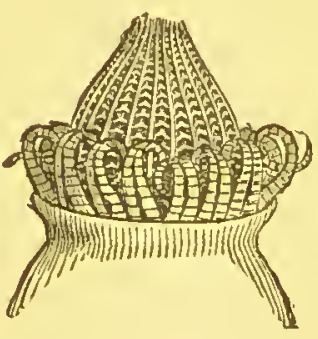

Fig. 430.-Mouth of the sporangium of fontinalis antipyretica, with an inner and outer peristome (after Schimper, $\times 30$ ).

as stolons. Those forms in which the growth is terminated by the production of antheridia or archegonia at the apex of the stem often exhibit prolification of the bud, as in Polytrichum (Fig. 427 IV.). Axillary buds by the side of the sporangium or of the antheridia often develope also by a process of renewal, forming growths known as innovations. 
The Musci are divided into two sub-classes, as follows :-

\section{SPhagnaCeæ. Bog-mosses.}

According as the Sphagnacex grow in water or on a solid substratum, they form a filiform or thalloid prothallium. [The globular

I.

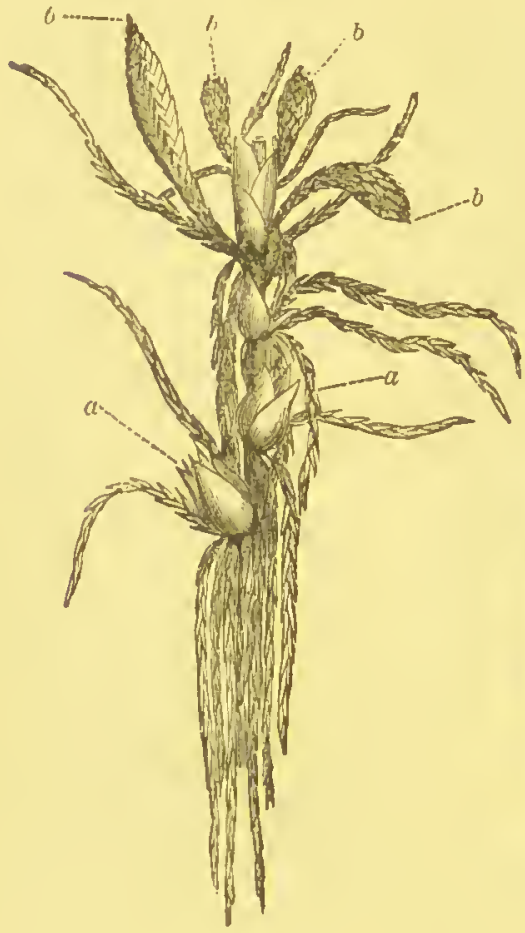

sporangium is elevated on a short stalk or psezdopodium, which is not, however, homologous with the seta of true mosses.] The mode of growth is shown in Fig. 43I. [This section includes the single genus Sphagmem].

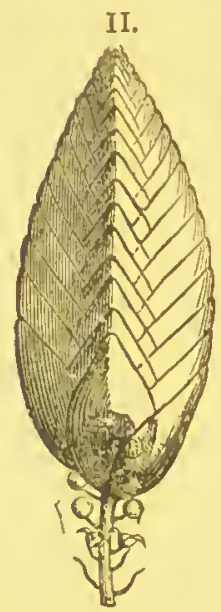

Fig. 43I.-Splagnum acutifolium: I, part of the stem with two sporogonia $a$ and four antheridial receptacles $b$ (after Schimper, $\times 3$ ): II. an antheridial receptacle separated, with the perigonial leaves removed from the separated, wo as to expose the stalked globular antheridia (more strongly magnified).

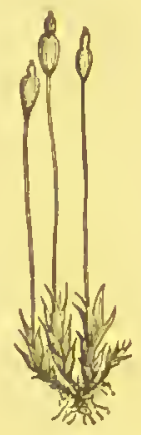

FIG. 432. - Splashnum ampullaceun (Acrocarpi ; maznified).

\section{BRYINE⿸广 Tine Mosses.}

Prothallium always filiform (protonema); only one kind of spore.

1. Andreacea. The ripe sporangium opens by four longitudinal slits (Fig. 429).

2. Phascacea. [The roundish sporangium ruptures the calyptra laterally, without raising it up as a cap; no operculum.] 
3. Bryacece. [The sporangium is covered by a calyptra, and opens by throwing off an operculum.]

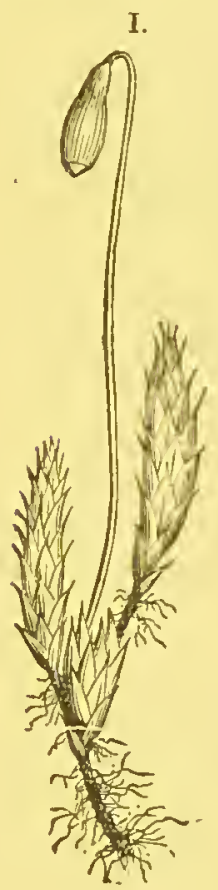

II.

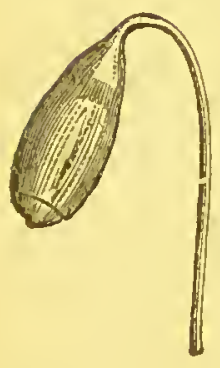

Fig. 433.-Bry um argentezm (Acrocarpi) : I. the whole plant (magnified) II. sporangium with operculum; III. sporangium burst, showing the peri. stome (more strongly magnified).

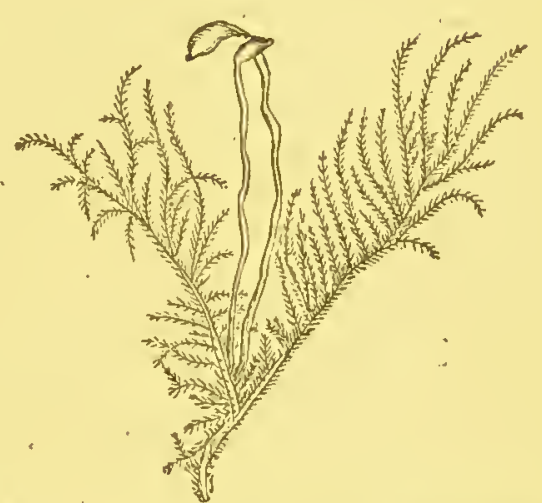

FIG. 434-Hypnzm fulicinzun (Pleurocarpi; natural size).

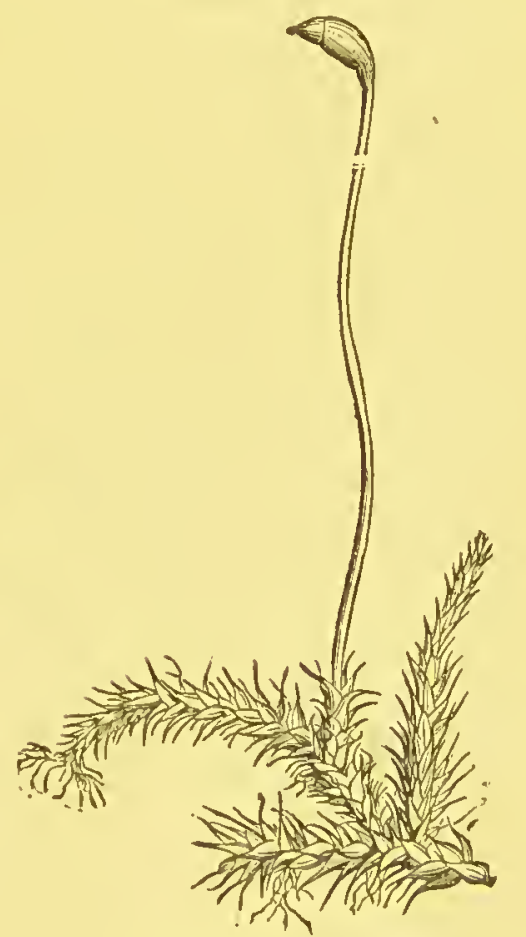

Fig. 435. - Hypnumz populeumz (Pleurocarpi ; magnified). 
a. Acrocarpi. The sporangium springs from the apex of the main stem or its branches; e.g. Funaria, Splachnum, Dicranum, Bryum, Polytrichum, \&c. (Figs. 427, 432, 433).

b. Pleurocarpi. The sporangium springs from the axil of a leaf; e.g. Iyppnem, Fontinalis, \&c. (Figs. 434, 435).

Mosses are generally distributed over the surface of the earth; only a few grow in water. They are of no economical importance; the species of Sphagmm contribute largely to the formation of peat.

\section{ISOSPOROUS VASCULAR CRYPTOGAMS}

\section{Class VII. Filicales.}

Ferns have usually a simple or branched creeping rhizome, either below or above the surface (Fig. 436); less often an erect woody stem, which is then always simple (Fig. 437). In either case the stem always continually dies off slowly at its lower end, or becomes lignified. Large numbers of adventitious roots provided with root-hairs break out from the lower part of the stem or from the rhizome, while the upper part frequently puts out aërial roots. The stem is covered, when young, with an epidermis provided, where above-ground, with stomata. The subjacent cortical tissue either consists entirely of thin-walled parenchymatous cells, or becomes differentiated into an outer cortex consisting of thick-walled cells, and a thin-walled parenchymatous inner cortex (Fig. $43^{8} R^{\prime}$ and $R^{\prime \prime}$ ), the latter passing over gradually into the fundamental tissue. The fibrovascular bundles of the entire plant are in direct communication with one another above and below. They divide and ramify in the stem, forming a complete network, and send out branches into the leaves. In the roots, on the contrary, the bundles coalesce into a single central or axial vascular bundle. The separate bundles, as seen in transverse section, are sometimes roundish and sometimes ribbon-shaped, and are usually separated from the cortical and medullary cells by 
a vascular bundle-sheath (Fig. $43^{8}$ in., s), consisting of narrower thick-walled cells, which again is often invested by a layer of brown sclerenchymatous cells $(x)$. The vascular

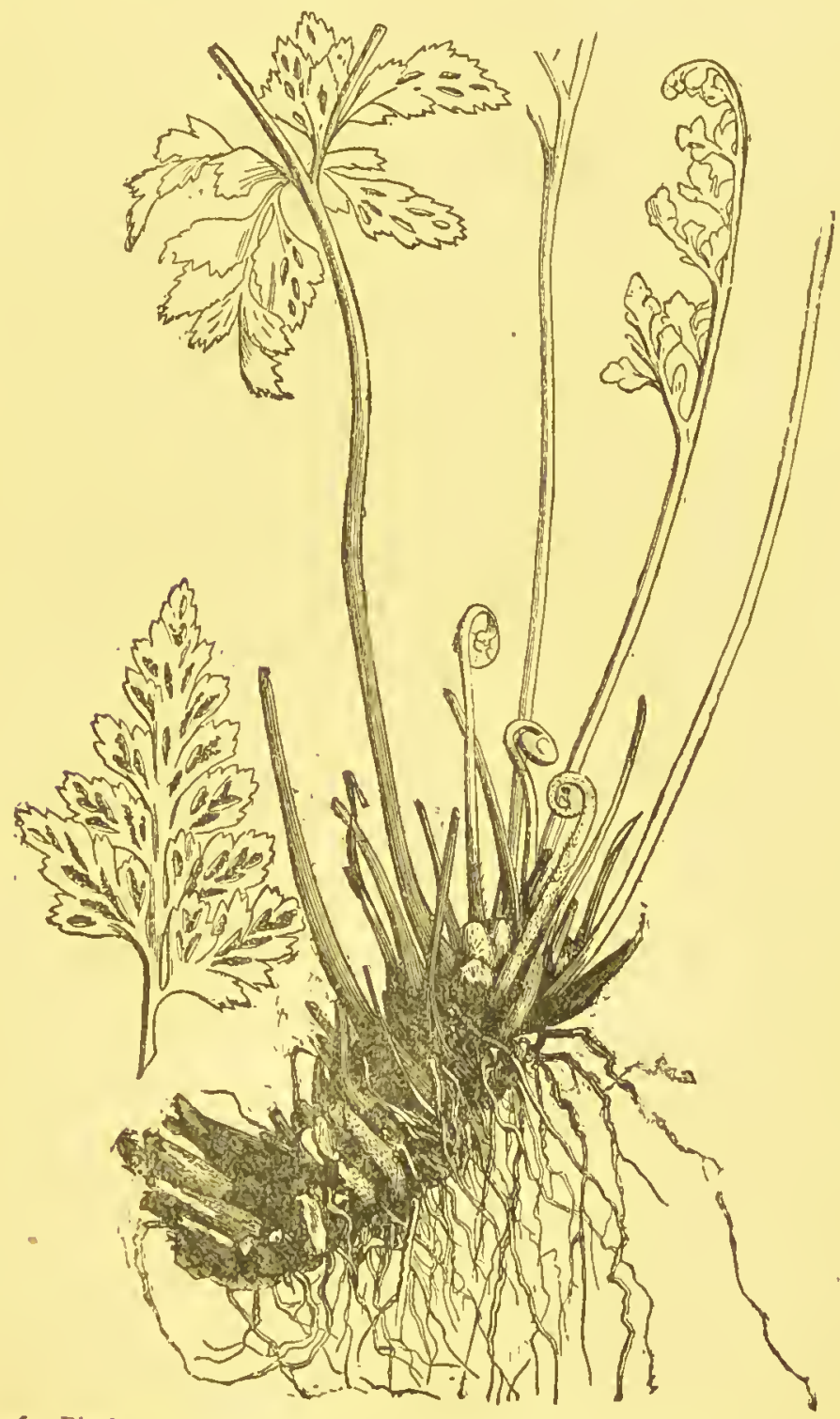

FiG. 436.-Black spleenwort, Asplenium Adiantum-nigmum, showing a part of the rhizome (natural size, with a single pinna magnified). 
bundles are strongly developed, and are always closed, consisting of xylem and phloëm only, without any intermediate cambium. The xylem is composed chiefly of scalariform vessels (Fig. 69, p. 46), the phloëm of parenchymatous cells

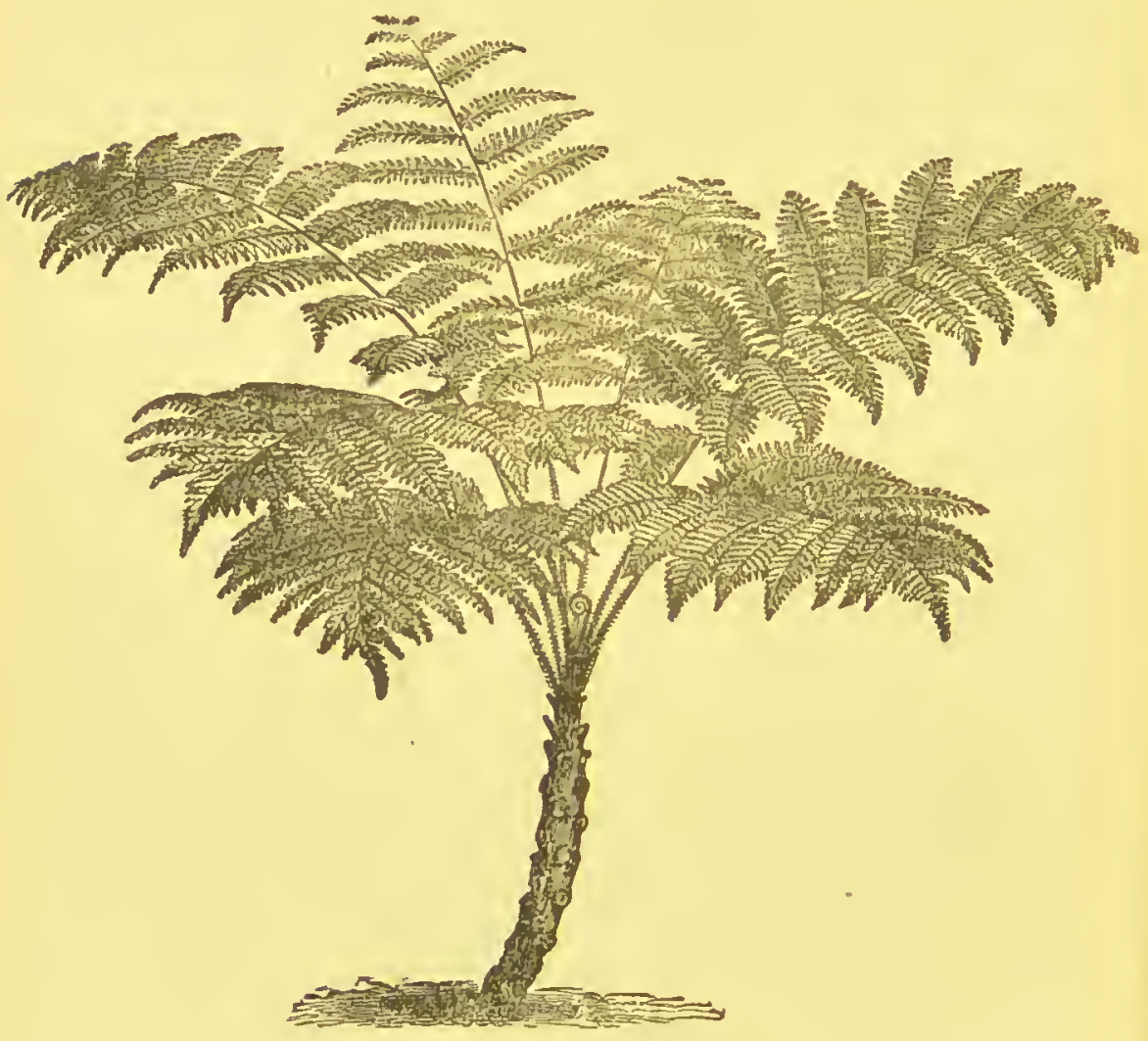

FIG. 437.-Alsoplita aculeata; a tree-fern (greatly reduced).

containing starch, bast-fibres, and sieve-tubes, and generally completely enclosed, the xylem in the form of a cylinder, constituting the kind of bundle known as concentric. The apex of the stem is always occupied by a single clearly distinguishable apical cell, by the continuous division of which the fundamental tissue is produced. 


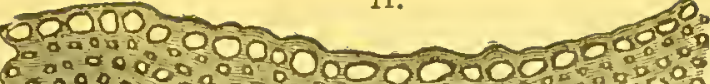

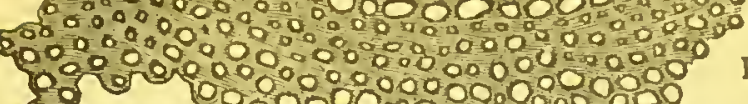

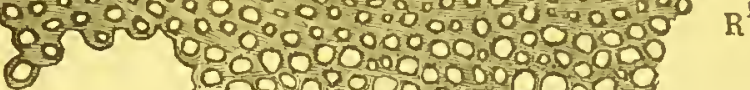

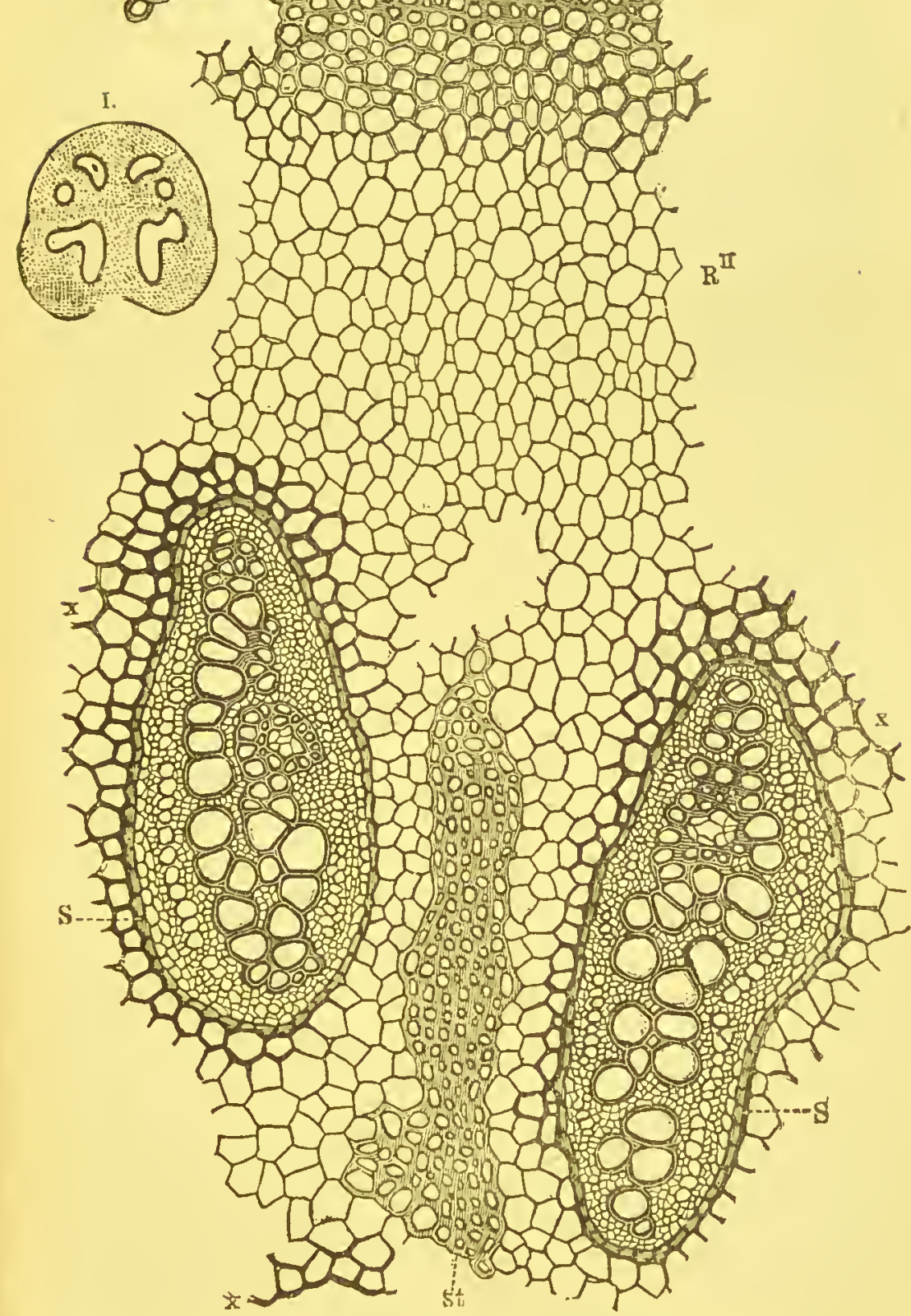

FIc. 458.-1. Transverse section through the rhizome of the common brake, Pteris aguiliza, showing the distribution of the vascular bundles (natural size); II. a part of the preceding figure: 0 epidermis ; $\mathrm{R}^{\prime}$ thick-walled, $\mathrm{K}^{\prime \prime}$ thin-walled cortical tissue; s vascular bundle-sheath; $x$ sclerenchymatous cells outside the latter; st bundles of prosenchymatous cells ( $X$ I 10$)$. 
The leaves of Ferns are commonly known as fronds. They originate, like those of higher plants, as small cellu-

III.

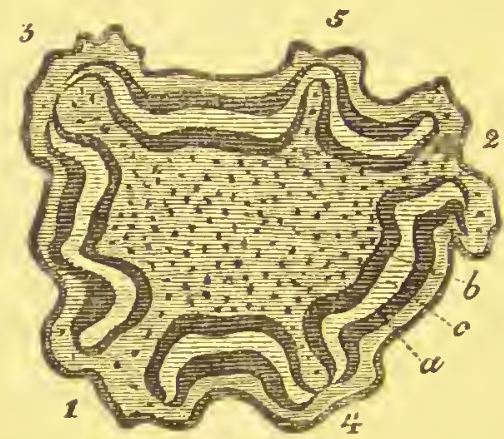

Frg. $43^{8}$ III. - Transverse section through the stem of a tropical Fern : $a b$ layers of lignified nearly solid parenchymatous cells, surrounding the vascular bundle $c$; I-5 the points of attachment of five leaves already thrown off (natural size).

lar elevations beneath the growing point of the stem, but increase in length, like branches, at their apex, below which the lamina is then formed. In all the families except the Ophioglossacer, the leaves are rolled up, when young, in a circinate manner; after maturity, they are thrown off periodically. They are produced only at the apex of the stem. Their form varies greatly, from lanceolate and entire to doubly or trebly pinnate. Except in the Hymenophyllaceæ they are almost always composed of several layers of cells, which very commonly separate into two clearly distinguishable laminæ, the upper one consisting of cylindrical cells placed vertically to the surface, and fitting more or less closely to one another, the lower of a looser tissue formed of cells of a more spherical form. Both sides of the leaf are covered by an epidermis provided with numerous stomata. The stem and the rachis of the leaves are clothed, in most species, with brown dry lanceolate or hair-like epidermal structures of a thin membranous texture, the palea or ramenta.

The sporangia are arranged in masses at definite spots, usually on the under side of the leaf, and are usually trichomes or outgrowths of its epidermis (Fig. 439) developed from a single cell, less often from a group of cells; while in the Ophioglossace of the leaf. The separate sori [or collections of sporangia] vary in form and arrangement, and afford distinguishing 


\section{Special Morplology and Classification.}

characteristics for the genera. They are occasionally naked, as in Polypodiun (Fig. 439 v.) ; but are more I.

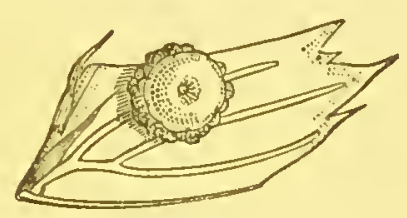

II.
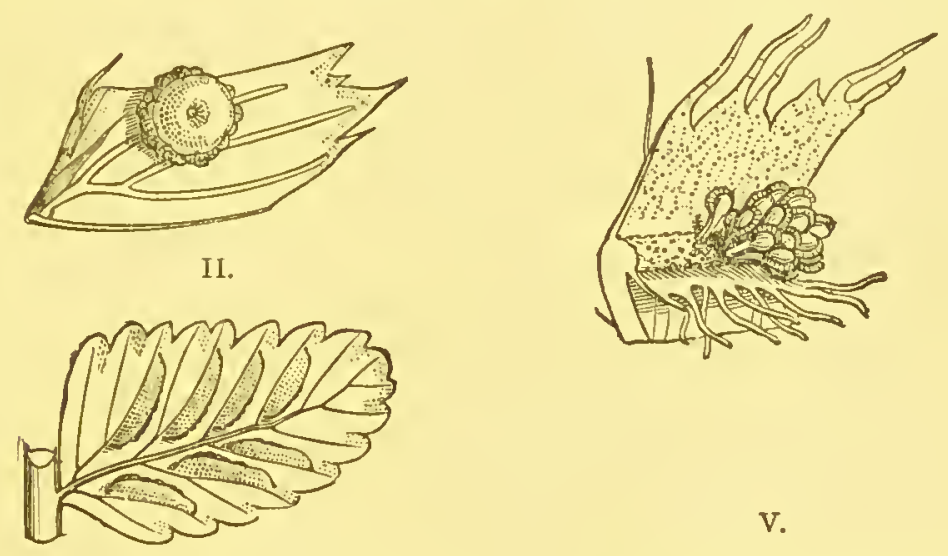

III.
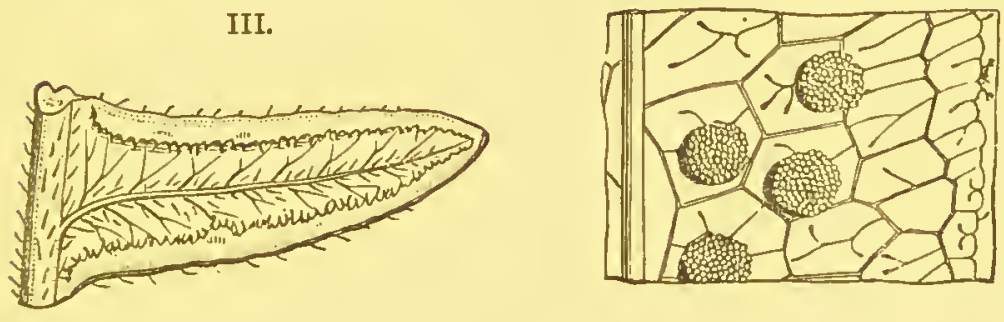

VII.

VI.
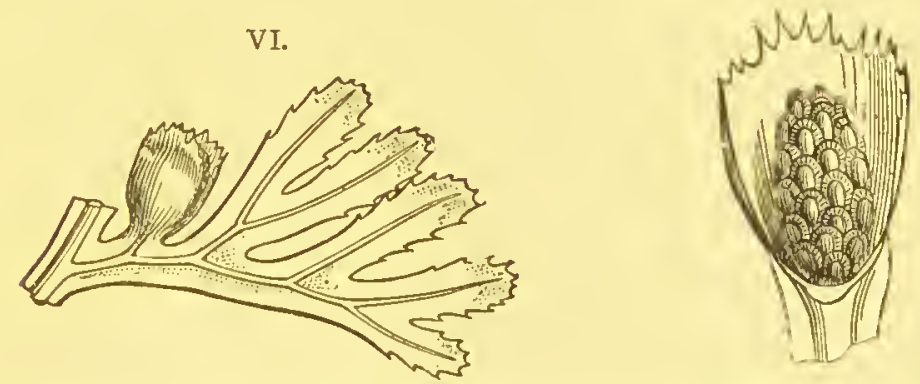

FIg. 439. - Pinnæ of fronds of Ferns with sori; I. Aspidium, the sporangia visible at the margin of the peltate indusium; II. Asplenium: 1I1. Pteris aquilina: IV. the same with the indusium thrown back to show the mode of artachment of the sporangia; V. Polypodium, indusium wanting ; VI. Hymenofhyllum or filmy fern: VII. the same; the indusium partly removed to show the sporangia (all magnified).

often covered by a membranous skin, the indusimm [which is usually an extension of the epidermis] (Fig. 439 I.). In 
most Ferns the sporangia are provided with an elastic ring, the amnulus, running over the apex, which [by its contraction] causes the sporangium to burst [to allow the escape of the spores] (Fig. 440 I.); less often it surrounds the sporanI.

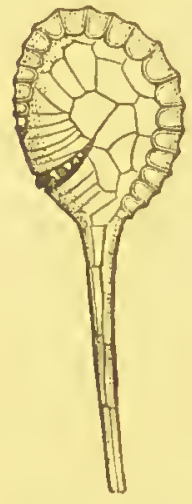

II.

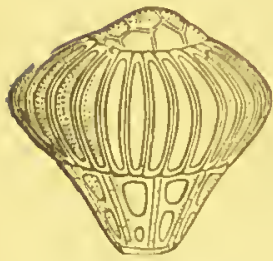

III.
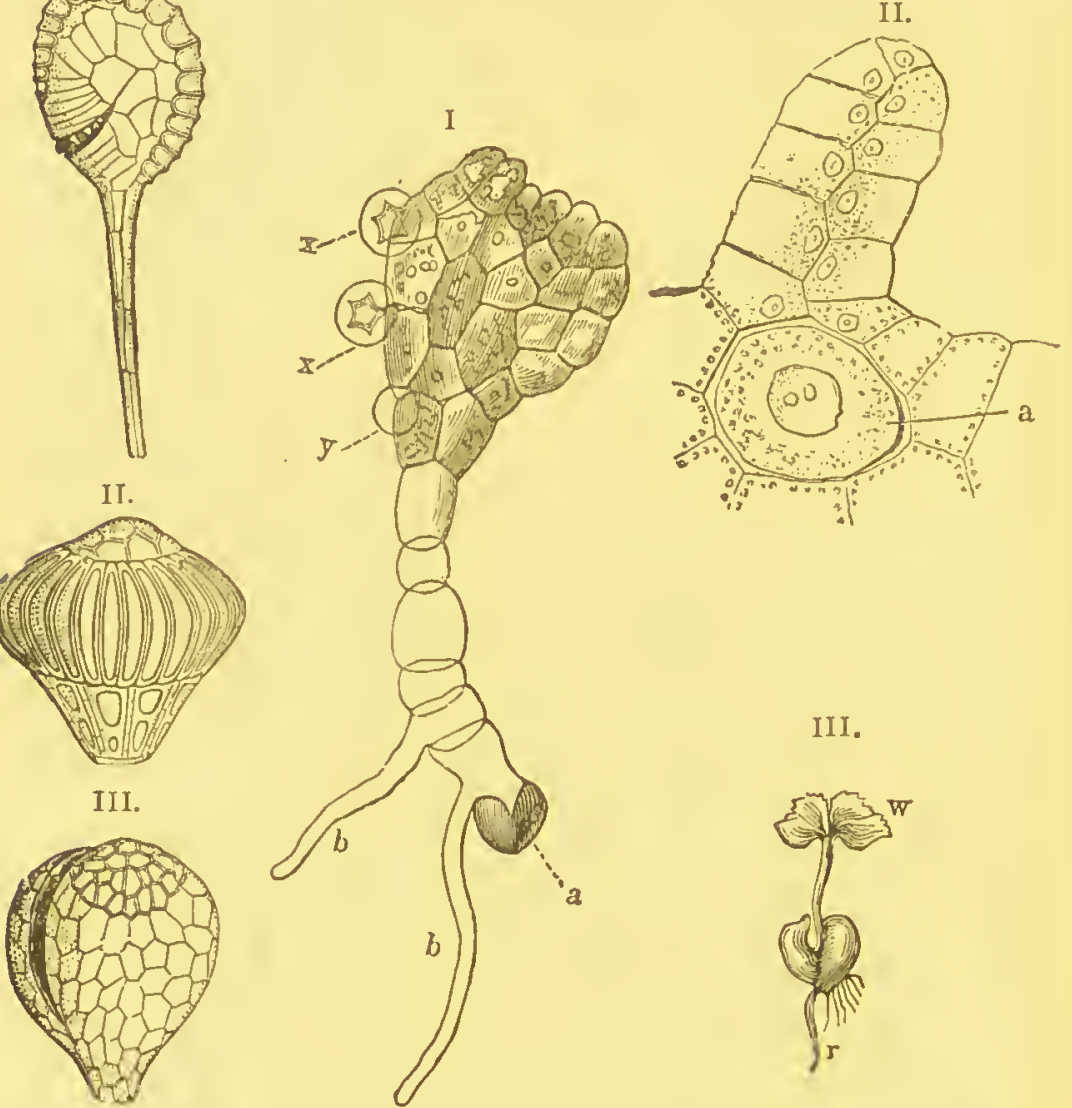

FIG. 440. - Sporangia of Ferns; I. Aspidium with vertical annulus: II. Trickomanes with horizontal annulus; III. Osmunda regalis, royal fern, with incomplete

FIG. 44r.-Reproduction of a Fern, Pteris serrulata; I. the prothallium proceeding from the spore; $a$ spore, $b$. rhizoids, $x y$ antheridia $(x 80)$; II. an archegonium near the period of opening, $a$ central cell $(x 400)$; III. the young plant springing from the cordate prothallium; zo first leaf, $r$ first root (natural size).

III.

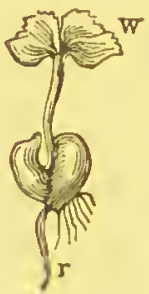
annulus (all greatly magnified).

gium in a horizontal or oblique direction (Fig. 440 II. III.). On germinating, the spore first gives rise to a green thalloid 
leaf-like often kidney-shaped structure, lying flat on the surface of the ground, the prothallizm (Fig. 44 I I1r.), which. puts out rhizoids from its under side, and forms the archegonia and antheridia among them. In the latter are produced the ciliated antherozoids (Fig. 442); from the former, which agree in almost all points with the archegonia of
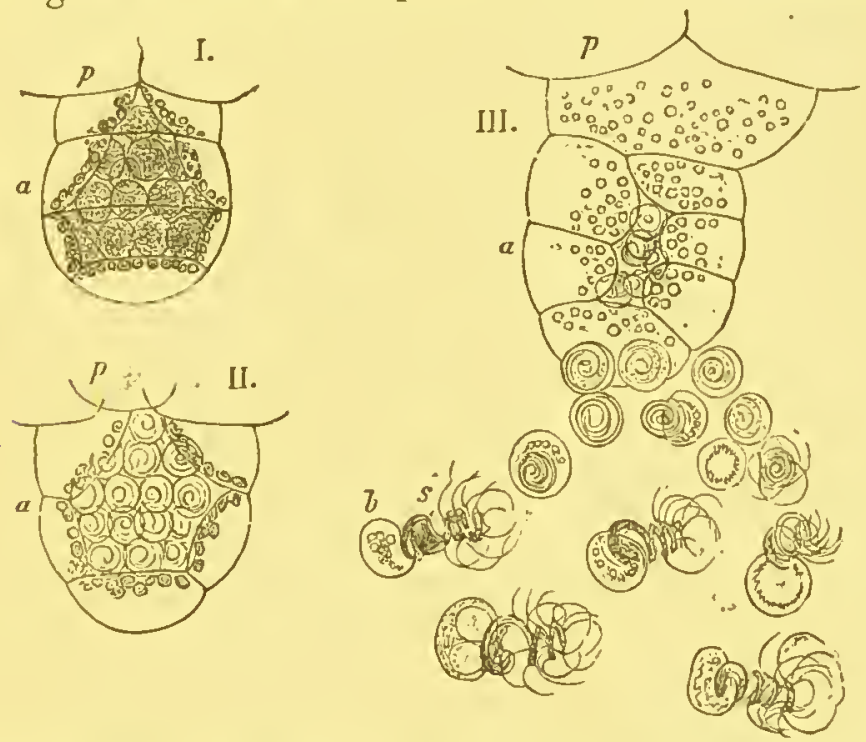

FIG. 442.-Antheridia of Adiantum capillus-veneris, maidenhair fern: I. not yet mature; 11. the antherozoids fully developed; IIl. the antherozoids escaping from the burst antheridium; $p$ prothallium, $a$ antheridium, $s$ antherozoids, $b$ mother-cell of an antherozoid ( $x$ 500).

Mosses, the young plant is developed, after the fertilisation of the oosphere by the antherozoids; the prothallium then disappearing. [The central cell of the archegonium divides first into four cells, of which the two lowest subdivide and become imbedded in the substance of the prothallium. The two upper of the four cells also subdivide, one developing into the rhizome, the other into the first rootlet of the young. Fern.]

An alternation of generations is very strongly marked in Ferns; the first [sexual] generation includes the formation of the prothallium and sexual organs; the second [nonsexual] generation the spore-producing Fern-plant itself. 
[A remarkable exception to the ordinary alternation of generations is presented by the phenomenon of apogamy, as seen in Pteris cretica and some other ferns, where antheridia only are formed on the prothallium, from which the non-sexual generation springs in a purely vegetative manner. The converse phenomenon of apospory or development of a prothallium directly on the frond, has also been observed. Ferns are also reproduced by means of gemme which grow on the stalk or surface of the leaves.

Ferns have been applied to but very few economical uses. The rhizome of the 'male fern,' Neplirodium filix-mas, and of the common polypody, Polypodizun vinlgare, and the palex of a Sumatram species, Cibotinn glancescens, are used in medicine as vermifuges. Abundant remains of Ferns are found in the fossil state, for which see Chapter VIII.

[The Filicales are conveniently divided in three orders, viz. :-

I. Filices or true Ferns. Prothallium above-ground and green. Leaves not stipulate, circinate in vernation. Sporangia formed from single epidermal cells, not coherent, on the back or margin of the leaves. They include the following sub-orders :-

I. Hymenoplyyllacea. Sporangia formed on a prolongation of a vein projecting beyond the margin of the leaf, and surrounded by a cup-shaped indusium. Annulus oblique or transverse, and dehiscence, therefore, longitudinal : leaves often very thin and delicate : Hymenophyllinn, Trichomanes, Loxsoma, \&c. (Figs. 439 VI., vir., 440 II.)

2. Gleicheniacea. Sporangia sessile, with a complete transverse annulus : dehiscence longitudinal: Gleichenia.

3. Schizcacece. Sporangia sessile or shortly stalked; annulus complete, forming an apical cap-like zone; dehiscence longitudinal: Schizaa, Anemia, Ly'sodizum.

4. Osmnndacee. Sporangia shortly stalked; annulus running round one side only; dehiscence longitudinal. Upper part of fertile fronds marked by the absence of parenchyma between the veins which bear the sori: Osmunda, Todea. (Fig. 440 III.)

5. Cyatheacere. Annulus complete, oblique, eccentric; dehiscence transverse; sorus generally on a strongly developed receptacle: Alsophila, Hemitelia, Cyathea ; most tree-ferns. (Fig. 437).

6. Polypodiacee. Annulus vertical and incomplete; dehiscence transverse: Acrosticlizm, Polypodizun, Adiantum, Pteris, Bleclinum, Asplenium, Scolopend'rium, Aspidium, Sc. (Fig. 439 I-V., 440 I.) 
II. MArattiace E. Prothallium above-ground and green. Leaves usually of great size, stipulate, and circinate in vernation. Sporangia

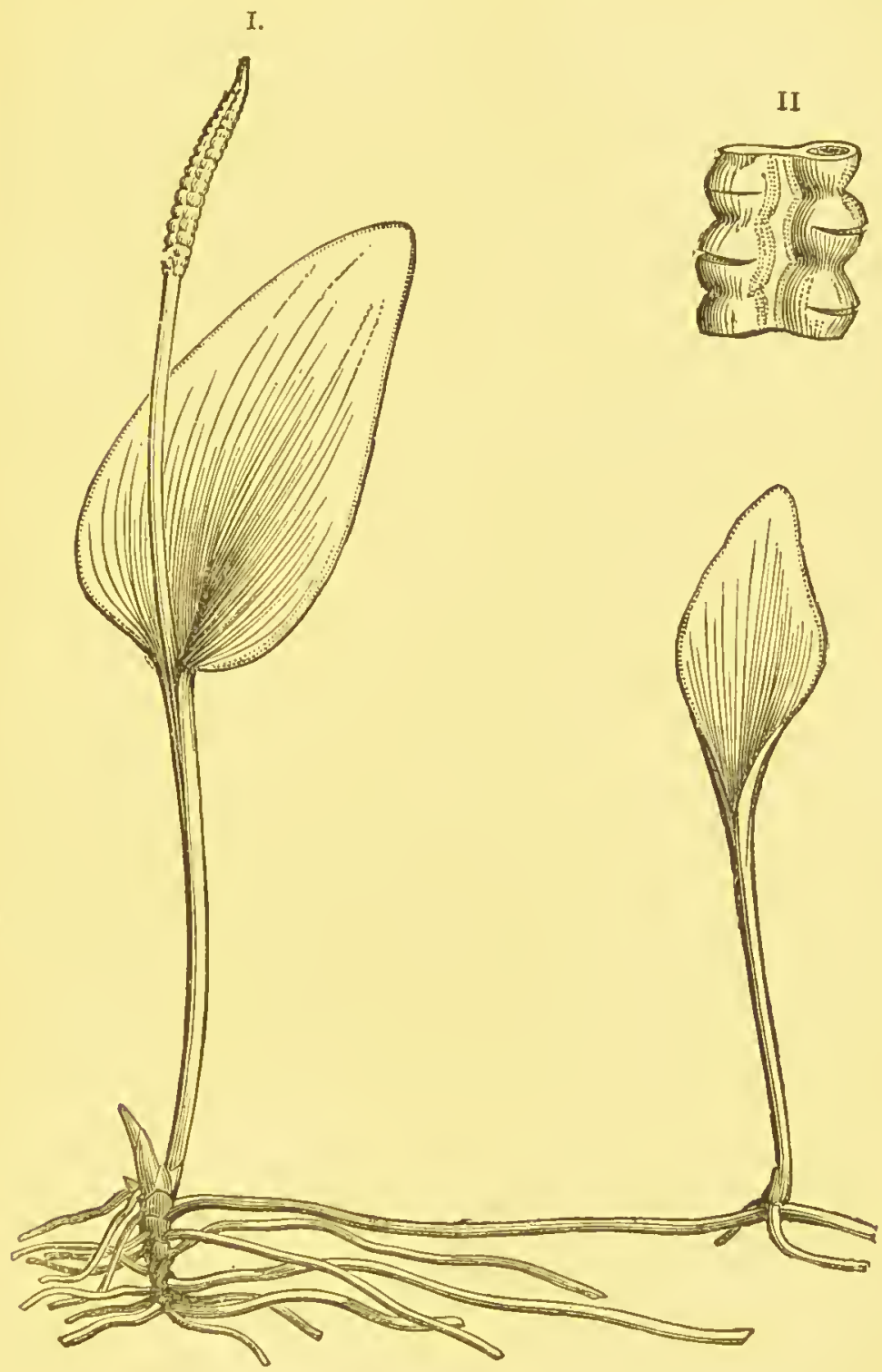

Fig. 443.-Adder's-tongue, Ophioglossum vulgatum: I. whole plant (natural size): II. a part of the fertile portion of the leaf with four sporangia in the act of
bursting (magnificd). 
on the back of the leaves, cohcrent into a many-cellcd sorus, opening by a pore, and each developed from a group of cells: NIarattia, Danaa, Kaulfussia, Angiopteris.-ED.]

III. OPHIOGLOSSACEÆ. This order is distinguished by its underground prothallium, which is destitute of chlorophyll ; by the mode of development and the form of the sporangia; and, finally, by the stem never branching. The primary root seldom branches; and the small flat stem is enclosed by the sheathing base of the leaf. The number of leaves, which are always annual, is small; our two native species, Ophioglossum vulgatum (Fig. 443), and Botrychium Lunaria, never producing more than one cach year. The leaves are also remarkable for the slowncss of their growth; those of the latter species requiring four years for thcir development, thc first three of these being spent entirely boneath the soil. As soon as the plant has attained a certain age, thc leaf branches, one half developing into a receptacle or spike of sporangia, [the othcr into the green lamina of the leaf]. The sporangia arc developed from a group of cells, are two-valved, and without an annulus. In Oplioglossum they arc arranged in two rows in a simple spike (Fig. 443 I., I1.), and arc cohcrent; in Botrychium, on the contrary, they are distinct, and form a branched spike or paniclc. The tetrahedral sporcs produce, on germination, prothallia, on which are developed the anthcridia and archegonia. In Ophioglossum there is also a vegctative modc of reproduction by means of adventitious buds on the roots (Fig. 443 I.). The prevalent form of tissue is parenchymatous fundamental tissue, consisting of long, nearly cylindrical cells, thin walled and full of sap, and with large intercellular spaces. Both sidcs of the lcaves are covcred by an epidermis provided with numerous stomata. Thic vascular bundles form a network in the stem, the tissue which occupics the space between the meshes being frequently changed into scalariform vessels, so that the stem then forms a closed hollow cylinder. This often talies place only on one side.

\section{Class VIII. Equisetales.}

This class is composed of the single order Equisetacea, which is made up of the single genus Equisetum or 'Horsetails.' The aërial stem springs from a creeping rhizome which produces at its nodes a number of adventitious roots. The stem is herbaceous, usually furrowed, simple or branched, jointed, and provided at the joints or nodes with 


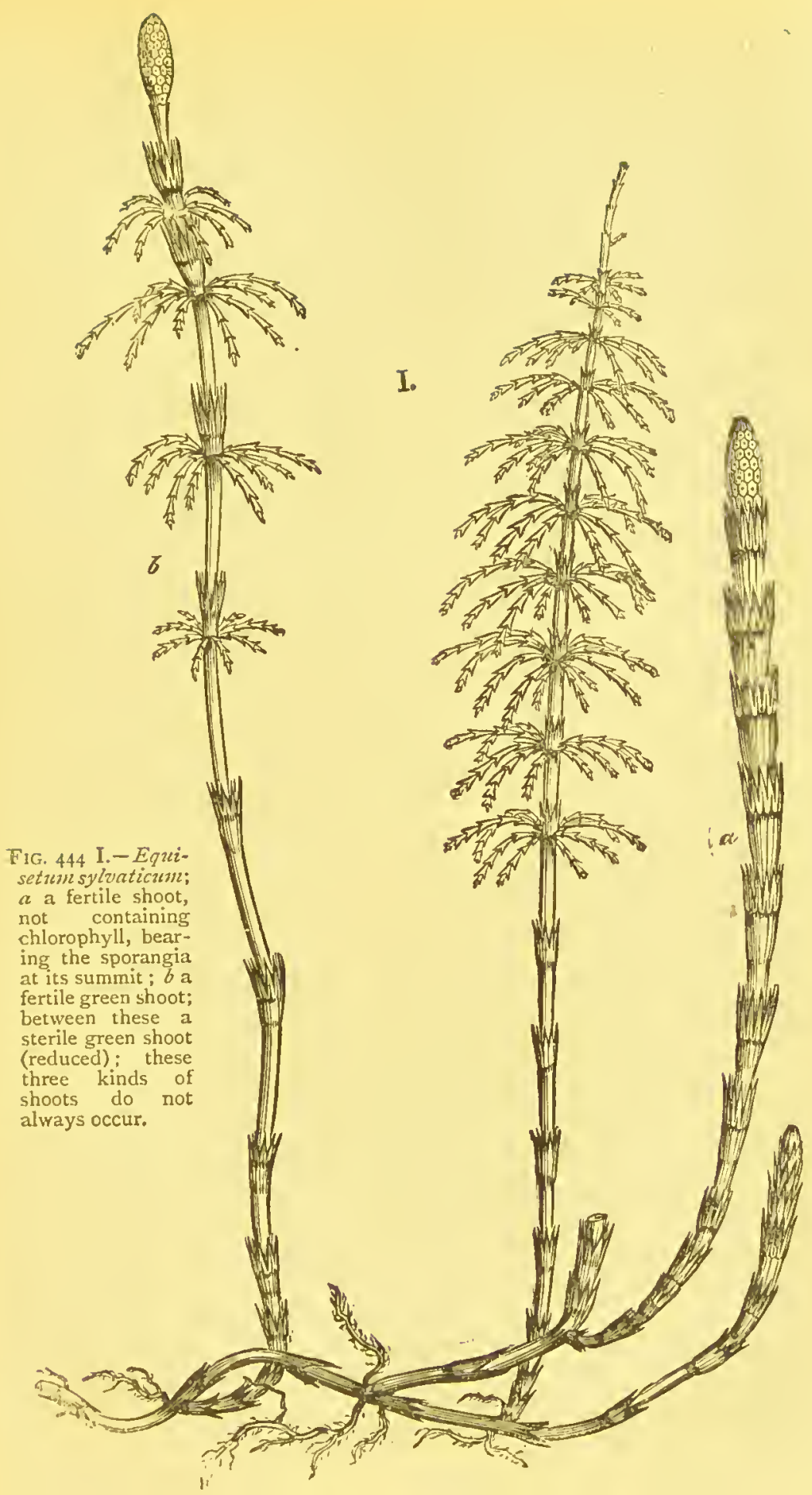


toothed sheaths, formed by the coalescence of the leaves at their base. The habit of the plant depends on this mode of formation of the leaves, and on the verticillate arrangement of the branches which spring from buds in the cortex (Fig. 444 I.). The stem, rhizome, and root are all derived

IV.
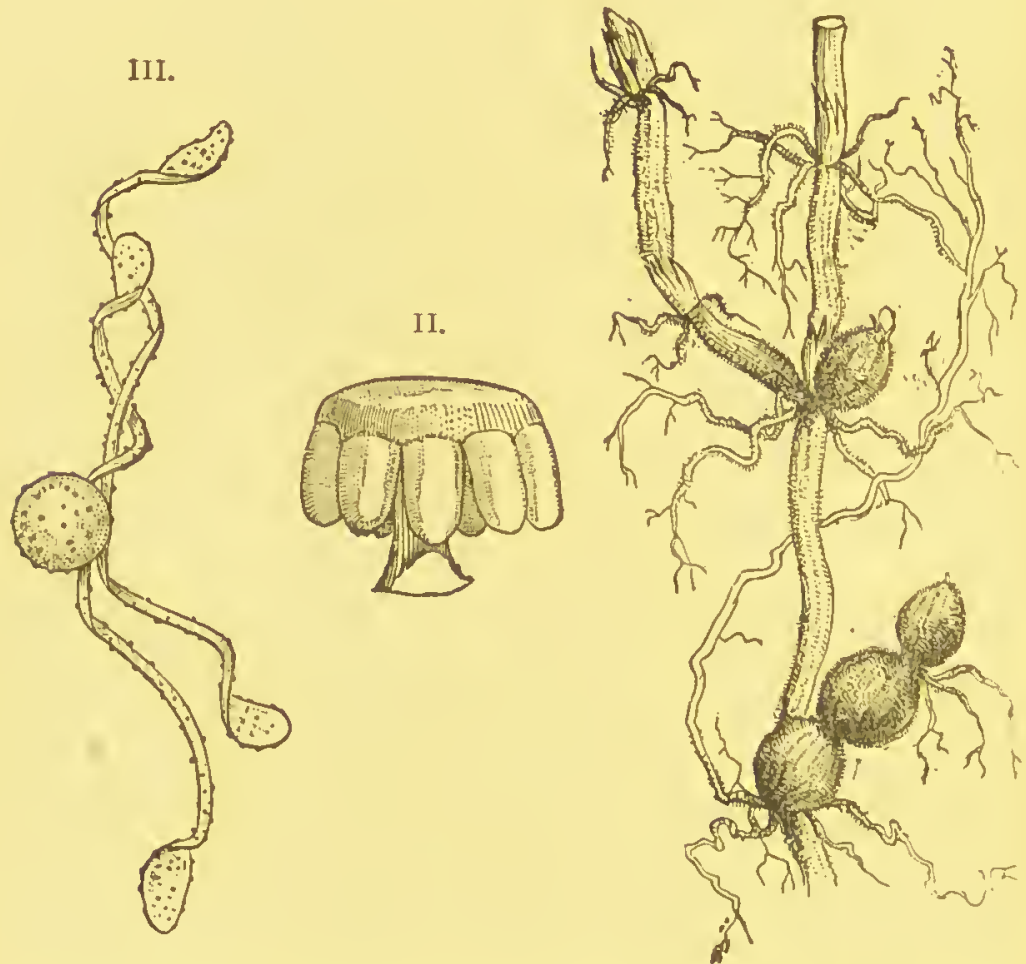

FIG. 444 II.-A peltate scale bearing the sporangia on its inner side facing the stem, five being visible (magnified); III. spore with the elaters unrolled which were previously coiled spirally round it (greatly magnified); IV. E. fuviatilc; rhizome covered everywhere with root-hairs, and having four tubers about the size of hazel-nuts which would, under favourable conditions, develope into new stems.

from a single apical cell, which divides into three series of segments. In the internal structure of the stem the aircavities are of great importance. Its centre is occupied by a large central air-cavity (Fig. $445 \mathrm{~A}, c$ ) ; and in the surrounding ring of tissue, which is often rather narrow, there is almost 


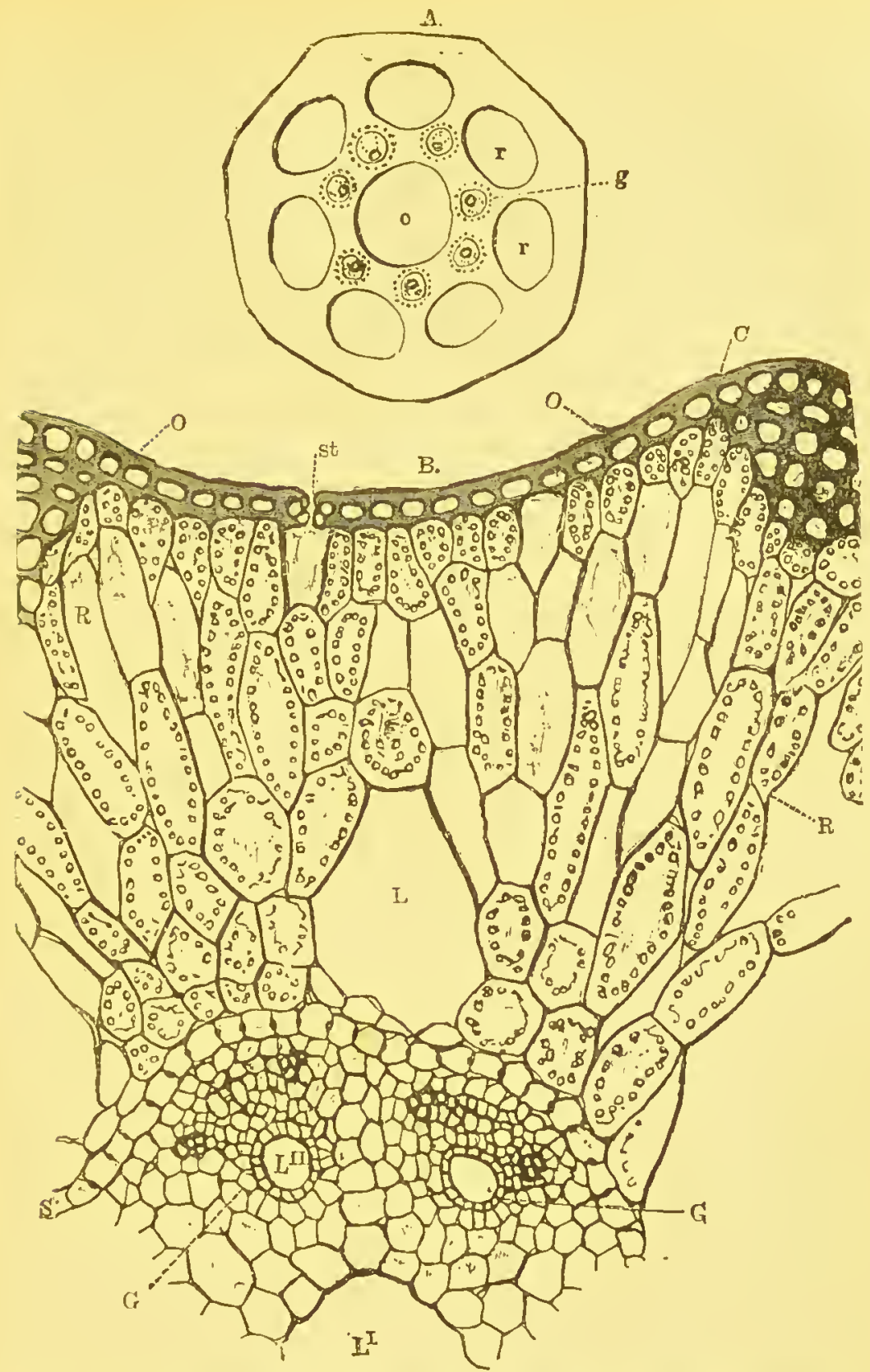

F1G. 445.-A. Transverse section through the rhizome of Equisetum littorale: $g$ vascular bundle surrounded by a sheath ; 0 central, $r$ cortical air-cavities $\left(x_{2} 6\right)^{s}$; B. transverse section through a young stem of $E$. sytzaticum; o epidermis; C collenchyma; $\mathrm{R}$ cortical parenchyma, many of the cells containing chlorophy:ll; $S$ vascular bundle-sheath : $G$ vascular bundle ; $L$ cortical air-cavity ; $L$ ' central aircavity; $L^{\prime \prime}$ air-cavity of the vascular bundle; st stoma ( $x$ 150). 
always a cortical air-cavity (Fig. $445 \mathrm{~A}, r$ ) between each pair of vascular bundles $g$. In addition, there often occur also the so-called 'essential' air-cavities (Fig. 445 B, L') in the vascular bundles. The stomata (Fig. $445 \mathrm{~B}, s t$ ) are usually placed in a single or in several rows between the elevated ridges of the stem. The cortex consists of thinwalled or of only moderately thick-walled parenchyma. It is separated on the inside from the vascular bundles by a sheath which sometimes encloses all the bundles together (Fig. $445 \mathrm{~B}, \mathrm{~s}$ ); while at other times each separate bundle is surrounded by a sheath (Fig. $445 \mathrm{~A}, g$ ). The vascular bundles ascend in a vertical direction, and parallel to one another, through the internodes, and form annular coils in the nodes. [They are always 'closed' bundles, containing no cambium]. Two other groups of vascular cells are found on the cortical side of the bundle. The bast-portion contains three elements: parenchyma, bast-fibres, and sieve-tubes ; it lies between the four groups of vascular cells and the vascular bundle-sheath. In the root is an axial bundle of vascular cells surrounded by elongated parenchymatous cells, with which sieve-tubes and bast-fibres are intermixed. The sporangia are capsules placed on the under side of scales belonging to the fructification (Fig. 444 II.). The fructification or receptacle is often placed on special shoots which are distinguished by their external form and by their brown colour from the sterile green stems (Fig. 444 1.). The spores are provided with two hygroscopic bands or elaters (Fig. 444 III.), only loosely attached to them, [formed by the splitting into narrow strips and the partial detaching of the exospore or outermost of the three coats of the spore, and serving, by their hygroscopic properties, to assist in their dissemination]. On germination the spore gives rise first to a flat prothallium, upon which are produced the antheridia and archegonia (Fig. 446); most species of Equisetum are diœcious, the female being many times larger than the male prothallium. In the antheridia are developed 
a very large number of motile antherozoids; in the archegonium is a single central cell containing an oosphere, which, after impregnation, developes gradually into the young plant. The alternation of generations is therefore precisely similar to that of Ferns. The Equisetaceæ are also propagated in a vegetative non-sexual manner, by means of subterranean stolons and tubers (Fig. 444 IV., p. 320).

\section{II.}

III.
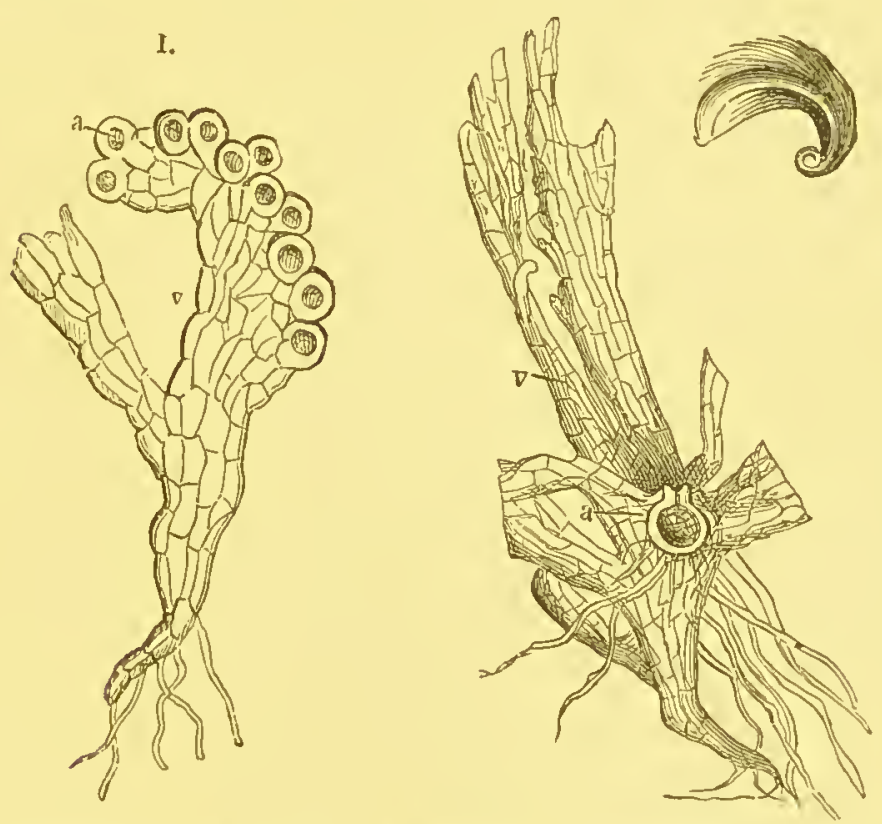

FIG. 446.-Equisetum maximum : I. prothallium $z$ with eleven antheridia $a(\times 30)$;

II. prothallium $v$ with archegonium $a(x 30)$; III. an antherozoid $(\times 500)$.

The class includes only a single genus, Equisetum. A quantity of silica is deposited in the stems, and especially in the epiclermis; $E$. hyemale being on this account especially used as a substance for polishing, under the name of 'Dutch rushes.' $E$. arvense is a troublesome weed. [Calamites are the stems of fossil Equisetacex; large plants of this order probably formed a great proportion of the vegetation during the carboniferous period. See also Chapter VIII.] 


\section{Class IX. Iycopodiales.}

The plants belonging to this class are characterised by having minute leaves, traversed by a single fibrovascular bundle. The larger number of species belong to the genus Lycopodium, with procumbent stem which repeatedly dichotomises, and closely imbricate leaves. The exotic Phylloglossum and Psilotum are erect shrubs in which cladodes or leaf-like branches take the place of true leaves; the latter genus is also destitute of true roots, their function being performed by underground branches of the stem. The fibrovascular bundles of the stem and root are very characteristic, forming a large axial cylinder, within which lie several bands of xylem enclosed in phloëm, without any cambium, the whole enveloped in a vascular bundle-sheath (Fig. 447). Between the epidermis and the fibrovascular cylinder is the parenchymatous fundamental tissue, or outer and inner cortex. Adventitious roots are given out from the forks of the stem.

The sporangia are borne in the axils of the leaves, sometimes of those belonging to the ordinary branches, more often on special modified branches (Fig. $45^{x}$ A, p. 330), which form a cone-like or spike-like kind of fructification. They are capsular bodies, bursting when ripe and containing a large number of minute spores. The spores on germinating give rise to a green prothallium of large size, which is more highly developed than that of other Vascular Cryptogams, and which bears both antheridia and archegonia. It has been but very rarely seen.

Several native species of Lycopodium are commonly known as 'stag's-horn moss' or 'club-moss.' Some species have been used as emetics or purgatives. The powder used by druggists for enveloping
pills consists of the spores of a Lycopodium. The spores of several species contain a large amount of an inflammable oil, and are used for making artificial lightning. The fossil Lcpidodendron and Sigillaria were the stem, and Stigmaria the root, of trees belonging to this class, 


\section{-}

(1)

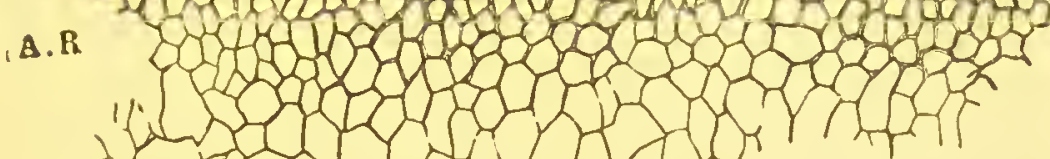

J.R

Bspi
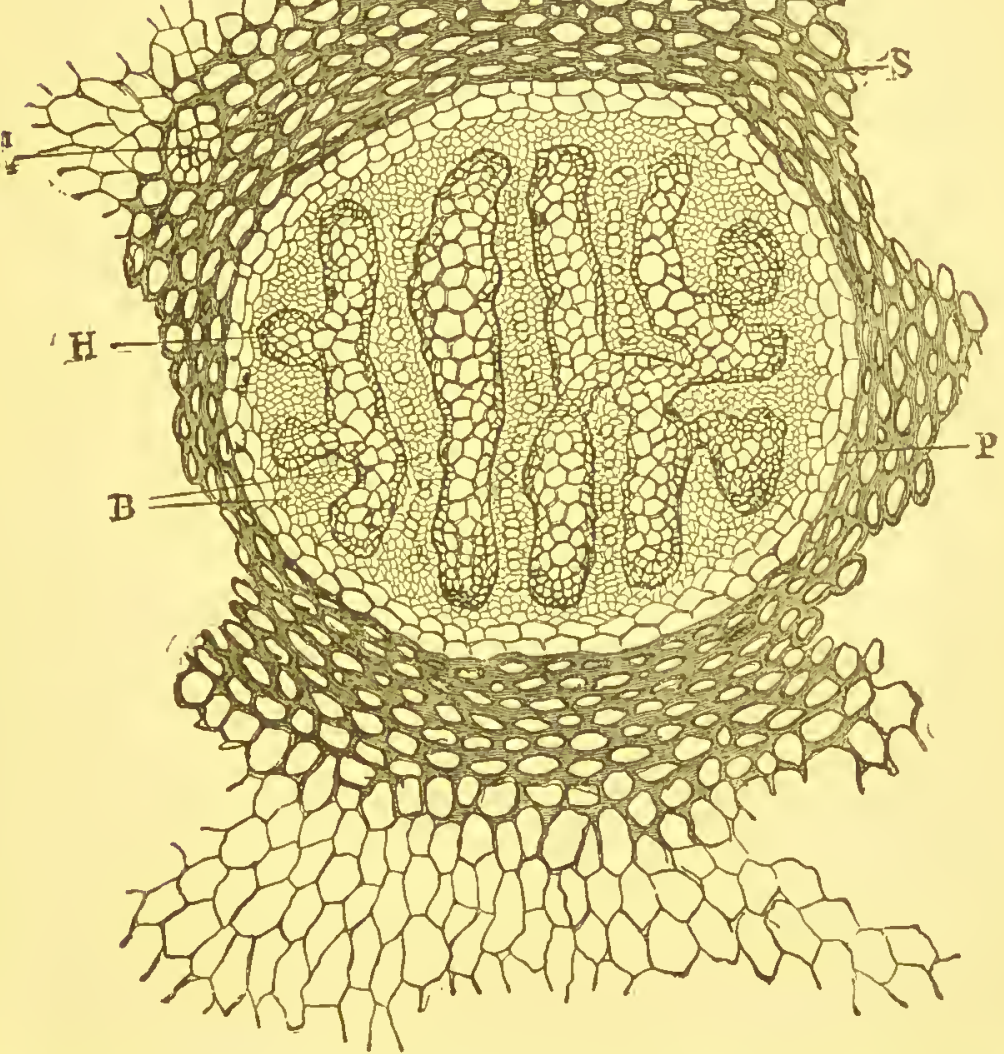

FIG. 447.-Transverse section through the stem of Lycopodium annotinum: o epidermis ; A R outer cortex; J R inner cortex; $s$ outer sheath; $P$ vascular bundle sheath: $\mathrm{H}$ xylem-, B phloëm-portion of the vascular bundle: Bsp, Bspt' leaftraces, or branches of the vascular bundle proceeding to the leaves ( $X 120)$. 
or to the Selaginellacex, which flourished in the carboniferous period ; Lepidostrobnes is regarded, with great probabiliy, as their cone-like inflorescence. See also Chapter VIII.

\section{HETEROSPOROUS VASCULAR CRYPTOGAMS.}

\section{Class X. Rhizocarpec.}

The Rhizocarpex are plants floating on the surface or creeping along the bottom of water, and derive their name from the circumstance that their fructification is placed at the base of the leaves or between the fibres of submerged leaves. From their mode of life they have also been called 'Hydropterides' or Water-ferns. The stem has a simple vascular bundle in its axis, which branches with the stem and also passes into the leaves, and is surrounded by an annular layer of lignified cells and a parenchymatous cortex. The woody part (xylem) of the bundle consists of very thickwalled vascular cells, among which occurs here and there an elongated parenchymatous cell, while the phloëm-portion contains parenchyma, vessels, and bast-fibres. The root has also a central bundle, which is, however, surrounded by a sheath. The fructification consists of conceptacles or sporocarps, containing a number of sporangia collected in groups or sori. The sporocarps are either unilocular or multilocular, and are developed from metamorphosed leaves. The spores themselves are of two kinds: megaspores, and much smaller microspores. They are formed in different sporangia, megasporangia and microsporangia; the two kinds being found either in the same or in different sporocarps (Figs. 448 Ir., 450 I.). Only one megaspore in each megasporangium comes to maturity. The antheridia are either formed directly from the microspores, as in Marsilea and Pilularia; or, in Salvinia, the microspores germinate and produce spore-sacs, the apices of which develope into antheridia. At the apex of the megaspore is a papilla con- 
taining protoplasm, from which is developed the primary cell of the prothallium (Fig. 450 I. a). The contents of this apical papilla, which is enclosed in the epispore, a thick

I.

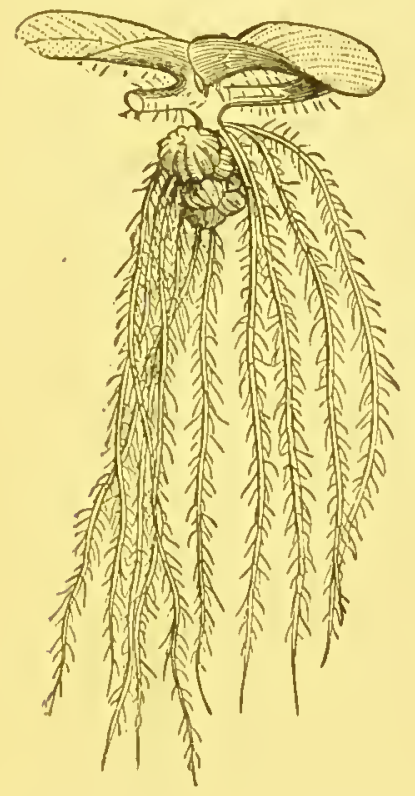

II.

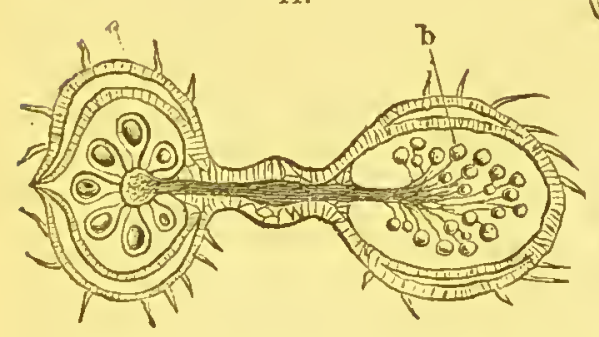

FIG. 448.-Salvinia matans: 1. a piece of the plant with two aërial leaves, and one deeply divided root-like submerged leaf with sporocarps (natural size): 1I. a section through two sporocarps; $a$ sporocarp with megasporangia, $b$ with microsporangia (greatly magnified).

gelatinous coat resulting from the disorganisation of the remaining megaspores, divide, when the spore begins to germinate, into a central cell and several superficial ones. 
The latter become filled with chlorophyll, and grow into a body which is placed like a cap on the apex of the megaspore, and then form the cells which immediately surround the central cell, and which therefore constitute the archegonium. At the proper time one or more antherozoids force themselves. through the neck of this archegonium, and presumably dis-

I.

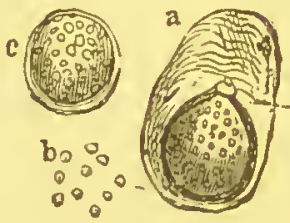

II.

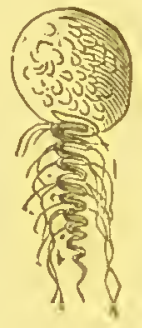

III.

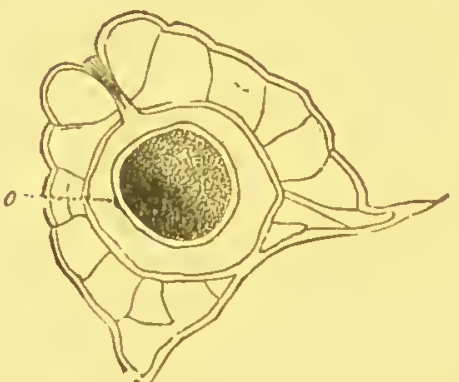

IV.

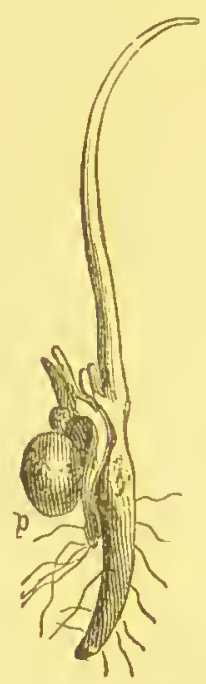

FIG. 450.-Marsilea salvatrix : I. a megaspore before fertilisation with its mucila. ginous envelope; the prothallium is developed from the roundish papilla $p$ at the apex of the spherical spore $\left(X I_{5}\right) ; b$ microspores $(X+5) ; c$ single microspore $(x$ IOo): II. antherozoid with its attached vesicle $(x 690)$ : III. pro-embryo with oosperm seen in transverse section: the spherical oosperm $o$ has already a cell. wall $(x 200)$; IV. young plant seven days later, still at tached to the spore $p\left(x_{7}\right)$. (All after Hanstein.)

appear in the interior of the central cell, i.e. in the oosphere. The oosperm or fertilised oosphere then becomes surrounded by a cell-wall (Fig. $45^{\circ}$ III., o), divides into new cells, and gradually grows into a new plant (Fig. $45^{\circ}$ Iv.). In Azolla both kinds of sporangium contain a frothy mucilage, which, in the microsporangium, is collected into distinct lumps known as massula, each of which encloses a number of 
microspores. In their alternation of generations Rhizocarpere do not differ from the other classes of Vascular Cryptogams. Salvinia (Fig. 448) is absolutely rootless. On the older parts of the plant the leaves stand in whorls of three, the two upper leaves of the whorl being aërial leaves with entire margins, the lower one a submerged leaf divided into very narrow root-like segments.

There are only four genera of Rhizocarper, which are classified, as follows, into two orders :-

1. Marsileacece. Perennial plants creeping in mud ; the microsporangia and megasporangia are contained in the same sporocarp. The prothallium bears a single archegonium. The leaves are circinate in vernation: Marsilea, Pilutaria.

2. Salviniacere. Annual plants floating on water; the microsporangia and megasporangia are formed in different sporocarps. The prothallium bears several archegonia : Salvinia, Azolla.

The sporocarps of several Australian species of Marsilea (Fig. 449) are known as 'nardoo,' and are used by the natives as an article of food.

\section{Class XI. Selaginellales.}

The plants belonging to this class present considerable diversities in relation to their vegetative organs. The Selaginellaceæ (Fig. 45 I B) have usually a procumbent stem which branches dichotomously, but the branches develope only in one plane, so that the plant presents an external resemblance to the Jungermanniex among the Hepaticæ. The leaves are simple, sessile, and with a single central vein ; they are placed in four rows, and are of different sizes, the lateral rows consisting of larger, the upper and under rows of smaller leaves. A number of adventitious roots are produced on the under side of the stem facing the ground. The Isoëtacer (Fig. 452), consist mostly of aquatic plants with a simple cylindrical but only slightly developed stem and elongated grass-like leaves. The single genus belonging to this family, Isoites, is the only one at present known 
A. I.

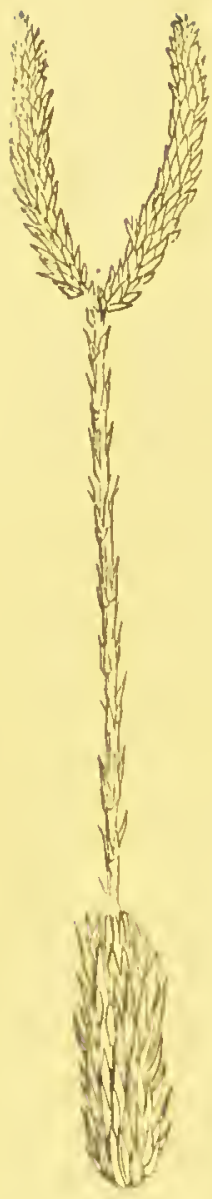

A. II.

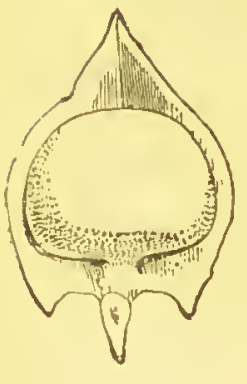

B. II.

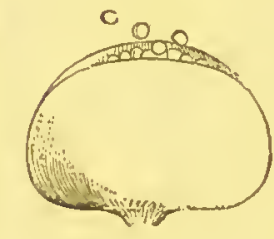

क्सेंगे
B. I.

B. III.

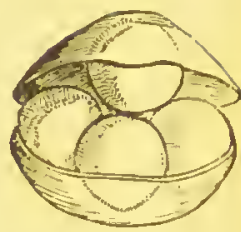

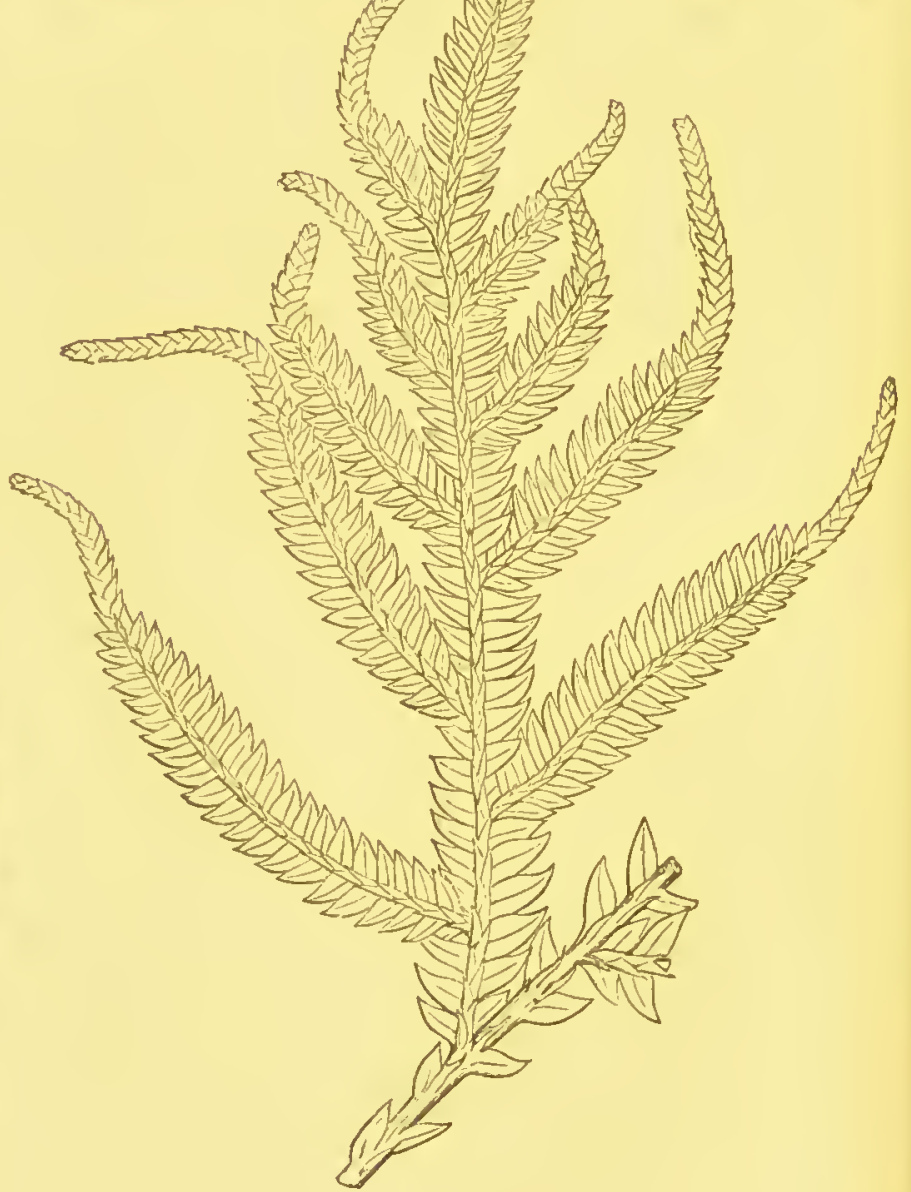

Fig. 451.-A. Lycopodium clavatum; I. fertile branch or receptacle (natural size); II. small leaf or bract bearing a sporangium (greatly magnified): B. Selaginella inargualifolia: I. fertile branch (natural size); II. microsporangium; III. megasporangium (the two last greatly magnified). 
among Cryptogams in which the stem permanently increases in thickness; and this takes place by an annual formation of new masses of tissue round the central vascular bundle, the older ones gradually dying off on the outside. Since this process takes place almost entirely at two spots directly opposite to one another, the stem ultimately has the form of a plate or disc (Fig. 452 11.). The axis of the stem is occupied in all plants of this class by one or several closed vascular bundles separated from one another by intermediate parenchymatous fundamental tissue. In the Selaginellaceæ the vascular bundle is connected with the cortex by a very loose spongy tissue, so that it appears to lie almost isolated in a cylinder filled with air and connected with the walls only here and there by parenchymatous cells. The structure of the vascular bundle itself is always uniform. The xylemportion consists of wider vascular cells in its inner, of narrower vascular cells in its outer part; the phloëm-portion possesses vessels, bast-fibres, and parenchymatous tissue. The axial vascular bundle sends out ramifications into the branches and leaves.

The fructification consists of sporangia or capsules which burst open when ripe, seated beneath a ligule at the base of the leaves; in Isoëtes in a fovea or pit. These sporangia are of two kinds (Fig. 45 I B, 11., 111.): megasporangia, in which are formed four large megaspores; and microsporangia, in which a greater number of much smaller spores, the $m i$ crospores, are developed. The microspores are themselves the antheridia, and break up into a small number of cells, one of which remains unproductive and may be regarded as an abortive prothallium, while antherozoids are developed in the remainder. The megaspores, on the other hand, as in the Rhizocarpex, produce a transitory prothallium, which bears archegonia opening outwardly (Fig. 452, 1., 1v.), and in their interior a central cell with its oosphere. In the Isoëtacex the prothallium entirely fills up the megaspore; while in the Selaginellaceæ it is attached to its apex as a 
I.

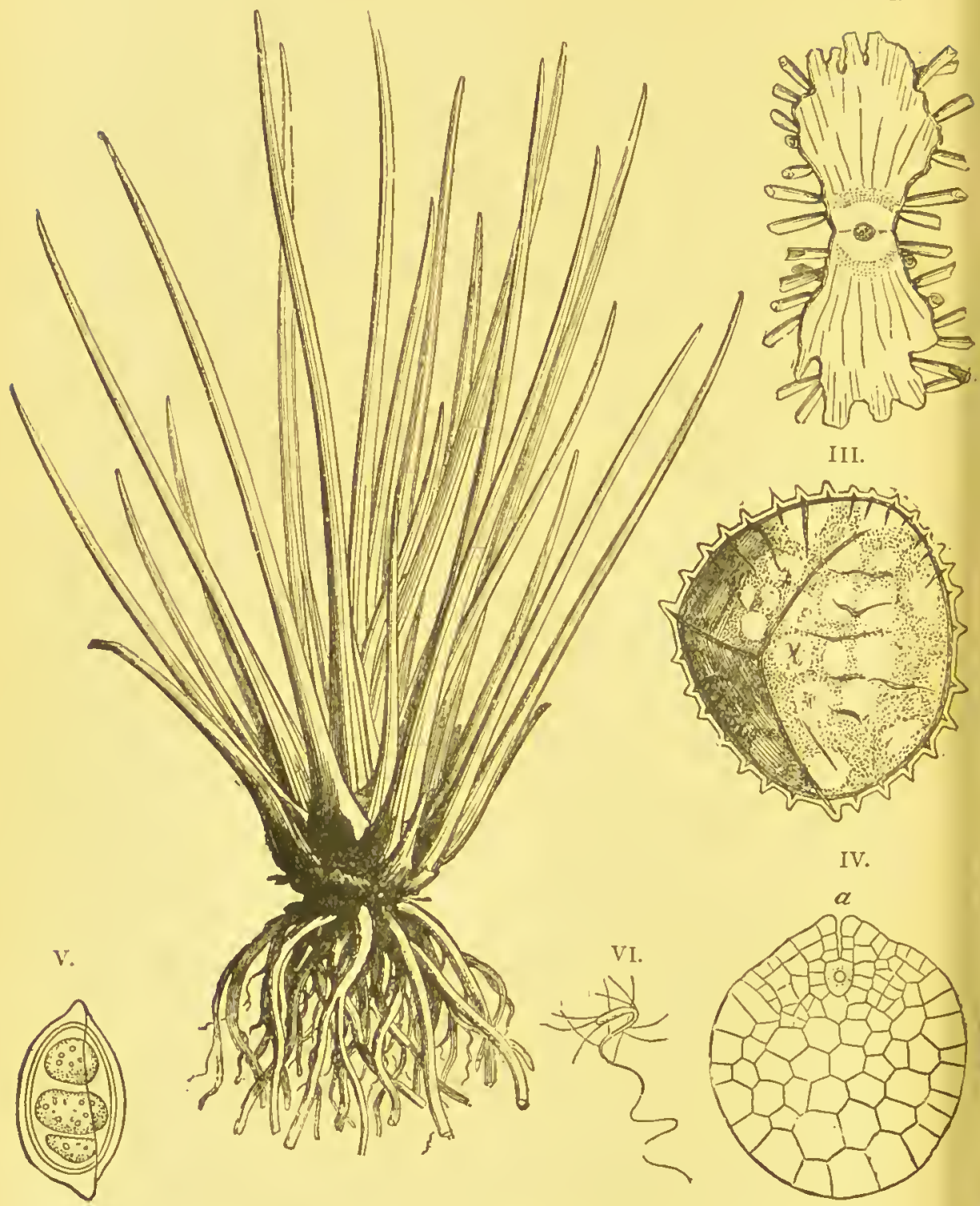

FrG. 452 -Isoëtes lacustris; I. the whole plant (natural size); II. transverse section through the peculiarly thickened stem (natural size); III. megaspore ( $x 60)$ : IV. longitudinal section through the prothallium with an archegonium $a(x 40)$ : $V$. microspore with three mother-cells of antherozoids $(x 500)$; VI. antherozoid $(\times 500)$. 
cap-shaped appendage. After fertilisation the embryo is, in Isoittes, developed directly from the oosperm, while, in Selaginella, the latter forms at first a filiform pro-embryo or suspensor, on which the young plant is then developed. The process of alternation of generations resembles therefore that which prevails in other Vascular Cryptogams. 'The Selaginellales are also propagated in a non-sexual vegetative manner by means of gemmae, that is, by buds formed in the axils of the leaves, which become detached from the parentplant and develope into new individuals.

[The Selaginellales are divided into two families, as under :

I. Selaginellacee. Terrestrial plants with small leaves of two different sizes, often cultivated for their elegance : Selaginella.

2. Isoëtacea. Aquatic or rarely terrestrial plants with long grasslike leaves : Isoëtes.]

They are of no known economic value. [On fossil forms, see p. 325].

\section{FLOWERING PLANTS.}

\section{Class XII. Gymnosperma.}

[The main characteristic of Gymnosperms, as distinguished from the other classes of Flowering Plants, is the absence of an ovary, the ovules being gymnospermous, entirely naked, and unprotected even by a perianth; and the flowers are always unisexual. With this is necessarily connected a difference in the mode of fertilisation, which has already been explained (p. rgi). In their reproductive organs, therefore, the Gymnosperms exhibit a decidedly lower type of organisation than Monocotyledons or Dicotyledons, and in many respects occupy an intermediate position between these classes and Cryptogams. The pollen-grains suggest a homology with the microspores of Selaginella, the nucellus with the megasporangium, and the corpuscules or secondary embryo-sacs with the central cell of the arche- 
gonium in the Heterosporous' Vascular Cryptogams. The male flowers consist of a prolonged axis, on which are inserted a number of stamens, each consisting of a scale bearing on its under side two pollen-sacs. In the female flowers the ovules are sometimes borne directly on the axis, sometimes on the under side of scales, which are regarded by some as bracts, by others as open carpels. The ovule has only one integument, and the ripe seed always contains endosperm. In the anatomical structure of the wood Gymnosperms resemble Dicotyledons in all essential particulars (see also pp. 37I-373, Figs. 478, 479).] The class is divided into three orders :-

Order 1. CyCADEAs. The Cycadex (Fig. 453) are all tropical trees with simple stems, resembling Palms in their habit and Ferns in the mode

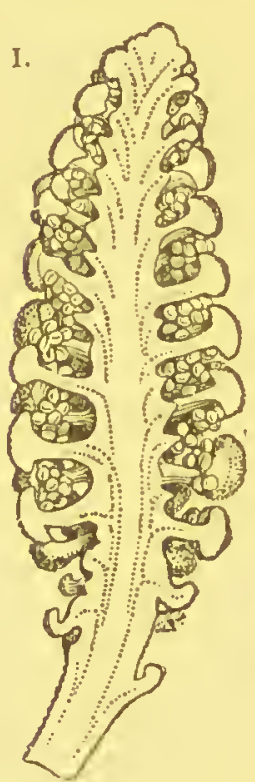

of development of their leaves. Their columnar stems attain a considerable diameter, are tuberous or globular when young, and often even at a later period, and bear two kinds of leaves: the one dry, brown, hairy,

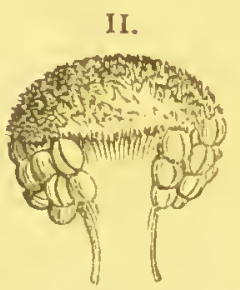
sessile scales of a coriaceous texture and comparatively small size, the other large, stalked, simply pinnate foliage-leaves. They are dicecious. Both kinds of flowers are always placed in terminal cones at the apex of the stem, in the centre of the crown of leaves, and have no floral envelope or perianth, but consist simply of an axis, which is in the one case densely covered with peltate stamens, in the other bears the ovules. The two cotyledons are unlike in form, are connate with one another at their apex, and remain, on germination, enclosed in the albuminous seed. The pith of some species, as the East Indian Cyias circinalis, and the South African Encephalartos lanuginosus, afford a kind of sago. [Principal genera: Cycas, Stangeria, Diöon, Encephalartos, Zamia.] 
Special Morploology and Classification. 335

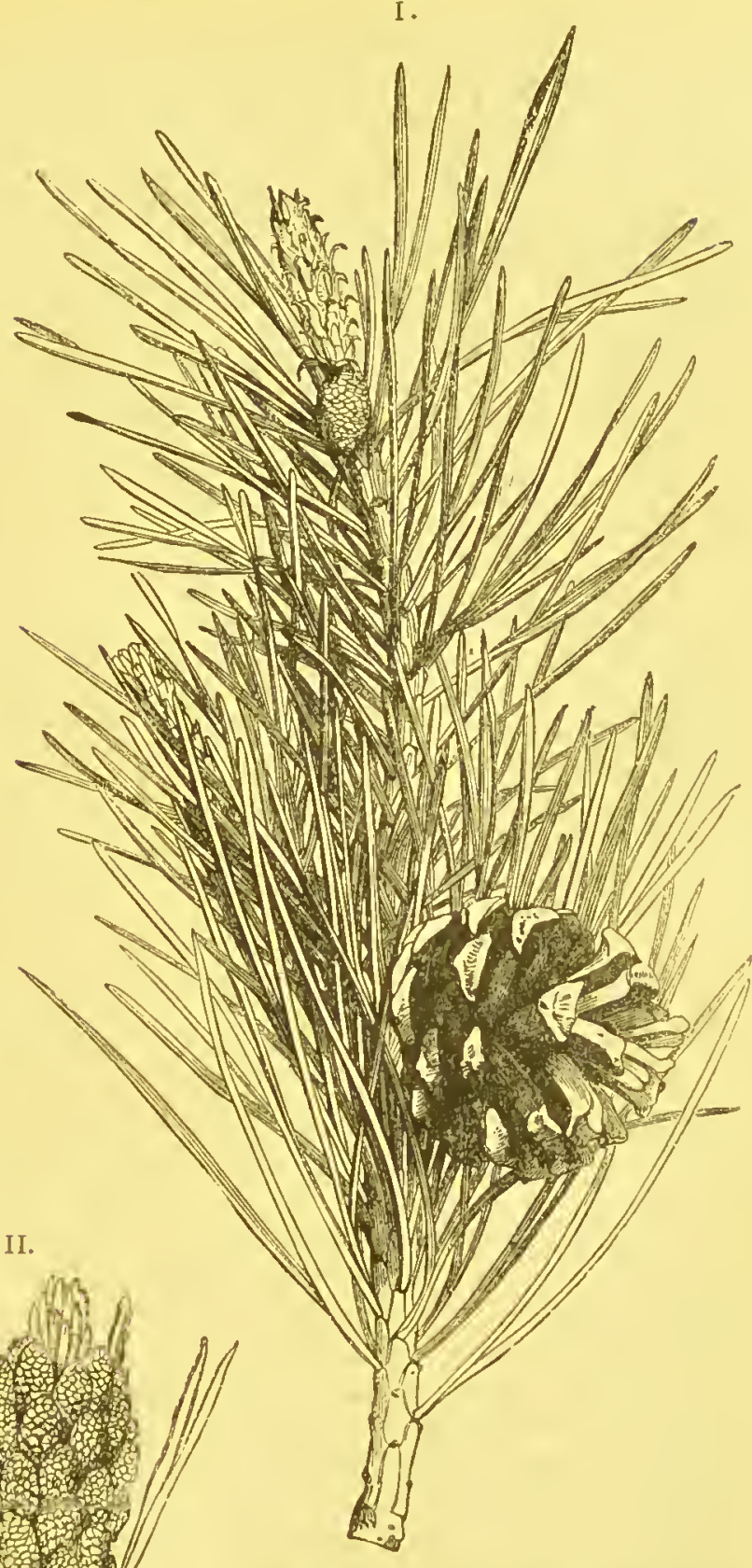

Fig. 454.-Pinns sylvestris, the Scotch fir: I. a branch (reduced); II. a male flower (natural size). 
Orider 2. Conifere. Trees or shrubs, with stems growing at their apex for not unfrequently several centuries, and attaining a height of 200 to 350 feet or more. Either all the leaves have the form of foliageleaves, as in Juniperus and Thuja, or folinge-leaves alternate with membranous scales which serve to protect the buds, as in the Abietinex. The leaves are small, usually acicular (Fig. 454), and persistent through the winter, in some cases enduring for several years. [The stem increases, as in Dicotyledons, by a ring of cambium ; but the seconclary wood contains no true vessels, consisting entirely of tracheïds or woodcells, the walls of which bear peculiar bordered pits (see Fig. 27, p. I8).] The flowers are always incomplete (without perianth), and either

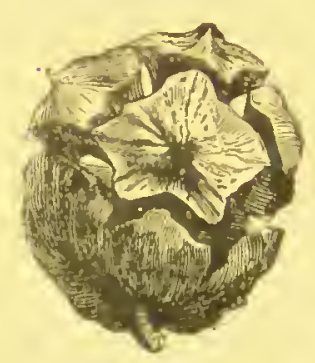

Fig. 455.-Ripe cone of Cupressus (natural size).

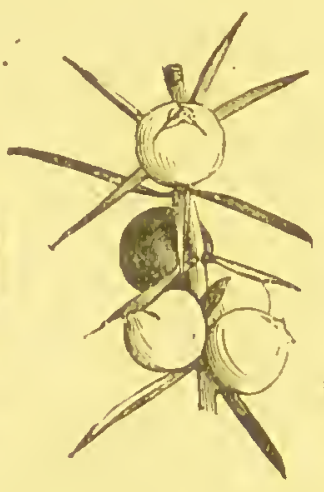

Fic. 456. - Berry-like fruit of the juniper (natural size).
I.

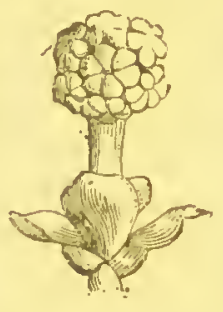

II.

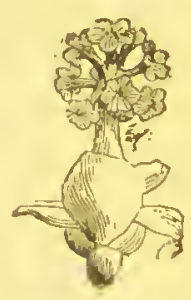

Fig. 457. - Male flower of the yew : I. before, 11. after the discharge of the pollen (magnified).

monocious, as in Abies, or diœcious, as in the yew and juniper. The male flowers, which are often incorrectly called catkins, consist of stamens borne on an elongated axis, each bearing two or more pollen-sacs on its under side. The female flowers are of various forms, and are either solitary or united into peculiar cone-like inflorescences. In some genera the seed takes two years to come to maturity. In the Cupressince (Figs. 455, 456) the stamens are broad, and bear two or three pollensacs on a shield-like mid-rib. The ovules are erect and orthotropous, and stand in the axils of the bracts or carpellary scales. In some genera, as Thuja and Cupressus, the fruit is a cone ; in others, as Junipernes, it is berry-like, and formed by the coalescence and softening of several female flowers. The embryo has two or three cotyledons, which remain in the ground on germination. The fruit of the juniper, Juniferus commminis, is officinal, and is applied to many purposes; as also are the 
young branches of the poisonous savine, Fumiperus Sabina, and the resin from the North African Callitris quadrivalvis. The anthers of the Taxinea (Fig. 457) are 2-8-lobed. The erect ovules (see Fig. 328, p. I54), which are either solitary or arranged in groups on a special branch, and either terminal or lateral, develope into nut-like seeds surrounded by a more or less thickened and fleshy envelope or aril. The embryo has two cotyledons which in some genera rise above the ground, while in others they do not. The poisonous leaves of the yew, Taxus baccata, are officinal. The Abictinea (Figs. 454, p. $335 ; 458$, 459) approach the Taxinex in their two-lobed anthers, and the Cupressinee

J.

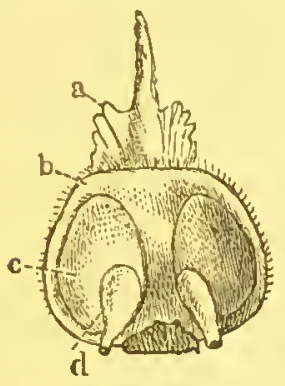

IV.
II.
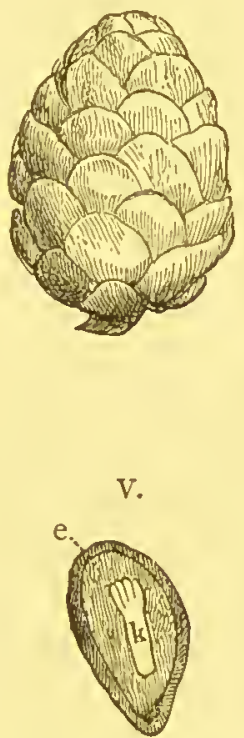

FIG. 458.- Larch (Pinus Larix); I. a seed-scale $b$ from a young cone, seen from the inner side, with the bract $a$, and the two inverted naked ovules $d$; II. ripe cone ; III. a scale $a$ from a ripe cone, seen from the outer side, $b$ the bract which has not grown along with the scale, and is therefore smaller; IV the seed $b$ with its wing $a ; \mathrm{V}$. longitudinal section through the seed,

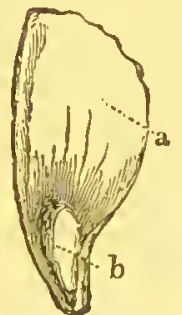
the small embryo $z$ lying in the endosperm $e$.

III.
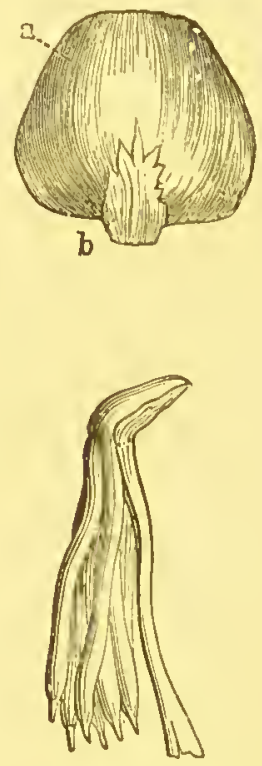

FIG. 459.- Anthers of Arancaria.

in their fruit, which is a cone ; but differ from both these suborders in their anatropous ovules with the micropyle directed downwards, and in the number of their cotyledons, which varies from five to twelve [or rather from two to fifteen]. The cone is also constructcd differently from that of the Cupressinex, being composcd of imbricate bracts and 
carpellary scales, each of which bears two winged ovules. These scales overtake in their growth the bracts which are situated between them, and which are arrested in their growth and become coriaceous or woody. The cedar of Lebanon, Cedrus Libani, is of historic interest, but has now nearly died out, and is related to the exotic Araucariex. The best-known European representatives of the sub-order are the Scotch fir, Pinns sylvestris, the Spruce fir, Pinns excelsa, the larch, Larix europar, [and the stone pine, Pinns Pinea.] The various trees belonging to it are of the highest value for a great variety of purposes; the wood being employed for fuel and for building purposes, for joining and turning work, for the manufacture of musical instruments, \&c. [and for the navy]. The wood of the root is lighter and is less used for fuel than that of the trunk, but is richer in resinous substances, and therefore more serviceable for the production of tar. Pimns syldestris, Pinea, nigricans, and Pinaster, all yield common turpentine, from which turpentine-oil, pine-resin, colophony, and pitch are obtained. Venetian turpentine is prepared from the larch. Abies balsamea and canadensis of North America yield Canada-balsam; Dammara orientalis from the Moluccas, and $D$. australis from New Zealand, the Dammar resin or kauri-gum. Pinites succinifer is one of the extinct sources of amber. The starchy and oily seeds of Pinus Pinea and $P$. Cembra are edible. Many of the resins and volatile oils are officinal. [Principal genera :Arancaria, Dammara, Pinns, Larix, Cedrus, Picea, Abies, Sequoia, Cryplomeria, Taxodinm, Frenela, Callitris, Libocednes, Thrija, Biola, Cupressus, Funipenns, Taxus, Torrcya, Phyllocladns, Salisburia, Cephalotaxus.]

Order 3. Gnetaces. To this order belong only three genera, of remarkably different habit. The various species of Ephedra are shrubs destituie of foliage-leaves, with long slender cylindrical green-barked branches; at the joints of the stem are two opposite minute leaves, which grow together into a bidentate sheath, and from their axils spring the lateral branches. In Gnetnm the leaves are also opposite on the jointed stem, but are stalked, and have a broad lanceolate lamina. Wilwilschia mirabilis, the only representative of the third genus, never has more than two leaves, but these are of inmense size.

\section{Class XIII. Monocotyledones.}

The embryo has only one cotyledon. The perianth is simple, or, when double, usually without distinction of colour, and the prevalent number of its parts is three or six. The leaves are most commonly parallel-veined. 
The stem in its young state is always provided with an epidermis, the cells of which often contain silica, as in Grasses and Palms, giving the surface a vitreous appearance. The simple cortex consists of polygonal or roundish parenchymatous cells, among which are sometimes formed strongly thickened cubical sclerenchymatous cells, prosenchymatous cells, and bast-vessels. When very young the cortex is separated from the subjacent tissue by an annular layer of formative tissue, or cambium-sheath, in which the vascular bundles are formed, but the cambium possesses in general only a limited activity; and when this is exhausted, the stem no longer continues to increase in diameter at that spot; the cortical parenchyma then passes over gradually into fundamental tissue, or is separated from it by the lignified cambium-sheath (Fig. 460 I., v.). The vascular bundles stand singly in the fundamental tissue. The cauline bundles, or those which belong to the stem only, run parallel to the surface; by far the greater number, however, pass from the stem into the leaves; and these, termed the leaf-traces, at an early period cease to grow in a vertical direction, and turn towards the pith, bending outwards again from there to enter the leaves. When a number of bundles have been formed in this manner, every bundle which bends from the inner to the outer portion of the plant must cross all the younger ones in succession (Fig. 460 II.). The fibrovascular bundles are necessarily closed, in contrast to the open bundles of Dicotyledons and Gymnosperms. The term Endogens was previously applied to Monocotyledons, [and still is commonly in works on Descriptive Botany], because it was thought that the vascular bundles originated in the centre of the stem, and grew outwardly only in order to enter the leaves (see Fig. 9.5, p. 68).

In many species the course of the vascular bundles is essentially different from this, passing through the separate internodes in a parallel direction, while they bend irregularly 
I.

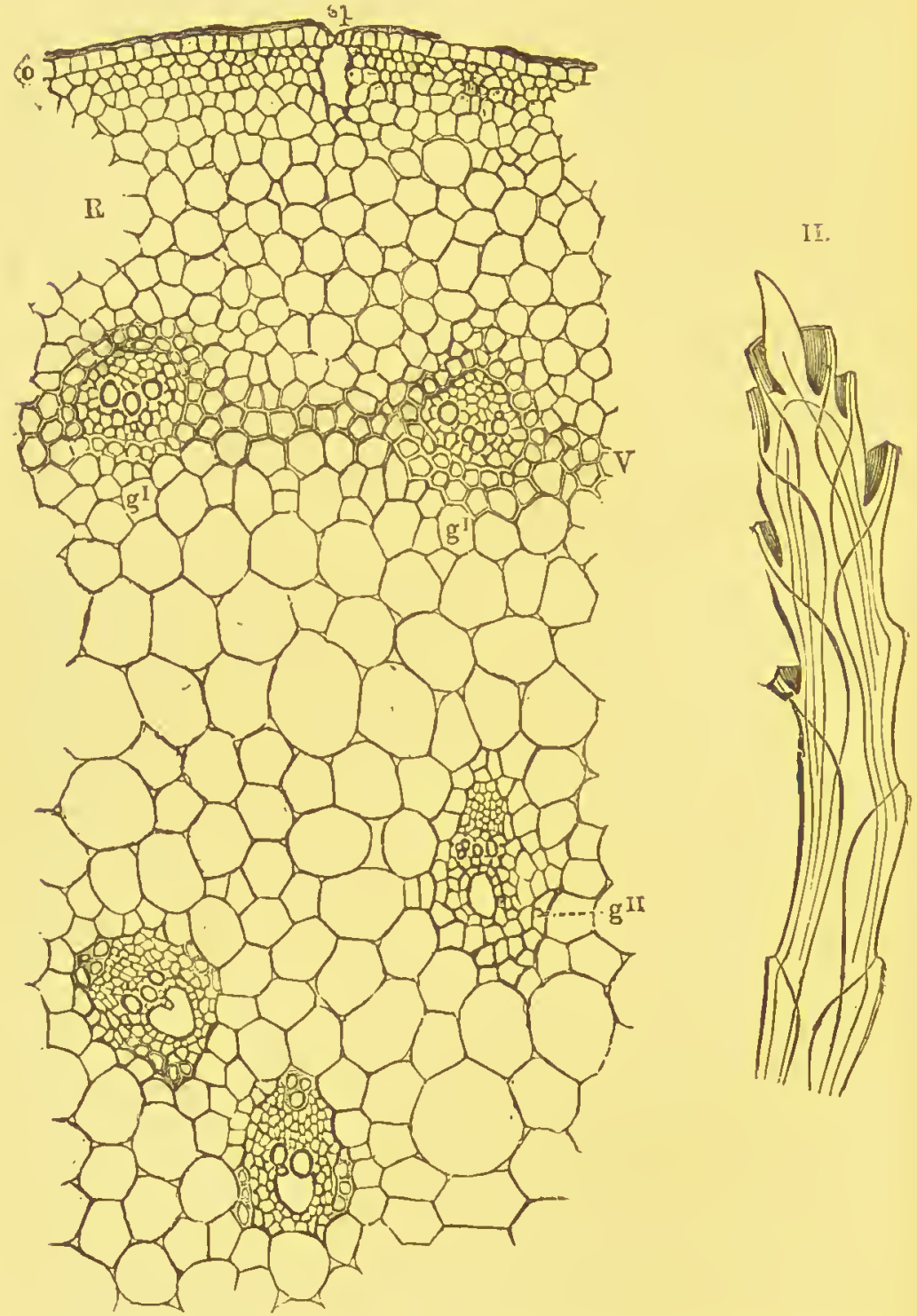

FIG. $460-$ I. Part of a transverse section through the stem of Tradescantia Scllo: : $o$ epidermis, with a stoma $s p ; \mathrm{R}$ cortex; $\mathrm{v}$ thickening-ring with the outer vasclllar bundles $\rho^{\prime \prime}$ inner vascular bundles $(x, 75)$; II, course of the vascular bundles of Iris in longitudinal section (diagrammatic). 
and branch in the nodes. This occurs, for example, in the culms of Grasses. The pith also disappears at a very early period in these cases, from rupture and desiccation, and probably also partly from resorption, so that the stem subsequently becomes hollow.

The separate vascular bundles are in general more highly developed than in the classes already described; but their increase in thickness is limited, and soon ceases. The xylem-portion of the bundles may consist of wood-fibres, vessels, and parenchymatous cells; the phloëm-portion of bast-fibres, sieve-tubes, and parenchymatous cells, with which are sometimes associated laticiferous vessels. The wood-fibres are sometimes more, sometimes less strongly thickened, but always lignified, and have a smaller number of scattered, slightly bordered, oval pits; sometimes they are pointed at the ends, forming a prosenchymatous tissue, and resemble elongated parenchymatous cells. The bastfibres are of similar structure, but, as a rule, more pointed. The vessels of the xylem-portion are annular, spiral, reticulated, or pitted. It is not uncommon also to find single vascular cells not united with others into true vessels. The lateral walls of the sieve-tubes are usually horizontal, and provided with sieve-discs; the partition-walls, on the contrary, are mostly smooth, and only rarely, when united in growth with similar ones, also penetrated by sieve-pores, thus forming conducting sieve-cells. The parenchymatous cells, both of the xylem- and of the bast-portion, are usually elongated, and hence resemble prosenchymatous cells; but always have horizontal partition-walls, and are either not at all lignified, or, at all events, less so than the wood-fibres. The laticiferous vessels are also sometimes found outside the vascular bundle; and are then, when they contain raphides and belong to the cortex, called utricular vessels (see Fig. 75, p. 50). The arrangement of these separate elements of the vascular bundles of the stem is in general 
as follows (see Figs. 93, 94, pp. 65, 66). At their inner side next the pith is a bundle of wood-fibres, and in close contact with this are the vessels and vascular cells, which are partly surrounded by the parenchymatous cells of the xylem, partly intermingled with them. Then follows an easily distinguished thin-walled part consisting of sieve-tubes, conducting sieve-cells, and parenchymatous cells belonging to the phloëm-portion; and finally, towards the cortex, a bundle of bast-fibres. Sometimes the bundles of fibres of the xylem and the phloëm coalesce laterally with one another by means of narrower or broader groups of wood-fibres, so as to form a closed ring surrounding the other elements of the vascular bundle.

The root of Monocotyledons has an epidermis provided with numerous root-hairs. The cortex is parenchymatous, and is often differentiated into an outer and an inner cortex. It is frequently separated from the inner portions by a sheath. The vascular bundle forms a closed hollow cylinder which encloses the central pith. The phloëm-cells, which are usually elliptical, lie between the radially placed vessels of the xylem. The xylem-and the phloëm-portions of the vascular bundle are separated by wood-fibres. The phloëmportion consists of sieve-tubes lying within and of parenchyma pressed outwards.

The leaves are penetrated by fibrovascular bundles. When several enter a leaf, they may first unite into a leafstalk, or may be separated in their entire course, as occurs in many sessile leaves, like those of Grasses. The xylemportion of the bundle faces the upper, the phloëm-portion the under side of the leaves. The skeleton of the leaf, formed of the vascular bundles, is surrounded by the parenchyma of the leaf. This parenchymatous portion or mesophyll separates-independently of the epidermis, which is always present and is provided with stomata and often with hairsinto two layers, the upper layer consisting of cylindrical, the 
under of rounder cells; the latter being, therefore, of a looser texture and often penetrated by wide air-passages.

[The following are the more important orders of Monocotyledons, arranged, with slight variation, according to Bentham and Hooker, those of less importance, and even one or two of the cohorts, being omitted :

\section{Diviston I. Flowers glumaceous.}

Cohort I. Glumales. Flowers in the axils of scales (glumes), which are arranged in spikelets; perianth absent, or consisting of minute scales or hairs or bristles; stamens one to three, rarely more ; ovary unilocular with one ovule; fruit a caryopsis; endosperm fleshy or floury; embryo immersed or not. Grasses or grass-like herbs.

Order I. Gramineæ. Perianth absent, or of two, rarely three or six minute oblique scales; anthers versatile; fruit grooved on one side; embryo outside the endosperm on one side of its base; stem usually fistular, terete ; leaf-sheaths split to the base.] Herbs, rarely, as in the bamboo, woody, shrubby plants; the cylindrical, usually hollow, stem, septated at the nodes, is called a culm. At the point of union of the divided leaf-sheath and the lamina-which is always entire and parallel-veined-is a membranous structure [of a stipular character], the ligule (Fig. 147, p. 92). The flowers are lermaphrodite, seldom nonoe. cious, as in the maize, and are usually arranged in a panicle or spike, which, however, bears secondary spikes or spikelets instead of flowers. Each of these spikelets (Fig. 46r) consists of a rachis, on which are placed the small inconspicuous flowers, concealed among closely crowded foliar structures. The two lowermost of the scale-like bodies usually have no flowers in their axis, and thus serve as a common envelope for the whole spikelet, and are termed glumes. The flowers, which are arranged in two rows, are solitary in the axils of the next scales; and since each flower has also at its base a special scale, it has two belonging to it, which are called palea, an exterior or inferior, and an interior or superior one. The inferior pale has a mid-rib, which is often prolonged at the apex into a bristle, projecting from the back of the pale, and is called an aqun (Figs. 462, 463). The inner pale has no midrib, but often two lateral nerves, and is hence bidentate at the apex. Within the palex, and alternating with them, are two, rarely, as in the sugar-cane, three minute scales, the lodicules, whicll correspond to the perianth. The stamens are three, rarely two (in Anthoxanthum), or six (in the rice), the anther's being versatile at the end of long filaments (Fig. 270, 1). 138). The ovary is superior, unilocular and with a single ovule, and usually bears two, less often (in Nardus) one, or 
(in the sugar-cane) three stigmas. The fruit has a dry pericarp, and is an indehiscent caryopsis, the seed adhering in its growth to the pericarp and 'often to the palex. The embryo is small, on the outside of a large floury endosperm, and is enveloped by the single large cotyledon,

I.

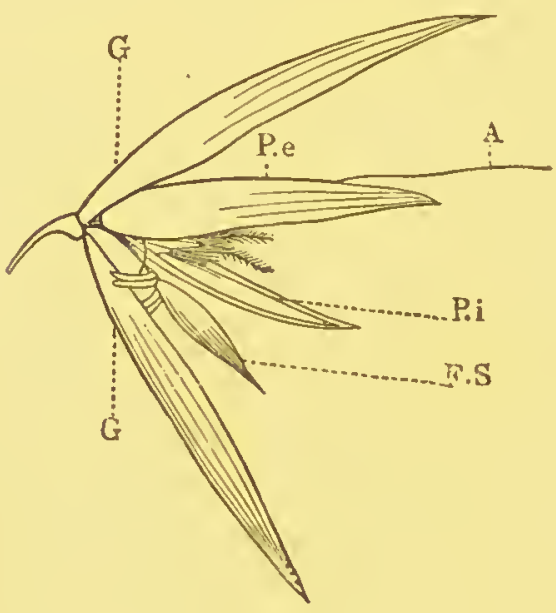

III.

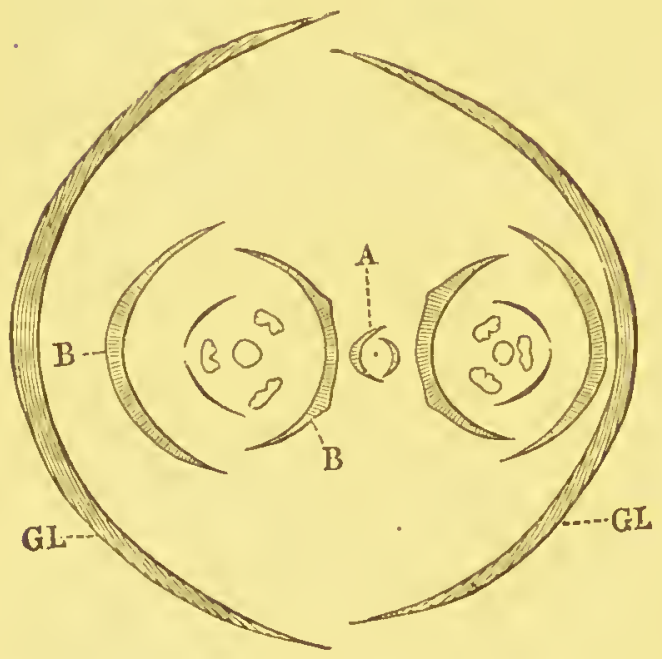

II.

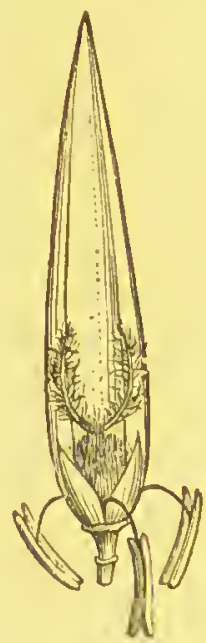

FiG. 46r.-I. Expanded spikelet of the oat, with a fertile and a barren flower Fs; G glumes: l'e outer pale, with awn A; $P i$ inner pale; within are the feathery stigmas; II. fertile flower with the outer pale removed (all much magnified): III. diagram of a spikelet with two fertile and one barren flower $A ; B$ palex : $G L$ glumes; IV. longitudmal section of a seed; A endostrerm; $c$ the single cotyledon (scutellum); G plumule ; $\mathrm{R}$ radicle; $\mathrm{T}$ testa; o hairs (greatly maguified). 
which is called the scutellum (Fig. 46I, IV.); [though the scutellum is by some considered an outgrowth of the axis]. The Grasses constitute one of the largest orders in the vegetable lingdom, and are universally distributed, but form meadows only in the temperate zone. Many genera are cultivated for the sake of the nutriment contained in the seed, and form our cereal crops. Among these are wheat Triticum vulgare, spelt $T$. spelta, rye Secale cereale, barley Hordeum vulgare, hexastichon, and other species, various species of oat Avena, millet Panicum miliaceum, maize or Indian corn Zea Mais,

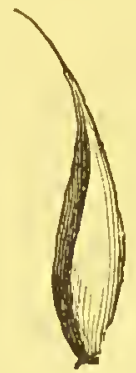

Fig. 462.- Seed of Dactylis glomerata, with terminal awis.

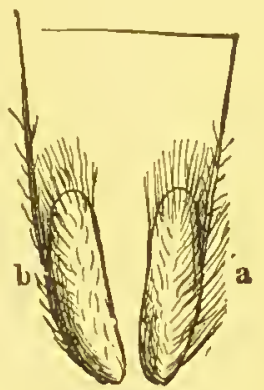

FIG. 463.-Outer palea of the two barren flowers of a spikelet of Anthoxanthum; $b$ with a straight, $a$ with a bent dorsal awn. rice Oryza sativa, and Egyptian millet Sorg/hum vulgare. The seeds of many species, especially wheat, contain gluten (protein) in addition to starch. Sugar occurs in the stem of most Grasses, but chiefly in the sugar-cane, Saccharm oficinarum. Among officinal products are the rhizome of the couch-grass, Triticum repens. Among the more serviceable meadow-grasses are Anthoxanthum odoratum, Alopecurus pratensis, Phileum pratense, Agrostis vulgaris, Holcus lanatus, Avena flavescens and pubescens, Briza media, Poa anmua, trivialis, and pratensis, Dactylis glomerata, Cynosumes cristatus, Festuca ovina, pratensis, mubra, and elatior, Bromus mollis, and Lolium perenne. The largest species is the East Indian bamboo, Bambusa armalinacea (Fig. 464), 30 to 60 feet high. [Important genera:-Andropogon, Panicum, Digitaria, Setaria, Zizania, Oryza, Arthoxanthum, Phalaris, Zea, Coix, Phleum, Alopecurns, Agrostis, Milium, Macrochloa, Stipa, Calamagostis, Arundo, Plragmites, Ammophila, Cynodon, Spartina, Aira, Arrhenatherum, Avena, Holcus, Poa, Glyceria, Briza, Melica, Molinia, Dactylis, Cymosurus, Festuca, Bromus, Bambusa, Lolium, Triticum, Elymus, Nardus, Hordeum, Secale, Sorghum, Saccharum.]

Order 2. CYPERACE E. Perianth absent or consisting of bristles, rarely scales, or of a sheathing bract; anthers basifixed; fruit compressed or trigonous; embryo at the base of endosperm; stem usually solid and triangular; leaf-sheaths entire. Perennial plants of grass-like habit, often with creeping underground tuberous rhizomes (Fig. 465). The aerial portion of the stem is, with the exception of the inflorescence, unbranched, unseptated, and usually triangular; the leaves are all radical, 


\section{Structural and Pliysiological Botany.}

with a sheathing but not split base, and no ligule; the lamina is parallelveined, and often three-edged. The flowers are arranged in spikes,

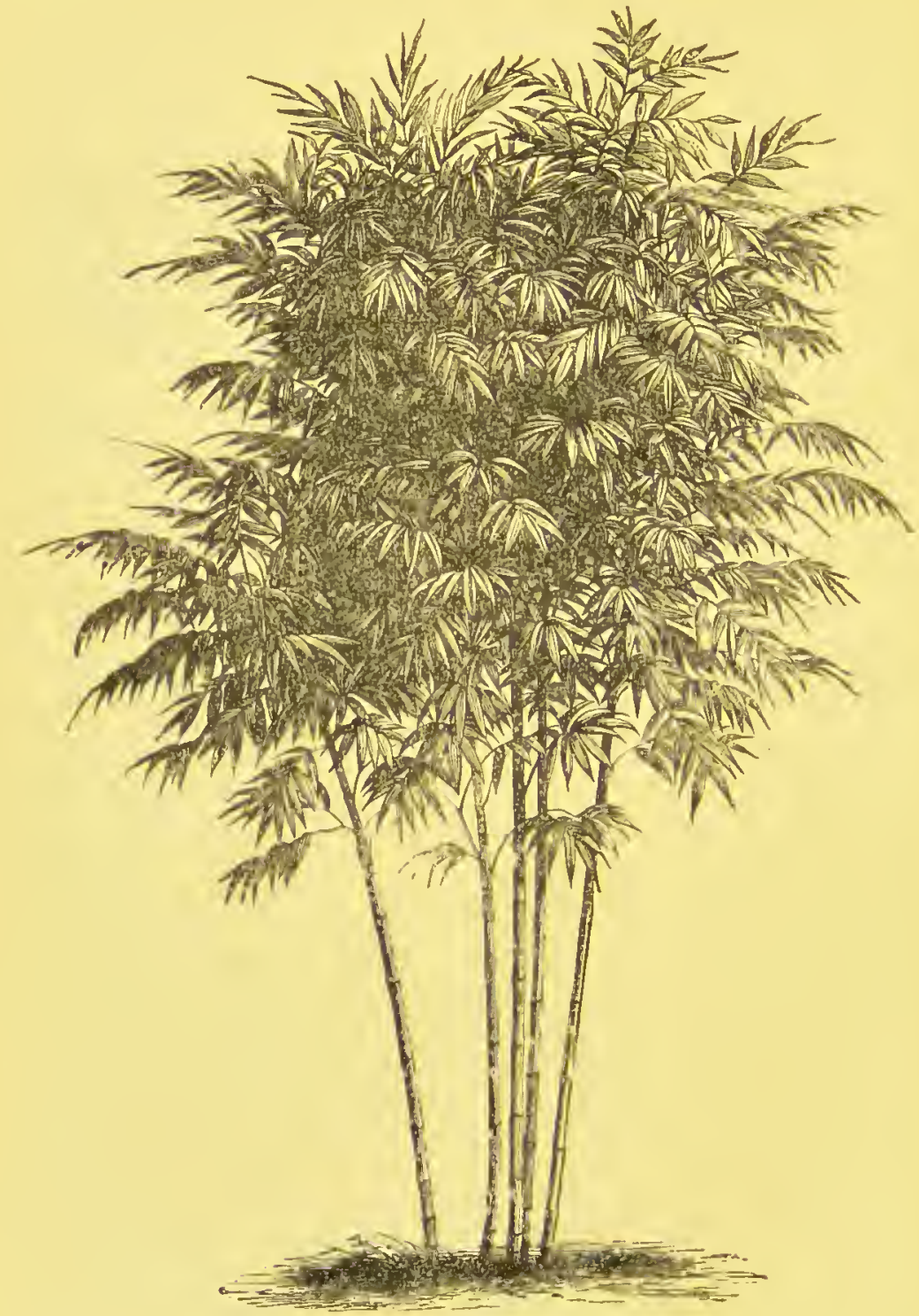

FIG. 464.-Bambusa Thotarsit, the bamboo (greatly reduced).

panicles, capitula, or cymes, ancl are either hermaphrodite or unisexual, and in the latter case usually, as in Carex, the male and female flowers 
are placed in different spikes on the same stem. Each flower stands in the axil of a bract, which is called a glume or pale, two of these
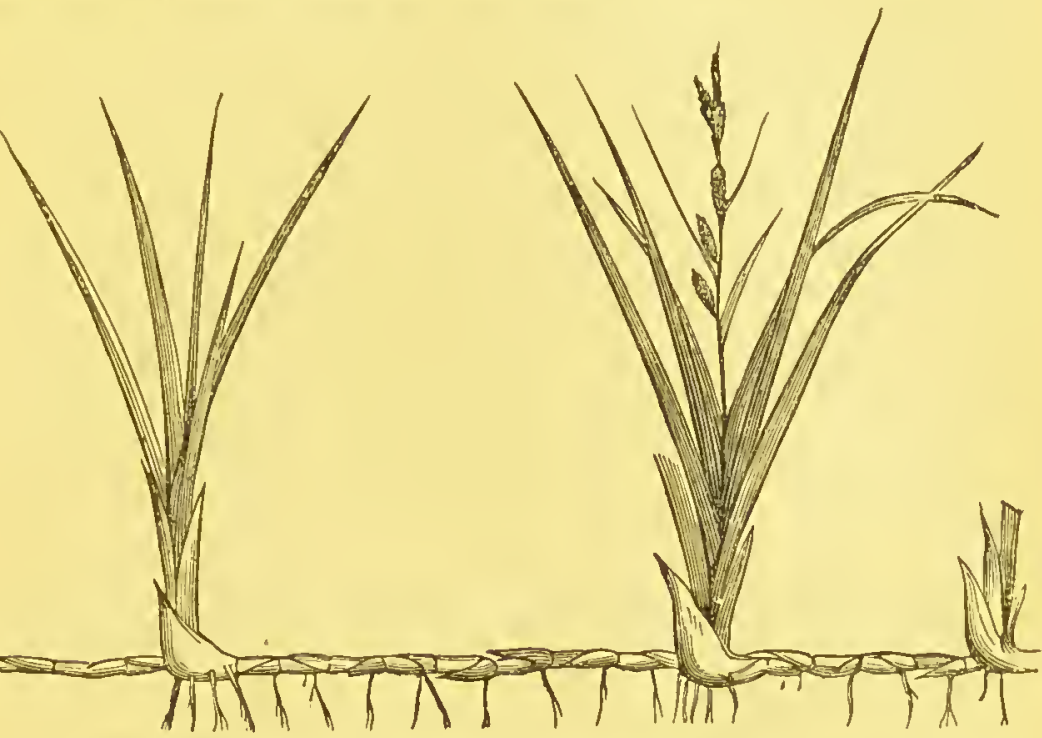

FIG. 465.--Creeping rhizome of Carex (greatly reduced).

pales usually occurring in each flower; and then the inner one is either adherent to the rachis, or, as in Carex, is transformed into a sheathing bag or utricle enclosing the flower. The genera with hermaphrodite flowers are either entirely destitute of a perianth, as Cyperus (Fig. 466) and Cladium, or it is composed of bristles, either few in number, as in Scirpus and Rhynchospora, or in large numbers, and in that case forming a tuft of hairs closely resembling cotton-wool springing from the inflorescence, as in the cottongrass, Eriophomen. In Carex the male flower consists of three starnens, the female flower of a tubular envelope, the utricle, surrounding the fiee ovary, which is generally unilocular and one-seeded, but with three stigmas (Fig. 467). The fruit is a caryopsis; the small embryo is surrounded

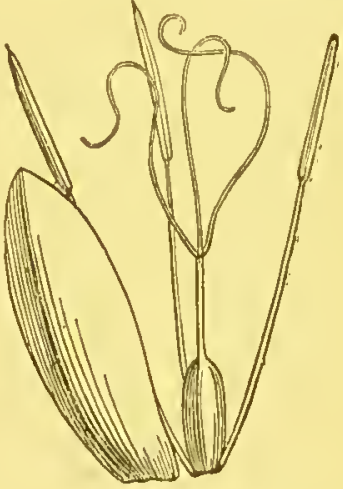

FIg. 460.-Flower of Cyperus longus with the parts separated (magnilied). by the floury endosperm. The rhizome of many Cyperacee is rich in starch and gelatine; and that of Cyperus esculentus is used as an article 
of food in the South of Europe; several species of Carex are offcinal. Papyrus antiquorum, the papyrus of Egypt and Sicily, was the first material usedi as paper. [Principal genera :-Papyrus, Cyperus, Eleocharis, Eriophorum, Scirpus, Isolepis, Schanus, Cladium, Rhynchospora, Carex.]

I.

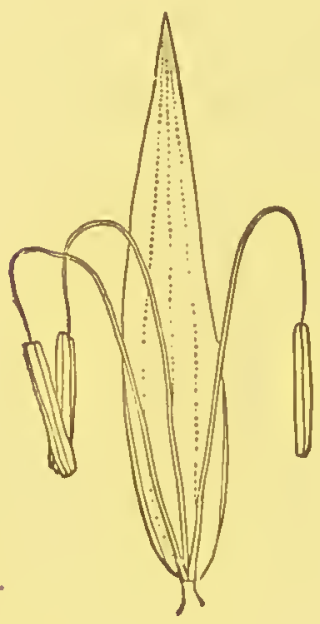

II.

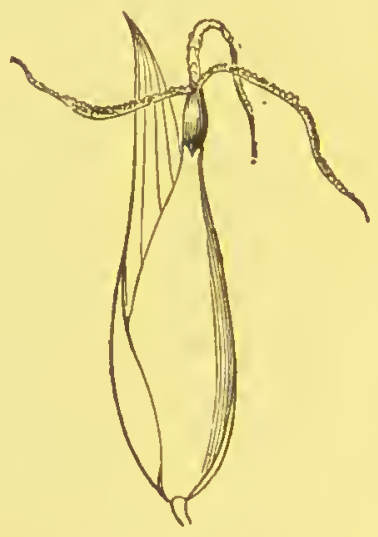

Fig. 467,--I. Male flower, II. female flower of Carex (magnified).

Division il. Flowers petaloid. Ovary inferior (with a few exceptions). Perianth usually distinct, in two rows, and colonred.

[Cohort II. Amomales. Albumen (perisperm) floury; embryo distmct; flower usually hermaphrodite and very irregular; perianth of five or six segments; stamens six, one or five with anthers, the rest petaloid, or all with anthers in Bromeliacex; ovary usually trilocular; fruit a berry or capsule. Tropical plants with large stalked leaves with broad lamina, the lateral veins at right angles to the mid-rib. The cohort comprises the orders Cannacee (Canna, Maranta); Zingiberacea (Zingiber, A momum, Alpinia); Musacea (Musa, Strelitzia); Bromeliacea (Bromelia, Tillandsia).

Cohort III. ORCHIDALES. Endosperm absent or cellular; embryo very obscure; flower hermaphrodite and very irregular; perianth of six, rarely three, segments; stamens one, two, or three, confluent with the style (gynandrous); fruit a capsule.

Order I. ORCHIDEA. Stamens one or two, confluent with the style and stigma; ovary unilocular, rarely trilocular; seeds very 


\section{Special Morphology and Classification.}

minute.] Our native orchids have a tuberous root (Figs. I I9, I20, p. 8I), and an annual herbaceous stem. The tropical species, on the contrary, have often a perennial, and some of them a climbing stem, or peculiar aërial pseudo-bulbs. The amplcxicaul or sheathing leaves are always entire, usually lanceolate, fleshy or succulent, rarely scale. like. The flowers are rarely solitary, usually in spikes, racemes, or panicles; and the superior perianth consists of two whorls, each of three leaves. Of these the inner whorl is always irregular, and often has a spurred lip or labelium, the remaining five leaves of the pcrianth forming together the galea or helmet. The stamens are united with the style into a fleshy column or gvnostegizm, upon which the anthers are so placed as to stand above the stigma, which is but little developed, and consists usually of a large viscid surface. Of the six stamens which are probably originally present, only one, less often two, attain perfect development. When only one is thus developed, it is always opposite the labellum; but when two, then one is on each side of the gynostegium. Only a few Orchids have the pollen-grains perfectly distinct; usually they are united together in fours, and these again into granular masses ; or the grains are combined by a viscid fluid into a club-shaped mass or pollinium within each anther-lobe (Fig. 468, v.). The two pollinia terminate at their lower end in a pedicel consisting of the dried-upviscid substance, connected together by a viscid gland or rostellum as in the bee-orchis, or distinct as in Orchis Morio. Sometimes the rostellum is concealed in a fold of the stigma. The fruit is a capsule, usually dehiscing longitudinally. The numerous very small exalbuminous seeds are usually covered with a reticulated testa, and do not contain any trace of a cotyledon. In the tubers are mucilage and starch; Orchis Morio, mascula, militaris, and other species, yield salep. The fruits of some species are rich in aromatic substances; the officinal vanilla is obtained from Vanilla aromatica, planifolia, and perhaps some other species from tropical America. [Principal genera :-Dendrobizm, Masdevallia, Malaxis, Bolbophyllum, Cattleya, Epidendrum, Odontoglossum, Maxillaria, Vanda, Saccolabium, Stanhopea, Oncidium, Lycaste, Angracum, Catasetum, Orchis, Serapias, Aceras, Satyrium, Ophrys, Platanthera, Gymnadenia, Habenaria, Limodonum, Corysanthes. Vanilla, Listerd, Neottia, Epipactis, Spiranthes, Cypripedium.]

[Cohort IV. NARCISSAlEs. Flowers hermaphrodite, regular or irregular; perianth usually petaloid; stamens three or six, inserted on the perianth-tube : ovary trilocular; seeds with copious fleshy or horny endosperm, and a distinct embryo ; leaves parallel-veined. Principal orders:-Iridere (Gladiolus, Iris, Crocus, Tigridia); Amaryllidec ( $G a$ lanthus, Narcissus, Crinum, Pancratium, Amaryllis, Leucojum, Agave). 


\section{Special Morphology and Clissification.}

Cohort V. Dioscorales. Flowers diøecious, regular; perianth herba. ceous; stamens six, inserted at the base of the perianth-segments; ovary trilocular; fruit a berry or capsule; seeds with copious fleshy endosperm, and a distinct included embryo. Climbing herbs or small shrubs, with netted-veined leaves. Order Dioscoreacea (Dioscorea, Tamus, Testudinaria).

\section{Division III. Flowers petaloid. Ovary superior.}

Cohort VI. Potamales. Ovary apocarpous (rarely reduced to one carpel); flowers hermaphrodite or unisexual ; perianth of three, four, or six segments, or absent; stamens one to six ; seeds exalbuminous ; embryo conspicuous. Usually water-plants. Principal orders:Butomacee (Butomus); Alismacee (Alisma, Sagittaria); Potamea (Potamogeton); Naiadere (Zostera, Naias).

Cohort VII. Palmales. Ovary syncarpous (rarely apocarpous); flowers unisexual, arranged on a simple or branched spadix, enclosed in a spathe or not; perianth of distinct bi-seriate coriaceous segments, green, rarely coloured or absent; fruit a one- rarely two-seeded drupe or berry; seed albuminuus. Shrubs or trees with flabellate or pinnately divided, rarely simple leaves.

Order I. PaLme. Flowers usually diclinous on a branched spadix; perianth green ; stamens usually six, hypogynous or perigynous; ovary tri- rarely uni-locular, or of three separate carpels; styles short, free or connate; loculi with one, rarely two, ovules; seed large ; embryo minute, sunk in a pit of the fleshy or horny endosperm. Trees or shrubs.] Although the Palms appear to belong to the more highly developed Monocotyledons from their stately arborescent stems and their large leaves, the insignificance of their flowers reminds one of the lower families, and the habit of many species even of the Grasses; while the structure of the flower and inflorescence allies them to the Arales (Figs. $469,470,47 \mathrm{r}$ ). The stem is usually simple, rarely dichotomously branched, as in the doom-palm, generally erect, sometimes climbing, as in the rattan, and commonly bears a crown of leaves only at its summit. The leaves, often called fronds, are fan-shaped in the fan-palms, pinnate in the featherpalms, rarely undivided. The flowers are placed on a simple or branched rachis, which is surrounded in

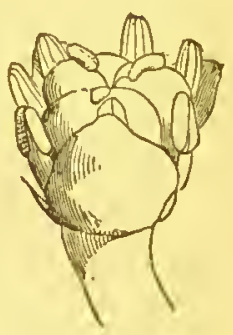

Fig. 469. - Flower of the European d warf - palm, Chamaerops hatmilis. vernation by a common envelope or spathe; they are originally perfect, but almost always become, in the course of development, diclinous or polygamous from the abortion of stamens or pistils. The six perianth- 
leaves are in two whorls. The stamens, three, six, or more in number, are adherent to the perianth-segments. The superior ovary is either uni-

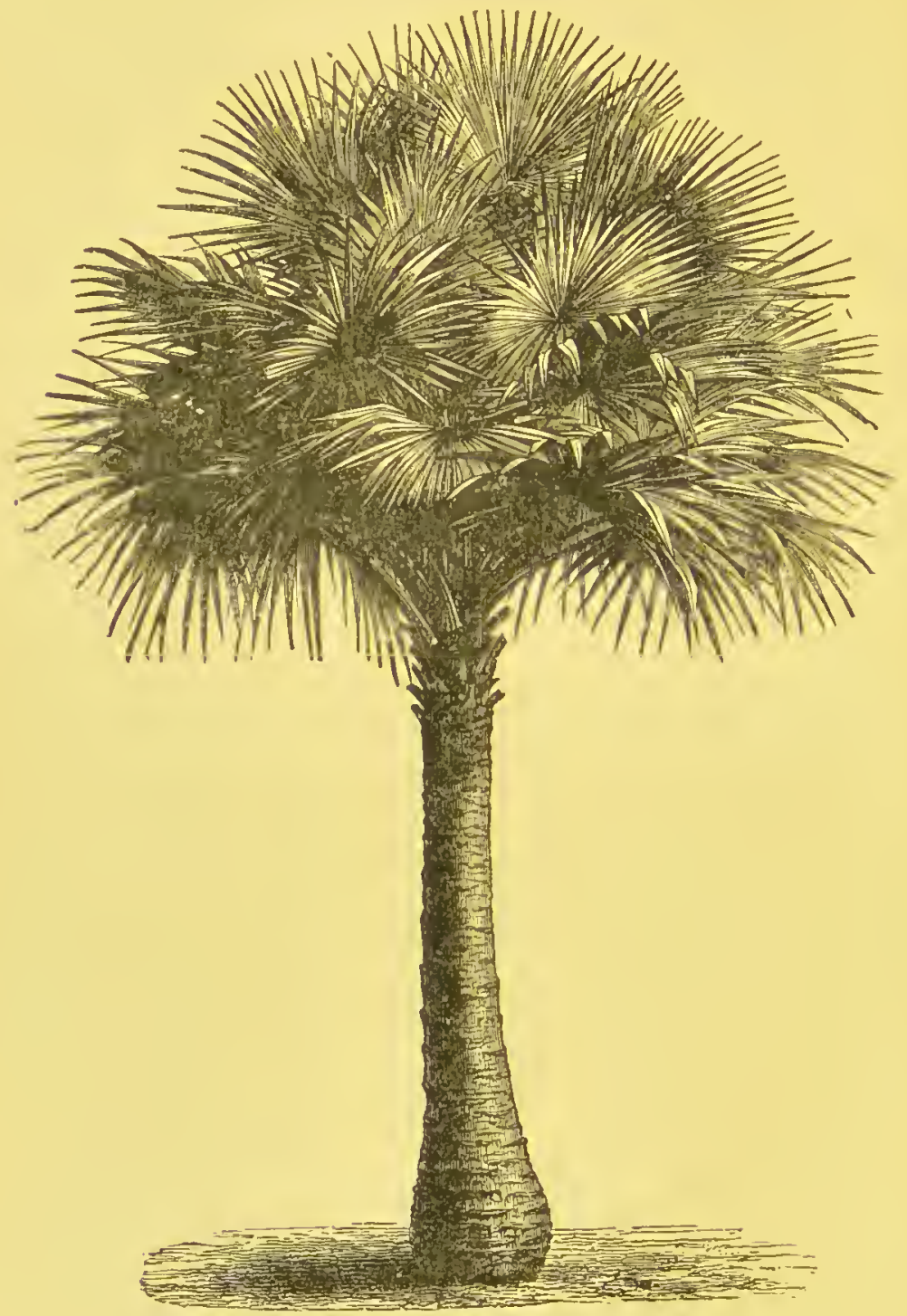

Fig. 470.-Liristonia australis, a fan-palm (greatly reduced).

locular, consisting of three united carpels, or trilocular and apocarpous. Each of the three loculi contains a single ovule, which is generally ercct 
and orthotropous; but two of the ovtles ustally clisappear before maturing into seeds. The fruit is a one- or three-seedecl drupe or berry, the

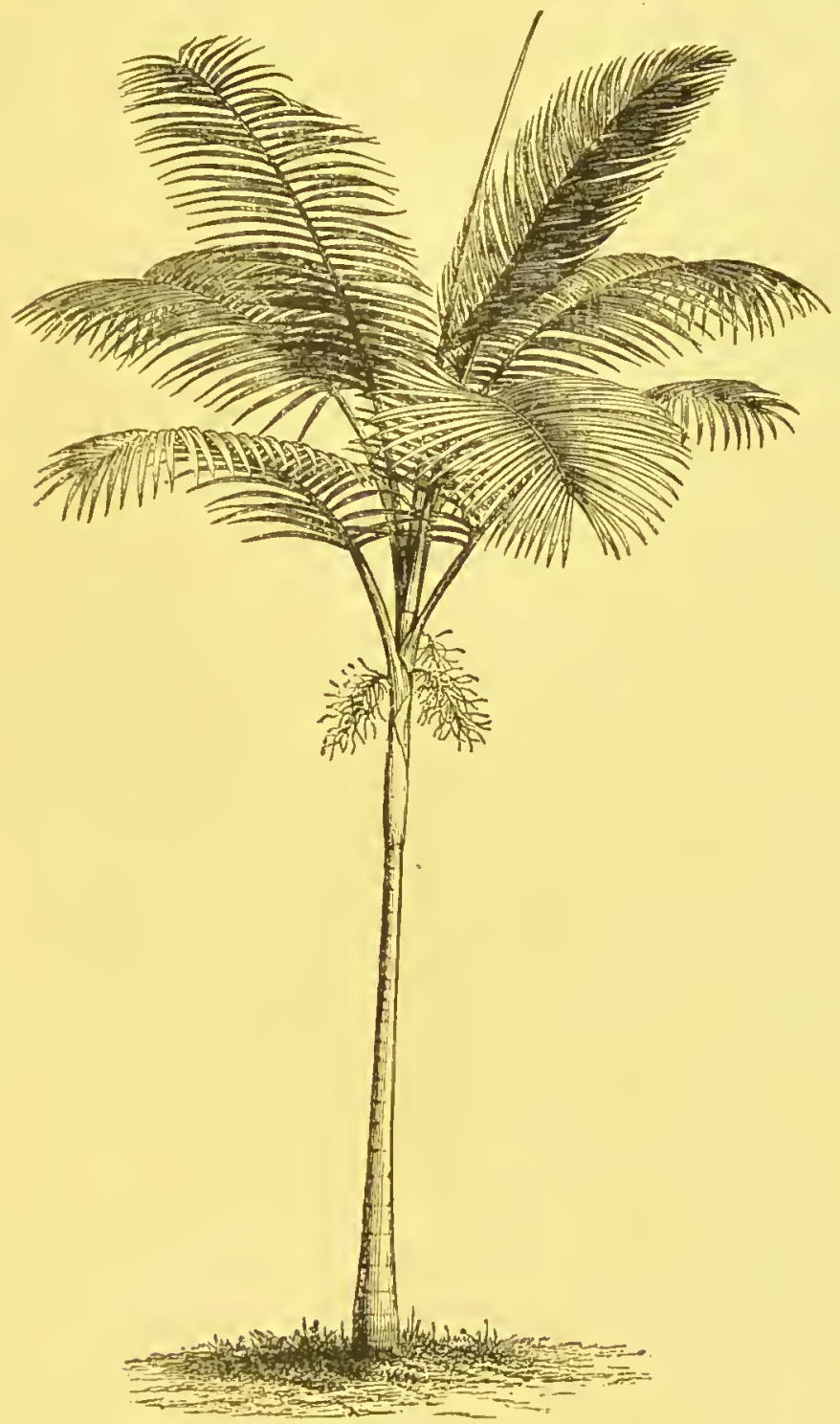

Fig. 471.-Secforthia elegans, a feather-palm (greatly reduced).

seed consisting of a minute embryo buried in a very large oily or horny endosperm, which is at first milky, afterwards solid, and often 
hollow. The embryo lies in a hollow in the periphery of the endosperm (see Fig. 305, p. 148), and is covered by a thin layer of the latter like a lid. There are about three hundred species of palms, nearly all tropical. The only native European species is the dwarfpalm, Chamarops humilis (Fig. 469), which is found as far as $45^{\circ}$ north latitude. The uses of palms are innumerable. The inhabitants of entire territories live on the fruits of some linds, as the date-palm, Phanix dactylifera, in India, Arabia, Persia, and Egypt, and the cocoanut palm, Cocos micifera, in all tropical countries. The stems of some species, as Sagus Rumphii, Corypha umbraculifera, and Borassus flabelliformis, contain a starch known in commerce as sago. The leafbuds of Areca oleracea, Cocos nucifera, Sic., are enten as vegetables; and the sap which flows from the punctured leaf-buds and stems is fermented, and yields palm-wine. Arenga saccharifera from the Moluccas, and Cocos nucifera, yield palm-sugar; Copernica cerifera palm-wax ; and the oily endosperm of many palm-seeds, especially of the West African Elacis grineensis, is used in the production of palmoil. The endosperm of species of Phytelephas is known in commerce under the name 'vegetable ivory.' Palm-bast is obtained from many kinds; that of the leaf-sheath of Attalea funifera of Brazil bears the special name 'piassava.' The young pinnate leaves of many palms are manufactured into textile fabrics, hats (Carludovica palmata furnishes the Panama-hats), and mats; and the stems are made into canes. [Principal genera:-Chamadorea, Areca, Arenga, Oreodoxa, Ceroxylon, Caryota, Calamus, Sagzis, Borassus, Copernicia, Rhapis, Chamarops, Sabal, Phanix, Cocos, Elacis, Fubra, Livistonia.

Cohort VIII. Arales. Ovary syncarpous ; flowers hermaphrodite or unisexual, arranged in a spadix or spike, with or without a spathe, or sunk in pits of a minute scale-like frond ; perianth of distinct pieces, white or green, or of minute scales, or absent; fruit a drupe or berry with one, few, or many small albuminous seeds. Herbs, often very large, rarely trees; leaves simple or pinnatifid, very rarely pinnately divided, sometimes netted-veined.

Order 1. AROIDEA. Flowers hermaphrodite or unisexual, in cylindric or oblong spadices, enclosed in a green, white, or coloured spathe ; perianth absent, or of from four to eight scales ; stamens few or many, anthers sessile or on very short filaments, extrorse or opening by pores ; ovaries aggregated in from one to four loculi; styles distinct or absent; ovules one or more, basal or parietal ; berry one- or more-seeded; seeds minute; endosperm fleshy or floury or absent. Herbs, stemless or with erect or scandent stems; leaves usually large, simple or pinnatifid, 
usually net-veined (Fig. 194, p. I06). Principal genera:-Acorzs, Orontium, Anthurizm, Pothos, Calla, Richardia, Colocasia, Caladium, Arum.

To this cohort belong also Pandanacee (Pandanus), and several other less important orders.

Cohort IX. LrLIales. Ovary syncarpous; flowers hermaphrodite, very rarely unisexual, solitary or in spikes, racemes, or panicles, rarely capitate; perianth of six (very rarely four) nearly similar pieces, or gamopetalous and six-lobed, regular (rarely irregular), usually all coloured and petaloid (sometimes coriaceous or subglumaceous); embryo immersed in a copious endosperm (not external to nor in a lateral cavity).

Order I. Lillace.e. Stamens six, hypogynous or perigynous; anthers usually introrse; ovary tri-locular, ovules usually many in each loculus ; style entire; fruit a capsule; seed glabrous, with a membranous or crustaceous testa ; endosperm fleshy. Stemless herbs or shrubs with a simple or branched trunk; root fascicled or stem bulbous. Principal genera:-Tuulipa, Yucca, Fritillaria, Lilium, Gagea, Agapanthus, Phormium, Hemerocallis, Aloe, Scilla, Allium, Hyacinthus, Ornithogalum, Funkia, Asphodelus.] Among useful and medicinal species are the Aloë socotrina, the Scilla or squill, the various species of Allium which yield the onion, leek, garlick, \&c., the Asparagus, [Dracana or dragon's blood, and Phormium tenax or New Zealand flax.

[Mr. Bentham, in a paper read before the Linnean Society, and only recently published, arranges the monocotyledonous orders in four series, viz. :-I. EPIGYNж. Flowers with a double, usually petaloid, perianth ; ovary usually inferior, synctrpous. 2. CORONARIEE. Flowers with a double, usually petaloid, perianth; ovary superior, almost always syncarpous. 3. NUDIFLORE. Flowers usually achlamydeous, or with a dry scarious perianth; ovary mostly apocarpous. 4. GLUMales. Perianth replaced by membranous scales (pales or lodicules); ovary always uniovular. The orders are arranged thus in the four series :-

\section{EPIGYNe.}

Hydrocharide:c.

Scitamineæ (including Musaceæ, Orchidex.

Burmanniacere.

Iridex.

Amaryllideæ (including IræmoTaccacer.

Dioscoridex.

Bromeliacex (?).

\section{Coronariere.}

Roxburghiacex.

Liliaceæ (including Smilaceæ, Melanthaceæ, \&c.).

Pontederiacex.

Philydracex.

Xyridex.

Commelynaceæ.

Juncex.

Palmæ. 
III. NUDIFLORE.

Pandanex.

Aroidex.

Typhacex.

Lemnaceæ.

Naiades (including Juncaginere).

Alismacex (?).
IV. Glumales:

Eriocaulere.

Centrolepideæ.

Restiacex.

Cyperaceæ.

Gramineæ.

ED.]

\section{Class XIV. Dicotyledones.}

Dicotyledons are distinguished from Monocotyledons by the embryo having two cotyledons, by the structure of the stem, by the prevalent number of parts in the floral whorls being 4 or 5 , and by the leaves being usually net-veined.

The stem consists, as a rule, of four parts, strongly differentiated from one another,-Epidermis, Cortex, Fibrovascular Bundles, and Pith.

A well-developed epidermis provided with stomata and often with subsidiary organs, entirely covers the younger parts. Earlier or later, often even in the first year, it is thrown off by the formation beneath it of a corky tissue, that part of the plant then losing its green colour.

The cortical tissue is very commonly separated into two portions, an outer and an inner cortex. At an early period in its development bast-fibres, bast-vessels, and laticiferous vessels are gencrally distributed through it, in addition to the parenchymatous tissue which is always present; the vessels containing, according to circumstances, chlorophyll, starch, crystals, tannin, latex, oil, resin, \&c. In the course of its growth the cortex undergoes peculiar changes, with which we are not yet thoroughly acquainted, especially in the case of perennial plants. It is at first greatly stretched from within by the tissue formed beneath it, and finally split. The crevices and wounds thus formed are partly filled up by the new cells of the phlö̈m-portion of the vascular bundles and those of the intermediate tissue, partly 
covered up by the cork-tissue. The cortex very commonly exhibits also crevices and furrows on the outside, and is often partially thrown off in the form of bark. The portions of the cortex which are fresh formed every year are collectively distinguished as secondary cortex, in contradistinction to the layer of primary cortex already formed in the growing point. [The inner fibrous portion of the bark is known as the litier, and this is often of great tenacity, as in the case of the 'bast' of the lime-tree.

In annual stems, and in perennial stems during the first year, the arrangement of the fibrovascular bundles in Dicotyledons resembles that in Monocotyledons, standing isolated in the fundamental tissue (Fig. 472 A). But in later stages both their structure and arrarigement are, with the exception of a few abnormal cases, strikingly different (see Fig. 95, II., p. 68, also Fig. 472 B). They are open and collateral. The inner portion of each bundle, or that nearest the pith, is always more or less strongly lignified, and forms its xylem-portion, the outer part, or that facing the cortex, is composed of thin-walled cells and constitutes the phloëm or bast-portion, while between the two is always found, while the bundle is still in a growing condition, a portion of intermediate or fundamental tissue, the intrafascicular cambium, from which fresh xylem is continually being formed on one side, fresh phloëm on the other side. The phloëm does not form a cylinder surrounding the xylem, as in Vascular Cryptogams, but the xylem and phloëm lie parallel side by side. From the main fibrovascular system of the stem branches of the bundles, the leaf-traces, pass into the leaves, and there ramify into the reticulated fibrovascular system of the leaf; but as these do not always bend into the leaf immediately on branching off, but remain as a separate bundle running through a considerable length of the stem, they cause the vascular-bundle-system often to appear very complicated. In addition to the primary bundles, and between them, secondary fibrovascular bundles are very often 


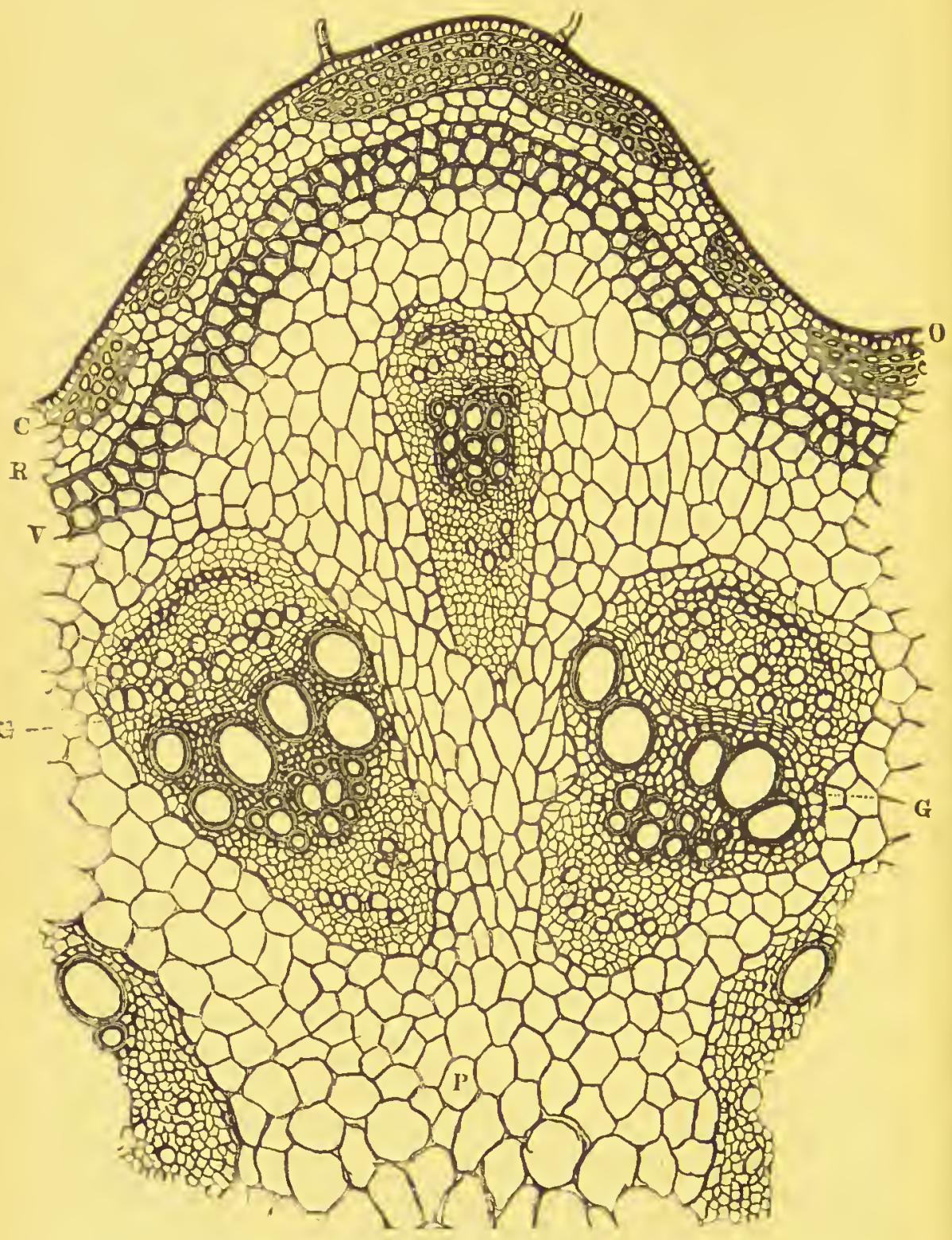

FIG. 472. - A. Part of a transverse section through the stem of Bryoniz alba: o epidermis: C outer cortex (collenchyma); $\mathrm{R}$ inner cortex; $\mathrm{v}$ ring of lignified cells : P parenchyma of the stem; $G$ vascular bundle $(x 80)$. 


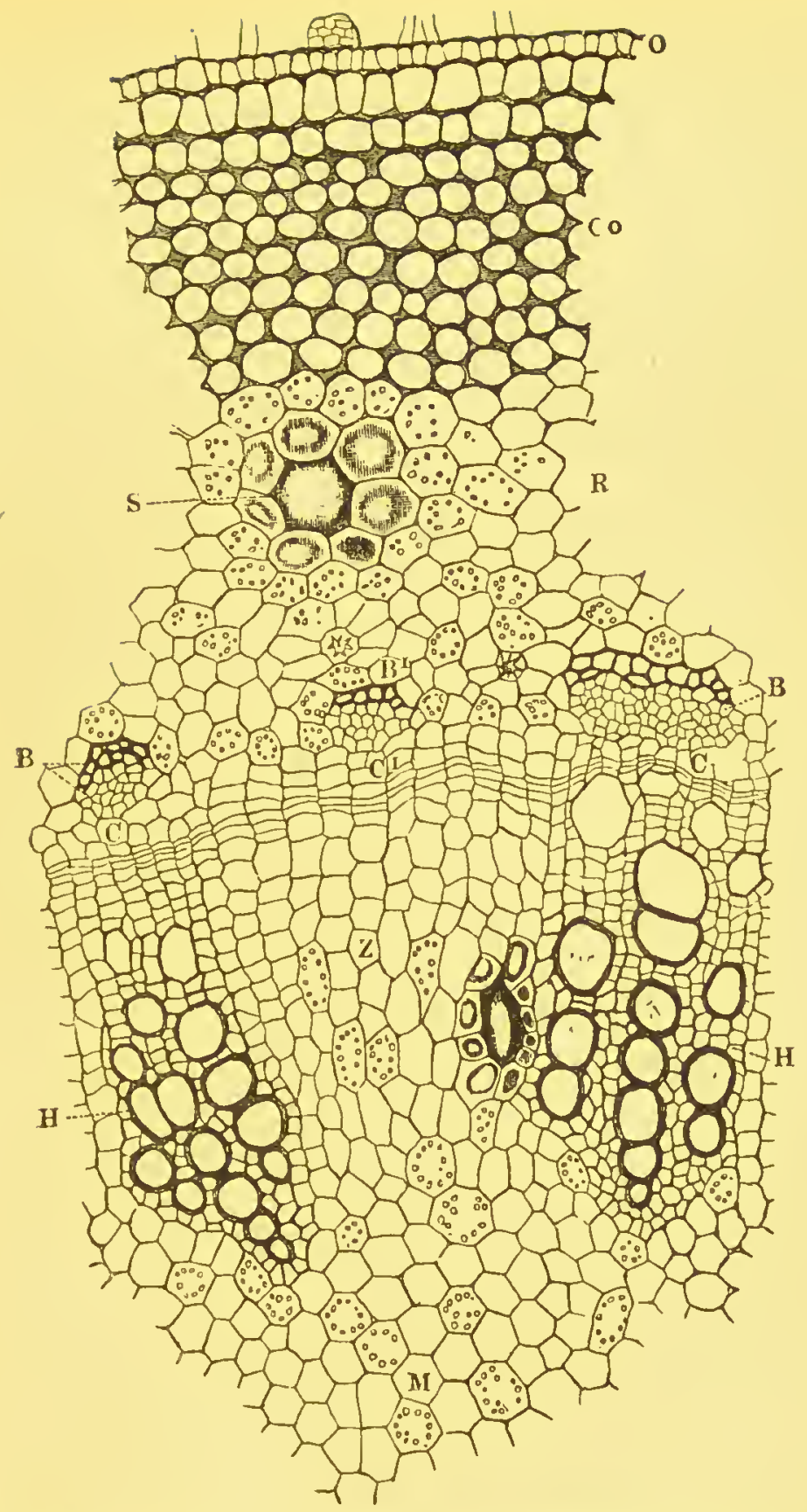

LiG. 472.-B. Transverse section through a young internode of Bahmeria argentea ; o epidermis: co outer cortex (collenchyma); $\mathbf{R}$ inner cortex; $\mathbf{s}$ intercellular space: $c$ cambium of the vascular bundle ; $c^{f}$ cambium of the thickening-ring : 13 phloëm-portion; $H$ xylem-portion of the vascular bundle; $\mathrm{s}^{\prime}$ the phloëm formed from the intermediate cambium ; $z$ medullary ray; 1 pith ( $x$ 120). 
formed in the stem of Dicotyledons. Since the whole growth in diameter of the stem and branches is due to the activity of the annual cambium-ring formed in the spring of each year outside the latest ring of wood, and its subsequent development during the same year into an additional ring of wood, Dicotyledons are known as Exogens in contrast to Endogens. The stem of Exogens is always protected externally by a well-developed bark, among the constituents of which is usually the tissue known as 'vasa propria' consisting of elongated cells with thin walls.]

In Fig. 473 we have a diagrammatic representation, after Nägeli, of the course of the vascular bundle through twenty-two internodes of

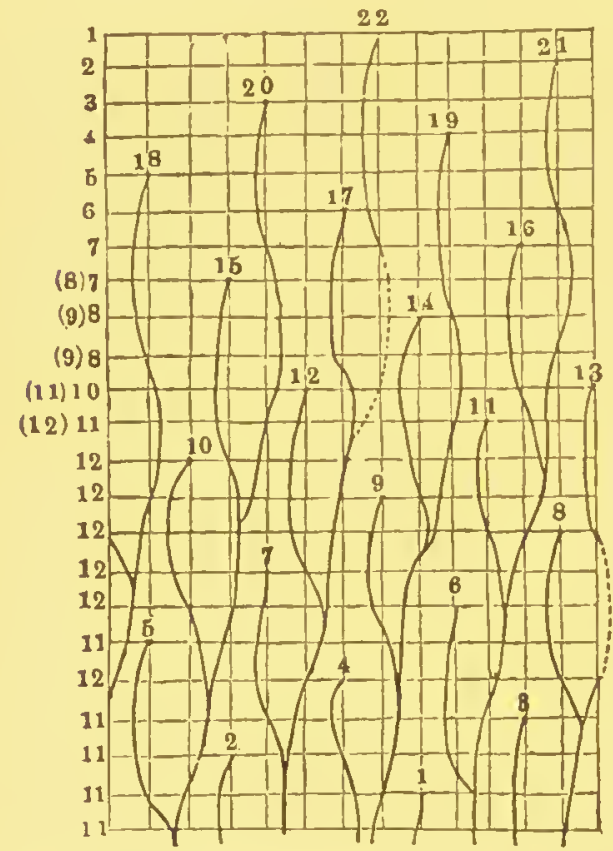

FIG. 473.-Diagrammatic representation of the course of the vascular bundles in Iberis a mara (after Nägeli). the apex of the stem of Iberis amara. Each of the leaves has a vascular bundle, the leaf - traces of which are drawn as far as the points of attachment of the leaves. The internodes are separated by the horizontal lines. Each leaf-trace appears, therefore, when seen in transverse section, to run as a separate bundle through ten or eleven internodes, and invariably unites with the bundle from the fifth leaf below; thus the fifth with the tenth, the tenth with the fifteenth, \&c. If transverse sections are made through the internodes, the number of vascular bundles which will be found exposed on each section is indicated by the number given on the left-hand side of the figure.

In the leaf-trace of the twenty-second leaf are found fully developed vessels, the probable subsequent course of which is indicated by the dotted line.

The course of the vascular bundles is not, however, always 


\section{Special Morphology and Classification.}

so simple as in these cases; for although the bundles of most Dicotyledons run in a vertical direction, they nevertheless occasionally unite, and form combinations which are often rendered yet more complicated by new separations. In the Labiatæ, Umbelliferæ, Balsamineæ, and many other herbaceous plants with jointed stems, the vascular bundles are arranged in a circle, and all run in a parallel direction through the internode. In the node, however, they branch, and are here united with the vascular bundles of the leaves, as we have seen to be the case with Grasses (see p. 34r).

The vascular bundles always become closer as they descend in the stem, the separate bundles approaching nearer and nearer to one another through increase in their thickness, often coalescing into a ring which is interrupted only by narrow medullary rays (Fig. 95, 11., p. 68).

It will be seen from this description that there is no difference between the mode of growth of annual and perennial Dicotyledons, when young plants of the latter are examined, or shoots still in their first year of growth. After this, growth ceases in annual plants; while in those that are perennial further changes, which will be afterwards referred to, take place in the spring, when vegetation wakes from its winterrest, and the activity of the cambium recommences.

With reference to the composition of the vascular bundles, a distinction must be drawn between herbaceous and woody plants. In herbaceous plants they are separated by layers of an intermediate tissue of more or less considerable thickness, so that they either lie isolated in the tissue of the stem, or form a ring which is only interrupted by narrower intervals of intermediate tissue (Fig. 47.2, A). This intermediate tissue, a part of the fundamental tissue, is often composed of cells which are narrower and otherwise of different form from those of the pith and cortex, and it then constitutes the medullary rays. The vascular bundles grow for some time by means of the cambium which lies between their xylem- and phloëm-portion. The xylem- 
portion consists of elongated wood-cells, which sometimes resemble an elongated parenchymatous, sometimes a fusiform prosenchymatous tissue, and in addition of vessels and a thin-walled parenchyma that is but little or not at all lignified; while the phloëm-portion contains on its outer side a bundle of bast-fibres. In contact with it on the inside are thin-walled sieve-tubes and elongated parenchymatous cells. In many plants phloëm-cells are also formed next the pith on the axial side of the vascular bundle; in others laticiferous vessels also occur, usually in the phloëm-portion of the vascular bundle, but also in the cortex. [The portion of the xylem of the innermost bundles of the stem frequently forms a closed ring completely enclosing the pith, and this is then known as the medullary sheath; it consists chiefly of spiral vessels.]

The vascular bundles of woody dicotyledonous plants have, at the end of their first year of growth, the structure already described, but are already distinguished by the regularity of their phloëm-bundles, as well as by possessing vessels dispersed through the xylem. The stems of many tropical trees in which the growth is never subject to intermission, as the cocoa- and coffee-bush, remain in this condition, and only gradually increase in diameter by the formation of portions of the vascular bundles exactly resembling those already in existence. But in those tropical trees and shrubs which cast their leaves periodically and have closed buds, like the bread-fruit tree, the activity of the thickening-ring is renewed afresh on the recurrence of the active period of vegetation, as in our deciduous trees; and fresh medullary rays and new xylem- and phloëm-portions of the vascular bundles are formed in exact continuation of the similar parts already in existence. This process is repeated every year, a new layer of cells being annually separated on each side of the thickening-ring, which may even be recognised at a later period as a sharply defined annual rins (Fig. 95, II. p..68). 


\section{Special Morplology and Classification.}

There may be several reasons for this sharp.definition of the separate annual rings. It is possible that the cells formed in the spring, those of the spring-wood, are larger than those of the autumn-wood (see Fig. 479, p. 373); or their walls may be thinner, or the cells otherwise of a different kind; and the abundance and size of the vessels in the springwood must also be taken into account. The structure of the root corresponds to that of the stem in the presence or absence of annual rings. The separate annual rings are not always of a uniform thickness, but are often more strongly developed on one side than on the other. From these facts it is possible to form an idea of the life of the tree during each year of its growth. Its age is estimated from the number of these rings; from their breadth it is known what years were favourable, and what unfavourable to its growth; and some knowlcdge can even be attained respecting the growth of the roots, since the growth of any side of the stem is known to correspond nearly to the development of the roots that branch out on that side.

Sometimes even in the earliest, but always in the later years, the vascular bundles become penetrated in a fanlike manner by new parenchymatous cells formed inside themand arranged in bands, the secondary medullary rays. Those cambiumcells which were at one time called cells of the medullary rays, always produce only the same kind of cells; so that the secondary medullary rays, when seen in transverse section, always reach to the thickening-ring; but they never get as far as the pith. The breadth of these rays varies in different plants ; in some species they are one cell, in others several cells wide; broad and narrow bands sometimes alternate with one another; but they never penetrate through the whole length of the plant, as can be easily seen on tangential sections (Fig. 474). Both the primary and secondary medullary rays are generally easily recognised by the naked eye, and form the pattern on the wood ordinarily known as the ' silver grain.' They consist of parenchymatous cells usually elongated in the radial direction (see Figs. 474, 475).

Both the xylem- and the phloëm-portion of the vascular bundles of the stem of Dicotyledons consist-with the exception of the fundamental tissue of the medullary rays-of elements which may be arranged into three 
groups :-prosenchyma, parenchyma, and vessels. The prosenchymatous cells of the xylem-which are also called

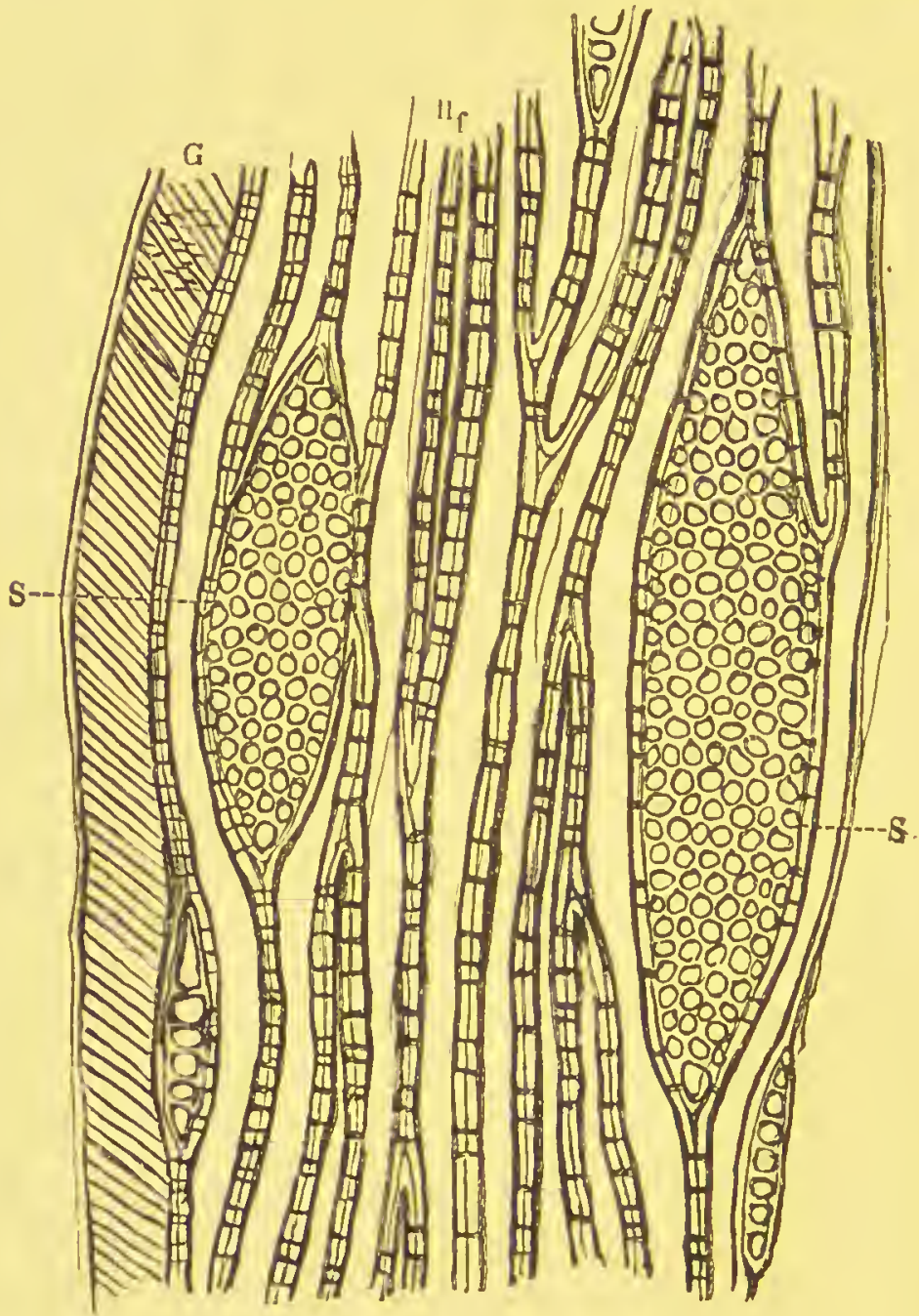

FrG. 474. -Tangential section through the wood of the maple; G vessels; H $f$ woodfibres; s 'silver-grain' ( $x$ 200).

zuood-cells, wood-fibres, simple bast-like wood-fibres, or libriform fibres-are always fusiform, comparatively strongly thickened and lignified, unbranched, and, as a rule, furnished 
with extremely small bordered pits (Fig. 14, p. I3). Even when the latter are larger, they differ in size and form from those of the vessels which occur along with them. The

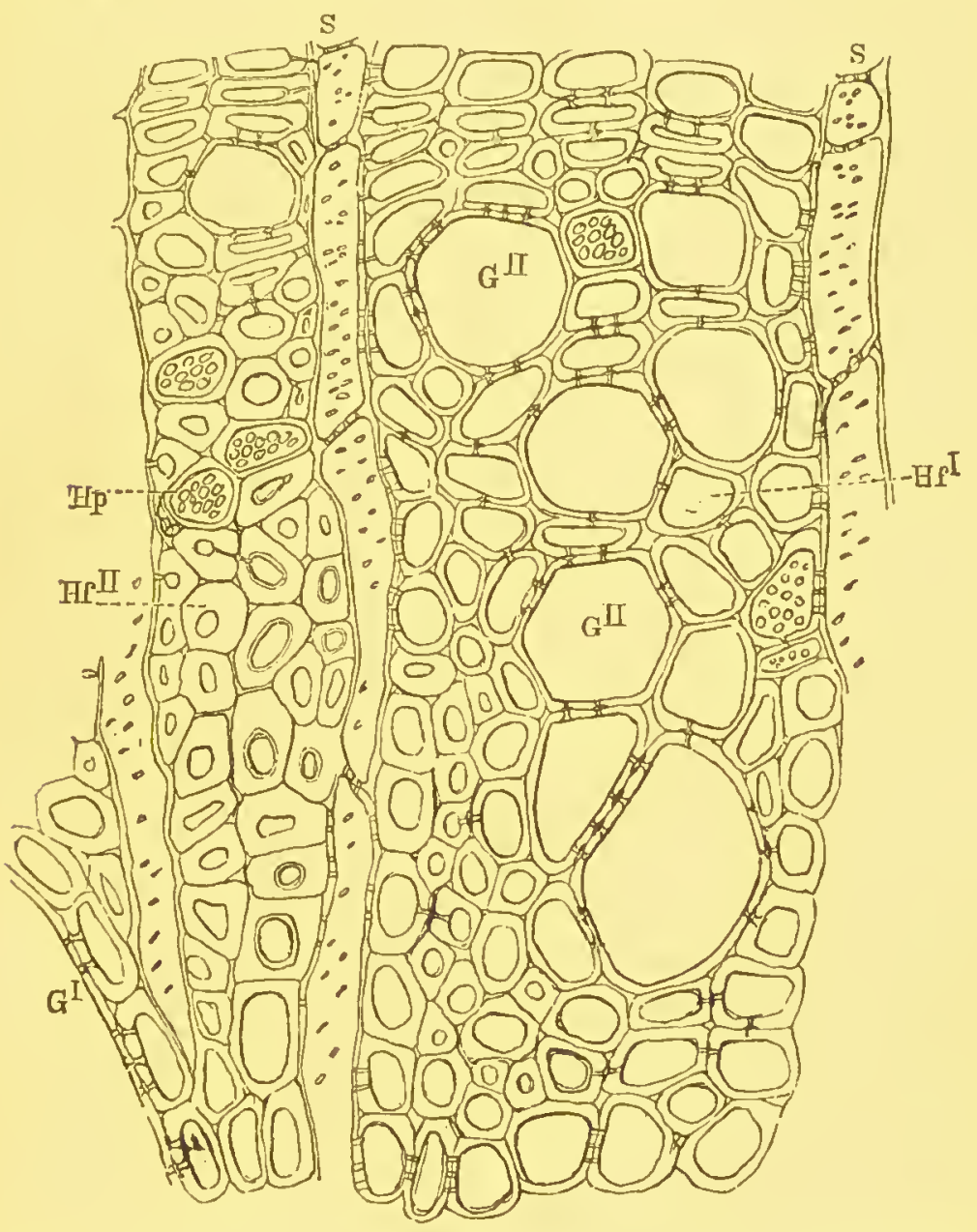

FIG. 475. - Transverse section through the wood of the oak; H $f^{\prime}$ thin-walled, "ff "strongly thickened wood-fibres; $H p$ parenchyma of the xylem; s fibres of the 'silver-grain': $G$ " small vessels ; adjoining $G$ ' is a very large vessel, the size of which is only slightly indicated by the curved border-line.

wood-cells of the inner spring-wood are, as a rule, much less strongly thickened than those of the outer autumn-rood (Fig. 479, p. 373). There is nowhere found in the wood-cells 
any strongly developed spiral thickening, nor usually even the spiral striation already mentioned (p. I6). In the winter, especially when vegetation is dormant, they usually contain starch. It is comparatively rare for the wood-cells to become septated, when their thickening-layers are nearly completely formed, by one, still more rare by several partition-walls, into daughter-cells, which are then enclosed by the thick-walled wood-cells, and are termed septated wood-cells. They rarely possess pits ; and, when present, these are cleftshaped, and placed obliquely in a spiral running to the left. In the winter they usually contain a small quantity of starch.

The parenchymatous cells of the xylem, which are scarcely ever wanting in woody Dicotyledons, are distinguished from the other elements of the vascular bundles by their walls being less strongly thickened, by their having pits which are always closed and never bordered, and by the absence of any spiral thickening. They may be formed in three different ways:-by direct growth from a cambium-cell, or as a daughter-cell either in a cambium- or in a young prosenchymatous cell. In the first case they are isolated; in the two latter cases they are still enclosed within the walls of their parent-cells. These cells also usually contain starch in winter.

The vessels of the xylem have usually bordered pits. In the early condition of the vascular bundles, annular, spiral, and reticulated vessels are found only near the pith, in the medullary shcath; the younger parts, on the contrary, contain nothing but pitted vessels. The partitionwalls of the separate vascular cells are either horizontal or oblique, and scalariform or penetrated by pits, i.e. by a round orifice. A scalariform perforation has at present only been observed in pitted and reticulated, but not in spiral or annular vessels. When the walls of the vessels are not spirally thickened, the pits are most numerous on the side where the vessel borders other vessels or thin-walled woodcells. At these spots the borders of the pits are also the 


\section{Spccial Morphology and Classification.}

largest, and the pits themselves always open; in other cases they are always closed. When the walls of the vessels are also thickened spirally, as is the case in the so-called tracheids (Fig. 35, p. 20), this thickening sometimes disappears at those parts of the vessels which adjoin the xylemparenchyma or medullary rays; but remains, the pits diminishing greatly in number or altogether disappearing, when the tracheids are surrounded by strongly thickened wood-cells. As regards the size or diameter of the vessels, those of the first annual ring are narrower than the succeeding ones; and this is especially the case in the large vessels of the spring-wood. In the oak, for example, the vessels do not attain their full size before the sixth and succeeding rings. The vessels become lignified at an early period, and are then filled with air ; it is only when young that they contain sap. When, in a few cases, substances of the nature of gum, resin, or latex occur in them, as in the cherry, these have passed over into them from adjoining elements of the tissue, but have not been formed in them.

The whole of the elements of the xylem need not be present. With regard to their relative position, the separate elements are arranged in rows or groups, or irregularly without any definite arrangement; but even then they are distributed in such a characteristic manner that anyone with experience can determine from a small fragment of wood the genus, or not unfrequently even the species, from which it was taken (Fig. 475). The inner portion of the wood, the cells of which have become firmer and stronger from their walls having undergone lignification for a longer period, is called the duramen, in contradistinction to the alburmum, or younger layers, the walls of which are less thickened and lignified, and which still contain sap. When a very irregular or twisted course of the separate elements of the wood is caused by branches, or buds, or any similar cause, a very peculiar appearance is imparted to those spots, and they are termed knots 
The prosenchymatous cells of the phloëm, which are also called bast-tubes, bast-fibres, or bast-cells, are as a rule fusiform and unbranched. Septated phloëm-cells, similar to the sep.

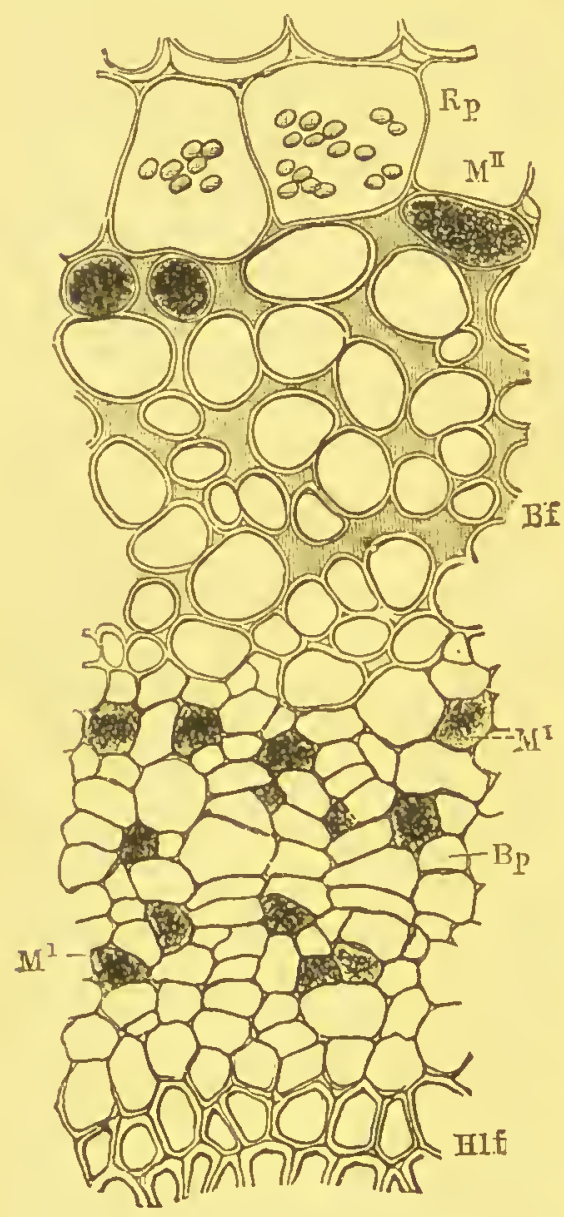

FIG. 476. - Part of a transverse section through the phloëm of the wild lettuce, Lactuca scariola: 18 bast-fibres; $1 p$ phloëmparenchyma ; $\mathrm{I}^{\prime \prime}$ outer, $\mathrm{M}^{\prime}$ inner laticiferous vessels; $\mathrm{R} p$ cortical parenchyma; $\mathrm{H} l f$ wood-fibres $(x 40)$.

In woody Dicotyledons the pith and the parts of the cortex which do not belong to the vascular bundles are very inconsiderable in comparison with these latter. The pith of

tated wood-cells (p. 366), are less common than the latter, but occur in the grape-vine and cactus. When young the phloëm. cells contain a protoplasmic sap, at a later period usually air. In the Asclepiadeæ and Apocynaceæ they contain a peculiar greenish sap related to the latex of other plants. The phloëm-parenchyma agrees almost entirely in its development and structure with the xylem. The vessels of the phloëm are sieve-tubes or laticiferous vessels.

The presence or absence, and the arrangement, of the separate elements in the cortex, are so characteristic of most stems that they can be determined from these characters. A general idea may be obtained by a transverse section through a bast-bundle of the wild lettuce (Fig.

$476)$. 
the stem only increases for a short time, and then only by the increase in size of the separate cells, and occupies therefore but a small space in comparison with the wood and the fundamental tissue of the medullary rays. It consists of a parenchymatous tissue, in which other elements, as laticiferous vessels, are sometimes, though rarely, enclosed.

Deviations are not unfrequent from the normal structure and course of the vascular bundles here described. In many water-plants, such as Hippuris, Myriophyllum, Ceratophyllum, and Trapa, a sheath is formed which limits the increase in diameter of these plants. (Fig. 94, p. 66.)

The roots of Dicotyledons always possess, when young, a thin-walled epidermis, which soon becomes replaced, like that of the stem, by cork-tissue. The cortex of the root is also very similar to that of the stem, consisting of the same elements; and its cells contain the same substances within them. It is very usual for a vascular bundle-sheath to separate the axial bundle from the cortex. While, as has already been mentioned (p. 362), the vascular bundles of the stem have a centrifugal growth, the development of those of the root is in many plants centripetal ; i.e., the first vessels are formed on the outside of the formative tissue, and their further development and lignification advance from the centre towards the axis (Fig. 477, 1.). The development of the pith is by this means so much checked that it is always less developed in the root than in the stem; and in many roots it has entirely disappeared when their vascular bundles have attained their full development. As soon as the vascular bundles have met in the axis of the root, their development progresses outwardly, the new vessels, the bast-bundles, pressing themselves towards the periphery (Fig. 477, 11.). A growth of this nature is found especially in herbaceous plants, e.g. Cicuta, and in those in which the stem has isolated vascular bundles. The root of other Dicotyledons, especially if woody, shows a similar structure to that of the stem. The cell-cavities, both of the xylem- and phloëm-cells, are however considerably 
larger in the root than in the stem; this being the cause of the smaller specific gravity, and the less value as fuel, of the root as compared with the stem. The annual rings are also often much narrower. The essential peculiarity of the root is the possession of a root-cap (see p. 72).

I.

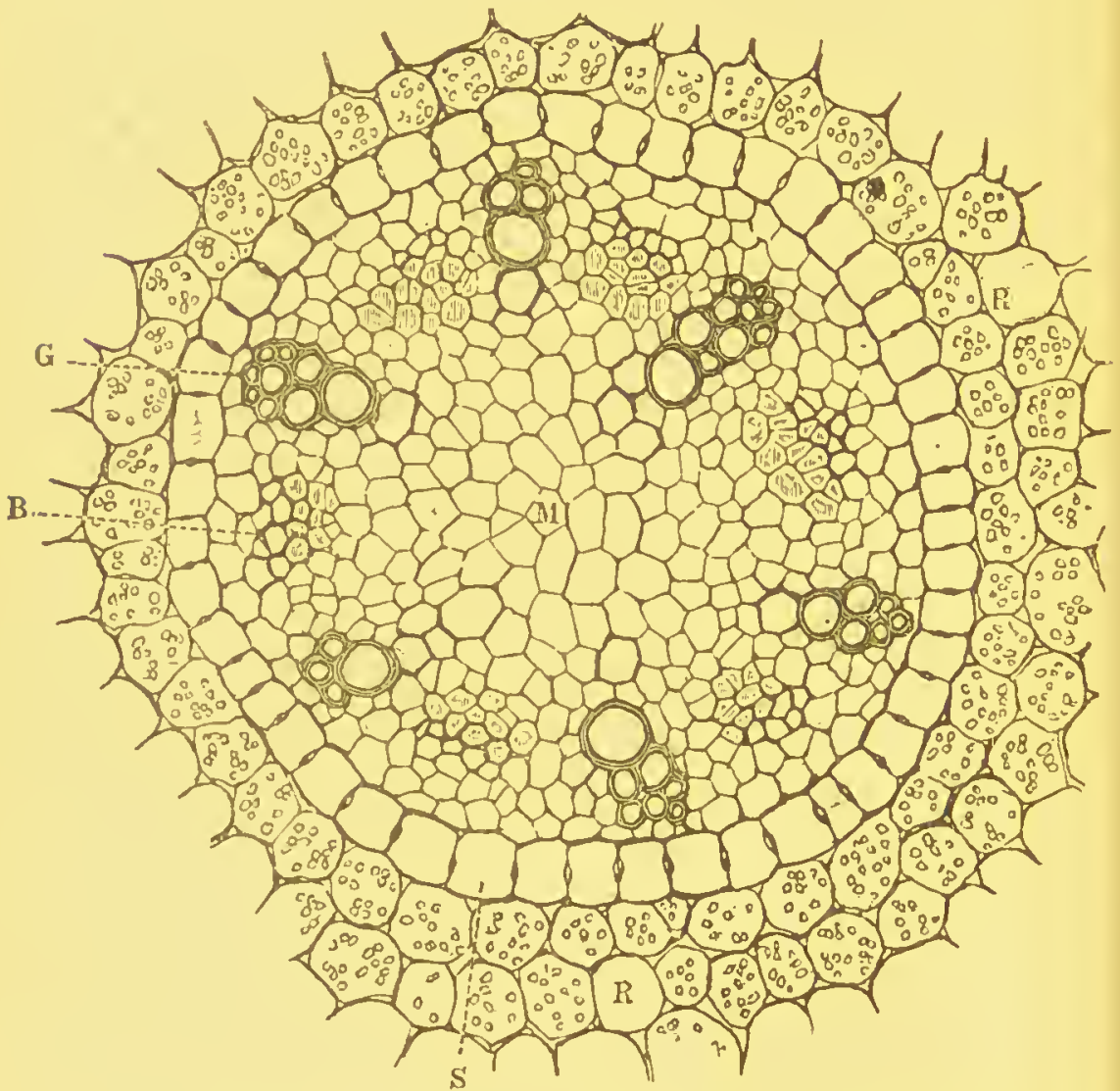

FiG. 477 I.-Transverse section through a young root of Ranunculus acris; G group of vessels just formed; $B$ young bast-bundle; $\mathrm{S}$ vascular bundle-sheath; $\mathrm{R}$ cortical parenchyma : $M$ pith $(\times 200)$.

The leaves of Dicotyledons present no essential difference from those of Monocotyledons [except in the arrangement of the vascular bundles or veins]. 
The structure of the wood of Dicotyledons agrees in its main features with that of Gymnosperms (see p. 333), a class of a generally lower type of organisation. The main distinction lies in the structure of the individual vascular bundles. In Gymnosperms there are in general no true

II.

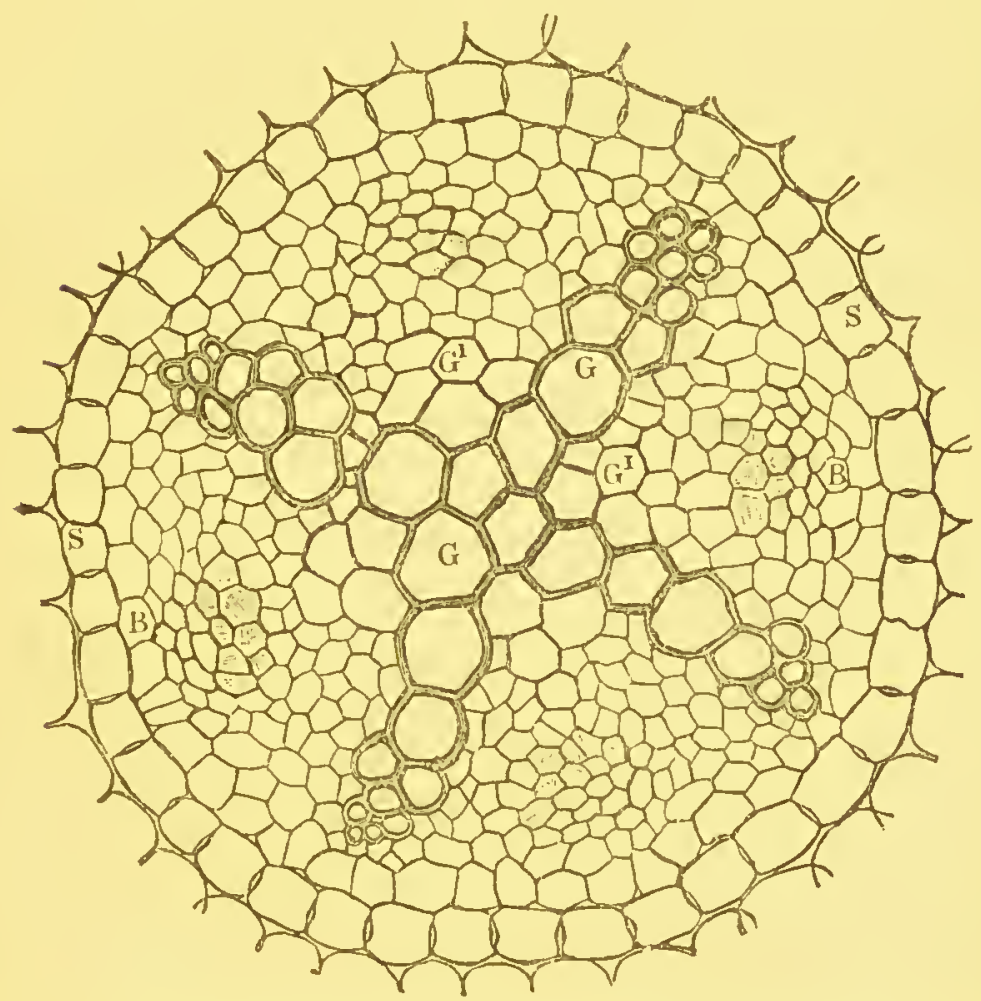

FIG. 477 II.-Transverse section through an older root of Ranzunculues acris : G vessels formed centripetally; $G^{\prime}$ young vessels formed centrifugally; B B bastbundles; $\$$ vascular bundle-sheath $(x 200)$.

vessels; rows of vascular cells, which occur only in the medullary sheath, taking their place, and even then manifesting only a spiral or reticulate thickening (Fig. 478). The small exotic order of Gnetacex furnishes an exception, the whole 
of the wood containing true vessels with bordered pits. The wood of Conifers consists mainly of elongated cells possessing as a rule large pits on the side that faces the medullary rays. The characteristic position of the pits, which in the cells of the stem are usually arranged in one, in

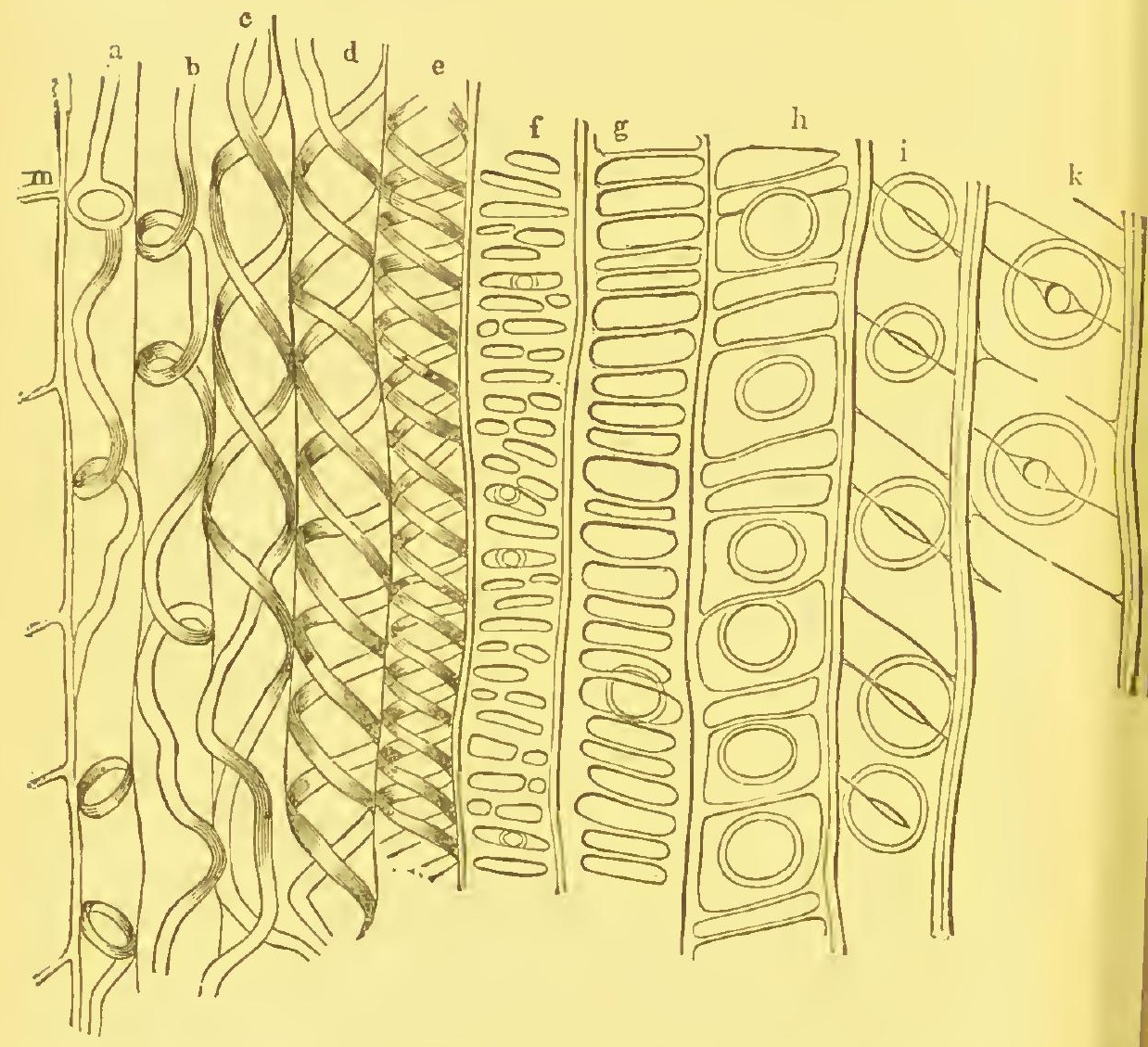

FiG. 478.-Longitudinal section through the medullary sheath of the spruce-fir: $a-\varepsilon$ spiral vessels or vascular cells; $f-i$ transitional forms into the ordinary woodfibres; $k$ normal wood-fibre; $m$ cells of the pith $(x+00)$.

those of the root often in several rows, as well as that of the resin-passages, which are especially abundant in Coniferæ, form an excellent diagnosis to distinguish the different kinds of wood (Fig. 479). The structure of the swollen stem of 
the Cycader is similar, the large pith containing a quantity of starch (known as sago), and surrounded by a com-

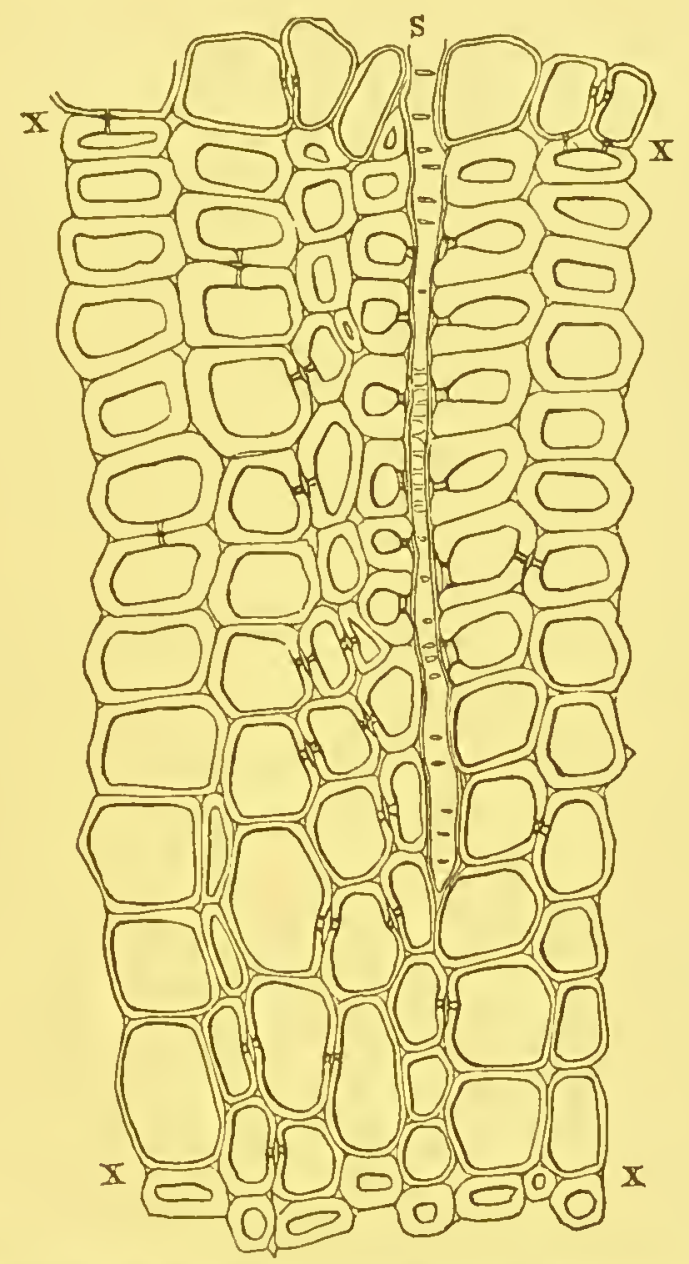

Fig. 479.-Transverse section through the wood of the Scotch fir with moderately large annual ring; $x \mathrm{x}$ boundary of the annual ring; s silver-grain ( $x 200)$.

paratively slightly dereloped wood. Gum-passages replace in them the resin-passages of the Coniferæ. 
[Dicotyledons are subdivided as under, viz. :-

\section{DiVISION I. APETALÆ, INCOMPLET Perianth consisting of only a single whorl of leaves, or entirely absent, or occasionally of a double whorl of sepaloid leaves.}

\section{SUBDIVISION I. Ovary superior; perianth usually distinct.}

Cohort I. Chenopodiales. Flowers usually hermaphrodite; perianth green or coloured, usually regular, sometimes in two whorls, tube short or absent, segments imbricate in bud ; ovary of one, 'rarely several carpels; ovules solitary, rarely two or more, basal; embryo usually coiled or curved. Herbs or shrubs. This cohort includes the orders Phytolaccacece (Phytolacca); Polygonacea (Eriogonum, Polygonum, Fagopyrum, Rheum, Rumex); Amaranthacea (Amaranthus, Celosia); Chenopodiacee (Beta, Chenopodium, Atriplex, Spinacia, Salicomia, Salsola); and Nyctaginece (Mirabilis, Buginvillea).

Cohort II. LAURALES. Flowers usually unisexual; perianth green or coloured, usually regular ; ovary unilocular; stigma one; ovule solitary; embryo straight, with or without endosperm. Mostly aromatic trees or shrubs; almost entirely tropical. Orders:-Monimiacer (Monimia, Laurelia) ; Myristicacea (Myristica); Lauracee (Cimnamonum, Persea, Sassafras, Laurus, Cassytha, Camphora, Nectandri, Oreodaphne).

Cohort III. DAphnales. Flowers usually hermaphrodite; perianth green or coloured, regular or irregular, often tubular ; ovary unilocular, rarely bilocular; stigma one; ovule usually solitary, pendulous or suberect; embryo straight, with no or very little endosperm. Trees or shrubs, mostly tropical or soutlern. Principal orders :Thymelcacea (Daphne, Pimelea); Elacagnacece (Hippophaë, Elacagnus); Proteacece (Lencodendron, Grevillea, Banksia, Protea, Vakea).

Cohort IV. URTICALES. Flowers diclinous, or less often polygamous or hermaphrodite; perianth green, usually regular, rarely absent ; stamens opposite the perianth-lobes or sepals; ovary unilocular, rarely bilocular; stigmas one or two; ovule solitary, micropyle always superior; fruit usually an achene or samara ; embryo straight, with or without endosperm. Principal orders:-Urticacea (Urtica, Baimeria, Parietaria); Moracece (Artocarpus, Ficus, Dorstenia, Morus, Maclura); Cannabinea (Cannabis, Humulus); Ulmacece (Ulmus).

Cohort V. Amentales. Flowers diclinous, in catkins, cones, $\mathrm{Or}^{-}$ heads; perianth absent or sepaloid, or of one or more bristles, bracts, bracteoles, or scales; ovary uni- or bi-locular; seed without endosperm. Trees or shrubs, with alternate, simple, usually stipulate leaves.] 


\section{Special Morphology and Classification.}

Order I. BetUlace ${ }^{.}$(Fig. 480.) Trecs or shrubs, with altcrnate simple leaves, and free deciduous stipulcs. Flowers moncecious, both male and female arranged in catkins, and subtended by scale-like bracts. Male flowers in threes in the axil of a bract, and formed of a two- or four-cleft perianth, in front of the teeth of which the stamens are placed ; female flowers also in twos or threes in the axil of a bract, but consisting simply of a free ovary with two locult, in each of which is a pendulous ovule; fruit usually a samara, and seeds exalbuminous. The two genera of this order, Betula the birch, and Alnus the alder, furnish useful woods. From the bark of the birch is obtained the birch-oil used in the manufacture of Russia-leather, and imparting to it its peculiar odour.

Order 2. SalicaceA.

(Fig. 48I.) Trees or shrubs, with simple alternate leaves and deciduous stipules. Flowers diøcious, and both male and female always in catkins; instead of perianth, each kind has a few small scales or a glandular or cup-

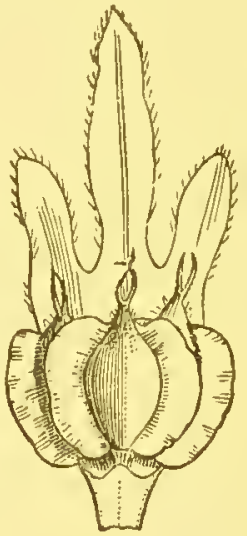

Fig. $480 .-$ Bract of the birch, Betula, with three samarae in its axis. shaped fleshy disc. The male flowers consist, in addition, of from two to twenty-four free or monadelphous stamens; and the female of a free bicarpellary pistil, standing in the axil of a scale, and having generally two stigmas. The unilocular ovary contains a number of pendulous ovules attached to two parietal placentæ; and the fruit is a two-valved capsule; the seeds without endosperm, but furnished with a tuft of hairs. The two genera of which this order is composed, Salix the willow, and Populus the poplar, are divided into a large number of species, varieties, and hybrids, distributed over the whole globe. The nearer thcy approach the poles, the smaller are they in stature; and the arctic willow, Salix polaris, is only an inch in height. Some species, as $S$. purpurca and $r u b r a$, unfold their catkins before their leaves; among the best-known species are $S$. babylonica the weeping willow, $S$. vitellina the osier, $S$. alba the white willow, Populus tremula the aspen, $P$. nigra the black poplar, $P$. pyramidalis thic Lombardy poplar, $P$. alba the white poplar, and $P$. balsamiferc the American balsam poplar. The wood of some species is valuable on account of its toughmess and elasticity, and is used for basket-work and other purposes. The bark of others, as S. pentandra and fragilis, is officinal, affording the substance known as salicine.

' [The orders Betulacex and Salicaceæ, together' with Cupuliferæe and Corylacex from the cohort Quernales, constitute the Amcntacea of the syllabus of the University of London. - ED.] 
To this cohort belong also the small orders Platanacea (Plaianus); Myricacea (Myrica); and Casuarinacea (Casuarina).

[Cohort VI. EuphoRbiales. Flowers hermaphrodite or diclinous; perranth green, coloured or absent ; ovary bi. or multi locular; ovules

I.

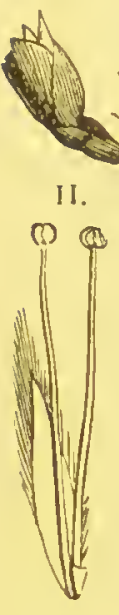

IV.

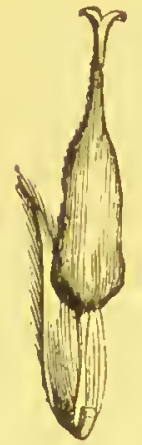

III.

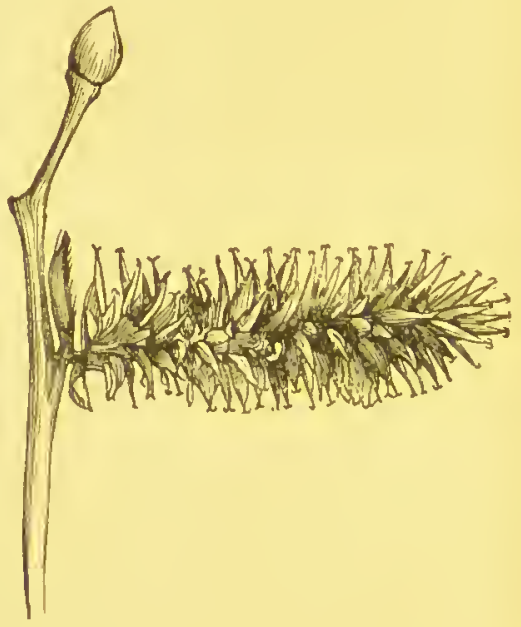

VI.

VII.

Fig. 481.-Sallow, Salix Caprea: I. male catkin (natural size); II. male fower (magnified) ; III. female catkin (natural size); IV. female flower (magnified); V. transverse section of ovary: VI. fruit ; VII. ripe seed (magnified).

one or many in each loculus, pendulous, anatropous; fruit usually a uni- or multi-locular capsule ; seeds solitary or numerous.]

Order I. EuphorbIACEA. (Figs. 482, 483.) Trees, shrubs, or herbs, containing a watery, often acrid, more rarely tasteless latex. The stem of some species is fleshy, resembling that of the cactus, and is then leafless, or the leaves are, replaced by small scales, spines, or 
hairs. Flowers solitary or collected into an inflorescence, and hermaphrodite, monocious, or diœcıous. The tropical species especially are so polymorphic, and yet so nearly related, that then classification is attended with extreme difficulty. The genera of northern Europe agree in never having a double perianth separable into calyx and corolla; in the styles and stigmas being distinct ; in the fruit being a three-valved

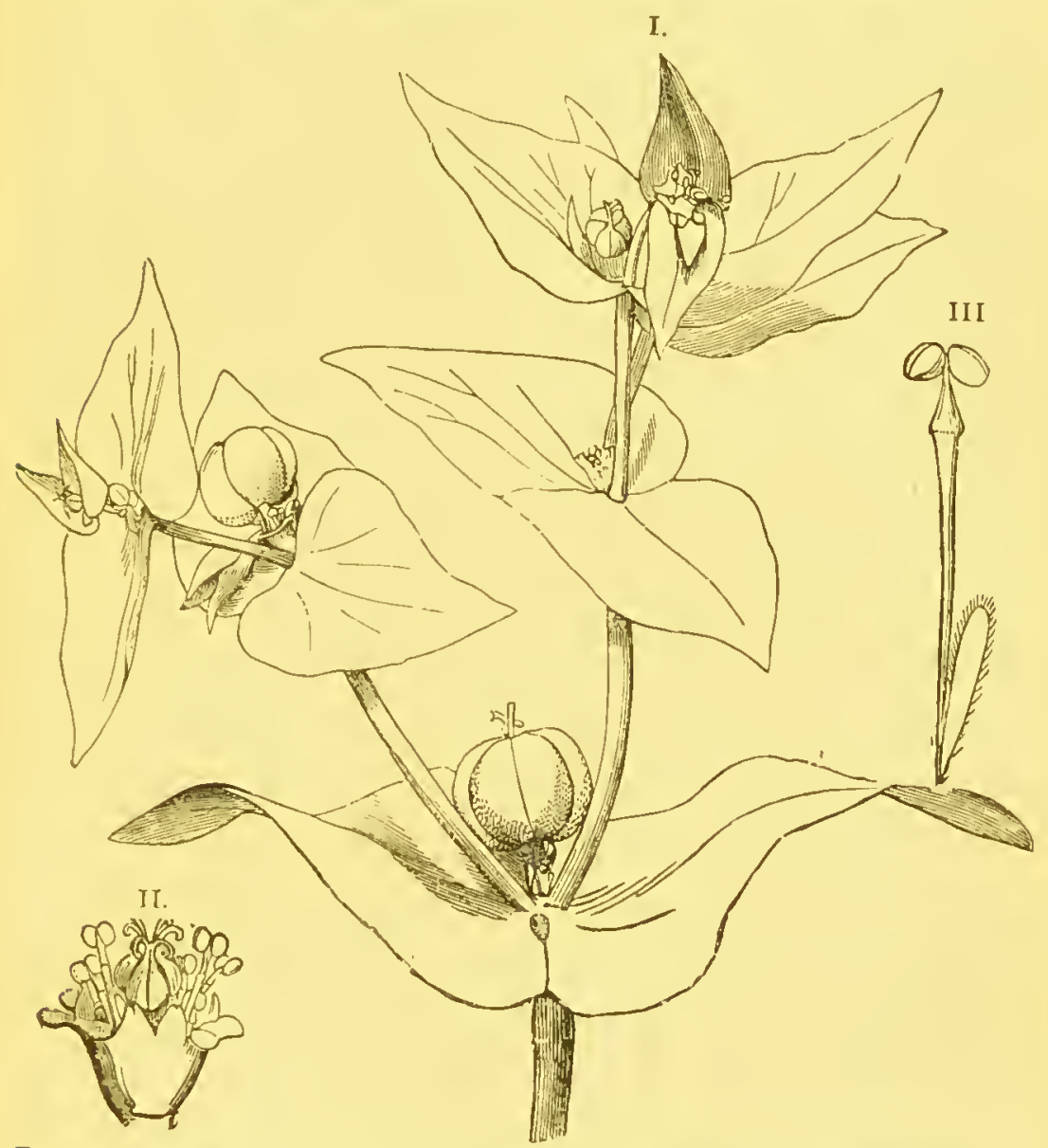

Fig. 482.-Euphorbia Lathyris: I. part of a plant (natural size); II. inflorescence; 1II. male flower (magnified).

capsule, the valves separating elastically from a central axis; and in the seed being straight, the embryo lying in the centre of a fleshy and oily cndosperm. [Among the more inportant genera of this very large order, which is divided into a number of suborders, are Phyllanthus, Anti- 
desma, Croton, Ffippomane, Crozophora, Mercurialis, Acalypha, Calebogyne, Ricinus, Manihot, Fatropha, Euphorbia, Siphonia.] A large number of species possess a poisonous latex, which is espccially dangcrous in some tropical kinds, as Ifippomane Mancinella of tropical America. On the other hand the dried latex of Euphorbia officinarum and of some

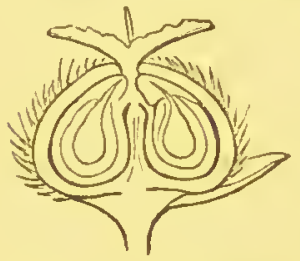

Fig. 483.-I, - ongitudinal section through the fruit of Mercurialis perenuis (magnified). other African species, is used in medicine under the name euphorbium; and of late years also the oil-glands and hairs of the East Indian Rottlera tinctoria, known as camala, and previously used only as a dye. Other officinal preparations are cascarilla, the bark of Croton Eluteria; castoroil, derived from the seeds of Ricinus conmumis, and croton-oil from those of Croton Tiglium. Shell-lac is obtained from the East. Indian Croton lacciferum; caoutchouc or indiarubber from the dried latex of Siphonia elastica and brasiliensis from Brazil and Guiana. The starchy rhizome of Manihot utilissima, cultivated in many tropical countries and especially in America, affords, after the removal of the acrid latex, tapioca, from which cassava-bread is made. The castor-oil plant is cultivated for the beauty of its foliage.

[To this cohort bclong also Buxacea (Buxus), and several other unimportant orders.

Cohort VII. Piperales. Flowers hermaphrodite or diclinous, usually in spikes or catkins; perianth rudimentary or absent ; ovary unilocular with a single ovule, or of scveral free carpels with two or more ovules. Orders :-Piperacea (Piper, Cubeba, Peperomia); Chloranthacea (Chloranthus).

SUBDIVISION II. Ovary inferior; perianth more or less distinct in either male or female flowers, or both.

Cohort VIII. Asaral.es. Flowers hermaphrodite or diclinous; perianth usually coloured; stamens epigynous in the hermaphrodite flowers ; ovary uni- or multi-locular ; fruit a capsule or berry. Orders:Aristolochiacea (Asarum, Aristolochic); Rafflesiacea (Raflesia, Hy'dnora, Cytinus).

Cohort IX. QUernales. Flowers diclinous; the male flowers in catkins, the female solitary or in spikes; perianth green, that of the male flower lobed or reduced to a scale, of the female flower minute, 2-6-lobed or toothed; ovary 1-6-locular; ovule solitary basal, or one or more pendulous; fruit one-seeded; seed without endosperm. Trees with simple or compound leaves].

Order 1. Cupulifers. Trecs or shrubs with simple alternate 
leaves, deciduous stipules, and monœcious flowers. Male flowers arranged in catkins, with a 4 - or 5 -cleft perianth or none at all, and five to ten stamens attached to the perianth or bracts; female flowers solitary, or in clusters or spilics, their perianth superior, with a toothed often almost obsolete margin; ovary with from two to six stigmas, and the same number of loculi; in each loculus one or two pendulous ovules with two integuments. Fruit indehiscent, and, by abortion, usually unilocular and one-seeded, and surrounded at its base by a cup-shaped envelope, the cupule, as in the oak, or entirely enclosed within it, as in the beech. This cupule proceeds from an inferior disc (Fig. 303, p. I47), and not from a leaf of the perianth, as in the Corylacex. The seed is without endosperm, and has a large embryo with thick fleshy cotyledons. The fruit of the Spanish or sweet chestnut, Castanea vesca, is edible. The two British oaks Quereus sessiliflora (Robur) and pedunculata, and Q. Cerris and infectoria from Asia Minor and Turkey, are valuable for their wood, and the latter especially for its galls, from which tannin is obtained. Almost the whole of the cork of commerce is the produce of Q. suber from Spain, South Italy, and northern Africa. The wood of Q. tinctoria of North America is used as a yellow dye. The beech, Fagus sylvatica, is valuable for its wood and the oil of its seeds.

Order 2. CORYLACEÆ. (Figs. $4 \delta_{4}, 485$.) This order is so closely allied on the one hand to the Cupuliferæ, on the other hand to the Betulacer, that we may trace a gradual transition between the three. From the Cupuliferre it is distinguished by the presence of a spurious foliar cupule, and by the ovules having only a single integument; from the Betulacere by the cupule, the superior though usually rudimentary perianth of the female flowers, the absence of a perianth to the male flowers, and by each anther-lobe bearing a tuft of hairs (see Fig. 268, p. I37). The best-known representatives of the order are the hornbeam, Carpinus Betulus, valuable for its timber, and the hazel or filbert, Corylus Avellana, for its fruit and wood.

[To this cohort belongs also the order Fuglander (Fuglans, Carya).

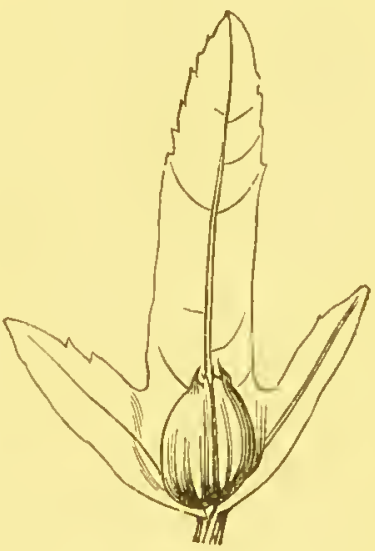

IG. 484.-Fruit of the hornbeam, Carpinus Betulus, with its three-lobed perianth (natural size).

Cohort X. Santalates. Flowers hermaphrodite or diclinous ; periinth usually conspicuous, coloured, polymorphic, and valvate; ovary 
uni- or multi-locular, loculi with one or many ovules, ovules usually reduced to a naked nucleus; fruit a one-seeded berry or drupe. Parasitic herbs or shrubs. Orders:-Loranthacea (Loranthus, Viscum, Mysodendron); Santalacea (Thesium, Santalum); Balanophoracee (Cy. nomorium, Balanophora, Langsdorffia).

I.

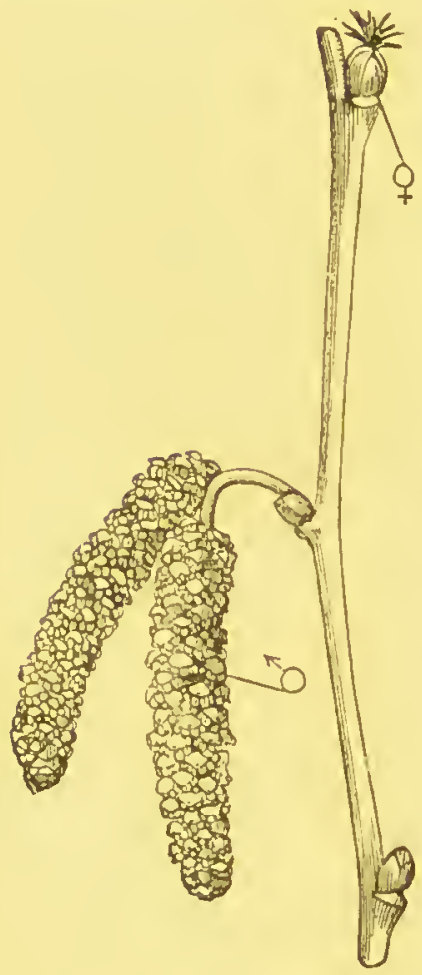

II.

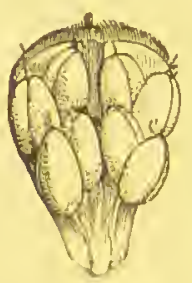

III.

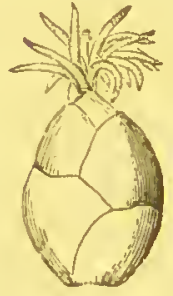

V.

IV.
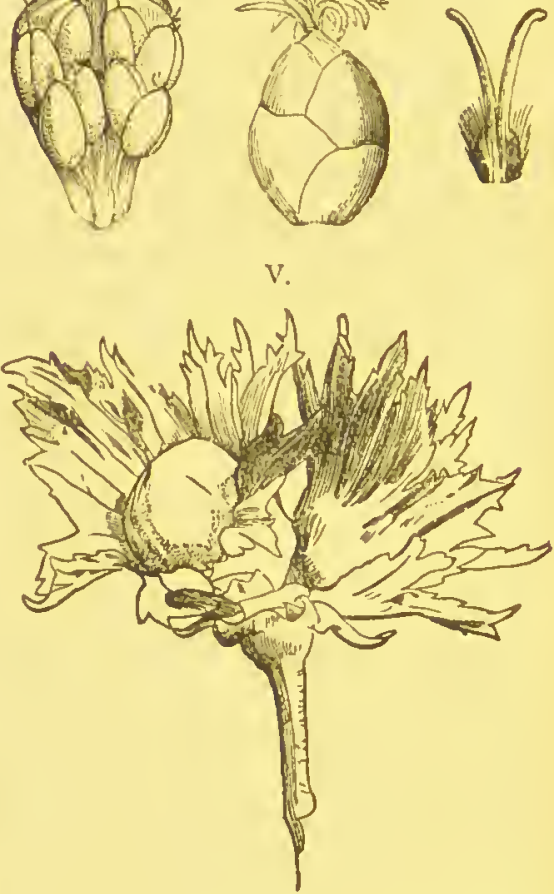

Fig. 485.-The hazel, Corylus Avellana: 1. branch with male and female flowers (natural size); II. male flower: III. female inflorescence; IV. female flower (magnified); V. fruit (nut) with laciniated spurious cupule (natural size).

Division II. GAMOPETAL.E. - Flowers furnished with both calyx and corolla, the latter gamopetalons.

SUBDIVISION I. Ozary superior (rarely inferior).

SECTION I. Flowers very irregular (rarely regular).

Cohort I. Personales. Corolla gamopetalous, hypogynous, often bilabiate; stamens fewer than the corolla-lobes, rarely as many, unequal, usually four and didynamous, rarely two; ovary I-2-rarcly 
Special Morphology and Classification. $\quad 38$ [

4-locular; style simple; stigmas one or two; ovules usually very numerous ; fruit usually a capsule. Herbs, rarely shrubs or trees, with exstipulate leaves.]

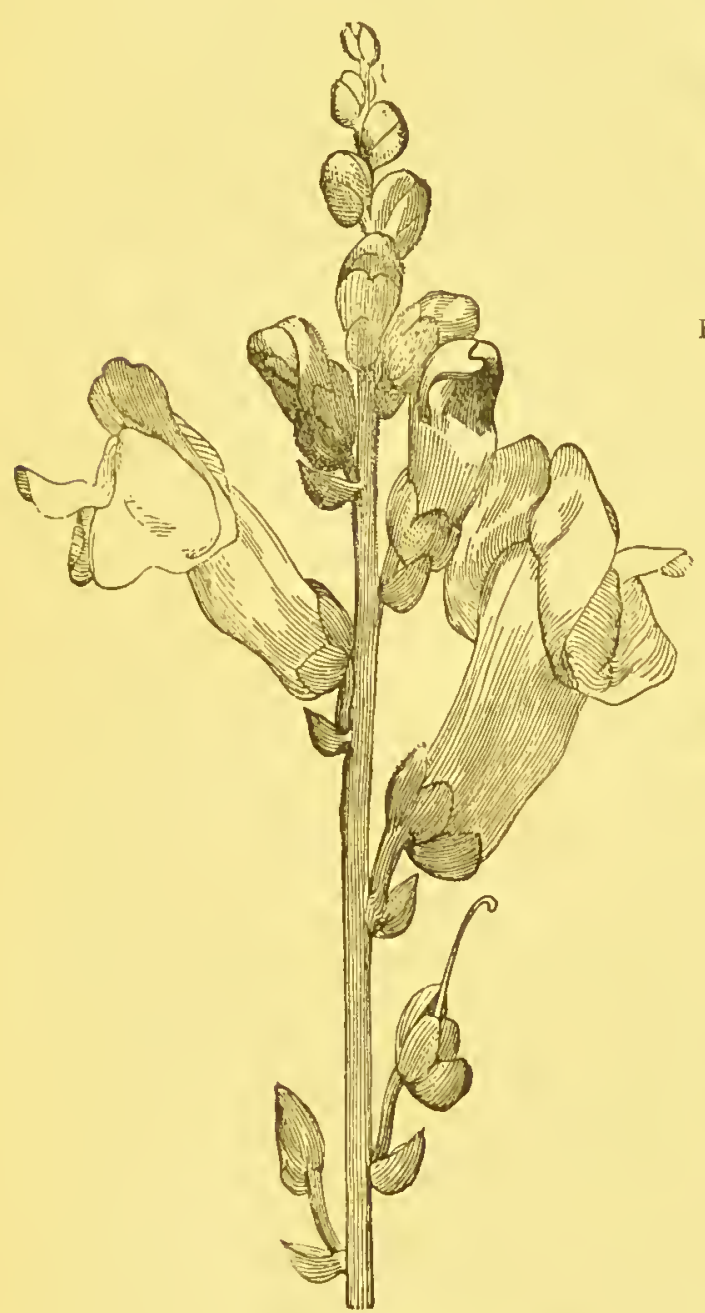

Fig. 486.-Antirrlinum majus
(natural size).

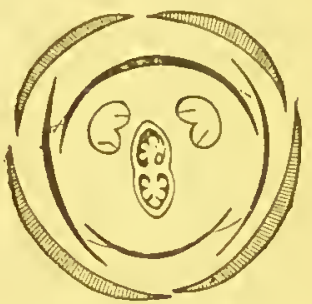

FIG. 487.-Floral diagram of Veronica (Scrophulariaceæ).

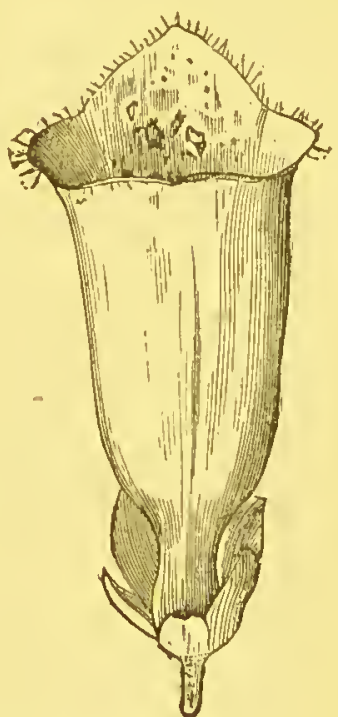

FiG. 488.-Flower of fox. glove, Digitalis purpurea (natural size).

Order r. Scrophulariacede. (Figs. 486-488.) Mostly herbaceous plants, with alternate, opposite, or verticillate exstipulate leaves. Calyx and corolla bilabiate, rarely nearly regular, and $4^{-}$or 5 -cleft ; stamens 
usually four and diclynamous, less often two, as in Veronica; ovary superior, and generally surrounded by a disc, syncarpous and bilocular, with a large number of anatropous ovules attached to an axile placenta divided by the dissepinent. Fruit capsular, rarely baccate; seeds with endosperm and straight embryo (see Figs. 249 and 297, pp. I30, 144). [The genera are very numerous, and include Salpiglossis, Schizanthus, Calceolara, Linaria, Antirrhinm, Maurandia, Lophospermum, Paulownia, Scrophularia, Penstemon, Mimulus, Gratiola, Digitalis, Veronica, Bartsia, Euphrasia, Melampyrum, Rhinanthus, Pedicularis, Verbascum.] The most important medicinal species is the foxglove, Digitalis purpurea ; the leaves of Gratiola officinalis are also officinal. A large number of genera are cultivated in gardens for the beaty of their flowers. Many species are root-parasites.

[To this cohort belong also the orders Utriculariacee (Utricularta, Pinguicula); Orobanchacea (Orobanche, Lathrea); Gesneracec (Gesnera, Gloxinia, Achimencs, Columnea, Cyrtandra); Bignoniacca (Bignonia, Catalpa, Tecoma, Eccremocarpus); Acanthacce (Ruellia, Goldfussia, Acanthus, Fusticia, Adhatoda); Sesamacece (Sesamum, Craniolaria, Martynia, Pedalizm).

Cohort II. Lamiales. Perianth usually bilabiate, rarely ncarly or quite regular, hypogynous; stamens fewer than the corolla-lobes, rarely as many, unequal, usually four and didynamous, rarcly two ; ovary 2-4locular; style simple; stigmas onc or two; ovules solitary in each loculus, very rarely two or more; fruit an indehiscent drupe, or composcd of two or four nucules. Herbs, shrubs, or trees, with exstipulate leaves.]

Ordor I. Labiat e. (Figs. 4S9-492.) Herbaceous or suffruticose plants, usually with square stem and opposite (decussatc) or verticillate exstipulate leaves. The flowers are arranged in compact cymes (zcrticillasters) in the axils of the leaves; and the separate inflorescences are often so crowded as to give to the whole the appearance of a compound spilie. The tubular, usually bilabiate, calyx is persistent ; the corolla usually ringent and bilabiate, rarely regular; in the former case the upper lip consists of two, the lower lip of three teeth (petals); the structure of the bilabiate calyx being the reverse. Stamens rarely two, usually four, of two unequal lengths (didynamious); but the anthers arc not always perfectly developed, sometimes consisting of one lobe only, the other lobe being barren, as in Salvia (Fig. 269, p. I3S). The mode of dehiscence of the anthers also varies; in Galcopsis it is transverse. The style is gynobasic, or rises from the base of the deeply four-lobed ovary, which is placed on an infcrior disc; each division of the ovary contains only a single ovule, with its micropyle dircctcd downwards. Fruit 
Special Morphology and Classification. $\quad 383$

I.

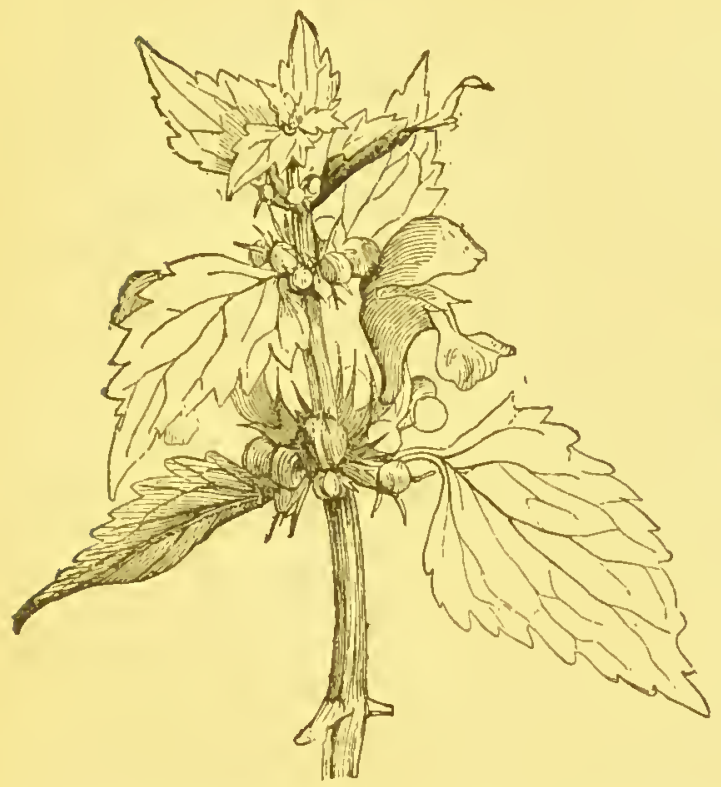

Fig. 489.-Lamizum album: J. part of plant (natural size): II. longitudinal section of flower (magnified); III. floral diagram (see also Figs. $230,248,273$, pp. r25, I30, I39).

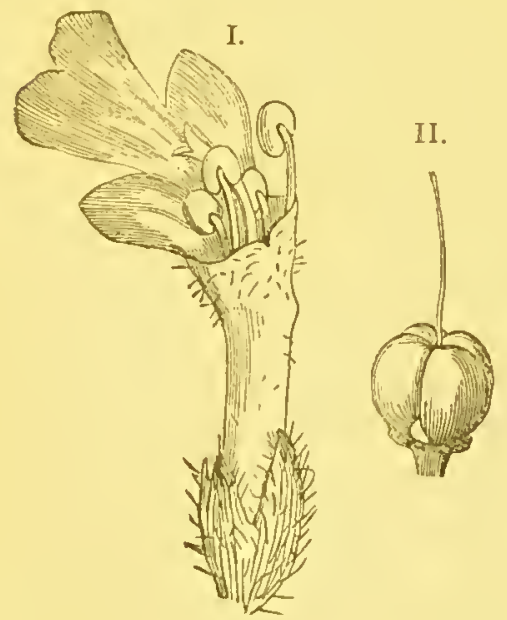

Fig. 490.-Ajugn reptans: 1. fower ; II. carcerulus (magnified).
II.

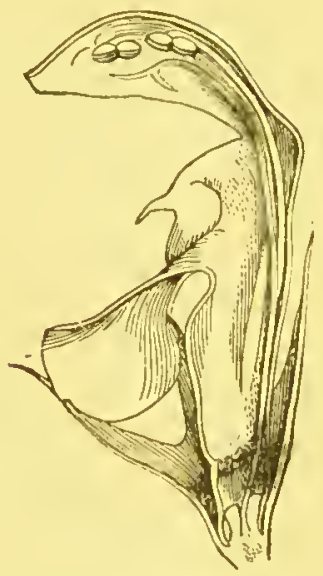

III.
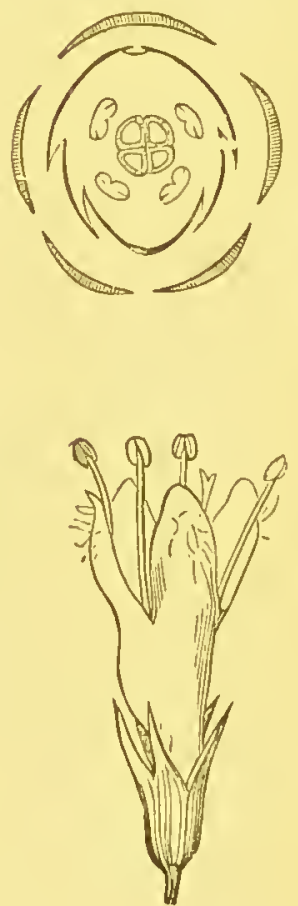

Fig. 491-Stamen Fig. 492. - Nearly of Prun $e^{2}$ lla regular flower of (magnified). 
enclosed in the base of the calyx, and consisting of four moules, cach containing a single secd. [Among the numerous genera of this largc and important order are Coleus, Lavandula, Menzha, Origanum, Thymun, Calamintha, Melissa, Nepeta, Prumella, Scute.laria, Metittis, Marrabizm, Stachys, Lamium, Ballota, Phlomis, Galeopszs, Tencrium, Ajuga, Salvia.] The plants belonging to it abound in volatile oils contained in special glands, and a large number are consequently officinal; as Mentha piperita peppermint, $M I$. crispa curled mint, Lavandula angustifolia lavender, Thymus serpyllum and vulyaris the wild and garden thymes, Rosmarinus officinaiis rosemary, Ocymmum basilicum basil thyme, Origanum Majorana and Julgaie marjoram, \&c. Salvia officinalis is valuable on account of the large quantity of tannin contained in it; Plectranthus graveolens of the Mascarene Islands is the source of patchouli.

[The only other important order of the cohort is Verbenacer, which inclucles the genera Verbena, Lantana, Tectona, Clerodendron, Vitex, Avicennia.

\section{Section II. Flozvers usnally regular.}

Cohort III. Polemoniales. Corolla gamopetalous, hypogynous, regular or oblique; stamens as many as the corolla-lobes, epipctalous, equal or unequal, often exserted ; ovary I-5-locular, syncarpous (rarely apocarpous); seeds very numerous, or only one to two in each loculus. Herbs, rarely shrubs or trces, with exstipulate, alternatc or geminate, rarely opposite, leavcs.]

Order r. SOLANACE.E. (Figs. 493-497.) Herbaceous or suffruticose plants with alternate, in the upper part geminate, leaves, one of each pair being always smaller than the other. Calyx usually 5partite and persistent; corolla regular, deciduous, folded in the

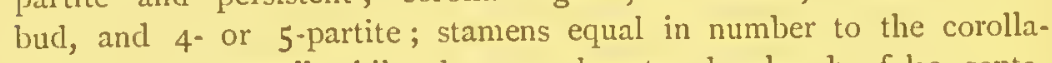
lobes; ovary usually bilocular, or almost 4-locular by false septa, rarely 3- or 5-locular. The numerous seeds have an abundant fleshy endosperm; fruit a capsule or berry. [Among the more important genera are Nicotiana, Petnnia, Datura, Hyoscyamms, Nicandra, Lycopersicum, Lycizm, Physalis, Atropa, Capsicum, Mandragora, Solannm, Nolana.] The useful and officinal plants belonging to it are numerous, including the potato Solanum tuberosum, $S$. dulcaman the bitter-sweet, Lycopersicum esculentnm of the East Indies the tomato, Capsicum annumm of the West Indies or Cayenne pepper, Nicotiana Tabacum tobacco, Airopa Belladonna the deadly nightshade, Hyoscyamus niger the henbane, Datura Stramonium the thorn-apple, Physalis Alkckengi the winter cherry, \&c. 
This cohort includes also the following orders :-Hydrophyllacece (Hydrophyllum, Nemophila, Eutoca); Polemoniacece (Phlox, Collomia, Gillia, Polemonium, Cobara); Convolvulaceg (Cuamoclit, Batatas, Pharbitis, Iponta, Convoluulus, Evolvulus, Porana, Cuscuta); and Borraginere (Heliotropium, Cerinthe', Echium, Borrago, Symphytum, Anchusa, Lycopsis, Lithospermum, Pulmonaria, Myosotis, Cynoglossum, Ompha. lodes).

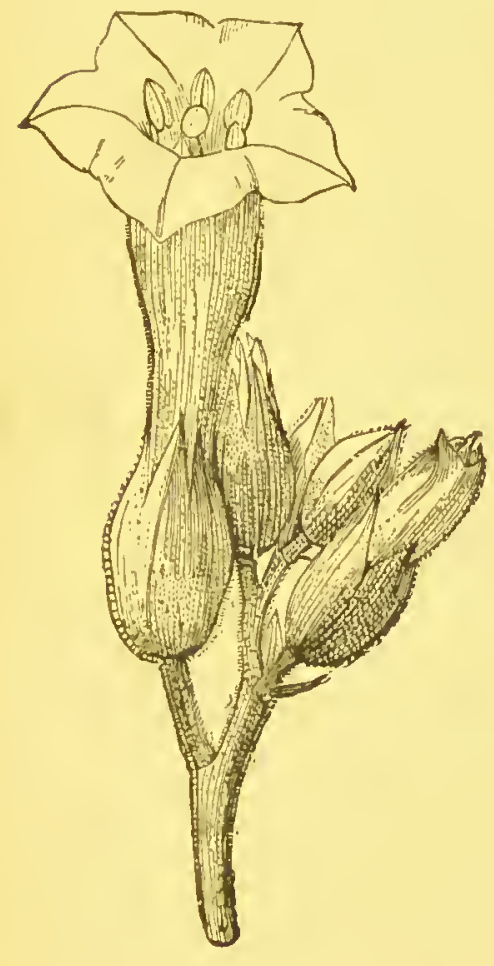

Fig. 493.-Flower of tobacco, Nicotiana Tabacum (natural size).

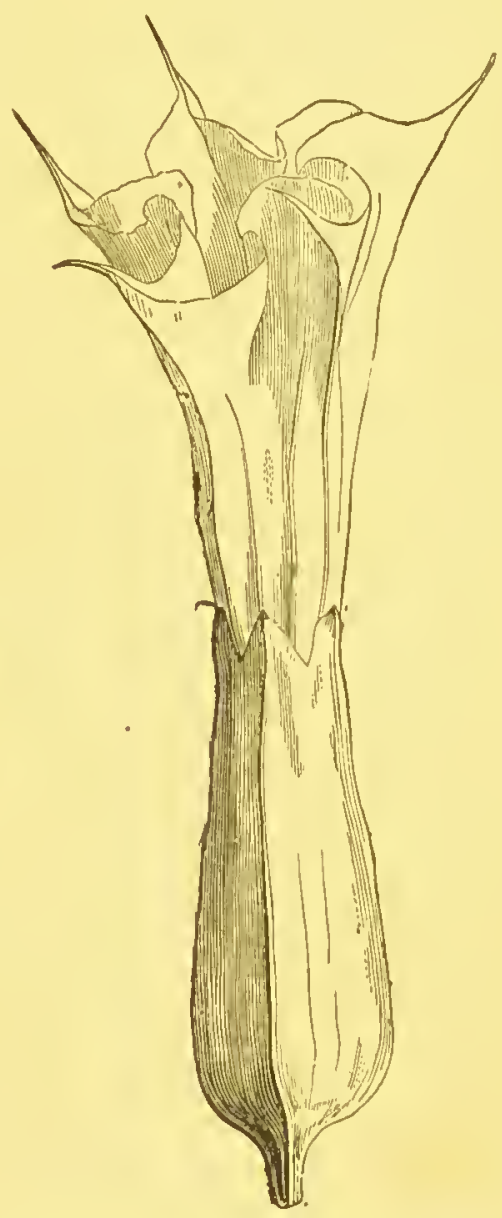

FIG. 494,-Flower of thorn-apple, Datura Stramonizm (natural size). See Fig. 3IO, p. I50.

Cohort IV. Gentianales. Corolla gamopetalous or rarely nearly apopetalous, hypogynous, stamens same in number as corolla-lobes or 
I.

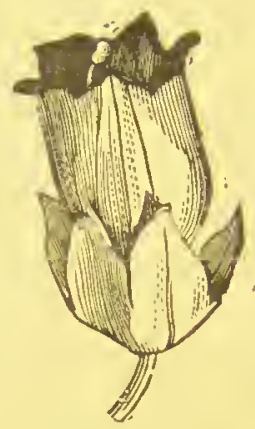

II.

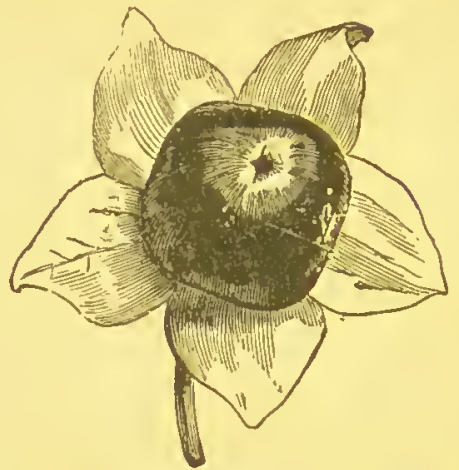

Fig. 495.-Deadly nightshade, Atropa Belladonna; I. flower ; II. fruit (natural size).

I.
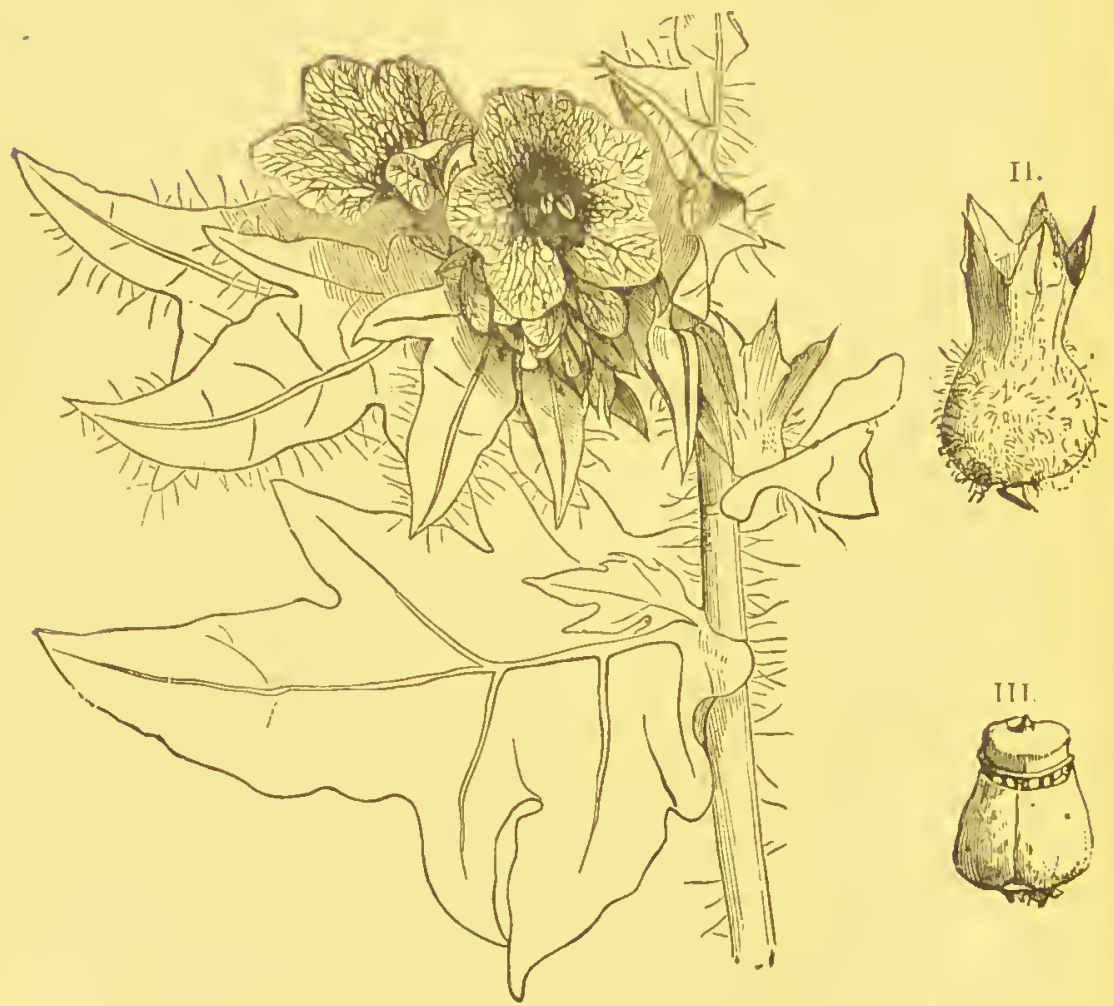

III.

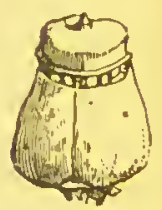

Fig. 496.-Henbane, Hyoseyamzes ziger; I. part of plant ; II capsule surrounded by the accrescent calyx ; III. capsule (pyxis) (natural size). 
fewer, epipetalous and usnally included in corolla-tube ; ovary usually syncarpous and bilocular. Herbs, shrubs, or trees, almost always with opposite or verticillate exstipulate leavcs. Orders:-Oleacee (Fasminum, Olea, Ligustrum, Phillyrea, Fraxinuts, Syringa, Forsythia); Apocynacece (Allamanda, Tabernamontana, Vinca, AP̂Focynum, Nerium); Asclepiadca (Vincetoxicum, Cynanchum, Asclepias, Stcphanotis, Hoya, Stapelia); Loganiacere (Logania, Spigelia, Strychnos); Gentianacea (Erythraa, Chlora, Gentiana, Villarsia, Menyanthes, Limnanthemum).

I.

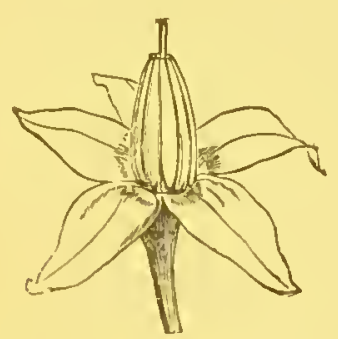

II.

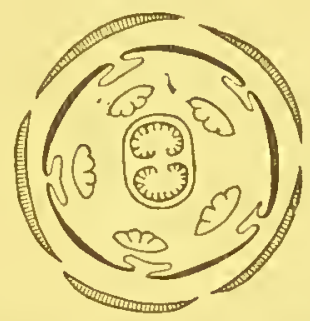

Fic: 497--I. Flower of Solanzm Dulcamara (magnified); II. Floral diagram of potato Solanacece).

Cohort V. EBenales. Corolla gamopetalous or apopetalous, hypogynous or epigynous, rarely perigynous; stamens usually many more than the corolla-lobes, or if equal in number usually alternate with them ; ovary 2- or multi-locular; ovules usually few; fruit rarely capsular. Shrubs or trees, with alternate exstipulate leaves. Principal orders:-Ebenacee (Diospyros); Styracere (Symplocos, Styrax, Halesia).

Cohort VI. Primulales. Corolla regular, hypogynous, rarely epigynous, gamopetalous, rarely apopetalous; stamens equal in number to corolla-lobes and opposite to them, or if more numerous one series always opposite, hypogynous or epipetalous; ovary unilocular, with free central placentation. Herbs or shrubs, rarely trees, with exstipulate usually alternate leaves.

Order I. Primulaces:. (Figs. 138, 298, 306, 3ir.) Characters essentially those of the cohort. Principal genera:-Soldanella, Cyclamen, Lysimachia, Primula, Anagallis, Hottonia. Other orders :-Plumbaginea (Plumbago, Armeria, Statice); Myrsmacea (Myrsine, Ardisia).

Cohort VII. Ericales. Corolla hypogynous or rarely epigynous, gamopetalous or rarely apopetalous; stamens as many ur twice as many as corolla-lobes, hypogynous or epipetalons ; ovary uni- or multi-locular; ovules one or many; stigma simple, entire or lobed; seeds minute. IIerbs, shrubs, or trees, often with heath-like leaves, or sometimcs parasitic. Orders:-E Ericacea (Arbuttus, Gantlheria, Andromeda, Erica, Calluna, Rhodora, Phyllodoce, Ledum, Kalmia, Azalea, Rhododendron, 
Epigaa, Clethra); Monotropacece (Monotropa, Lathraa); Vacciniacce (Vaccinum, Oxycoccus); Epacridea (Epacris); Pyrolacca (Pyrola).

\section{SUB-DIVISION II. Epigynous; ovary inferior.}

Cohort VIII. Campanales. Flowers usually irregular, rarely unisexual or collected into involucrate capitula ; stamens as many as eorolla-

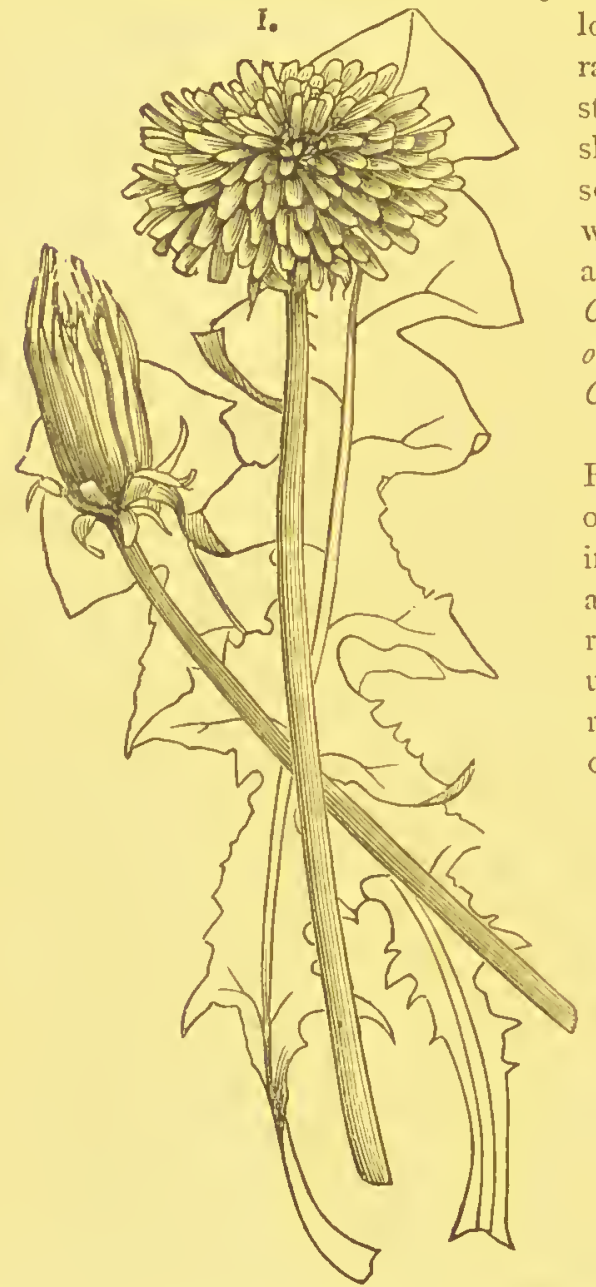

lobes or fewer; ovary 2-6rarely uni-loeular; style simple; stigma often enveloped in a sheath; ovules numerous, rarely solitary. Herbs or rarely shrubs, with exstipulate leaves and often a milky juiee. Principal order : Campanulacece (Phyteuma, Fasione, Specularia, Campanula, Clintonia, Lobelia).

Cohort IX. Asterales. Flowers regular or irregular, often unisexual and collected into involuerate eapitula; stamens as many as eorolla-lobes, rarely fewer, epipetalous; ovary uni-loeular, ovule solitary, (or rarely 2-3-loeular, all but one then barren). Herbs or

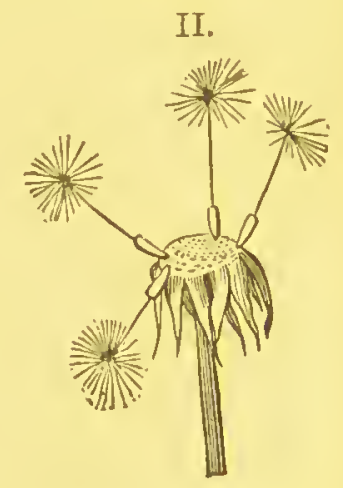

FIG. 498.-Dandelion, Taraxacum officinale: I. entire plant (natural size);

II. receptacle with fruits (magnified). (See also Figs. 213, 2I4, 217, 218, 219).

shrubs, rarely trees, with exstipulate leaves; calyx-limb usually reduced to a pappus, or absent. (Figs. 498-503.)] 
Special Morplology and Classification. $\quad 389$

I.

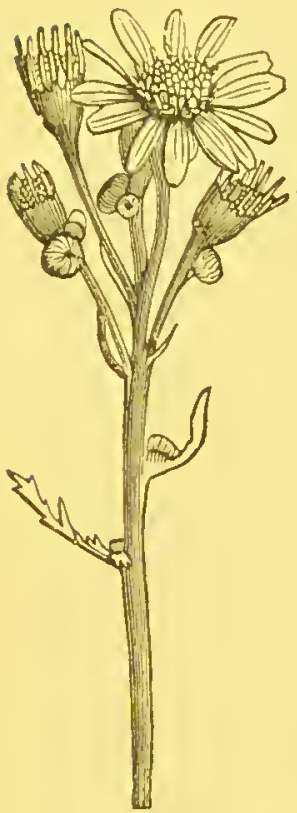

II.

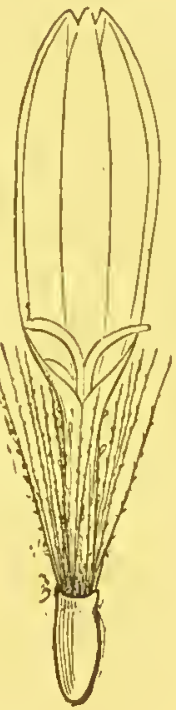

III.

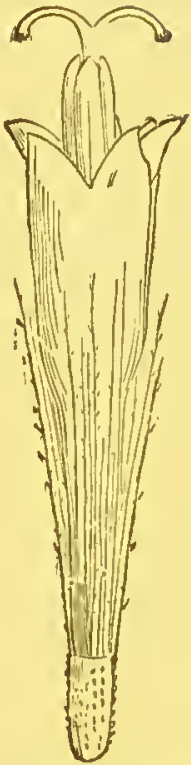

FIG. 499--Senecio Facobar; I. inflorescence (natural size) : II. ligulate flower ; II. tubular flower (magnified).

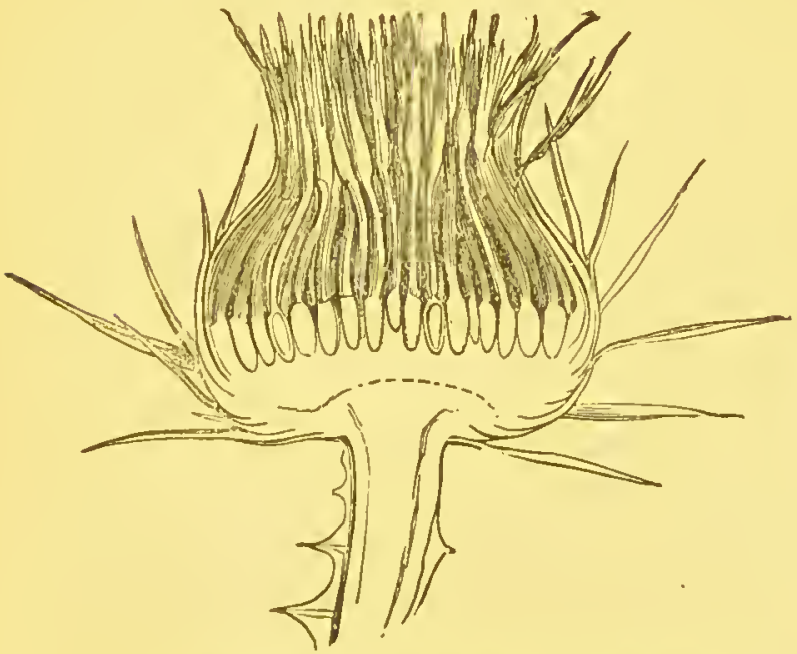

FIG. 500.-Longitudinal section through the capitulum of .

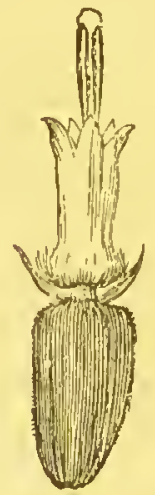

Fic. 50r.-Tubular flower of sunflower, Helinnthus annums, with inferior ovary (magnified). 
Order r. Compositæ. This order is not only one of the largest, but one of the best characterised and most natural in the vcgctable kingdom. It numbers about twelve thousand species clistributcd over the whole surface of the globe. The species are herbaceous, rarely

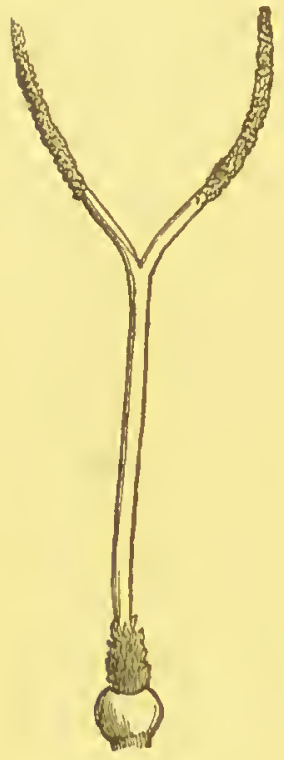

Fig. 502. - Pistil of Eupatorizm (magnified).

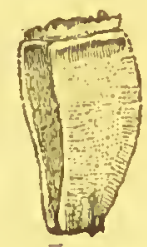

FIG. 503. - Fruit of chicory, Cichorium Intybus, with coronate pappus (magnified). shrubby, and often (Liguliflorx) containing a milky latex ; the leaves are cxstipulate and usually alternate. The flowers are hermaphrodite, male, female, or neuter (containing neither stamens nor pistil). They are placed on a common broadly expanded receptacle, and are crowded into a capitulum, and surrounded by a general involucre of densely crowded bracts. The individual flowers are usually situated in the axils of small bracts, which are called palea, and the receptacle is then said to be palcaccous; when these are absent it is naked. Rarcly each flowcr has a special involucel. The calyx consists of an epigynous tube, the free margin of which developes after the withering of the flower, sometimes remaining membranous and entire, but usually transformed into bristles, hairs, scales, or a silky pappus (see p. 127). The corolla is always gamopetalous, and is usually $5^{-}$but sometimes $4^{-}$or $3^{-}$ cleft, is either tubular and regular, or bilabiate, having in the lattcr case two divisions in the upper and three in the lower lip, or ligulate. The five stamens are attached to the corolla-tube and are alternate with its teeth; their filaments are free, but their anthers coherent into a tube (syngenesious), always furnished at the apex with one, sometimes at the base with two appendages. The ovary is inferior and milocular, and contains a single erect ovule. The style branches in the upper part into two arms, and is usually furnished with collecting hairs which act like a brush in collecting the pollen. The fruit is a cypsela containing a single seed without endosperm. The flowers (florets) of the central part of the capitulum are often of a different structure and colour from those of the margin; and the two kinds are hence often called florets of the disc and florets of the ray. [The order is divided into three suborders, as follows :-

I. Liguliforis. Flowers all hermaphrodite and ligulate; style with 
filiform branches, pubesccnt ; stigmatic bands separate, and not half as long as the branches of the style. Herbs with alternate leaves and a milky latcx :-Catananche, Cichoriun, Picris, Crepis, Hieracium, Hypocharis, Leontodon, Taraxacum, Lactuca, Sonchus, Tragopogon, Scorzonera, Scolymus.

2. Labiatiflore. Corolla of the hermaphrodite flowers usually bilabiate; of the male and female flowers ligulate or bilabiate:Mutisia.

3. Tubuliflora. Flowers sometimes all tubular, regular and hermaphrodite, rarely irregular and neuter, sometimes those of the disc tubular, of the ray ligulate, the former hermaphrodite, the latter female or neuter :-Vernonia, Enpatorium, Mikania, Solidago, Bellis, Astcr, Erigeron, Conyza, Filago, Gnaphalium, Helichrysum, Inula, Pulicaria, Silphinm, Xanthium, Zinnia, Rudbeckia, Helianthns, Coreopsis, Dahlia, Bidens, Achillea, Anthemis, Chrysanthemum, Matricaria, Tanacetum, Artemisia, Tussilago, Petasites, Arnica, Doronicum, Cineravia, Senecio, Calendula, Echinops, Carlina, Carduns, Cuicus, Onopordon, Cynara, Centaurea, Carthamus.]

Since the Compositze abound in latex, bitter principles, and volatile oils, a large number of species are officinal, while others are of technical or economical value. Among the most important are the following :the flowers of Arnica montana; chamomile flowers from Matricaria Chamomilla and Anthemis nobilis; wormwood from Artemisia chinensis and Absinthium ; coltsfoot from Tussilago Farfara; the leaves of Cnicus benedictus; the roots of Lappa tomentosa, officinalis, and minor, and Anacyclusofficinanm ; elecampane from Inula Holenium; taraxacum from Taraxacum officinale; absinthe from Artemisia Absinthium; the ethereal oil of the tansy, Tanacetum vulgare; the dried latex of Lactuca virosa and satiza. Mikania Guaco of Central America is a remedy against snake-bites; the crushed flower-buds of Pyrethrum carnenm from the Caucasus are used as an insecticide. Among culinary vegetables are the lettuce Lactuca sativa, endive Cichorium Endivia, tarragon Artemisia Dracunculus, chicory Cichorium Intybus, scorzonera Scorzonera hispanica, the Jerusalem artichoke Helianthus tuberosus, and the artichoke Cynara Scolymus. The seeds of the sunflower, Helianthus annuus, yield a useful oil, as does the fruit of Madia sativa; safflower is obtained from the flower-heads of Carthanus tunctorins. 'Everlastings' arc the dried flower-heads of species of Helichrysum and Gnaphalium, and G. leontopodium is the 'Edelweiss' of the Alps. The common marigold is a species of Calendula.

[To this cohort bclong also Valerianacea (Valeriana, Centranthus, Fedia); and Dipsacacere (Dipsacus; Knautia, Scabiosa). 
Cohort X. RUBIALEs. Flowers regular or irregular ; stamens as many as corolla-lobes, epipetalous; ovary 2 - or multi-locular ; ovules solitary or numerous; seeds with or very rarely without endosperm. Shrubs or trees rarely herbs, with opposite or verticillate often stipulate leaves ; calyx never pappose.

Order 1. RUBIACEÆ. (Figs. 504, 505.) Trees or shrubs, rarely herbs, with simple, entire, opposite leaves.] The stipules are in many

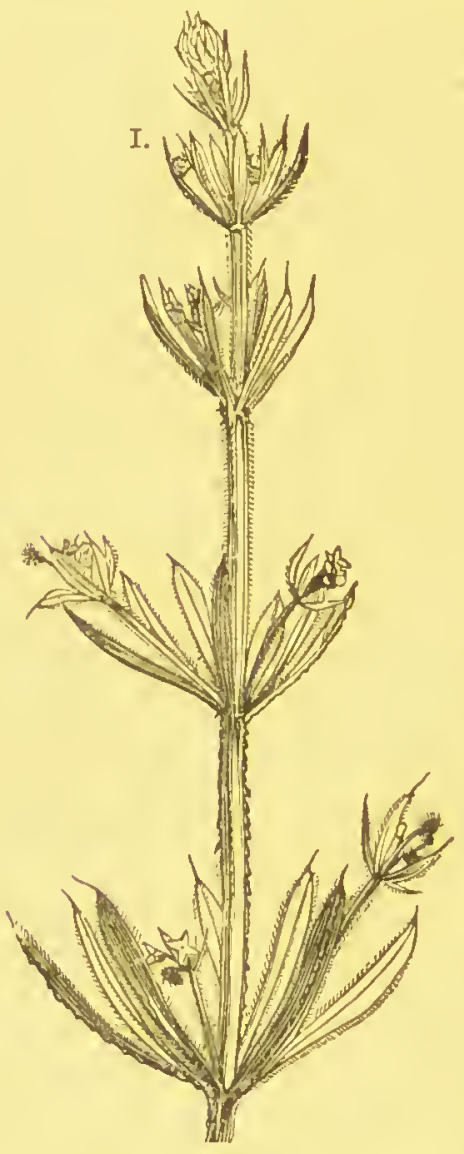

II.

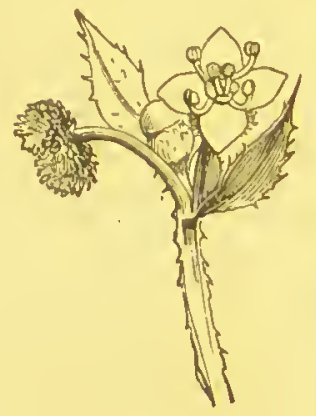

III.

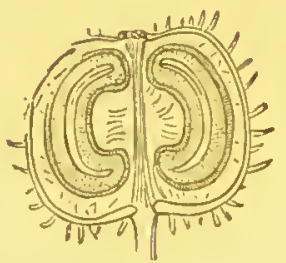

Fig. 504.-Galium Aparine; I. part of plant (natural size); II. flower and fruit (magnified); III. longitudinal section through fruit (greatly magnified).

genera so similar to the true leaves as to give the appearance of a spurious whorl. The stamens are equal in number to the corolla-lobes and alternate with them; the ovary bilocular, the seeds solitary or rarcly two in each loculus, or multilocular and the seeds several in each division. 
The fruit is a drupe, berry, capsule, or achene, or is sometimes dehiscent ; the endosperm large and horny, as in the cuffee-berry, or fleshy. [Th: orcler is a very large one, and is divided into a large number of tribes.

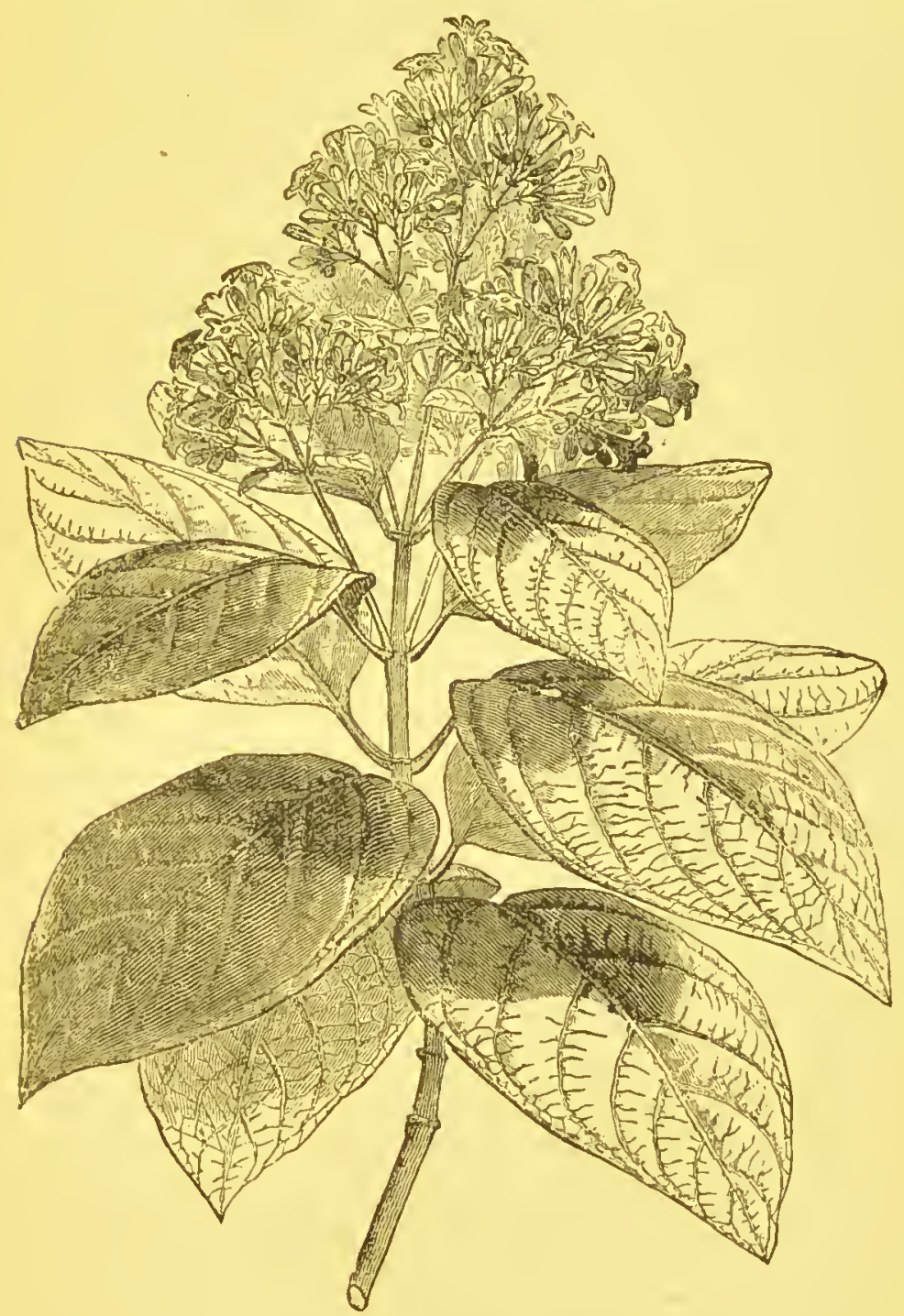

Frg. 505.-Peruvian Bark, Cisthona condamisica (reduced).

The suborders Stellate, Cinchonec, and Coffece of some authors are distinguished by the first having the leaves in apparent whorls from the inter- 
petiolar stipules; the second has opposite leaves and a multilocular ovary with liumerous seeds ; the third opposite leaves and a bilocular two-seeded ovary. The European species all belong to the Stellate, and are herbaceous. Among the morc important genera of the order are the following:-Uncaria, Nauclea, Cinchona, Cascarilla, Conda. minea, Mussanda, Gardenia, Ixora, Coffea, Cephaëlis, Spermacoce, Rubia, Galium, Asperula.] It includes plants of very great medicinal and economical value. Peruvian bark and quinine are obtained from various species of Cinchona, all natives of central and western South America ; the best kind is the product of $C$. Calisaya of Bolivia ; others of $C$. glandulifera of Peru, $C$. condaminea of northern Peru and southern Ecuador, and $C$. succirubra of Chimborazo. It is cultivated with success in Java and India. Coffer arabica, the source of coffee, grows in Arabia and the East and West Indies. Ipecacuanha is the root of Cephailis Ipecacuanha of Brazil. Catechu is the product of the East Induan Uncaria Gambir. The important dye known as madder is obtained from the root of Rubia tinctorum.

[The only other order belonging to this cohort is Caprifoliacee (Ley. cisteria, Symphoricarpus, Linnaa, Weigelia, Lonicera, Vibumum, S(zmbucus).

Division III. CALYCIFLORA.-Sepals connati, rarely free, often adnate to the ovary; petals distinct, in a single whorl, perigynous or epigynous ; disc adnate to the base of the calyx, rarely lumid or raised into a torus or gynophore; stamens perigynous or epigynous, usually" inserted in or benealh the outer margin of the disc; ovary frequenlly inferior.

Cohort I. UMBEILALES. - Flowers usually hermaphrodite; stamens usually definite; ovary inferior, I-, 2-, or multi-locular ; ovules solitary, pendulous; styles free or connate at the base; ovules with the coats confluent with the nucleus; seeds albuminous; embryo usually minute ; flowers generally in umbels.]

Order I. UMBELLIFERÆ. (Figs.506-513.) IIerbs, rarely shrubs, with round or furrowed jointed stem, ard alternate usually compound leaves sheathing at the base. The flowers are hermaphrodite [except occasionally the outermost in the umbel], and are arranged in simple or compound umbels, which in some genera are contracted into capitula by the shortening of the axis; the inflorescence is usually surrounded by an involucre consisting of a single whorl of bracts; when this includes the entire inflorescence it is called the gencral involucre; when it includes only a secondary umbel, a partial involucre or involucel. The calyx-tube 
is adherent to the ovary, but with a free five-toothed or entire maigin [which is however sometimes almost obsolete]. The petals are five, distinct, entire, emarginate or two-lobed, the outer ones often larger than.
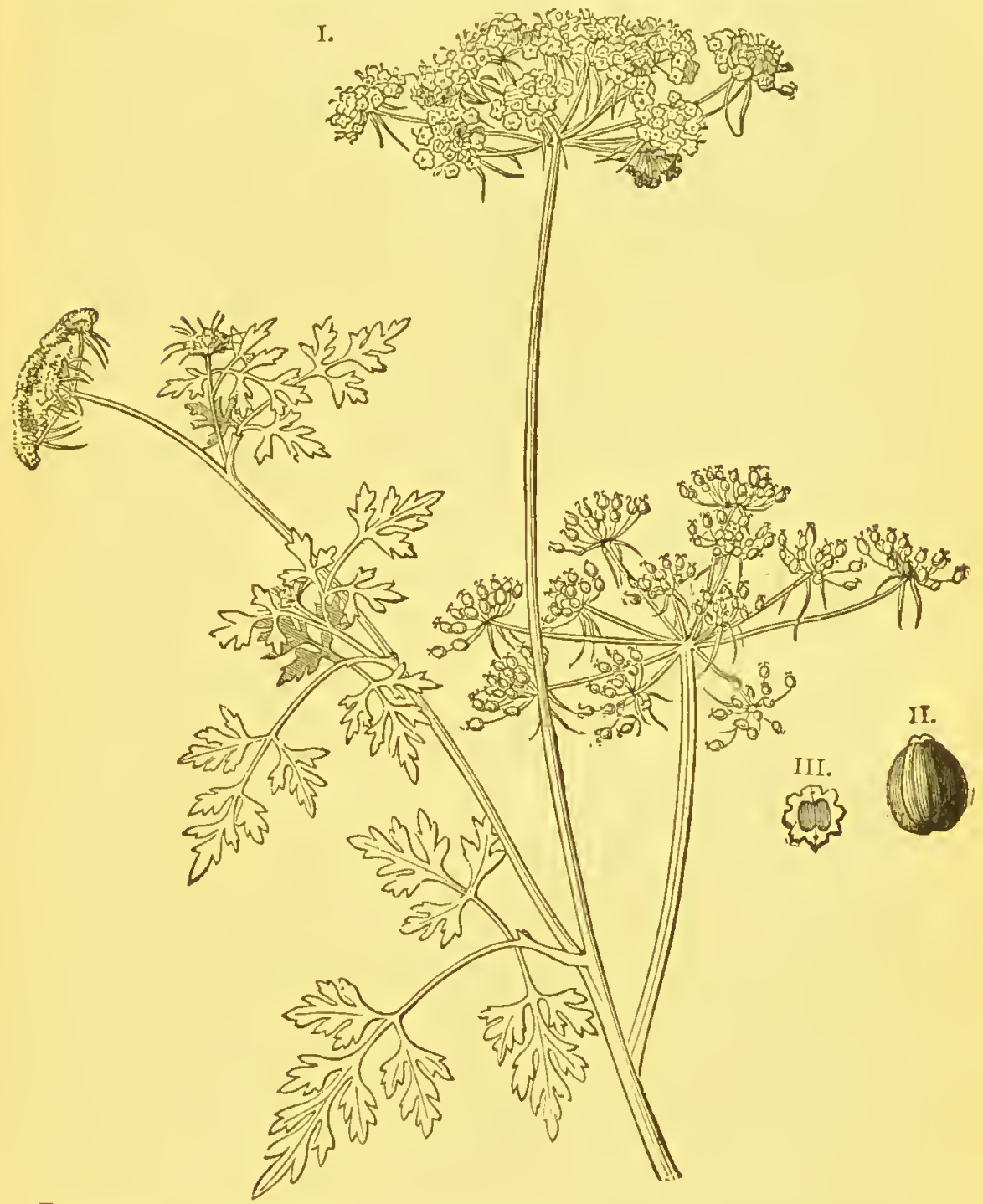
F1G. 506.-I. AEthusn Cynnpimm, fool's parsley (natural size) ; II. fruit (magnified):
III. section of fruit.

the inner, or rayed; adherent to the calyx and alternate with its teeth. The stamens are five, rolled up in vernation; the ovary usually bi-, rarely 
I.

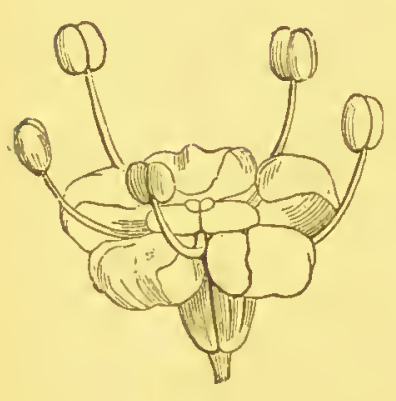

II.

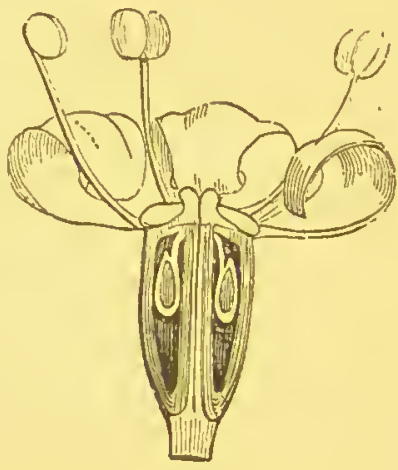

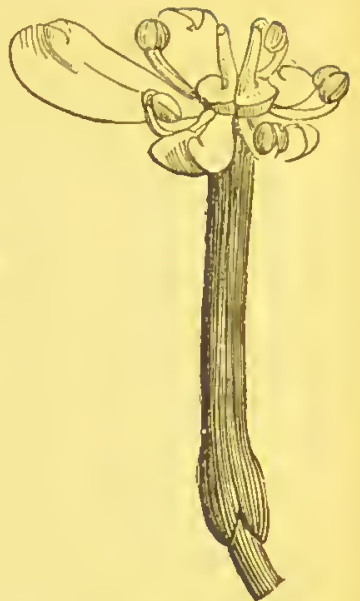

Fig. 507.-Flower of fennel, Faniculum officinale, I. entire; II. in longitudinal section (magnified).

I.

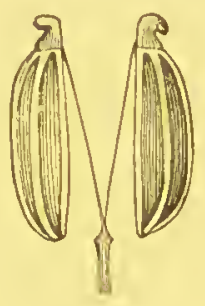

II.

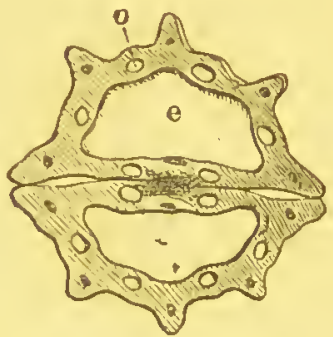

Fig. 508.- Rayed tlower of Venus's cumb, Scandix pecten-Veneris (magnified).

III.

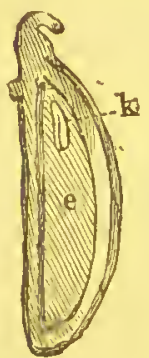

FIG. 509.-I. Fruit of fennel, Faniculum officinale; II, transverse section, $e$ endosperm, $o$ vittæ; III. longitudinal section ; $k$ embryo (magnified).

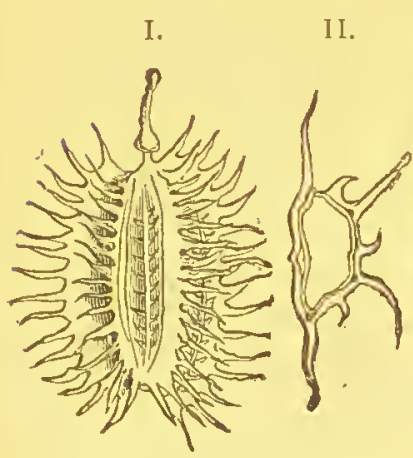

Eig. 510. - I. Fruit of carrot, Dauctes Carota (Orthosperma); II transverse section; the four secondary ridges are conspicu-

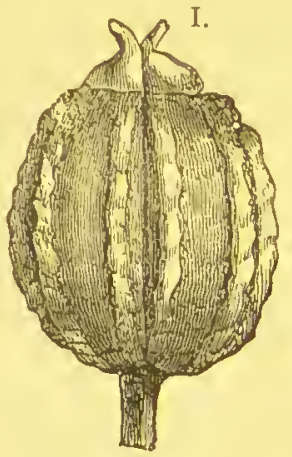

FIG. 5II.-I. Fruit of hemlock, Conium maculatum (Campylosperma) : II. transverse section : part of the embryo is seer in the centre of the endosperm (magnified).
II.

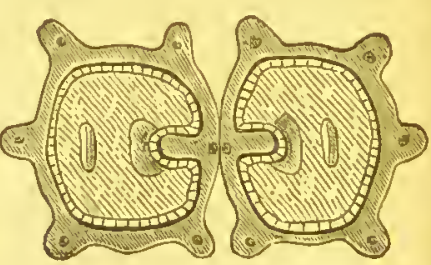

ous : of the primary ridges the two lateral ones are scarcely visible, the median (carina) and mtermediate ones are spiny (magnified). 
uni-locular, and contains a single pendulous ovule in each loculus. Each of the two styles is expanded at its base into the disc, which crowns the apex of the ovary and is termed the slylopode. The fruit is a bipartite

I.

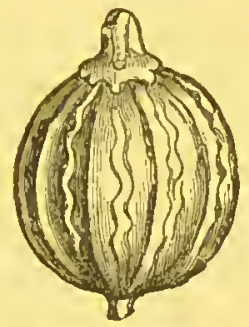

II.

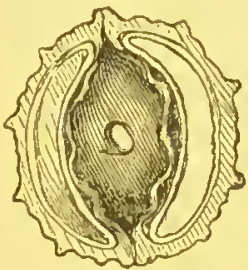

FIG. 512. -I. Fruit of coriander, Corinudrnun sativum (Cœlospermæ) ; II. transverse section (magnified).

schizocarp or cremocarp, separating from below upwards, two halves (mericarps) separating from the columella or carpophore, the carpophore itself splitting from the apex halfway down or to the base (Fig. 509).

I.

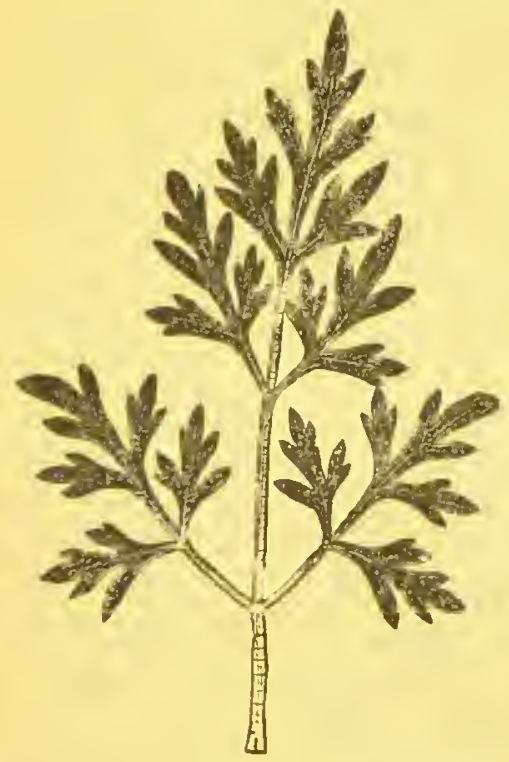

II.

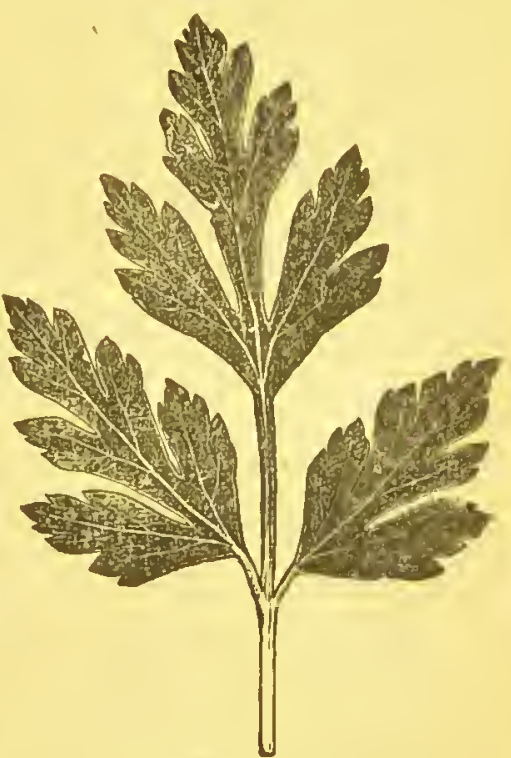

FIG. 513.-I. Lcaf of FEthusn; II. leaf of parsley (nature-printed).

The small embryo is enclosed in the apex of a large endosperm. The free and usually convex outer sides of the mericarps, which are attached to one another by their inner surfaces, are termed the back, and each 
mericarp has five more or less conspicuous longitudinal ridges or primary juga, the median of which is the carina ; the two outermost are the marginal or lateral; those that lie between the intermediate ridges. Alternate with the primary are often four secondary ridges, which are not unfrequently more strongly developed than the primary oncs, but are always at once recognised by their position, the central onc or carina being always a primary ridge. The intervals which separate thc primary ridges are termed furrows; and beneath their surface are a number of slightly projecting canals or vitte containing a volatile oil, which are usually visible only on making a transverse section. The endosperm is on the ventral side, and is either flat, in the suborder Orthosperma, or less often channelled longitudinally by the incurving of the margins (Campylosporme); or hollowed out (Calosperma). [Among the vcry numerous genera belonging to this large and important order are Iy'drocotyle, Eryngium, Astrantia, Sanicula, Conium, Smynnium, Buplourum, Apinm, Cicnta, Ammi, Carnm, Sinn, Sison, AEgopodinm, Pimpinella, Conopolinm, Myrrhis, Charophyllum, Anthriscus, Seseli, Fianculnm, Crithmum, Gsnanthe, Ethusa, Menm, Ligusticum, Itaristicum, Angetica, Archangelica, Ferula, Pencedanum, Heraclanm, Opopanax, Coriandmu, Cuminum, Dancus, Petroseliuum, l'astinaca, Bunium, Ancthum.] The roots contain abundance of 1esin, and the fruits a volatile oil. Among culinary vegetables are the carrot Duncus Carota, chervil Anthriscus cerefolium, celery Apium gra* acolens, parsley J'etroselinum sativum, parsnip Pastinaca sativa, fennel Faniculum officinale, S.c. Among medicinal products are the caraway Carum Carni, coriander Coriandrum sativnm, water-fennel Enanthe Phellandrinm, dill Anethum graveolens, anise Pimpinella Anismm, pimpinella Pimpinella Saxifraga, archangel Archangelica officinalis, lovage Levisticum officinale, assafoetida Narthex Assafotida, ammoniacunı Dorema ammoniacum, and galbanum Galbanum officinale, the last three from Persia. The following are poisonous :- Hemlock Coninm maculatum, fool's parsley Ethnsa Cynapinm, dropwort Enanthe fistulosa, water-hemlock Cicuta virosa, and wild chervil Charophyllnm temulum.

[To the same cohort belong Araliacea (Aralia, Hedera, Panax); and Cornacea (Cornus, Benthamia, Aucuba).

Cohort II. Ficoidales. Flowers regular or nearly so; ovary syncarpous, inferior half-inferior or superior ; unilocular with parietal placentæ, or 2- to multi-locular with basilar or axile placentæ; seed albuminous with curved embryo, or exalbuminous with oblique embryo. Succulent herbs. Orders :-Cactacca (Melocactus, Mamillaria, Echizo- 
cactus, Cereus, Phyllocactus, Epiphyllum, Rhipsalis, Opuntia); Ficoidece (Aizöon, Telephium); Mesembryanthemacer (Mesembryanthemum).

Cohort III. PASSIFLORALES. Flowers usually regular, hermaphrodite or unisexual ; ovary usually inferior, syncarpous, unilocular, with parietal placentx, sometimes $3^{-}$or multi-locular by the produced placentæ; styles frec or connate. Mostly twining or climbing herbs or shrubs, commonly furnishcd with tendrils. Principal orders :-Passifloracia (Malesherbia, Passiflora, Tacsonia, Modecca, Carica); Cucurbitacee (Luffa, MTomordica, Cucumis, Citrullus, Cucurbita, Bryonia, Elaterium, Sicyos, Gynostemma); Bigroniacere (Begonia).

Cohort IV. Myrtales. Flowers regular or nearly so, usually hermaphrodite ; ovary syncarpous, usually inferior ; styles united, very rarely free; placentre axile or apical, rarely basal. Trees, shrubs, or rarely herbs, with simple usually entire leaves.]

Order I. MYRTACEÆ. Trees or slübs, rarely herbs, usually with opposite exstipulate leaves, which appear punctated by glands containing a volatile oil ; flowers solitary in the axils of the leaves; stamcns numerous, with the filaments sometimes cohcrent into one or more bundles; ovary inferior or half-inferior, uni- or multi-locular; the fruit a berry or capsule, generally crowned with the calyx-limb. [Anong the more striking genera of this large and important order, chiefly natives of tropical or subtropical countries, are Callistemon, Melaleuca, Metrosileros, Calothammus, Leptospermum, Eucalyptus, Psilium, Myrtus, Pimenta, Eugenia, Caryophyllus, Barringtonia, Bertholettia, Lecythis, Napoleona.] The flower-buds of Caryophyllus aromaticus of the Moluccas and Antilles are the cloves of commerce; other officinal products of the order are cajeput-oil from Melalenca minor of the Moluccas, and kino, the dried sap of Eucalyptus resinifera of Australia; Eugenia Pinenta of the West Indies is known as allspice. The wood of Metrosideros vera of Australia is the hard and valuable iron-wood. Several species of the Australian genus Eucalyptus or gum-tree, especially the Tasmanian $E$. globulus, are much cultivated for the rapidity of their growth and the anti-miasmatic properties of their leaves. The fruit of Psidium pyriferum is the guava of the West Indies; Brazil nuts are the seeds of Bertholettia excelsa of Brazil ; the fruits of Lecythis ollaria are known as 'monkey. pots."

The other important orders of the cohort are Melastomacea (Melastoma); Lythracee (Lythrum, Lagerstramia); Onasiacee (Epilobium, Fuchsia, Fussieun, Circea, Godetia, Clarkia, Enothera); Rhizophoracea (Rhizophora); Combretacee (Quisqualis, Combretum, Terminalis).

Cohort V. Rosares. Flowers usually hermaphroditc, rcgular or irregular; carpels one or more, usually quite free in the bud, sometimes 
variously united afterwards with the calyx-tube, or enelosed in the swollen top of the peclunele; styles usually distinct or only one.]

Order I. Leguminose. Herbs, shruls, or trees, with stipulate leaves, usually alternate and compound. Calyx either imbricate or valvate in bud, 2 -lipped, 5-cleft or 5-toothed, the odd section being below; very rarely 4-cleft; petals equal in number to the calyxteeth, seldom fewer ; stamens usually double as many, often much more numerous. The monocarpellary, unilocular, free, superior ovary develops into a legume or lomentum, bearing on its ventral suture the seeds, which have no or very little endosperm.

This very large and important order is divided into three well-marked suborders, as follows :-

I. Papilionacere. (Figs. 514-516.) Herbs, shrubs, or trees of very various habit, nsually with alternate and compound, pinnate or digitate leaves. The petiole has two stipules, and sometimes each pinna has also a stipella ; the stipules are sometimes transformed into thorns [or tendrils]; and the petiole frequently ends in a tendril. The flowers are seldom solitary, usually collected into spilies, racemes, or umbels, but never in eompound infloreseences. The ealyx is gamosepalous, 5 -toothed, and often 2-lipped ; the corolla attached to its base, and irregular, 5-leaved, and papilionaceous. The two inferior petals are mostly more or less coherent and form the keel or carina (see Fig. 253, p. 132), the two lateral ones being the wings or alc, and the superior the standard or zixillum. Sometimes all the petals are coherent into a tube [as in Trifolium]. The filaments of the ten stamens are either coherent into a tube (monadelphous) surrounding the pistil, or nine of them form a tube open above, the tenth lying in front of the cleft (diadelphous). The ovary is superior, bearing the ovules on its ventral suture; usually unilocular, but sometimes, as in Astragalus (Fig. 2SS, p. 142), almost bilocular from the folding in of the margin of the carpel. The fruit is a unilocular capsule (legume), splitting into two valves by both dorsal and ventral suture; but sometimes nearly biloeular, like the ovary, or multiloeular by the formation of masses of eellular tissue between the seeds; and then it sometimes breaks up into seetions by the eontraction of the periearp between the seeds, when it is termed a lomentum (Fig. 516, Ir.); rarely indehiscent, as in the sainfoin. The seeds are usually exalbuminous, rarely with a small endosperm; the embryo eurved, with the radicle lying on the cleft of the cotyledons. [Among the more important genera are Baptisia, Crotalaria, Lupinus, Genista, Ulex, Cytisus, Ononis, Trigonella, Medicago, Melilotus, Trifolium, Anthyllus, I.otus, Psoralea, Indigofera, Wistaria, Robinia, Colutia, Astragalus, Oxytropis, Glycyrrhiza, Ornithopus, Coronilla, Hippocrepis, Hodysarum, Onobrychis, Adismia, Arachis, Desmodium, Cicer, Vicia, 
Lens, Lathyrus, Pisum, Kennedya, Butea, Phaseolus, Dolichos, Dalbergia, Pterocarpus, Sophora, Niyroxylon, Swartzia.] The most valuable agricultural and culinary plants are the scarlet-runner and French bean, Phaseolus multiflorus and zulgaris; the field and garden-pea, Pisum sativum; the vetch, Vicia sativa; the bean, Vicia Faba; the lentil,

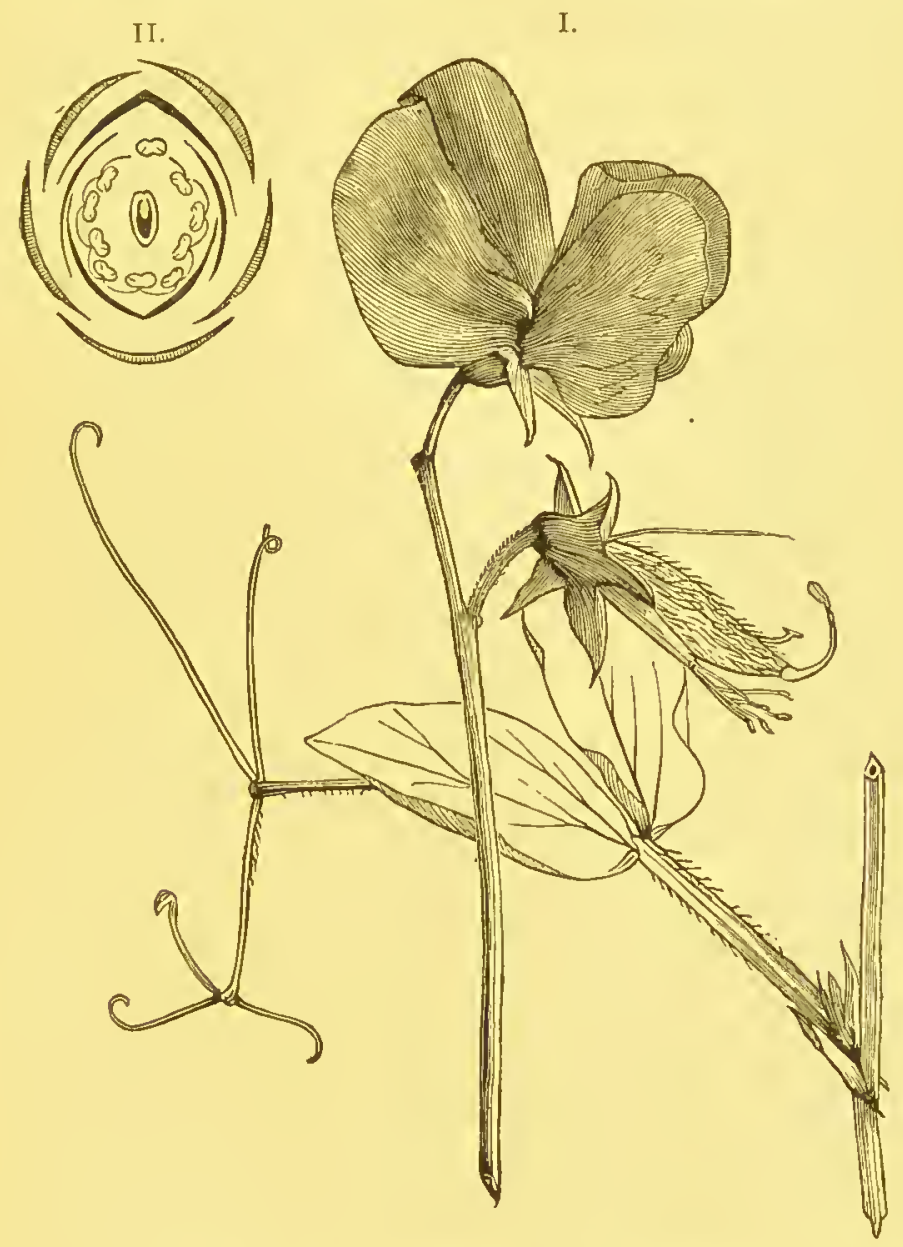

Fig. 514.-Sweet-pea, Lathyrus odoratus ; I. natural size ; II. floral diagram.

Ervum Lens; the chick-pea, Cicer arietinum; the lucerne, Medicago sativa; the sainfoin, Onobrychis sativa; the white lupin, Lupinus albus; and the clovers, Trifolizm pratense, repens, and incarnatum. Among officinal products are the root of the rest-harrow, Ononis spinosa, and 
the foliage and inflorescence of the melilot, Melilotus officinalis. Liquorice is obtained from the roots of Glycyrrhiza cchinata and glabra from southern Europe ; several species of Myroxylon of Peru and Colombia yield balsam of Peru; the boiled sap of the bark of Drepano. carpus senegalensis is known as 'kino africanum;' gum-tragacanth is obtained from several species of Astragalus from Asia Minor; and indigo from the East Indian Indigofera tinctoria; sandal-wood is the

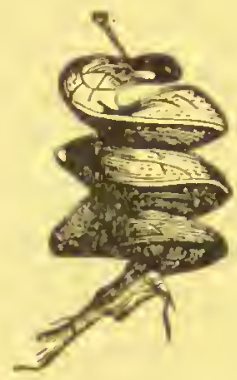

I.

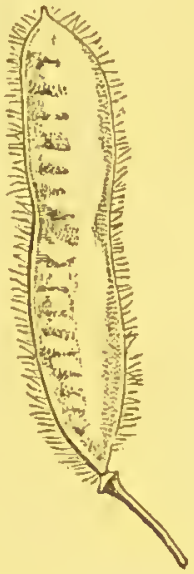

II.

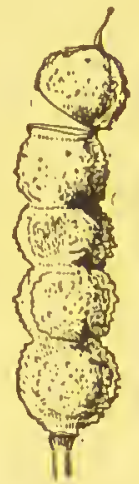

Frg. 5r5. - Twisted legume of lucerne, Medicago sativa (magnified).
FIG. 516.-I. I.egume of Genista : II. lomentum of Hedysarum (natural size).

timber of Pterocarpus santalinus from the East Indies. [The seeds of Arachis hypogaca (earth-nuts) are eaten in the West Indies; Colutea arborescens is the bladder-senna.]

2. Casalpinica. This suborder is distinguished from the Papilionacex by the almost regular not papilionaceous corolla, which is, however, sometimes absent, by the straight embryo, and by the ten or fewer stamens being all free (not coherent). They are always trees or shrubs. [Important genera:-Casalpinia, Hamatoxylon, Gleditschia, Cassia, Ceratonia, Bauhinia, Cercis, Amherstia, Tamarindus, Hymenca, Copaifera.] This suborder is entirely extra-European, but yields a considerable number of officinal or economical products. Tamarinds are the fruit of the East Indian Tamarindus indica; the leaves of Cassia lanceolata and clongata are senna; balsam of copaiba comes from several species of Copaifora, natives of the West Indies and Guiana; Ceratonia Siliqua of the eastern Mediterranean is the carob; and Dipteryx odorata of Guiana the poisonous tonka-bean. Casalpinia echinata and brasilicnsis of Brazil yield Brazil-wood, containing a 


\section{Spccial Morphology and Classification.}

red colouring principle; C. Sappan is the red sappan-wood of Eastern India, and Hematoxylon campechianum of Central America, logwood.

3. Mimosece (Fig. 517). This suborder is also extra-European and chiefly Australian and East Indian. They are distinguished from the

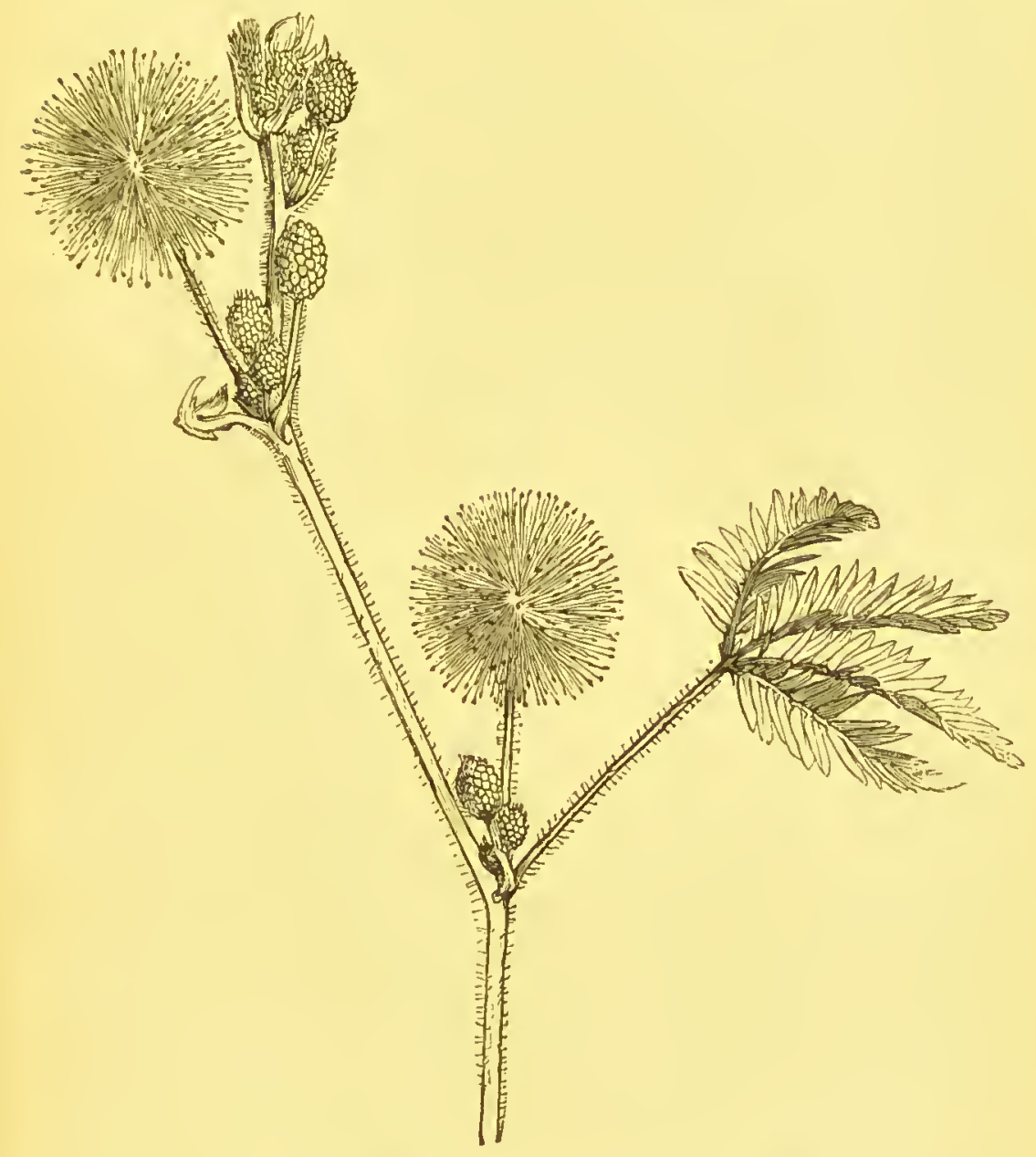

FIG. 517.-Sensitive-plant, Mimosa pudica (natural size) (see p. 202).

Papilionacex by the valvate rstivation of the calyx, and the regular, often gamopetalous, corolla. The stamens are sometimes very numerous, and either coherent or free. [The leaves are often replaced by phyllodes,) see p. 9I). Principal genera :-Mimosa, Acucia. The suborder includes the sensitive plants Mimosa pudica and sensitiva 
[see p. 202), and the true Acacias.] Gum arabic is obtained from Acacia Seyal, tortilis, and Ehrenbergiana, all natives of tropical Africa ; 'terra japonica,' or catechu, is the sap of Acacia Catechu of Bengal and Coromandel.

Order 2. ROSACE E. The leaves are stipulate ; the calyx regular and usually gamosepalous and 5-partite, the odd section superior; the corolla regular; the petals distinct, attached to the margin of the calyx, and equal in number with its teeth ; the stamens perigynous, usually many times the number of the petals, and bent inwards in vernation; the ovary sometimes monocarpellary, but more often multicarpellary, the carpels being either free or coherent with one another and with the calyx; the fruit dry or succulent, a berry, drupe, or a number of achenes or follicles ; the seeds exalbuminous. This large and important order is again divided into suborders :-

I. Ponee. (Figs. 518, 519). Trees or shrubs with alternate usually simple leaves furnished with free deciduous stipules. The flowers are

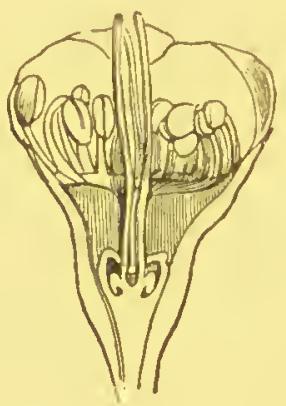

FIG. 518. - Longitudinal section through the flower of the pear (magnified).

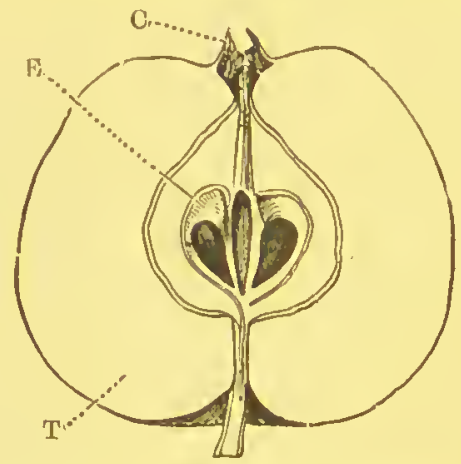

FIG. 5xg. - Longitudinal section through an apple ; c dry persistent calyx-limb ; E loculi with cartilaginous pericarp; T mesocarp (reduced).

regular and arranged in short terminal umbels, racemes, or cymes, often corymbose; the calyx-limb is 5-cleft or 5-toothed, imbricate in æstivation, and remaining dry and persistent on the fruit; the stamens numerous, and, like the five petals, attached in a ring to the base of the calyx (Fig. $5^{\mathrm{I}} 8$ ); the ovary is as a rule 5-, more rarely 2 - or 3 -locular, each loculus usually containing two ovules; styles equal in number to the loculi. The fruit [or pseudocarp (see p. 147)] is succulent, a berry or pome, or formed of a number of drupes, the pericarp being thin, cartilaginous, or stony. [Principal genera :-Pyrus, Coloneaster, Crategus, DTalus, Sorbus, MTespilus, Cyclonia.] Among edible fruits are the apple and pear Pyrus Malus and communis, the quince Cydonia vulgaris, the 
medlar Mespilus gcrmanica, the hawthorn or whitethorn Cratagus oxyacantha, and the mountain ash Sorbus aucuparia.

2. Rosea (including Sanguisorbeæ, Dryadeæ, and Spiræeæ) (Figs. 520-522). Herbs, shrubs, or trees, usually with pinnate or digitate leaves, provided with stipules adherent to the base of the petiole. In

I.

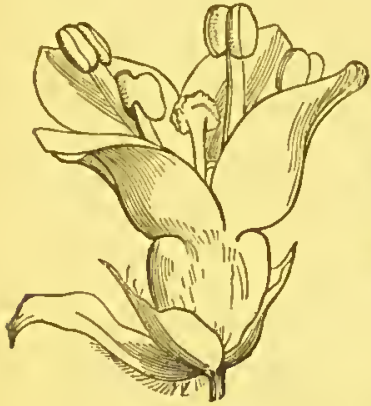

FIG. 520.-Sanguisorbo officinalis ; 1. Hower ; II. fruit (magnified).

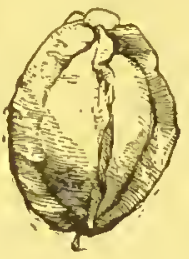

II.

I.

II.
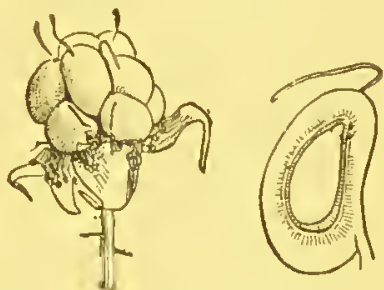

FrG. 521.-Fruil of dewberry $(R u$ buts coesizes); 1. natural size ; II. a single drupel (magnified).

the number and structure of the parts of the flower Rosex agree for the most part with Pomeæ, but are best distinguished by the numerous free and unilocular ovaries, not adherent to the calyx. The 5-, rarely 4-cleft gamosepalous calyx has a tube of various structure, and is often surrounded by a 4- or 5-cleft epi-calyx or involucre, the leaves of which alternate with the sepals; the petals are perigynous [sometimes wanting]; the stamens rarely so few as five, usually 2 to IOO, free and also perigynous; the ovaries mostly with only a single anatropous ovule; and the style usually more or less lateral. [Principal genera :-Rosa, Alchenilla, Poterium, Sanguisorba, Agrimonia, Rubus, Fragaria, Geum, Comanum, Dryas, Po. tentilla, Spirca.] The fleshy calyx-tube or receptacle of the rose forms an edible

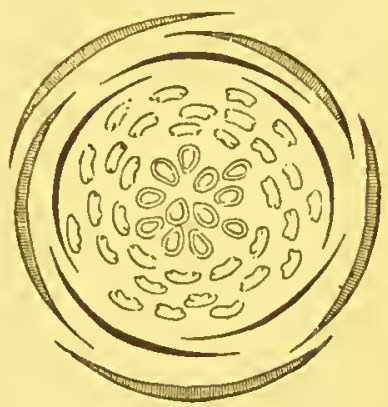

FIG. 522.-Floral diagram of the rose. See Fig. 256, p. 133. pseudocarp known as a hip ; true edible fruits are borne by the raspberry Rubus Idcus, and blackberry $R$. fruticosus; an edible receptacle or pseudocarp (see p. I46) by the strawberry Fragaria vesca, clatior, and grandifolia. Oil of roses is obtained from Rosa moschata and damascena of Asia Minor. The bark of Quillaja saponaria of Chile is saponaceous, and known as soap-wood; the flowers of Margera anthelmintica 
of Abyssinia are a powerful anthelmintic; the root of Gcum urianum and of Torncentilla resta are also officinal.

3. Amygdalex (or Drupaceæ). Shrubs or trees with simple alternate leaves provided with free deciduous stipules. This suborder is distinguished from the rest of the order by the ovary, which is composed of a single superior carpel not adherent to the calyx, and which developes into a drupe (see p. I52). In the course of development the pericarp becomes differentiated into three layers, of which the outermost or epicarp forms a more or less tough skin, the middle layer, the mesocarp or sarsocarp, a more or less pulpy flesh, and the inncr one, the endocarp or putamen, a hard stone. The fruit contains one or rarely two seeds. with fleshy cotyledons, and radicle directed upwards (see Figs. 220 and 325 I. pp. II9, I53). [Principal genera :-Amygrilalus, Cerasus, Persica, Prunus, Armeniaca.] This suborder is marked by the tendency to form substances containing hydrocyanic acid, which is found especially in the seeds of the pench, apricot, cherry, plum, sloe Prinus spincsa, bitter almond, and in the leaves of the cherry-laurel Prunus lauro-ceresus. Edible fruits or seeds are furnished by the almond Amygralus communis, peach Persica ontgaris, nectarine $P$. lueris, cherry, species of Cerasus, apricot Armeniaca vulgaris, and plum Prunus domestica. [The stem of many species yields gum, and the wood a valuable timber for cabinct-work.

Besides other less important orders belonging to this large cohort, are Saxifragacece (Saxifraga, Chrysosplenium, Hoteia, Astilhe, Cunonia, Hydrangea, Escallonia, Deutzia, Ribes, Cephalotus, Philadelphus, Parnassia) ; Crassulacece (Tillaca, Cotyledon, Crassula, Sedum, Sempervizum, Bryophyllun, Echeveria, Umbilicus); Drosiracea (Drosera, Dionca ; see pp. 169, 203).

Division IV. Digcifloræ.-Sepals distinct or united, free or adnate to the ovary; petals distinct; disc usually conspicuous as a ring or cushion, or spread over the base of the calyx-tube, or confuent with the base of the ovary, or broken up into glands; staments usually clefiniti, iusertid upon or at the outer or inner base of the disc; ovary superior.

Cohort I. SAPINdales. Flowers often irregular and unisexual ; disc tumid, adnate to the base of the calyx or lining its tube ; stamens perigynous or inserted upon the disc, or between it and the ovary, usually definite ; ovary entire, lobed, or apocarpous; ovules one to two in each loculus, usually ascending with a ventral raphe, or rcversed, or pendulous, from a basal funiculus, rarely indefinite and horizontal ; seed usually exalbuminous; embryo often curved or crumpled. Shrubs or 
trees, mostly with compound leaves. Principal orders :-Sapindacece (Paullinia, Esculus, Sapindus, Pavia, Acer, Negunndo, Dodonca, Staphylea); Terebinthacec (Rhus, Pistacia, Mangifera, Anacardium).

Cohort II. Celastrales. Flowers hermaphrodite, regular ; corolla hypogynous or perigynous ; disc tumid, adnate to the base of the calyx-tube or lining it ; stamens as many as the petals or fewer, rarely twice as many, perigynous or inserted outside the disc or on its edge ; ovary usually entirc ; ovules one to two in each loculus, erect; raphe ventral. Shrubs or trees, rarely herbs, usually with undivided leaves. Principal orders:-Celastracee (Euonymus, Elcodendron, Celastrus, Hippocratia); Rhamnacece (Paliuns, Zizyphus, Rhamnus, Ceanothus) ; Ampelidere (Cissus, Vitis, Ampelopsis).

Cohort III. Geraniales. Flowers often irregular; disc usually annular, adnate to the stamens or reduced to glands, rarely absent; ovary multicarpellary, syncarpous or subapocarpous; ovules one to two, rarely numerous in each carpel, ascending or pendulous; raphe usually ventral. To this very large cohort belong the following orders, in addition to others of less importance:-Linacece (Linum, Erythroxylon); Malpighiacere (Malphigia); Zygophyllacee (Tribulus, Zy'gophyllum, Fagonia, Guaiacum); Geraniacea (Geranium, Erodium, Pelargonium, Tropacolum, Limnanthes, Oxalis, Biophytum, Averrhoa, Impatiens); Rutacea (Ruta, Dictamnus, Peganum, Diosma, Barosma, Eriostemon, Correa, Zanthoxylum, Citrus, AEgle, Limonia); Simarubacea (Quassia, Samadera, Simaba, Cneorum, Simamba, Brucea, Ailantus, Balanites, Picramnia); Burseracece (Boswellia, Canarium, Balsamodendron, Bursera, Amyris) ; Meliacece (Melia, Swietenia, Cedrela, Chloroxylon).

Division V. Thalamiflor A.-Sepals usually distinct and separate, free from the calyx; petals in one, two, or many whorls, hypogynous; stanens hypogynous, rarely inserted on a longer or shorter receptacle or on a disc; ovary superior.

Cohort I. Malvales. Flowers usually regular; sepals five, rarely two to four, free or united, valvate or imbricate; petals as many as sepals, or absent ; stamens usually indefinite and monadelphous; ovary 3-locular or more, rarely monocarpellary; placentation axilc. Shrubs, rarely herbs or trees, with alternate, usually stipulate, simple or compound leaves.]

Order I. Malvace E. (Fig. 523.) Herbs, shrubs, or trees, with simple, alternate, stipulate leaves. The calyx is 3 - to 5 -cieft, and usually surrounded by an epi-calyx or involucre of bracts; the petals are equal in 
III
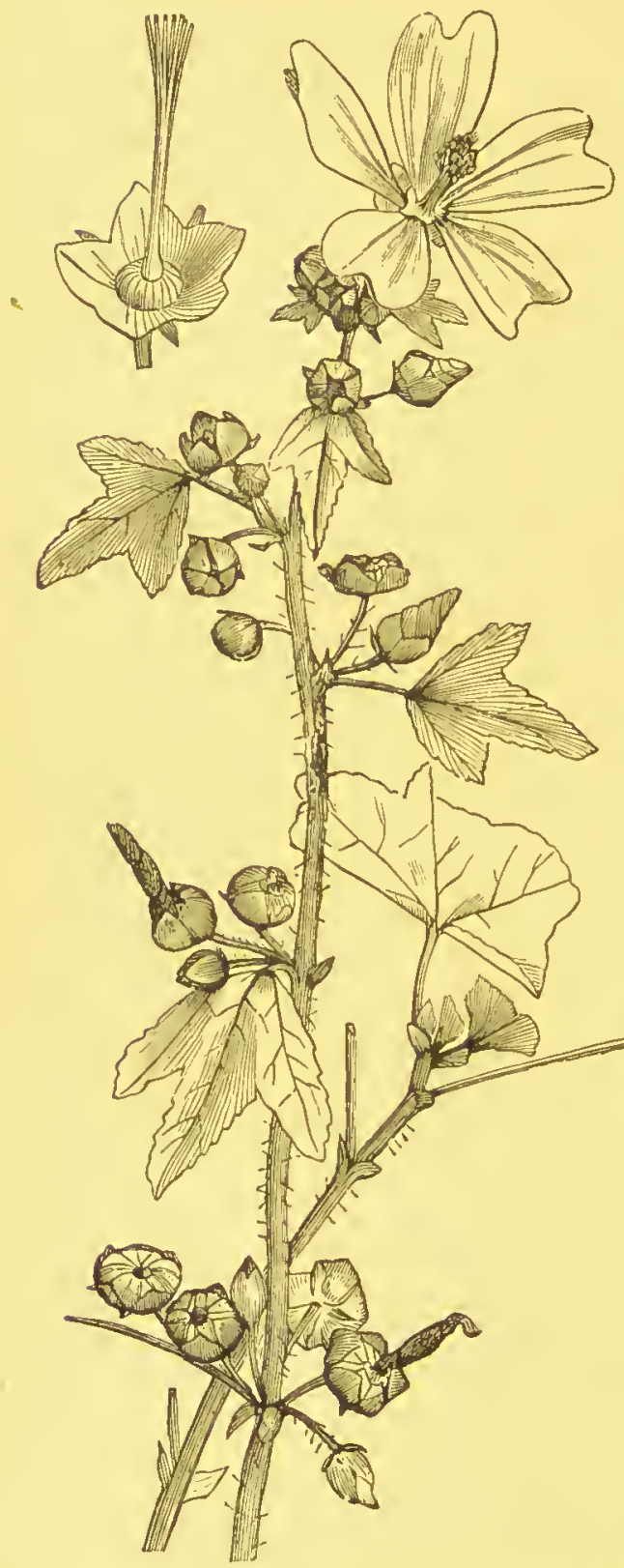

Fig. 523.-Malza sylvestris: I. portion of plant (reduced); II. the monadelphous stamens (magnified); III. the pistil. IV. the fruit (natural size) 
number to the lobes of the calyx, and contorted in rstivation [while the calyx is valvate]; the filaments of the numerous stamens are coherent at their base with the petals, and united into a tube which encloses the superior ovary; the anthers are unilocular and dehisce in a semicircular line; the ovary multicarpellary, the carpels arranged round a central axis, and either free or united; the fruit a capsule or schizocarp ; the cotyledons of the straight embryo are folded together, and the seed has little or no endosperm. [Principal genera:-Malope, Althaa, Lavatera, Malva, Hibiscus, Gossypinm, Sida, Abutilon, Adansonia, Bombax, Eriodendron, Durio.] Many plants belonging to this order are officinal on account of the quantity of mucilage they contain, as the roots of Althea officinalis, the flowers of the hollyhock Althea rosea, and of A. sylvestris, and the foliage of Malva rotundifolia. Cotton consists of the hairs attached to the testa of several species of Gossypium, especially $G$. herbaceum, arborenm, and religiosum, natives of all tropical countries. The baobab, Adansonia digitata of West Africa, is one of the most gigantic of trees. [The fruit of Durio is edible.

The other orders of the cohort are Sterculiacee (Lasiopetalum, Buttneria, Theobroma, Sterculia, Thomasia); and Tiliacece (Grewia, Tilia, Triumfetta, Corchons, Elcoocarpus).

Cohort II. GutTiferales. Flowers regular; sepals and petals each usually four or five, imbricate in bud ; stamens usually indefinite ; ovary 3 - to multi-locular, rarely 1 - or 2-locular; placentation axile. Trees or shrubs, rarely herbs. Principal orders :-Hypericacee (Hypericum); Guttifere (Clusia, Garcinia); Camelliacece (Ternstramia, Camellia, Thea, Caraipa, Marcgravia); Dipterocarpacee (Dryobalanops, Dipterocarpus, Shorea, Vateria).

Cohort III. Caryophyllales. Flowers regular; sepals two to five, rarely six; petals usually as many as sepals ; stamens as many or twice as many, rarely more or fewer ; ovary unilocular, or imperfectly 2- to 5-locular; placentation free central, rarely parietal; ovules campylotropous ; embryo usually curved, in a floury endosperm.]

Order 1. Caryophyllaces. (Figs. 524, 525.) Herbs, very rarely shrubs, with simple, entire, opposite leaves, springing from tumid nodes, and cymose inforescence. The flowers are regular and pentamerous; the calyx 5 -cleft or 5 -toothed, sometimes of 5 distinct sepals; the corolla of 5 distinct petals, which are often deeply bifid; the stamens Io, in two rows, though all are not always perfectly developed, the five inner ones often coherent with the base of the petals ; the pistil consists of from two to five carpels; the placentation is free central, from the original dissepiments breaking away from the outer wall of the ovary before maturity ; the styles are free and equal in number to the original 
divisions of the ovary; the fruit a capsule dehiscing with tecth. The seeds have a floury endosperm, and a long curved embryo, which either entirely surrounds the endosperm or lies on one sidc of it. Some species are monœecious, diœcious, or polygamous, from the abortion of pistil or stamens. [Principal genera:-Agrostemma, Silene, Lychnis, Cucubalus, Viscaria, Saponaria, Gypsophila, Dianthus, Cerastium, Stellaria, Arenaria, Alsine, Spcrgula.] With the exception that some species are

I.

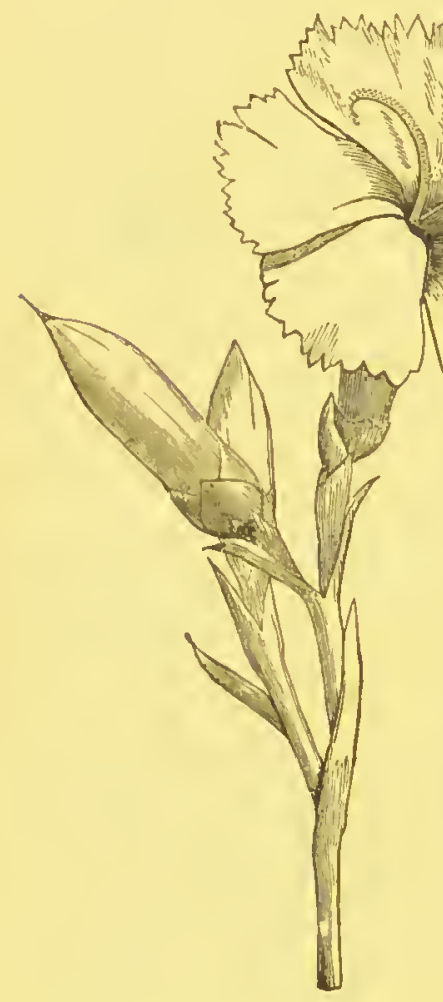

FIG. 524.-Dianthus Caryophyllus:

I. portion of plant (natural size): II. stamens (magnified). See Figs. 250,251 , P. $131 ; 254,255$, p. 132.
II.

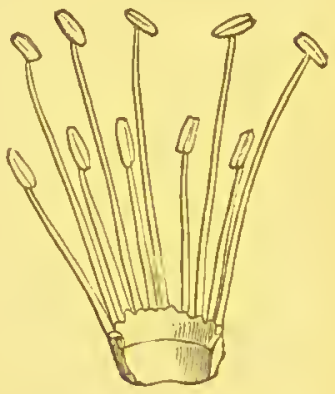

I.

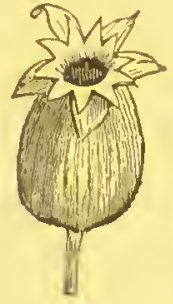

II.

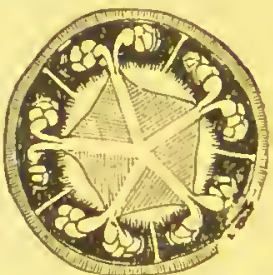

FIG.525.- White campion, Lychnis nespem tima: I. fruit (natural size); II. transverse section through ovary. See fig. 254, p. 132.

saponaceous, the order is entirely destitute of economic propcrties ; but many are grown in garuens for the beauty of their flowers.

[The only other order of importance belonging to the coliort is. Portulacacea (Claytonia, Portulaca, Sesuvium, Mollugo).

Cohort IV. Polygalales. Flowers regular or irrcgular; sepals 
and petals five each, rarely four or three ; stamens as many or twice as. many as petals; ovary 2-locular, rarely unilocular or more; endosperm fleshy, rarely absent. Herbs, shrubs, or trees, with exstipulate leaves. Principal order Polygalacece (Polygala, Krameriu, Securidaca).

Cohort V. Parietales. Stamens definite or indefinite; carpels connate into a unilocular ovary with parietal placentation, rarely spuriously bilocular or more by the prolongation of the placentæ (carpels occasionally free; ovary occasionally 3 -locular or more).]

Order I. Papaveracee. (Fig. 526.) Herbs with a yellow or white: latex. The sepals are two, distinct, deciduous; the petals four, arranged

II.
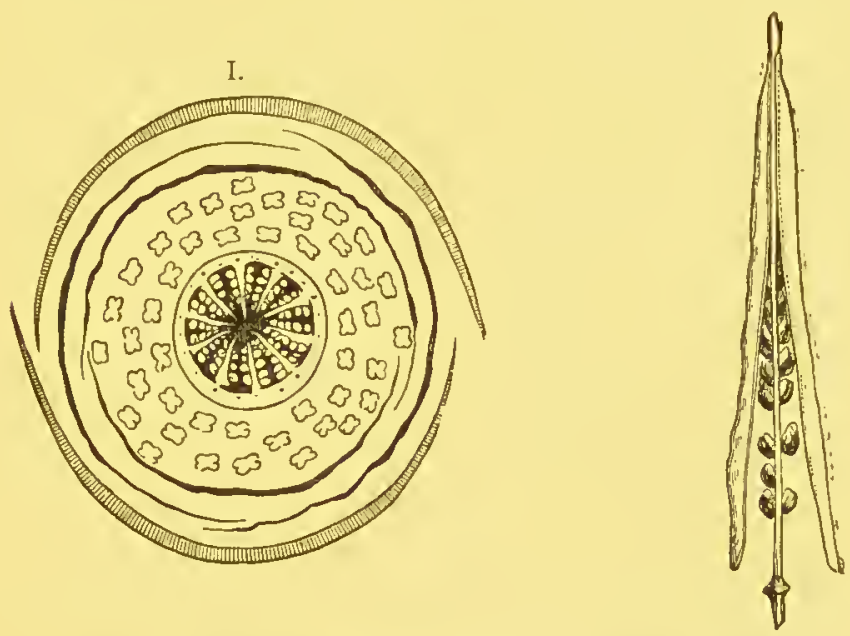

FIG. 526.-I. Floral diagram of Papaver ; II. capsule (siliqua) of Chelidonizm (natural size).

in two whorls, regular [and deciduous]; the stamens indefinite, free and hypogynous; the ovary unilocular or spuriously multilocular; the seeds with a small straight embryo at the base of a copious endosperm; the fruit a capsule, either bursting into two valves, and resembling a siliqua (Fig. 526, II.), or opening by pores, four to twenty in number, situated beneath the peltate stigma (see Figs. 233, 294, 313, pp. 126, 144, I50). [Principal genera:-Platystemon, Chelidonium, Sanguinaria, Papaver, Eschscholtzia, Argemone, Glaucium, Meconopsis, Rameria.] Among officinal products of the order are the foliage of the larger celandine Chelidonium majus, the petals of the common poppy Papaver Rhoas, and the dried latex of the unripe capsules of the opium-poppy Papaver somnifertum. The latter is an important article of commerce from Egypt, Turkey, [India, and China], yielding opium and laudanunı. 
Order 2. CRUCIFERæ. (Figs. 527-530.) Herbs with alternate exstipulate leaves. 'The sepals are four, usually deciduous; the petals four,

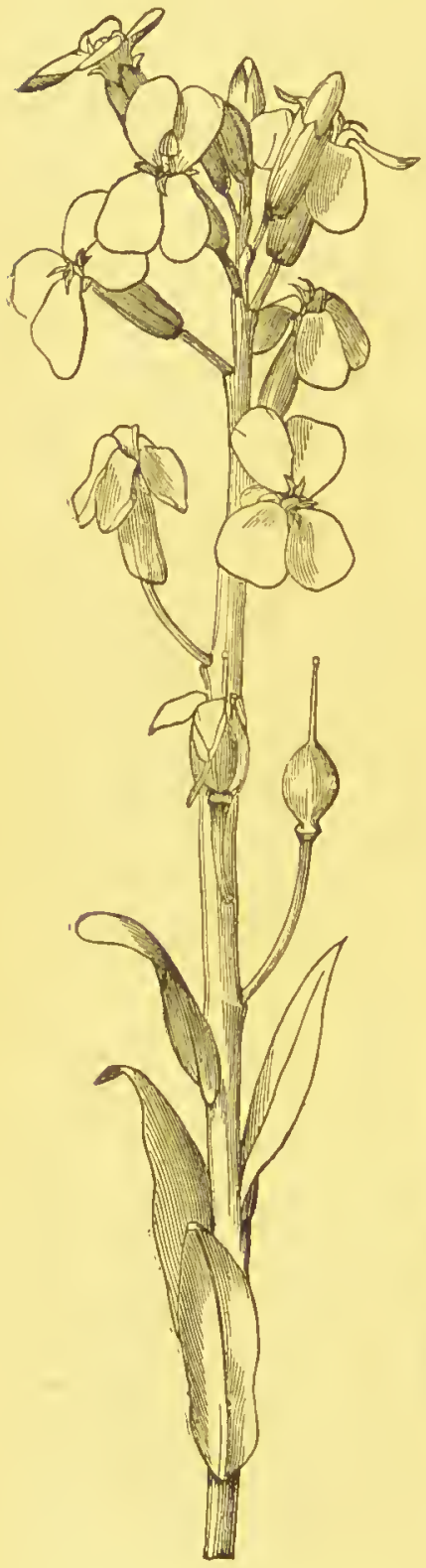

FrG. $527-V e s i c a r i a$ utriculata (Siliculosie, natural size).

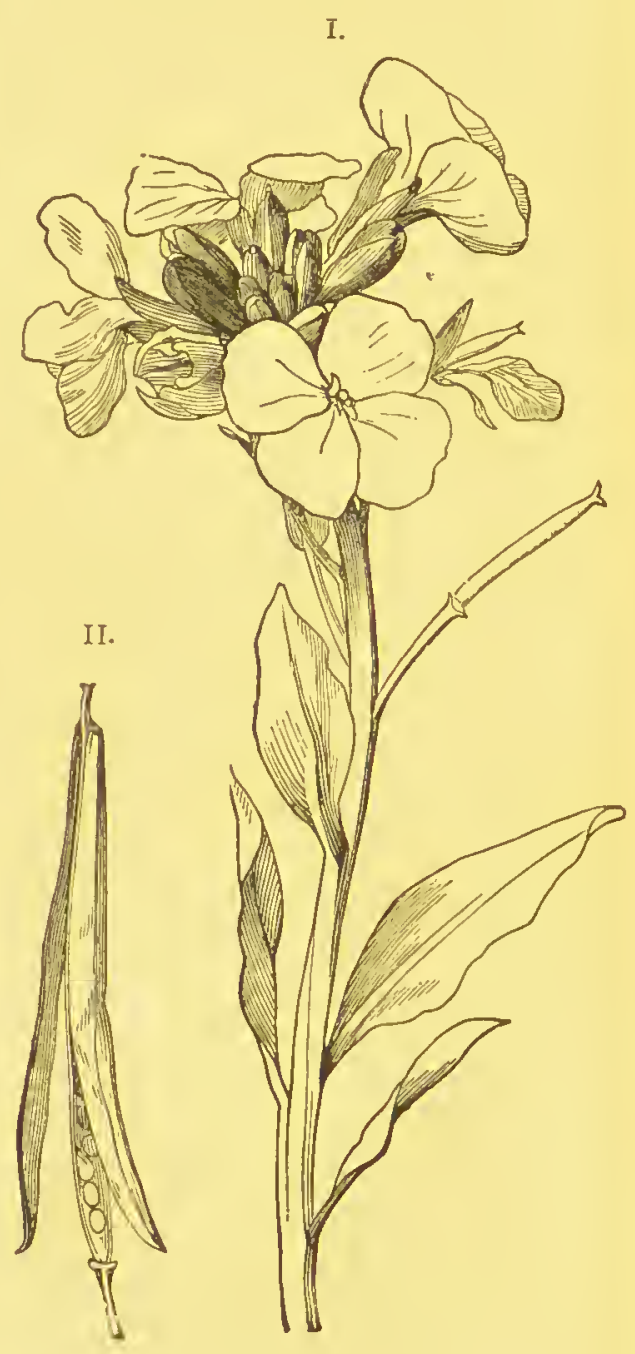

FIG. 528.-- Wallflower, Cheiranthus Cheiri (Siliquosa): I. part of plant; II. siliqua (natural size). 
alternate with them, arranged in a cross, and usually unguiculate; the stamens six, tetradynamous, the two shorter ones belonging to an outer whorl and opposite to the carpels, the four longer ones to an inner whorl and attached in front of the placentæ (see Figs. 200, 204, pp. III, I I2). The ovary is superior; the fruit as a rule a bilocular capsule, bursting from the base upwards ; if it is several times longer than broad, it is termed a silizua (Fig. 528 , II.); if only slightly or not at all longer than broad a silicula (Fig. 527). According as the dissepiment or replum, when seen in transverse sections, occupies the shorter or longer

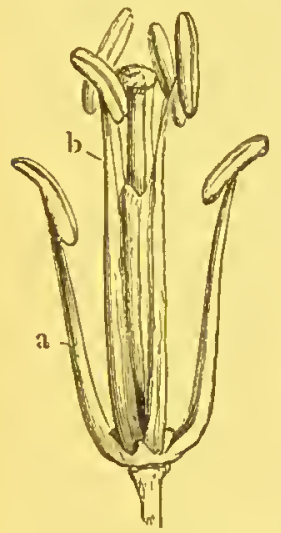

Fig. 529. - Tetradynamous stamens and pistil of Brassica nigra; $a$ shorter, $b$ longer stamens.
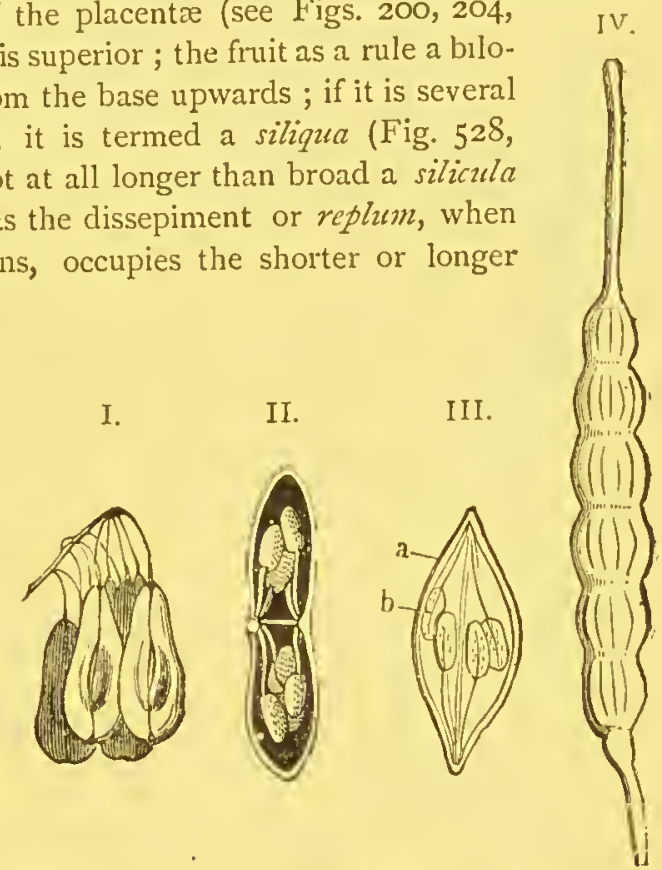

FIG. 530.-I. Schizocarps of Isatis tinctoria ; II. transverse section of angustisept silicula of Capsella: III. transverse section of latisept silicula $a$ of Camelina : $b$ four seeds; IV. lomentum of Raphanis.

diameter, the silicula is said to be angustiscpt, as in the shepherd's purse, Capsella (Fig. 530, II.), or latisept as in Camelina (Fig. 530, III.). Less. often the siliqua splits transversely, forming a lomentım, as in the radish, Raphanues (Fig. 530, IV.), or the fruit is a schizocarp, often at first bilocular, but ultimately unilocular by the disappearance or perforation of the dissepiment, as in the dyer's woad Isatis (Fig. 530, I.). The seeds are exalbuminous, with a curved embryo, the position of which is an important character in the classification of the genera belonging to the order (see p. 157). [This large and important order is divided into several suborders, and includes a large number of genera, of which the following are the more important:-Matthiola, Cheiranthus, Nasturtuzm, Barbarea, Arabis, Cardamine, Anastatica, Lunaria, Aubrietia, Vesicaria, Alyssum, Draba, Cochlearia, Schizopetalum, Hesperis, Malcolmia, Sisymbrium, Erysimum, Braya, Camelina, Brassica, Sinapis, Era. 
castrum, Diplotaxis, Vella, Capsella, Senebuera, Lepidum, Megacarpara, Thlaspi, Tberis, Teesdatia, Isatis, Myagrum, Bunias, Crambe, Cakile, Erucaria, Raphanus, Dentaria, Alliaria, Armoracia, Pringlea.] It furnishes a large number of culinary vegetables. The common cabbage, Brassica oleracea, is the parent-form of all the varieties, as kohl-rabi, savoy, Brussels sprouts, broccoli, cauliflower, \&c. [the two latter forms owing their peculiarity to a suppression of the floral organs, and an abnormal development of the pedicels of the inflorescence]. The seeds of other species contain an oil known as rape-seed oil. The turnip and Swede are varieties of Brassica Napus. Other culinary species are the water-cress Nasturtium officinale, and the garden-cress Lepidium sativum. The rhizome of Cochlearia Armoracia is known as horse-radish; the root of Raphanus sativus is the common radish; mustard is obtained from the seeds of Sinapis nigra. [The antiscorbutic properties possessed by so many plants belonging to this order are due to the presence of a principle containing sulphur.] A large number of species are grown for the beauty of the flowers, among others the so-called 'rose of Jericho,' Anastatica hicrochuntica. [The leaves of the woad, Isatis tinctoria, yield a blue dye.

[Order 3. VIOLACE.E. Herbs with alternate, usually stipulate leaves; corolla of 5 unequal petals, often spurred; stamens 5 , with adnate anthers and often prolonged connective. Fruit a unilocular 3-valved capsule with 3 parietal placentæ. Several species are purgative. Principal genera :-Viola, Tonides, Alsolleia.]

The remaining orders of importance belonging to the cohort are Fumariacee (Hypecöum, Dicentra, Fumaria, Corydalis) ; Capparidea, (Cloome, Capparis); Resedacece (Reseda); Cistacece (Cistus, Helianthenum); Bixacea (Bixa, Cochlospermum, Flacourtia).

Cohort VI. RANales. Stamens almost always indefinite ; carpels free or immersed in the receptacle, very rarely syncarpous; micropyle usually inferior ; embryo minute in a fleshy endosperm.]

Order I. RanunCUlace.e (Figs. 531-533). Herbs with alternate, or less often shrubs [with opposite] leaves, exstipulate and often divided and semi-amplexicaul. The sepals are from three to six, [deciduous] and often petaloid; the petals from 4 to 15 , arranged in one or more rows, [some or all of them] often small and assuming the form of nectaries, (Fig. 533 IIr.) ; or the corolla is entirely absent; the stamens free, indefinite, and hypogynous. The fruit consists of an indefinite number of one-seeded, indehiscent achenes, each representing a carpel with its own style and stigma [Ranuuculus, Anemone], or of several follicles, j.c. capsules opening by the ventral suture only, [Caltha, Pronia, Delphinium, Acoutum], or is more rarely a one- or several-seeded 
berry [Actæa]. The small embryo is enclosed in a copious fleshy endosperm. [Among the more important genera of this large order

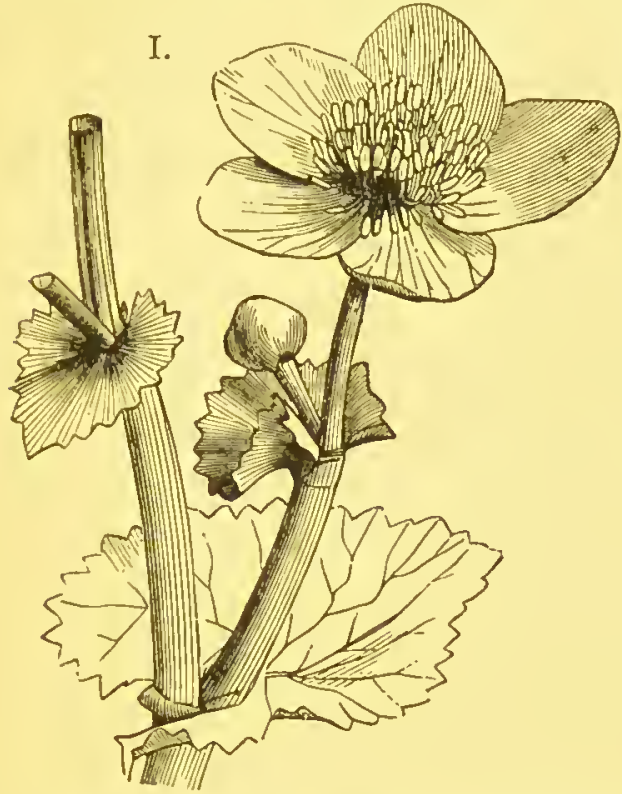

II.

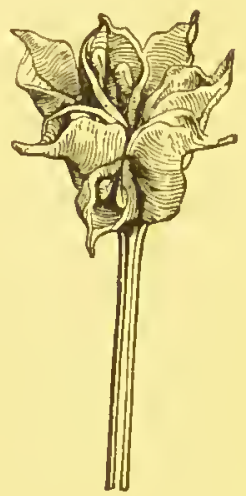

Fig. 53x.-Marsh marigold, Caltha palnstris; I. part of plant ; II. fruit, consisting of follicles (natural size).

are Clematis, Thalictrum, Anemone, Adonis, Myosurus, Ranunculns, Caltha, Hydrastis, Trollizı, Helleborns, Eranthis, Nigella, Aquilegia,

I.

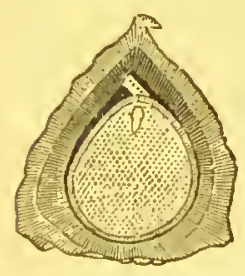

II.

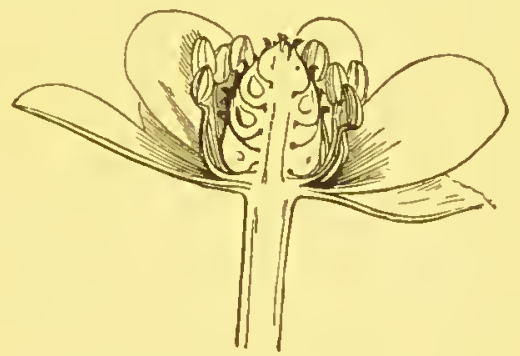

FIG. 532.- Pheasant's eye, Adonis: I. longitudinal section through achene : II. longitudinal section through flower (magnified). (See also Fig. 209, p. $11_{5}$.)

Delphinium, Aconitum, Actaa, Cimicifuga, Pconia.] Officinal products are the roots of the hellebore Helleboris viridis, the tubers of the 
monkshood Aconitum Napellus (Fig. 533), the seeds of Delphinium Staphisagria, and the foliage of Anemone Pulsatilla. Many are poisonous, as the various species of Helleborus and Aconitum, and Ranuculus. sceleratus; and a large number are grown as ornamental plants.

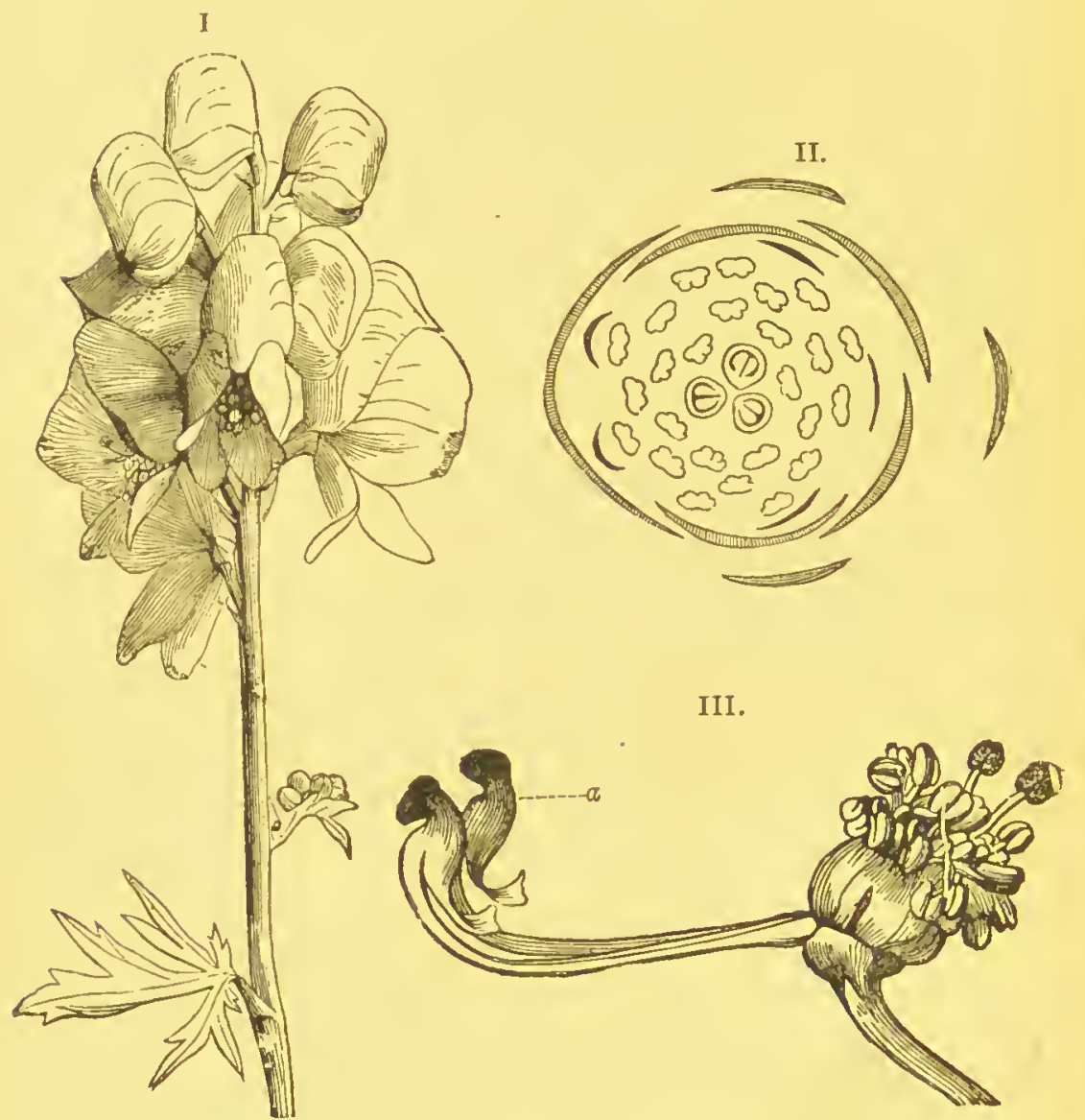

FIG. 533.-Monkshood, Acouitum Nopellus; I. part of plant (natural size); II. floral diagram; III. flower(magnified), the coloured calyx having been removed, showing the two petals $a$ developed into nectaries, the remaining petals being reduced to scales or altogether abortive.

[The remaining more important orders of the cohort are Magnoliacea (Magnolia, Liriodendron, Drimys, Illicium); Anonacea (Uvaria, Anona); Menispermacea (Cissampelos, Cocculus, Anamirta, Menispermum); Berberidea (Berberis, Mahonia, Epimedium, Podophyllum); Nymphaacea (Nuphar, Nymphaa, Victoria, Cabonba, Nelumbium).] 


\section{CHAPTER VII.}

THE CHANGES WHICH HAVE TAKEN PLACE IN THE VEGETATION OF THE GLOBE IN THE COURSE OF GEOLOGICAL PERIODS.

GEOLOGY, or the history of the formation of the earth, proves that the distribution of land and water on the surface of the globe has not always been the same as it is now ; many dis. tricts which are now continents were at one time seas, and vice versâ. The main agent in carrying away masses of land from one spot and reconstructing them in alıother, has been water, either slowly by gradual action, or suddenly by mighty convulsions. Some idea may be conceived of the extent of this agency, from the reflection that the mass of particles in a state of suspension and solution which the river Ganges now carries down to the sea every year is equal in bulk to seventy pyramids as large as the largest of the Egyptian pyramids, that of Cheops. Wherever the substances that are carried down are deposited at the bottom of the sea or in sea-basins, strata are formed which at first fill up the unevennesses of the ground, the uppermost layers then forming gradually more and more horizontal deposits. On strata of this nature already in existence fresh layers of different substances are everywhere deposited. Such a stratification of the crust of the globe has not however occurred once only or a few times at one particular spot; but at almost every place where the surface has been excavated it manifests a structure stratified in the greatest variety of ways.

Nothing is more natural than that in these changes which have taken place on the surface of the earth, multitudes of plants ${ }^{1}$ should have become enclosed in the soft deposits of

1 No account is taken in the sequel of the preservation of animal remains. 
mud, and their remains preserved in the rock which results from the hardening of the mud. The soft and delicate parts could not be perpetuated in this manner; and it is found in fact that only the harder parts, like the wood, bark,

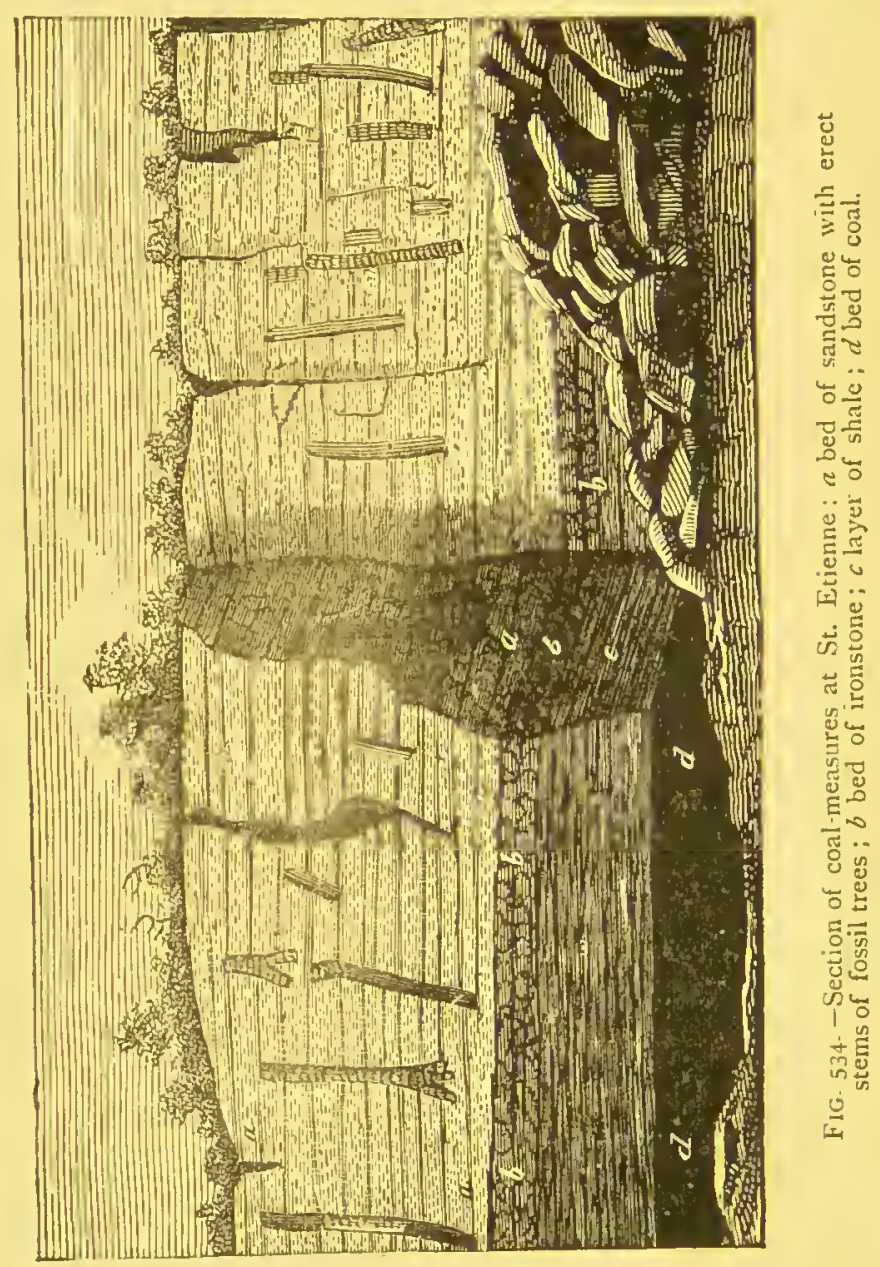

and fruits, are preserved (Fig. 534). The softer portions have been more or less quickly decomposed; although, under specially favourable conditions, there has been some preservation even of them. The delicate parts, for example, are 
found enclosed in amber, and even in diamonds, or have been covered up by the hardening mud, and have at least left impressions in it, from which the form and even the species can be recognised. The numberless small cavities - cells and intercellular spaces-which are found in the substance of the plant are also not unfrequently filled with a fluid, the mineral constituents of which-usually silica-become gradually solid, and thus preserve the structure of the plant in a fossil form, the organic parts undergoing decomposition. From the mode in which these impressions and fossils are formed, it is evident that they can be found only in stratified rocks. The number and systematic position of the fossil remains obtained in this manner vary greatly in the different superincumbent strata; but are subject to the following general rules:-In the lowermost and consequently the oldest strata no remains of plants now living are found. In the higher strata are found gradually more and more highly organised kinds, and more nearly allied to those at present existing; this being most strikingly manifested in the uppermost or most recent beds, in which a number of fossil plants, or their impressions, are found, which belong to our existing flora. If, indeed, an attempt is made to form, from the few remains at present found, an idea of the entire vegetation-not, perhaps, of the whole earth, but of those regions which have furnished most material for examination-the result may not differ very widely from the reality. It is best to commence with the oldest strata, from which a gradual approach may be observed towards the existing vegetation of the earth.

In considering the variety of the fossil remains in the different strata, special attention must be paid to the changes which have taken place in the climate of the earth in the course of the different geological periods. ${ }^{1}$

${ }^{1}$ [In his Genera et Species Plantarum Fossilum, published in 1850 , Unger reckoned the number of genera and species of fossil plants known up to that time as under:-Exogens, 151 genera, 547 species; Endo- 
In reference to the relative position of the strata, and to. the fossil remains (chiefly those of animals) found in them, a number of geological systems are distinguished, which are again divided into groups.

The lowest strata of the Primary or Palaozoic age (i.c. the period of the oldest living beings)-viz. the strata of the Silurian ${ }^{1}$ system-contain the earliest remains that have been preserved of the vegetable world. Only a few marine Algæ are known; but others may have altogether perished, their existence being indicated only by the occurrence of carbonaceous or bituminous limestone.

In the Devonian system the number of species, genera, and families has greatly increased. In addition to a considerable number of Algæ, the first land-plants have made their appearance. They consist almost entirely of the remains of Vascular Cryptogams, with a few Cycadex and Coniferæ. The aspect of this period, as also of that next in succession, must have been extraordinarily uniform and monotonous ; but vegetable life had extended over the surface of the earth in a variety and luxuriance of forms far surpassing our existing vegetation.

In the Carboniferous period Ferns attained a special development. We find lofty trees or shrubs with multipinnate leaves several feet in length, forming magnificent groups of plants, in the shade of which other smaller species grew as underwood (Figs. 540-542). Among the largest forms of which these forests were composed were certain Lycopodiacer-to which nothing now existing is comparable -known as Sigillaria aid Lepidodendra (Figs. 535-539).

gens, 43 genera, 142 species; Gymnosperms, 56 genera, 363 species; Cryptogams, I 52 genera, I, I 72 species; Doubtful, 35 genera, 197 species. Since that time the number of both genera and species has been enormously increased, especially by the additions to the Tertiary flora made by Heer and Ettingshausen.--ED.]

' [Geologists now distinguish the oldest stratified beds from the superimposed Silurian as the Laurentian and Cambrian systcms. They contain but few remains of organic life. - ED.] 
The former had a columnar unbranched stem, 20 metres in height, and rising from a square base I metre in diameter,

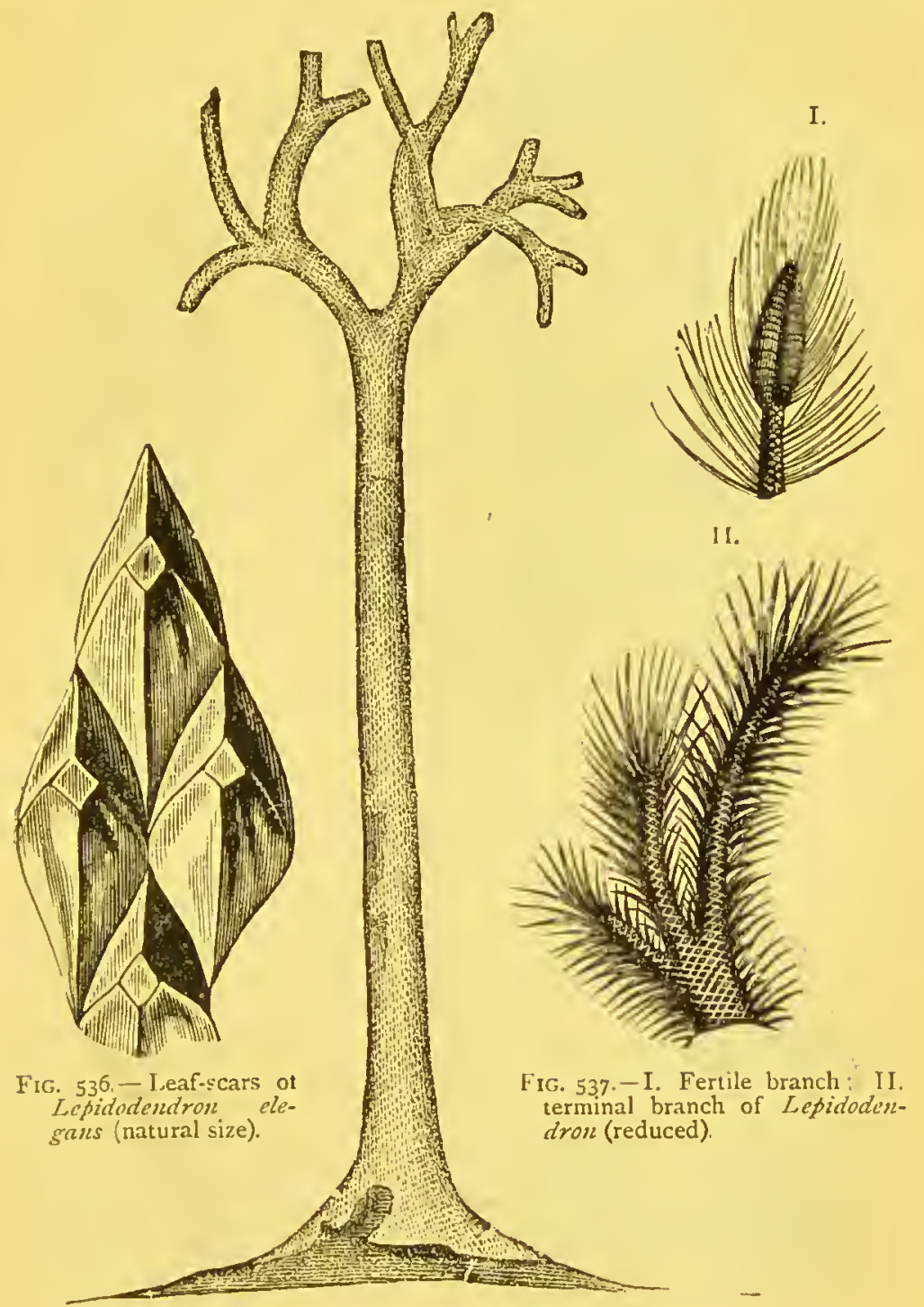

FiG. 535.- Branching stem of Lepidodendron, from the coal-beds of Bohemia (reduced).

the bark being covered with a number of longitudinal rows of diamond-shaped leaf-scars ; [and it is now generally believed 
that the fossils known as Stigmaria, and formerly regarded as a distinct plant, are in reality the roots of Sigillaria.] The

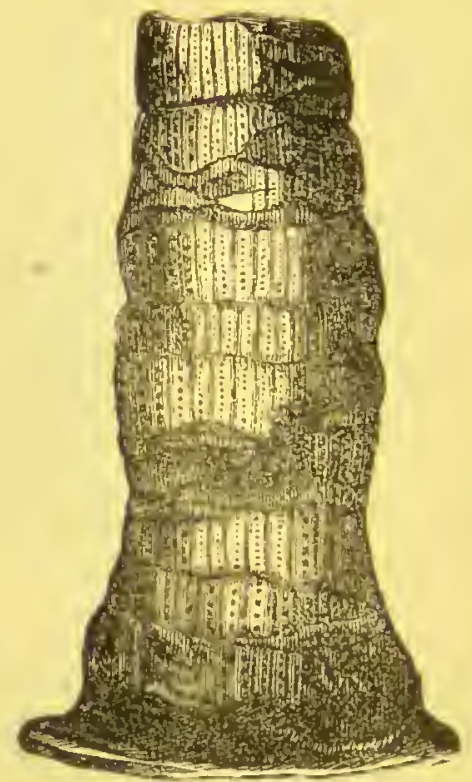

Frg. 538.-Stem of Sigillarza, from English coal-bed (reduced).

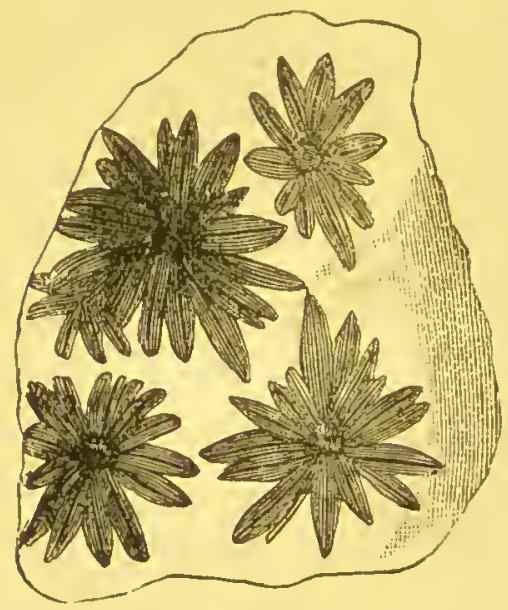

Fig. 540.-Anumlaria fertilis.

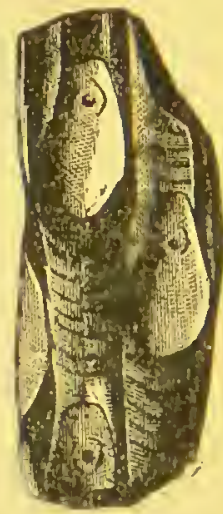

FIG. 539.-Leaf-scar of Sigillaria Graseri (natural size).

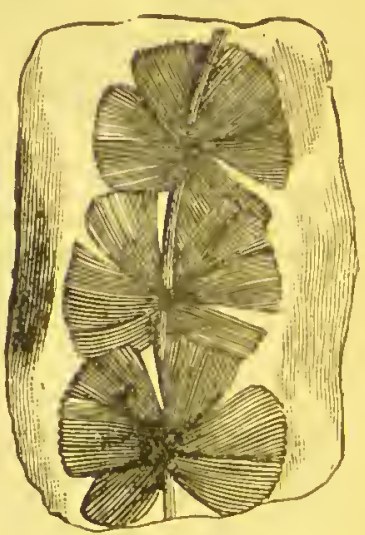

FIG. 54x.-S个henophyllum annulatun.

Lepidodendra, on the other hand, had much-branched stems, 30 or more metres in height, and 4 metres in girth, and 
were also beautifully marked with scars. Associated with these were gigantic Equisetacere known as Calamites, of which those now existing are as dwarfish representatives as the Lycopodia are of the Sigillarix and Lepidodendra. There existed, however, also in those forests-the true primeval forests of the earth-herbaceous plants (Ferns), such as Annularia, Asterophyllum, and Spenophyllnum, as well as some Monocotyledons, Cycadere, and Coniferæ ; and

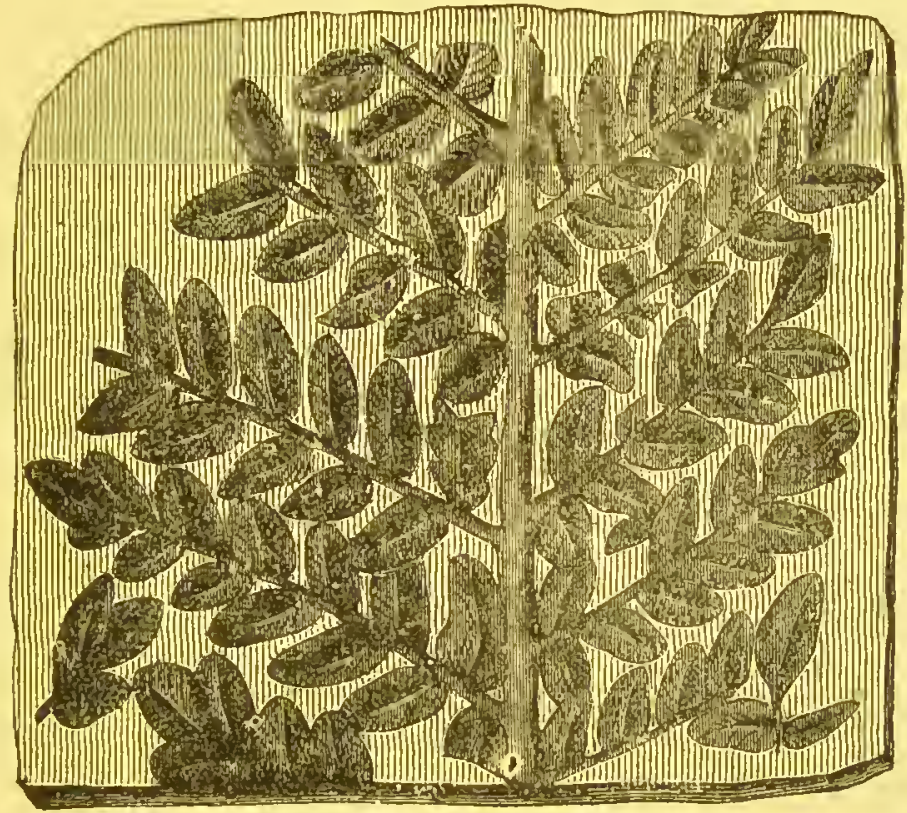

FiG. 542.-Neuropteris heteropliylla.

even the number of species was quite considerable. The Sigillariæ, Lepidodendra, Calamites, Asterophyllites, and possibly also the Tree-ferns, attained in this formation their maximum development; in the succeeding one their number diminishes. In connection with other plants, and perhaps also with sea-weeds, they form the valuable deposits of coal. In this form they have undergone sometimes more, sometimes less change, no trace of their vegetable structure 
often remaining, while the accompanying beds of earth receive their impressions, and preserve a correct image of them. It frequently happens, however, that entire stems have become fossilised (Fig. 534, p. 4I8), and still show their cellular structure in a wonderfully beautiful manner. We have no knowledge of the length of time during which the Carboniferous period lasted; but if it may be estimated from the thickness of the deposits of coal, many authorities would place it at millions of years.

It is impossible to suppose that deposits of coal occurred only in the Carboniferous period; they are found in almost all strata higher in the series, but in a different form. In the uppermost we find peat, the coal-formation of the present ; below it is lignite or brown coal, bearing sometimes a greater resemblance to peat, sometimes to the true coal which lies beneath it. The origin of the latter from peat is therefore not improbable, and in some cases is unquestionable. The mode of formation of peat must therefore be first investigated. When Algæe and other plants grow undisturbed in perfectly stagnant water, to the bottom of which they fall quietly as they decay, the layer of organic matter thus formed grows gradually thicker and thicker; the reeds, rushes, sedges, and Equiseta retreat from the shore, the dense matting of their roots gradually advancing farther and farther on the muddy soil. Every year the dead leaves and stems of the water-lilies, water-Ranunculi, Potamogeta, and Lemnx. fall to the bottom ; the mass of vegetable remains and the roots and rhizomes which penetrate among them become denser and denser, and more and more space is constantly taken from the water, until at length a densely interwoven substance results, resting on a soft layer of mud. Sphagna, Eriophora, marsh trefoil, Vaccinia, and other plants, establish themselves on this unstable foundation. The vegetable remains covered in this way, and protected against the action of the air, still decay, but not so completely ; they are continually losing oxygen, hydrogen, and nitrogen, while the carbon accumulates. The mass is also increasing upwards; for long after the lower parts of the bog-mosses (Sphagna) which take an especially important part in these processes have died off, the upper parts still maintain a vigorous life, drawing up the water from below like a sponge. The substructure, which was at first very soft, becomes therefore gradually clenser in the course of time, until at last a firm poratmoss is formed beneath the superficial vegetation. The ground is however constantly liept moist by the peat, and a luxuriant vegetation is 
hence cleveloped on it, fed by the abundance of food-material whicl it contains. As soon as it becomes firmer, trees and shrubs, willows, alders, and buckthorns, spring up on it, and finally also conifers; but the life of these larger plants is as a rule somewhat limited; and when they are blown down by the wind or fall by their own weight, the peatmoss grows over them, and in the course of years they become entirely covered up by it. Therc, excluded from the action of the air, they do not decay, the structure of their wood being retained perfectly for centuries. This is the mode in which peat is formed.

Even in lignite the remains of plants can be abundantly recognised. This is less the case in truc coal, and scarcely at all in anthracite, the hardest coal with most of a mineral character. It is often possible to deternine the plants which have contributed to the formation of coal only from the fossils and impressions found in the accompanying beds of earth. The exclusion of the atmosphere, and the pressure, often immense, which beds of peat that have been flooded and buried beneath the surface liave had to sustain from the superincumbent layers of earth, explain their transformation, first into lignite and then into true coal. In many beds of coal, as for instance those of Silesia, their origin from layers of peat is sufficiently evident ; in others this explanation does not seem to apply, and we must assume that driftwood has been the source from which they were formed. Even at the present time the gigantic rivers of America tear down from their banks and carry away trunks of large trees; and when these trunks have become completely saturated by water, they arc left behind by the current, and sink either in an inland lake, at the mouth of the river, as in the Mississippi, or in the sea as drift-wood, and thus form immense deposits which may very easily be transformed into coal. But these trunks nust retain some traces of their journeyings, and must be intermixed with the remains of water-animals, and, when the deposition takes place in the sea, of marine plants. These phenomena are in fact observed in many of the coal-formations of north Germany, the production of coal having taken place in the manner already indicated. The formation of coal from the deposition of successive layers of plants in primeval forests is very improbable.

It is remarkabie that after the Carboniferous period the luxuriance of vegetation appears to have diminished. As if the earth were already exhausted, one form after another of the existing vegetation disappears; and in the Permian series, oniy the lower strata, the Nero Red Sandstone, 
contain any quantity of plants, and then chiefly in a silicified state. The Magnesian Limestone which rests upon it contains but very few vegetable remains. The Permian has only one form in common with the lower, and only a few with the upper strata of the Carboniferous system. The prevalent forms are still Sigillariæ, Calamites, Ferns, Lepidodendra, \&c.; but in addition are found Palms and Cycadeæ, the latter order attaining here their maximum development.

A different vegetation characterises the Secondary or Mesosoic strata. The forms characteristic of the Palæozoic beds, Sigillariæ, Lepidodendra, and Asterophyllites, disappear, and others make their appearance which bear a greater resemblance to those of the present day. The Conifera began in the Devonian, attained a maximum in the Carboniferous, and again diminished in the Permian system.

In the lowest system belonging to the Secondary strata, the Trias, Coniferæ must have formed the main part of the forests; while of Cryptogams, so largely developed in the lower rocks, only Ferns remain, those however belonging to new, and partly to peculiar and highly developed genera. The chief forms of Coniferre in these forests were species of Voltzia (Fig. 543) and Albertia. The former were lofty trees, not unlike our Cryptomeria, while the latter had broad leaves pcnetrated by delicate longitudinal veins. With them are associated certain Cycader (Zamites, Figs. 545, 546) and water-plants, as well as Calamites with verticillate leaves, and gigantic Equisetacer, which may have clothed the margins of the sheets of water. Of the three well-characterised sections into which the Trias is divided, the lowest or Bunter Sandstein contains but few vegetable remains, the middle or Muschelkalk scarcely any, and the uppermost or Keuper only a few. The flora of the Trias, in its gigantic Ferns and peculiar Coniferæ, bears a greater resemblance to that of New Zealand than of any other country at the present time. 


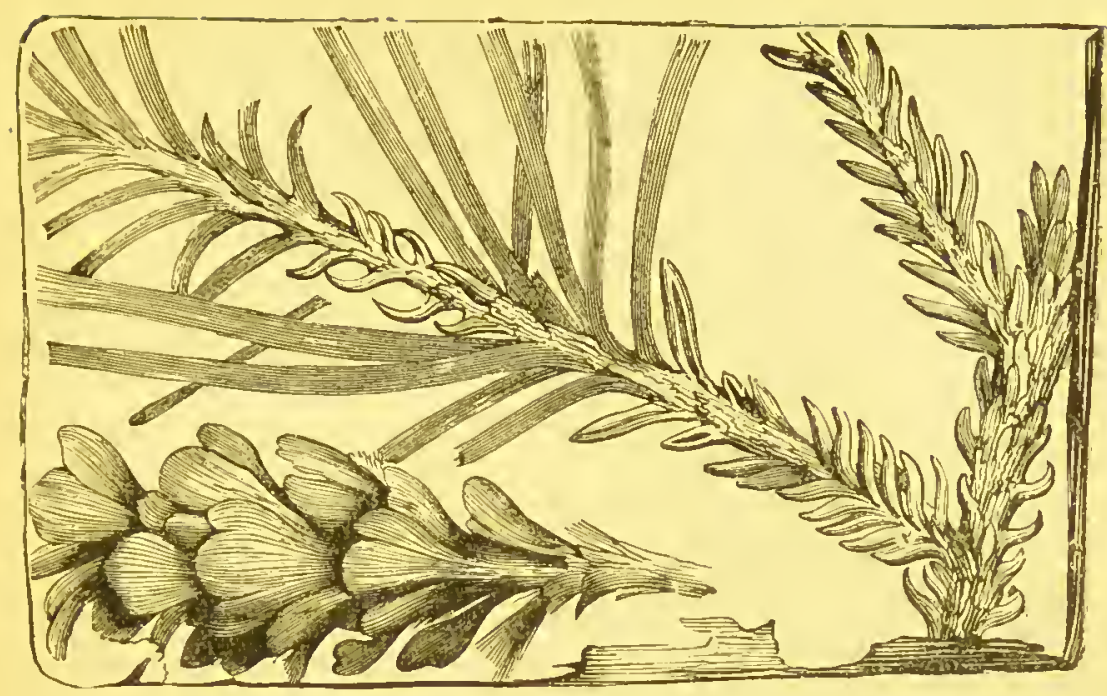

F1G. 543.-Terminal. middle, and fertile branch of Voltzia (Schisonenan) heteropliylla, from the Vosges.

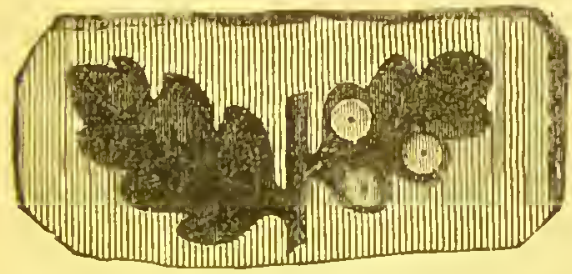

Fic. 544.-A fertile and barren pinna of a Fernfrond, Goniopteris Murreyana.
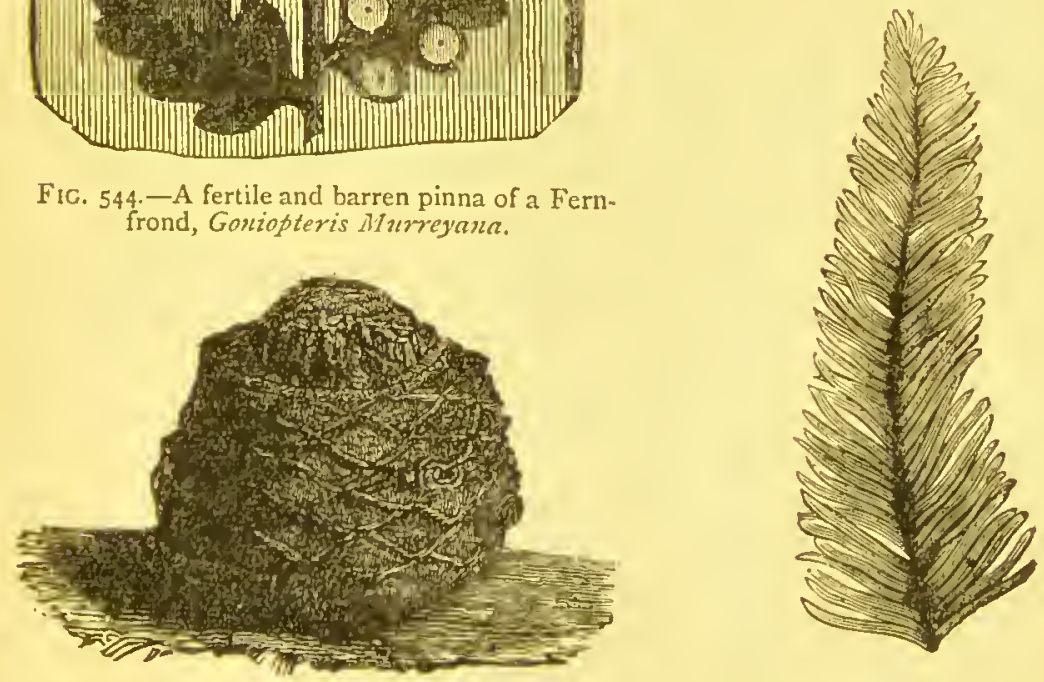

Fic. 545.-Stem of Cycadoidea megalopliylla (Cycadea), from Fortland Isle.

Fig. 546. - Liranch of Presleanum (Cycadeie). 
The uniformity of vegetation characteristic of the Carboniferous is still more marked in the Triassic system.

Next in succession above the Trias is the Jurassic system, which again is divided into three sections, the Lias, and the Lover and Upper Oolite. The fossil remains found in this formation lead to the conclusion that the marine plants of the Lias did not differ essentially from those of the present time in their external appearance, although the species may have been very dissimilar. The case is different with the terrestrial vegetation, in which we still find a considerable coincidence with that of the Keuper. The prevalent forms in the forests consisted of Cycadex, of which fifty-eight species have been described. From this point, this beautiful form of vegetation, which in regard both to its habit and to its morphological and anatomical structure occupies an intermediate position between the Ferns, Palms, and Coniferæ, decreases, only a few species existing at the present time. With these were associated numerous Coniferæ nearly related in form to our Araucarias and Thujas. The underwood of the forest still consisted of Ferns, along with fleshy Fungi. The marsh-loving Calamites have disappeared, and the Equisetacex of that period scarcely exceeded our own in size. Plants allied to Typhaceæ, Naiadeæ, Cyperaceæ, and Juncaceæ, fringed the edges of the water. This sketch gives, however, only an imperfect idea of the vegetation of that system; for its coal shows that in magnitude it must have resembled that of the Carboniferous period. The vegetation of the Lower Oolite presents no great difference from this. A number of sea-weeds have been preserved; the earlier forms of Ferns and Cycadex disappear, and others take their place more nearly related to those of the present time. The flora of the Upper Oolite does not include any marine plants, only a single freshwater Alga, and in other families also fewer forms than the Middle period. There would seem to have been an exhaustion of the earth similar to that which apparently succeeded the Carboniferous period. 
In the Cretaceous system appear the first dicotyledonous trees. The lowest strata contain mostly marine plants, sea-weeds and sea-grasses, with a few trunks of a species of cypress which floated on the sea in the form of drift-wood. The fossil remains of the Middle Cretaceous are much richer. The Cycadex diminish in numbers; but in their place appear the first exogenous trees, Juglandites and Acerites, related to our walnuts and maples. Among the Ferns, which had hitherto formed almost the entire undergrowth of the forests, rose shrubs allied to our willows; alders and horn-beams, Alnites and Carpinites, attained the size of trees; and we find also allies of our Myrica or sweet-gale. We have no certain knowledge of the existence of herbaceous Monocotyledons; but certain impressions which bear a resemblance to lilies or gingers make it probable. The marine and littoral plants of that system are similar in essential points to those of the Lower Cretaceous. The Upper Cretaceous, including the Chalk, affords only a very few vegetable remains, and those entirely of Algæ.

The lowest of the Tertiary or Cainozoic rocks are the Eocene. In this period dicotyledonous trees first begin to contest the supremacy with Cryptogams and Cycadeæ, and the entire outward form of the vegetation approaches that of our time. The lowest strata of this system furnish a marine flora consisting of sea-weeds. This is succeeded by a beautiful littoral flora, with Equisetaceæ, Characeæ, and Naiadeæ. Land-plants finally appear; and among these palms are especially conspicuous, and with them bananas, Myrtaceæ, Lauraceæ, and other exogenous and coniferous trees, which must, according to our present knowledge, have belonged to a tropical climate. Remains of the Ferns, Cupressineæ, and Cycadeæ belonging to this system have been found in Greenland in $70^{\circ} \mathrm{N}$. lat. We know of no country at the present time which affords a similar grouping of plants to the flora of the Eocene formation, taken as a whole. That of the basin of the Mississippi probably 
presents the greatest similarity to it; but there are also points of resemblance to those of California, New Zealand, and Australia.

The next systems, the Miocene and Pliocene, are separated somewhat arbitrarily from the preceding and from one another, if the floras only of the formations be considered; the transition from one to another, and from these to the present, being quite gradual. We find, the higher we ascend in the Tertiary strata, an increasingly greater number of forms which indicate a cooler climate. The tropical plants gradually disappear, and are replaced first by subtropical forms, and then by those adapted to a temperate climate. Especially in the Middle Tertiary or Miocene system we find large masses of carbon deposited in the earth in the form of beds of 'brown coal' or lignite. It is evident that the German deposits of lignite are almost entirely composed of the remains of Coniferæ; while in the marls, the sandy, loamy, and argillaceous strata which accompany the lignite, a number of the impressions of exogenous leaves are always found. But these coniferous forests did not exhibit a dull uniformity, as is the case with those of the present time; there was, on the contrary, an abundant and cheerful variety of forms, as is seen even now in the forests of Canada and Asia, though not to so great a degree. There must also have been enormous quantities of resin exuded by some of these trees, genera resembling Thuja and Cupressus, the preserved stores of which are eagerly sought for ; this resin, hardened by external conditions, being now known as ambcr. In addition to the Coniferæ already mentioned, we find, in what appears to be near the close of the Tertiary period, that the forests of northern and central Europe consist largely of dicotyledonous trees-oaks, beeches, birches, alders, and willows. Plants belonging to the Primulaceæ, Scrophulariaceæ, Crassulaceæ, and other existing orders, sprung from the ground beneath the trees, covered with moss and fungi, and adorned with Rhododen- 
drons, Azaleas, and other beautiful bright-coloured Ericacer. Species of honeysuckle formed bushes or climbed up the trees, on which grew parasitic plants allied to our mistletoe. In Italy are found the remains of species of Salisburia and Liriodendron, the allies of which now grow only in Japan and South America. Many species of these recent formations probably exist to the present day. Up to the year I853, Goeppert had described the remains of 162 plants belonging to 64 genera preserved in amber; 30 of these he recognised with certainty as belonging to the present time, while others do not admit of a perfect identification.

The Post-pliocene, Pleistocene, or Alluvial formation includes deposits believed to be formed immediately before the historic period. It is to these strata that the remains of the mammoth, mastodon, and other gigantic animals belong; but the number of species of plants found is only small, and these have only been partially determined with certainty. How unequal has been the preservation of the remains of this period is shown by the circumstance that our only source of knowledge of the existence at that time of our pines and arbor-vitæ is the fact that the remains of food found in the hollow teeth and stomachs of mastodons which had become enveloped in ice belong to these plants.

From these Alluvial formations we pass to the present age, with its forests, meadows, steppes, deserts, seas, lakes, and marshes, each of which has its peculiar flora and its special physiognomy. Among the endless variety of species of plants by which this latter is determined there are a certain number of leading forms which arrest the attention of the observer. Among these are Hymenomycetous Fungi, Lichens and Algæ, Mosses and Lycopodiaceæ, Ferns and Equisetaceæ, Coniferæ, Cycadeæ and Palms, Grasses, bulbous plants, Agaveæ and Aloïneæ, Scitamineæ and Musaceæ, Aroideæ, Orchideæ, lianes, ${ }^{1}$ Casuarinaceæ, willows,

1 Climbing or twining plants, mostly tropical, and often with tendrils, Passifloraceæ, Bignoniaceæ, Aristolochiacer, reeds, palms, \&c., 
Cupuliferæ, Ericaceæ, Myrtaceæ, Melastomaceæ, Lauraceæ, Compositæ, Umbelliferæ [Labiatæ, Cruciferæ, Primulaceæ], Cactaceæ, arborescent Euphorbiaceæ, [Mesembryanthemaceæ], [figs], Malvaceæ, Mimoseæ, and Nymphæaceæ.

\section{CHAPTER VIII.}

\section{BOTANICAL GEOGRAPHY.}

Botanical GEOGRAPHy treats of the distribution of plants on the surface of the earth; it collects the plants of any particular country into a Flora, and investigates the causes, operating either at the present time or in the past, which have led to each species acquiring its special habitat, and have resulted in only a few plants-termed cosmopolitan becoming distributed over the whole globe, or even over a large part of it. ${ }^{1}$

The earth does not everywhere produce those plants which are especially adapted to each particular region. If this had been the case, the same species would be constantly met with in widely separated countries that enjoy a similar climate, and no immigration of foreign plants would take place, such as often happens before our eyes. Each species has, in fact, become disseminated only at particular spots; it has its centre of distribution at the spot from whence it originally sprang ; but the limits of these centres are often obscure, because plants have found conditions suitable for their existence outside these bounds, and

feebly represented by our grape-vine, ivy, hop, honeysuckle, [Convo!vulus], \&c.

1 The phyto-geographical map at the end of the volume must be consulted in connection with this chapter. It indicates the boundaries of the twenty-four plyyto-geographical regions adopted by Grisebach in his 'Vegetation der Erde,' each region being coloured uniformly. The regions of a more generally wooded character are coloured green and dark blue, the steppes and deserts yellow and red, while those regions which have no special character of their own are of some other colour. [The statements of Grisebach-on whose work the whole of this chapter is founded-are somewhat too unqualified, both with regard to the bounrlaries between the regions and to the characters which distinguish them firom one another. - ED.] 
have thus occupicd morc and more ground by migration. All plants are, however, not equally capable of migration; if this were the case, the strongest would cverywhere have rcplaced the rest, and have occupied the wholc of the space devoted to vcgetation. The unlimited distribution of plants is also prevented by seas, deserts, mountainchains, differences of climate, and even by the existencc of othcr plants and animals.

A natural flora results from the interchange of a number of fornis belonging to different centres of vegetation, and their union into a whole with definite characters. The limits of such a flora are determincd by climate, or by the hindrance to the distribution of species afforded by a broad ocean or other obstacle; and these floras are the more natural the more sharply they are defined, and the less thcir aboriginal inhabi. tants have mingled with immigrant forms. The most effectual hindrance to this intermingling is presented by the ocean. Almost as completely the great Sahara scparates the flora of tropical Africa from that of the Mediterranean region; and the forcst-region of equatorial America is an insurmountable obstacle to the migration of the native plants of the grassy plains of Venezuela and Brazil. The chief factor, however, in the separation of floras is difference in climate.

The comparison of different floras, and of the regions to which they belong, brings out the law that the species of a gcnus or the genera of an order are thc more nearly related to one another--in other words more closely resemble one another-the less the distance between their centres of distribution, or the more similar the climates of thcse centres. It is scarcely possible, for example, to have greatcr differences of climate than those which subsist between the base and the summit of lofty mountains ; and yet the vegetable productions of the most elevated regions not unfrequently bear the closest systematic relationship to those of the warm valleys out of which the mountain rises; a phenomenon which suggests the supposition that the plants of the heights have ascended from the valleys, and have adapted themsclves to the new vital conditions as far as was necessary to their perpetuation. But the transitions from one species to another which might be expected in the gradually ascending mountain regions are most commonly wanting ; the Alpinc species make their appearance, and those of the plains disappear, suddenly, at particular elevations. Contiguity of locality is, however, except in the case of mountain-ranges, usually accompanicd by resemblance in climate. But there are also resemblances of climate without geographical contiguity ; and allied genera or species appear in the most widely separated regions, if their climate is similar. Wellknown cxamples of this fact are furnished by the beeches of Japan 
and the Straits of Magellan, and by the heaths of the Cape of Good Hope and of western Europe.

Sinee one of the main problems of phyto-geography is the investigation of the means by which a plant ensures its existenee, a physiological system may be contrived, aecording to the plan proposed by Humboldt, in whieh those organs of a plant whieh serve for the maintenanee of its life-in other words its habit - are first taken into aeeount ; these eharaeters determining to a great extent the natural features of the vegetation. A eertain conneetion ean indeed usually be recognised between the external form of the vegetation and the climatal eonditions which determine its geographical distribution. On this plan the vegetable kingdom may be divided into the seven following classes:I. Woody plants; 2 . Suceulent plants, suel as the eaeti ; 3 . Climbing plants (lianes) ; 4. Parasites or epiphytes, like the mistletoe ; 5 . Herbaccous plants; 6. Grasses; 7. Cellular plants; and eaeh of these groups may be divicled into a greater or smaller number of sections.

In order to obtain an idea of the entire vegetation of the globe, the surface of the earth has been divided by Grisebach into twenty-four natural floras, or regions of vegetation. Each of these floras is again subdivided into zones, the phyto-geographical character of which is determined by its elevation above the sea-level; a succession of zones being thus obtained, until at length the line of perpetual snow sets a limit to almost all vegetable life.

The determining conditions and the actual boundaries of these floras are, however, at present but imperfectly known, [and, indeed, any such division must be considered as very inadequately representing the endless variety and complexity of nature. In all such classifications there is a definiteness and sharpness of outline, which is really an inherent logical defect of all classifications of natural phenomena, rather than a representation of anything that has an exact counterpart in nature]. The districts characterised by the occurrence of similar forms and often identical species, occupy as a rule lower zones of elevation with an increase in the latitude [north or south], and advance from elevated regions in lower latitudes to less elevated regions in higher latitudes. Thus a number of species of the Swiss 
and Italian Alps occur at a much lower elevation on the mountains of Norway and in Lapland; and plants found above the snow-line on Mont Blanc belong also to the Arctic flora. The floras of mountain and of Arctic regions nevertheless exhibit some considerable differences.

At the base of the mountains of the equatorial zone, from the sea-coast to the height of about 630 metres, the external conditions, and therefore also the character of the vegetation, are similar to those of the plains. This is the zone of palms and bananas. It is followed, as far as a height of I,300 metres, by the zone of tree-ferns and figs. In India these lofty trees are covered by multitudes of Piperaceæ, Aroidex, and Orchideæ. In the islands of the southern ocean the figs are replaced by arborescent Urticacer; and the valuable Cinchonea are characteristic of the South American region. In the zone of myrtles and laurels, which succeeds as far as a height of I,900 metres, trees with thick shining leaves are predominant, Myrtaceæ, Camelliaceæ, Magnoliaceæ, and others; but the Acacias and Ericaceæ also attain here their maximum development, and evergreen oaks are very abundant. The laurels occur especially towards the upper limit of this zone, and are found also abundantly in the next, that of evergreen trees, which extends from about I,900 to 2,500 metres. Next comes the zone of trees with deciduous foliage, which extends to a height of about 3,200 metres, and under the tropics is seen only on the elevated plains; and a luxurious arborescent exogenous vegetation scarcely reaches beyond 2,800 metres. At this point a variety of Coniferæ make their appearance, such as with us are intermingled with the exogenous trees. From 3,200 to 3,800 metres is the zone of Coniferæ, and from that to 4.500 metres that of Rhododendrons. Lofty trees now disappear, and are replaced by luxuriant meadows and pastures, among the brilliant herbaceous vegetation of which Rhododendrons and Azaleas are conspicuous, not only by their shining coriaceous leaves, but also by their magnificent 
clusters of flowers, often of gigantic size. The eighth and last zone, that of Alpine herbs, extends from the elevation of 4,500 metres to the limits of perpetual snow. Here are found chiefly low-growing perennial plants with woody roots, a small amount of foliage, and comparatively large brightly-coloured flowers; and almost all the herbaceous plants are marked by containing resinous and bitter substances.

The Alps and other mountains of Central Europe possess, on the other hand, only six phyto-geographical zones. The zone of fruit-trees, that of the spurs of the mountains, rises on an average to about 660 metres. The apple and the grape-vine usually ascend to this elevation, while the walnut reaches as high as to 1,000 metres. In this zone the vegetation of the plain is predominant; the woods consist mainly of beeches, birches, alders, larches, and pines, and the upper limit of the oak occurs here. The zone of beeches, or the lower mountain zone, extends in the Alps to a height of 1,500 metres, in the Sudetes of Silesia to $\mathrm{I}, 000$, and in the Hartz mountains only to 600 metres. The birch, the sycamore, the service, the hazel-nut, the wild cherry, and many herbaceous plants, such as species of Lamium, Plantago, Artemisia, Taraxacum, Asperula, and Chrysanthemum, attain their upper limit here, and disappear with the beech. At the same time we reach the lower limit of Rhododendron, Gentiana, Primula, \&c. The zone of pines, or the upper mountain region, reaches in Switzerland an elevation of $I, 800$, in the Sudetes of 1,500 , and in the Hartz mountains of I,, 00 metres. Here we have the upper limit of the spruce fir and larch, while the Rhododendrons attain their maximum development. Pinus Mughus and Cembra form great forests in this zone of the Alps, extending also. into the next in succession, the lower Alpine region. This. ascends to the upper limit of Pinus Mughus, an elevation of about 2,300 metres. In the granitic Alps of Switzerland this tree is often replaced by the green alder. This is also tne highest limit of animal life in the Alps; only a few 
species being found at a greater height. The zone of Alpine herbs, or the upper Alpine zone, extends to the limit of perpetual snow, 2,800 or 3,000 metres. Of woody plants this zone has only the dwarf willows, with perhaps a few Rhododendrons, the beautiful mountain heath, Erica carnea, and the single Azalea found in the Alps, A. procumbens. In the zone of Cryptogams, or the snow region, above the limit of perpetual snow, all phanerogamic vegetation has disappeared; only Mosses and Lichens are still found, and the 'red-snow,' Protococcus nivalis, temporarily colours the white tracts of snow.

It will illustrate how the distribution of plants in altitude is modified by local circumstances, to mention that in the northern Alps the upper limit of the cultivation of the grape-vine is 500 metres, in the central Alps 600, while in the groups of Monte Rosa and Mont-Blanc it ascends to 900 metres.

\section{REGIONS OF VEGETATION.}

\section{The Arctic Region.}

The Arctic flora embraces those regions of the extreme north which lie beyond the polar limits of the forests. Its character is determined by the shortness of the period of regetation, and the comparatively low temperature during this period. The plants belonging to it must be able to undergo a period of hibernation of at least nine months each year. The portion of them which rises above the surface is comparatively small, and their underground stems are almost always perennial; annual plants are almost entirely wanting. Hepaticæ, Lichens, Grasses, and Cyperaceæ, a few shrubs and sub-shrubs-willows, birches, and Vacciniaceæ —as well as evergreen Rhododendrons and Andromedas, form the flora characterised [in part] by the size and brilliant colour of its flowers. There are no cultivated plants. In this region occur the 'Tundren,' broad plains covered with Mosses and Lichens. The Mosses are partial to moisture, and hence form the 'moist Tundren;' the 
brown, black, gray, or yellow Lichens grow, on the contrary, on the sandy products of the decomposition of masses of granitic rock, and form the 'dry Tundren.' These latter furnish food for animals, and are therefore more valuable than the former.

\section{The Europuo-Siberian Forest-Region.}

The general climatic character of this region, which gives rise to the uniform nature of its vegetation, is the uniform average temperature of its entire vegetative period, and the absence of a rainless season to interfere with the growth of its trees. Combined with these is a condition peculiarly favourable to its arboreal vegetation, a period of activity always amounting to more than three months in each year, which distinguishes it from the Arctic Region; while the permanent moisture of the ground from constant rainfall, separates it from the steppes which lie to the south and from the Mediterranean district.

On the borders of the ocean, especially on the Atlantic coasts, the sea produces an effect on the climate, moderating both the cold of winter and the heat of summer, and thus producing a mild maritime climate, in contrast with the more widely extended continental climate. The longer duration of the period of vegetation, and the gradually increasing temperature of the summer, are noticeable in passing through this region from north to south.

There are also large tracts of country in which the forests have been made to yield to cultivation, and which render the general term for the region somewhat inapplicable. This clearing of the forests in Europe has also made the climate more continental by diminishing the rainfall. This destruction of forests alters the climate, not only because the trees shade the ground and hence keep it cooler, but also because they retain in the soil and in their tissue larger quantities of moisture, which are gradually restored to the atmosphere by transpiration. 
Dependent on these conditions, the whole of this forestregion from the Atlantic to the Pacific Ocean may be divided into seven zones:- $\mathbf{r}$, the French zone of the sweet chestnut; 2, the German zone of Pinus Picea; 3, the Hungarian zone of Quercus Cerris; 4, the central Russian zone of exogenous forests; 5 , the northern zone of Coniferæ; 6, that of Quercus mongolica; and 7, that of Betula Ermani.

Among all the forest-trees of Europe the beech is the most characteristic of a maritime climate; but the zone of the beech passes gradually into those of the chestnut, Pinus Picca, and Qucrcus Cerris. These three zones correspond to particular districts of the maritime climate characterised by the difference in mean temperature between the coldest and warmest months of the year. In the first zone, the mean monthly temperature varies between $12^{\circ}{ }_{5}$ and $17^{\circ}{ }_{5}$ C. ; in the second between $17^{\circ} .5$ and $22^{\circ} .5$; and in the third between $22^{\circ} \cdot 5$ and $23^{\circ} \cdot 5 \mathrm{C}$. The characteristics of the central Russian zone of exogenous trees, of the northern zone of Coniferæ, and of that of Quercus mongolica, depend on their continental separation from the influence of the ocean. The broad girdle of forests of the Russian lowlands, which consist mainly of oaks, is limited on the north by the decreasing temperature, on the east by the insurmountable barrier of the Ural mountains. To the north of it is found therefore a belt of Conifers-pines and larches-accompanied by birches, which reaches to the Arctic Region, and across the Ural through Siberia, till at length it reaches the Amoor and the sea-coast of Ochotsk. The zone of the Amoor or northern Mantschuria has a completely continental character. The trees, among which Quercus mongolica is the most characteristic, belong for the most part to European genera, but to peculiar species ; the Siberian Coniferæ occur here only on the mountains. The last zone, that of Bctula Ermani, owes its peculiarity-a long period of vegetation with a diminished summer temperature-to the neighbour- 
hood on the one hand of Siberia and on the other hand of the sea.

Among the cultivated crops of this region the most remarkable are the potato, apple, grape-vine [and the cereal grasses]. Of the latter barley extends the farthest to the north, accompanied by the potato. In Europe generally the cereals vary with the geographical latitude; barley in the north, then rye [and oats], and wheat in the southern parts. The apple and grape-vine, on the contrary, are more dependent-at least at their northern limits-on direct sunshine, and in consequence flourish there only in the most sunny localities. Special mention must be made of the turf-forming grasses, and the nueadows which they produce, found to the same extent in none of the neighbouring regions; heaths, moors, and alder-fens are also almost peculiar to this region.

\section{The Mediterranean Region.}

The most important peculiarities of the climate which determine the flora of this region are the rainlessness of the sumnier and the mildness of the winter. While, therefore, in the forest-region the chief development of vegetation takes place in the warmer portion of the year, in the countries which border the Mediterranean, on the contrary, plants grow during the spring, remain stationary during the dry period of summer, and renew their growth under the influence of the autumn rain. This peculiarity shows itself on the mountainous border of the region, and in the neighbourhood of the Sahara; but is fully developed only on the shores of the Mediterranean. The flora of the elevated plains and mountains indicates an approximation, sometimes to that of the steppes, sometimes to that of the forest-region, sometimes to Alpine and Arctic forms.

Agriculture has here this advantage; that the same plot of ground will produce several crops in one year, but often only by carefully regulated irrigation. The olive is a specially 
characteristic product of this region; the further oneadvances south, the greater is the number of plants cultivated for food or for some other useful quality. Along with cereals, the grape-vine and olive, are found the mulberry, maize, millet, rice, water-melon, orange, fig, cotton, and even the datepalm, sugar-cane, plantain, and batatas. Many of these plants, as well as the Indian fig (Opuntia), agave, and aloe, grow in this region only under cultivation. One of its peculiarities is the great abundance of evergreen trees-the laurel, myrtle, oleander, olive, evergreen oak, \&c.-as well as of thorny shrubs. These latter often cover wide tracts, to the exclusion of almost all other vegetation, frequently forming dense thickets.

\section{The Steppe Region.}

This region stretches from the mouth of the Danube to the affluents of the Amoor; from the central Volga to the coast of the Persian Gulf and the crests of the Himalayas. The gradual rise of the ground from the basin of the Caspian Sea to the Asiatic highlands neutralises the approach towards the equator, amounting to $27^{\circ}$ of latitude. Throughout this immense region there prevails a uniform alternation of three periods in the year; the severe and protracted winter is followed by a short spring, and this by a rainless burning summer, which is succeeded almost immediately by the snow-fall of winter. It is only the short spring that is favourable to the growth of vegetation. The peculiar plants of the steppes have therefore, in some cases, a short existence, in others special means of protection against the drought of summer. Among the most characteristic forms of vegetation are plants with bulbous underground stems, yielding a volatile oil, or covered with spines or hairs. The different kinds of steppes-grass, salt, and sand-maintain peculiar forms of vegetation; trees, or even shrubs, occur only where vegetable life is aided by abundance of water or artificial irrigation. Of cultivated plants, rice, cotton, and 
sesame thrive; but fruit-trees need protection against the cold of winter.

\section{The Chino-Fapanese Region.}

The Chinese lowlands, including the Japanese archipelago, have the advantage over Europe of a more regular distribution of the rainfall. This is in consequence of the monsoons, which extend as far as $40^{\circ}$ or even $45^{\circ} \mathrm{N}$. lat., and cause a rainy period in the spring. The extremely regular succession of seasons which results is favourable to a careful garden-like agriculture, the chief crops being wheat, cotton, indigo, the sugar-cane, and orange, but especially rice. the mulberry, and the tea-tree. There are no meadows or fodder-crops. The aboriginal vegetation has been driven back to the highlands. A characteristic of the native flora is the large number of trees and shrubs, many of them, like the Camellia, evergreen.

\section{The Indian Monsoon Region.}

This region is not characterised by any special climatal conditions, but only by the general phenomena of the tropics. Growth takes place exclusively in the rainy season. Accordingly as the monsoon is a land- or a sea-breeze, is it dry or moist; and the monsoon region, in fact, includes every description of climate which is possible within the tropics. On its northern border, for example, its conditions approximate to those of the temperate zcne; and at the foot of the Himalayas there is an immediate transition from the desert landscape to the most luxuriant tropical forests. Besides the gigantic forests, characteristic forms of vegetation are presented by the savannahs and the jungles. Among the prominent features of the flora. of this region are palms, bamboos, and tree-ferns; the banyan, Ficus indica, which emits aërial roots from its branches to the ground; mangroves, which put out roots from the seeds while they still 
remain in the fruits attached to the branches, and thus, like the banyan, can produce a group of trees from a single individual ; laurels, teak-trees, lianes, numerous beautiful Orchideæ, Nepenthaceæ, and Nymphæaceæ. The most important food-plant is rice. Cotton, the opium-poppy, ginger, sesame, and indigo are also widely cultivated crops. Among fruit trees and useful shrubs, the coffee-plant is grown in Java, cinnamon in Ceylon, the nutmeg and clove in the Moluccas, the bread-fruit and the cocoa-nut-palm in the South Sea Islands, camphor in Borneo, pepper in Malabar and Siam. In addition the plantain, orange, and other sweet fruits are universal.

\section{The Sahara.}

This is the region of the unchecked prevalence of the trade-winds in northern Africa, northern Arabia, and southern India, and is almost rainless. Any vegetation is possible only from the occasional occurrence of thunderstorms or dew, or from the rainfall of adjoining regions being carried underground as surface-water, and giving rise to springs or wells. But it is scarcely conceivable that there are even in the Sahara any large tracts in which a scanty vegetation cannot thrive at certain times. The nature of the surface indicates four varieties of landscape :-the stony plains of the Hammada; the undulating deserts of the Areg covered with shifting sand ; the deep gullies or Wadis; and the Oases. The Hammada brings forth only at particular spots scanty thorny or leafless shrubs, and sometimes also saline plants. The: Areg sometimes produces Grasses. The rest of the scanty vegetation of the desert, oily and bulbous plants, \&c., retreats to the Wadis and the Oases with their date-palms. The date-palm is the only tree which has its original and uncontested home in the Sahara ; the rest, as well as a number of other plants, have migrated from elsewhere or been introcluced by man. 


\section{The Sudan Region.}

This region includes Central Africa from $20^{\circ} \mathrm{N}$. lat. to $20^{\circ} \mathrm{S}$. lat., as well as southern Arabia; and enjoys, in general, a refreshing rain only when the rays of the sun strike vertically downwards, remaining at other tines under the influence of the dry trade-winds. Growth is therefore possible only as an occasional phenomenon; and the prevalent character of the vegetation is that of the savannahs. Copious dew and sharp changes of temperature contribute to render the climate of this region extremely ill-adapted for the immigration of foreign forms; so that the aboriginal fauna and flora have been preserved in their primitive aspect. A characteristic feature is the gigantic Grasses, often 6 or 7 metres high; peculiar to it are the enormous stems of the baobab and leaves of Musa Ensete. Among the more important useful plants are the tamarind, the fig-sycamore, the palms, especially the doom palm and the oil palm Elacis guincensis, and the succulent and poisonous arborescent Euphorbias. Acacias and thorny shrubs are generally distributed. A not inconsiderable portion of the Sudan flora has migrated into Upper Egypt. South Arabia was at one time treated as a separate region, on account of its balsamic vegetation.

\section{The Kalahari Region.}

The Kalahari region extends along the Atlantic coast of Africa from $20^{\circ}$ to $29^{\circ} \mathrm{S}$. lat. It is altogether destitute of water, and forms a connecting link between deserts, savannahs, and steppes covered with shrubs; and has no oases with a settled population, but is tenanted only by wandering nomads. Peculiar to this region is the remarkable Welavitschia (see P. 338); and the most prominent members of the scanty Alora are spiny Acacias and other shrubs which almost entirely impede locomotion, a number of bulbous and tuberous plants, Grasses, and the south African water-melon. There are no palms. 


\section{Io. The Cape Region.}

The interior elevated plains of the Cape of Good Hope, which lie south of the Orange River, slope downwards through rocky mountains or precipitous descents to the level of the sea. The climate may be compared to that of the elevated plains of Spain. In both districts an extraordinary variety of vegetation is promoted by the unequal distribution of temperature, of the annual rainfall, and of the humidity of the air. The highest terrace (about I,000 metres above the level of the sea), the Roggefeld, is at times completely bare, and at other times is covered only by small compositous. bushes. The middle terrace, the Karroo-plain (700 metres), is also clothed with a uniform steppe-vegetation; the socalled ' rhinoceros-bush' (Stocbe rhinocerotis) belonging to the Compositæ, covers the widest tracts of country; it is only in August that the soil becomes clothed for a few weeks with a luxuriant green, carpeted with numberless flowers, belonging to the Compositæ, Liliaceæ, Mesembryanthemaceæ, \&c. From the Karroo-plain to the coast the character of the vegetation is determined by the evergreen shrubs, constituting what is called the 'bush.' This is perhaps the richest spot on the whole earth in species of plants, and is especially the paradise of flowers. - Ericaceæ, Proteaceæ, Euphorbiaceæ, Stapelias, Liliaceæ, Iridex, and ' everlastings' (Hclichrysum, belonging to the Compositæ) are the most conspicuous elements of the vegetation. Especially noteworthy is the Prionium or palmet (Juncacex), the stems of which grow so closely crowded together that they detain and impede the courses of rivers like wears.

\section{The Australian Region.}

Northern Australia has a tropical climate with a summer rainy period. In the sub-tropical zone, from $19^{\circ}$ to $29^{\circ} \mathrm{S}$. lat.; is a deser belt, in which the reign of the trade-winds is uninterrupted. The climate of South Australia may be compared to that of the Mediterranean, the rainfall being limited 
to the winter; while in Tasmania rain falls at all seasons. Most of the rivers are dried up for considerable periods, and leave gradually diminishing 'creeks' of water only where their beds are deepest. Woody savannahs termed 'grass-lands,' and thickets of bushes known as 'scrub,' occupy the greater part of Australia so far as it has been opened to colonisation. The grass-land is a carpet of meadow interspersed with occasionai forests of Eucalyptus, and adorned in the rainy season with numerous bulbous plants, Liliacer, Orchidex, \&c., and 'everlastings.' 'The scrub consists entirely of densely interwoven shrubs, Proteaceæ, Epacrideæ, Myrtaceæ, Leguminosæ, \&c., among which rise sometimes lofty trees, Eucalypti and Acacias; but is destitute of herbaceous plants and grasses. In the valleys of the creeks there is only a dense scrub; and here, among other plants, are found the Casuarinas (she-oaks), palms, and the grass-tree, Xanthorrhor. In addition, Australia has also, like the Asiatic steppe-region, grass-, salt-, and sand-steppes.

\section{The North American Forest-Region.}

The regions of vegetation of North America correspond to those of the eastern hemisphere. A broad forest-zone passes through the whole continent from Behring's Strait to Newfoundland, and southwards as far as Florida and the mouths of the Mississippi. The narrow strip of coast of California may be compared with the Mediterranean region in its rainless summer period; and the Asiatic steppes correspond to the prairies between the Sierra Nevada and the Mississippi.

As compared with the Europæo-Siberian, the American forest-region is colder in the same latitude, and the difference may be estimated as, on an average, one of $10^{\circ}$ of lat. Thus, for example, the average annual temperature at New York, in $45^{\circ} \mathrm{N}$. lat., is $10^{\circ} .5 \mathrm{C}$. ; and that of Brussels, in $5 \mathrm{I}^{\circ} \mathrm{N}$. lat., is $10^{\circ} .4 \mathrm{C}$. The difference is less than this in the southern 
portions, but increases gradually towards the north. The temperature diminishes very rapidly as we advance northwardis, the cold waters of the Polar sea having no sufficient outflow southwards through the narrow Behring's Strait and Hudson's Bay. Europe has also the advantage of a less variable maritime climate, from the inland seas penetrating to a greater depth. In consequence of this, New York has the summer-temperature of Rome and the winter temperature of Copenhagen ; Quebec the summer of Paris and the winter of Petersburg. The character of the vegetation is determined by this alternation of summer and winter temperatures.

The northern belt includes the zone of Pinus alba and nigra, which in America replace the European firs. Coniferous forests, the individuals of which are often of an immense size, mixed with a few exogenous trees, mark, in the zone of the Oregon pine, the passage to that of deciduous exogenous trees. These forests are distinguished from the corresponding oak- and beech-zones of Europe by the greater variety of their oaks, and by the species of elm, ash, and maple. 'The forest-zone of the Southern States is, as in South Europe, characterised by evergreen exogenous trees intermixed with representatives of tropical families. In its moist summer the climate of these States resembles that of China; the most noticeable crops are cotton, rice, and the sugar-cane. But these advantages are again partially counterbalanced by the sandy and marshy nature of the soil from Louisiana to Virginia, [the Great Dismal Swamp], covered by Pinus australis, and by the almost inaccessible swampy lowlands of the Atlantic coast.

Most European crops thrive in North America as well as with us; but the great alternations of temperature are unfavourable to the more tropical species, as the orange. The maize is cultivated to higher latitudes than in Europe, while the cultivation of the grape-vine is scarcely anywhere carried on with much success. 


\section{I3. The Prairie Region.}

The prairies, the steppes of North America, are treeless plains, in which the severe cold of winter is succeeded by a short period of active growth ushered in by a transitory rainy season, and a dry rainless summer. The cause of the summer drought is the dryness of the prevalent western Pacific winds; and this is the result of the moisture of the air being previously withdrawn by the Rocky Mountains and the chain of mountains along the Californian coast. The heavy rains which fall on these mountains are, it is true, the feeders of great rivers which cross the prairies; but these water-courses, which are often of great size, the affluents of the Mississippi, tlie Colorado, and the Rio Grande del Norte, are of but little service for the irrigation of the soil, because they have worn their way down into the soil, often to such a depth that no arable land is left in the deep chasms or river-beds known as 'cañons'; and sometimes there is not even a belt of trees by the side of the stream. The south-western portion of the region is covered by an inhospitable salt-desert, where the soil is often completely bare, or produces a vegetation consisting almost entirely of a few sparse Chenopodiacer and social Artemisias. There are, however, here and there in the prevailing desert, a few scattered onses, among which that of the Great Salt Lake is the most important. A contrast to the salt-desert is afforded by the northem portion of the region, a true grass-steppe, the home of the bison; while in the south agaves, aloes, and yuccas abound, and the Cactaceæ attain their maximum development. The few trees and shrubs which are found here and there on the banks of the rivers and slopes of the mountains, have mostly migrated from the forest-region. Among the characteristic forms of vegetation are the Mimosex, especially the genus Prosopis, which forms by itself the feature in the landscape 
known as 'mezquit,' while, associated with other thorny shrubs, it constitutes the 'chaparals.'

\section{The Califormian Region.}

The climate of this strip of coast, which is of a purely maritime character, is determined by the uniformity of the temperature-that of summer and winter differing by only a few degrees-and the regular alternation of a moist cooler season with a rainless summer. In the mildness and short duration of the winter, in the rainless summer of the forest-region beyond the Oregon, and-in contrast to the prairies - in the length of the period of active growth necessary for the development of arborescent vegetation, the climate of California resembles that of the Mediterranean, although the mean temperature is not so high. The culture of the vine has struck root here, and that of cereals and fodder-crops yields in places extraordinary results. Arboreal vegetation here attains its maximum development in the gigantic mammoth-trees, the Sequoia [or Wellingtonia] gigantea, the loftiest of known trees. Other gigantic though somewhat less lofty conifers, and evergreen exogenous trees, oaks, limes, ashes, and willows, shrubs allied to the oleander, myrtle, and heaths, as well as numerous smaller bushes and grasses growing in great masses, complete the flora of this small but remarkable region, which often assumes a parklike character.

\section{The Mexican Region.}

This region may be divided, according to its elevation above the sea-level, into three zones:-the gulf-zone, the zone of the Mexican highlands, and the Pacific zone. The first, a narrow strip of coast, rises above the dry sea-shore in gently sloping grass savannahs, interrupted here and there by woody tracts, and even by groups of palms. A much 
richer vegetation of tropical growths fills the moister ravines, the 'barrancas,' which score the volcanoes on all sides. The upper portion of the tropical zone is covered by damp mountain-woods with evergreen foliage. Associated with the lofty exogenous trees are tree-ferns, arborescent Liliacex, numberless lianes, among which are the sarsaparilla and the vanilla, an immo:se variety of copiously flowering Orchideæ and Bromeliaceæ, including the pineapple. The cultivation of the coffee, plantain, and sugarcane are here carried on with success. A striking contrast to this wealth is presented by Yucatan, the chief product of which is its logwood forests. The highland of tropical Mexico enjoy's an extrenely uniform climate, with a temperature resembling that of the summer at Paris. In the character of its vegetation, its agaves, spiny Mimosas, and cacti, it approaches the southern prairies, but is admirably adapted to the cultivation of the olive, mulberry, and vine, and especially of the agaves which yield the drink known as pulque. The forests consist chiefly of oaks and Coniferæ. The gradual slope of Mexico towards the Pacific, or Pacific zone, has a less uniform character than the narrow Gulfzone. Its flora is less rich than that of the Gulf-zone, the rainfall being less; but the sea-coast is bordered by a tropical forest which yields logwood and the cocoa-1rut.

\section{The West Indian Region.}

The West Indies form a phyto-geographical region of their own. Each of the solstices is followed by a rainy season, which causes the West Indian archipelago to be well wooded to the tops of the mountains. The present vegetation is, however, different from the aboriginal. When first discovered by Europeans the whole of Jamaica was almost entirely covered with mahogany trees and Cedrelas; maize was the only crop. The forests, however, soon disappeared on the coasts ; the sugar-cane became the principal product of the low districts, and coffee-plantations arose on the hills. 
Since the emancipation of the slaves, these crops have been to a considerable extent replaced by pasture land; and even the meadows are being changed by the introduction of foreign grasses.

\section{I7. The Cis-equatorial Region of South America.}

The shores of this region are covered with dense forests, while in the interior of the continent, where the seawinds have been deprived of moisture by the action of the chains of mountains, extend the great savannahs of Guiana, and the boundless llanos of Venezuela, covered by an extraordinarily rich fauna, and characterised by a sharp contrast of dry and moist seasons. These forests, which clothe especially the shores of the Amazon, are mostly evergreen, with but few Coniferæ, and marked by Passifloraceæ, Piperacex, Phytelephas, Tabernamontana, and a great variety of palms. The savannahs are grass plains sprinkled but sparingly with trees; in the spring they resemble the northern prairies, splendidly gay with the most brilliant flowers; while in the autumn they produce thinly-sown corn-crops, till the commencement of the rainy season brings again the grass and the flowers. The llanos are grass plains often entirely destitute of trees, sometimes dry deserts, at others flooded by continuous rain.

\section{The Amazon Region.}

The uniformity of a tropical temperature, and the regular increase of moisture, produce on the banks of the Amazon and neighbouring streams a forest-region known as 'Hylæa.' In the main stream the greatest height of the water exceeds the lowest by as much as from I 3 to I 7 metres; and since the shores are perfectly flat, the forest is flooded every year on both sides of the river to a breadth of several geographical miles. This tract of country is known as 'igapo,' consisting of forests in which the trunks 
of the trees stand for months in water from 3 to 13 metres deep. Among the more important trees are Mimosas, Lauraceæ, and Ficuses, intermixed with and overtopped by magnificent palms, among which is the Moriche-palm, Mauritia flexuosa; there are no woody lianes. Beyond the region of the floods are the Ete- or Guaçu-forests, in which the prevalent forms are the dusky Lauraceæ, with the brazil-nut, Bertholettia, covered everywhere by stout lianes. "The forests on the Rio Negro differ from those near the Amazon in the rarity of palms and lianes. The natural products of all these forests are unbounded:-brazilnut, caoutchouc, cocoa, vanilla, sarsaparilla, with valuable woods, vegetable fibres, and medicinal plants in the greatest variety.

\section{The Brazilian Region.}

Along the whole of the south-east coast of Brazil stretches a chain of mountains, the Serra do Mar, rising to an elevation of 7,000 feet, the slopes of which are exposed to the trade-wind, and collect a considerable amount of moisture. This is succeeded in the interior by a broad table-land consisting of argillaceous slate, deprived by the Serra do Mar of the Atlantic moisture, and therefore covered everywhere, except where there is running water or bogs, by savannahs, called in Brazil 'campos.' Here, in the southern summer, the rainy period produces, as if by magic, a vegetation which is dormant during the dry season, the alternation being exhibited especially in the widely distributed savannah-forests, the 'catingas.' The campos are naturally divided into a northern plain, a central table-land, and southern tracts beyond the tropics. In the northerly campos, as in the llanos north of the equator, the savannah-grasses flourish with their loose tufts, and among them rise a few columnar cactus-stems. On the table-land the number of shrubs with coloured flowers 
increases with the elevation of the ground; and Melocactus takes the place of the columnar forms. Both sections possess thickets and forests, but composed of different trees. The almost unmixed groups of Araucaria brasiliensis are peculiar to the southern savannahs. To the west the savannahs extend as far as the affluents of the Paraguay and Madeira. Here, as on the coast, we come again to primeval forests, the 'pantanals,' of a tropical luxuriance, which, like the forests of Hylæa, owe their peculiarities to running water. To the south of these the plains of Gran-Chaco, and the woody highland of Paraguay, alternating with open grassplains, almost entirely fill up the space between the Andes and the southern table-land of Brazil. Here are found the forests of 'algarob,' belonging to the Mimoser, and the Brazilian wax-palm, Copernicia cerifera.

\section{The Tropical Andean Region.}

Throughout almost the whole of this region, like the last, there is a natural distinction between a chain of mountains rising almost immediately from the shore of the Pacific, forming a kind of littoral cordilleras, and an eastern series of peaks which slope down to the broad lowlands of South America. In Peru and Bolivia the western chain includes an extensive highland, the Sierra or Puna district ; while on the southern tropic both the ridge and the peaks disappear, and give place to the desert of Atakama. The Pacific coast of this entire region is an altogether rainless country, which is only watered in winter by slight mists, the 'garuas;' the Antarctic current of Humboldt which skirts the coasts bringing constantly fresh quantities of cold water, and causing the condensation of the aqueous vapour brought by the sea-winds. Drought prevails therefore not only on the land, but also on the sea, as is shown by the guano-deposits of the Chincha Islands. Only on the shores of the short rivers, or by means of artificial irrigation, can cultivation be 
carried on in detached spots. Even the higher portions of the coast-range, as well as the Puna district, are treeless, but are covered with an Alpine herbaceous and shrubby vegetation. A richer tropical vegetation is to be met with in the Peruvian Andes only on the eastern slope of the eastern Cordilleras, or in the valleys which intersect the Puna district with deep rocky channels, and lead to the lowlands and the sea. A long rainy season in summer is here a source of inexhaustible fertility ; coffee, the plantain, sugarcane, and cocoa, are the cultivated crops. While the botanical features of the district at the foot of the Cordilleras. and in the deep valleys, merge gradually into those of the Brazilian flora, the upper belt of woods, the Ceja of the Montaña, present some peculiar features, tree-ferns, palms, Guttiferæ, Scitamineæ, and especially the most important of all, the Cinchona or Peruvian bark.

\section{The Pampas Region.}

By a Pampas is meant a treeless pasture-land covered with grass; but in the region of vegetation so designated must be inclucled the whole country extending from the boundary of Brazil, where the regular rainy seasons of the tropical zone cease, across the States of La Plata and Patagonia nearly to the southern extremity of the continent. The true pampas resembles the grass plains on the Missouri; and the thickets and thin woods which occur in the provinces of La Plata lying nearer to the southern limit of the tropic, resemble the chaparals or mesquit-thickets of Texas and New Mexico. The nature of the vegetation is here determined by the distribution of the moisture; the greater part of the rainfall takes place in the form of sudden thunderstorms, while at other times the air is extremely dry, but with copious dews at night. Long periods of drought intervene, the storms often failing altogether for years. This is the cause of the entire absence or the extreme scantiness of 
the arborescent vegetation. The climate is not, however, in itself unfavourable to the growth of trees, as is the case with the prairies and the steppes of the Old World. In Uruguay generally the cultivation of trees is possible; in Buenos Ayres the peach is grown for the sake of its wood.

The Pampas-region may be divided into three zones :the interior north-western Chanar-steppe ; the true Pampas; and the southern plains of Patagonia. The first is not occupied to any great extent by grass, but is chiefly covered by underwood, especially the chanar-shrub, an Acacia known as 'espinillo,' and species of Cactus. At the foot of the Andes it includes some salt lowlands, the Argentine 'salinas,' where the vegetation consists of only a few saline plants. The true Pampas are grass-plains, in which the trees are confined to narrow strips of low woods along the rivers. There are scarcely any native shrubs or herbaceous plants ; but some from the south of Europe have become naturalized; thistles and fennel have increased to an enormous extent; Onopordon acanthium has entirely displaced the grass over many square miles, and forms impenetrable thickets, exceeding a man's height. Where the grass-steppe ceases, at the Patagonian Colorado and Rio Negro, a low, sparse, thorny, shrubby vegetation begins, growing among louse stones, until at length this also becomes scarce, and the arid ground, parched by the dry air, produces only a few tufts of a hard brown grass. A small Acacia, which is found alone and solitary in the neighbourhood of the Rio Negro, is so remarkable a phenomenon to the natives that it is regarded as sacred.

\section{The Chilian Transition-Region.}

This region, which includes the northern and central provinces of Chile, enjoys a climate similar to that of the Mediterranean ; but the season of active growth is interrupted by longer periods of drought; for during one-half of the 
year vegetation appears dead and the land almost barren. Even on the sea-coast there is no great quantity of trees; the foliage of the bushes is to a considerable extent replaced by spines; and the desolate character is intensified by the wildness of the naked mountains untouched by sea-breezes. Tropical forms of plants are nowhere found.

\section{The Antarctic Forest-Region.}

The Antarctic flora may be compared with that of the north of Europe and of the European Alps. As in northern Europe, the equatorial currents of moist air alternate irregularly with the clear sky of the polar currents; and the rainfall is, in consequence, distributed through all the seasons of the year, and vegetation is usually plentifully supplied with moisture. But since this rainfall is associated with a milder winter than in the northern hemisphere, the greater number of the trees preserve their foliage throughout the year. But notwithstanding this uniform temperature, there is, even in southern Chile, where snow and frost are unknown, a distinct period of repose of vegetation during the winter. While even in the last (Chilian transition) region an increase in the vigour of vegetation coincides with the rainy season, the deciduous trees here lose their leaves at the time when the greatest quantity of rain falls and the temperature is also falling.

The Antarctic region may be divided into a northern and a southern zone. Forest prevails everywhere. In the northern zone, which includes also the island of Chiloë, the forest is composed of a great number of trees belonging to different families, including Liaraceæ, Myrtaceæ, Oleaceæ, and even bamboos; lianes and parasites cover the stems and fill up the space, as in the tropical forests, but not with the same abundance of forms. In the southern zone, on the other hand, almost the only trees are beeches; but since the most common deciduous species, Fagus antarctica, is 
accompanied by an evergreen kind, the general aspect of the forests is quite different from that of northern Europe. It is only in the extreme south, where the diminished temperature and the moisture which remains in the ground are favourable to the formation of peat, that the forests yield to open moors. But the vegetation of these moors is peculiar, consisting of a saxifrage and a plant allied to the lilies, associated with cranberries, Ranunculi, and rushes.

\section{Oceanic Islands.}

The native plants of islands often differ considerably from those of the nearest continent; the aboriginal flora has been preserved in greater purity than elsewhere ; and it is to insular floras of this character that the important theory of the migration of plants owes its origin.

The Azores, Madeira, and the Canaries, an archipelago formed of lava and volcanic rocks, possess a flora altogether independent, but enriched from without, and known as the Atlantic Flora. That of the Azores resembles the Mediterranean flora; evergreen shrubs and forest trees belonging to the Lauraceæ, together with beautiful Ferns, cover the greater part of the islands. Madeira was, at the time of its discovery, completely clothed with wood down to the shore. But the so-called cedar of the island, a timber-tree with a valuable scented wood, disappeared after a great forest-fire. The vegetation has been completely altered by cultivation. Together with the sugar-cane, which has taken the place of the vine-the latter having been almost destroyed by the vine-disease since 1852 - the plantain has been generally cultivated; tropical fruit-trees are abundant; but there are no palms. Other noteworthy native plants are the dragontree Draccena, the luxuriant forests of laurels, the shrubby heaths, magnificent Ferns, and dense underwood, which characterise the district of the thickets above the laurelwoods. The flora of the Canary Islands has an African 
character in its lower districts; the prevalent forms here are numerous succulent plants, especially Euphorbiaceæ, the date-palm, and tamarisks. These districts are generally arid, especially since the change introduced in consequence of the vine-disease; and the Opuntias, which serve for the nourishment of the cochineal-aphis, have become one of the most important objects of cultivation. The remaining districts, characterised by laurel-woods, thickets, pines, and Genistas, indicate an Atlantic flora, although the evergreen woods have been to a large extent destroyed.

The Cape-de-Verde Islands differ from those already mentioned in their more tropical climate. The rocks and loose stones, uncovered by wood or even by the least stratum of soil, are heated to so high a temperature by the rays of the sun that it is impossible for the aqueous vapour brought by the trade-wind to become condensed; and since there is sometimes no rainy period, the vegetation of the islands is sparse. Four-fifths of the surface is said to be entirely unproductive; the only cultivated plants are a few introduced cocoa-nut and date-palms, coffee-bushes and fruit-trees. The native flora is generally similar to the Atlantic, while the introduced plants indicate the proximity of Africa.

The volcanic island of St. Helena was, at the time of its discovery at the commencement of the sixteenth century, covered with wood, but the young branches were so completely destroyed by introduced herds of goats, which increased with great rapidity, that three centuries later there was a scarcity of wood, when the goats were taken away and trees introduced from all parts of the globe. The climate, refreshed by a steady trade-wind and two rainy seasons, is extraordinarily fertile; but the introduced plants, and especially the European pines, have completely displaced the native flora.

Madagascar, traversed by lofty chains of granite mountains, which slope on both sides to a littoral lowland, marshy 
or occupied by lagunes, has a seven months' rainy season. The greater part of the isiand is in consequence covered with moist tropical forests bordered in the interior by elevated grass savannahs. In the south a scanty thorny vegetation prevails. The most remarkable product of the forests is the 'travellers' tree,' Ravenala, a plantain, the fan-shaped leaves of which are hollowed out at their point of insertion into a spacious cavity in which water is caught and retained, so that when pricked they give out a refreshing fluid. Here is also found the aquatic Ouvirandra or lattice plant, the leaves of which consist almost entirely of a perforated lace-like network. There are also epiphytic Orchids with enormous flowers, tree-ferns, impenetrable lianes, heaths, bamboos, pitcher-plants, Nepenthes, and a few palms.

The flora of the Mascarene Islands (Mauritius and Bourbon) is allied to that of Madagascar. That of the Seychelles is distinguished by the double cocoa-nut, Lodoicea Seychellarum, with its gigantic fruits.

The Sandwich Islands enjoy a climate resembling that of Jamaica. In Hawaii plantations of the cocoa-nut palm and bread-fruit alternate with sugar-cane fields; and above the cultivated plain a belt of wood surrounds the volcanoes. The commonest native tree, an Acacia known as 'koa,' raises its crown of leaves above a dense thicket of evergreen underwood. The once abundant sandal-wood has already become scarce from the demand for its timber.

The flora of the Feejee Islands approaches nearest to that of the Indian monsoon region. To the summits of their basaltic mountains they are covered with the most luxuriant tropical vegetation. The most important foodplants are the plantain, cocoa-nut palm, bread-fruit, and in the cultivated fields tapioca (Arum esculentum), yams, Tacca, and batatas.

New Caledonia exhibits in its flora a resemblance to that of Australia. Its woods are destitute of undergrowth; 
Myrtaceæ are scattered over its arid grass-plains at wide distances; its stony mountains are barren.

The flora of Norfolk Island, not unlike that of New Zealand, is remarkable for the Norfolk Island pine, Araucaria excelsa.

New Zealand is more nearly related in its flora to the forest region of south Chile than to Australia, which lies so much nearer. The evergreen forest, composed of Myrtaceæ, Lauraceæ, and broad-leaved Coniferæ (among them the Dammara australis) includes also tree-ferns and arborescent Liliaceæ, and is often rendered impenetrable by dense thickets of lianes. Shrubs and Ferns mixed together clothe the open slopes of the mountains and the dry plains; Ferns are often the sole representatives of the grass of other countries, and clothe boundless stretches of open land; so that some resemblance may be traced, in the abundance of its fern vegetation, between the flora of New Zealand and that of prehistoric times, especially of the vegetation of the Carboniferous formation. Among the Ferns Pteris esculenta is noteworthy for supplying food; and of other native products the valuable New Zealand flax, Phormizm tenax, belonging to the Liliaceæ.

The uninterrupted southern trade-winds impart to the archipelago of the Galapagos Islands an arid climate. Ascending above the lava fields, covered with light dwarf shrubs and Cactaceæ almost destitute of leaves, we find on the mountains a tolerably luxuriant forest-flora, but with no tropical character. More than one-half of the species are endemic (i.e. peculiar to the islands); the rest have migrated from the shores of the Isthmus.

Juan Fernandez is densely covered with forests alternating with grassy plains. No considerable inmigration of foreign plants has taken place; and the forests are covered with climbers, which, like the trees up which they twine, occur nowhere else on the surface of the earth. Ferns, tree-ferns, and palms prevail. 
The Falkland Islands are densely covered with lofty grasses which have extended themselves over immense layers. of peat.

The vegetation of the basaltic Kerguelen's Land, like that of the Falkland Islands, consists of a few Grasses intermixed with tufts of an Umbellifer. There are no woody plants. The most interesting species is the 'Kerguelen's land cabbage,' a Crucifer, Pringlea antiscorbutica [differing from most of the Cruciferæ of Europe by being chiefly windfertilised].

In the extreme southern latitudes south winds laden with snow alternate with northerly currents of air saturated with aqueous vapour, and perpetual white fogs of unparalleled density spread over the surface of the sea. These fogs are formed also on the islands which lie near this zone, almost entirely depriving them of the rays of the sun. Both flora and fauna are extremely scanty. The remarkable difference between the climates of the two polar zones depends. on the great excess of water in the extreme southern latitudes, on the consequent cloudy sky, and on the masses of icebergs which break loose in the summer, and, in melting, reduce the temperature of the better part of the year. But in these southern latitudes, where life is now so scanty, there was once a warmer prehistoric epoch ; for, like the extinct forests of Greenland, the evidence of well-preserved fossil stems proves that a luxuriant arborescent vegetation once inhabited Kerguelen's Land. 



\section{GLOSSARIAL INDEX.}

$A B I$

4 BIETINE $E$, 337. Fig. 454, 458, 459 Abnormal phenomena, 216

Ábortion, 217

Absinthe, $39 \mathrm{I}$

Abstriction, 268. Fig. I, 402 II.

Acanthacex, $3^{82}$

Acaulescent, 76

Acclimatisation, 217

Accrescent, 126, I34. Fig. 234, 496 Ir.

Acerose. See Acicular

Acetic fermentation, 250

Achene, 153, 414. Fig. 327, 501, 503

Achlamydeous, II2. Fig. 201, 202

Achorion, 247

Acicular, 94. Fig. 454

Acorn, 154. Fig. 303

Acotyledones. See Cryptogamia

Acrocarpi, 308. Fig. 427, 432, 433

Acrospore. See Basidiospore

Acuminate, 97. Fig. 164

Adaptation, 215

Adhesion, II6, 219

Adnate, 9I, 140. Fig. 182, 282

Adventitious buds, 82

Adventitious roots, 75. Fig. $1 \times 5,121$, $34^{8}, 43^{6}$

Ecidiomycetes, 276. Fig. 400

Ecidiospore, 277

ÆEcidium, 277: $27^{8}$

Aërial hyphæ, 284. Fig. I

Aërial roots, 73,162

Estivation, 84. Fig. $124^{-1} 3^{1}$

Ethalium, 270

Age of plants, 235

Air-bladder, 259. Fig. $3^{87}, 3^{89}$

Air-cavity, 320. Fig. 86,445

Alæe, I32, 400. Fig. 253

Albumen. Sec Endosperm

Albuminoids, 30, I 73

Albuminous, 156, 19o. Fig. 305, 333, 365

Alburnum, $365,3^{6} 7$

Aleurone, 3 I

Algx, 239, 250. Fig. 38, 4I, 54, 56, 58, $81,82,3^{82-393}$

Alismacex, 35 I
ANT

Alkaloids, 3 I

Allspice, 399

Alluvial formation, 431

Alpinus, 4

Alternate, 87

Alternate æstivation, 84 . Fig. I2y

Alternation of generations, $177,26 \%, 276$, 300,315

Amaranthacex, 374

Amaryllideæ, 349

Amazon region, 45I

Amber, 430

Amentacex, 375

Amentales, 374

Amentum, 121, 375, 379. Fig. 223, 453, 481,485

Amoboid movement, 269

Amomales, $34^{8}$

Ampelidex, 407. Fig. 196, 257, 265

Amphigastrium, 297. Fig. 424, 425

Amplexicaul, 92. Fig. 148

Amygdaleæ, 406. Fig. 325

Anatomy of plants, 2, 5, 6

Anatropous, 146 . Fig. 30011.

Andreæaceæ, 306. Fig. 429

Androcium, III, 137

Androspore, 255, 262. Fig. 386

Anemophilous, 183

Angiocarpous, 279, 289

Angiosperms, 183, 241, $35^{8}$

Angustisept, 413. Fig. 530 II.

Annual, 76, 235

Annual ring, 362. Fig. 9511.

Annular cell, 20. Fig. $3^{I-34}$

Annular vessel, 47

Annulus, 279, 314. Fig. 401, 402, 440

Anonace 2 , 416

Antarctic forest-region, 456

Anthela, 122

Anther, 137. Fig. 267-286, 459, 461 II.

Anther-lobe, 137. Fig. $267^{-269}, 468 \mathrm{II}$.

Antheridial receptacle, 300 . Fig. 422, $427,43 I$

Antheridium, 240, 255, 274279,293 , 299, 31 5, 322. Fig. 385,398 , 418 111 ., $420,428,43 I, 44 I, 442,446$ 


\section{ANT}

Antherozoid, 200, 251, 255, 261, 267, 274, 293. Fig. 371, 385, 386, 387, 420, 427 V., $428,442,446,450,452$ v1.

Anthocerotex, 300 . Fig. 421

Antholysis, 222

Antipodal cells, 187. Fig. 360

Apetala, 374

Apetalous, 112. Fig. 207, 259, 260

Aphides, 233, $45^{8}$

Apical cell, 55, 310. Fig. 83 1.

Apiculate, 105

Apocarpous, 142. Fig. 314, 315

Apocynacex, $3^{8} 7$

Apogany, 316

Apopetalous, 129. Fig. 232, 250, 252, 255

Apophyllous, I 34

Aposepalous, 124. Fig. 231-233

Apospory, 316

Apothecium, 282. Fig. 407, 414, 4I5

Appendages, I41, 154, I55. Fig. 283$285,319,328,329$

Appendicular organs, 72, 86

Apple, Fig. 519

Applied botany, 2

Aquatic roots, 73

Arales, 354

Araliacea, $39^{\circ}$

Archegonial receptacle, 300. Fig 422

Archegonium, 191, 240, 299, 315. Fig. $418,422,428,44 I, 446,452$ IV.

Arctic region, 457

Areg, 443

Arillode, 155

Arillus, 154, 337. Fig. 328

Aristolochiacex, 378. Fig. 279

Aristotle, 3

Aroidea, 354. Fig. I94

Asarales, $37^{8}$

Ascidiform, 107. Fig. I93, 356

Ascidium. Sec Pitcher

Asclepiadex, 387. Fig $355 \mathrm{E}$

Ascogonium, 283, 289

Ascomycetes, 281. Fig. 375, 403-417

Ascophorous hyphæ, 285, 289. Fig. 413

Ascospore, 267, 268, 281. Fig. 404, 406

Ascus, 268, 281, 289. Fig. 403, 404, 406, 414

Asexual reproduction, 178

Asexual reproductive cell, $I_{7} 8$

Assimilation, $161,172,213$

Asterales, 388

Atropous. See Orthotropous

Auriculate (shaped like an ear), Fig. 185

Australian region, 445

Auxiliary cells, 266

Auxospore, 260

Awn, 343. Fig. 462,463

Axile placentation, 145. Fig. 297

Axillary, Fig. 138

Axillary bud, 82 . Fig. 123

Axis, 70, 220. Fig. $97,99,368,370,426$

Azores, 457

\section{BRI}

BACILLARIEA. See Diatomacere Bacillus, 245, :47. Fig. 380

Bacterium, $245,=46,247$. Fig. 380

Balanophoracea, 380

Balsam, 402

Bamboo, Fig. $4^{6}$

Banyan, 75, 442

Baobab, 409

Bark, 357. Fig. 66, 67, 35I, 352

'Barrancas,' 450

Basidiomycetes, 278. Fig. 65, 401, 402

Basidiospore, 267, 268, 278. Fig. 402

Basidium, 268, 276, 278. Fig. 400,402

Basifixed, 140 . Fig. $280,28 \mathrm{I}, 283,284$

Basilar, 143. Fig. 290

Bast, 357. Also see Phloëm

Bast-bundle. Fig. 95, 477

Bast-cell, 368 . Fig. 17, 18, 26, $66^{\circ}$

Bast-fibre, 48, 341, 368. Fig. I4, J5, $67,93,95,476$

Bast-tube. Scc Bast-fibre

Bast-vessel. Sce Sieve-tube

Bauhin, 4

Beet-disease, 231

Begoniacex, 399

Bentham, 6, 239, 355

Berberidea, 419. Fig. 281

Berkeley, 6

Berry, 153. Fig. 326, $495 \mathrm{IJ}$.

Betulacere, 375. Fig. 480

Bicarpellary, I42. Fig. 296, 297

Biennial, 76, 235

Bifid, 125, 131. Fig. 251, 254

Bignoniacex, 382 . Fig. 329

Bilabiate, 1 25, I 29, 382, 390. Fig. 230, 248,489 1I.

Bilocular, I40, 144. Fig. 280-284, 297, $31511 ., 317$

Binomial nomenclature, 238

Bipinnate, 103. Fig. 143,190

Bisepalous, 125. Fig. 233

Biseriate (in two rows), Fig. 228

Biserrate, 99. Fig. I 70

Bisexual. Sce Hermaphrodite

Biternate, 103. Fig. 188

Bixacea, 414

Bladder, 184,263 . Fig. 356,392

'Bleeding,' 16r, 233

Bock, 3

Ponnet, 6

Bordered pits, I9, 365. Fig. 14, 22-24, 27,70

Borraginex, 385. Fig. I5I, I99, 227, 245,262

Botanical geography, 2, 432

'Botrytis," 283

Boussingault, 6

Bract, 86, 116, 220. Fig. 201, 458, 480

Branch-spine, Iog. Fig. 197

Praun, 5

Brazil-nut, 399

Brazilian region, 452

Bristle, 6I 
BRI

Brittleworts. Sec Characea

Bromeliacex, 348

Brongniart, 6

Broom-rape, 232

Brown, Robert, 6

Brown coal. See Lignite

Brunfels, 3

Bryacex, 307. Fig. $427,428,430,432-435$

Bryinex, 306. Fig. $427-430,432-435$

Bud, 82, I78, I79. Fig. 99, I2I, I 23

Bud.scales, 83,86

Budding, I79, I8I. Fig. 354

Bulb, 80. Fig. 122

Bulbil, 83, I79, 295. Fig. I21, 122, 350

Bunt, 227

Bunter Sandstein, 426

Burseraceæ, 407

Butomaceæ, 35 I

Butyric fernentation, 247

Buxaceæ, 378

CABBAGE, 414

C Cactacez, 398

Caducous, I 25. Fig. 233

Casalpinieæ, 402

Cæsalpinius, 4

Cainozoic rocks, 429

Cajeput-oil, 399

Calamite, 323,423

Calamus, 77

Calcium, 162

Calcium carbonate, 249

Californian region, 449

Callus, 46 , 180. Fig. 351,352

Calyciflorae, 390

Calycifioral flower, II 4. Fig. 208

Calyptra, 300, 304. Fig. 427, 435

Calyx, IIO, I24, 300. Fig. I99, 200, 204-206, 208-210, 228-239, 496

Cambiform tissue, 6

Cambium, 43, 64. Fig. 95, 352, $472 \mathrm{~B}$

Cambium-ring, 360

Cambrian system, 420

Camelliacea, 409

Camerarius, 4

Campanales, 388

Campanulaceæ, 388 . Fig. 242

Campanulate, I 25, I29, I3 I. Fig. 242, 26 I

Camphor-gland, 53

Campos, 452

Campylospermæ, 398. Fig. 5 II

Campylotropous, I46. Fig. 300 III., 333

Canal-cell, 299

Canary Isles, 457

Canker, 224

Cannabinea, 374

Cannacex, $34^{8}$

Cañons, $44^{8}$

Caoutchouc, 24, I76, 378

Cape-de-Verde Islands, $45^{8}$

Cape of Good Hope, 444

Capillarity, 160

Capillitium, 270. Fig. 394

\section{CEL}

Capitate, $144 . \quad$ Fig. 287,290

Capitulum, I17, 295, 388. Fig. 2I3, 2I4, 219, 499, 500

Capparidea, $4 \mathrm{I} 4$

Caprifoliacex, 394. Fig. 150, 272

Capsule, I48. Fig. 289, 306-313, 468 vi., 496,525

Carbon, 162, I ́ 5

Carbon dioxide, Decomposition of, 172 , 173,213

Carbonic acid. See Carbon dioxide

Carboniferous system, 420 . Fig. $534^{-542}$

Carcerulus, I52. Fig. 321, 490 II.

Care.x, Fig. 465,467

Carina, I 32, 398, 400. Fig. 253, 510

Carnivorous plants, 169, 203. Fig. 193, $37^{2}$

Carpel, I42, 220

Carpogonium, 265, 276, 282, 288

Carpomycetes, 276. Fig. 400-4I7

Carpophore, 152, 397. Fig. 318, 509

Carpophyceæ, 265. Fig. $3^{82}, 3^{8} 7$

Carposperm, 265

'Carrageen moss,' 257

Carraway, 398

Carrot, 398. Fig. 510

Caruncle, 155

Caryophyllaceæ, 409. Fig. 226, 250, 251, $254,255,333,524,525$

Caryophyllaceous corolla, I32. Fig. 254

Caryophyllales, 409

Caryopsis, 154, 344. Fig. 46 I IV.

Cascarilla, 378

Caspary 6,

Cassava, 378

Castor-oil, 378

Casuarinaceæ, 376,446

Cataphyllary leaves, 87 . Fig. 346

Catechu, 394

Catingas, 452

Catkin. See Amentum

Caudex, 77. Fig. 470, 47I

Caulerpa, Fig. 380

Caulicle. See Tigellum

Cauliflower, 2Ig, 4I4

Cauline, ro7

Cauline bundle, 339, 357. Fig. $340 \mathrm{Ir}$.

Cayenne pepper, 384

Celastracea, 407

Celastrales, 407

Cell, 7, 12. Fig. I $36,40,41,50,52$, $53,81,380$

Cell-cavity, I9. Fig. 2-6, I6, 374

Cell-contents, 24. Fig. 2, 42-47

Cell-division, 32. Fig. 54 A, 55 I., 56

Cell-family, 37, 248. Fig. 58, 59

Cell-tluid, 8

Cell-formation, 32

Cell-fusion, 37,47

Cell-sap, 8

Cell.wall, 8, 249. Fig. 2, 72, 374, 38I, 449

Cellular Cryptogams, 239

Cellular plants, 67

Cellulose, 12, 21, 173 
CEN

Central cell, r92, 290, 3I5. Fig. 422 IV., 44 III.

Centre of distribution, 432

Centrifugal, I24.

Centripetal, I23.

Chalaza, 146. Fig. 300,359

Chalk, 429

Chamomile, 391

Chaparals, 449

Characea, 240, 29I. Fig. 37I I., 4I8-420

Charales, $240,29 I$

'Charbon," 247

Chemical processes, 196, 213

Chenopodiacea, 374

Chenopodiales, 374

Chicory, 391

Clino-Japanese region, 442

Chlamydospore, 272

Chloranthacea, 378

Chloranthy, 222

Chlorine, I62

Chlorophyll, 24, 108, I73, 249. Fig. 40, $4 \mathrm{I}, 47,5 \mathrm{I}, 54,445$

Chlorophyll-bodies, 24

Chroococcacea, 242. Fig. 8

Chytridiacea, 273

Cicinnobolus, Fig. 376

Ciliate, 99. Fig. I7 1

Cilium, 200, 243, 261, 268. Fig. 371, $386,397,399$

Cinchona, 394, 454. Fig. 505

Cinchonex, 393

Circinate, 85,312 . Fig. 436,437

Circulation of protoplasm, ro, I99. Fig. 3,40

Circulation of sap, $x 75$

Circumnutation, $\mathrm{I}_{5}$, $20 \mathrm{I}$

Circumscissile dehiscence, I49. Fig. 3I2, 496 III.

Cirrhus. Sce Tendril

Cis-equatorial region of South America, $45 \mathrm{I}$

Cistacere, $4 \mathrm{I} 4$

Cladode, 324

Clasping root, 72

Class, $23^{8}$

Classification, 2, 4, 237

Cleistogamic flowers, 186

Climbing plants, 20I. Fig. II 3, I I 4

Closed bundle, $64,67,310,322,339$

Cloves, 399

Club-moss, 324

Clusius, 3

Coal, $423,424,428$

Coal-measures, Fig. 534

Cocoa-nut, rgo, 443, 459 . Fig. 305

Colosperma, 398. Fig. 512

Ccenanthium, II7. Fig. 216

Ccenobium, 26r

Coffee, 394

Coffeea, 393

Coherent, II4. Fig. 229, 230, 240-249, 275,278

Cohesion 116
COR

Cohn, 6

Coleochatex, $26_{5}$

Coleorhiza. Sic Root-sheath

Collateral bundle, 66, 357

Collenchyma, 39. Fig. $64,80,445,472$

Colour of flowers, 128

Columella, 27x, 300, 304

Conbretacex, 399

Commensalism. Sec Symbiosis

Common receptacle, 117 . Fig. 213,214 , $217,218,498$ I1., 500

Composita, 390. Fig. 53, 77, 203, $21_{3}$, $214,217^{-219}, 235^{-239}, 244,278,327$, 476, 498-503

Compound leaves, 94 , 100

Compound spike, rzo

Compound umbel, I20

Concentric bundle, 66, 310

Conceptacle, 264, 326. Fig. 349, 393, 448,449

Conducting cell, $4^{8}$

Conducting tissue, 48 . Fig. 359

Cone, r $21,147,337$. Fig. 224, 304, 455, 458

Cone of growth, 40

Confervacex, 257

Conidiophore, 273, 282. Fig. 397

Conidium, $178,273,274,276,28 r, 284$. Fig. $1,376,397$

Conifera, I47, I9I, 24r, 336, 372, 420, 423,426 . Fig. 23, 24, 27, 78, 79, 224, $280,304,328,335,366,367,454-459$, $478,479,543$

Conjugatæ, $25^{8}$. Fig. II, $38,41,54,56$, $3^{89}, 390$

Conjugating cell, 272. Fig. 396

Conjugation, 32, 47, 251, 257, 259, 267, 271. Fig. $54,389,396$

Connate, 93. Fig. 150,187

Connective, 137. Fig. $267-269$

Continuity of protoplasm, 31, 190,203,266

Contorted astivation, 85 . Fig. I3I

Contorted vernation, 86. Fig. 137

Convolute vernation, 85 . Fig. I34

Convolvulacex, 385 . Fig. I 13,243 , 37811 .

Coralline, $26_{5}$. Fig. 382

Cordate, 95 . Fig. 156

Coriaceous, 107

Coriander, 398

Cork, 22, 43, 379. Fig. 66, 80, 352

Cork, Conversion into, 22

Corm, 8r. Fig. I21

Cormophytes, 69

Cornacex, 398. Fig. $3^{25}$ II.

Corolla, I I I, I28. Fig. I99, 200, 203206, 208-210, 240-257

Corona, 133,134 . Fig. 254, 26r, 263

Coronariea, 355

Coronate pappus, I27. Fig. 239, 503

Coronet, Fig. 330

Corpuscule, I9I, 333. Fig. 367

Cortex, 56, 283, 287, 322, 356. Fig. 78 . $95,406,408,447,452,460,47^{2}$

Cortical layer, 264 


\section{Glossarial Index.}

COR

Cortical tissue, 356. Fig. 78, 83 II., $426,438,445,476,477$

Corylacea, 379. Fig. 268, 484, 485

Corymb, I22

Cotton, 409

Cotyledon, 70, 86, 156, 338, 356. Fig. $97-99$, I I $9,335,368,369,46 \mathrm{I}$ iv.

Covering-leaves, 86

'Coxcomb,' 219

Crassulacex, 406 . Fig. I92

Creeping root, 75

Cremocarp, 151, 397. Fig. 318, 509-512

Crenate: 99. Fig. I 39

Crenulate (finely crenate)

Cretaceous system, 429

Cross-fertilisation, 185

Croton-oil, $37^{8}$

Cruciferæ, 412. Fig. 195, 200, 204, 232, $252,274,317,336-339,527-530$

Cruciform corolla, I3I. Fig. 252

Crude sap, I6r

Crumpled estivation, 85

Crumpled vernation, 86

Crustaceous Lichens, 287, 290

Cryptogamia, 239, 242

Crystal, 3o. Fig. 48-5I, 67

Crystalloid, 31. Fig. 52

Cucurbitacex, 399. Fig. 7 I

Culm, 77, 343. Fig. I 42,464

Cuneate, 97. Fig. 163

Cup, Fig. 4I 4

Cupressineæ, 336 . Fig. $455,+56$

Cupule, I47, 299, 379. Fig. 303, 349, 485

Cupulifera, 378. Fig. 223, 303, 379

Currents of water, 159

Cuscuta, 331. Fig. $378 \mathrm{Il}$.

Cuspidate, I05

Cuticle, 58. Fig. 2 I

Cutting, $179,18 \mathrm{r}$

Cyatheaceæ, 316. Fig. 437

Cycadex, 24I, 334, 373, 420, 423, 426, 428 . Fig. $453,545,546$

Cylindrical, zo6. Fig. 192

Cyme, 122, 382. Fig. 226, 227

Cyperacea, 345. Fig. $465-467$

Cypsela, I54, 390. Fig. 235-239, 327, 501,503

Cystidium, 28r

Cystocarp, 255, 265, 276

Cytoblast. See Nucleus

Cystolith, 20. Fig. 37

\section{DAPHNALES, 374}

Darwin, 6,163

Daughter-cell, 32

Deadly nightshade, 384. Fig. 495

De Bary, 6

De Candolle, 5, 239

Deciduous, 108, 125, I 34

Decurrent, 92, 94. Fig. I5 I, I52

Decussate, $76,87,382$. Fig. 138
DUR

'Dédoublement,' 218, 22I

Definite inflorescence, I24. Fig. 226, 227

Degradation-products, 177

Dehiscence by pores, I4I. Fig. 282,284

Dehiscence by recurved valves, I4I. Fig. 28I, 283

Dehiscence of capsules, I48. Fig. 306-313

Dehiscent, 148 . Fig. 306-318

Deltoid, 105

Dentate, 98, 127. Fig. 168, I72

Denticulate (finely dentate)

Dermatogen, 56. Fig. 8311 .

Desmidiea, 259. Fig. I $1,3^{89}$

Desmodium, 205

Devonian system, 420

Diadelphous, I39, 400. Fig. 276

Diatomacez, 260 . Iif. $38,384,390$

Diatomin, 260

Dichlamydeous, I 2

Dichogamy, I 85

Dichotomous, $76 . \quad$ Fig. 226, 3781 .

Dichotomous cyme, 123. Fig. 226

Diclinous. See Unisexual

Dicotyledones, 156, 242, 356, 429

Dicotyledonous, 356

Dictyogens (a term sometimes given to those Monocotyledones which have net-veined leaves)

Didynamous, $13^{8}, 380,382$. Fig. $27 x$, 273,490

Diffusion. See Osmose

Digestive ferment, 204

Dimorphism, 185

Diœecious, II 2, 257, 289

Dionæa, I69, 203. Fig. 372

Dioscorales, $35 \mathrm{I}$

Dioscoreacea, $35 \mathrm{r}$

Dioscorides, 3

Diosmose. Sec Osmose

Dippel, 6

Dipsacacere, 4I9

Disc, 80, 141, 397, 406. Fig. 122

Disciflor'x, 406

Discomycetes, 282, 283. Fig. 403, 404

Diseases of plants, 224

Dissepiment. See Septum

Diurnal position, 206

Division, 245, 25I, 268

Dodder. See Cuscuta

Dodonaus, 3

Dormant buds, $8_{3}$

Dorsal suture, I 42

Dorsifixed, I 4 O. Fig. 282

Dotted vessels, 47

Double flowers, 141, 218, 221. Fig. 286

Drosera, 169,203

Droseracex, 406. Fig. 263,372

Drupacea, 406 . Fig. 3251 .

Drupe, 1 52, 406. Fì. 325

Drupel (a small diupe), Fig. 52I II.

Dry rot, 282

Juct, 47. Fig. 35

Duhamel, 6

Duramen, $3^{6} 7$ 


\section{DUT}

'Dutch rushes,' 323

Dwarfing, 217

Dwarf male, 255, 20́3. Fig- 386

\section{F BENACEA, 387}

Ebenales, 387

Ebracteate (without bracts).

Ectospore. See Basidiospore

Edelweiss, 39I

Egg-apparatus, 187. Fig. $360-363$

Eisodial opening, $6 \mathrm{I}$

Elaborated sap, I6I

Elæagnacea, 374. Fig. 9 I

Elater, 240, 300, 322. Iig. 422111 . 444 III.

Electrical equilibrium, 214

Elementary organs, 8,55

Eleutheropetalous, See Apopetalous

Eleutherophyllous. Sec Apophyllous

Eleutherosepalous. Set A posepalous

Elliptical, 95. Fig. I54

Emarginate, 97. Fig. 167

Embryo, 70, 156, 188, 189 . Fig. 83 11.,97, $98,305,334-342,363-365,458,509,5$ I I

Embryo-sac, 145, 187. Fig. 300, 359$362,364,367$

Embryonic vesicles, I87. Fig. $360-363$

Encysted, 243

Endlicher, 5, 239

Endocarp, 148, I52, 406. Fig. 305, $3^{2} 5$

Endagens. Sec Monocotyledones

Endophytic, 244

Endosmose, 164

Endosperm, 156, 190, 414. Fig. 55 I., $305,333,363-365,45^{8}, 4^{6}$ I IV., 509, 5 II

Endospore, 273, 283

Enfolding astivation, 84. Fig. 127

Ensiform, 94

Entire, 98, I3I

Entomophilous, I83

Entomophthorex, 276

Eocene system, 429

F.pacrideæ, 389

Epicarp, 148, 406. Fig. 305, 325

Epidermal tissue, 56, 57. Fig. 8o, 83 II., 426

Epidermis, 58, 356. Fig. 21, 64, 80, 85, 86 , Ioo, $43^{8}, 445,447,452,460,47^{2}$

Epigyin, 355

Epigynous, II5, 140. Fig. 210,279

Epipetalous, I15, I40. Fig. 271, 272

Epiphyte, 233

Epispore, 327

Equisetacea, 318 . Fig. 83 1., 444-446

Equisetales, $24 \mathrm{r}, 3^{18}$

Erect, 145

Ergot, 227, 285. Fig. 375

Ericacea, 387. Fig. 240, 282, 284

Ericales, 387

Erysiphe, 228. Fig. 376

'Espinillo,' 455

Etiolation, 25, 212

Eucalyptus, $399,44^{6}$
FLO

Euphorbiacex, 376. Fig. $46,76,4^{82} 483$ :

Euphorbiales, 376

Europaeo-Siberian forest-region, 438

Evergreen, I08

'Everlastings,' 391, 445

Exalbuminous, 156, I90. Fig. 97, 336339

Excipulum, 289

Exogens. See Dicotyledones

Exosmose, 164

Exospore, 273, 283, 322. Fig. 444 III.

Exstipulate (without stipules)

Extine I86. Fig. 358,366

Extrorse, 14I

Eyes, 80. Fig. II6, II7

FALKLAND ISLANDS, 461 Family, 238

Farinose, 27

Fasciation, 2 I9

Fasciculated root, 75. Fig. Io6, I07

'Favus,' 247

Feejee Islands, 459

Female ( $P$ ), I12, I82. Fig. 202, $26011 .$, 303, 48r'II.-V., 485 III., iv.

Fennel, 398. Fig. 507, 509

Fermentation, 247, 248

Ferns. Sice Filices

Fertile hyph:e, 267

Fertilisation, 182, 186, 191, 251. Fig $359,361,362,366,367,3^{8} 5^{\circ}-3^{8} 7,398$

Fertilising tube, 274. Fig. 398

Fibrous root, 74. Fig. 105

Fibrovascular bundle, $64,322,324,339$, $356,357,37$ I. Fig. 93, 95, 438, 44ः, $45^{2}, 460,472,473$

Fibrovascular system, 56

Ficoidales, 398

Ficoidea, 399

Fig, Fig. 215

Filament, 137. Fig. $267-270,272278$, $28 \mathrm{I}-285$

Filicales, 24I, 308

Filices, 316, 420, 423. Fig. 36, 69, 436$442,540-542,544$

Filiform, 73, 107, I44. Fig. 104, 177

Filiform apparatus, I89. Fig. $36 \mathrm{I}$

Fimbriate, 118, 131. Fig. 250

Fission, 251

Fistulose (containing hollow chambers), 107

Fleshy, 107. Fin. I92

Floating roots, 73

Floccose, I Io

Floral diagram, II3. Fig. 204-206, 46 I 111., 468 111., 487,489 111., 497 11., 5 I4 II., 522, 526, 533 II.

Floral leaves, 86

Florets of the disc, I20, 390. Fig. 214, $244,492111$.

Florets of the ray, 120, 390. Fig. 214 , 210, 492 II.

Florider, 265. Fis. $382,3^{87}$ 
FLO

Flower, 70, 110, 182. Fig. 199-214, 488$490,492-497,507,508,532,533$

Flowering plants. Sec Phanerogamia

Flowerless plants. See Cryptogamia

'Flowers of tan,' I 99, 270

Folded vernation, 85. Fig. I 32

Foliaceous Lichens, 287,290 . Fig. $4 \mathrm{I} 7$

Foliage-leaves, $86,87,220$. Fig. 138I95, 513

Foliose Hepatica, 296, 298. Fig. 423425

Follicle, 149, 4I4. Fig. 3I4; 3I5, 53 I II.

Foramen. See Micropyle

Formative tissue, $4 \mathrm{I}$

Fossil, 419. Fig. 534-546

Fovea, 331

Fovilla, I86

Free, 92. Fig. I 54

Free cell-formation, 34, rgo, 249, 283 . Fig. $5511 ., 38 \mathrm{I}$

Free central placentation, I45, 409. Fig. 298,525

Freezing, Effects of, $21 \mathrm{I}$

Fringed, 13I. Fig. 250

Frond, 263, 312. Fig. $388,391,437$

Frondose Hepatica. See Thalloid Hepatica

Fructification, 267, 278. Fig. 375, 392, 401, 402, 404, 406

Fruit, 7O, II2, I46, 304. Fig. 305-327, $48 \mathrm{I}, 483,485,501,504,509-512,523 \mathrm{IV}$.

Frustule, 260

Fruticose Lichens, 287, 290. Fig. 4074 IO, 4I5, 4 I 6

Fucacere, 263. Fig. 388, 392, 393

Fuchs, 3

Fumariaceæ, $4 \mathrm{I} 4$

Fundamental tissue, $56,57,67,{ }_{3}^{6} 61$. Fig. 83 II.

Fungi, 239, 266. Fig. I, 65, 347, 374$377,394-417$

Fungus cellulose, $26_{7}$

Funiculus, I44, I54. Fig. 97, 299, 3I6, 326

Furrow, 398. Fig. 509-5I2

Fusiform, 73. Fig. IO2

\section{GALAPAGOS ISLANDS, 460 Galea, 349}

Galls, 233, 379. Fig. 379

Gamopetalæ, 380

Gamopetalous, I29. Fig. 240-249

Gamophyllous, 134. Fig. 207

Gamosepalous, I24. Fig. 229, 230

Gangrene, 224, 233

'Garnas,' 453

Gasteromycetes, 28I

Gelatinous Lichens, 285, 287, 291. Fig. 4 I3

Geminate (when two leaves spring from the same node, but are not opposite), 384

Gemma, 83, 178, 299, 305, 3r6. Fig. 349

\section{GYN}

Gemmation, 34, 222, 248. Fig. 381

Generating tissue, 4 I

Generation, 177

Gentianacex, $3^{8} 7$

Gentianales, $3^{85}$

Genus, $23^{8}$

Geography of plants, 2, 6, 432

Geological systems, 420

Geotropism, 207

Geraniacea, 407. Fig. 231, 320, 322

Geraniales, 407

Germ-cell, 178, I82, 25 I

Germinal vesicles. See E.nbryonic vesi. cles

Germination, 192. Fig. 368-370

Gesneracex, 382 . Fig. 296

Gessner, 3

Glabrous (entirely destitute of hairs)

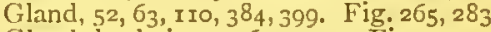

Glandular hair, 52, 64, I 10. Fig. 92

Glans, 154. Fig. 303

Gleba, 28I

Gleicheniacex, 316

Globoid, 3 I

Globose, I29, I31. Fig. 240

'Globule,' 293. Fig. 4I8III., 4 I9

Glomerulus, 123

Glucose, I 76

Glumaceous, I34

Glumales, 343,355

Glume, $86,343,347$. Fig. $461,466,467$

Gnetacex, 24I, 338, 37 I

Goeppert, 5, 6, 43I

Goethe, 6, 220

Gonidial layer, 287. Fig. 408

Gonidium, I78, 285. Fig. 409, 410, 4 I2, $4 \mathrm{I} 3$

Graft, 179, I8r. Fig. 353

Graminea, 343. Fig. 70, 93, 142, 292, $368,46 I-464$

Granulose, 27

Grasses. Sce Graminex

Gravitation, 215

Gray, Asa, 6

Grew, 5

Grisebach, $43^{2}$

Ground tissue. See Fundamental tissue

Growing point, 40, 56, 295. Fig. 60

Guard-cell, 58. Fig. 85

'Gulf-weed,' 256. Fig. $3^{88}$

Gum, 404, 406

Gum-passage, 53, 373

Gutta-percha, 24

Guttiferæ, 409

Guttiferales, 409

Gymnocarpous, 270, 280. Fig. 402, 407

Gymnospermous, Fig. $304,45^{8}$

Gymnosperms, I47, I9I, 241,333

Gymnostomous, 304

Gynaceum, II I, I42

Gynandrous, I4O. Fig. 279, 468 IV.

Gynobasic, 382. Fig. 290, 490 II.

Gynostegium, 349. Fig. 468 IV. 
HAI

HAIR, 6r, Iog. Fig. 87-92

Half-inferior, 6

Hanstein, 6

Hartig, 6

Hastate, 96. Fig. I6I

Haustorium, 73, 75, 228, 231, 275. Fig. 376,378

Head, 295

Healing-tissue, 43

Heat, 208

Heliotropism, 207, 2 $\mathrm{r}_{4}$

Hellebore, 4I5

Hemlock, 398. Fig. 5 I I

Henbane, 384 . Fig. 496

Hepaticx, 240, 296. Fig. 349, 42I-425

Herbaceous, 77,107

Hernıphrodite, 112. Fig. 200, 204-210

Hesperidium, $\mathrm{I}_{54}$

Heterocyst, 244

Heteromorous Lichens, 285, 290. Fig. $407-410,4 x_{5}^{-4}+17$

Heteromorphic (of more than one different form), Fig. 177, 195

Heterophyllous, 107. Fig. I 77, 195

Heterosporous Vascular Cryptogams, 240,326

Heterostylism, 185. Fig. 357

Hildebrand, 6

Hilum, 146, 154

Hippocrates, 3

Hirsute, 110

Hispid, 1 Io

Hoffmann, 6

Hofmeister, 6

Homoiomerous Lichens, 285, 29r. Fig. 4 II -413

Honey $\cdot$ dew, 228

Honey-gland. Sec Nectary

Hooded, I3I

Hooker, 6

Hormogonium, 244

Horn, 255

Horse-tails. Sce Equisetacex

Host, 165, 231, 278. Fig. 346, 347, 374, 378

Humboldt, 6, 434

Hyacinth-pest, 23 I

Hybrid, r 94

Hydrocyanic acid, 406

Hydrogen, I62, I67

Hydrophyllacea, 385

Hydropterides. See Rhizocarpez

Hylaxa, 45x

Hymenial layer, 280

Hymenium, 268, 278. Fig. 402, 4I4

Hymenomycetes, 279. Fig. 40I, 402

Hymenophyllacea, 316 . Fig. 439 VI., vij., 440 II.

Hypanthodium, II7. Fig. 215

Hypericacea, 409

Hypha, 266. Fig. 347, 399, 400, 402, 404, 4I 4

Hypochlorin, 24
ISO

Hypocrateriform, I29. Fig. 247

Hypoderma, 58

Hypodermia. Sec Ecidiomycetes

Hypogynous, I15, J40. Fig, 209, 294

Hypsophyllary leaves, 86

'I CELAND MOSS,' 288, 29I 'Igapo,' 45I

Imbricate, 84, I 19. Figs. 127-I3I, 219.

Imparipinnate, Ior. Fig. 184

Imperfect, II2

Impregnation. Sec Fertilisation

Incised, 99, 125. Fig. 173, 174

Incompletx, 374

Incrustation, 2 I

Indefinte inflorescence, 123,409 . Fig. $212,222,225$

Indehiscent, 148. Fig. 305

Indian monsoon region, 442

Induplicate astivation (folded in at the edges), Fig. 126

Indusium, 313. Fig. 439 I.-1V.

Inferior, 114. Fig. 499, 501

Infiltration, 21

Inflated, 107, 125. Fig. 234

Intlorescence, It6. Fig. 212-227, 481, $482,485,486,499$

Infundibuliform, I25, I29. Fig. 243

Ingenhousz, 6

Innate. Sic Basifixed

Innovation, 305

Inorganic substances, I

Insertion, II4

Integ ument, 145, 155. Fig. 97, 300

Intercalary surface-growth, 263

Intercellular passage, $3^{6}$

Intercellular space, 36 . Fig. 23, 60, 63, $472 \mathrm{~B}$

'Intercellular substance,' 36 . Fig. 57

Internode, 76 . Fig. 418, $472 \mathrm{~B}, 504$

Interruptedly pinnate, 103. Fig. I86, 187

Intine, 186. Fig. $358,{ }_{3} 66$

Intrafascicular cambium, 357

Introrse, 141. Fig. 274

Intussusception, 15, 27, I77, 196

Inulin, 31. Fig. 53

Involucel, 120, 390, 394. Fig. 221, 506

Involucre, $87,118,120,390,394$. Fig. $2 I_{3}, 2 I_{4}, 210,500$

Involute vernation, 86. Fig. ${ }_{13} 6$

Iodine, 160

Ipecacuanha, 394

Iridex, 349. Fig. 12x, 261, 293

Iron, 162,568

Irregular, 124, 129. Fig. 230, 231, 246, 24 b, 249, 253

Irritability. See Sensitiveness

Isoëtacea, 329, 333. Fig. 452

Isosporous Vascular Cryptogams, 240, 308 
JUA

TUAN FERNANDEZ, 460

Juglandea, 379

Jugum, IоI, 398. Fig. 184, 185, 187, 309-512

Jung, 4

Jungermannieæ, 301. Fig. 423-425

Jurassic system, 428

Jussieu, 5, 239

K ALAHARI REGION, 444

Karsten, 6

Keel. Sce Carina

Kerguelen's Land, ${ }_{4}^{6}$ I

Keuper, 426

Knot, 367

'Koa,' 459

ABELLUM, 349. Fig. $468 \mathrm{I}$.

Labiata, 382. Fig. 230, 248, 267, $269,273,321,489-492$

Labiatifloræ, 39I

Laciniate, I00. Fig. I77

Lamella, 279. Fig. 401

Lamiales, 382

Lamina, 89, I31. Fig. I42, I47-r95, 250

Laminarieæ. See Phæosporeæ

Lanceolate, 94. Fig. I53

Lateral, I45. Fig. 34I

Lateral dehiscence, I I I

Lateral ribs, I05

Lateral root, 73. Fig. 99

Latex, 5I, 378, 39I, 4II

Laticiferous cell, 5 I

Laticiferous vessel, 5I, 34I, 368. Tig. $51,76,77,476$

Latisept, 413. Fig. 530111.

'Lattice-plant,' 459

Latticed cell, 49

Lauracea, 374,452 . Fig. 283

Laurales, 374

Laurentian system, 420

Layering, I 79

Leaf, 70, 71, 86, 220, 342, 370. Fig. 99, $1_{3} 8-196,513$

I eaf-cycle, 87

Leaf-sheath, 82. Fig. I42, I 47

Leaf-spine, 109, 220. Fig. 152, 172

Leaf-stalk, Sce Petiole

Leaf-tendril, Iog. Fig. 146,514

Leaf-trace, 339, 357, 36o. Fig. 447, 452, $46011 ., 473$

Legume, I50, 400. Fig. 288, 316, 515, 5161 .

Leguminose, 400. Fig. 97-99, 143, $x_{4} 6$, $182,184,185,212,253,276,288,316$, $324,514-517$

Ientibulariacex. See Utriculariacex

Lenticel, 46

Lepidodendron, 324, 420 .

Fig. $535-537$

\section{MAN}

Lepidostrolus, 326

Leptothrix, $245,2+6$

Liane, $43^{x}$

Liber, 357

Libriform cell, $36_{4}$

Lichenin, 288, 291

Lichens, 285. Fig. 407-4I7

Light, 2 II

Lignification, 22

Lignin, 22

Lignite, 424, 430

Ligulate, 129, 390. Fig. 246, 499 II.

Ligule, 92, 132, 331, 343. Fig. 142, I47, $25 \mathrm{I}, 254$

Ligulifloræ, 390

Liliacer, 355. Fig. I12, 287

Liliales, 355

Linacea, 307

Lindley, 6, 239

Linear, 94. Fig. $I_{47}$

Linnæus, 4, 238

Liquorice, 402

Litmus, 29 I

Liverworts. Sce Hepatica

Llanos, 45x

Lobed, I00, I25. Fig. 179

Lobelius, 3

Loculicidal dehiscence, I49. Fig. 307

Loculus, I $40, I_{44}, 1_{4} 8$. Fig. $280-284$, 296-298, 519

Lodicule, I 34,343

Loganiaceæ, 387

Logwood, 403, 450

Lomentum, I52, 400, 4I3. Fig. 324 , 516 II., $530 \mathrm{IV}$.

Longitudinal dehiscence, I4I. Fig. 270, 280

Longitudinal section, 69. Fig. 96

Longit udinal tension, I 98

Loranthacea, 380 . Fig. $378 \mathrm{I}$.

Lycopodiales, 24I, 324. Fig. 447, 45 I A

Lyrate, 99. Fig. I 76

Lysigenous gland, 52

Lythracex, 399

MACROSPORANGIUM. Sec Megasporangium

Macrospore. See Megaspore

Madagascar, 458

Madder, 394

Madeira, 457

Magnesian limestone, 426

Magnesium, I 62

Magnoliacea, 4I6. Fig. 3I4

Male (ठ) ) II2, 182, 25I. Fig. 20I, 260, $43 \mathrm{I}, 454,457,48 \mathrm{I}, 482,485$

Malpighi, 5

Malpighiacex, 407

Malvacea, 407. Fig. 275, 323, 523

Malvales, 407

'Mammoth-tree,' 236, 449

Mangrove, 75,442 


\section{MAN}

Manometer, Fig. 343

Manubrium, 295

Manures, 170

Marattiacex, 3I 7

Marcescent, 183

Marchantieæ, 301. Fig. 349,422

Marsileacex, 329. Fig. 449, 450

Martius, 6

Mascarene Islands, 459

Massula, 328

Matthioli, 3

Mediterranean region, 440

Medulla, 287. Fig. 408. Also see Pith

Medullary rays, 67,361 . Fig. 66,95 , $472 \mathrm{~B}$

Medullary sheath, 362,366 . Fig. 478

Megasporangium, 326, 331. Fig. 448, 45 I B.

Megaspore, 24I, 326, 33I. Fig. 448, 450-452

Melastomacea, 399

Meliaceæ, 407

Menispermacex, 4I6. Fig. 34I

Mericarp, 15I, 397. Fig. 319-323, 509

Meristem, $4 \mathrm{I}$

Mesembryanthemaceæ, 399. Fig. 210

Mesocarp, I48, 152, 406. Fig. 305, 325, 5 I 9

Mesophyll, 68, 223, 342

Mesozoic strata, 426

Metabolism, 176

Metamorphosis of organs, 220

Metastasis, $16 \mathrm{r}, 176$

Mexican region, 449

'Mezquit,' 449

Micellæ, 158

Micrandres. See Dwarf male

Microbe, 247

Micrococcus, 245, 246, 247. Fig. 380

Micropyle, I45. Fig. 300
Microsporangium, 326, 33I. Fig. 448 . $451 \mathrm{~B}$.

Microspore, 241, 326, 331. Fig. 448, $450-452$

Mid-rib, 105

Migration of plants, 433

Milde, 6

Mildew, 226, 28I

'Milk' of cocoa-nut, Igo

Mimosa. Sec Sensitive plant

Mimosea, 403, 448. Fig. I43, 517

Miocene system, $43^{\circ}$

Mistletoe, 23I. Fig. 378 I.

Mitræform corolla, I33. Fig. 257

Mohl, 5

Molecule, $15^{8}$

Monadelphous, 139, 400. Fig. 275, 323

Monimiaceæ, 374

'Monkey·pot,' 399

Monkshood, 4 I6. Fig. 533

Monocarpellary, I42. Fig. 288, 316, 325 I.

Monocarpic, 235

Monochlamydez, 364

Monochlamydeous, II2. Fig. 207, 259

\section{NOD}

Monocotyledones, I56, 241, 338, 428 . Fig. 95, 305, 460-471

Monocotyledonous, 338

Monocious, 112, 257, 289

'Monopetalous.' Sec Gamopetalous

'Monophyllous.' Sec Gamophyllous

'Monosepalous.' Sec Gamosepalous

Monosiphonous, 265

Monotropaceæ, 388

Moracea, 374. Fig. 302

Morphology, I, 69

Mosses. Sce Musci

Mother-cell, 32. Fig. 83 I., 85, 386, 442

Motility of protoplasn, 10, I99, 210

Mould, 250, 262, 279, 281. Fig. I, 396

Mlovement of water in plants, ${ }_{59}$

Movement, Phenomena of, I95

Mucilage, Conversion into, 23, 249. Fig. 39

Micor, 27r. Fig. 395, 396

Mucorini, 27I. Fig. 395,396

Mucronate, 97. Fig. I66

Mulberry, Fig. 302

Multifid, 125

Multinucleated cells, II, I89, 258

Musaceæ, 348

'Muscardine,' 283

Muschelkalk, 426

Musci, 240, 30r. Fig. 426-435

Muscinex, 244, 296. Fig. 42I-435

Mushroom, 279. Fig. $40 \mathrm{I}$

Mycelium, 267, 278, 284. Fig. 398, 402

Myricaceæ, 376

Myristicaceæ, 374

Myrsinacez, 387

Myrtaceae, 399, 446

Myrtales, 399

Myxamcebæ, 270

Myxomycetes, I99, 269. Fig. 394

N $\ddot{A G E L I}, 6$

Naiadeæ, 35 I

Naked, Ix 8, 390. Fig. 304

Napiform, 73. Fig. 103

Narcissales, 349

Nardoo, 329

Neck, Fig. 422 IV.

Neck-cell, I92

Nectary, 53, 135. Fig. 231, 266, 533

Negative helioptropism, 207

Nepenthes, 169. Fig. 193

Net-veined, 106, 356. Fig. 181, 191

Neuter, II2. Fig. 203

New Caledonia, 459

New red sandstone, 425

New Zealand, 460

Nightshade, 384. Fig. 495

Nitella, 292, 294. Fig. 371 I., 420

Nitrogen, 162, I 68

Nocturnal position, 206

Node, 76. Fig. I42, 2 II , 4 I 8, 504 


\section{NON}

Non-sexual reproduction, 178

Non-sexual reproductive cell, ${ }_{7} 8$

Norfolk Island, 460

Normal root, 75. Fig. InI-IOA

North American forest-region, $44^{6}$

Nosology, 216

Nostocacex, 244

Notorhizal, 157. Fig. 337

Nucellus, 145, 156, 187. Fig. 300, 360

Nuclear plate, 33. Fig. $54 \AA$

Nucleolus, 11. Fig. 2, 3

Nucleus, 8, I 1, 32, 187,266 . Fig. 2-6, $54 \dot{A}, 55$ I., $3^{60}, 422$

Nucule, 152, 293, 384. Fig. 321, 4I8 I11., 419,490

Nudifloræ, 355

Nut, 154. Fig. $485 \mathrm{v}$.

Nutrient substances, 162

Nutrition of plants, 162

Nyctagirea, 374. Fig. 342

Nymphacaceæ, 4r6. Fig. 365

AK-APPLE, Fig. 379

Oak-gall, 235. Fig. 379

Oak-spangle, 235

Oases, 443

Obcordate, 95, 97, 131. Fig. I 57

Oblique section, 69. Fig. 96

Obovate, 95

Obsolete, r16, 395. Fig. 507

Oceanic islands, 457

Ochrea, go

CEdogoniaceæ, 255, 262. Fig. 371 II., 386

Oidium. See Erysiphe

Oil, $24,176,384$

Oil-gland, 53

Oil-passage, 52

Oleacea, 387. Fig. 247, 299

Onagraceæ, 399. Fig. 330

Oogonium, 255, 26r, 273, 274. Fig. 386, $39^{8}$

Oolite, 428

Oomycetes, 273. Fig. 397-399

Oophyceæ, 26r. Fig. 388, 39I-393

Oosperm, 189, 251, 255, 261, 273, 274, 293, 328. Fig. 450111 .

Oosphere, I78, I82, I89, I92, 26I, 267, $269,273,299,328$. Fig. 385,422

Open bundle, 64,357

Operculum, 240, 304. Fig. 433, 435

Ophioglossacer, 3 18. Fig. 443

Opisthodial opening, $6 \mathrm{I}$

Opium, 4I I

Opposite, 76, 87, 158, 409. Fig. 138, I5) 341

Orbicular, 95. Fig. I55

Orchiciales, 348

Orchidex, 348. Fig. I 19, 120, 468

Order, 238

Organic substances, I

Orobanchacea, 232,382 . Fig. 346

Orthoplozic, 157. Fig. $33^{8}$

Orthospermæ, 398 . Fig. 5 ro
PAR

Orthotropous, $x_{45}, 336$. Fig. 300 1., 359

Oscillatoriex, 244

Osmose, $160,163,176$. Fig. 344

Osmundaceæ, 316. Fig. 440111.

Oval, 95. Fig. I 54

Ovary, I42. Fig. 287, 290-292, 359, $48 \mathrm{I}$ v., 524 II.

Ovate, 95. Fig. I68

Overgrowth, 46. Fig. 68

Ovule, 144, 182. Fig. 297, 298, 300, $359,360,45^{8}$

Ovum-cell. Sec Oosphere

Oxygen, I62, I67

PALÆOPHYTOLOGY, 2, 6, 4 I7
Palæozoic rocks, 420

Palate, 130. Fig. 249

Palea, 6I, 86, I $8,134,312,343,347$. Fig. 46r, 463

Paleaceous, II8, 390. Fig. 218

Palisade cell, 68

Palma, 35I, 45I, 452. Fig. 95, 305, 469, $47 x$

Palmales, 35 I

Palmate, 99. Fig. I 8 I

Palmate tuber, Fig. 120

Palmatifid, 99

Palmatilobed, Ioo

Palmatipartite, 99. Fig. 183

Palmatisect, 99. Fig. I73

Palmella, 243,244

Palmellacea, 243. Fig. 59

Palmet, 445

Palminerved, ro5. Fig. r8I, I9r

Pampas region, 454

Pandanacea, 355

Pandorineæ, 258

Panicle, 122

'Pantanals,' 453

Papaveraceæ, 4II. Fig. 233, 294, 313, 526

Papilionacex, 400 . Fig. 97-99, 146, 253, $276,288,3^{16}, 324,5^{14}-5^{16}$

Papilionaceous cords, I31, 400. Fig. 253. 514

Papilla, 326. Fig. 84, 295, 450 I.

Papillose, 144. Fig. 295

Pappus, 127, 390. Fig. 235-239, 499, 502

Paracorolla. Sie Corona

Parallel-veined, 105, 106, 338. Fig. I08

Paraphysis, 264, 268, 282, 289, 304. Fig. 393, 404

Parasite, 165, 225, 23I, 275, 285. Fig. $346,347,374,378$

Paratonic curvalure, 207, 214

Parenchyma, 39, 364, 366. Fig. 25, 51, $60-63,67,86,93,426,472,475-477$

Parictal, 1 45, 4 Ir. Fig. 296, 326, 468 IIr., 5261.

Parietal utricle, 9

Parietales, 4I I

Paripinnate, ror. Fig. 185 
PAR

Parthenogenesis, 276

Passage, 52. Fig. 78, 79

Passifloracex, 399

Passiflorales, 399

'Pasteur's solution,' 249

Payer, 6

Peat, 424

Peat-moss, 424

Pedate, Ior. Fig. 183

Pedatinerved, 105. Fig. 183

Pedicel, 116. Fig. 225

Pedicellate, IIo. Fig. 200

Peduncle, Ir6. Fig. 221, 225

Peloria, 223

Peitate, 63, 97, 110, 144. Fig. 9x, I62, 294, 313, 439 I., 444 II.

Peltinerved, 105. Fig. I62

Pendulous, I 45

Penicillate, 144. Fig. 29r

Penicillium, 7, 284. Fig. I

Pepo, 153

Perennial, 76

Perfect, II2

Perfoliate, 93. Fig. I49

Perforated, I07. Fig. 194

Perianth, IIo, III, I33. Fig. 215, 258$26 \mathrm{I}$

Periblem, 56

Pericarp, 148. Fig. 97, 305, 316, 326, 519

Perichætium, 300

Periderm, 44. Fig. 67

Peridium, 277, 28I

Perigonium, 304. Fig. 427 IV.

Perigynium, I34

Perigynous, II 5, I40. Fig. 207, 208, 256

Periodical movements, 206, 210

Peripheric, 158. Fig. 340,342

Perisuerm, 19o. Fig. 365

Peristome, 304. Fig. 430, $433 \mathrm{III}$.

Perithecium, 268, 282, 289. Fig. 403 , 406

Permanent tissue, 4 I

Permian system, 425

Peronosporea, 230, 273. Fig. 377, 397

Persistent, 126, 134. Fig. 234

Personales, 380

Personate, I วo. Fig. 249

Peruvian bark. Sec Cinchona

Petal, 128, 220. Fig. 250-253, 263, 286, 533

Petaloid, 134, I44. Fig. 261, 293

Petiolate, 9o. Fig. $148,154^{-162}$

Petiole, 89, 9o. Fig. 148, I54-162

Petiolule, 94

Phreosporez, 263. Fig. 39I

Phanerogania, 67, 24I, 333

Phascacea, 306

Phloëm, 66, 326, 341, 357. Fig. 63, 94, $447,472 \mathrm{D}, 476$

Phosphorescence, 28I

Phosphoric acid, I69

Phosphorus, I62

Phycochromacea. See Protophycex
POL

Phycocyanin, 242

Phylloclade, 78 . Fig. II2

Phyllode, 9I, 218. Fig. I43

Phyllotaxis, 87

Physiology, 2, 6, I58

Phytolaccacea, 374

Phytophthora, 230, 275. Fig. 397

Pictorial Lichens, $285,287,291$. Fig. 4 II, 4 I2

Pigments, 25

Pileus, 279. Fig. 401, 402

Pilose, 127. Fig. 235, 236

Pinguicula, 160

Pinna, 104. Fig. $184-190,436,439$

Pinnate, 100. Fig. $184-187$

Pinnatifid, 99

Pinnatinerved, ro5. Fig. 163

Pinnatipartite, 99

Pinnatisect, 99. Fig. 174

Pinnule, 104. Fig. 188-190

Piperacea, 378

Piperales, 378

Piptoce phalida, 273

Pistil, III, I42, Fig. 200, 202, 215, 265, $287-299,322,502$

Pistillate. $S \varepsilon \varepsilon$ Female

Pitcher, 91, 107. Fig. I93

Pith, 67, 356. Fig. 19, 95, 100, 352 $472 \mathrm{~B}, 477,47^{8}$

Pitted, ir 8

Pitted canal. Sce Pore-canal

Pitted cell, 20, 372. Fig. 27, 35, 70

Pitted vessel, 47,366 . Fig. 93,478

Placenta, I 44. Fig. 296-298, 316, 326

Plasmodium, I99, 269

Platanace $x, 376$

Pleistocene formation, $43^{1}$

Plerome, 57

Pleurocarpi, 308. Fig. 434, 435

Pleurococcus, Fig. 59

Pleurorhizal, I57. Fig. 336

Plicate vernation, 85. Fig. 133

Pliny, 3

Pliocene system, $43^{\circ}$

Plum-disease, 229

Plumbaginea, 387. Fig. 295

Plumose, 127, 144. Fig. 237, 238, 292

Plumule, 71,76 , I56, 194. Fig. 97,98 , 368,46 I IV.

'Pocket, 229

'Pod,' 220

Polar nuclei, 187

Polemoniacea, 385 . Fig. 39

Polemoniales, 384

Pollen, II, I3 8 , I40, I82, I87. Fig. 355

Pollen-grain, 140, 186. Fig. 355, 358, $359,366,367$

Pollen-tube, 186. Fig. 358, 359, 361, $362,364,366,367$

Pollination, 183

Pollinium, I4 I, I84, 349. Fig. 355 E, 468

Pollinodium, 276, 282

Polyadelphous, 139. Fig. 277

Polycarpellary, x+2. Fig. 323, 525 
POL

Polycarpic, 235

Polyembryony, I 89

Polygalacee, 4 I I

Polygalales, 4 ro

Polygamous, II3

Polygonacex, 37+ Fig. 258, 359

'Polypetalous.' See Apopetalous

'Polyphyllous.' See Apophyllous

Poly podiacea, 316. Fig. 439 I.-v., 440 I.

Polysepalous." Sec Aposepalou's

'olysiphonous, 265

Pome, 147,404 Fig. 519

Pomex, to4. Fig. 518,5 I9

Pore-canal, I9. Fig. 19, 20, 22-25, 27

Pore-capsule, I 49 . Fig. $3 I_{3}$

Portulacacea, 4 Io

Positive heliotropism, 207

Post-pliocene formation, 43I

Potanales, $35 \mathrm{I}$

Potamex, $35 \mathrm{I}$

Potassium, I62, I 60

Potato, 384. Fig. 42, II6, 497

Potato-disease, 230, 275. Fig. 377

Practical botany, 2

Prairie region, $44^{8}$

Prepotency of pollen, I86

Prickle, 63, 109. Fig. 90, 198

Priestley, 6

Primary cell-wall, 15. Fig. 19, 20

Primary cortex, 64,357

Primary meristem, 4 I

Primary rocks, 420

Primary root, 73. Fig. 99, 102-104

Primary stem, 76

Primine, I45. Fig. 300

Primordial cell, 10, I2, 199, 243

Primordial utricle, 9

Primulaceæ, 387. Fig. $138,298,306$, 3II

Primulales, 387

Pringsheim, 6

Procambium, 43, 57, 64. Fig. 8311 .

Pro-embryo, I89, 192, 332. Fig. 83 11., 363,450 iII.

Progressive metamorphosis, 222

Prolification, 222, 305. Fig. 427 iv.

Promycelium, 275, 276. Fig. 4co

Prosenchyma, $39,36_{4}$

Prosenchymatous cell, $309,364,368$. Fig. I4, 15, 26, 27, 438

Proteacere, 374

Proteid ; Proteinaceous substances. See Albuminoid

Protein-crystal. Sec Crystalloid

Proterandrous (proteros, earlier), I 85

Proterogynous, 185

Prothallium, 240, 294, 300, 305, 315, 321, 322. Fig. 4I8II., 44I, 442, 446, 450,452 IV.

Protococcus, 243

Protomycetes, 245

Protonema, 305

Protophycex, 242

Protophyta, 239, 242. Fig. 59, 380, 38I

\section{RES}

Protoplasm, 8, 31. Fig. 2, 3, 361, 399

Pseudo-bulb (pseudos, false), 349

Pseudocarp, I2I, I27, I46, 404, 405. Fig. 301, 302, 5 I9

Pseudo-parenchyma, 40, 252, 267, 279. Fig. 402

Pseudopodium, 270, 306

Pseudo-syncarp, I47. Fig. 302

Pubescent, i to

Puccinia, 226, 276. Fig. 400

Pulvinus, 90, 203

'Punctum vegetationis.' See Growing point

Putamen, 152, 406. Fig. 325

Putrefaction, 246

Pycnidium, 268, 282, 288

Pyrene, 153

Pyrolacex, 388. Fig. 334

Pyxis, 149. Fig. 311, 312, 496 III.

\section{UADRILOCULAR, 6 \\ Quernales, 378}

Quincuncial, 84. Fig. I30

Quinine, 394

Quinquelocular, I 44

Quinquepinnate, IO4

\section{RABENHORST, 6 \\ Race, 237}

Raceme, I2I. Fig. 225

Rachis, I0I, II 6

Radical leaves, 107

Radicle, I56, I93. Fig. 97, 98, 368: $46 I$ IV.

Rafflesiaceæ, 378

Ramentum, 312

Ranales $4 \mathrm{I} 4$

Ranunculaceæ, 4I4. Fig. 206, 209, 266, 3 I 5,53 I -533

Raphe, 146 . Fig. 300

Raphides, 30, 168. Fig. 50, 75

Ray, 6

Rayed, I20, 395. Fig. 215, 508

Receptacle, II4. Fig. $2 \div 3^{-2}$ I8, 45I, $498^{\circ}$

'Red snow,' 209, 244

Reduplicate estivation (folded out at the edges), Fig. I 25

Regions of vegetation, 434,437

Regular, 124, 129. Fig. 229, 240-245, 493-494

'Reindeer moss,' 29I

Rejuvenescence of cells, 32

Renewal of ceils, 32

Reniform (kidwey-shaped), 96. Fig. I59

Repand, 99

Replum, I5I, 4I3. Fig. 3I7, 530

Reproduction, I77

Reproductive cells, I77

Resedacex, 4 I 4

Reserve materials, $29, I 59,172$ 


\section{RES}

Reservoir of reserve materials, I 74

Resin, 24, 176, 338, 398

Resin-gland, 53. Fig. 80

Resin-passage, 52. Fig. 78,79

Resorption, 23

Respiration, I67

Resting-spore, 244, 255, 258, 269, 276

Reticulate cell, 20. Fig. 28

Reticulate venation. Sie Net-veined

Reticulate vessel, 47. Fig. 100

Retrogressive metamorphosis, 220

Revolute, IO5

Revolute vernation, 85. Fig. I35

Rhamnaceæ, 407. Fig. 205, 208

'Rhinoceros-bush,' 445

Rhizine, 287

Rhizocarpea, 24I, 326. Fig. 448-450

Rhizoid, 294, 297, 315. Fig. 441 111.

Rhizome, 79. Fig. 108, I15, 436, 438, 444,445

'Rhizomorph,' 281

Rhizophoracea, 399

Rhodospermin, 265

Rhomboidal, 96

Ricciex, 300

Ridges, 398. Fig. 509-512

Ringent, 130. Fig. 248

Rivulariez, 244

Roggefeld, 445

Root, 70, 71, 72, 342, 369. Fig. 99-107, 477

Root-cap, 72, 370. Fig. 8311 ., I00

Root-hair, 61, 75. Fig. $345,444 \mathrm{lv}$.

Root pressure, 160

Root-sheath, 67. Fig. 94

Root-stock. Sec Rhizome

Rosacex, 404. Fig. 191, 198, 228, 256, $301,3231 ., 518-522$

Rosaceous corolla, $x_{33}$. Fig. 256

Rosales, 399

Rose-gall, 233

Rosex, 405. Fig. 198, 228, 256, 301, 520-522

Rostellum, 349. Fig. 468

Rotate, I25, 129, 131. Fig. 245

Rotation of crops, I7I

Rotation of protoplasm, I0, 295

Rubiacex, 392. Fig. I39, 504, 505

Rubiales, 392

Runcinate, 99. Fig. I75

Runner, 77, 179, I80

Rust, 226, 276

Rutacex, 407. Fig. 277

SACCATE, 125. Fig. 232

Saccharomyces, 247 . Fig. $38 \mathrm{I}$

Saccharomycetes, 247. Fig. 38I

Sachs, 6

Sagittate, 96. Fig. 160

Sago, 334, 354, 373

Sahara, 443

St. Helena, 448

\section{SEC}

St. Hilaire, 6

Salicacex, 375. Fig. 48I

Salicine, 375

'Salinas,' 455

Salviniacex, 329. Fig. 448

Samara, I54. Fig. 319, 480

Sandwich Islands, 459

Santalacea, 380

Santalales, 379

Sap, Circulation of, I 75

Sapindacere, 407. Fig. 319

Sapindales, 406

Saprogenous (causing putrefaction), 246

Saprolegnieæ, 276. Fig. 398, 399

Saprophyte, 165

Sarcina, 247

Sarcocarp, 148, 152, 406. Fig. 305, 325

Sarracenia, 169

Saxifragacere, 406. Fig. 225, 326

Scabrous, 99

Scalariform cell, 20 . Fig. 36

Scalariform vessel, 47, 310, 366. Fig. 69

Scale, 63, 81, I10. Fig. 91, I21, 263, $304,44411 ., 458$

Scale-leaf, 87, 220 . Fig. 346

Scaly, 81, 134. Fig. 122

Scandent, 79

Scape, 77. Fig. 108, I21

Scattered, 76, 87

Schacht, 5

Schizacacer, 326

Schizocarp, I51. Fig. 318-323, 5231V., $530 \mathrm{I}$.

Schizogenous gland, 52. Fig. 78, 79

Schizomycetes, 245,246 . Fig. $3^{80}$

Schleiden, 5

Schwendener, 6

Sclerenchyma, 40

Sclerenchymatous cell, 20, 309. Fig. $25,438,472$

'Sclerotium,' 227, 267, 283, 285. Fig. 375

'Scolecite,' 283

Scorpioid cyme, 123. Fig. 227

Scrophulariacex, 381. Fig. 249, 297, 486-488

Scutellum, 345. Fig. 46r 1v.

Scytonemex, 244

Secondary cortex, 357

Secondary embryo-sac. Sec Corpuscule

Secondary fibrovascular bundle, 357

Secondary head, 295

Secondary medullary rays, 363

Secondary products of metastasis, 176

Secondary root, 73. Fig. 99, IOI

Secondary stem, 76

Secondary strata, 426

Secretional diseases, 224

Secretory system, 52

Section, 69,238 . Fig. 96

Secund (when all the flowers or other organs grow from one side of the rachis), Fig. 108, 227

Secundine, 145. Fig. 300 


\section{SEE}

Seed, 70, I12, 154. Fig. $97,98,3_{116,317,}$ $326,365,368-370,458,46 x$ Iv., 462 , $48 \mathrm{I}$ V11., $532 \mathrm{I}$.

Seed-leaf. Sit Cotyledon

Selaginellacex, 329, 332. Fig 45 I B

Selaginellales, $24 \mathrm{I}, 329$. Fig. $45^{\mathrm{I}} \mathrm{B}, 45^{2}$

'Selective power,' I 70

Self-fertilisation, $x 85$

Senna, 402

Sensitive plant, 202, 403. Fig. 5I7

Sensitiveness, 202, $2 \mathrm{I}_{4}$

Sepal, 124, 220. Fig. 228-233

Sepaloid, r33. Fig. $258-260$

Septated wood-cell, $3^{66}$

Septicidal, 149. Fig. 308

Septifragal, 149. Fig. 309

Septum,-I44. Fig. 307-310

Series, 238

Serrate, 98. Fig. I60

Serrulate (finely serrate)

Sesamacea, 382

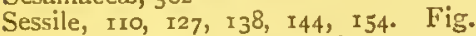
$235,237,238,271,279,298$

Seta, 300. Fig. 427 I.

Setose, IIo, II8. Fig. 217

Sexual reproduction, 182

Sheath, 320. Fig. 444 I.

Shell-lac, 378

Shells, Formation of, 16. Fig. 20

Shield, 205. Fig. 418 III.

Shrub, 76

Sieve-disc or Sieve plate, 48. Fig. 72-74

Sieve-pores (the perforations of sievediscs), Fig. 72-74

Sieve-tube, 48,368 . Fig. $67,7 x, 72,74,93$

Sigillaria, 324,420 . Fig. 538,539

Silica, $169,249,323$

Silicula, I5I, 4I3. Fig. 3I7, $53^{\circ}$ II., III.

Siliqua, I5I, 413 . Fig. 526,528

Silky, I Io

Silurian system, 420

'Silver-grain,' 363 . Fig. 474, 475, 479

Simarubaceæ, 407

Simple, 94, 120

Sinuate, roo. Fig. 180

Siphonex. See Vaucheriaceæ

Siphonocladacex, I I, I2, 257. Fig. 8I, $3_{3} 3_{3}$

Slit, roo

Smut, 226, 278

Sodium, I62

Soft bast, 50,67

Solanacex, 384. Fig. 1I6, 234, 310, 493497

Solitary, In 6

Soredium, 288. Fig, 410

Sorus, 312, 326. Fig. 439

Spadix, 12I, 354

Spathe, 86, I2I, 35I, 354

Spathulate, 97. Fig. 165

Species, 194, 237

Sperm-cell, 25 I

Spermatia, 276, 282, 288. Fig. 405, 406

Spermatozoid. See Antherozoid
STR

Spermogonium, 276, 282, 28g. Fig. 400, 4 I 6

Sphaerobacteria, 246

Sphagnacea; 30r, 306, 424. Fig. 426 I., $43 \mathrm{I}$

Sphere-crystal, 3I. Fig. 53

Spike, r20. Fig. 222

Spikelet, I2r. Fig. 46 I r.

Spine, 109, 217. Fig. 197

Spiny, 99. Fig. 152, I72, 184, 333, 5rC

Spiral cell, 20. Fig. 29, 30, 33

Spiral embryo, 157. Fig. 339

Spiral vessel, 47. Fig. 93, roo, 478

Spirillum, 245. Fig. 380

Spirogyra, 258. Fig. 4I, 54

Sporangiophore, $27 \mathrm{I}$

Sporangium, $178,268,271,304,312$, 326. Fig. $394,395,427,429,430,433$, $439,440,443,44$ I I., 444 II., 45 I

Spore, I 78, 245, 249, 25I, 267, 268, 27I, 284. Fig. $376,377,394,395,418$ 11., 44I, 444 I11., 450 I.

Sporidesmium, 268

Sporidium, 269, 275 . Fig. 400

Sporocarp, 326. Fig. 448, 449

Sporogonium, 240, 299, 304. Fig. 421, 427,431

Sprengel, 6

Spur, I35, I36. Fig. 23I, 264, 266

Spurred, I25, r30. Fig. 231, 264, 266

'Spurred rye." See Ergot

Squanıose bulb, 82. Fig. I22

Stag's-horn moss. See Club-moss

Stamen, III, I37, 220. Fig. 20I, 2072 I I $265^{-286}, 459,49 \mathrm{I}, 524,529$

Staminate. See Male

Staminode, I35, I37. Fig. 262

Standard. Sce Vexillum

Starch, 27, 173. Fig. $42-46$

Stellatæ, 393. Fig. 139, 504

Stellate parenchyma, 40. Fig. 63

Stem, 70, 7I, 75. Fig. 108-122

Stem-tendril, rog. Fig. 196

Sreppe-region, $44 \mathrm{I}$

Sterculiacez, 409

Sterigma, 268, 282

Stichidium, 266

Stigma, 142, I43. Fig. 2II, 287, 290$295,359,46 \mathrm{I}, 468$

Stigmaria, 324,422

Stinging hair, 63, r 1 . Fig. 88

Stipella, 92, 400

Stipes, 279. Fig. 401, 402

Stipitate (stalked), 127. Fig. 236

Stipule, 9I. Fig. $\mathrm{I}_{44}-\mathrm{I}_{4} 6, \mathrm{I}_{54}, \mathrm{I} 82, \mathrm{I} 84$ $185,187,5 I_{4}$

Stolon, 305

Stoma, 58, r6r, 3cr, 322. Fig. 85, 86, 445,460

Stone-fruit. See Drupe

Strasburger, 6

Stratification, 4I7

Stratified Lichens, 285, 287. Fig. 408

Strawberry, I46, 405. Fig. 30r 
STR

'Streaming' of protoplasm, I99

Striation, I6. Fig. 26

Strobilus, I2I

Stroma (the hyphx supporting the perithecium in some Pyrenomycetes)

Strophiole, 155

Style, I 42, I43. Fig. 287, 290, 291

Stylopode, 397. Fig. $507 \mathrm{I1}$.

Stylospore, 268, 282288

Styracex, $3^{8} 7$

Suber. See Cork

Suberisation, 22

Subfamily, 239

Subkingdom, 238

Subrotund (nearly round), 95

Subsidiary organs, 108,134

Subspecies, 237

Subtribe, 239

Subulate, 105

Subvariety, 237

Succession of crops, 170

Succulent, I07, 134. Fig. I92, 302, 326

Sudan, 443

Suffruticose, 77

Sugar, 345

Sulphur, I62, I68

Sundew. See Drosera

Suntlower; 39 I

Superior, I I 4

Supradecompound, r03. Fig. I88-19o

Suspensor, 189, 333. Fig. 83 II., 363

Sutural dehiscence, 149

Suture, ${ }^{4} 2$

'Swarming,' Io

Swarmspore. See Zoospore

Symbiosis, 267, 289

Symmetrical, 124, I29

Sympetalous. Sec Gamopetalous

Symphyllous. See Gamophyllous

Sympodium, 76, 122

Syncarp, 146

Syncarpous, I42. Fig. $3^{1} 3,320,3^{2} 3$, 326

Synergidx, I88. Fig. $3^{60-362}$

Syngenesious, 140, 390. Fig, 278, 49911 .

Synsepalous. See Gamosepalous

\section{TABERNEMIONTANUS, 4 \\ 'Tamarind, 402}

Tangential section, 69. Fig. 96

Tannin, 579

Tap-root, 73. Fig. ror

Tapioca, 378

Taxineæ, 337. Fig. 328,457

Teeth, r 49. Fig. 306, 525 I.

Tegmen, I 55

"Tela contexta," 39. Fig. 65

'Telegraph -plant,' 205

Teleutospore, 267, 276. Fig. 400

Temperature, 208

Tendril, 108, 20I, 205, 400. Fig. 146, Ig6, 5I4
TRI

Tension of tissues, 176,197

'Tentacle,' 203

Teratology, 216

Terebinthaceæ, 407

Terminal bud, 82 . Fig. 123

Terminal style, 143-. Fig. 289, 29x

Ternate. See Trifuliolate

Terpinnate, 104. Fig. 189

Tertiary rocks, 429

Testa, 70, I55. Fig. 97, 305, 33I-334, $365,369,370,46 \mathrm{r} i v$.

Tetradynamous, I38, 413. Fig. 200, 274,529

Tetrasporangium, 266. Fig. 382

Tetraspore, 25 1 , 266. Fig. $3^{82}$

Thalamiflora, 407

Thalamifforal corolla, II4. Fig. 209

Thalanius, I I4. Fig. 209

Thalloid Hepatica, 296, 298. Fig. 349, $42 \mathrm{r}, 422$

Thallophytes, 69, 239, 242

Thallus, 69, 285. Fig. 392, 408, 413, 415, 4 16, 422

Theca, 268. Fig. 427, 429, 430, 433

Theophrastus, 3

Thickening-layer, I5. Fig. IO-2I

Thickening-ring, 43. Fig- $460,472 \mathrm{~B}$

Thorn-apple, 384. Fig. $3^{10}, 494$

Thymelæaceæ, 374. Fig. 207

Thyrse, 122

Tigellum, 76

Tiliacea, 409

Tissue, 37

Tobacco, 384 . Fig 493

Tomato, 384

Tomentose, Iro

Toothed, 125, I3I. Fig. 230, 250

Torula. See Saccharomyces

Tournefort, 4

Tracheï, 334,367 . Fig. 27, 35

Transition from stamens to petals, I4I, 221. Fig. 286

Transpiration, I59

Transverse dehiscence, I4I, I49. Fig. $311,312,496 \mathrm{I11}$.

Transverse section, 6g. Fig. 96

Transverse tension, I98

'Traveller's tree,' 459

Tree, 76

Tree-fern, Fig. 437

Triangular, 95. Fig. I 58

Triassic system, 426. Fig. 543-546

Tribe, 238

Tricarpellary, 142. Fig. 289

Trichogonium. See Trichogyne

Trichogyne, 255, 266, 28g. Fig. 387

Trichome, 6r, 312

Trichophore, 266

Trichophyton, 247

Trifid, 100, 125

Trifoliolate, Ior. Fig. I82

Trilobed, 100. Fig. I79

Trimorphism, 185 
TRI

Trisepalous, 125

Tropical Andrean region, 453

Trulfie, 283. Fig. 406

Truncite, 97

Trunk, 76

Tuber, 79. Fig. II6-I20, 444 IV.

Tuberous root, 74. Fig. I06, I07

Tubular, 125, 129, 390. Fig. 244, 499, 501

Tubulifloræ, 39r. Fig. 499, 500

'Tundren,' 437

Tunicated bulbs, 82. Fig. I22

Turbinate, I25. Fig. $229 \mathrm{l}$.

Turgidity, 198

Twining stem, 20I. Fig. II3, Ir4

\section{ULMACEE, 374. Fig. 259 \\ Ulvacex, 257. Fig. 82}

Umbel, I20, 394. Fig. 220, 221, 506.

Umbellales, 394

Umbelliferæ, 394. Fig. 221, 318, 506513

Umbellule, r2o. Fig. 22 I

Underground stems, $7 \vec{j}$. Fig. IO8, II5I22

Unger, 5, 6, +19

Unguiculate, I3I. Fig. 250-255

Unguis, I31. Fig. 250-252

Unicellular plants, $55,242,25$ I. Fig. 3: $59,8 \mathrm{r}, 380,38 \mathrm{r}, 3^{8} 3,3^{84}$

Unilocular, 140, 144. Fig. 296, 298, 299, 325 I., 326

Unisexual, 112. Fig. 201, 202

Unsymmetrical, 107, 124, 223. Fig. 156

Urceolate, I25, I29. Fig. 229 II., 24I, 256

Uredineæ, 276. Fig. 400

'Uredo,' 278

Uredospore, 267,277 . Fig. 400

Urn. Sec Theca

Urticacex, 374. Fig. 88, 260

Urticales, 374

Ustilaginex, 226,278

Utricle, 347

Utricular vessel, 50, 34I. Fig. 75

Utricularia, I84. Fig. 356

Utriculariaceæ, 382

\section{VACCINIACEA, 388. Fig. 24x
Vacuole, 9}

Vaginule, 304. Fig. 427 I.

Valerianacer, 39r. Fig. 264

Vallisnerin, I84

Valvate estivation, $84,403,409$. Fig. 124-126

Variety, 237

Variety-hybrid, 195

'Vasa propria,' 360

\section{WOR}

Vascular bundle. Sec Fibrovascular bundle

Vascular bundle-sheath, $67,309,324$, 369 . Fig. $438,445,447,45^{2}, 477$

Vascular cell, 47 . Fig. $47^{8}$

Vascular Cryptogams, 67, 240. Fig. $43^{6}-45^{2}$

Vascular plants, 67

Vaucheriacea, 12, 255, 261. Fig. $3^{8} 5$

'Vegetable ivory,' I58, 354

Vegetable Palaontology. Sce Palæo. phytology

Vegetable pathology, 216

Vegetative cone. See Cone of growth

Vein, I05

'Velum partiale,' 279. Fig. 401, 402

'Velum universale,' 279. Fig. 402

Venation, 105. Fig. 162, 163, 178, I81, I9I

Ventral suture, I 42

'Venus's fly-trap.' See Dionæa

Verbenacex, 384. Fig. 222, 27 I

Vernation, 85. Fig. I32-I 37

Versatile, I40. Fig. 270

Verticillaster, I23, 382. Fig. 489

Verticillate, 76, 87. Fig. 139, 211 , 418, 443 I., 504

Vesicular vessel. See Utricular vessel

Vessel, 47, 364. Fig. 69, 75-77, 93, 94, $474-477$

Vexillary astivation, 84 . Fig. I28

Vexillum, 132, 400. Fig. 253

Vibratile cilia. Sce Cilium

Vibrio, 245. Fig. 380

Vine-mildew. See Erysiphe

Violacer, +14

Vitta, 398. Fig. 509

Viviparous, 83,222

Volatile oils, $384,391,398$

Voltzia, 426. Fig. 543

Volvocineæ, 26 I

WADIS, 443

'Weeping' 54

Welwitschia, $33^{\circ}, 444$

Vest Indian region, 450

White smut, $23 I$

Whorl, II7. Fig. I 39, 2 I $\mathrm{x}, 4 \mathrm{I} 8,444$ 1., 504

Whorled. See Verticillate

Willow-gall, 233

Winged, 90, I55. Fig. $x_{5} 1,152,304$, 329

Wings. Sec Ala

Wood, 371

Wood-cell, 364

Wood-fibre, 364. Fig. 93, 474-476, $47^{8}$

'Worm-moss,' 257

Wormwood, 391 
XYL

X YLEM, 66, 324, 326, 34I, 357, 364. Fig. $93,447,452,472 \mathrm{~B}, 475$

$\mathrm{YEAST}^{\mathrm{E} 247}$

ZAMITES 426. Fig. 545 2 Zingiberacee, $34^{8}$

Zooglea, 245, 246
ZYG

Zoosporangium, 268, 274. Fig. 401

Zoospore, 200, 251, 253, 257, 268, 273, 274. Fig. 82, 386, 397, 399

Zygnemaceæ, 258 Fig. 4I, 54

Zygomycetes, 27x. Fig. 395, 396

Zygophycex, 257. Fig. II, 38, 4I, 58, $8 \mathrm{r}, 82,383,390$

Zygophyllacex, 407

Zygosperm, 257, 258, 271, 272. Fig. 54. 396

LIBKARY

LONDON : PRINTED BY

STOTTISWOODE AND CO., NEW-STREET SQUARE

AND PARLIAMENT STREET 



